\title{
Commercial Second-Generation PFBC Plant Transient Model Task 15
}

\section{Topical Report}

Jay S. White

Robert T. Getty

Mark R. Torpey

April 1995

Work Performed Under Contract No.: DE-AC21-89MC25177

For

U.S. Department of Energy

Office of Fossil Energy

Morgantown Energy Technology Center

Morgantown, West Virginia

By

Gilbert/Commonwealth, Inc.

Reading, Pennsylvania 


\section{DISCLAIMER}

This report was prepared as an account of work sponsored by an agency of the United States Government. Neither the United States Government nor any agency thereof, nor any of their employees, makes any warranty, express or implied, or assumes any legal liability or responsibility for the accuracy, completeness, or usefulness of any information, apparatus, product, or process disclosed, or represents that its use would not infringe privately owned rights. Reference herein to any specific commercial product, process, or service by trade name, trademark, manufacturer, or otherwise does not necessarily constitute or imply its endorsement, recommendation, or favoring by the United States Government or any agency thereof. The views and opinions of authors expressed herein do not necessarily state or reflect those of the United States Government or any agency thereof.

This report has been reproduced directly from the best available copy.

Available to DOE and DOE contractors from the Office of Scientific and Technical Information, 175 Oak Ridge Turnpike, Oak Ridge, TN 37831; prices available at (615) 576-8401.

Available to the public from the National Technical Information Service, U.S. Department of Commerce, 5285 Port Royal Road, Springfield, VA 22161; phone orders accepted at (703) 487-4650. 


\title{
Commercial Second-Generation PFBC Plant Transient Model Task 15
}

\section{Topical Report}

Jay S. White

Robert T. Getty

Mark R. Torpey

Work Performed Under Contract No.: DE-AC21-89MC25177

\author{
For \\ U.S. Department of Energy \\ Office of Fossil Energy \\ Morgantown Energy Technology Center \\ P.O. Box 880 \\ Morgantown, West Virginia 26507-0880 \\ By \\ Gilbert/Commonwealth, Inc. \\ 2675 Morgantown Road \\ Reading, Pennsylvania 19607
}

April 1995 
TASK 15:

Commercial Second-Generation PFBC Plant Transient Model

Table of Contents

SUMMARY

$\begin{array}{lll}1.0 & \text { INTRODUCTION } & 6\end{array}$

2.0 TECHNICAL APPROACH

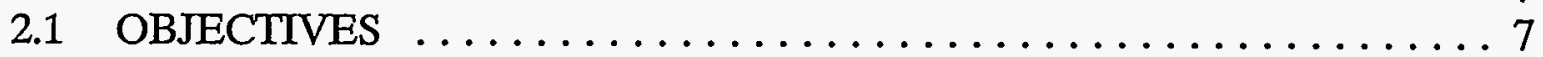

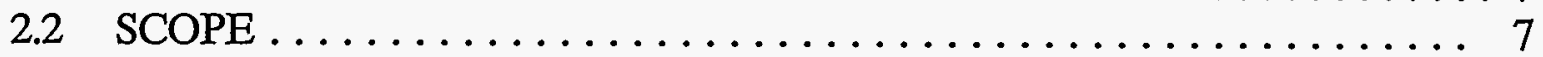

$\begin{array}{llr}3.0 & \text { DYNAMIC MODEL } & 11\end{array}$

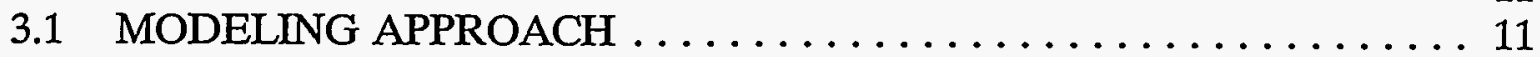

3.2 REFERENCE SYSTEM UPGRADE $\ldots \ldots \ldots \ldots \ldots \ldots \ldots \ldots \ldots \ldots 11$

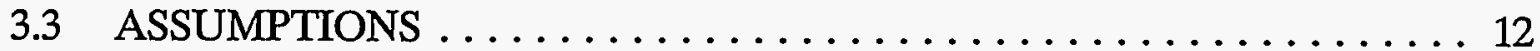

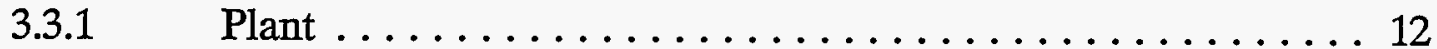

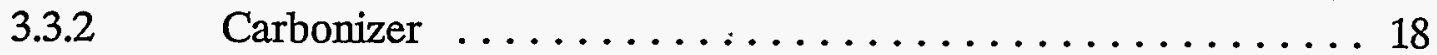

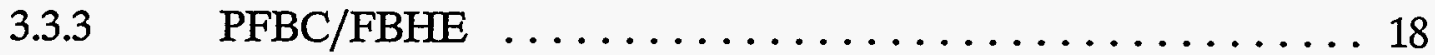

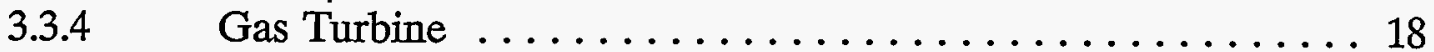

3.3.5 Steam Turbine . . . . . . . . . . . . . . . . . 19

3.4 INTEGRATED PLANT MODEL $\ldots \ldots \ldots \ldots \ldots \ldots \ldots \ldots \ldots$

$\begin{array}{lll}4.0 & \text { STEADY-STATE SIMULATIONS } & 22\end{array}$

$\begin{array}{llr}5.0 & \text { TRANSIENT SIMULATIONS } & 28\end{array}$

5.1 TURNDOWN FROM $100 \%$ TO $90 \%$ LOAD . . . . . . . . . . 28

5.2 TURNDOWN FROM $100 \%$ TO $50 \%$ LOAD . . . . . . . . . . 32

6.0 OPERATING PHILOSOPHY DEVELOPMENT 48

6.1 PFBC-II CONTROL PHILOSOPHY $\ldots \ldots \ldots \ldots \ldots \ldots \ldots \ldots . \ldots 48$

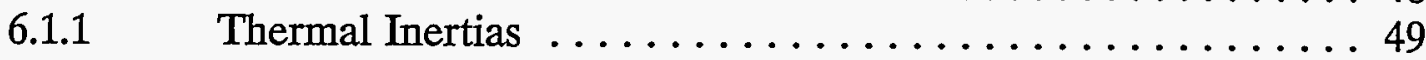

6.1.2 Plant Control Mode .................... 50

6.1.3 Control Valve Pressure Drops ............... 50

6.2 CARBONIZER AND CHAR HOPPER $\ldots \ldots \ldots \ldots \ldots \ldots \ldots \ldots .51$

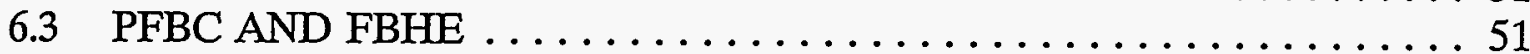

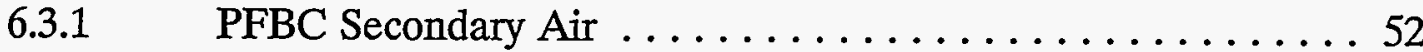

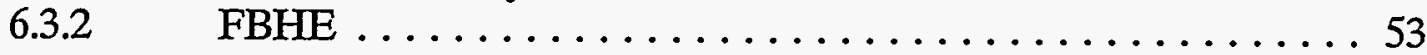

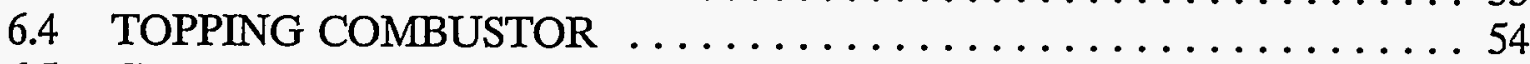

6.5 GAS TURBINE AND HRSG $\ldots \ldots \ldots \ldots \ldots \ldots \ldots \ldots \ldots \ldots \ldots$

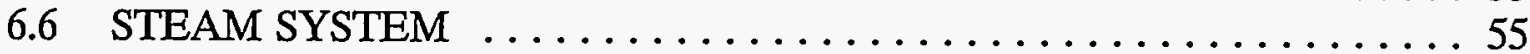

$6.6 .1 \quad$ Steam Temperature $\ldots \ldots \ldots \ldots \ldots \ldots \ldots \ldots \ldots \ldots$

$6.6 .2 \quad$ Drum Level . . . . . . . . . . . . . . . . . 56

6.6.3 Steam Header Pressure $\ldots \ldots \ldots \ldots \ldots \ldots \ldots \ldots \ldots 6 . \ldots \ldots$ 
6.6.4 Deaerator Storage Tank Level . . . . . . . . . . . . 56

6.6.5 Condenser Hotwell Level . . . . . . . . . . . . . . 57

6.6.6 Ash Cooler Water Flow ................. 57

$\begin{array}{lll}7.0 & \text { POTENTIAL MODEL DESIGN CHANGES } & 58\end{array}$

8.0 TRIAL CONTROL SCHEMES 61

$\begin{array}{lll}9.0 & \text { CONCLUSIONS } & 1\end{array}$

10.0 REFERENCES

APPENDICES

A DYNAMIC MODEL OVERVIEW

A.1 PLANT DESCRIPTION . . . . . . . . . . . . . . . . . . . 1

A.2 MODEL DESCRIPTION $\ldots \ldots \ldots \ldots \ldots \ldots \ldots \ldots \ldots \ldots$

A.3 BLOCK FLOW DIAGRAMS $\ldots \ldots \ldots \ldots \ldots \ldots \ldots \ldots \ldots \ldots$

A.4 HOW TO USE MODEL $\ldots \ldots \ldots \ldots \ldots \ldots \ldots \ldots \ldots \ldots \ldots \ldots$

B PC TRAX AND CUSTOMIZED INTERFACES 1

B.1 INTRODUCTION $\ldots \ldots \ldots \ldots \ldots \ldots \ldots \ldots \ldots \ldots \ldots \ldots \ldots \ldots$

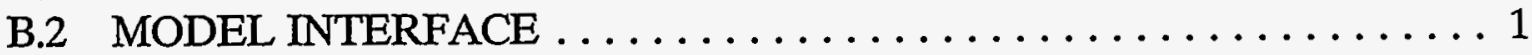

B.3 MODEL INTERFACE VARIABLES $\ldots \ldots \ldots \ldots \ldots \ldots \ldots \ldots$

C CARBONIZER MODEL

C.1 CARBONIZER CHEMISTRY $\ldots \ldots \ldots \ldots \ldots \ldots \ldots \ldots \ldots \ldots$

C.2 HYDRODYNAMTC MODEL . ................... 11

C.2.1 Carbonizer Hydrodynamic Model Assumptions . . . . . . . . . 11

C.2.2 Carbonizer Particle Elutriation ............... 11

C.2.3 Carbonizer Pressure Drop . . . . . . . . . . . . 13

C.2.4 Carbonizer Pressure $\ldots \ldots \ldots \ldots \ldots \ldots \ldots \ldots \ldots \ldots$

C.3 CARBONIZER ENERGY BALANCE ................ 15

D PFBC MODEL 1

D.1 PFBC CHEMISTRY $\ldots \ldots \ldots \ldots \ldots \ldots \ldots \ldots \ldots \ldots \ldots \ldots$

D.2 HYDRODYNAMIC MODEL $\ldots \ldots \ldots \ldots \ldots \ldots \ldots \ldots \ldots \ldots$

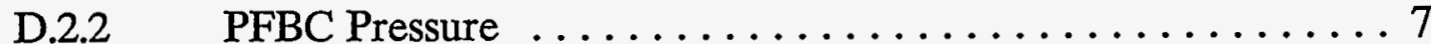

D.3 ENERGY BALANCES $\ldots \ldots \ldots \ldots \ldots \ldots \ldots \ldots \ldots \ldots$

E FLUID BED HEAT EXCHANGER MODEL 1

E.1 INTRODUCTION $\ldots \ldots \ldots \ldots \ldots \ldots \ldots \ldots \ldots \ldots \ldots \ldots$

E.2 HYDRODYNAMIC MODEL $\ldots \ldots \ldots \ldots \ldots \ldots \ldots \ldots \ldots \ldots$

E.3 FBHE ENERGY BALANCE $\ldots \ldots \ldots \ldots \ldots \ldots \ldots \ldots \ldots$

F CHAR HOPPER MODEL 1 
G ASH COOLER MODEL

G.2 HYDRODYNAMIC MODEL ...................

H TOPPING COMBUSTOR MODEL 1

$\begin{array}{llr}\text { I INSTRUMENTATION DIAGRAMS } & 1\end{array}$

J MACRO SOURCE LISTING

K FORTRAN SOURCE LISTING $\quad 1$

L ACSL SOURCE LISTING 


\section{List of Figures}

S-1 Coal Flow, G/T Power, and S/T Power for 10 Percent Load Change ................... 5

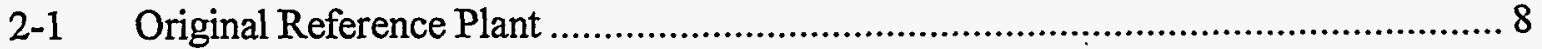

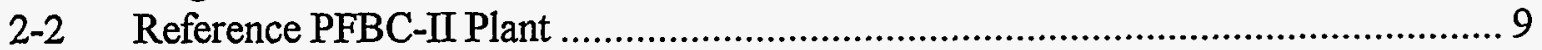

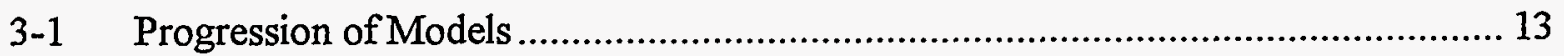

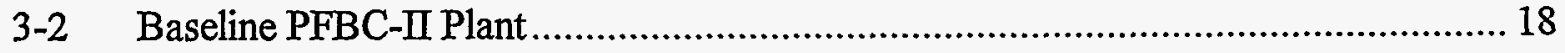

4-1 Steady-State Cycle Temperatures .......................................................... 22

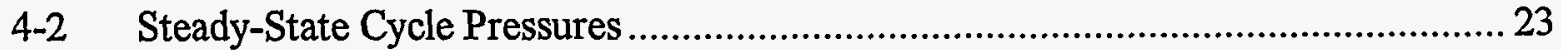

5-1 Carbonizer Temperature for 10 Percent Load Change ...................................... 31

4-3 Steady-State Cycle Power..................................................................... 24

5-1 Carbonizer Temperature for 10 Percent Load Change.......................................... 31

5-2 Fuel Gas Production for 10 Percent Load Change............................................ 32

5-3 Carbonizer Parameters for 10 Percent Load Change............................................. 33

5-4 PFBC Temperature for 10 Percent Load Change ............................................... 34

5-5 Reheater Solids Flow for 10 Percent Load Change............................................ 35

5-6 Process Air Flows for 10 Percent Load Change ................................................ 36

5-7 G/T Temperature for 10 Percent Load Change............................................... 37

5-8 H/P Steam Flow for 10 Percent Load Change ................................................ 38

5-9 PFBC Temperature and H/P Steam Flow for 10 Percent Load Change.................. 39

5-10 Process Pressures for 10 Percent Load Change ............................................... 40

5-11 G/T and S/T Power Output for 10 Percent Load Change ................................... 41

5-12 Process Pressures for 50 Percent Load Change ................................................ 42

5-13 PFBC Temperature for 50 Percent Load Change ............................................. 43

5-14 G/T and S/T Power Output for 10 Percent Load Change ................................... 44

A-3.1 G/T Block Diagram .......................................................................... A-9

A-3.2 Transfer Block Diagram........................................................................... A-10

A-3.3 Air Header Piping Block Diagram ......................................................... A-11

A-3.4 PFBC Air Header Block Diagram .............................................................. A-12

A-3.5 Carbonizer Feeds Block Diagram......................................................... A-15

A-3.6 Transport Air Cooler Block Diagram .......................................................... A-16

A-3.7 Fuel Gas Flare and Piping Block Diagram .................................................... A-19

A-3.8 Vitiated Air Block Diagram ............................................................... A-20

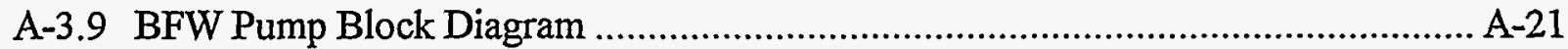

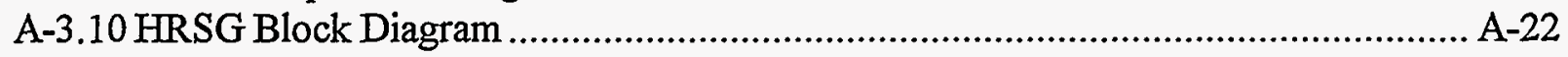

A-3.11 FBHE Steam Drum Piping Block Diagram.............................................. A-23

A-3.12 Steam Piping Block Diagram .................................................................. A-23

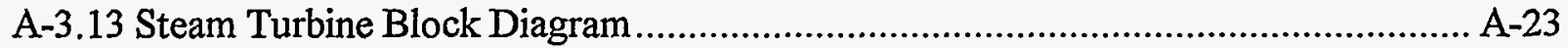

A-3.14 H/P Turbine and Reheater Block Diagram ................................................ A-29

A-3.15 I/P Turbine Block Diagram ................................................................. A-30

A-3.16 L/P Turbine Block Diagram .............................................................. A-31

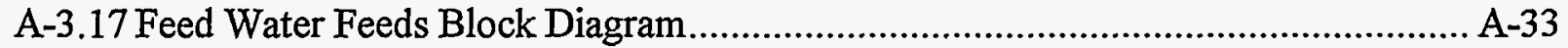

A-3.18 Deaerator Block Diagram ............................................................................ A-34

B-1.1 PC-TRAX Interconnection Scheme ............................................................. B-1

C-1.1 Reaction Zones................................................................................... C-3

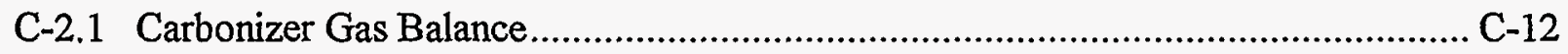




\section{List of Figures (continued)}

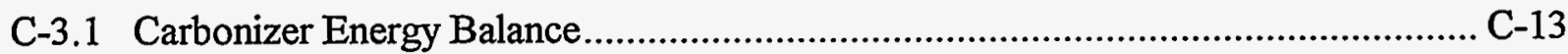

D-2.1 CPFBC Circulation Diagram................................................................... D -4

D-2.2 Solids Circulation and Secondary Zone Velocity ............................................. D-5

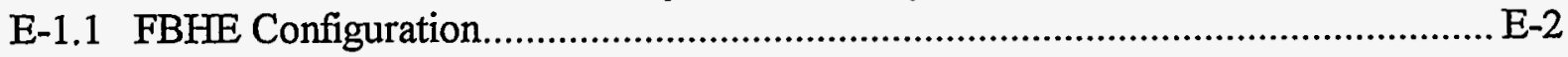

E-2.1 FBHE Cell \#2 Gas Schematic ................................................................ E-3

E-2.2 FBHE Steam Drum Schematic ................................................................... E-5

G-1.1 Ash Cooler Schematic............................................................................. G-2

$\mathrm{H}-1.1$ Topping Combustor Schematic ............................................................

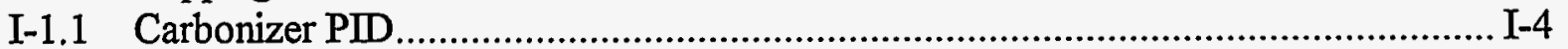

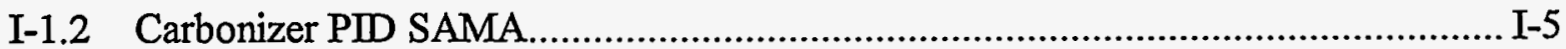

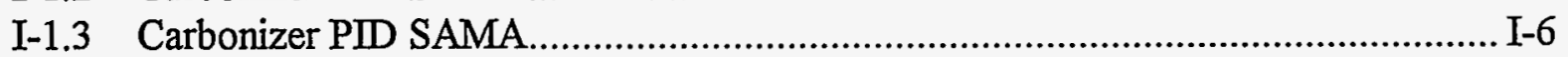

I-1.4 TRAX Control Scheme : Sorbent Flow...................................................... I-7

I-1.5 Sorbent Flow Set Point............................................................................ I-8

I-1.6 TRAX Control Scheme : Coal Flow............................................................... I-9

I-1.7 TRAX Control Scheme : Transport Air Flow .................................................. I-11

I-1.8 TRAX Control Scheme : Primary Air Flow .................................................. I-12

I-1.9 Coal Flow Set Point............................................................................. I-13

I-1.10 Air Flow Set Point ............................................................................. I-14

I-1.11 TRAX Control Scheme : Steam Flow ......................................................... I-15

I-1.12 Steam Flow Set Point ................................................................. I-16

I-1.13 TRAX Control Scheme : Steam Temperature ............................................. I-17

I-2.1 PFBC/FBHE PID ............................................................................ 18

I-2.2 PFBC/FBHE PID SAMA .................................................................. I-19

I-2.3 TRAX Control Scheme : PFBC Inlet Solids Flow ........................................... I-20

I-2.4 TRAX Control Scheme : PFBC Bed Temperature ......................................... I-21

I-2.5 PFBC Air Flow Set Point...................................................................... I-22

I-2.6 PFBC Secondary Air Flow Set Point........................................................ I-23

I-2.7 TRAX Control Scheme : PFBC Air Flow...................................................... I-24

I-2.8 TRAX Control Scheme : FBHE Air Flow ...................................................... I-26

I-3.1 Topping Combustor / GT PID ............................................................... I-27

I-3.2 Topping Combustor / GT PID SAMA ...................................................... I-28

I-3.3 TRAX Control Scheme : Main Air Header Flow ........................................... I-29

I-3.4 TRAX Control Scheme : Main Air Header Flow ............................................. I-30

I-4.1 Steam Drums PID ............................................................................... I-32

I-4.2 Steam Drums PID SAMA ..................................................................... I-33

I-4.3 TRAX Control Scheme : HRSG Steam Drum Level ......................................... I-34

I-4.4 TRAX Control Scheme : FBHE Steam Drum Level .......................................... I-35

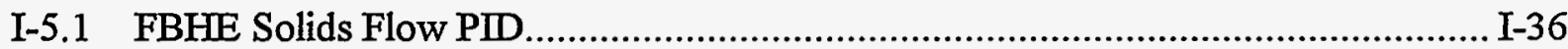

I-5.2 FBHE Solids Flow PID SAMA.......................................................... I-37

I-5.3 TRAX Control Scheme : S/H Outlet Temperature ........................................... I-38

I-5.4 TRAX Control Scheme : R/H Outlet Temperature......................................... I-39

I-5.5 S/H Outlet Temperature PID ............................................................... I-40 


\section{List of Figures (continued)}

I-5.6 R/H Outlet Temperature PID ......................................................................... I-41

I-5.7 S/H Outlet Temperature PID SAMA …………................................................ I-42

I-5.8 R/H Outlet Temperature PID SAMA.............................................................. I-43

I-5.9 TRAX Control Scheme : S/H Outlet Temperature ......................................... I-45

I-5.10 TRAX Control Scheme : R/H Outlet Temperature .............................................. I-46

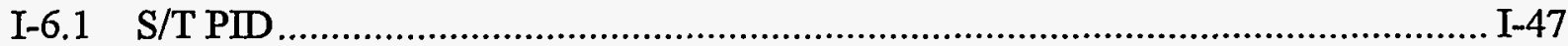

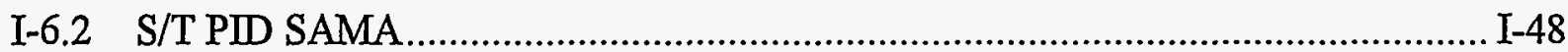

I-6.3 TRAX Control Scheme : S/T Header Pressure ................................................... I-49

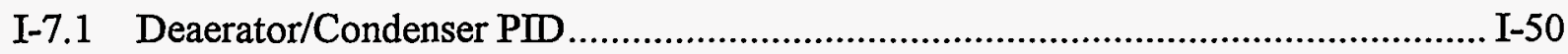

I-7.2 Condenser PID SAMA .............................................................................

I-7.3 TRAX Control Scheme : Condenser Hot Well Level.......................................... I-54

I-7.4 Deaerator PID SAMA …............................................................................. I-55

I-7.5 TRAX Control Scheme : Deaerator Level..................................................... I-56

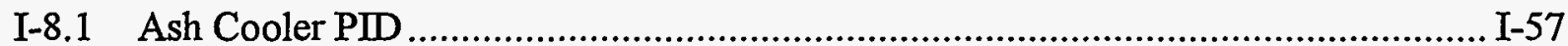

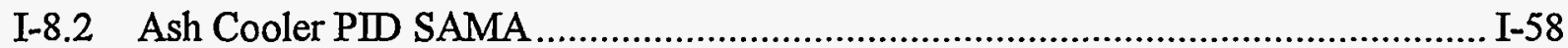

I-8.3 TRAX Control Scheme : Ash Outlet Temperature .............................................. I-59 


\section{List Of Tables}

S-1 Steady-State Calibration Comparison.............................................................. 3

S-2 Performance at 90 Percent Load ...................................................................... 4

3-1 Revisions to Reference Plant........................................................................... 14

3-2 Rev. D and PC-TRAX Carbonizer Comparison..................................................... 15

3-3 Air, Coal, and Sorbent Assumptions ………………........................................... 16

3-4 Model Display Parameters ................................................................................ 19

4-1 Steady-State Calibration Comparison .................................................................. 21

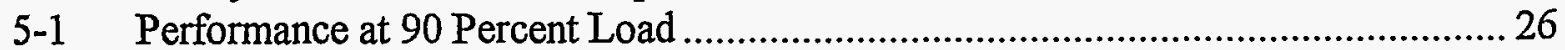

6-1 Operating Goals for 2nd Generation PFBC Plant ................................................. 46

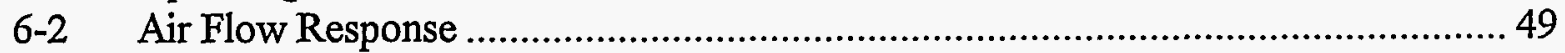

A-2.1 Hardware/Software Requirements................................................................. A-4

A-2.2 Subsystem Computer Models...................................................................... A-5

A-3.1 G/T Block Diagram Summary ................................................................... A-8

A-3.2 FBHE Fluidizing Air Header Block Diagram Summary ……............................... A-8

A-3.3 PFBC Air Header Block Diagram Summary.................................................... A-13

A-3.4 Carbonizer Feed Block Diagram Summary .................................................... A-14

A-3.5 Fuel Gas Flare and Piping Block Diagram Summary......................................... A-17

A-3.6 Vitiated Air Block Diagram Summary............................................................. A-17

A-3.7 HRSG Block Diagram Summary............................................................... A-18

A-3.8 Steam Piping Block Diagram Summary............................................................ A-23

A-3.9 H/P Turbine and Reheater Block Diagram Summary ........................................... A-27

A-3.10 I/P Turbine and Reheater Block Diagram Summary ........................................... A-28

A-3.11 L/P Turbine and FWH Block Diagram Summary................................................ A-35

B-2.1 Custom Tailored Modules.........................................................................

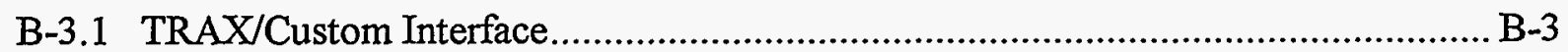

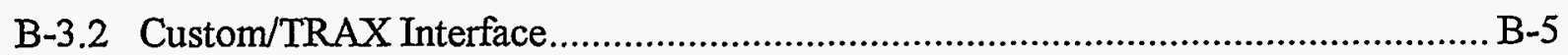

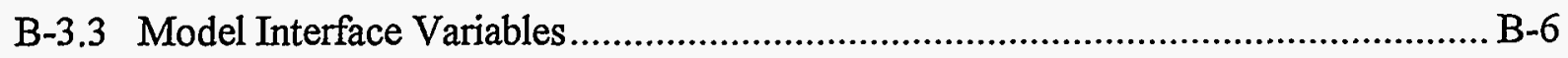

C-2.1 Particle Size Distribution For Char Generation............................................ C-10

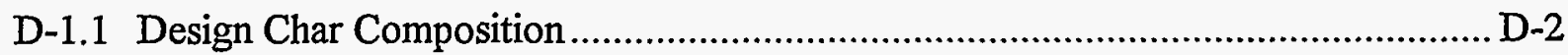

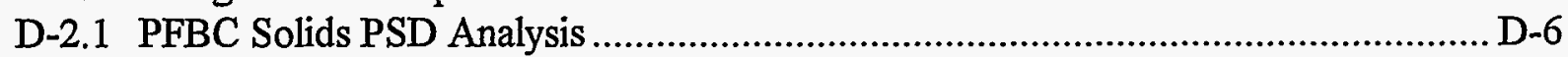

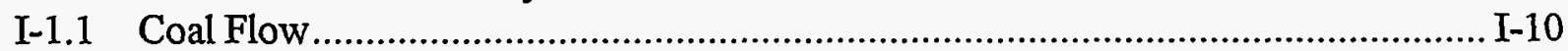




\section{SUMMARY}

Advanced Pressurized Fluidized Bed Combustor (APFBC) power plant concept utilizes coal to power a gas and steam turbine combined cycle for electrical power generation. Studies (Robertson, 1989;Rubow, 1992;Rubow, 1993) have shown that this technology has promise for thermal efficiencies greater than 50 percent (HHV). DOE has funded efforts to demonstrate the APFBC technology and extend application to a commercial level.

In the APFBC concept, coal is chemically reacted to form a low-Btu fuel gas and char through bubbling-bed gasification. Char is combusted with a large amount of excess air in a pressurized fluidized-bed combustor (PFBC). Flue gas from the PFBC, which contains a significant amount of oxygen, is then used to burn the fuel gas in a topping combustor. The topping combustor exhaust is expanded in a gas turbine to produce power. Waste heat is recovered in a HRSG and fluidized bed heat exchanger (FBHE) and used to generate high pressure superheated steam which is expanded in a steam turbine to produce additional electrical power.

The carbonizer and PFBC are large vessels each with significant volume. For a commercial-sized APFBC power plant, the carbonizer freeboard volume is an order of magnitude greater than the volume of the gas turbine. The PFBC volume is six times greater than that of the carbonizer. The dynamic interaction of the two large reaction vessels with the relatively small gas turbine has not been physically demonstrated, and therefore, not completely understood. Furthermore, the steam bottoming cycle contains two large steam drums which, due to the highly integrated nature of the APFBC concept, contribute additional dynamic response in the PFBC and FBHE. The dynamic behavior of the integrated topping and bottoming cycle components is complex and difficult to describe quantitatively.

The primary objective of this study is to identify the key operating parameters affecting the operation of a commercial-sized APFBC plant. It is also desired to quantify basic system response to transient upsets and changes in load demand. It is expected that an understanding of the dynamic behavior of the APFBC power plant will result in a robust control strategy appropriate for demonstration and commercial-sized APFBC power plants. A secondary objective of this study is the identification of plant design changes which result in increased plant stability and ease of operation.

A PC-TRAX ${ }^{\mathrm{TM}}$ based dynamic model of a commercial-sized APFBC power plant was constructed to simulate plant operation. Customized dynamic modules for the carbonizer, PFBC, FBHE, gas turbine, and ash cooler were developed and written in ACSL. The customized ACSL code was interfaced with the standard TRAX modules and is supported by FORTRAN subroutines. PC-TRAX ${ }^{\mathrm{TM}}$ modules are used to simulate the power plant controls. As part of the primary objective of this study, the dynamic model will help determine if the individual APFBC process elements can be made to operate together based 
on appropriate control strategies with minimal control elements, or if control strategies with additional control elements, i.e., valves, accumulators, bypasses, and vents, are required.

Following completion of the dynamic model and integration of the control strategy, simulated results for 100 percent load were compared to ASPEN ${ }^{\mathrm{TM}}$ generated results to verify model performance. ASPEN ${ }^{\mathrm{TM}}$ is a steady-state modelling tool and was used to build the template for the dynamic TRAX model. Model comparison revealed good agreement of all process variables, as shown in Table S-1.

Following verification of the model at 100 percent load, two transient simulations were run: 100 percent load to 90 percent load, and 100 percent load to 50 percent of load. Results at 90 percent of plant electric load are shown in Table S-2.

Analysis of variable plots indicate that while the plant can be turned down to 90 percent of load, the simulated power plant takes an extended period of time to stabilize after the 90 percent load point is reached. Figure S- 1 shows a plot of gas and steam turbine generator output powers for a 10 percent decrease in coal feed at one percent a minute. As can be seen in the figure, plant performance is less than optimal.

The effort described in this report was limited to developing the first approach for APFBC process control. The present control scheme produces marginal results. Pronounced interactions between the steam bottoming cycle and the FBHE inhibit a smooth transition during plant turndown. Further study is required to produce a more robust and stable control strategy. The lessons 1 earned and described in this report will provide a sound basis for further study.

Analysis has shown that the model can be a valuable tool for investigating the dynamic response of commercial-sized APFBC plants. Future work will utilize the model as a starting point for modeling the demonstration plant for a similar power system, the Power System Development Facility (PSDF), at Wilsonville, AL. 
Table S-1

Steady-State Calibration Comparison

\begin{tabular}{|l|r|r|r||}
\hline Parameter & ASPEN Model & PC-TRAX Model & Variance \\
\hline Coal Flow & $151,061 \mathrm{lb} / \mathrm{h}$ & $151,061 \mathrm{lb} / \mathrm{h}$ & $0 \%$ \\
\hline Carbonizer Temp & $1,600 \mathrm{~F}$ & $1,600 \mathrm{~F}$ & $0 \%^{*}$ \\
\hline Fuel Gas Flow & $325,727 \mathrm{lb} / \mathrm{h}$ & $326,000 \mathrm{lb} / \mathrm{h}$ & $-0.08 \%$ \\
\hline Char Flow & $112,754 \mathrm{lb} / \mathrm{h}$ & $112,550 \mathrm{lb} / \mathrm{h}$ & $0.16 \%$ \\
\hline PFBC Temp & $1,600 \mathrm{~F}$ & $1,600 \mathrm{~F}$ & $0 \%^{*}$ \\
\hline Vitiated Air Flow & $2,702,371 \mathrm{lb} / \mathrm{h}$ & $2,700,100 \mathrm{lb} / \mathrm{h}$ & $0.08 \%$ \\
\hline Topp Comb Temp & $2,350 \mathrm{~F}$ & $2,350 \mathrm{~F}$ & $0 \%{ }^{*}$ \\
\hline GT Exhaust Flow & $3,564,850 \mathrm{lb} / \mathrm{h}$ & $3,567,200 \mathrm{lb} / \mathrm{h}$ & $-0.07 \%$ \\
\hline GT Exhaust Temp & $1,141 \mathrm{~F}$ & $1,141 \mathrm{~F}$ & $0 \%$ \\
\hline HRSG Exit Temp & $280 \mathrm{~F}$ & $309 \mathrm{~F}$ & $-3.8 \%$ \\
\hline Throttle Stm Flow & $1,597,900 \mathrm{lb} / \mathrm{h}$ & $1,589,800 \mathrm{lb} / \mathrm{h}$ & $0.51 \%$ \\
\hline Deaerator Steam & $86,498 \mathrm{lb} / \mathrm{h}$ & $80,605 \mathrm{lb} / \mathrm{h}$ & $7.23 \%$ \\
\hline Gas Turb Power & $280 \mathrm{~kW}$ & $276 \mathrm{~kW}$ & $1.4 \%$ \\
\hline Stm Turb Power & $280 \mathrm{~kW}$ & $282 \mathrm{~kW}$ & $-0.7 \%$ \\
\hline Auxiliary Power & $22 \mathrm{~kW}$ & $22 \mathrm{~kW}$ & $0 \%$ \\
\hline Plant Net Power & $538 \mathrm{~kW}$ & $536 \mathrm{~kW}$ & $0.3 \%$ \\
\hline HHV Efficiency & $46.75 \%$ & $46.57 \%$ & $0.4 \%$ \\
\hline
\end{tabular}

* Temperature variances based on absolute temperatures. 
Table S-2

Performance AT 90 Percent Load

\begin{tabular}{|l|r|r|r||}
\hline Parameter & $100 \%$ Load & $90 \%$ Load & Change \\
\hline Coal Flow & $151,061 \mathrm{lb} / \mathrm{h}$ & $133,060 \mathrm{lb} / \mathrm{h}$ & $-11.9 \%$ \\
\hline Carbonizer Temp & $1,600 \mathrm{~F}$ & $1,600 \mathrm{~F}$ & $0 \%^{*}$ \\
\hline Fuel Gas Flow & $326,000 \mathrm{lb} / \mathrm{h}$ & $288,100 \mathrm{lb} / \mathrm{h}$ & $-11.6 \%$ \\
\hline Char Flow & $112,550 \mathrm{lb} / \mathrm{h}$ & $98,879 \mathrm{lb} / \mathrm{h}$ & $-12.1 \%$ \\
\hline PFBC Temp & $1,600 \mathrm{~F}$ & $1,600 \mathrm{~F}$ & $0 \%$ \\
\hline Vitiated Air Flow & $2,700,100 \mathrm{lb} / \mathrm{h}$ & $2,260,000 \mathrm{lb} / \mathrm{h}$ & $-16.3 \%$ \\
\hline Topp Comb Temp & $2,350 \mathrm{~F}$ & $2,160 \mathrm{~F}$ & $-8.1 \%$ \\
\hline GT Exhaust Flow & $3,567,200 \mathrm{lb} / \mathrm{h}$ & $3,542,200 \mathrm{lb} / \mathrm{h}$ & $-0.7 \%$ \\
\hline GT Exhaust Temp & $1,141 \mathrm{~F}$ & $1,019 \mathrm{~F}$ & $-7.1 \%$ \\
\hline HRSG Exit Temp & $309 \mathrm{~F}$ & $323 \mathrm{~F}$ & $+1.8 \%$ \\
\hline Throttle Stm Flow & $1,589,800 \mathrm{lb} / \mathrm{h}$ & $1,322,000 \mathrm{lb} / \mathrm{h}$ & $-16.2 \%$ \\
\hline Deaerator Steam & $80,665 \mathrm{lb} / \mathrm{h}$ & $69,708 \mathrm{lb} / \mathrm{h}$ & $-13.6 \%$ \\
\hline Gas Turb Power & $276 \mathrm{~kW}$ & $234 \mathrm{~kW}$ & $-15.2 \%$ \\
\hline Stm Turb Power & $282 \mathrm{~kW}$ & $242 \mathrm{~kW}$ & $-14.1 \%$ \\
\hline
\end{tabular}

* Temperature variances based on absolute temperatures. 


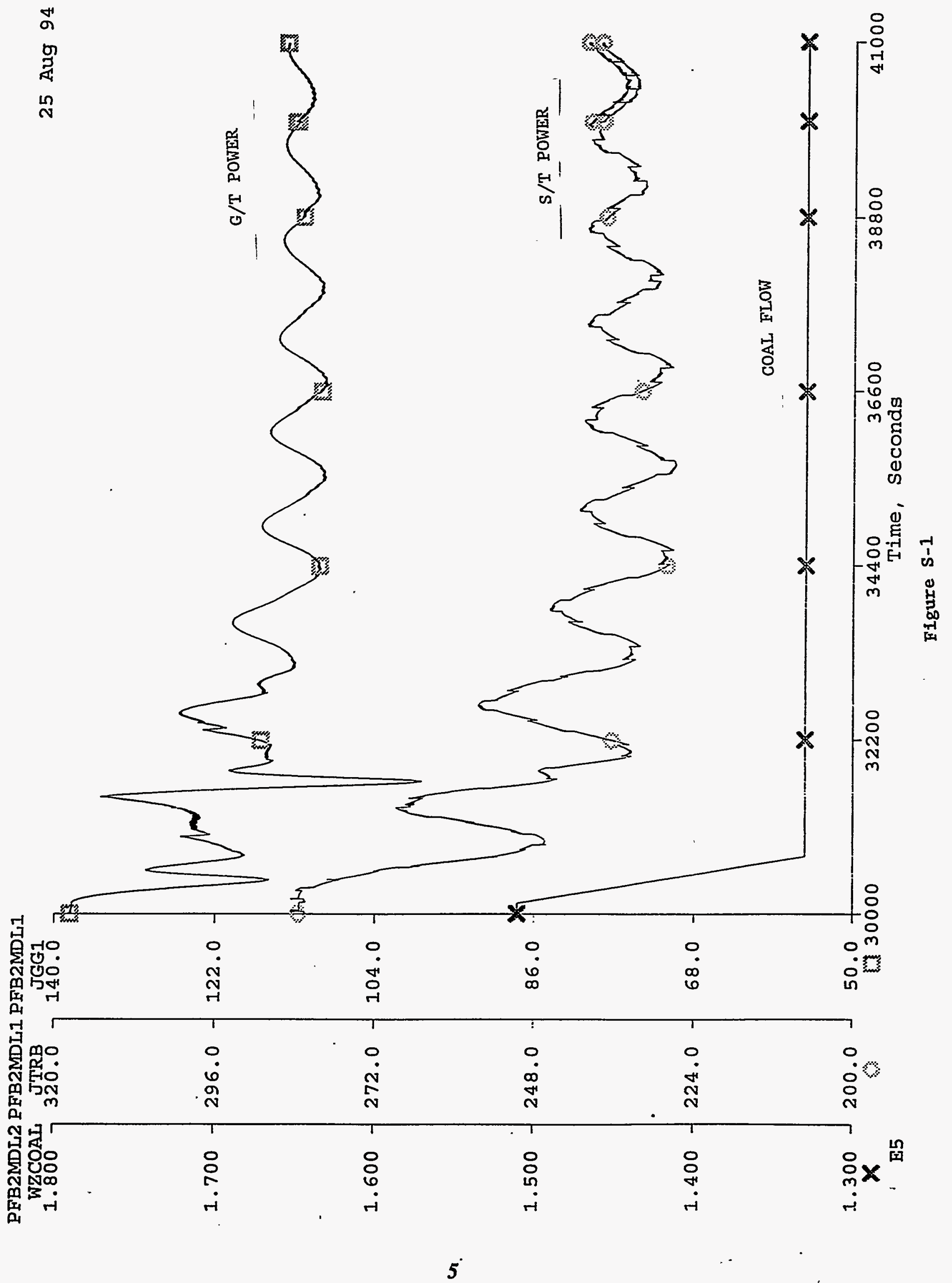


The advanced pressurized fluidized bed combustor (APFBC) power plant combines an efficient gas-fired combined cycle, a low-emission PFB combustor, and a coal pyrolysis unit (carbonizer) that converts coal, America's most plentiful fuel, into the gas turbine fuel. Previous studies (Robertson, 1989; Rubow, 1992; Rubow, 1993) has shown that the APFBC plant has the potential for high efficiency operation with low capital cost, resulting in a coal-fired plant with a busbar cost of electricity lower than that of competing coal-fired technologies.

From an operation standpoint, the APFBC plant is similar to an integrated gasification combined cycle (IGCC) plant, except that the PFBC and fluid bed heat exchanger (FBHE) allow a considerable fraction of coal energy to be shunted around the gas turbine and sent directly to the steam turbine. By contrast, the fuel energy in IGCC plants and most other combined cycles is primarily delivered to the gas turbine and then to the steam turbine. Another characteristic of the APFBC plant is the interaction among three large thermal inertias -- carbonizer, PFBC, and FBHE -- that presents unique operational challenges for modeling and operation of this type of plant.

This report describes the operating characteristics and dynamic responses of the APFBC plant and discusses the advantages and shortcomings of several alternative control strategies for the plant. In particular, interactions between PFBC, FBHE, and steam bottoming cycle are analyzed and the effect of their interactions on plant operation is discussed.

The remainder of this report is outlined below.

- The technical approach used in the study is described in Section 2.

- The dynamic model is introduced in Section 3 and described is detail in the appendices.

- Steady-state calibration and transient simulations are presented in Sections 4 and 5.

- The development of the operating philosophy is discussed in Section 6.

- Potential design changes to the dynamic model and trial control schemes are listed in Sections 7 and 8.

- Conclusions derived from the study are presented in Section 9. 


\subsection{TECHNICAL APPROACH}

The purpose of this study is to develop a transient (dynamic) model of a 2nd-Generation AFBC power plant, and to develop an operating philosophy to control transient modes created by operating this type of power plant.

This section outlines the objectives of the study and the technical approach used to attain those objectives.

\section{$2.1 \quad$ OBJECTIVES}

The objectives of this study are:

- to identify the key operating parameters affecting the 2nd-Generation AFBC plant,

- to quantify the basic responses of each major sub-system to changes in key operating parameters,

- to estimate the response of major sub-systems to expected changes in overall plant operations, and

- to recommend design changes that will improve the transient and off-design performance of the plant without adversely affecting the steady state operation of the plant.

These objectives are realized through the development and exercise of a dynamic mathematical model. The results of this task are expected to be useful for METC sponsored on $\rightarrow$ site and off-site PFBC projects, and should have application in the analysis of several technologies employing related processes.

\section{$2.2 \quad$ SCOPE}

The focus of the project is the development of a mathematical model of a 2nd-Generation PFBC (PFBC-II) power plant. The original reference plant used the $1600^{\circ} \mathrm{F}$ carbonizer described in Figure 94 of the Second-Generation PFBC R\&D Phase I report [Robertson and others, 1989], and a modified Westinghouse 501D5 gas turbine. The current reference plant is similar to the original, except that it incorporates recent developments in carbonizer and gas turbine technology. Foster Wheeler has developed new carbonizer performance data at $1600^{\circ} \mathrm{F}$ based on their recent tests, and Westinghouse has developed the 501F gas turbine, which has different characteristics than the modified W501D5 represented in the original study. Flow sheets of the original and current reference plants are shown in Figures 2-1 and 2-2, respectively. The differences between these plants are discussed under "Reference System Upgrade" in Section 3. 


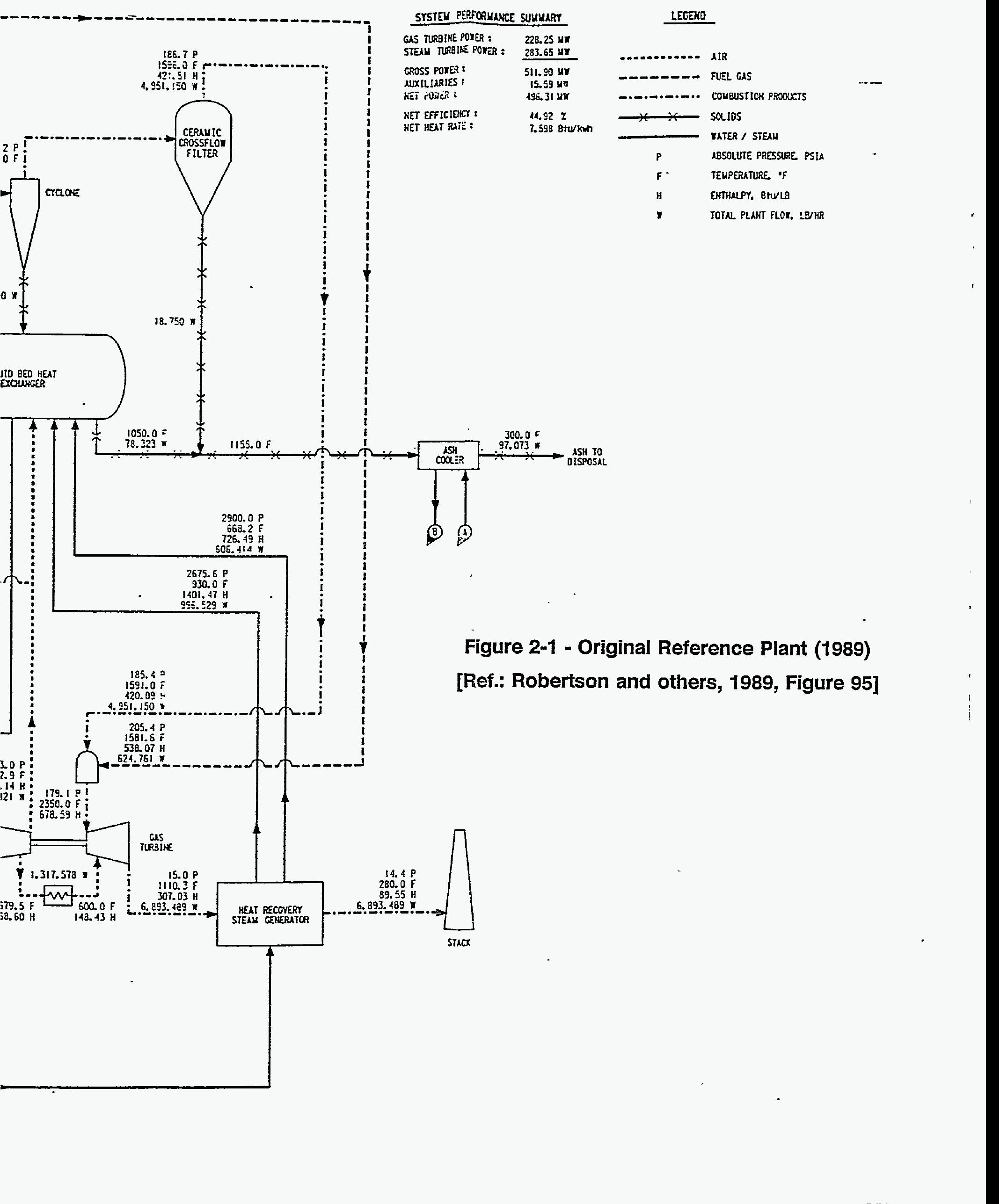




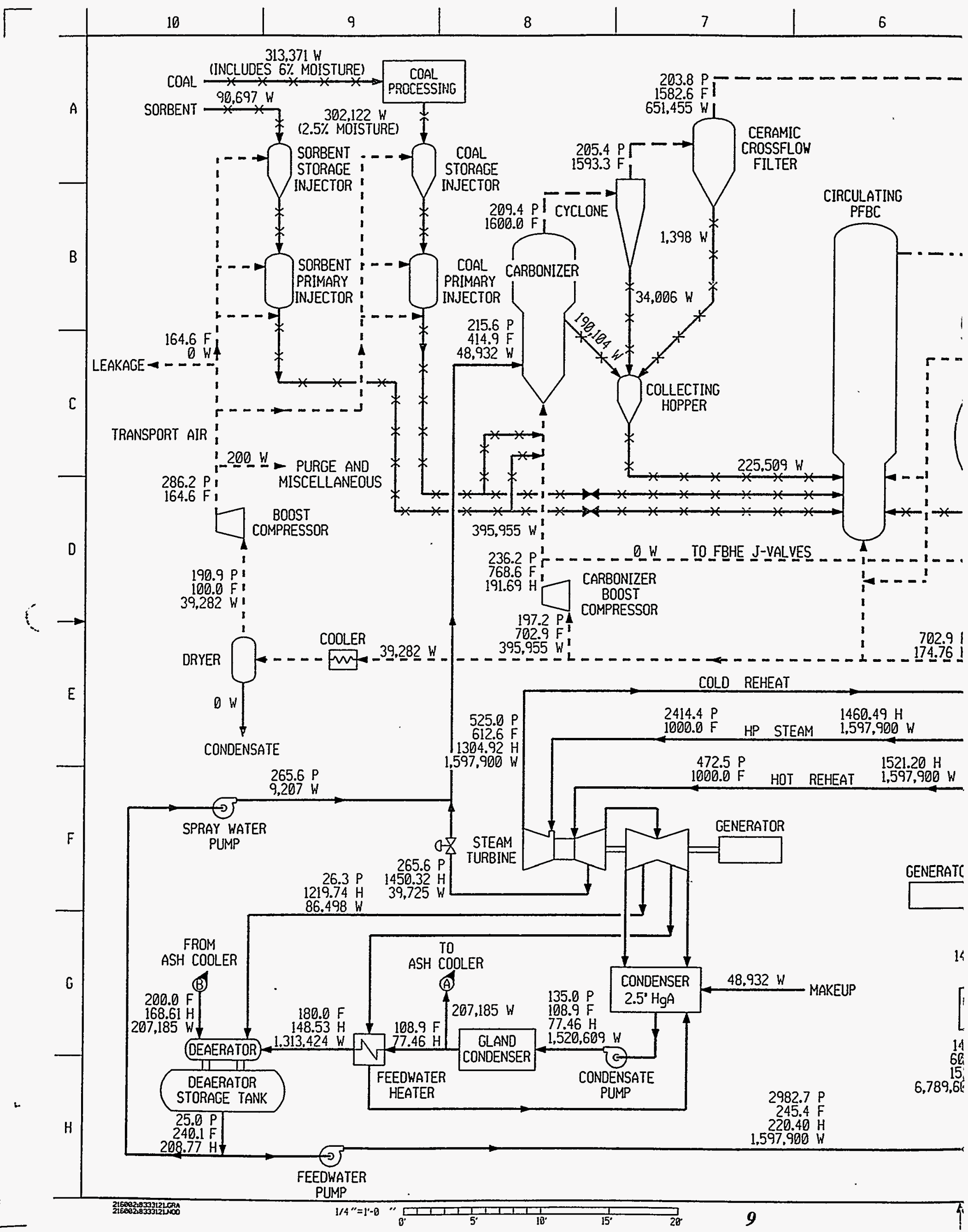




\subsection{DYNAMIC MODEL}

A PC-TRAX based dynamic model was constructed to simulate the performance of an Advanced (second-generation) Pressurized Fluidized Bed Combustion (APFBC) power plant under various transient conditions. PC-TRAX is a simulation package written in " $\mathrm{C}$ " language and mounted on a PC platform. To perform a simulation, PC-TRAX generates Advanced Continuous Simulation Language (ACSL) code, which is then converted in to Fortran, compiled, linked, and executed. The data package used by the model includes:

- Connectivity data, which define the interfaces between components blocks;

- Operational data, which specify the capacities of the equipment; and

- Performance data, which define the boundary conditions and internal settings within which the plant operates.

The carbonizer, char hopper, PFBC, fluid bed heat exchanger, ash cooler, and topping combustor are not part of PC-TRAX's standard library, so customized dynamic modules were written for these items in ACSL, which PC-TRAX combines with the PC-TRAX-written ACSL code. (The carbonizer and PFBC modules include cyclones and ceramic crossflow filters.) User-written Fortran subroutines have also been added for special, non-dynamic algorithms such as fluid properties that are not included with PC-TRAX software. Also, PC-TRAX macros are used to supplement the standard PCTRAX modules. Macro, Fortran, and ACSL source codes are included as appendixes.

This section describes the reference plant and preliminary assumptions used to construct the model. The complete PC-TRAX model is described in greater detail in the appendices.

\subsection{MODELING APPROACH}

The dynamic model is intended for use primarily to estimate steady-state and off-design performance, and secondarily to approximate the dynamic performance during selected transient conditions. Emission parameters are not calculated by the model.

The model was used to analyze the operation of the Reference PFBC-II plant under continuous-operation transients. During continuous-operation transients, all normally operating equipment is operating and flow paths remain in their normal configurations. Continuous-operation transients include: steady-state operation (for model calibration); turndown from $100 \%$ to $90 \%$ load; and turndown from $100 \%$ to $50 \%$ load. For continuous-operation transients, the TRAX model was used to track changes in key plant operating parameters.

\subsection{REFERENCE SYSTEM UPGRADE}

The original reference plant used the $1600^{\circ} \mathrm{F}$ carbonizer described in Figure 94 of the Second-Generation PFBC R\&D Phase I report [Robertson and others, 1989], and a 
modified Westinghouse 501D5 gas turbine. The current reference plant is similar to the original, except that it incorporates recent developments in carbonizer and gas turbine technology. Foster Wheeler has developed new carbonizer performance data at $1600^{\circ} \mathrm{F}$ based on their recent tests, and Westinghouse has developed the 501F gas turbine, which has different characteristics than the modified W501D5.

Figure 3-1 shows the progression of models from the steady-state base performance model (from the 1989 Phase 1 report) to the steady-state calibration model and the dynamic model used in this study. Revisions to carbonizer and gas turbine performance that cause the difference between the Phase 1 steady-state model and the Phase 2 steady-state model are listed in Table 3-1.

The PC-TRAX gas generation model is a simplified version of the gas generation "Spider" diagram 11/18/92, Rev. D. The Rev. D version shows the results of carbonizer tests, including small amounts of several gases, such as $\mathrm{NH}_{3}$ and $\mathrm{H}_{2} \mathrm{~S}$, which are not included in the PC-TRAX model. Table 3-2 compares the gas and char characteristics of the Rev.D diagram and the PC-TRAX model. For simplicity, transport air leakage, purge air, air to ash blowdown, and J-valve fluidizing air streams, which were part of the original steady-state flowsheet, are not modeled in the Update Reference Case.

\subsection{ASSUMPTIONS}

Preliminary assumptions used to construct the dynamic model are described below. Assumptions are described by area: plant, carbonizer, PFBC/FBHE, gas turbine, and steam turbine cycle. Detailed modeling assumptions can be found in the Appendices.

\subsubsection{Plant Assumptions}

The properties of ambient air, coal, and sorbent are characterized in Table $3-3$.

At $100 \%$ load, all coal and sorbent is fed to carbonizer, and none is fed to the PFBC.

The air flow network was simplified by combining several small air streams with the PFBC secondary air flow. The remaining principal air flows were maintained as shown in Figure 2-2. The small streams, which account for only about 1.5 percent of total air flow, are purge and miscellaneous air, leakage air, J-valve air, and ash blowdown air. In addition, condensate from the transport air dryer ( 0.007 percent of carbonizer air flow) is included with the transport air instead of being removed.

\section{$\underline{\text { 3.3.2 Carbonizer Assumptions }}$}

The original baseline plant had a $1600^{\circ} \mathrm{F}$ carbonizer fed by dry Pittsburgh No.8 coal and dry dolomite sorbent. Since then, Foster Wheeler developed new carbonizer performance data 
at $1600^{\circ} \mathrm{F}$ based on their recent tests, and the reference PFBC-II case was revised to reflect these developments. The revisions are listed in Table 3-1. 


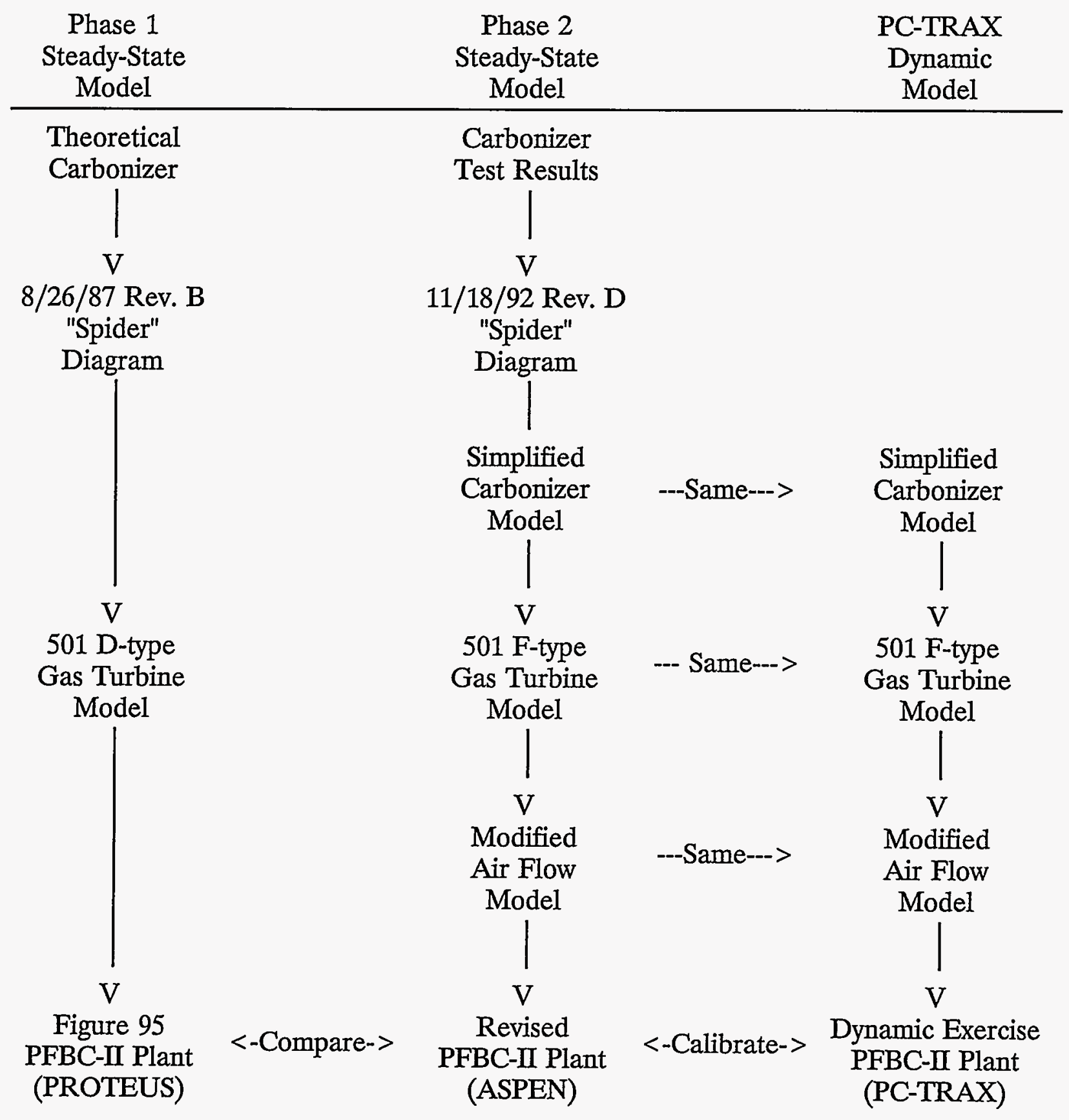

Figure 3-1 - Progression of Models 
Table 3-1

Revisions to Reference Plant

\begin{tabular}{|c|c|c|c|}
\hline $\begin{array}{l}\text { Module/ } \\
\text { Parameter }\end{array}$ & $\begin{array}{r}\text { Original } \\
\text { Plant } \\
\end{array}$ & $\begin{array}{r}4 / 15 / 94 \\
\text { Plant } \\
\end{array}$ & Reason \\
\hline Ash Cooler & Fig. 95 & $\mathrm{STP} / \mathrm{DF}^{*}$ & Carbonizer test results \\
\hline Air \& Gas Piping & Fig. 95 & $\mathrm{ST} / \mathrm{DPF}^{* *}$ & Carbonizer test results \\
\hline Ambient & $14.4 / 60^{\circ} \mathrm{F}$ & $14.4 / 60^{\circ} \mathrm{F}$ & \\
\hline Carbonizer Boost Compr & Fig. 95 & $\mathrm{ST} / \mathrm{DPF}^{* *}$ & Carbonizer test results \\
\hline $\begin{array}{l}\text { Carbonizer: } \\
\text { Diagram }\end{array}$ & $\begin{array}{r}\text { 8/26/87, } \\
\text { Rev. B }\end{array}$ & $\begin{array}{r}11 / 18 / 92, \\
\text { Rev. D }\end{array}$ & \\
\hline $\begin{array}{l}\text { Temperature } \\
\text { Steam Injection? } \\
\text { Gas/Coal flow, lb/lb } \\
\text { Gas HHV, Btu/lb } \\
\text { Gas/coal HHV Energy } \\
\text { Char/Coal flow, lb/lb } \\
\text { Char HHV, Btu/lb } \\
\text { Char/Coal HHV Energy }\end{array}$ & $\begin{array}{r}1600^{\circ} \mathrm{F} \\
\text { No } \\
2.140 \\
2,041 \\
36.3 \% \\
0.768 \\
8,839 \\
52.6 \%\end{array}$ & $\begin{array}{r}1600^{\circ} \mathrm{F} \\
\text { Yes } \\
2,150 \\
2,506 \\
41,7 \% \\
0.753 \\
8,800 \\
51.3 \%\end{array}$ & Carbonizer test results \\
\hline Coal \& Sorbent Feed & Fig. 95 & $\mathrm{STP} / \mathrm{DF}^{*}$ & Carbonizer test results \\
\hline Flare & Added & Added & Needed for control \\
\hline $\begin{array}{l}\text { Gas Turbine: } \\
\text { Basis } \\
\text { Inlet Airflow, lb/s } \\
\text { Firing Temp } \\
\text { Pressure ration }\end{array}$ & $\begin{array}{r}2 \times \text { W501D5 } \\
2 \times 925 \\
2350^{\circ} \mathrm{F} \\
14.1\end{array}$ & $\begin{array}{r}2 \times 501 \mathrm{~F} \\
2 \times 943 \\
22350^{\circ} \mathrm{F} \\
14.0\end{array}$ & $\begin{array}{l}\text { Newer turbine with } \\
\text { better capacity match }\end{array}$ \\
\hline HRSG & Fig. 95 & $\mathrm{STP} / \mathrm{DF}^{*}$ & Carbonizer test results \\
\hline $\mathrm{PFBC}+\mathrm{FBHE}$ & Fig. 95 & $\mathrm{ST} / \mathrm{DPF}^{* *}$ & Carbonizer test results \\
\hline Steam Turbine & Fig. 95 & $\mathrm{STP} / \mathrm{SF}^{*}$ & Carbonizer test results \\
\hline Steam \& Water Piping & Fig. 95 & $\mathrm{STP} / \mathrm{DF}^{*}$ & Carbonizer test results \\
\hline $\begin{array}{l}\text { Transport Air } \\
\text { Compressor }\end{array}$ & Fig. 95 & $\mathrm{ST} / \mathrm{DPF}^{* *}$ & Carbonizer test results \\
\hline
\end{tabular}


Table 3-2

Rev. D and PC-TRAX Carbonizer Comparison

\begin{tabular}{|c|c|c|c|}
\hline & $\begin{array}{r}\text { "Spider" } \\
\text { 11/18/92 } \\
\text { Rev. D } \\
\end{array}$ & $\begin{array}{r}\text { PC-TRAX } \\
\text { Carbonizer } \\
\text { Model } \\
\end{array}$ & \\
\hline Gas/Coal Ratio & 2.149 & 2.156 & $\mathrm{lb} / \mathrm{lb}$ \\
\hline Gas LHV & 2,247 & 2,185 & Btu/lb \\
\hline Char/Coal Ratio & 0.753 & 0.747 & $\mathrm{lb} / \mathrm{lb}$ \\
\hline Air/Coal Ratio & 1.441 & 1.441 & $\mathrm{lb} / \mathrm{lb}$ \\
\hline Steam/Coal Ratio & 0.162 & 0.162 & $\mathrm{lb} / \mathrm{lb}$ \\
\hline Sorbent/Coal Ratio & 0.300 & 0.300 & $\mathrm{lb} / \mathrm{lb}$ \\
\hline \multicolumn{4}{|l|}{ Gas Mass Fractions: } \\
\hline $\operatorname{Ar}$ & 0.0080 & - & included $\mathrm{w} / \mathrm{N}_{2}$ \\
\hline $\mathrm{CH}_{4}$ & 0.0268 & 0.0191 & \\
\hline $\mathrm{CO}$ & 0.2128 & 0.2057 & \\
\hline $\mathrm{CO}_{2}$ & 0.1629 & 0.1515 & \\
\hline $\mathrm{H}_{2}$ & 0.0141 & 0.0170 & \\
\hline $\mathrm{H}_{2} \mathrm{O}$ & 0.0691 & 0.0917 & \\
\hline $\mathrm{H}_{2} \mathrm{~S}$ & 0.0007 & - & \\
\hline $\mathrm{N}_{2}$ & 0.5033 & 0.5150 & \\
\hline $\mathrm{NH}_{3}$ & 0.023 & - & \\
\hline
\end{tabular}


Table 3-3

Air, Coal, and Sorbent Assumptions

AIR

\begin{tabular}{llll}
\hline 60.0 & ${ }^{\circ} \mathrm{F}$ & Ambient (dry-bulb) temperature \\
14.4 & $\mathrm{psia}$ & Ambient pressure \\
52.5 & ${ }^{\circ} \mathrm{F}$ & Wet-bulb temperature
\end{tabular}

COAL: Pittsburgh No. 8

\begin{tabular}{rrrl}
\hline Dried & As rec'd & & \\
\cline { 2 - 3 } 71.92 & 69.36 & $\%$ wt & Carbon \\
4.69 & 4.51 & \%wt & Hydrogen \\
1.26 & 1.22 & $\%$ wt & Nitrogen \\
6.33 & 6.08 & \%wt & Oxygen \\
2.99 & 2.89 & \%wt & Sulfur \\
10.31 & 9.94 & \%wt & Ash \\
2.50 & 6.00 & \%wt & Moisture \\
12,916 & 12,452 & Btu/lb & HFV
\end{tabular}

SORBENT: Plum Run Dolomite, as received

$\begin{array}{rll}54.5 & \% \text { wt } & \text { Calcium carbonate } \\ 43.3 & \% \text { wt } & \text { Magnesium carbonate } \\ 0.5 & \% \text { wt } & \text { Moisture } \\ 1.7 & \% \text { wt } & \text { Inerts } \\ 1.75 & : 1 & \mathrm{Ca} / \mathrm{S} \text { ratio }\end{array}$

The carbonizer model was simplified by assuming 100-percent sulfur capture and zero ammonia formation. Details of the carbonizer model are included in Appendix C.

\subsubsection{PFBC/FBHE Assumptions}

The circulating PFBC transfers heat through a separate fluid bed heat exchanger (FBHE). Details of the PFBC/FBHE model are included in Appendix D and E, respectively.

\subsubsection{Gas Turbine Assumptions}

The original gas turbine is a modified Westinghouse W501D5 with a 14.0:1 pressure ratio and a $2100^{\circ} \mathrm{F}$ topping combustor. The current reference gas turbine is a modified Westinghouse $501 \mathrm{~F}$ with a $14: 1$ pressure ratio and a $2350^{\circ} \mathrm{F}$ topping combustor. Details of the gas turbine model are included in Appendix $\mathrm{H}$. 


\subsubsection{Steam Turbine Assumptions}

The steam cycle is designed around a $2400-\mathrm{psig}, 1000^{\circ} \mathrm{F} / 1000^{\circ} \mathrm{F}$ reheat condensing steam turbine. Details of the steam turbine model are included in Appendix A.

\subsection{INTEGRATED PLANT MODEL}

The work is based on the baseline utility-sized PFBC-II plant described by the flow sheet in Figure 3-2. The plant model is divided into the areas coded below.

\begin{aligned} & Symbol Module \\ & \hline A Air piping \\ & B Steam bottoming cycle \\ & C Carbonizer area \\ & F Flare \\ & G Gas Turbine \\ & H HRSG \\ & P PFBC/FBHE area \\ & V Vitiated air \\ & \hline\end{aligned}

Relevant input and output parameters that functionally define the performance of each subsystem are listed in Table 3-4. Calibration was based on agreement between the results of the model and data from the revised Reference Plant (see Table 3-1) within the following accuracy bands:
a. Temperatures:
$+/-10^{\circ} \mathrm{F}$ of Revised Reference Plant data
b. Pressures:
$+/-10 \%$ of Revised Reference Plant data
c. Flows:
$+/-10 \%$ of Revised Reference Plant data

Mathematical models describing the response of each major subsystem to changes in its relevant parameters are outlined in Appendixes $\mathrm{C}$ through $\mathrm{H}$, and the source listings for the entire model are reproduced in Appendixes $\mathrm{K}, \mathrm{L}$, and $\mathrm{M}$. 
The model is much more detailed than the table below suggests, but, as a minimum, displays the basic operating parameters in Table $3-4$.

Table 3-4

Model Display Parameters

\begin{tabular}{|c|c|c|c|c|}
\hline ELEMENT & FLOW & PRESS & TEMP & OTHER \\
\hline Carbonizer & $\mathrm{X}$ & & & \\
\hline Sorbent & $\mathrm{X}$ & & & \\
\hline Plant & & & & $\begin{array}{c}\text { Gross } \mathrm{kW} \\
\text { Net } \mathrm{kW}\end{array}$ \\
\hline Carbonizer fuel gas & $\mathrm{X}$ & $\mathrm{X}$ & $\mathrm{X}$ & \\
\hline Carbo char/solids & $\mathrm{X}$ & $\bar{X}$ & $X$ & \\
\hline PFBC Coal & $\mathrm{X}$ & & & \\
\hline PFBC Vitiated Air & $\mathrm{X}$ & $\mathrm{X}$ & $\mathrm{X}$ & \\
\hline $\begin{array}{r}\text { Topping Combustor: } \\
\text { Fuel gas } \\
\text { Vitiated air } \\
\text { Gas exit }\end{array}$ & $\begin{array}{l}X \\
X \\
X\end{array}$ & $\begin{array}{l}X \\
X \\
X\end{array}$ & $\begin{array}{l}X \\
X \\
X\end{array}$ & \\
\hline Gas turbine air & $\mathrm{X}$ & $\mathrm{X}$ & $\bar{X}$ & \\
\hline Gas turbine exhaust & $X$ & $\mathrm{X}$ & $\bar{X}$ & \\
\hline Gas turbine & & & & Net kW \\
\hline $\begin{array}{r}\text { Heat Exchangers: } \\
\text { Hot Inlet } \\
\text { Hot Exit } \\
\text { Cold Inlet } \\
\text { Cold Exit } \\
\end{array}$ & $X$ & $\begin{array}{l}X \\
X \\
X \\
X \\
\end{array}$ & $\begin{array}{l}X \\
X \\
X \\
X \\
\end{array}$ & \\
\hline Throttle steam & $\mathrm{X}$ & $\mathrm{X}$ & $\bar{X}$ & \\
\hline Reheat steam & $\bar{X}$ & $\mathrm{X}$ & $\bar{X}$ & \\
\hline LP turbine exhaust & $\bar{X}$ & $\bar{X}$ & $\bar{X}$ & \\
\hline Steam turbine & & & & Net kW \\
\hline Condenser Condensate & $\mathrm{X}$ & $\mathrm{X}$ & $\bar{X}$ & \\
\hline $\begin{array}{r}\text { Condenser Cool'g Wtr } \\
\text { Cool'g water exit } \\
\end{array}$ & $\bar{X}$ & $\begin{array}{l}X \\
X\end{array}$ & $\begin{array}{l}\mathrm{X} \\
\mathrm{X}\end{array}$ & \\
\hline
\end{tabular}




\subsection{STEADY-STATE SIMULATIONS}

Following completion of the model, steady-state results at 100 percent of design load were compared to results generated with the steady-state software tool ASPEN ${ }^{\mathrm{TM}}$. ASPEN, an acronym for Advanced System for Process Engineering, provided the original steady-state conditions which served as a template for the dynamic TRAX based model.

Comparison of the steady state models showed good agreement amongst all of the process variables. The uncontrolled process model was sufficiently stable to run a half hour before generating a math coprocesser error. Good agreement between the steady-state models indicated it was time to proceed to the next modeling level.

Following satisfactory steady-state model performance, the control model was constructed and integrated with the process model. Each control loop was individually tuned to determine appropriate gains and constants. The fully integrated and controlled model results were then compared to the steady-state ASPEN results. Good agreement was found. Table 4-1 compares various primary process values generated by each model. The PCTRAX variables shown in Table 4-1 correspond to a run time of eight hours.

As can be seen in Table 4-1, there is very good agreement between most of the process variables listed. Carbonizer and PFBC temperatures and flowrates show very little variance. The gas and steam turbine power outputs also compare favorably. The most striking difference in model variables is the HRSG exhaust temperature which differs by $29^{\circ} \mathrm{F}$. This difference is due to small differences in the thermodynamic methods of the two codes. Both codes use the ASME steam tables but differ in the gas side calculation. Figure 4-1 contains a plot of the carbonizer, PFBC, and topping combustor temperatures at steady-state conditions. The time scale for the plot is 50 minutes. As can be seen in the figure, the carbonizer temperature shows little variation and remains steady. The PFBC temperature remains uniform but shows a slight variation of plus or minus $0.7^{\circ} \mathrm{F}$.

The variation in PFBC temperature requires further explanation. The temperature variation appeared following integration of the topping and steam bottoming cycle. The stand alone topping cycle model produced a PFBC temperature with no variation. The temperature wobble is due to the highly interactive nature of the power cycle as well as the chosen control strategy. These concepts will be discussed in Section 5.

Figure 4-2 shows a plot of the carbonizer, FBHE freeboard, PFBC, and topping combustor pressures at steady-state conditions. As was the case in Figure 4-2, the time scale for the plot is 50 minutes. The same scale for all four variables was used so that the direction of gas flow could be visualized. Carbonizer pressure is greatest, followed by the FBHE, then the PFBC, and finally the topping combustor. The FBHE freeboard pressure must be greater than the PFBC pressure so that the FBHE fluidizing air may pass into the PFBC 
secondary combustion zone. Obviously, the topping combustor pressure must be lower than that of the PFBC.

Table 4-1

Steady-State Calibration Comparison

\begin{tabular}{||l|r|r|r||}
\hline \hline Parameter & ASPEN Model & PC-TRAX Model & Variance \\
\hline Coal Flow & $151,061 \mathrm{lb} / \mathrm{h}$ & $151,061 \mathrm{lb} / \mathrm{h}$ & $0 \%$ \\
\hline Carbonizer Temp & $1,600 \mathrm{~F}$ & $1,600 \mathrm{~F}$ & $0 \%^{*}$ \\
\hline Fuel Gas Flow & $325,727 \mathrm{lb} / \mathrm{h}$ & $326,000 \mathrm{lb} / \mathrm{h}$ & $-0.08 \%$ \\
\hline Char Flow & $112,754 \mathrm{lb} / \mathrm{h}$ & $112,550 \mathrm{lb} / \mathrm{h}$ & $0.16 \%$ \\
\hline PFBC Temp & $1,600 \mathrm{~F}$ & $1,600 \mathrm{~F}$ & $0 \%{ }^{*}$ \\
\hline Vitiated Air Flow & $2,702,371 \mathrm{lb} / \mathrm{h}$ & $2,700,100 \mathrm{lb} / \mathrm{h}$ & $0.08 \%$ \\
\hline Topp Comb Temp & $2,350 \mathrm{~F}$ & $2,350 \mathrm{~F}$ & $0 \%{ }^{*}$ \\
\hline GT Exhaust Flow & $3,564,850 \mathrm{lb} / \mathrm{h}$ & $3,567,200 \mathrm{lb} / \mathrm{h}$ & $-0.07 \%$ \\
\hline GT Exhaust Temp & $1,141 \mathrm{~F}$ & $1,141 \mathrm{~F}$ & $0 \%$ \\
\hline HRSG Exit Temp & $280 \mathrm{~F}$ & $309 \mathrm{~F}$ & $-3.8 \%{ }^{*}$ \\
\hline Throttle Stm Flow & $1,597,900 \mathrm{lb} / \mathrm{h}$ & $1,589,800 \mathrm{lb} / \mathrm{h}$ & $0.51 \%$ \\
\hline Deaerator Steam & $86,498 \mathrm{lb} / \mathrm{h}$ & $80,605 \mathrm{lb} / \mathrm{h}$ & $7.23 \%$ \\
\hline Gas Turb Power & $280 \mathrm{~kW}$ & $276 \mathrm{~kW}$ & $1.4 \%$ \\
\hline Stm Turb Power & $280 \mathrm{~kW}$ & $282 \mathrm{~kW}$ & $-0.7 \%$ \\
\hline Auxiliary Power & $22 \mathrm{~kW}$ & $22 \mathrm{~kW}$ & $0 \%$ \\
\hline Plant Net Power & $538 \mathrm{~kW}$ & $536 \mathrm{~kW}$ & $0.3 \%$ \\
\hline HHV Efficiency & $46.75 \%$ & $46.57 \%$ & $0.4 \%$ \\
\hline \hline
\end{tabular}

* Temperature variances based on absolute temperatures.

Figure 4-3 contains a plot of steam turbine pressure, steam turbine power, and deaerator storage tank water level. Both the high pressure steam header pressure and deaerator storage tank level are very steady. However, the steam turbine power output shows a consistent saw-tooth variation of $2 \mathrm{MWe}$. This variation causes no real problems. The saw-tooth is due to a slight interface instability and is explained in further detail in Appendix B. 


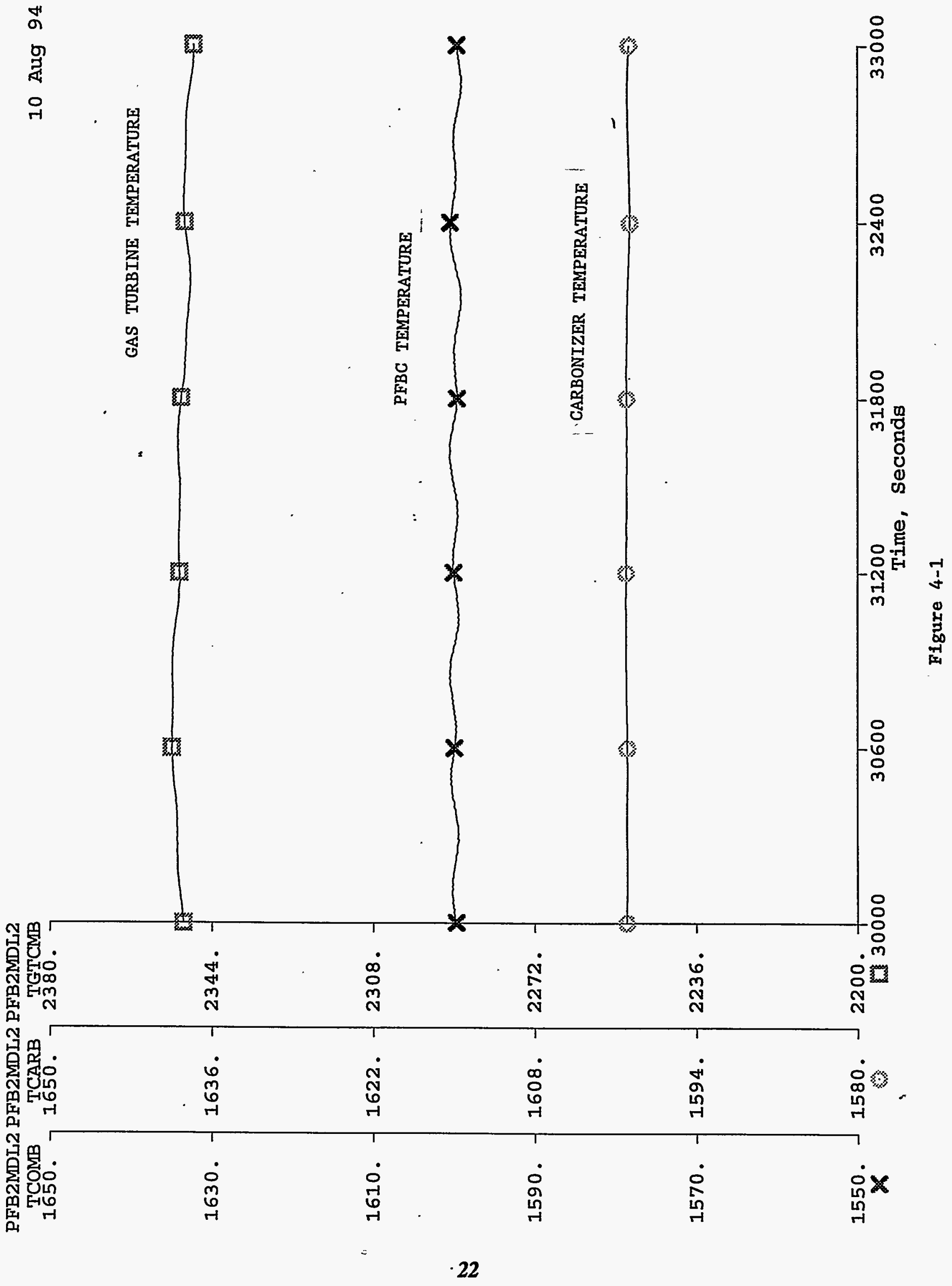




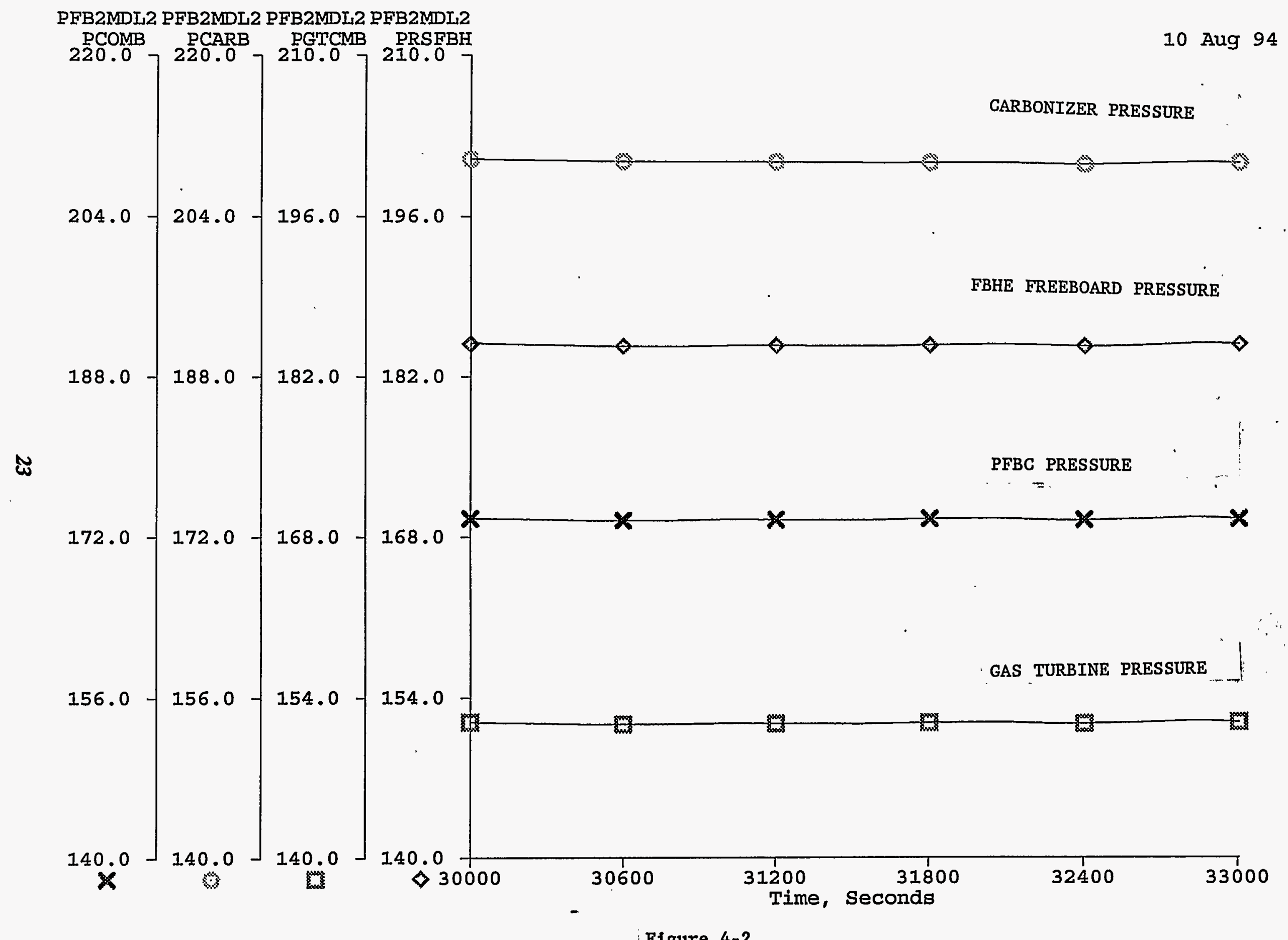

Figure 4-2 
PFB2MDL I PFB2MDL 1 PFB2MDL 1

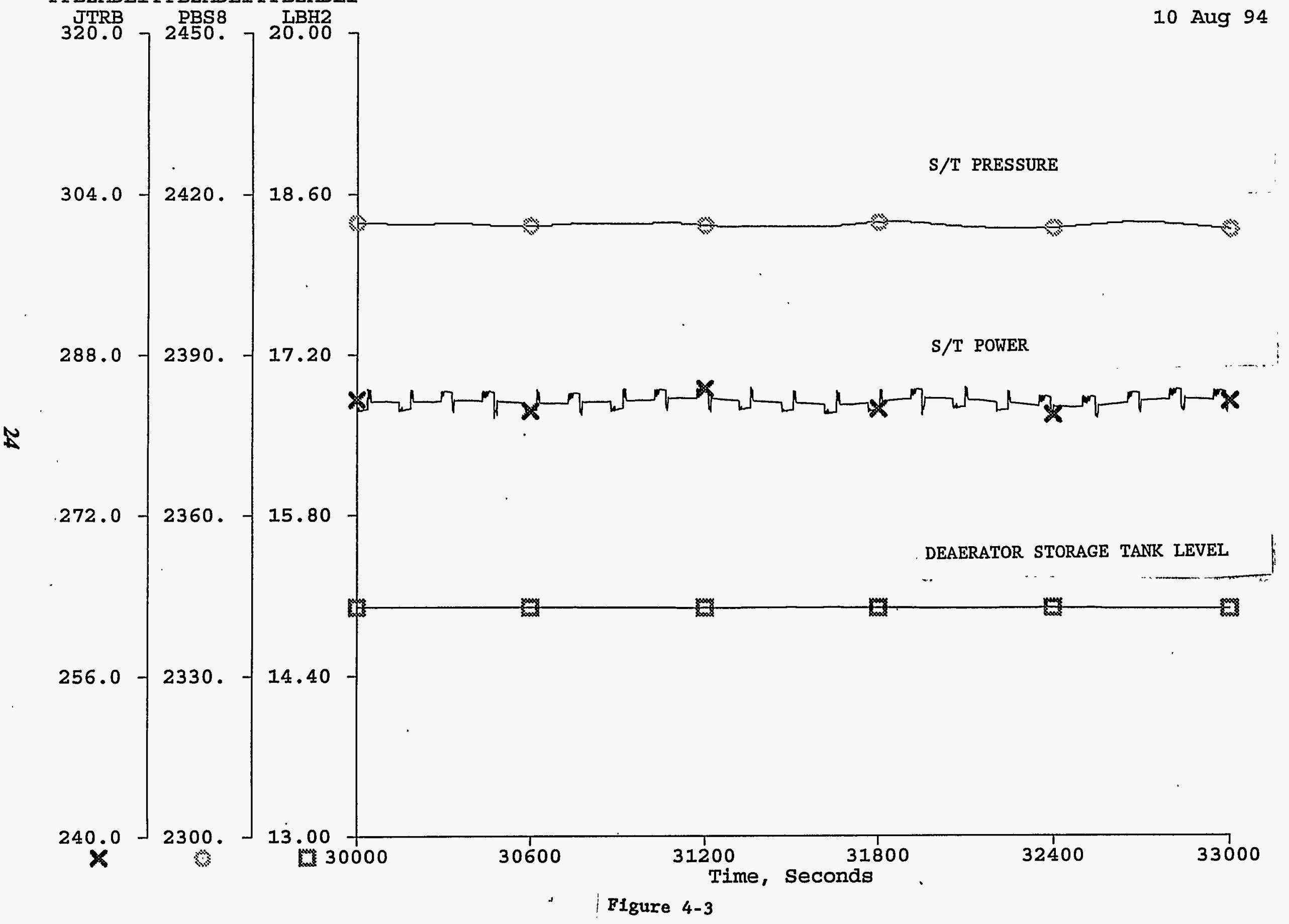




\subsection{TRANSIENT SIMULATIONS}

Following calibration of the model at 100 percent load, two transient simulations were run: 100 percent to 90 percent; and 100 percent to 50 percent. Transient simulations were run for four reasons:

1. To verify operation of the model by observing the interactions of major plant subsystems during a minor turndown from 100 percent to 90 percent load;

2. To determine whether the plant can be turned down to 50 percent load;

3. To determine what happens to the unrestricted variables (such as pressures, temperatures, and flows) when the plant is subjected to specified operating and upset conditions. (Ranges of process variables will not be restricted.)

4. To determine the speed with which the plant can shed or add load.

The commercial size PFBC-II plant consists of two identical topping cycle trains (carbonizer, PFBC/FBHE, ash cooler, topping combustor, gas turbine, and HRSG) and a single bottoming cycle train (HP/IP/LP reheat steam turbine, deaerator, condenser, and cooling tower). Since one of the purposes of this study is to determine the extent to which the plant can be turned down, the flows in both topping cycle trains are varied together to maximize the turndown of the plant. In actual operation, the two topping cycle trains could also be turned down individually to separate set points. Future studies could include this mode of operation as well and provide insight into the advantages of each method.

\subsection{TURNDOWN FROM 100\% TO 90\% LOAD}

With the present control scheme, total plant power output is varied by ramping coal flow. During execution of the model, the analyst manually inputs a ramp rate and final value. This section will discuss the results of a minor turndown. A ramp decrease of 10 percent coal flow at a rate of 1 percent a minute was used. Due to the transmitter range, the 10 percent change is actually a 11.9 percent change in absolute numbers.

Table 5-1 contains tabulated results for plant operation at 90 percent of load. These values are compared to those generated at 100 percent of load. At 90 percent load, the carbonizer temperature remains at $1,600^{\circ} \mathrm{F}$, but the fuel gas and char flows decrease by about 12 percent compared to the 100 percent load values. Similar results are generated by the PFBC.

The gas turbine is a constant volume machine that delivers nearly constant air mass (mass flow changes with ambient conditions and IGV position). Therefore, the mass 
flow through the GT and HRSG changes very little. A variance of 0.7 percent is shown in Table 5-1. What changes however, is the amount of fuel entering the GT. Less fuel input corresponds to more excess air, which produces lower turbine inlet and exit temperatures. The turbine inlet temperature decreased from $2,350^{\circ} \mathrm{F}$, at 100 percent load, to $2,160^{\circ} \mathrm{F}$ at 90 percent load.

Decreased plant fuel input results in less energy recovered by the bottoming cycle. This causes a decrease in throttle steam flow, as shown in Figure 5-1. Throttle steam flow decreased from $1,589,800 \mathrm{lb} / \mathrm{hr}$ at 100 percent load, to $1,332,000 \mathrm{lb} / \mathrm{hr}$ at 90 percent of load. This is a 16 percent decrease.

In the HRSG, decreased flue gas and water flows produce a new temperature profile, coupled with a fixed geometry, resulting in decreased energy removal. Since the boiler feed water temperature changes very little, this results in a higher flue gas outlet temperature. The HRSG exit temperature increased from $309^{\circ} \mathrm{F}$ at 100 percent load, to $323^{\circ} \mathrm{F}$ at 90 percent load.

Table 5-1

Performance at 90 percent Load

\begin{tabular}{||l|r|r|r||}
\hline Parameter & $100 \%$ Load & $90 \%$ Load & Change \\
\hline Coal Flow & $151,061 \mathrm{lb} / \mathrm{h}$ & $133,060 \mathrm{lb} / \mathrm{h}$ & $-11.9 \%$ \\
\hline Carbonizer Temp & $1,600 \mathrm{~F}$ & $1,600 \mathrm{~F}$ & $0 \% *$ \\
\hline Fuel Gas Flow & $326,000 \mathrm{lb} / \mathrm{h}$ & $288,100 \mathrm{lb} / \mathrm{h}$ & $-11.6 \%$ \\
\hline Char Flow & $112,550 \mathrm{lb} / \mathrm{h}$ & $98,879 \mathrm{lb} / \mathrm{h}$ & $-12.1 \%$ \\
\hline PFBC Temp & $1,600 \mathrm{~F}$ & $1,600 \mathrm{~F}$ & $0 \% *$ \\
\hline Vitiated Air Flow & $2,700,100 \mathrm{lb} / \mathrm{h}$ & $2,260,000 \mathrm{lb} / \mathrm{h}$ & $-16.3 \%$ \\
\hline Topp Comb Temp & $2,350 \mathrm{~F}$ & $2,160 \mathrm{~F}$ & $-8.1 \%{ }^{*}$ \\
\hline GT Exhaust Flow & $3,567,200 \mathrm{lb} / \mathrm{h}$ & $3,542,200 \mathrm{lb} / \mathrm{h}$ & $-0.7 \%$ \\
\hline GT Exhaust Temp & $1,141 \mathrm{~F}$ & $1,019 \mathrm{~F}$ & $-7.1 \%$ \\
\hline HRSG Exit Temp & $309 \mathrm{~F}$ & $323 \mathrm{~F}$ & $+1.8 \%$ \\
\hline Throttle Stm Flow & $1,589,800 \mathrm{lb} / \mathrm{h}$ & $1,322,000 \mathrm{lb} / \mathrm{h}$ & $-16.2 \%$ \\
\hline Deaerator Steam & $80,665 \mathrm{lb} / \mathrm{h}$ & $69,708 \mathrm{lb} / \mathrm{h}$ & $-13.6 \%$ \\
\hline Gas Turb Power & $276 \mathrm{~kW}$ & $234 \mathrm{~kW}$ & $-15.2 \%$ \\
\hline Stm Turb Power & $282 \mathrm{~kW}$ & $242 \mathrm{~kW}$ & $-14.1 \%$ \\
\hline \hline
\end{tabular}

* Temperature variances based on absolute temperatures.

Analysis of variable plots indicate that while the plant can be turned down to 90 percent of load, the turndown takes an extended period of time to stabilize. Also, plant turndown produces various excursions which are intolerable from the standpoint of 
real-life hardware. The problem is most pronounced in the operation of the PFBC. The present control scheme, which favored high efficiency operation during turndown, slaves the PFBC/FBHE to the steam bottoming cycle. The combination produces less than optimal results. The following discussion provides a more in-depth analysis of the turndown.

Figure 5-1 contains a plot of the carbonizer temperature, carbonizer primary air flow, and total plant coal flow. The time period plotted is roughly 3.3 hours and the coal ramp is for a 10 percent decrease at a rate of 1 percent a minute. For the first 10 minute ramp period, primary air flow is regulated to maintain a carbonizer temperature of $1,600^{\circ} \mathrm{F}$. Following the 10 minute ramp period, the primary air flow sharply increases before entering a prolonged period of oscillation. The overall trend is a decrease in the primary air flow, which is expected. Although the carbonizer temperature remains close to $1,600^{\circ} \mathrm{F}$, i.e., maximum excursion is $1,607^{\circ} \mathrm{F}$, operation is less than favorable.

Carbonizer $\mathrm{CH}_{4}$ and $\mathrm{H}_{2}$ production are shown in Figure 5-2 for the same 10 percent ramp. Both values decrease due to decreased fuel input. The decrease in these gases is expected. While $\mathrm{CH}_{4}$ production decreases smoothly, $\mathrm{H}_{2}$ production decreases in a jagged, oscillatory manner. The LHV content of the fuel gas varies along with $\mathrm{H}_{2}$ production.

Figure 5-3 contains a plot of the carbonizer pressure, carbonizer pressure drop, and solids elutriation rate. Solids elutriation rate decreases due to decreased superficial gas velocity through the carbonizer freeboard. Gas velocity decreases due to lowered primary air flow. A slight increase in the carbonizer pressure drop is shown. This reflects small changes in the bulk gas density due to decreased carbonizer pressure.

Figures 5-1, 5-2, and 5-3 reflect expected chemical, thermodynamic, and hydrodynamic phenomena. What wasn't expected is the large excursions some variables exhibit during the transient. This behavior results from interaction with downstream process variables.

Interaction between the PFBC/FBHE, topping combustor, process air supply, and the steam generating component of the bottoming cycle is highly pronounced. A change in one process variable of this group has a dramatic affect on the other variables. The present control approaches and integrated dynamics preclude a stable response to changes in load.

Figure 5-4 shows a plot of PFBC temperature and PFBC secondary air flow for a time period of roughly 1.5 hours. The plot was generated during the ramp decrease in coal of 10 percent at 1 percent a minute as shown in Figure 5-1. Initially, PFBC temperature drops about $10^{\circ} \mathrm{F}$ prior to recovering to $1600^{\circ} \mathrm{F}$. Following a smaller drop in temperature, the $\mathrm{PFBC}$ temperature sharply rises to $1630^{\circ} \mathrm{F}$ prior to entering a highly 
oscillatory response which requires several hours to damp out. . As can be seen in Figure 5-4, the secondary air flow changes in response to PFBC temperature.

It is obvious in Figure 5-4 that the secondary air flow is not causing the temperature swings. Rather, the air is changing in response to temperature swings in the PFBC. Figure 5-5 shows a plot of PFBC temperature and solids flow through the FBHE reheat pass for the same time period. The apex of the PFBC temperature plot corresponds to the nadir of the FBHE reheater solids flow. As solids are diverted from the reheater pass, less heat is removed in the FBHE and the PFBC temperature rises. An increase in solids flow through the reheater pass causes a sharp decrease in PFBC temperature.

Solids flow in the reheater pass are regulated to maintain superheat and reheat steam temperature. As less steam flows through the system, lesser amounts of solids are required in the FBHE superheater and reheater pass. As greater amounts of steam flows through the system, more solids are required in the FBHE superheater and reheater pass. Steam flow deceases with lowered waste heat generation and is expected due to the drop in fuel input. However, the lengthy oscillations are not expected.

Figure 5-6 contains a plot of process air header pressure and air bypass valve stem position. As the air requirements decrease in response to decreased coal feed, excess air is available and begins to increase the air compressor back pressure. A bypass valve is used to drain air out of the air header. For maximum efficiency, the air is routed to the topping combustor. Opening the air bypass valve deceases the air header pressure resulting in normal compressor work requirements.

Routing relatively cold air $\left(700^{\circ} \mathrm{F}\right)$ into the topping combustor $\left(2,350^{\circ} \mathrm{F}\right)$ produces a decreased topping combustor temperature. This can be seen in Figure 5-7 which shows a plot of the bypass air valve stem position and topping combustor temperature. As the valve opens, topping combustor temperature decreases. As the bypass valve closes, topping combustor temperature increases.

Lowered topping combustor temperatures result in lowered turbine rotor and exhaust temperatures. Lowered flue gas temperature and massflow contributes to a modified temperature profile in the HRSG. Constrained by pinch points, the HRSG becomes more inefficient, leading to decreased steaming and higher flue gas exhaust temperatures. Less heat is removed from the HRSG flue gas resulting in decreased steam production. Figure 5-8 shows a plot of HRSG drum feed flowrate, H/P steam flowrate, and solids flow in the FBHE reheater pass. As shown in the figure, decreased FBHE reheater solids flow follows decreased steaming in the HRSG.

Examination of the plots suggests the following. A decrease in plant load lowers the air requirements in the carbonizer and PFBC. Air is bypassed from the air header into the topping combustor to lower the compressor discharge pressure thereby lowering the 
compressor work requirements. Air bypass lowers the plant steaming rate which in turn decreases steam flow to the turbine. Lowered steam flow requires less solids to flow through the FBHE superheat and reheat passes, which in turn, causes the PFBC temperature to increase. This cycle is restarted as the air PFBC secondary air valve opens in an effort to lower the PFBC temperature. This can be seen in Figure 5-9 which shows a plot of $\mathrm{H} / \mathrm{P}$ steam flow, PFBC temperature, and PFBC secondary air flow.

Figure 5-10 shows a plot of the pressures in the carbonizer, FBHE, PFBC, and topping combustor. It can be seen that the carbonizer is least affected by the dynamics of the bottoming cycle. The other vessel pressures show wide oscillatory response. Allowing the FBHE solids distribution to be controlled as a function of steam flow and bypassing air into the topping combustor are believed to cause the unstable response shown in these figures. The unstable response is unacceptable from a controls point of view. Figure 5-11 shows steam turbine and gas turbine power for the coal ramp decrease.

To obtain adequate plant response, the control scheme must be changed. Several variations of the scheme were tried and discussed in Section 8. None were successful. Each control scheme involved the bypassing of compressor air from the air header into the topping combustor in response to decreased air requirements due to decreased coal flow.

Various alternative control schemes have been proposed. The proposed schemes attempt to make the PFBC/FBHE arrangement and steam bottoming cycle less interactive by introducing new control parameters such as attemperation in the reheater and superheater passes, or the inclusion of coal feed to the PFBC during transients. These alternatives will be investigated in future work.

\subsection{TURNDOWN FROM 100\% TO 50\% LOAD}

Due to the difficulties discussed in Section 5.1, stable operation at 50 percent of load could not be achieved with the current control scheme. The controls must be reworked to allow turndown to 50 percent. The three plots discussed below show the characteristics of the current scheme.

Figure 5-12 contains a plot of the vessel pressures in the carbonizer, FBHE, PFBC, and topping combustor for a 50 percent turndown at 1 percent a minute. Each vessel pressure decreases as expected.

Figure 5-13 shows a plot of coal flow, PFBC temperature, and PFBC secondary air flow for a 50 percent turndown at 1 percent a minute. As can be seen in the figure, PFBC temperature demonstrates oscillatory response to the change in load. Also, the PFBC secondary air flow rate is driven to zero, indicating that a more robust control scheme is required. 
Figure 5-14 shows the power output for the GT and steam turbine during the 50 percent decrease in coal flow. As seen in Section 5.1, turbine power output is not well behaved. 


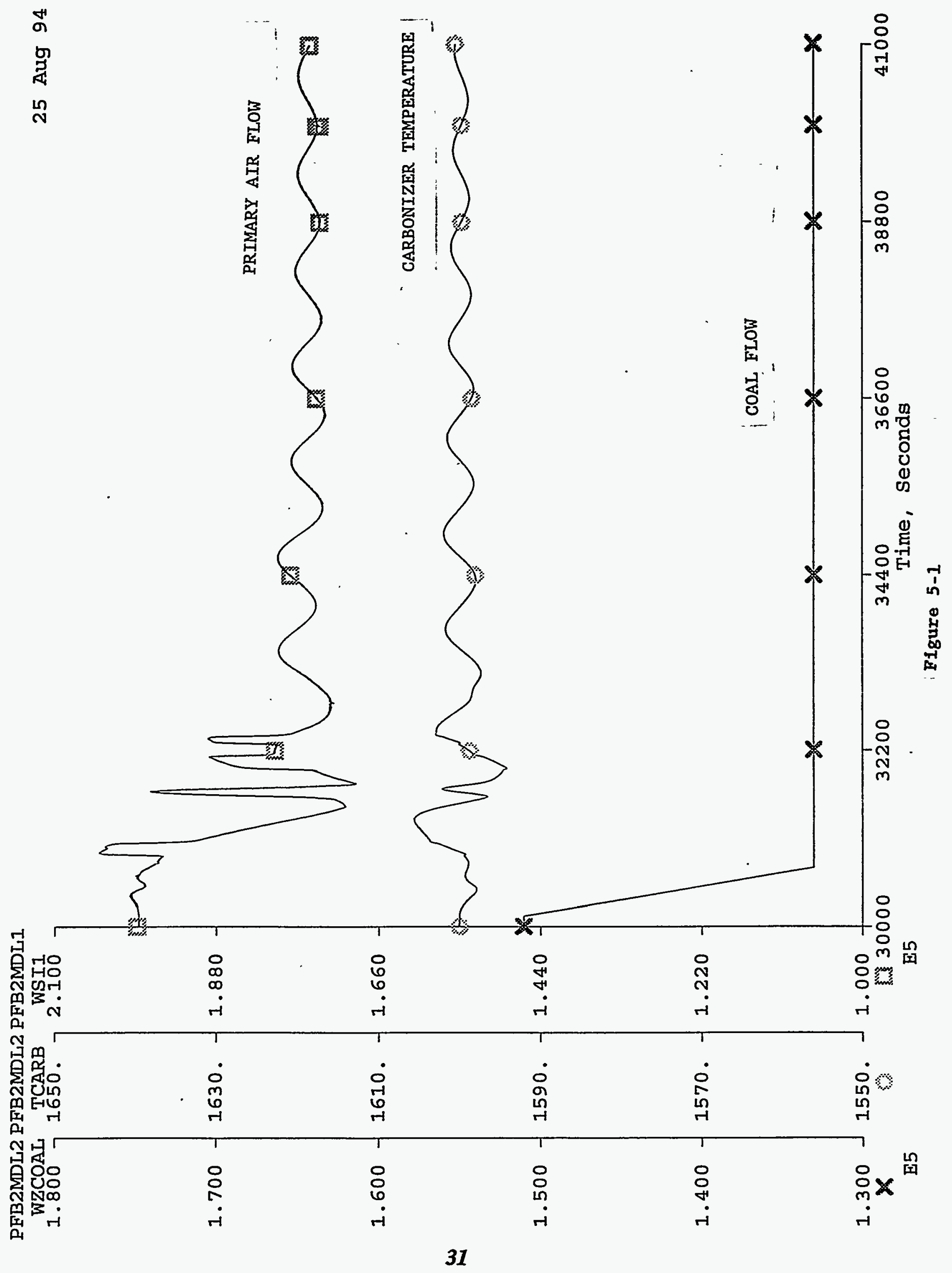




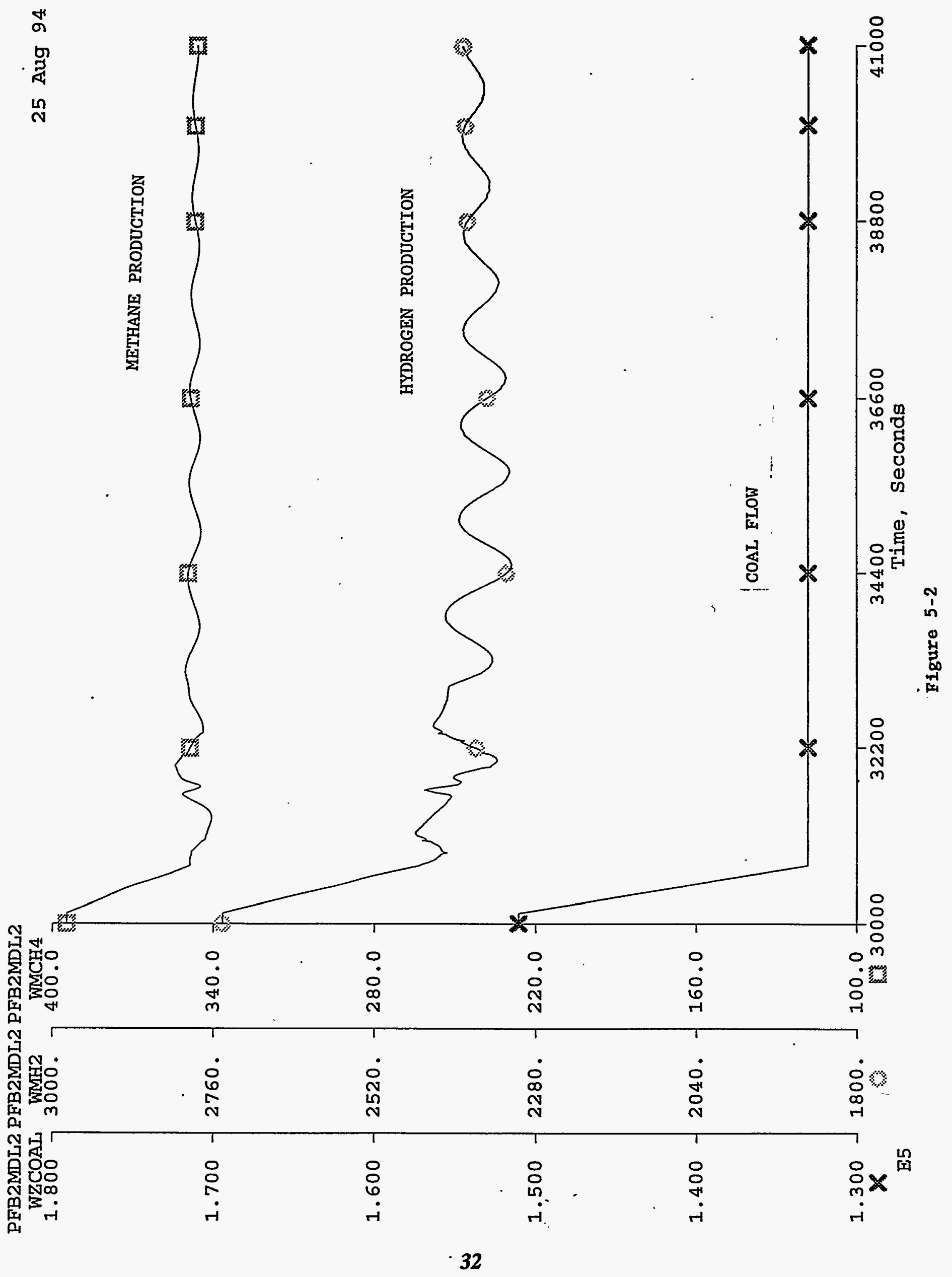




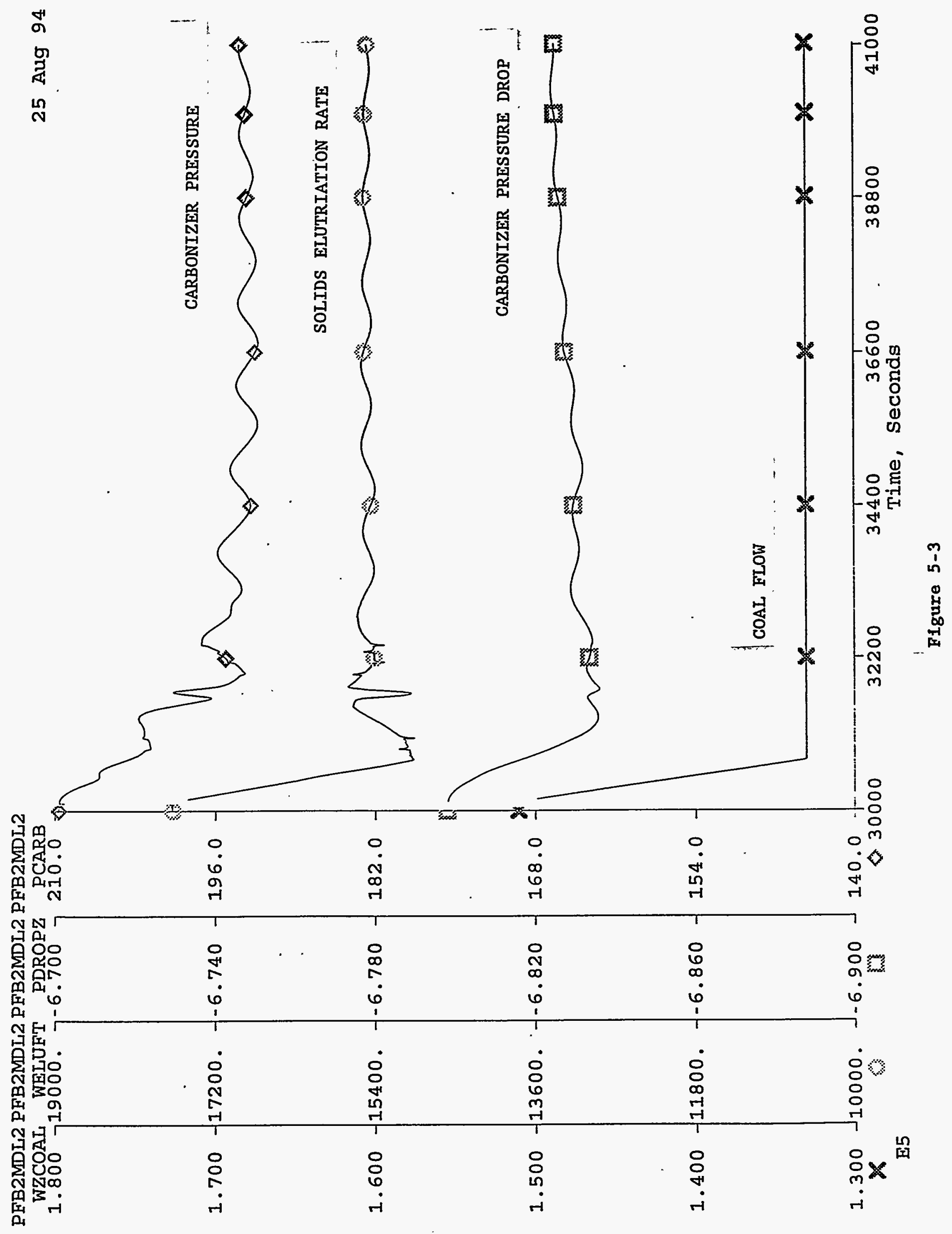




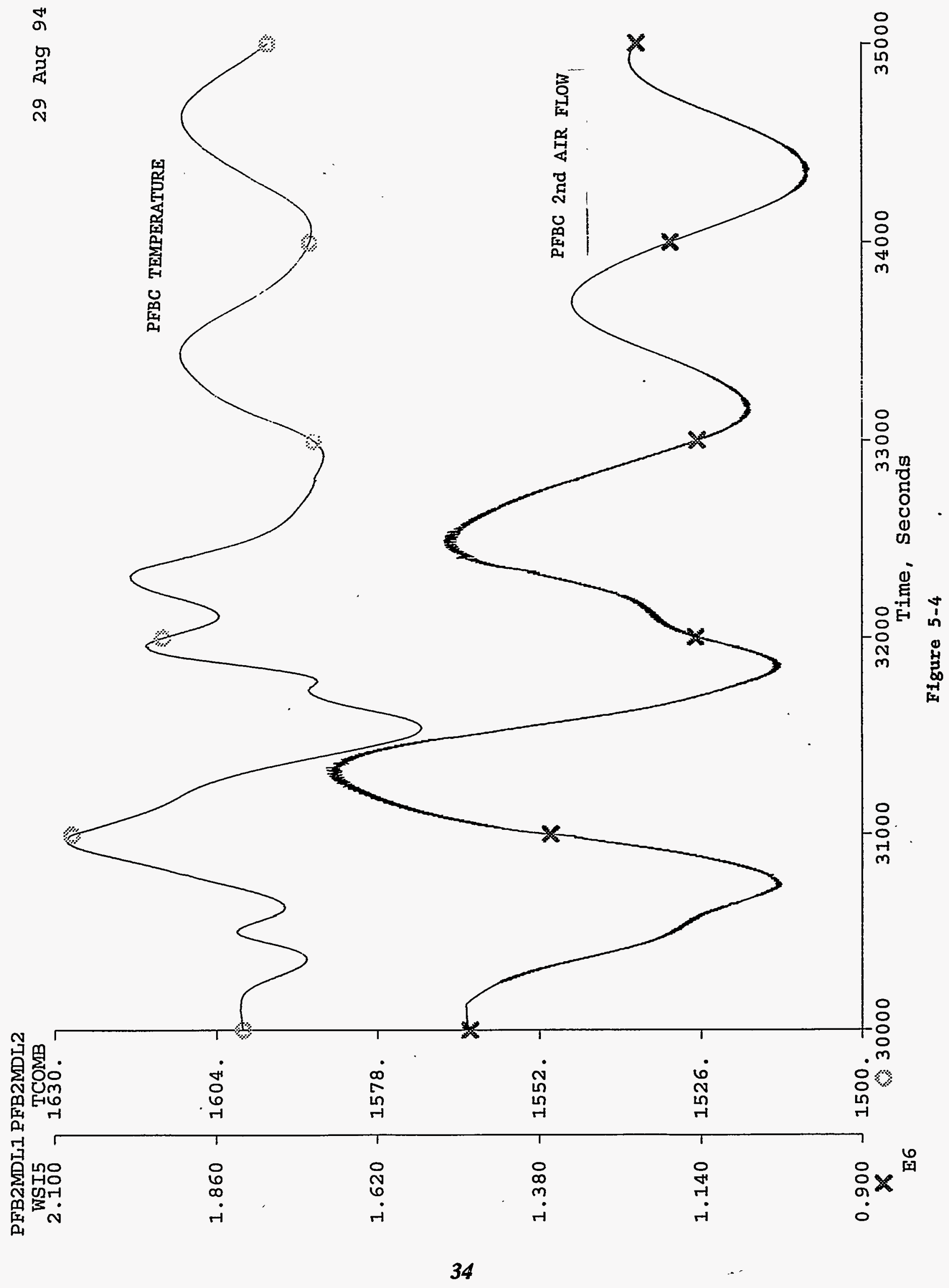




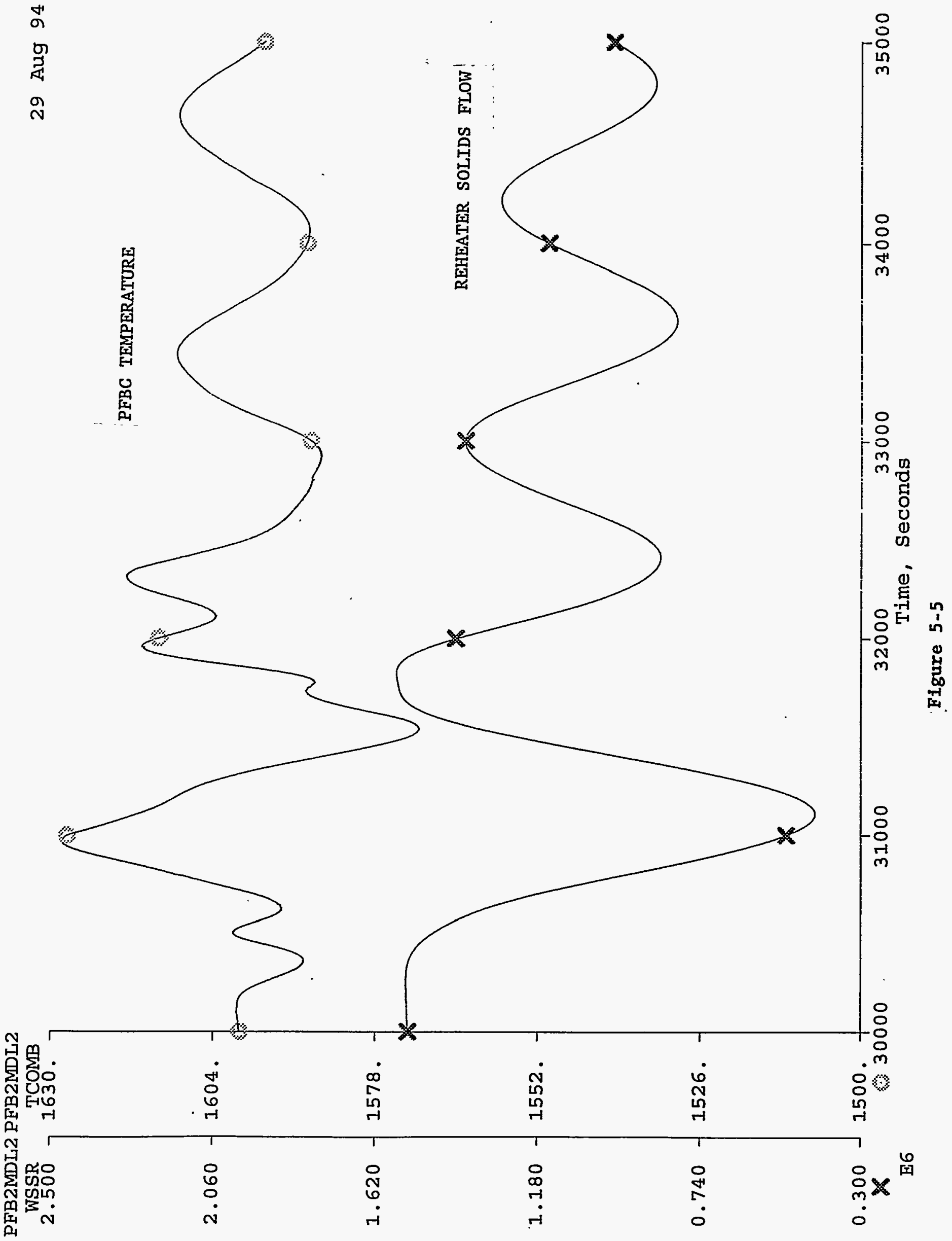




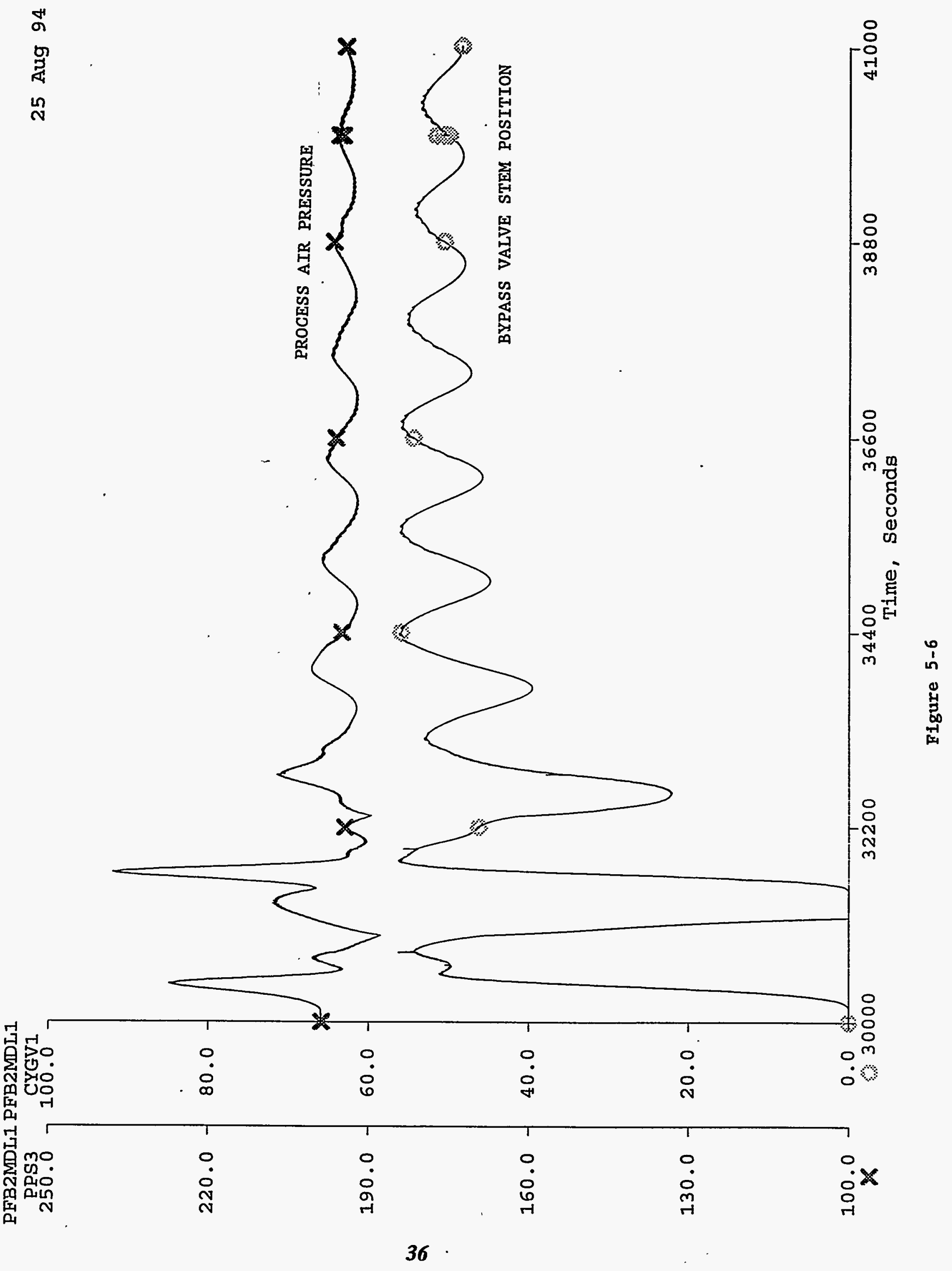




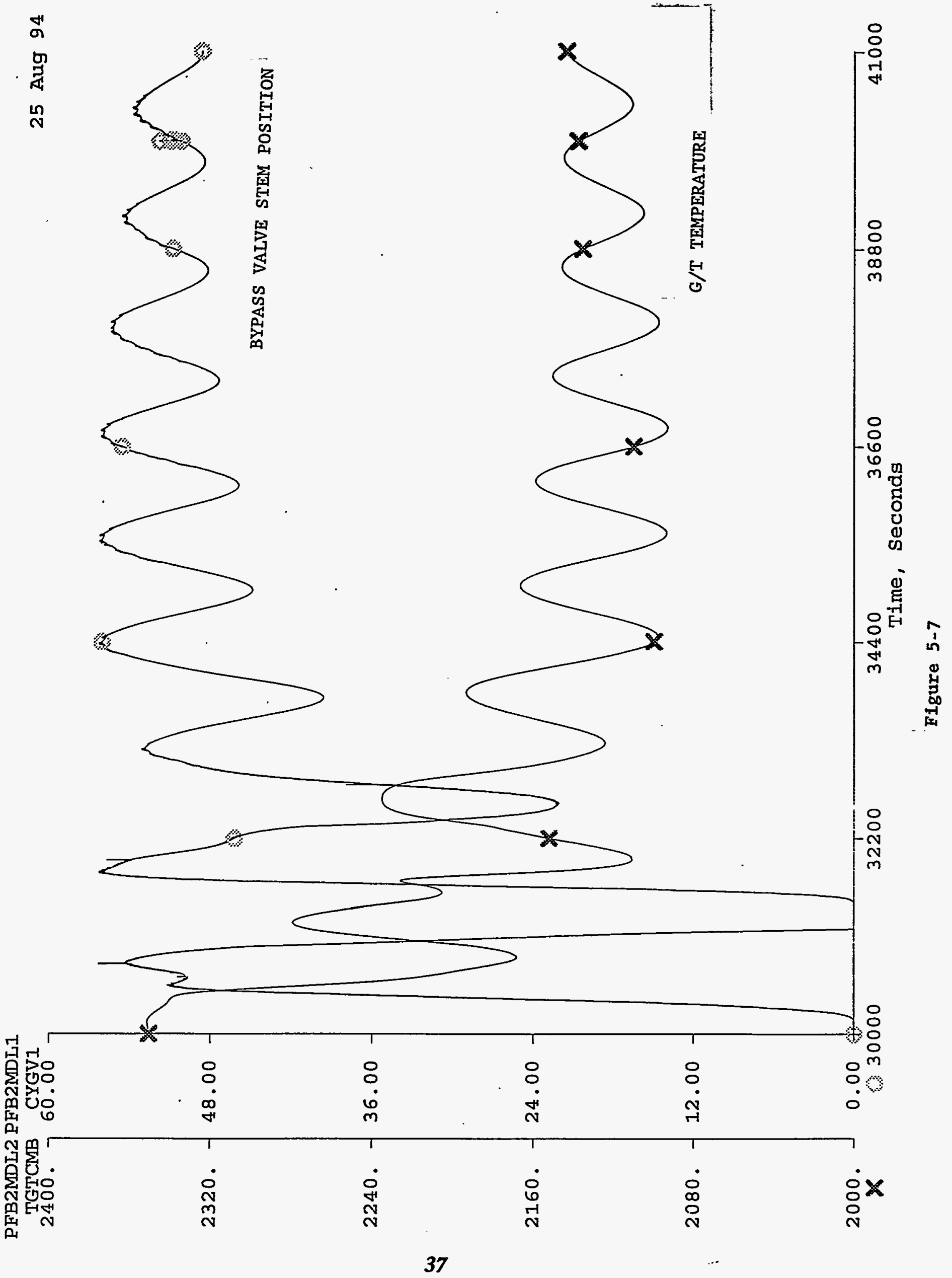




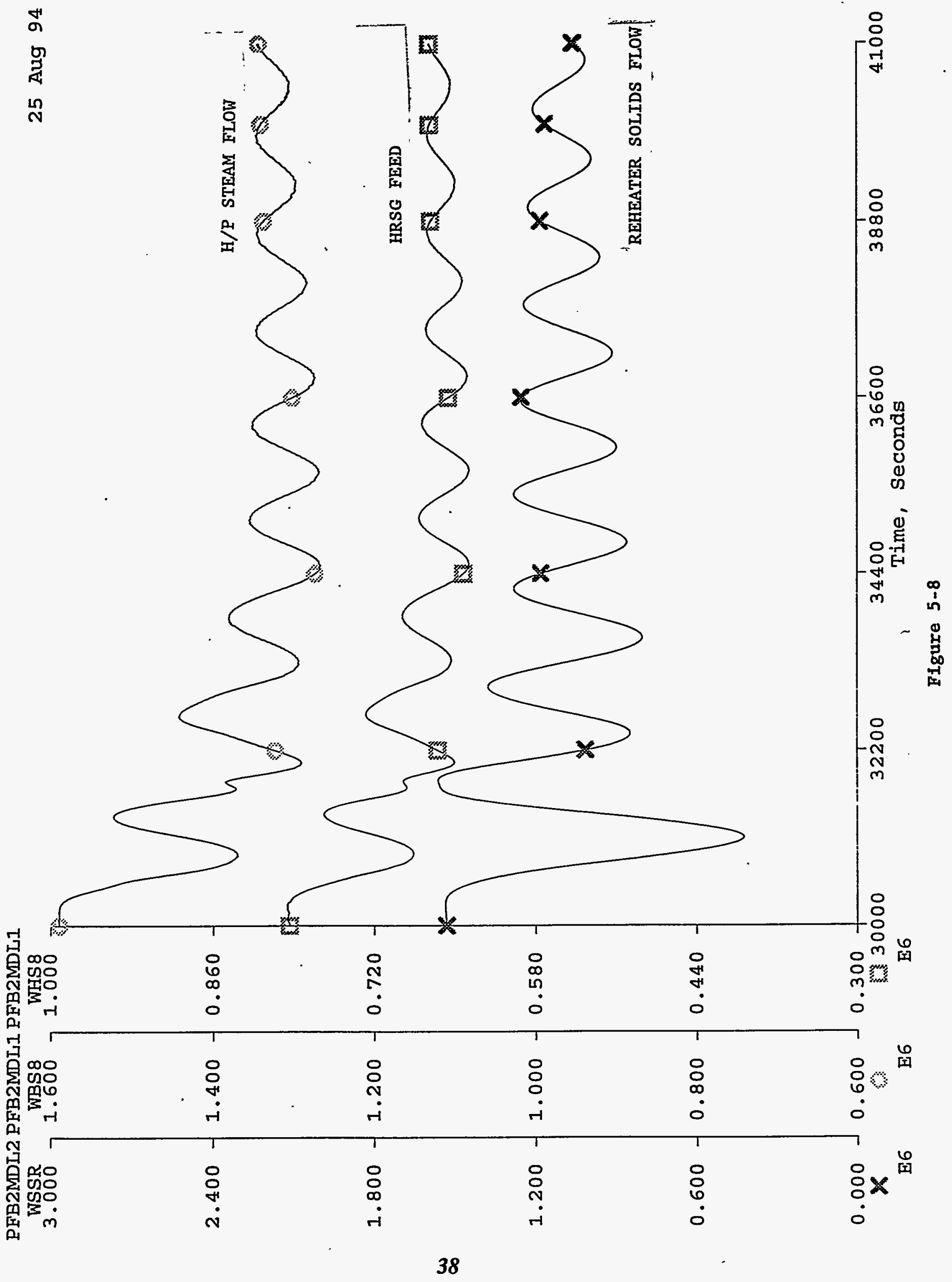




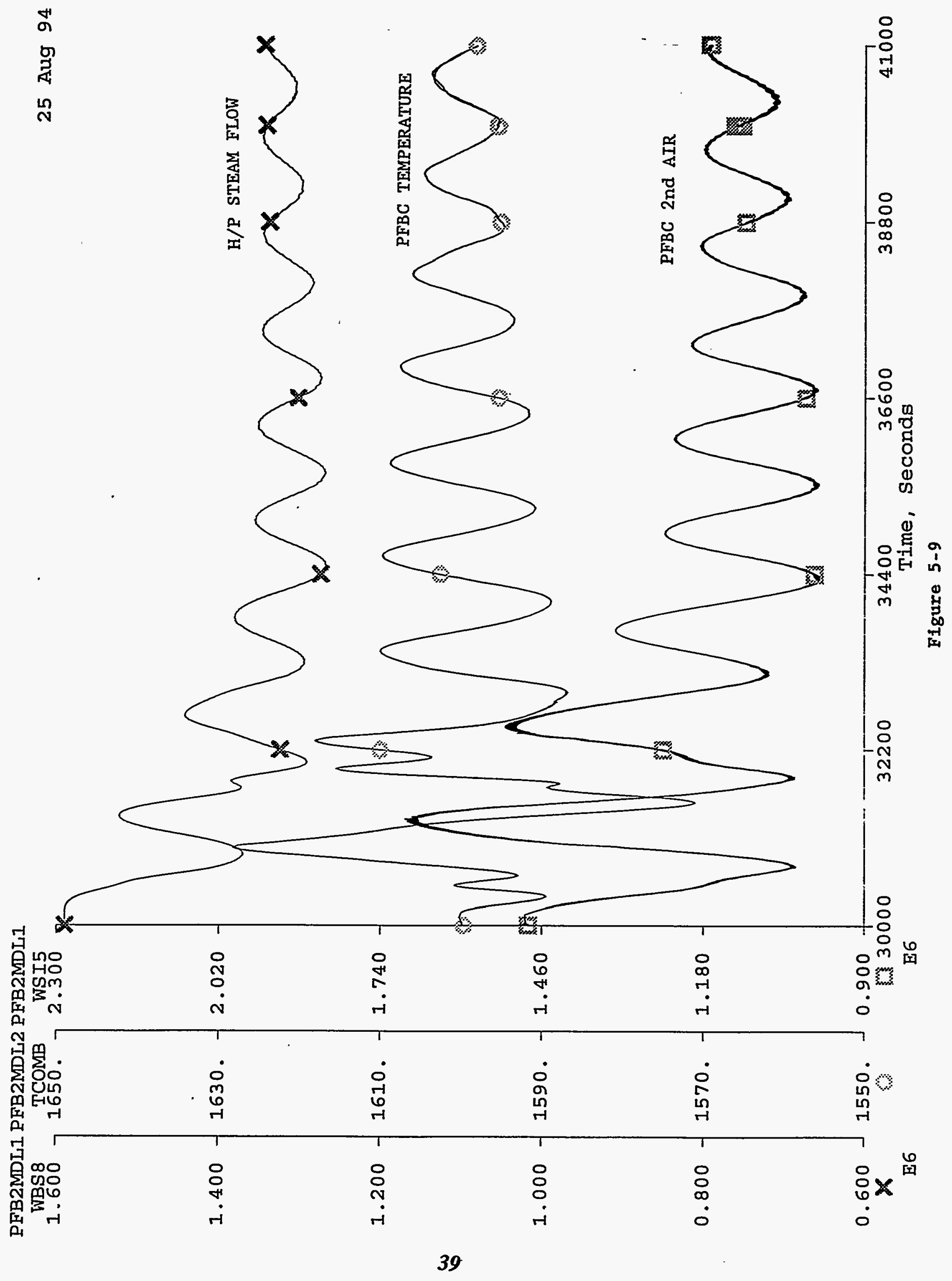


PFB2MDI2 PFB2MDL2 PFB2MDL2 PFB2MDL2

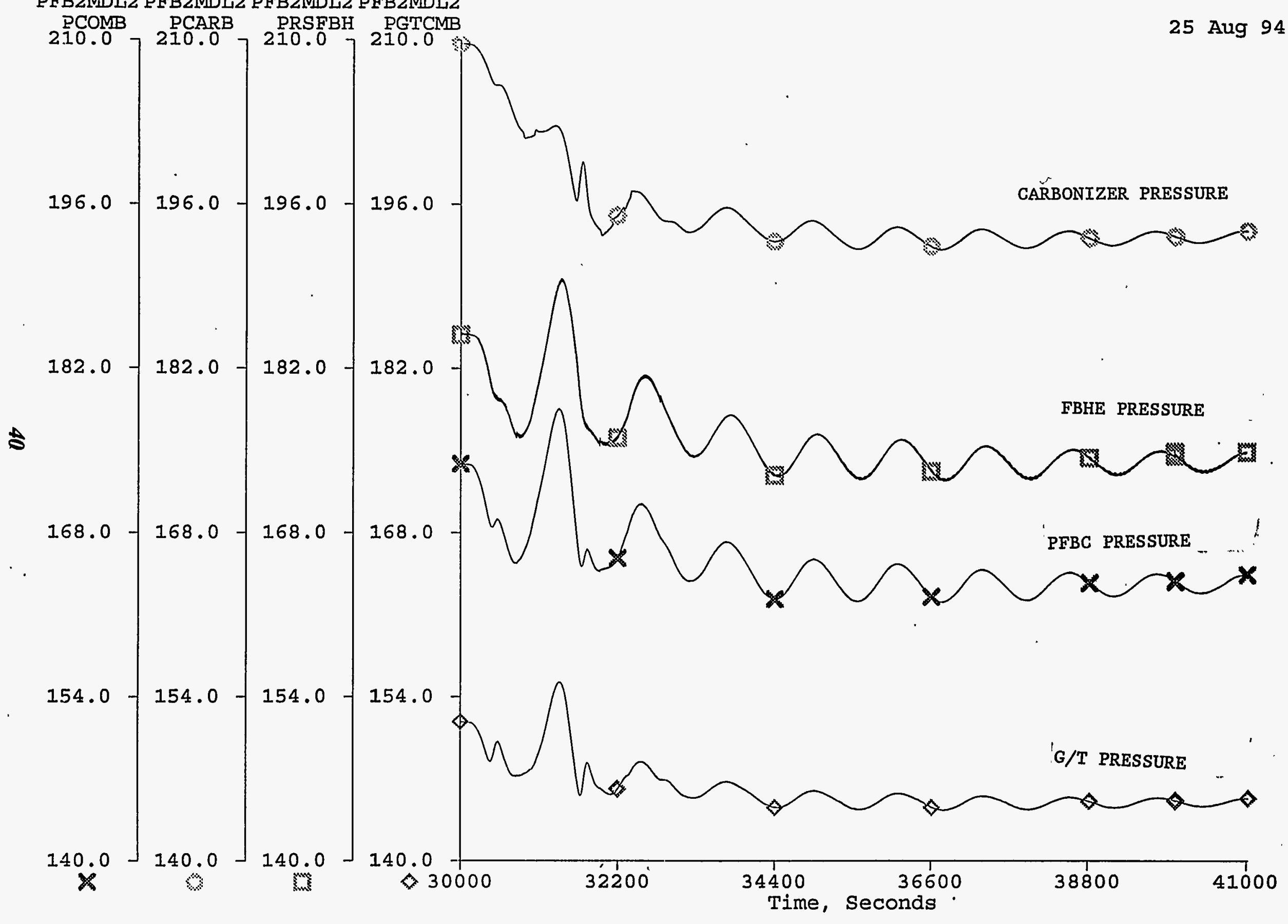

Figure 5-10 


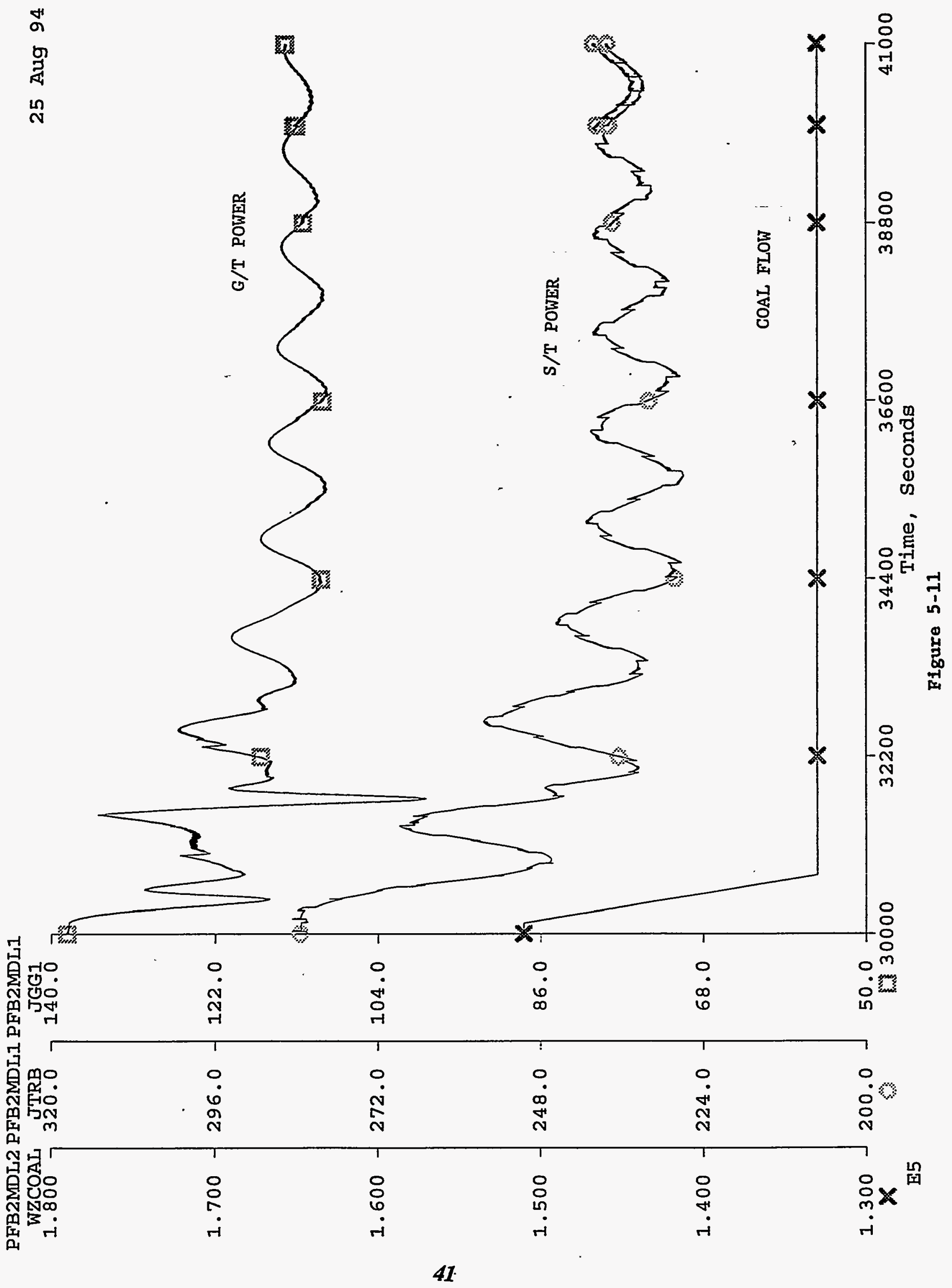




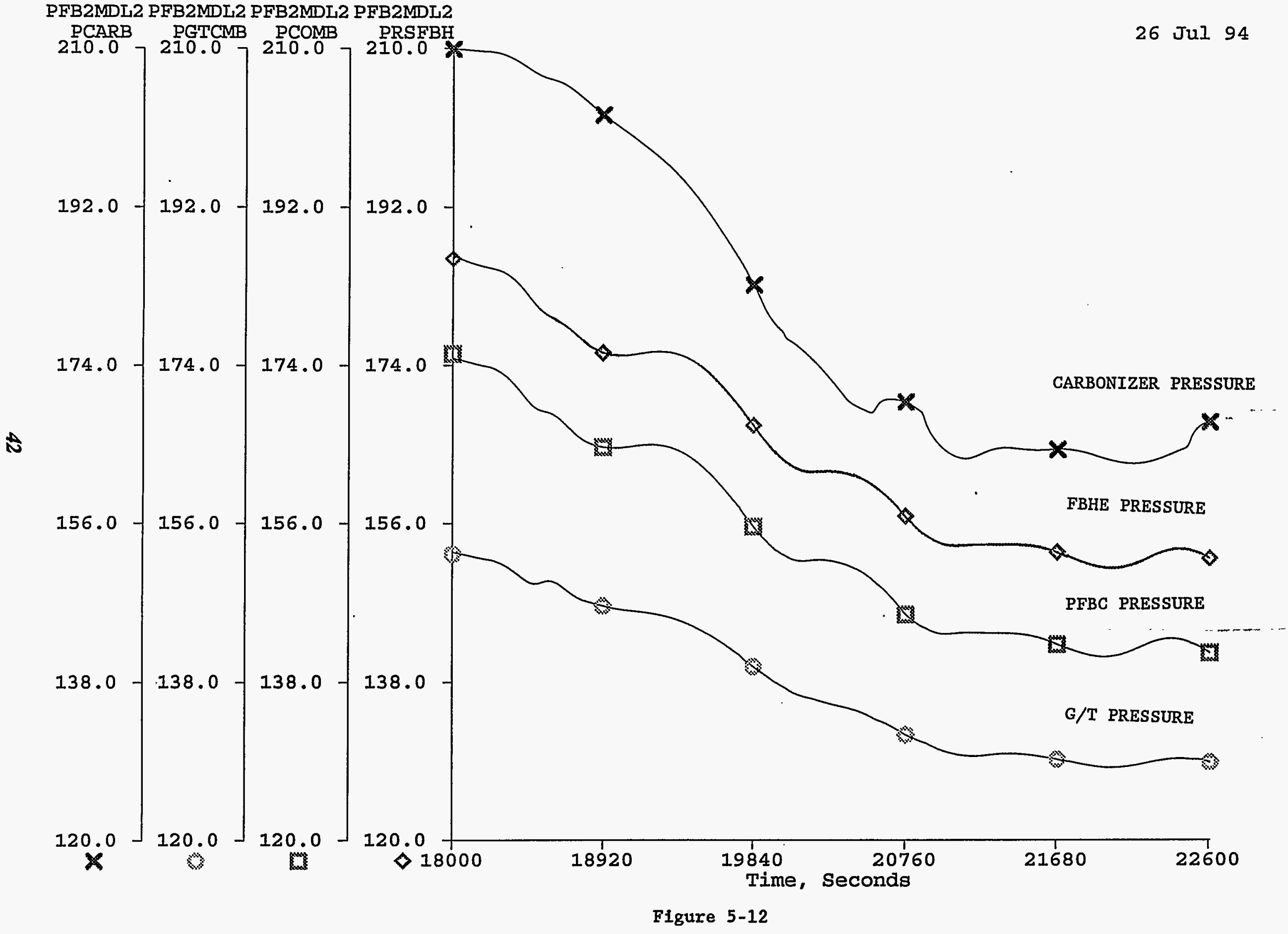




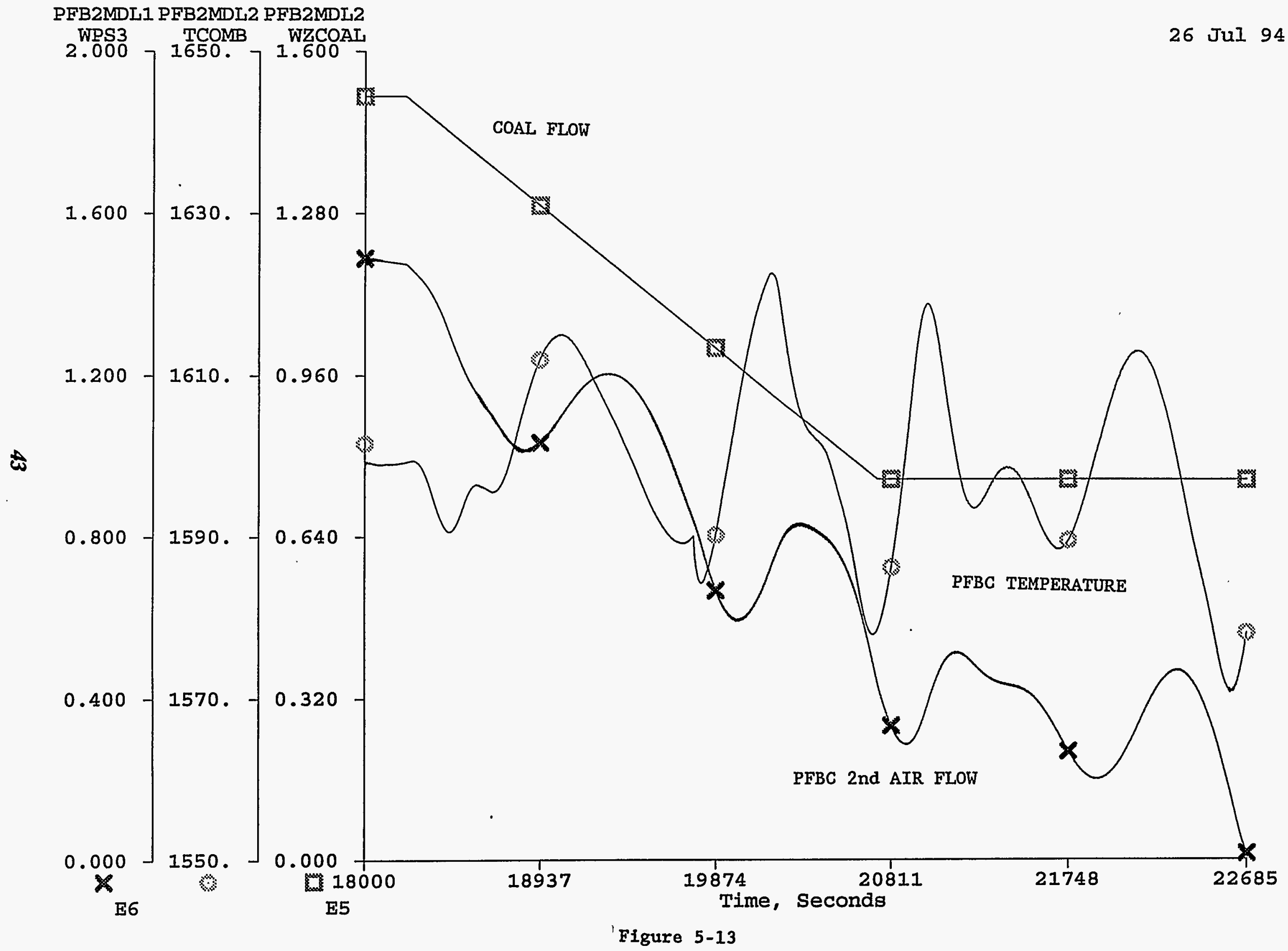


PFB2MDL1 PFB2MDL1 PFB2MDI2

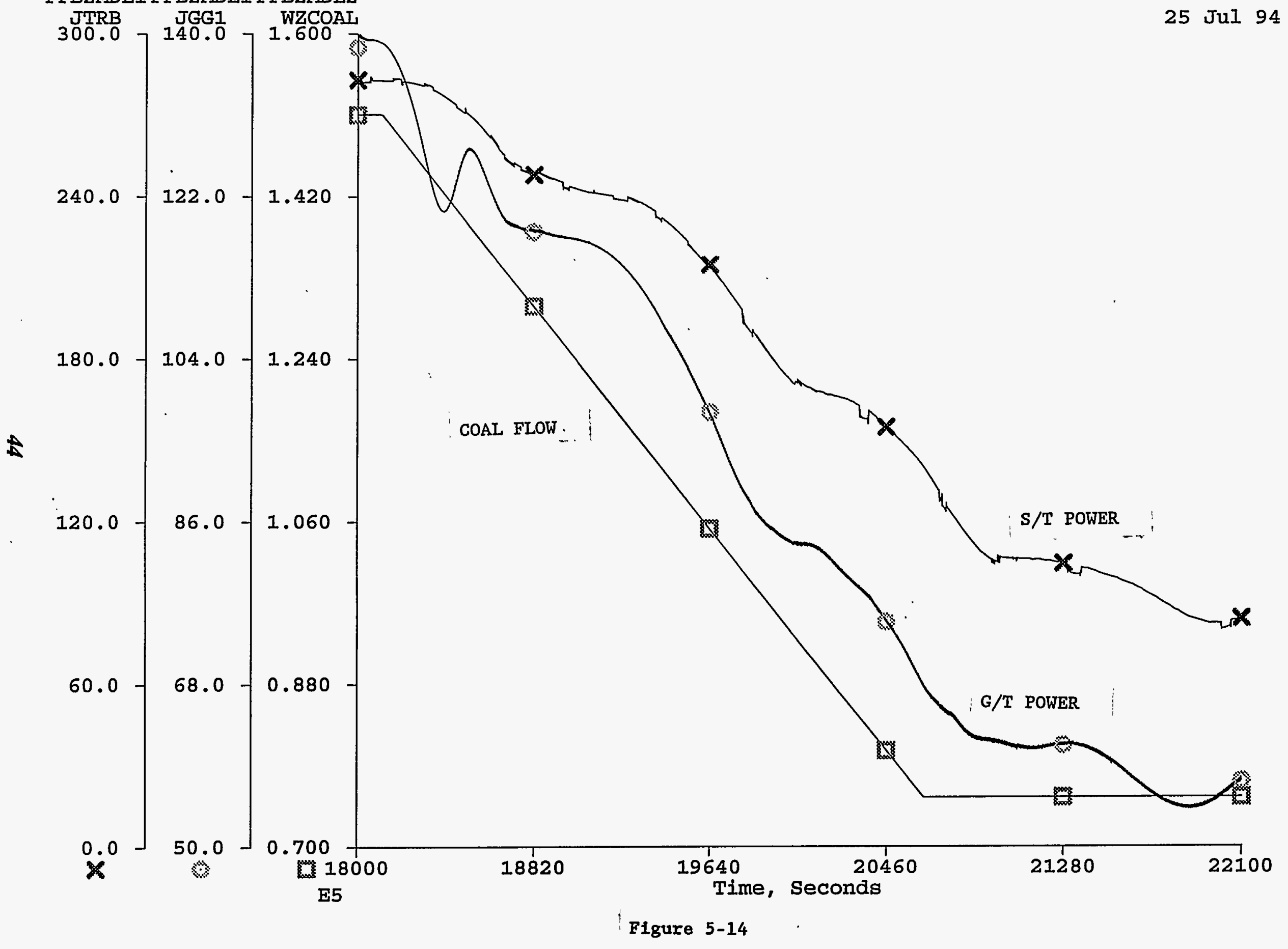




\subsection{OPERATING AND CONTROL PHILOSOPHY DEVELOPMENT}

The initial second-generation PFB combustion plant in commercial operation will be a base loaded unit with occasional turndown to 50-percent load. This is due to its high efficiency (low heat rate) and low emissions. If the plant is required to operate at full load for 5 days and at 50 percent for the weekend, normal demand fluctuations can be met by reducing the output on each of the two modules. If operating at 50-percent load for extended periods, one module is shut down entirely; the other is operated at 100 percent. During this time, maintenance on the idle carbonizer/CPFBC/gas turbine module can be performed.

The operating and control philosophy of the PFBC-II plant is developed here in the following sections:

6.1 PFBC-II control philosophy, including thermal inertias, plant control mode, and control valve pressure drops

6.2 Carbonizer and char hopper

6.3 PFBC, including PFBC secondary air and FBHE

6.4 Topping Combustor

6.5 Gas turbine and HRSG

6.6 Steam system, including steam temperature, drum level, steam header pressure, deaerator storage tank level, condenser hotwell level, and ash cooler water flow

\subsection{Steam turbine}

This section discusses requirements, issues, and approaches to controlling the plant. The control system itself is described in greater detail in Appendix I.

\subsection{PFBC-II CONTROL PHILOSOPHY}

Since the output of the PFBC plant will be maximized during its early years of operation, features often incorporated to accommodate extended/efficient low-load operation and rapid start-up/shut-down (e.g., variable pressure and 50-percent steam bypass) have not been considered. However with the competitive environment envisioned for the electric utility industry, it is practical to require a plant capable of load following from $50 \%$ to $100 \%$ to be required. The question of steam bypass capability has been considered in the operating philosophy, but only to the extent necessary to promote further definition of requirements.

The design criteria considered for plant operation are presented in Table 6-1. 


\section{Table 6-1 Operating Goals for Second-Generation PFBC Plant}

Cold Start:

0 to 100 -percent load in 16 hours

Warm Start (from weekend shutdown):

Hot Start:

Ramp Rates:
0 to 100 -percent load in 6 to 8 hours

4 to 6 hours

3-percent/min net electrical power

between 50 - to 100-percent load

Changes in load are initiated by changes in coal flow, supplemented by changes in air flows to various plant sections to maintain operation. In general, small changes in air flow are made by positioning the compressor's inlet guide vanes, while progressively larger air flow adjustments are made by modulating air supply control valves, then by opening bypasses, and finally by venting to atmosphere.

Design philosophies regarding bypasses and trips are different in the USA than they are in Europe. European plants have strong incentives to stay on line, so plant trips are avoided through the use of extensive bypass systems. In contrast, the international power grid to which US plants are connected is assumed to be able to compensate for sudden power losses from individual tripped units, so less emphasis is placed on keeping plants on line and, consequently, to bypass systems as well.

\subsubsection{Thermal Inertias}

This plant has three major thermal masses: the FBHE, the carbonizer, and the PFBC. These multiple thermal masses infer second- or third-order dynamic responses for the overall plant, inherently more oscillatory than the first-order response of a plant with a single, large thermal mass. An example of single large mass is the boiler in a coal-fired steam plant.

A concept that seems unlikely because of the high temperature requirements of the valves is the concept of "borrowing" energy from parts of the plant (PFBC, etc.) to improve the response time of other parts of the plant (gas turbine). This is analogous to the boiler and steam turbine in a steam power plant. All such schemes require valves to isolate the energy storage system. There does not seem to be any practical way to accomplish this with the topping cycle, so the energy "borrowing" proposal seems unworkable. 


\subsubsection{Plant Control Mode}

The desired electric power output determined by the coal feed rate. The coal feed set point is manually set along with a predetermined ramp rate and direction.

An earlier study (from Section 2.5.17, page 220 of the Phase 1 Report) had suggested that, the Second-Generation PFB combustion plant could be designed to operate in any of three modes: gas turbine leading, steam turbine following; steam turbine leading, gas turbine following; or coordinated/integrated gas turbine/steam turbine control.

Based on further work, the Control Mode referred to as "Gas Turbine Leading" is unworkable without a mechanism (control valve) for controlling fuel (energy) input to the Gas Turbine. The workability of any Coordinated Gas Turbine/Steam Turbine control mode is also unlikely without control of Gas Turbine energy input. At present the only mode that seems possible is a Gas Turbine and Steam Turbine Following mode with both responding to changes in coal (energy) input with the electrical generation split between the cycles.

\subsubsection{Control Valve Pressure Drops}

The pressure drop issue is a trade-off between plant efficiency and control response. From an efficiency standpoint, minimal pressure drops in the working fluid (air and fuel gas) lines results in the highest efficiency because it increases the amount of thermal energy that can be converted into mechanical energy by the expander stages of the gas turbine. From a controls standpoint, pressure drops across control valves are the motive force that causes fluid flows to change when the valve positions are changed and must meet minimum levels to allow the use of the valves as responsive control elements.

The following design conventions were used for valve configuration (sizing), based on values at the steady state "design" point:

- Allow $20 \%$ of upstream pressure for a pressure drop across valves (globe) on steam and water.

- Allow $10 \%$ of upstream pressure for a pressure drop across valves (butterfly) on air and gas.

Valves will be configured so that "design" flow is achieved at $80 \%$ valve stroke for globe valves and $65 \%$ for butterfly valves.

All valves for flow or pressure control will be configured as equal percentage characteristic. Level control valves will be configured as linear characteristic. 


\subsection{CARBONIZER AND CHAR HOPPER}

The defining process constraints for the carbonizer are:

- Pressure not to exceed 15 atmospheres

- Transport air velocity constant at all loads (a conservative approximation).

- Bed temperature constant at $1600^{\circ} \mathrm{F}$

- Sorbent/coal mass flow ratio constant at 0.3002

- Steam/coal mass flow ratio constant at 0.16196

- Base Primary Air / Dry Coal mass flow ratio at 1.3106 , with $\pm 25 \%$ correction of Primary Air flow for maintaining Carbonizer Bed Temperature at $1600^{\circ} \mathrm{F}$

Air flow for transport of coal and sorbent is controlled to keep a constant superficial velocity in the piping regardless of load. This is a good approximation based on the practical experience of FWDC. Transport air is controlled by the Inlet Guide Vanes (IGV's) on the Transport Air Boost Compressor.

Carbonizer temperature is controlled by regulating the amount of primary air to the carbonizer. The carbonizer boost compressor flow is modulated by using its inlet guide vanes.

Modulating the coal flow will cause a corresponding change in the dolomite flow; at the same time, appropriate changes are made in the primary air flow and steam flow. Primary air flow follows a function of coal flow with a time lag and $a+/-25 \%$ correction based on deviation from setpoint. Sorbent flows to the carbonizer will be controlled as a function of coal flow. Steam flow to the carbonizer is controlled as a percentage of coal flow.

Char inlet flow to the PFB combustor basically follows coal flow by maintaining a level in the collecting hopper. However, it is anticipated that allowing this level to vary during load changes can be a way of increasing system response.

\subsection{PFBC AND FBHE}

The essential, defining process constraints of the PFBC and FBHE are:

- Pressure should not exceed 15 atmospheres.

- PFBC temperature must be maintained between $1550^{\circ} \mathrm{F}$ and $1750^{\circ} \mathrm{F}$ for good sulfur capture.

- The bed fluidizing air velocity must be constant, to maintain a constant 6 -ft bed height. 
Currently the controls are not configured to maintain a specific split between Primary and Secondary Air flows. The Primary and Secondary Air Flow Control Valves are sized for a specific pressure drop in accordance with the "General Plant" constraints. The Primary Air flow is controlled to maintain a constant velocity $(8.89782 \mathrm{ft} / \mathrm{s})$ in the piping regardless of load. The Secondary Air flow is controlled to maintain a setpoint of $1600^{\circ} \mathrm{F}$ in the PFBC bed.

It is assumed that the bed is maintained at a constant height. Solids flows from the CPFBC are primarily driven by J-valve air, which fluidizes the solids in the recirculation line. A constant bed level is assumed at present, so there is no active control maintaining the PFBC BED height via the J-Valves or other means.

For steady state, the amount of heat removed from the FBHE to the steam cycle would eventually determine the bed temperature (as a consequence of an energy balance around the PFBC plus FBHE). The actual temperature in the PFBC bed, even though it is affected by the secondary air, is determined by the amount of steam going to the steam turbine cycle.

\subsubsection{PFBC Secondary Air}

For the purposes of designing the dynamic model and controlling the main flows of the plant, certain air flows are assumed to have negligible impacts on the operation of the plant. Accordingly, miscellaneous air losses, ash blowdown, and J-valve air are not modeled.

One of the control issues that may or may not be served by design changes for better control is the amount of secondary air going to the PFB. As long as the unit is on line and the gas turbine is running at synchronous speed, its compressor will provide an essentially constant flow of air to the power island. That air is divided among the subsystems in Table 6-2.

\section{Table 6-2 Air Flow Response}

Air Stream Control Variables

Air to the FBHEs Fluidizing velocity

Ash blowdown Solids feed rate (not modeled)

Carbonizer air Coal feed rate and carbonizer temp

Compressor flow Essentially constant

J-valve air Solids feed rate (not modeled) 


\author{
Miscellaneous air leaks Essentially constant (not modeled) \\ PFBC primary air Fluidizing velocity \\ Coal, sorbent transport air Superficial velocity \\ PFBC secondary air PFBC Bed temperature \\ Air bypass, vent Compressor flow minus all others
}

Although the air flows to the various sections of the plant are balanced at the design point, when the plant goes off design virtually all of these flows change in response to the needs of the plant, generally in proportion to the changes in solids flow rates.

For example, at reduced loads, the air needed for solids transport, carbonization, PFBC fluidization, and ash removal blowdown, are all reduced in proportion to the solids flow, and therefore the secondary air flow increases. The opposite result happens at loads slightly above the design point, where slightly greater air demands by the other systems leave slightly less secondary air for the PFBC. Changing secondary air flow is not a problem for small excursions from the design point; however, there are limits to the amount of variation in secondary air flow. For example, at a certain high-load point, all of the compressor air would be needed for transport, carbonization, and primary fluidization, leaving no secondary for the PFBC, and allowing the bed temperature to rise to unacceptable levels. On the other hand, at reduced load the reduced air needs by other parts of the plant result in large increases in secondary air flow to the PFBC, which, combined with reductions in coal and char flows, prevent the PFBC from maintaining its design temperature.

As another possibility, the PFBC Bed temperature can be maintained by bypassing air to the Topping Combustor and/or venting it to atmosphere. Control of Secondary Air could be programmed to allow PFBC Bed temperature to vary within the range of 1550 to $1750^{\circ} \mathrm{F}$ during transients before modulating Secondary Air flow.

The total air flow to the plant can be modulated to some by changing the inlet guide vanes to the compressor, but some other control approach (such as an air bypass around the PFBC) is needed for wider load excursions.

\title{
6.3.2 FBHE
}

Seven solids zones ( 6 heat exchanger and 1 adiabatic; see Figure 30 in Phase I report) are independently controlled. Air flow to each zone is controlled to maintain superficial 
velocity of $0.50 \mathrm{ft} / \mathrm{sec}$. Pressure drops across the control valves are about $10 \mathrm{psi}$ at the $100 \%$ load.

\subsection{TOPPING COMBUSTOR}

The essential, defining process constraints of the topping combustor are:

- Pressure should not exceed 14 atmospheres.

- Exit temperature should not exceed $2350^{\circ} \mathrm{F}$

Air not needed for transport, carbonizer operation, PFBC, or FBHE can be bypassed to the topping combustor (where it lowers the turbine inlet temperature) or vented to atmosphere. Air will be vented during brief transients, and bypassed to the topping combustor during steady-state. The rate of change of bypass air flow must be limited by the thermal shock (mechanical strength) limitations of the turbine and HRSG. Venting would be required to accommodate the difference between the air flow not used by the carbonizer and PFBC, and the maximum air flow that can be accommodated by the topping combustor:

Total compressor exit air flow

-Transport air flow

-Carbonizer air flow

-PFBC fluidizing air flow

-PFBC secondary air flow

-J-valves, losses, and miscellaneous

$=$ Excess compressed air

-Max allowable bypass air to topping combustor

$=$ Vented air (temporary)

The venting of air is a transient activity until the plant can come to a new equilibrium point with a new gas turbine firing temperature (and corresponding pressure ratio). The steady-state flow of bypass air to the topping combustor is determined by load.

Air bypass from the gas turbine compressor header to the topping combustor will dramatically lower the gas temperature leaving the topping combustor.

Load changes generate transients that may affect the topping combustor gas exit temperature entering the gas turbine. These temperature excursions may exceed the maximum allowable inlet gas turbine temperature requiring injection of spray water into the line leaving the topping combustor. (Water absorbs about 1,000 Btu/lb as it evaporates, so each pound of sprayed water could reduce the temperature of 1,000 pounds of gases by about $4^{\circ} \mathrm{F}$ (assuming $\mathrm{cp}=0.25$ ). The maximum amount of 
water that could be sprayed into the combustor shell without causing compressor surge is about 5 percent of the compressor inlet air flow.) If the final control system design mitigates or eliminates this temperature excursion, water injection may not be required.

\subsection{GAS TURBINE AND HRSG}

The essential, defining process constraints of the gas turbine are:

- Compressor surge must be avoided.

- Compressor exit temperature not exceed $800^{\circ} \mathrm{F}$.

- Inlet flow parameter $\mathrm{W}^{*} \mathrm{sqrt}(\mathrm{T}) / \mathrm{P}$ will remain constant (not a controlled variable).

- Gas inlet temperature should not exceed $1200^{\circ} \mathrm{F}$.

- Gas inlet temperature not to change quickly (thermal shock to tubes).

The gas turbine fuel valve issue reflects the differing design requirements of the gas turbine and the carbonizer. Gas turbines fueled by oil or natural gas are normally controlled by changing the fuel flow with a throttle valve just upstream of the gas turbine combustor. Changing the fuel flow does not affect the oil storage tanks or natural gas pipelines.

The carbonizer, however, is constantly producing fuel gas for a relatively small pipeline. Changes in fuel gas flow can affect its operation because the gas flow changes almost instantaneously, while the coal feed rate and mild gasification process are slower to respond. Differences in carbonizer inlet flows, gas generation rates, and exit flows result in carbonizer pressure excursions.

The lack of gas turbine fuel/vitiated air inlet control valves limits the modes of integrated control as described under Section 6.1.2, "Plant Control Mode." The gas turbine cannot "lead" the plant without its own set of fuel (energy input) control valves. The high temperatures of the fuel gas and vitiated air lines to the topping combustor seem to make valves in those lines impractical, so the gas turbine can not lead the system.

\subsection{STEAM SYSTEM}

The steam generators consists of the HRSG, which recovers heat from the gas turbine exhaust gases, and the FBHE, which recovers heat from solids circulated through the CPFBC. Each steam generator requires a feedwater control system and a steam-temperature control system.

In the feedwater control system, the feedwater pump maintains the pressure in the feedwater supply header, and the feedwater control valves are controlled using a 
standard 3-element control scheme based on measurements of drum level, feedwater flow, and steam flow. Steam temperature from the HRSG is not controlled because it is only capable of supplying saturated steam. The FBHE superheater and reheater steam temperatures are controlled by diverting solids within the FBHE.

\subsubsection{Steam Temperature}

Steam temperature from the superheater and reheater are controlled by a combination of mechanical solids dampers and a finishing superheater bypass. The bypass (which was not modeled) raises the final steam temperature to the required set point during start-up. Each steam bypass contains a control valve, an isolation valve, and a desuperheating system for bypassing steam around the HP and IP/LP turbines.

The bypass system provides the means to start up either CPFBC, raise the pressure and temperature of the steam generated by the second CPFBC, match the pressure temperature of the first boiler, and blend the two steam flows in a controlled manner.

The solids diverter is controlled to establish equal temperatures at the outlets of the reheater and final superheater.

\subsubsection{Drum Level}

The HP steam drums on both the HRSG and the FBHE are maintained by 3-element feedwater control systems. Steam flow out and feedwater flow in are maintained in balance with a trim to maintain water level at a fixed set point. Two valves downstream of the HRSG economizer section are used to regulate flow. No valve is required upstream of the HRSG.

\subsubsection{Steam Header Pressure}

Steam flow into the hp steam turbine is controlled by a three-mode controller to maintain steam header pressure setpoint.

\subsubsection{Deaerator Storage Tank Level}

The deaerator level is controlled by a three-element control. Condensate flow into the deaerator is compared to feedwater flow out, with correction for level deviation from a fixed setpoint. This error is applied to a three-mode controller that maintains level by controlling the condensate flow to the deaerator. 


\subsubsection{Condenser Hotwell Level}

Condenser hotwell level is maintained at a pre-set level by a three-mode controller. This controller's output controls two valves: the spillover valve to the condensate storage tank, and the makeup valve from the condensate storage tank. These valves are split-ranged and opposite-acting. The spillover valve is direct acting and opens as the controller signal goes from $50 \%$ to $100 \%$. The makeup valve is reverse acting and goes from open to close as the controller signal goes from $0 \%$ to $50 \%$.

\subsubsection{Ash Cooler Water Flow}

The essential, defining process constraints of the ash cooler are:

- Water temperature must be maintained below saturation flash temperature $\left(206^{\circ} \mathrm{F}\right)$

- Ash exit temperature must be maintained below $300^{\circ} \mathrm{F}$.

Water flow to the ash cooler is controlled to prevent flashing in the ash cooler and associated piping. Several simulation runs showed that flashing could occur in the ash cooler. 


\subsection{POTENTIAL MODEL DESIGN CHANGES}

The purpose of this section is to discuss ideas and concepts of interest which may improve the operational performance and stability of the current model. Model and control improvements will be discussed first. A good portion of this discussion is taken from a brainstorming session with METC, G/C and FWDC conducted on August 2, 1994.

As discussed in Section 5, plant response to transients produced highly oscillatory behavior. Analysis of plant data suggests that the carbonizer and steam bottoming cycle controls produce acceptable response. However, the control scheme for the PFBC/FBHE, gas turbine, and steam generating components of the bottoming cycle resulted in highly coupled and unstable response. A few ideas on lessening this interaction are presented below.

Dumping Air to Ambient. As shown in Figure 5-7, bypassing process air directly into the topping combustor had an immediate cooling affect. A possible alternative is to dump the excess air to ambient. This may lessen the interaction between the topping and bottoming cycles. The ambient dump could be conducted only on a temporary basis, i.e., during the transient, rather than dumping air to ambient at all levels of reduced load operation. Temporary rather than prolonged air dumping to ambient would lessen the effects of lost efficiency. Dumping air to atmosphere would maintain an elevated gas turbine firing temperature, but since this action would reduce the mass flow through the turbine, it would probably reduce, not increase, the turbine power. This modification should be analyzed further to properly assess all potential influences on other portions of the process.

Coal to PFBC. The addition of coal to the PFBC as a means of maintaining PFBC temperature during decreases in load has been suggested by Robertson (1994). During turndown, there would be no air bypass to the topping combustor or ambient. Instead, excess process air would flow to the PFBC. Additional coal to the PFBC would inhibit a large temperature decrease. It is not known at this time what affect this mid-process fuel injection would have on overall plant stability. Increased coal combustion would most definitely decrease plant efficiency. The decrease in plant efficiency may be warranted if sufficiently stable plant response is attained.

Char Level Modulation. A PID controller is used to maintain a constant solids level in the char hopper. A decrease in coal flow to the carbonizer is mirrored by a decrease in char flow to the PFBC due to decreased flow of char from the carbonizer to the hopper. The char hopper may be utilized as a surge storage volume to promote smoother operation of the PFBC during transients. During a load change, the level in the char hopper could be allowed to either rise or fall to 
maintain a constant char flow to the PFBC. It is hoped that this approach could in some manner help stabilize the plant during load changes.

Sliding Pressure Steam Turbine. Currently, a PID controller modulates flow to the steam turbine to maintain a constant turbine inlet pressure. It has been suggested that sliding pressure operation of the steam turbine could be implemented in an effort to stabilize plant response during load changes. It is believed that this would have marginal effectiveness and provide additional complexity to the system. In addition, sliding pressure steam turbines are generally not favored by most utilities.

Water Spray to Topping Combustor. As discussed in Section 5, variations in topping combustor temperature affects the steaming rate in the HRSG. A method of smoothing out the GT inlet temperature could lessen the detrimental interactive affects. One method which could be used is a water spray into the gas turbine exhaust to control exit gas temperature. This may help smooth out operation of steam generation in the HRSG.

Steam Attemperation in FBHE. The FBHE can be partially decoupled from the steam generating portion of the bottoming cycle by introducing an additional control element, steam attemperation. The design of the superheater and reheater could be modified so that design steam temperature is attained at 30 or 40 percent of load. At higher loads, water spray would be used to control the temperature. This would free the FBHE solid diverters which could be utilized to control PFBC bed temperature.

Follow Char Flow. The current control scheme initiates load changes via a ramped change in feed coal. It has been suggested that a control scheme could be utilized that followed load changes in char flow to the PFBC. This would have the effect of moving the leading process element from the carbonizer to the PFBC. What affect this will have on plant operation is unclear.

Rethinking the IGVs. Gas turbine compressor IGV position should be 100 percent full open at 100 percent of load. Westinghouse maintains that the IGV's full range accounts for 20 percent of design flow. The current model assumed that the IGV's were at 0 percent open at 100 percent of load. A machine of this type would have to be specially built, and may have decreased performance. In light of this, the role of the gas turbine compressor in APFBC power cycles must be thought over more carefully from a control standpoint. The primary question is how introduce additional air to the plant when operating at 100 percent of design load.

The text above discussed possible model improvements. The improvements are designed to achieve stable APFBC plant operation during turndown. The remainder of this section will discuss possible follow on uses for the model. 
The current APFBC power plant concept relies on high temperature, particulate cleanup devices (PCD) to remove small solid particles from the fuel and flue gas streams prior to expansion. Depending on the design, these ceramic devices are generally referred to as cross-flow or barrier filters. The devices utilize a pulse injection of nitrogen to clean particulate matter from the surface of the filter. The present model, or portions of the present model, could be modified to investigate plant operation with the gas injections required by a commercial $\mathrm{APFBC}$ power plant.

The current model could be used as a starting platform for dynamic models of either Wilsonville or the Four Rivers Project. Modeling Wilsonville would require changes to model chemistry, vessel geometry, and model configuration such as removing the steam turbine bottoming cycle. Also, new design point condition would have to be calculated and integrated into the model. A control scheme would then have to be modeled. The model presented here will serve as a guide thereby facilitating the effort.

The Four Rivers Plant is fairly complex due to inclusion of a steam turbine and constant steam export requirement. A dynamic model of this plant would be a useful tool from both a control and training point of view.

The current model could be used as a starting point for the 1.5 Generation PFBC cycle. The carbonizer would have to be removed from the cycle, but a majority of the remaining layout would be similar. 


\subsection{TRIAL CONTROL SCHEMES}

As discussed in Section 5, the control scheme presented in this report produces inadequate responses to decreases in plant load. Even though the plant can be turned down from 100 percent of load to 90 percent, the transition is lengthy and characterized by several process variable excursions. Section 7 presented some model and control modifications that may or may not yield a more desirable response. This section will review the various control strategies which were tried as an initial attempt at a PFBC process control.

The control scheme associated with the carbonizer has more or less remained the same since its inception. The only modification was the addition of the lead/lag element on the coal flow transmitter for the primary air control loop. The lagged coal flow signal causes the carbonizer primary air control to respond preferentially to temperature changes rather than coal flow. Trial and error was utilized to arrive at this determination. It is felt that the present control scheme for the carbonizer is adequate.

Component control for the steam bottoming cycle, excluding steam generation, is typical of that found in contemporary steam power plants. Following controller tuning, the scheme has not been altered and is expected to yield adequate control.

The controls for the PFBC primary zone air and FBHE fluidizing air are maintained at a setpoint corresponding to preset superficial gas velocities. The control delivers satisfactory results and has not changed since initially proposed.

The control aspect that has seen the most modification and controversy is that associated with the process air header and bypass. At the heart of the issue is what should be done with the excess air available during a turndown in plant load. Several concepts were explored. Each yielded equally unsatisfactory results. The concepts are reviewed below.

The current control scheme opted for high plant efficiency, even during turndown. To achieve high plant efficiency, no fresh coal was combusted in the PFBC. During turndown, control valves on the process air stream close causing higher pressure at the compressor discharge and lower pressure at the expander inlet. This combination leads to decreased cycle efficiency. The air header pressure increase is due to more air being available to the carbonizer and PFBC than required.

Initially, the GT compressor IGV's were assumed 100 percent open at design load. Air could be bypassed from the GT compressor outlet to the topping combustor. The IGV's and bypass valve were split ranged and reverse acting. At 100 percent of design load, a control demand signal for less air would preferentially cause the IGV's to close, followed by opening of the air bypass valve. 
Small changes in process air demand could be accommodated by this scheme, however, moderate changes, such as a decrease in plant load from 100 percent to 90 percent, could not be accommodated by this scheme. The IGV's affect on PFBC temperature is small due to the relatively small amount of flow affected by their full range. Therefore, a large temperature drop (greater than $60^{\circ} \mathrm{F}$ ) in the PFBC would occur by the time the IGV's closed and the air bypass valve opened. A great deal of time was spent bringing the PFBC temperature back to $1600^{\circ} \mathrm{F}$. The results were unacceptable.

It became clear that to effect quick changes in flow around the PFBC, the bypass valve rather than the compressor IGV's would have to be preferentially modulated for decreased air flow demand. To this end, a scheme was initiated in which the bypass flow was maintained as a function of the ratio of air header pressure to total plant load. In this manner, decreased air requirements, as reflected in lower plant loads, would cause the bypass valve to open thereby relieve pressure in the air header.

All attempts to utilize this scheme failed. Due to the large volumes of the carbonizer and PFBC, changes in plant load initiated by decreases in carbonizer coal feed caused the carbonizer and PFBC air supply valves to limit flow for an extended period of time before the bypass valve was opened. It took several minutes to generate a significant enough change in electrical load to activate the bypass valve. This caused pressure in the air header to increase from a nominal valve of 200 psia to about 250 psia. When the bypass valve finally opened, the amount of air bypassed was so large that negative back pressure in the PFBC air feed piping was generated.

Similar results were experienced when the controller tuning constants were modified. Bypass valve position was also made a function of the ratio of air header pressure and coal flow. This scheme also failed to produce acceptable results. Various schemes including bypass to ambient continued to produce unacceptable results, usually accompanied by negative back pressure.

In an effort to ameliorate negative back pressure in the PFBC feed piping, the air bypass valve was moved from the GT compressor exhaust to the piping for the PFBC secondary air flow. It was reasoned that inertia contained in the piping between the compressor and $\mathrm{PFBC}$ would slow the pressure-flow dynamics such that negative back pressure would not be a problem. To increase the dynamics of the controllers, the control valve on the PFBC secondary air valve was removed and the bypass valve was made a function of PFBC temperature. Decreases in PFBC temperature caused the bypass valve to open, which decreases air flow to the PFBC, thereby increasing the vessel temperature.

This scheme produced results similar to those witnessed with the present control scheme as presented in Appendix I. Therefore, it was abandoned. Direct cooling of the topping combustor with bypass air coupled with the FBHE solids diverters slaved to steam temperature appear to give rise to the unstable plant response. 
Assuming that the component time constants are representative of those that would exist with actual commercial equipment, a more robust control strategy is needed. It seems that the qualified strategy will decouple the PFBC/FBHE, gas turbine, and steam generator. Possible control strategy modifications are discussed in Section 7. 


\subsection{CONCLUSIONS AND RECOMMENDATIONS}

A dynamic performance model for a commercial-sized Advanced Pressurized FBC power plant has been developed using PC-TRAX software. Currently, only a 1 MWe equivalent test rig is available for model calibration, eliminating the possibility of equipment-based calibration; however, important insights have been gained through the development of this dynamic model of a commercial-sized APFBC power plant.

1. The model features the following:

- Standard commercial "modules" for the conventional plant components/systems drawn from the PC-TRAX library,

- Custom-designed "modules" for the developmental/non-standard components/systems developed as part of this project,

- Interface software developed to facilitate exchange of flow, temperature, pressure, enthalpy, density and fluid composition data between standard and custom modules in a dynamic simulation of integrated plant operation,

- Standard commercial control "modules" which were used to implement the control strategy,

- Platform from which to exercise the plant (model and control strategies) in response to user initiated scenarios, such as a load change from 100 percent to 90 percent at 5 percent per minute,

- Capability to acquire and store data on all process parameters and to both display (CRT) and print this data in selected subsets in both tabular and trend formats, and,

- Detailed and commented documentation allowing users to exercise the plant and make changes to both the model and the control strategies.

2. Basic and elementary control strategy was integrated into the PC-TRAX model which features the following:

- Final control elements integrated within PC-TRAX modules,

- Commercial control designs such as three-mode controllers (PID), cascaded control strategies for certain parameters such as steam drum level control, and 
- Control of all process subsystems is initiated from a deviation between actual coal flow and the coal flow setpoint (in real practice, derived from a MWe demand) in a process disturbance from a setpoint reaction.

3. The model developed along with the initial control philosophies produced valid or "true" data. It did not hide or misrepresent process variable excursions in response to initiated disturbances. The process variable responses were logical (occurred in the expected direction and magnitude) and repeatable. The model has not been oversimplified, if anything, it is more complex than originally planned. This makes it a valid tool for future research.

4. Additional development of the control strategy is needed, particularly in the relationship of the Fluid Bed Heat Exchanger (FBHE) and the steam bottoming cycle. Oscillatory energy swings encountered after changing load indicate that this complex relationship requires more definition, and perhaps a significant changes in control strategy.

5. A dynamic model of a Particulate Control Device (PCD) should be developed and incorporated into the plant model. The dynamic PCD model would replace the quasi-static PCD model presently used in the model. Incorporating the PCD dynamics would greatly enhance the model by providing a more comprehensive representation of actual plant performance

6. Development of a 1.5 Generation PFBC power plant dynamic model, using the subject dynamic model as a starting point, is recommended. In the 1.5 Generation power plant concept, there is no carbonizer and coal is fed directly to the PFBC, eliminating one level of control/response, and simplifying the model. The model could be enhanced by the inclusion of a fully dynamic Particulate Control Device (PCD) model. This model would provide the opportunity to isolate and resolve problems associated with the relationship between the FBHE and the steam bottoming cycle.

7. The subject dynamic model is recommended as a tool for development and analysis of the Power System Development System (PSDF) in Wilsonville, AL. The PSDF includes the same major components, excluding the steam bottoming cycle, which is replaced by a cold-water heat sink. A PSDF plant model could aid designers by providing a platform on which to test various control strategies as well as investigating the placement of additional final control elements. Following construction of the PSDF, the model could be tuned with actual plant operating data, thereby providing valuable insight into future problems as well as a possible operator training tool.

8. It is recommended continued and additional support be provided to utilize the subject plant model as a tool to investigate the following: 
- Improved stability and rate of response to load changes for the CPFBC, FBHE and steam bottoming cycles;

- Experiment further with alternate primary control strategies, including char feed (vs. coal feed), gas turbine control lead (GT inlet control valve briefly tried as part of this study), or some combination of these approaches;

- Investigate the potential of char storage as a method of system energy storage to smooth the response to load change; and

- Investigate the potential of hybrid or full variable pressure operation to determine its potential in the APFBC to improve the viability of the selected control strategy.

- Application of current practice control strategies such as feedforward load demand to selected subprocesses with off line adjustment and variable gain controllers.

- $\quad$ Monitoring and analysis of primary and secondary process variables to determine the best process variables to use as primary control variables and secondary control variables (overrides). This may involve a combination of strategies and variables over a range of operation.

- After determining that current process control strategies do not produce the desired results it may be necessary to investigate advanced control strategies such as state variable and Smith predictor.

- Resize components based on providing a control point from which a control strategy (control element, mode of control and control variable) can be developed and implemented successfully. An example of this is utility boiler superheat and reheat temperatures. Boiler design is conducted based on achieving temperature setpoint (optimum) at nominally 70 percent load, not 100 percent of load. At loads less than 70 percent overfiring can be utilized to build pressure and improve load response with reduced probability of producing over temperature. At loads equal to or above 70 percent, control elements such as burner tilts RH/SH pass dampers and spray attemperation are constantly used to return high temperatures to setpoint during steady state, process disturbance, and load disturbance scenarios. 
Advanced Continuous Simulation Language (ACSL) Reference Manual, Mitchell and Gauthier Associates, Concord, Massachusetts, 1987.

Churchill, S. W., "Friction-Factor Equation Spans All Fluid-Flow Regimes," Chemical Engineering, Nov. 7, 1977.

Feugier, A., C. Gaulier, and G. Martin, "Some Aspects of Hydrodynamics, Heat Transfer, Follow and Gas Combustion in Circulating Fluidized Beds," Proceedings of the 5th International Fluid Bed Conference, Boston Massachusetts, May 1987.

Martinelli, R. C., and D. B. Nelson, "Prediction of Pressure Drop during Forced Circulation Follow Boiling of Water," ASME Transactions, Vol. 70, August 1948, pp. 695-702.

PC-TRAX Analyst Instruction Manual, TRAX Corp., Lynchburg, Virginia, 1992.

PC-TRAX Programmer Manual, TRAX Corp., Lynchburg, Virginia, 1992.

Robertson, A., R. Garland, R. Newby, A. Rehmat, and L. Rubow, Second-Generation Pressurized Fluidized Bed Combustion Plant - Conceptual Design and Optimization of a Second-Generation Pressurized Fluidized Bed Combustion Plant, Foster Wheeler Development Corporation, DOE Contract DE-AC21-86MC21023, Phase I Task 1 Report, September 1989.

Robertson, A., R. and J. S. White, telephone conversation, January-May 1994.

Smith, L. P., PC-TRAX Theory Manual, TRAX Corp., Lynchburg, Virginia, 1992.

Thom, J. R. S., "Prediction of Pressure Drop during Forced Circulation Boiling of Water," Int. J. Heat Mass Transfer, Vol. 7, pp. 709-724, Pergamon Press, Great Britain, 1964.

Yiqian, Xu, Jiang Peijun, Shen Xianglin, and Zhen Jianhong, "Study on Operation Performances of a Pressurized Circulating Fluidized Bed (PCFB)," Proceedings of the 5th International Fluid Bed Conference, Boston, Massachusetts, May 1987.

Rubow, L. N., D. A. Horazak, M. R. Hyre, and T. L. Buchanan, PFBC Concepts Analysis for Improved Cycle Efficiency and Cost, Gilbert/Commonwealth Inc., DOE Contract DE-AC01-88FE61657, Task 2 Report, June 1992. 
Rubow, L. N., J. S. White, P. M. Witman, and T. L. Buchanan, Very Low Sulfur Emission (VLSE) PFBC System, Gilbert/Commonwealth Inc., DOE Contract DE-AC0188FE61657, Task 6 Report, August 1993. 


\section{A DYNAMIC MODEL OVERVIEW}

The dynamic model presented in this report is a commercial-sized APFBC power plant. A description of the power plant is provided in Section A.1 to provide a fuller understanding of the model. The plant description is based on work completed by Robertson (1989). A preliminary model description is given in Section A.2. The model description introduces the basic concepts which are extended in other sections. Section A.3 presents block diagrams representing the TRAX module configuration. Section A.4 provides the model user with the basic concepts needed to use and modify the model.

\section{A.1 PLANT DESCRIPTION}

The APFBC power plant is comprised of four primary subcomponents; the carbonizer, CPFBC/FBHE, gas turbine, and steam turbine. The model presented in this report dynamically simulates the integrated performance of all these subunits. A better understanding of the computer model can more easily be obtained with the help of a plant description. Please refer to Figure 2.2 during the reading of this section. The carbonizer is a bubbling-bed reactor that utilizes air and steam to convert coal into a low-Btu fuel gas at high temperature and pressure. Coal processed in the carbonizer is initially dried to 2.5 percent moisture. Dry coal and sorbent is pneumatically conveyed to the carbonizer. High pressure air is provided by a booster compressor. A calcium-based sorbent is used to limit gaseous sulfur emissions that are predominantly in the form of $\mathrm{H}_{2} \mathrm{~S}$. The design used in this study specifies a carbonizer operating temperature of $1,600^{\circ} \mathrm{F}$ and a vessel pressure of approximately 209 psia. The low-Btu fuel gas produced in the carbonizer has an LHV of 2,247 Btu/lb.

Unconverted coal, in the form of char, is gravity-drained from the carbonizer vessel along with unspent sorbent. Entrained solid material is removed from the gas phase by a combination of cyclones and barrier filters. Solid material elutriated with the fuel gas accounts for approximately 16 percent of the total solid material produced. The char LHV is about $11,700 \mathrm{Btu} / \mathrm{lb}$. Char and sorbent are stored in a hopper prior to being fed to the PFBC.

The PFBC generates hot vitiated air that is utilized in the topping combustor. Hot air is generated by combusting char, generated in the carbonizer, in a large volume of excess air. Large amounts of excess air help the combustion process and ensure ample $\mathrm{O}_{2}$ for fuel gas combustion in the topping combustor. Also, larger amounts of excess air promote increased thermal energy transfer of the char to the topping combustor by direct heat transfer.

The PFBC is a fluidized-bed reactor that operates at $1,600^{\circ} \mathrm{F}$ and 185 psia. There are two combustion zones: the primary zone is substoichiometric, and the secondary zone is 
characterized by large amounts of excess air. Recirculation of solid material promotes high carbon conversion through increased solids residence times. Sorbent not sulfided in the carbonizer reduces $\mathrm{SO}_{2}$ emissions from the PFBC. Overall sulfur capture by the process is approximately 90 percent.

Waste heat generated in the PFBC is removed in the FBHE. Solid material is circulated from the PFBC, to the cyclone, to the FBHE, then returned to the PFBC. Heat transfer surface in the FBHE is used to remove heat from the solid material. In this manner, the PFBC temperature can be maintained at a desired value. The energy removed is used to generate high pressure and reheat steam.

The FBHE is divided into seven cells. Each of the seven cells is fluidized with air. Fluidization velocities are approximately $0.5 \mathrm{ft} / \mathrm{sec}$. The FBHE fluidizing air is collected in a common freeboard area and routed to the PFBC secondary combustion zone. In the first FBHE cell, solid material is either diverted to the superheat or reheat steam passages or returned to the PFBC. This cell is referred to as the adiabatic zone. Solids flowing to the superheat pass flow through cells 4,3 , and 2 which contain tube bundles for finishing superheat, secondary superheat, and primary superheat respectively. Solids flowing to the reheat pass flow through cells 7,6 , and 5 which contain tube bundles for finishing reheat, primary reheat, and steam generation respectively. The tube bundles in each of the six cells are submerged in a fluidized solid bed where the primary mode of heat transfer is convection.

Each of FBHE cells that contain submerged tube bundles also contain submerged and exposed enclosure wall heat transfer surface. Convection is the predominant mode of heat transfer for the submerged walls while radiation predominates in the freeboard region. The enclosure wall surface serves a steam drum positioned above the FBHE. Evaporation occurs in the enclosure walls and the tube bundle of cell 2.

Fuel gas generated in the carbonizer is burned in the topping combustor with hot air produced in the PFBC. The hot air from the PFBC assists the low-Btu fuel gas in generating a topping combustor temperature is $2,350{ }^{\circ} \mathrm{F}$. High temperature combustion products are then expanded in a Westinghouse 501F GT to generate approximately $140 \mathrm{MW}_{\mathrm{e}}$ of electrical power. The GT expander also produces the work required to compress the process air steam. The turbo-set is a single spool, constant speed machine. Gas turbine exhaust, approximately $1,170^{\circ} \mathrm{F}$, passes through a HRSG prior to exhaust to ambient.

Waste thermal energy is removed from the process in the FBHE and HRSG. This energy is used to generate high-pressure superheated steam. Steam turbine throttle conditions are $2400 \mathrm{psig}$ and $1000^{\circ} \mathrm{F}$. Reheat steam temperature is $1000^{\circ} \mathrm{F}$. Steam is expanded producing approximately $280 \mathrm{MW}_{\mathrm{e}}$ of electrical energy. Steam deaeration is obtained through steam extraction. The condenser operates at $2.5^{\prime \prime} \mathrm{Hg}(\mathrm{a})$. 
Two gas turbine trains operate in parallel. The gas turbine train includes the carbonizer, PFBC/FBHE, and associated equipment. Waste heat from the two trains drive one steam turbine set. The net power produced by the plant is approximately $538 \mathrm{MW}$ e Net plant efficiency is around 46.7 percent with a corresponding heat rate of 7,299 Btu/kW-hr.

The carbonizer and PFBC are large vessels containing significant volume. The freeboard volume of the carbonizer is approximately an order of magnitude greater than that of the GT. The PFBC volume is roughly six times greater than that of the carbonizer. The carbonizer, PFBC, and FBHE all have large thermal inertias due to the presence of solid particles. Acknowledging the volume differences and presence of large thermal inertias is important in the understanding of the dynamic model.

The steam bottoming cycle contains both slow dynamics, such as those associated with evaporative steam drums, and quick dynamics, such as those present in a high pressure steam header. The dynamic response of each component in the bottoming steam cycle affects the topping cycle components due to the highly integrated nature of the APFBC combined cycle concept. Component integration is of primary interest to this modeling effort. 


\section{A.2 PRELIMINARY MODEL DESCRIPTION}

The platform for the dynamic model generated in this study is PC-TRAX. A basic description of the model was given in Section 3. This section provides a more pragmatic description of the model and is oriented towards the eventual end user.

PC-TRAX is a commercial software tool that allows for the dynamic analysis of fossil-based power plants. PC-TRAX was chosen because it contains standard modules appropriate for describing the dynamic behavior and control of much of the components which make up the APFBC concept. Standard PC-TRAX modules were used to model all of the plant control hardware, the GT, most of the steam turbine bottoming cycle, as well as the plant valving and piping. The minimum hardware and software requirements to run PC-TRAX is given in Table A-2.1.

Table A-2.1 - Hardware/Software Requirements

HARDWARE REOUIREMENTS
IBM AT compatible $80 \times 86$ computer (or Pentium)
8 MByte of RAM
30 MByte of free disk space
A parallel or serial port (may be used by a peripheral)
An $80 \times 87$ math co-processor ( 80386 only)
SOFTWARE REOUIREMENTS
IBM OS/2 2.1 or higher
WATCOM 386/77 FORTRAN (Supplied with PC-TRAX)

Since the APFBC power plant is an advanced technology concept, some component models are not available in PC-TRAX's library of standardized dynamic modules. These advanced components include the carbonizer, char hopper, PFBC, FBHE, topping combustor, and ash cooler. Therefore, customized dynamic modules were developed to describe the performance of these components.

The customized dynamic models were coded in Advanced Continuous Simulation Language (ACSL). ACSL is a general computer language designed to dynamically model continuous time-dependent systems and is commercially available from Mitchell and Gauthier Associates. The customized ACSL models were then dynamically interfaced with the standard PC-TRAX modules. Shared variables are passed between the interface and the two models are executed simultaneously. PC-TRAX provides an easy method for the interface of the ACSL modules and standard TRAX code. 
The customized ACSL modules are supported by custom FORTRAN subroutines which were utilized to perform non-dynamic algorithms. Table A-2.2 lists which components were modeled by the TRAX modules and which required customized ACSL models. Appendix B gives a brief overview of the customized model interface. Appendices L and $M$ contain the FORTRAN and ACSL source codes respectively.

Table A-2-2

Subsystem Computer Models

\begin{tabular}{|r|c|c|}
\hline SUBSYSTEM & MODEL TYPE & REFERENCE \\
\hline Carbonizer* & Custom ACSL & Appendix C \\
\hline Pressurized FBC & Custom ACSL & Appendix D \\
\hline FB Heat Exchanger & Custom ACSL & Appendix E \\
\hline Char Hopper & Custom ACSL & Appendix F \\
\hline Ash Cooler & Custom ACSL & Appendix G \\
\hline Topping Combustor & Custom ACSL & Appendix H \\
\hline Compressors & PC-TRAX & \\
\hline Gas Turbine & PC-TRAX & \\
\hline HRSG & PC-TRAX & \\
\hline Steam Turbines & PC-TRAX & \\
\hline Condenser & PC-TRAX & \\
\hline *Piping & PC-TRAX & \\
\hline Control Valves & PC-TRAX & \\
\hline
\end{tabular}

* Includes cyclone and crossflow filter

To produce worthwhile results, a dynamic model of a commercial-sized APFBC power plant must provide all of the mathematical statements necessary to reflect the power cycle as described in Section A.1. The process model must incorporate the thermodynamics, hydrodynamics, and chemistry in sufficient detail to provide accurate performance results during steady-state and transient operation. Each primary component must be described in sufficient detail so that it may successfully interact with the other components. This detail must be balanced with computational magnitude to yield an effective yet uncumbersome model.

The dynamic model developed in this study provides mass and energy balances, appropriate chemistry, pressure-flow relationships, and velocity affects. Descriptions of the standardized PC-TRAX modules can be found in the TRAX Theory Manual. Block diagrams showing the configuration of the TRAX portion of this model are shown in Section A.3. Descriptions of the customized ACSL modules are given in Appendices C through $\mathrm{H}$. 
An important element in a dynamic power plant model is the inclusion of a control scheme. The control scheme must be interfaced with the process model. As in the case of the dynamic process model, the control scheme must be of sufficient detail to provide usable results.

All process control model components utilize standard PC-TRAX modules. Module types that are used include: transmitters, various mathematical operators, function generators, three mode controllers (also known as Proportional-Integral-Derivative controllers PID), three element controllers, auto-manual stations, and lead-lag elements. Appendix I describes the control strategy and how the control strategy is realized within the TRAX framework.

\section{A.3 BLOCK FLOW DIAGRAMS}

The model presented in this report is actually two distinct models which are executed simultaneously. The first model consists of standard PC-TRAX modules. The second consists of customized ACSL code.

The TRAX model consist of standard PC-TRAX modules connected by material streams. The modules and streams are configured such that they represent the flow and volumes of the actual process which is being modeled. Each module describes the dynamics associated with a piece of plant hardware such as a valve, pipe, or deaerator. Information is passed between modules by the material streams. This scheme is best represented in the form of a block diagram.

This section describes the block diagrams illustrating the PC-TRAX process model. The reader is urged to consult Figure 2-2 so that the actual process configuration can be compared to the block diagram representation.

For the diagrams presented in this section, blocks represent plant hardware and are identified by a three character ID. The appropriate TRAX ID is also shown. The TRAX ID is to be used when referring to the TRAX Analyst Instruction Manual. Streams are also identified by an ID tag. Stream ID's are to be used to determine state point data. W ID, H ID, X ID, T ID, and P ID correspond to the stream flowrate, enthalpy, composition, temperature, and pressure respectively.

Block and stream ID's start with a alphabetic letter. The letter corresponds to the description of the plant subsection associated with that block. For instance, block and stream ID's corresponding to the HRSG section will start with the letter $\mathrm{H}$. The model area designation is shown in Figure 3-2 and described in Section 3.4. The first two letters in the model interface block ID's are MI for the TRAX components and II for the custom components. The first two letters of ID's for streams entering the custom 
model from the TRAX model are SI. The first two letters of ID's for streams exiting the custom model and flowing to the TRAX model are SO.

Two topping cycle trains power a single steam turbine. Only one topping cycle has been modeled. The heat recovery interface is duplicated so that the steam bottoming cycle assumes heat recovery from two topping cycles.

\section{A.3.1 PC-TRAX Gas Turbine Turbo-Set}

Figures A-3.1 and A-3.2 show the TRAX configuration for the gas turbine and topping combustor exhaust respectively. Air enters the flowsheet in block GB2 and is compressed to high pressure in block GC1. The air is distributed to the main air header, rotor cooling air, and turbine cooling air in streams GS5, GS7, and GS11 respectively. High temperature flue gas from the custom ACSL topping combustor model enters the TRAX model in stream SO3. Following direct cooling by stream GS8, the hot flue gas is expanded in block GT1. Turbine exhaust flows to the HRSG through stream GS14. Table A-3.1 contains summary descriptions of the blocks shown in Figures A-3.1 and A-3.2.

\section{A.3.2 PC-TRAX FBHE Fluidizing Air Valve Header}

Figure A-3.3 shows the TRAX configuration of the FBHE fluidizing air header. Air enters the header from the gas turbine compressor exhaust piping in stream GS6. Valves AV1 through AV7 control the flow of air to the seven fluidized FBHE cells. The control modules are described in Appendix I. The model interfaces MIA to MIG in the TRAX model interact with model interfaces IIA through IIG in the custom model. Table A-3.2 contains summary descriptions of the blocks shown in Figure A-3.3.

\section{A.3.3 PC-TRAX PFBC Air Feed}

Figure A-3.4 shows the TRAX configuration of the PFBC air header. Air enters this section of the flowsheet in stream AS9. Block PJ1 distributes air between PFBC primary air, PFBC secondary air, carbonizer area air, and bypass air which correspond to streams PS2, PS3, PS4, and PS8 respectively. Air flow to the PFBC primary and secondary zones is controlled by valves PV1 and PV2 respectively. The control modules are described in Appendix I. Blocks MI4 and MI5 provide the interface in the TRAX model. Blocks II4 and II5 provide corresponding service in the custom model. Table A-3.3 contains summary descriptions of the blocks shown in Figure A-3.4. 
Table A-3.1 - Gas Turbine Block Diagram Summary

\begin{tabular}{|l|l|l|}
\hline BLOCK NAME & \multicolumn{1}{|c|}{ TRAX } & \multicolumn{1}{c|}{ DESCRIPTION } \\
\hline GB2 & BCEGP & Boundary condition, inlet air to GT \\
GC1 & COMPSL & GT air compressor. \\
GJ2 & JUNCPA & Pressure node, air splitter. \\
GH3 & HXAA & Piping energy and pressure loss component. \\
GV2 & VALVEG & Control valve, air to ambient. \\
GB1 & BCLGP & Boundary condition, air to ambient. \\
GG1 & GENVS & GT generator. \\
GR2 & RSISTG & Pipe, flow resistance. \\
GJ3 & JUNCPA & Pressure node, air mixer. \\
GR2 & RSISTG & Pipe, flow resistance. \\
GR5 & RSISTG & Pipe, flow resistance. \\
GT1 & GTRB & Gas turbine expander. \\
GJ4 & JUNCPA & Pressure node, air mixer. \\
GV1 & VALVEG & Control valve, air bypass to top combustor. \\
MI6 & MILGP & Model interface, air bypass to combustor. \\
II6 & MIEGW & Model interface, air bypass to combustor. \\
GS3 & SET & Set block, variable Q. \\
GS4 & SET & Set block, variable Q. \\
GS5 & SET & Set block, variable Q. \\
GS7 & SET & Set block, variable valve position. \\
IO3 & MILGW & Custom model interface component. \\
MO3 & MIEGP & TRAX model interface component. \\
GR1 & RESIST & Piping pressure drop. \\
\hline
\end{tabular}

Table A-3.2 - FBHE Fluidizing Air Header Block Diagram Summary

\begin{tabular}{|l|l|l|}
\hline BLOCK NAME & \multicolumn{1}{|c|}{ TRAX } & \multicolumn{1}{c|}{ DESCRIPTION } \\
\hline AV1-AV7 & VALVEG & Air flow control valves. \\
MIA-MIG & MIEGP & TRAX model interface components. \\
IIA-IIG & MIEGW & Custom model interface components. \\
AJ1 & JUNCPA & Pressure node, air splitter. \\
AR1 & RSISTG & Piping pressure loss. \\
\hline
\end{tabular}




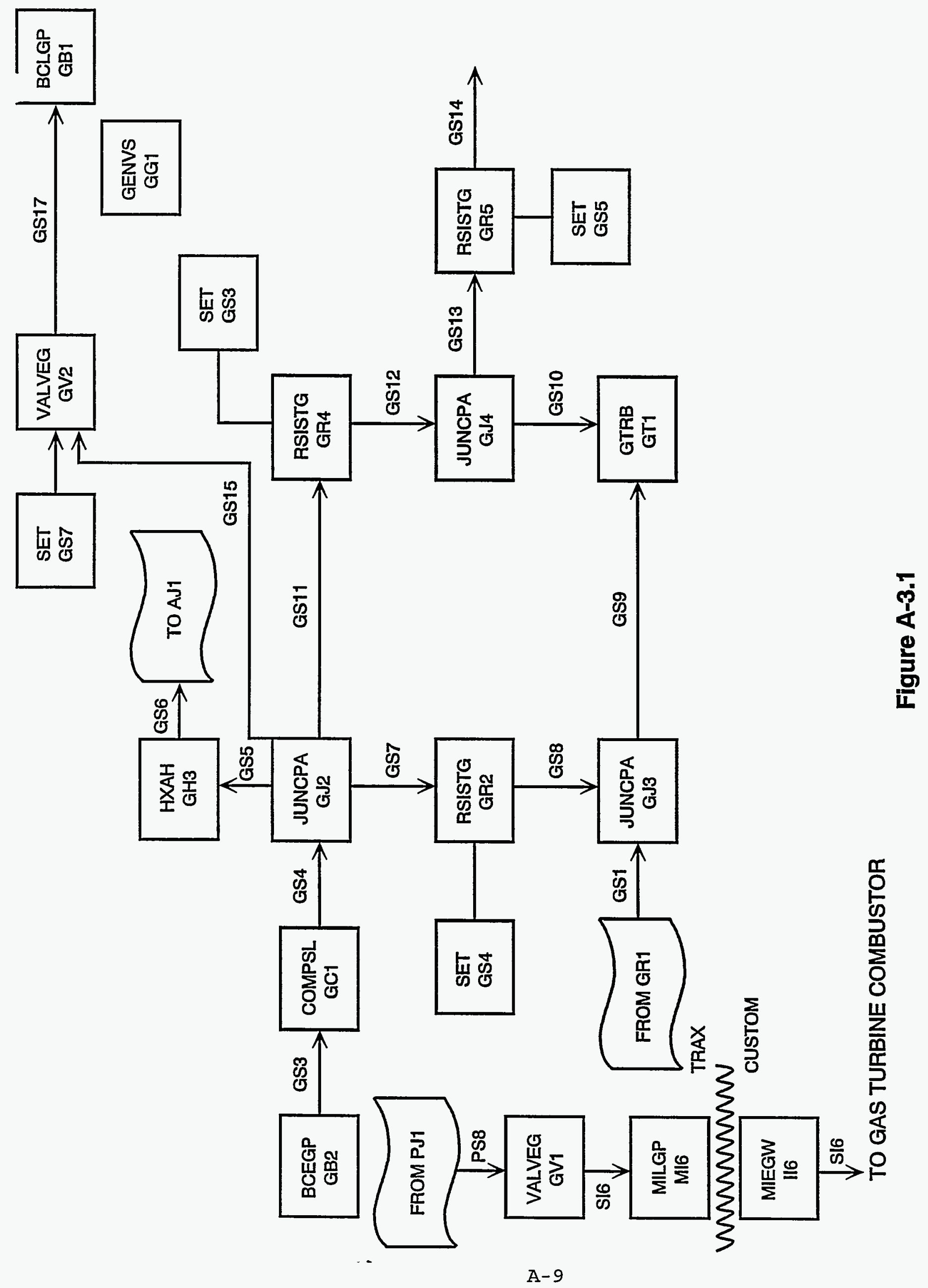




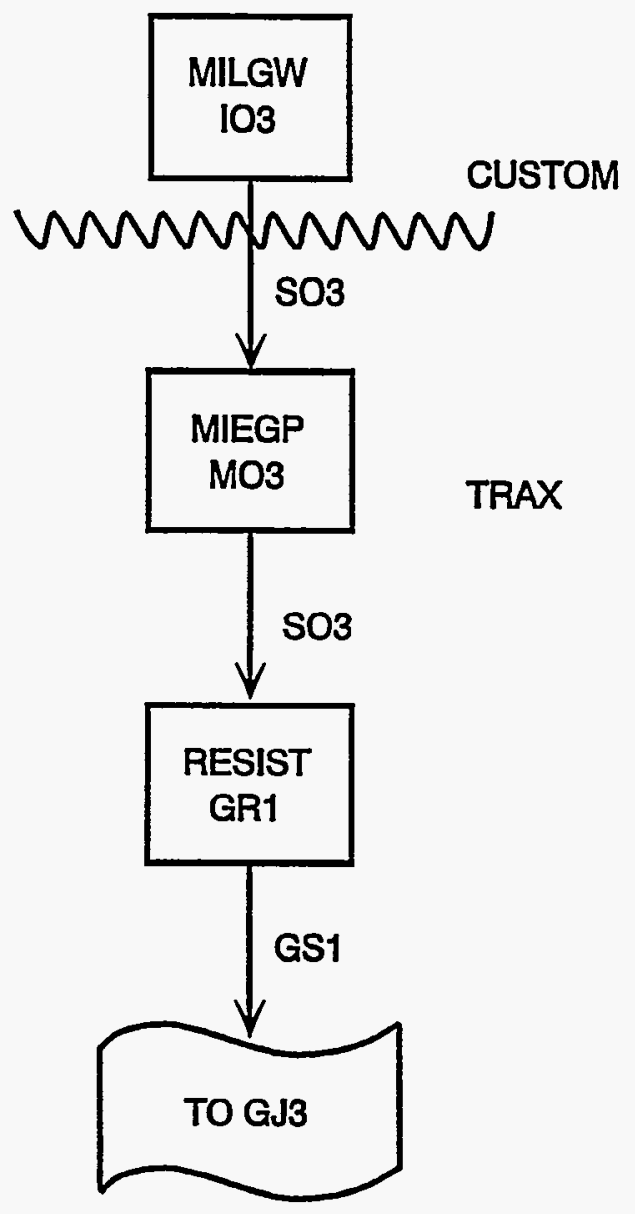

Figure A-3.2 


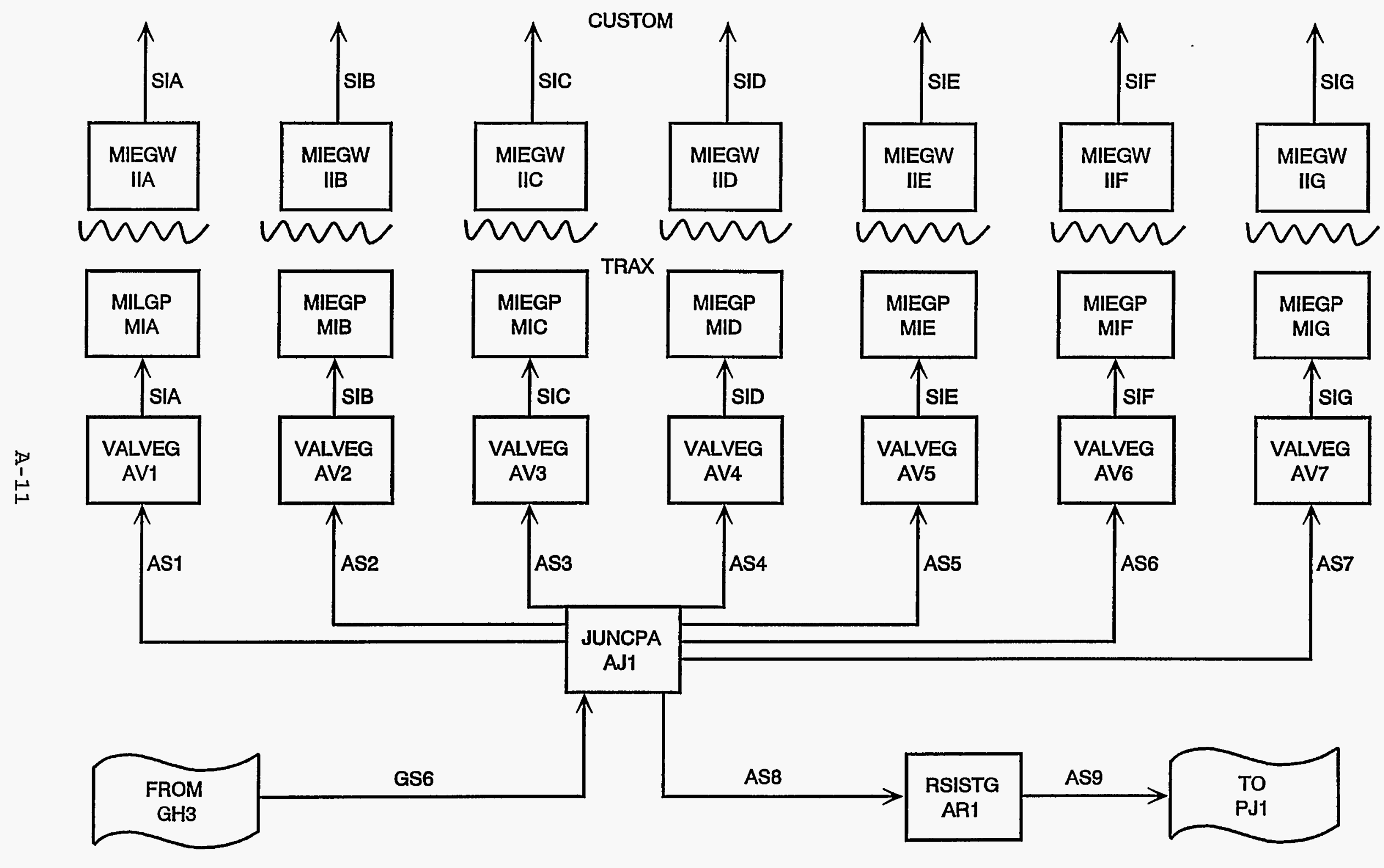

Figure A-3.3 


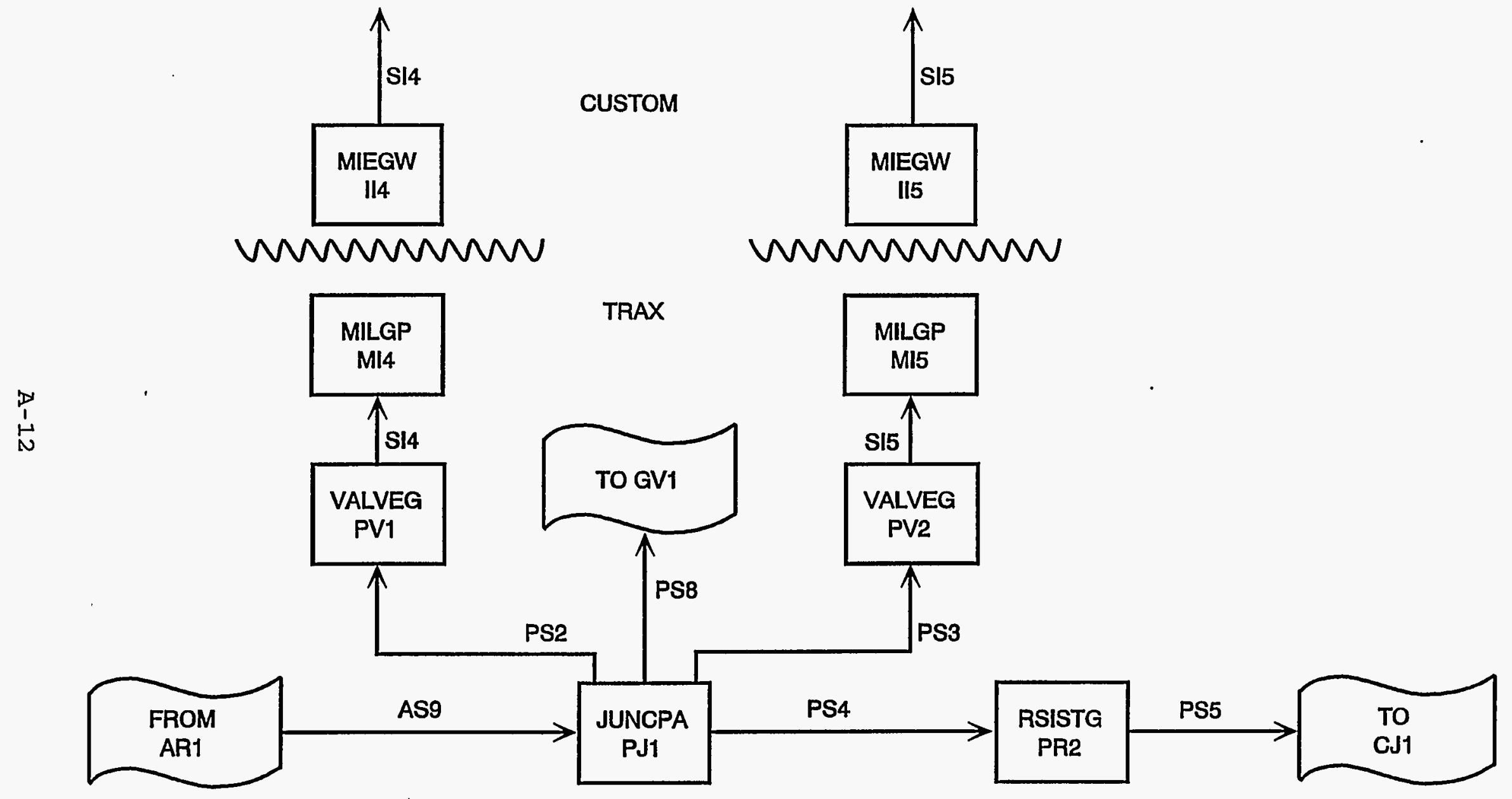

Figure A-3.4 
Table A-3.3 - PFBC Air Header Block Diagram Summary

\begin{tabular}{|l|l|l|}
\hline BLOCK NAME & TRAX NAME & \multicolumn{1}{|c|}{ DESCRIPTION } \\
\hline PJ1 & JUNCPA & Pressure node, air splitter. \\
PR2 & RSISTG & Piping pressure loss. \\
PV1 & VALVEG & PFBC primary zone air control valve. \\
PV2 & VALVEG & PFBC secondary zone air control valve. \\
M14 & MLGP & TRAX model interface component. \\
MI5 & MILGP & TRAX model interface component. \\
II4 & MIEGW & Custom model interface component. \\
II5 & MIEGW & Custom model interface component. \\
\hline
\end{tabular}

\section{A.3.4 PC-TRAX Carbonizer Air/Steam Feed}

Figures A-3.5 and A-3.6 show the TRAX configuration for the air and steam feed to the carbonizer. Air from the PFBC area in stream PS5 is divided between the transport and carbonizer primary air flow, which flows in streams CS6 and CS3 respectively. Steam enters this flowsheet subsection in stream BS65. Table A-3.4 contains summary descriptions of the blocks shown in Figures A-3.5 and A-3.6.

\section{A.3.5 PC-TRAX Fuel Gas Flare and Piping}

Figure A-3.7 shows the TRAX configuration for the fuel gas flare and associated piping. Fuel gas generated in the carbonizer flows to the TRAX model through stream SO1. FV1 and FV3 are valves which can dump fuel flow to a flare. FV2 is a block valve normally 100 percent open. Fuel gas is returned to the custom model through stream SI7. Table A-3.5 contains summary descriptions of the blocks shown in Figure A-3.7.

\section{A.3.6 PC-TRAX Vitiated Air Piping}

Figure A-3.8 shows the TRAX configuration for the fuel gas flare and associated piping. Vitiated air from the PFBC flows into the TRAX model in stream SO2. Following small pressure loss, vitiated air is returned to the custom model in stream SI8. Table A-3.6 contains summary descriptions of the blocks shown in Figure A-3.8. 
Table A-3.4 - Carbonizer Air/Steam Feed Block Diagram Summary

\begin{tabular}{|l|l|l|}
\hline \multicolumn{1}{|c|}{ BLOCK } & \multicolumn{1}{|c|}{ TRAX } & \multicolumn{1}{c|}{ DESCRIPTION } \\
\hline CJ1 & JUNCPA & Pressure node, air splitter. \\
CC1 & COMPSL & Primary air boost compressor. \\
CJ2 & JUNCPA & Pressure node. \\
CJ1 & VALVEG & Carbonizer primary air control valve (dummy). \\
CC2 & JUNCPA & Pressure node. \\
CJ4 & COMPSL & Transport air boost compressor. \\
CV2 & JUNCPA & Pressure node. \\
CJ5 & VALVEG & Transport air control valve (dummy). \\
CR3 & JUNCPA & Pressure node. \\
CV3 & RSISTG & Piping pressure loss. \\
MI1-MI3 & VALVE & Carbonizer steam control valve. \\
II1-II3 & MULGP & TRAX model interface component. \\
CH1 & MIEGW & Custom model interface component. \\
CH2 & HXAA & Air cooler for transport air. \\
CH3 & HXAA & Air cooler for transport air. \\
CJ6 & HXAA & Air cooler for transport air. \\
\hline
\end{tabular}

\section{A.3.7 PC-TRAX HRSG}

Figures A-3.9 and A-3.10 show the TRAX configuration for the boiler feed water pump and HRSG. Boiler feed water in stream BS57 is pressurized in block BP1 and distributed to both HRSG's. BFW also flows to the attemperators. Hot flue gas from the gas turbine expander flows into this subsection in stream GS14. Boiler feed water flows into the economizer in stream HS8. Superheated steam exits the flowsheet in stream HS14. Subcooled water exits the flowsheet in stream HS10. Table A-3.7 contains summary descriptions of the blocks shown in Figure A-3.9.

\section{A.3.8 PC-TRAX FBHE Steam Drum and Piping}

Figure A-3.11 shows the TRAX configuration for the boiler water piping leading to the FBHE steam drum. Control valve PV3 meters water which flows to the custom model through interface MI9 and II9. The controls are discussed in Appendix I. Figure A-3.12 shows the TRAX configuration for the HRSG superheated steam flow to FBHE finishing superheater and the superheater attemperating spray streams. Table A-3.8 contains summary descriptions of the blocks shown in Figures A-3.11 and A-3.12. 


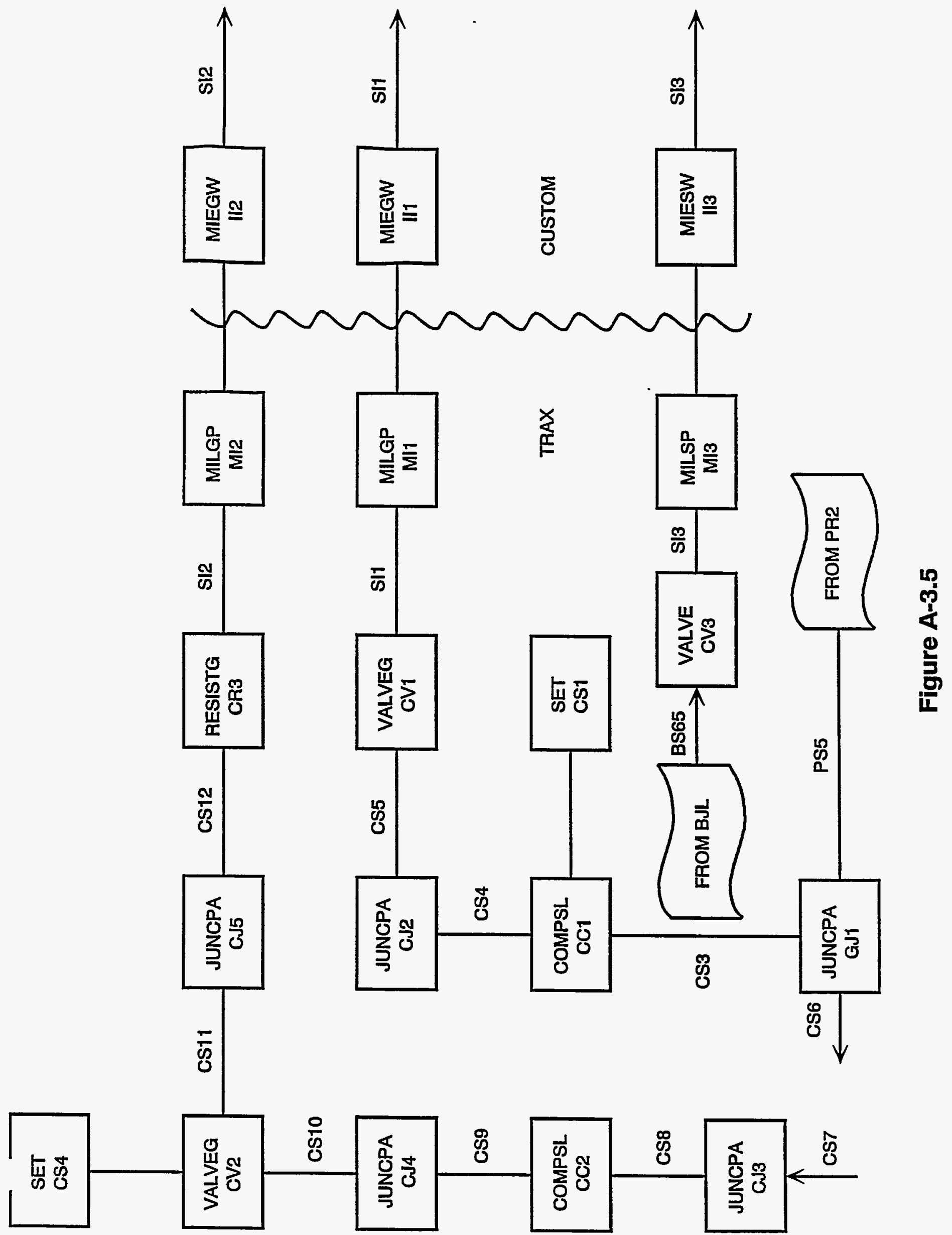




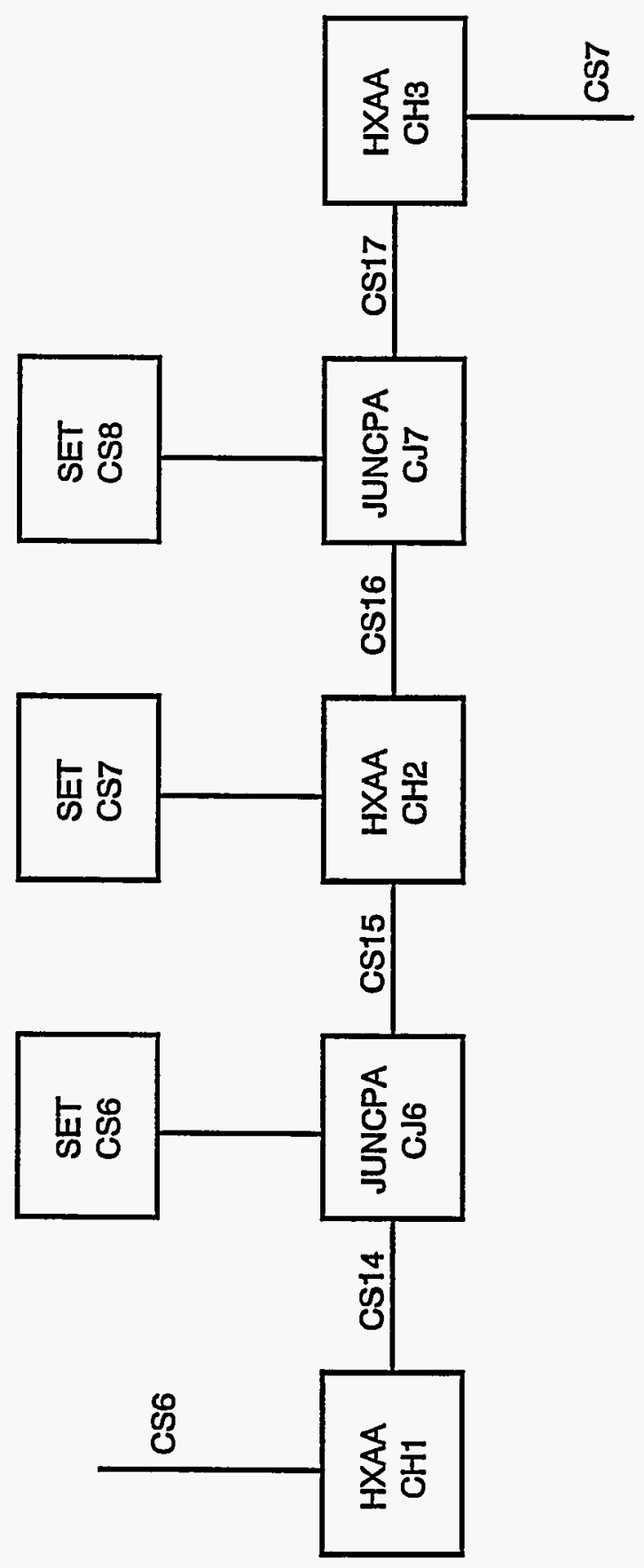

0
0
0
0
0
0 
Table A-3.5 - Fuel Gas Flare and Piping Block Diagram Summary

\begin{tabular}{|l|l|l|}
\hline \multicolumn{1}{|c|}{ BLOCK } & \multicolumn{1}{|c|}{ TRAX } & \multicolumn{1}{c|}{ DESCRIPTION } \\
\hline IO1 & MUGW & Custom model interface component. \\
MO1 & MUEGP & TRAX model interface component. \\
FR2 & RSISTG & Piping pressure loss. \\
FJ1 & JUNCPA & Pressure node. \\
FV1 & VALVEG & Valve to large vent. \\
FB1 & BCLGP & Large vent flow boundary condition. \\
FV2 & VALVEG & Control valve (dummy). \\
FJ2 & JUNCPA & Pressure node. \\
FV3 & VALVEG & Valve to large vent. \\
FB2 & BCLGP & Small vent flow boundary condition. \\
FR1 & RSISTG & Piping pressure loss. \\
M17 & MILGP & TRAX model interface component. \\
II7 & MIEGW & Custom model interface component. \\
\hline
\end{tabular}

Table A-3.6 - Vitiated Air Piping Block Diagram Summary

\begin{tabular}{|l|l|l|}
\hline \multicolumn{1}{|c|}{$\begin{array}{c}\text { BLOCK } \\
\text { NAME }\end{array}$} & TRAX NAME & \multicolumn{1}{c|}{ DESCRIPTION } \\
\hline IO2 & MILGW & Custom model interface component. \\
MO2 & MIEGP & TRAX model interface component. \\
VR1 & RSISTG & Piping pressure loss. \\
VP1 & JUNCPA & Pressure node. \\
VR2 & RSISTG & Piping pressure loss. \\
MI8 & MULGP & TRAX model interface component. \\
II8 & MUEGW & Custom model interface component. \\
\hline
\end{tabular}


Table A-3.7 - HRSG Block Diagram Summary

\begin{tabular}{|l|l|l|}
\hline \multicolumn{1}{|c|}{ BLOCK } & \multicolumn{1}{|c|}{ TRAX } & \multicolumn{1}{c|}{ DESCRIPTION } \\
\hline BP1 & PUMP & Boiler feed water pump. \\
HJ2 & JUNCP & Pressure node, water splitter. \\
BB2 & BCLSW & Boundary condition, train \#2 HRSG BFW flow. \\
HD1 & DUCTEX & HRSG ducting. \\
HS1 & SET & Set block, variable air split. \\
HS2 & SET & Set block, variable damper position. \\
HH1 & SUPER & Superheater. \\
HH2 & EVAPGT & Steam drum evaporator. \\
HH3 & ECNMZR & Economizer \\
HB4 & BCLSW & Boundary condition, blowdown. \\
GMERGE & HM1 & Gas path merge. \\
HJ1 & JUNCP & Pressure node, water splitter. \\
HV1 & VALVE & Control valve. \\
\hline
\end{tabular}

\section{A.3.9 PC-TRAX H/P Steam Turbine and Reheater}

Figure A-3.13 shows the TRAX configuration for the high pressure steam turbine and reheater. High pressure steam from the first train finishing superheater is mixed with the same from the second train in BJ2. Logic for the second train steam flow can be found in the ${ }^{*}$.CFM file. The combined high pressure steam flow passes through control valve BV1 prior to entering the high pressure turbine, BT1.

High pressure turbine effluent is split and routed to the reheaters. Logic for the second train reheat steam flow can be found in the *.CFM file. Train \# 1 reheater flow passes from the TRAX model to the custom model in stream SIJ. Hot reheat from the custom model is returned to the TRAX model through stream SO5.

Table A-3.9 contains summary descriptions of the blocks shown in Figure A-3.13. 


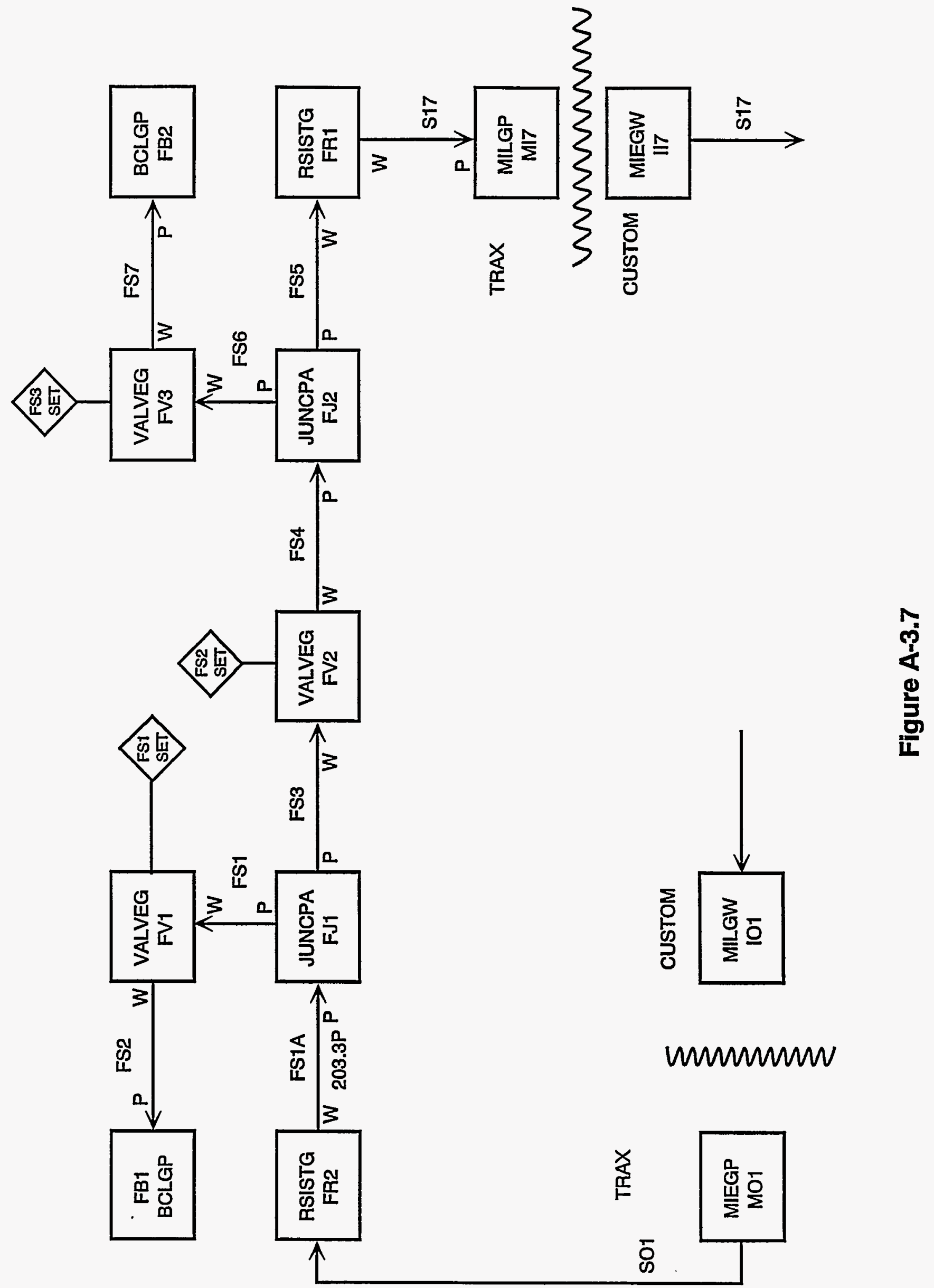




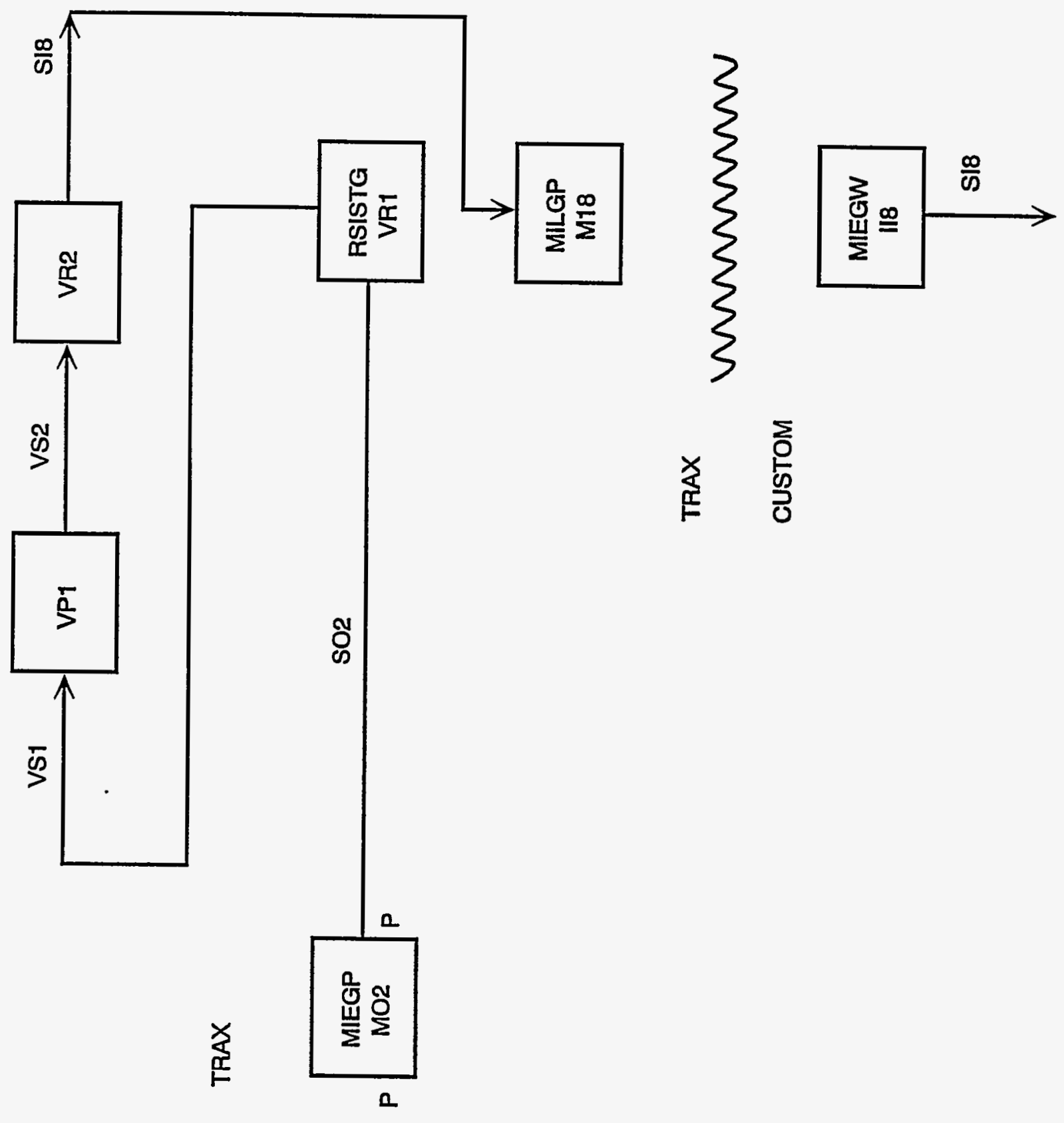

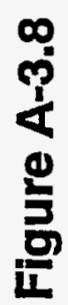

unumur

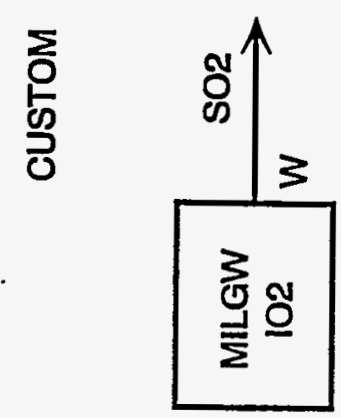




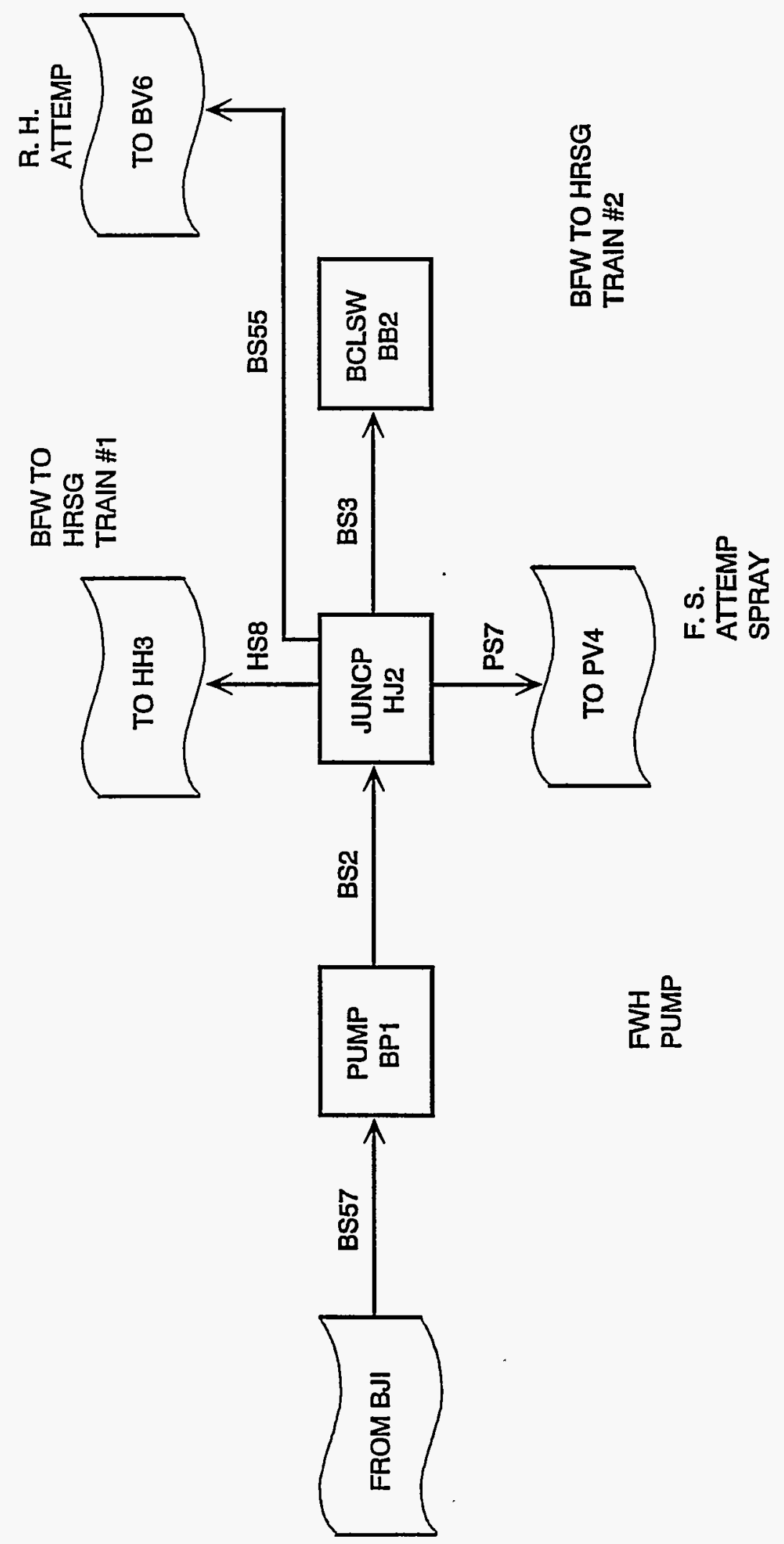

0
0
$\frac{1}{3}$
$\frac{1}{1}$ 


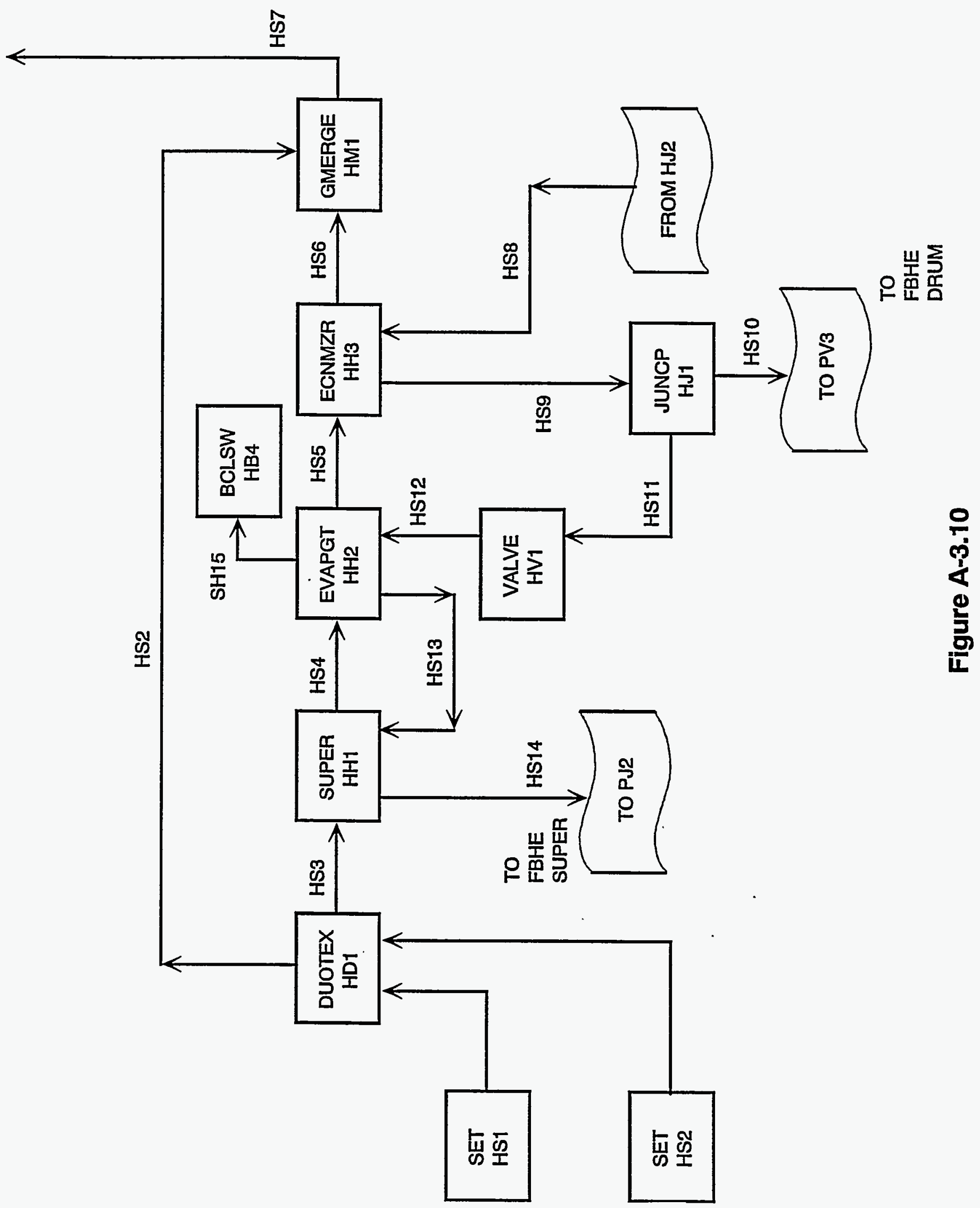


Table A-3.8 - Steam Piping Block Diagram Summary

\begin{tabular}{|l|l|l|}
\hline BLOCK NAME & TRAX NAME & \multicolumn{1}{c|}{ DESCRIPTION } \\
\hline PV3 & VALVE & Control valve, BFW flow to steam drum. \\
MI9 & MILSP & TRAX model interface component. \\
II9 & MIESW & Custom model interface component. \\
PV4 & VALVE & Control valve, attemperating spray flow. \\
MII & MILSP & TRAX model interface component. \\
III & MIESW & Custom model interface component. \\
PJ2 & JUNCP & Pressure node. \\
PR1 & RESIST & Piping pressure loss. \\
MIH & MILSP & TRAX model interface component. \\
IIH & MIESW & Custom model interface component. \\
\hline
\end{tabular}



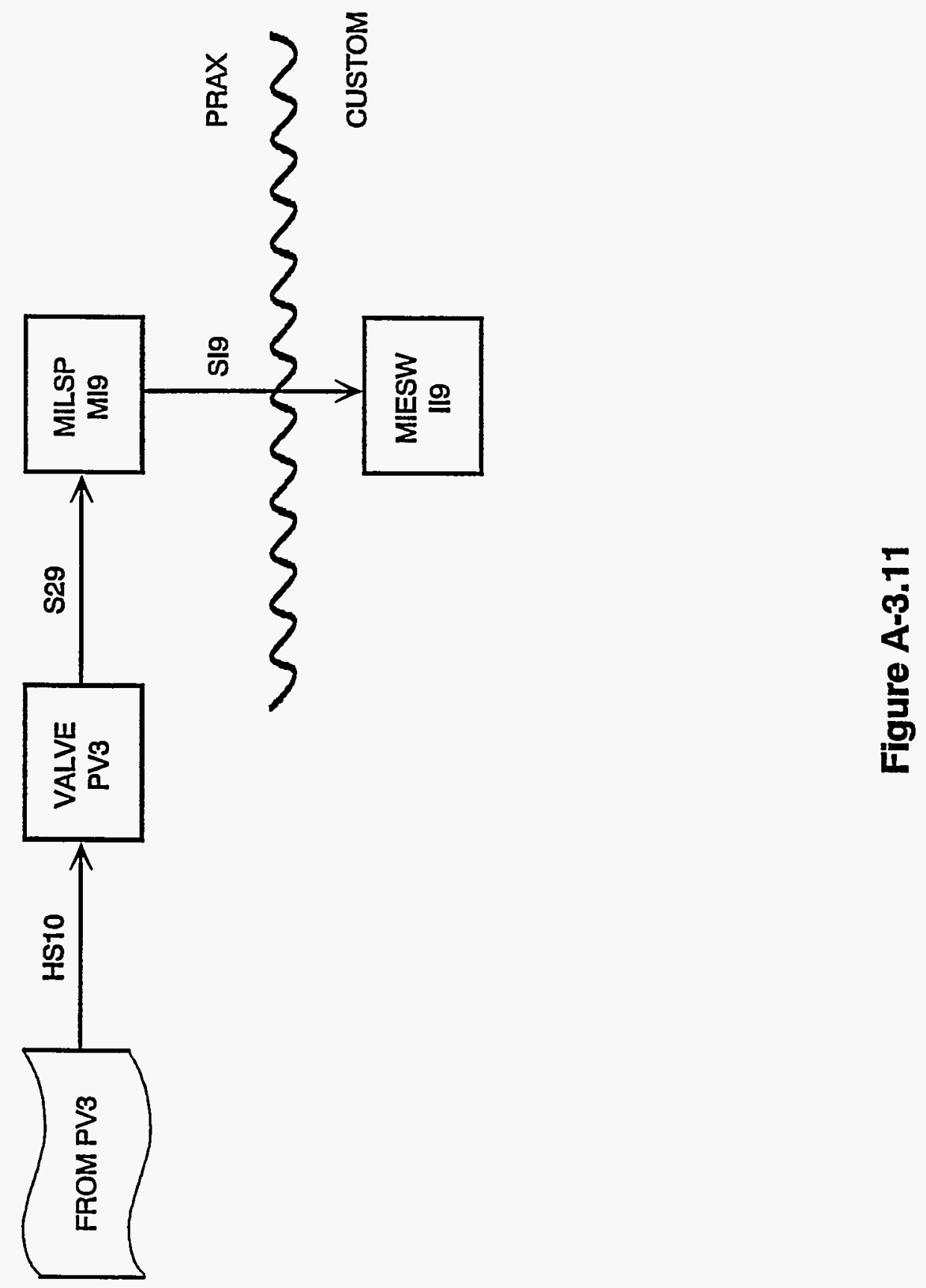


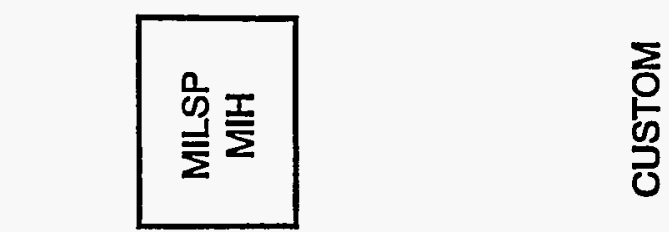

munnm

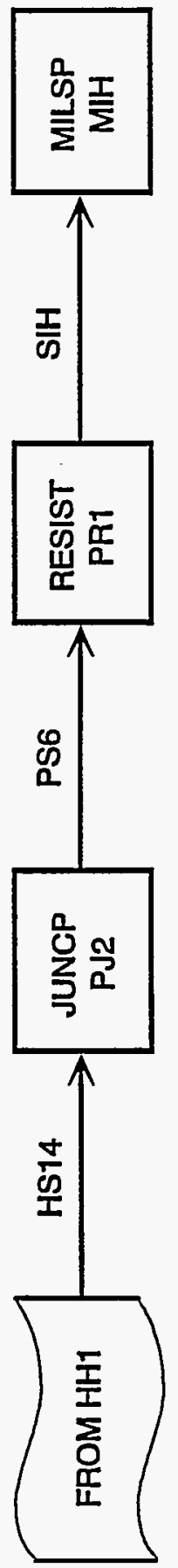

옹

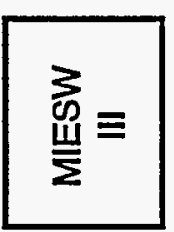

monnum

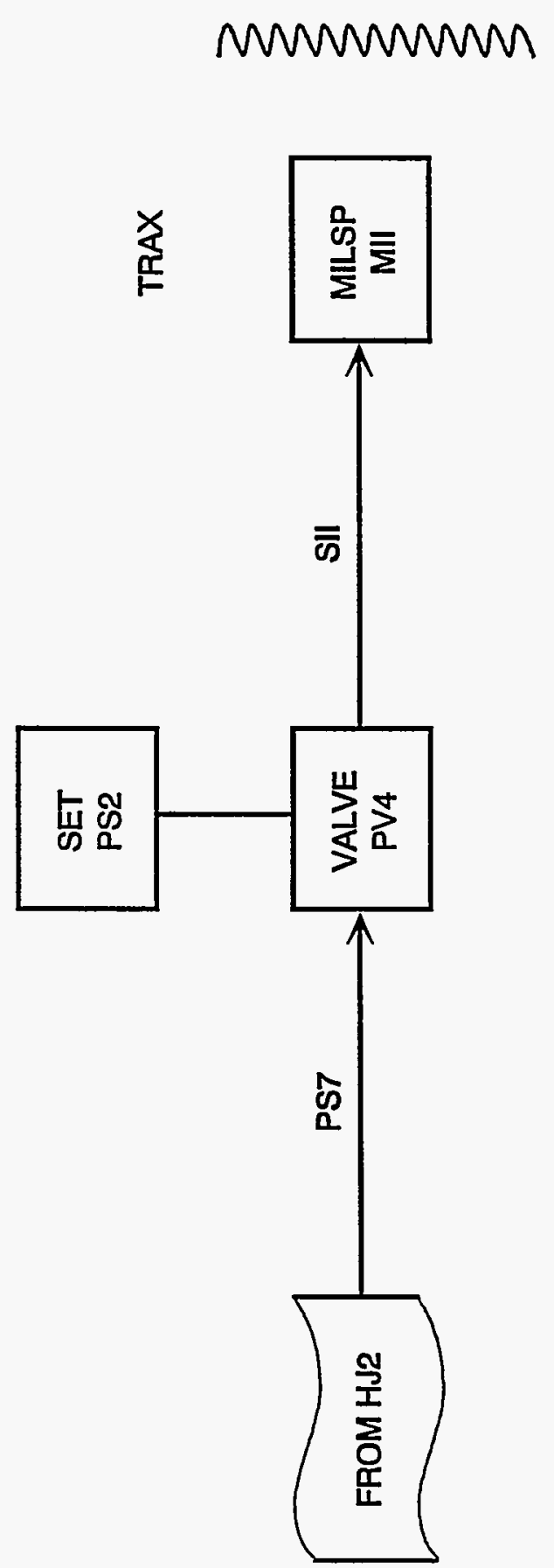


TRAIN \#1

SUPER HEATED

STEAM
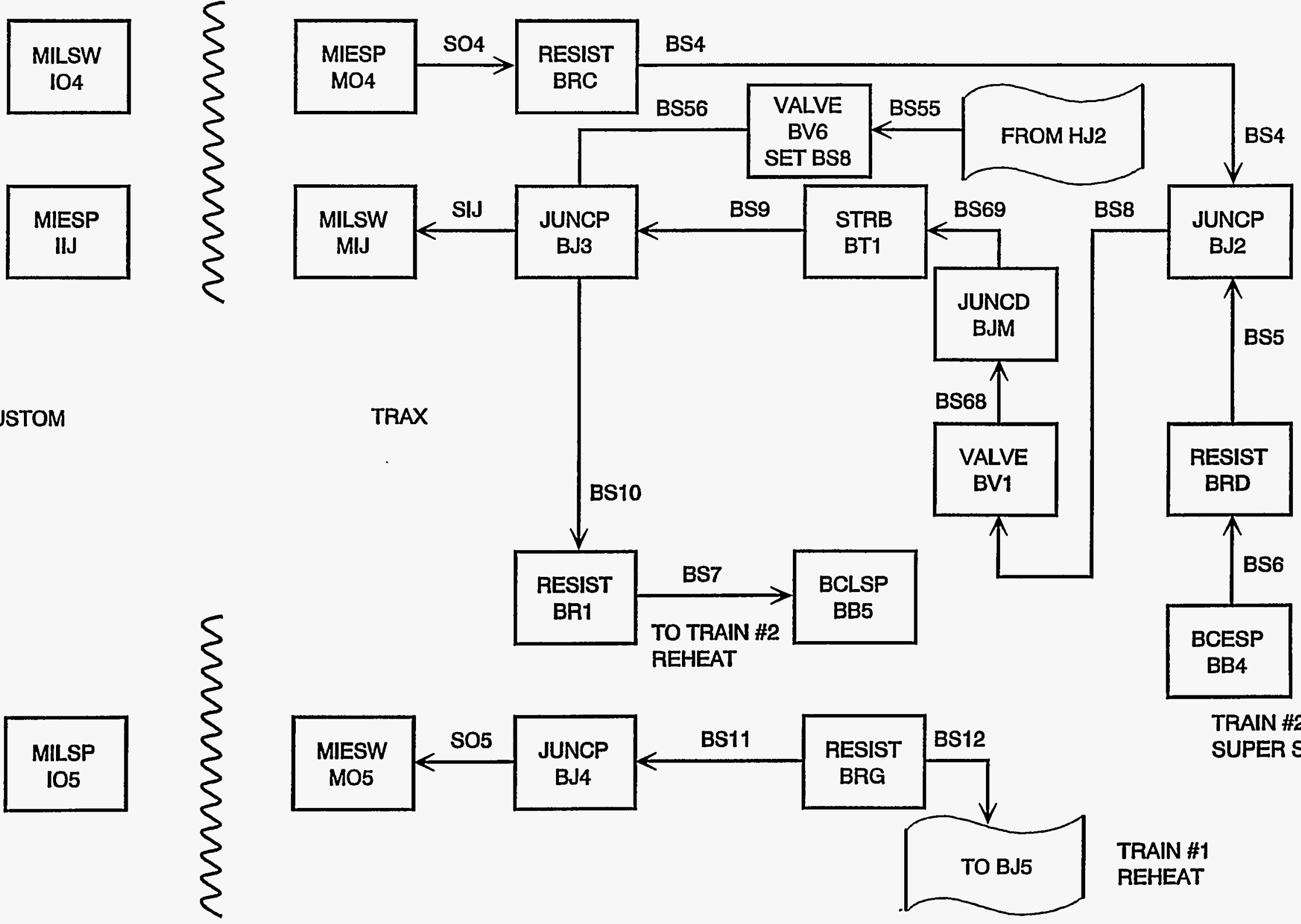

TRAIN \#2

SUPER STEAM

Figure A-3.13 
Table A-3.9 - H/P Turbine and Reheater Block Diagram Summary

\begin{tabular}{|l|l|l|}
\hline \multicolumn{1}{|c|}{ BLOCK } & TRAX NAME & \multicolumn{1}{c|}{ DESCRIPTION } \\
\hline IO4 & MILSW & Custom model interface component. \\
MO4 & MIESP & TRAX model interface component. \\
BRC & RESIST & Piping pressure loss. \\
BB4 & BCESP & Boundary condition, train \# 2 S/H steam. \\
BRD & RESIST & Piping pressure loss. \\
BJ2 & JUNCP & Pressure node, flow mixer. \\
BV1 & VALVE & Control valve, H/P steam flow. \\
BJM & JUNCP & Pressure node. \\
BT1 & STRB & H/P steam turbine. \\
BV6 & VALVE & Control valve, R/H attemperator flow. \\
BJ3 & JUNCP & Pressure node, splitter, mixer. \\
BR1 & RESIST & Piping pressure loss. \\
BB5 & BCLSP & Boundary condition, flow to train \#2 R/H. \\
MIJ & MILSW & TRAX model interface component. \\
IIJ & MIESP & Custom model interface component. \\
IO5 & MUSP & Custom model interface component. \\
MO5 & MIESW & TRAX model interface component. \\
BJ4 & JUNCP & Pressure node. \\
BRG & RESIST & Piping pressure loss. \\
\hline
\end{tabular}

\section{A.3.10 PC-TRAX I/P Steam Turbine and Carbonizer Steam Extraction}

Figure A-3.14 shows the TRAX configuration for the I/P steam turbine sections. Reheat from train \# 2 enters the flowsheet through stream BS13 and is mixed with the flow from train \# 1 in block BJ5. The combined flow enters I/P turbine section BT2. Carbonizer steam feed is provided by an extraction at block BJ6. Following further expansion, the deaerator extraction is taken at block BJ8.

Figure A-3.15 shows the TRAX configuration for desuperheating the steam extraction used for carbonizer feed. The steam extraction removed at block BJ6, from Figure A-3.14, is desuperheated by boiler feed water in block BJK. The resulting flow is split to the carbonizers. Stream BS65 is the steam feed to the carbonizer in train \# 1. Likewise, stream BS66 is the steam feed to the carbonizer in train \# 2. 
Table A-3.10 contains summary descriptions of the blocks shown in Figures A-3.14 and A-3.15. This summary will provide added insight during execution and analysis of this model.

Table A-3.10 - I/P Turbine Block Diagram Summary

\begin{tabular}{|l|l|l|}
\hline \multicolumn{1}{|c|}{ BLOCK } & TRAX NAME & \multicolumn{1}{c|}{ DESCRIPTION } \\
\hline BB6 & BCESP & Boundary condition, reheat from train \#2. \\
BV4 & VALVE & Control valve on train \#2 reheat flow. \\
BJ5 & JUNCP & Pressure node, steam mixer. \\
BT2 & STRB & I/P steam turbine section. \\
BJ6 & JUNCP & Pressure node, steam splitter. \\
BRB & RESIST & Piping pressure loss. \\
BT3 & STRB & I/P steam turbine section. \\
BJ7 & JUNCP & Pressure node. \\
BT4 & STRB & L/P steam turbine section. \\
BJ8 & JUNCP & Pressure node, steam splitter. \\
BR2 & RESIST & Piping pressure loss. \\
BT5 & STRB & L/P steam turbine section. \\
BP3 & PUMP & BFW pump. \\
BJJ & JUNCP & Pressure node. \\
BV7 & VALVE & Control valve, BFW flow to desuperheater. \\
BJK & JUNCP & Pressure node, water mixer. \\
BRA & RESIST & Piping pressure loss. \\
BJL & JUNCP & Pressure node, flow splitter. \\
\hline
\end{tabular}

\section{A.3.11 PC-TRAX L/P Steam Turbine and Feed Water String}

Figure A-3.16 shows the TRAX configuration for the L/P steam turbine and exhaust section. Also shown is the water storage tank and associated piping. An extraction for the feed water heater is removed at block BJ9. The remaining steam flow is expanded in block BT6. Block BT6 accounts for the exhaust loss. The turbine effluent flows into the condenser, block BC1. Condenser cooling water enters in stream BS22. Make-up is provided by storage tank BK1. 


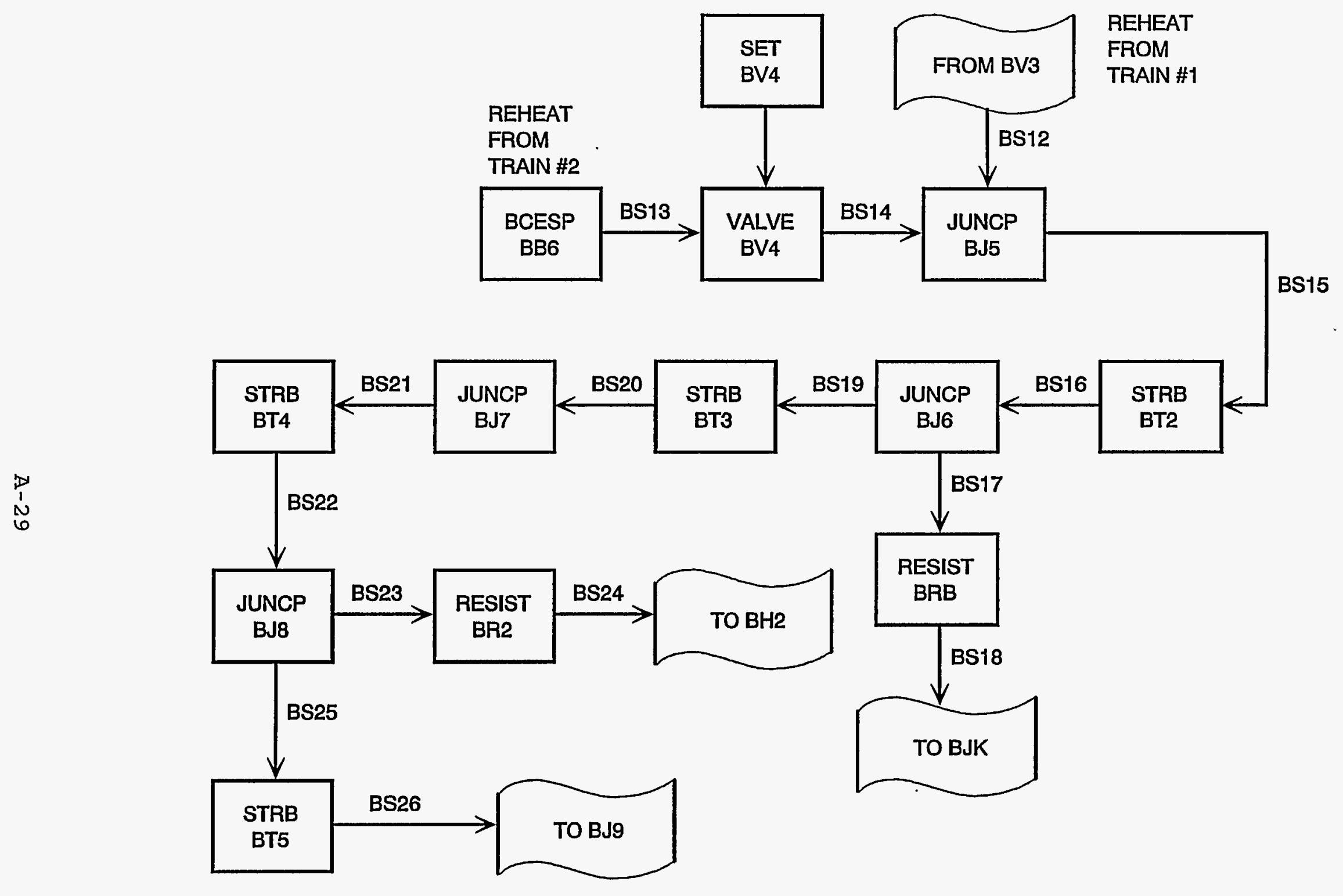

Figure A-3.14 


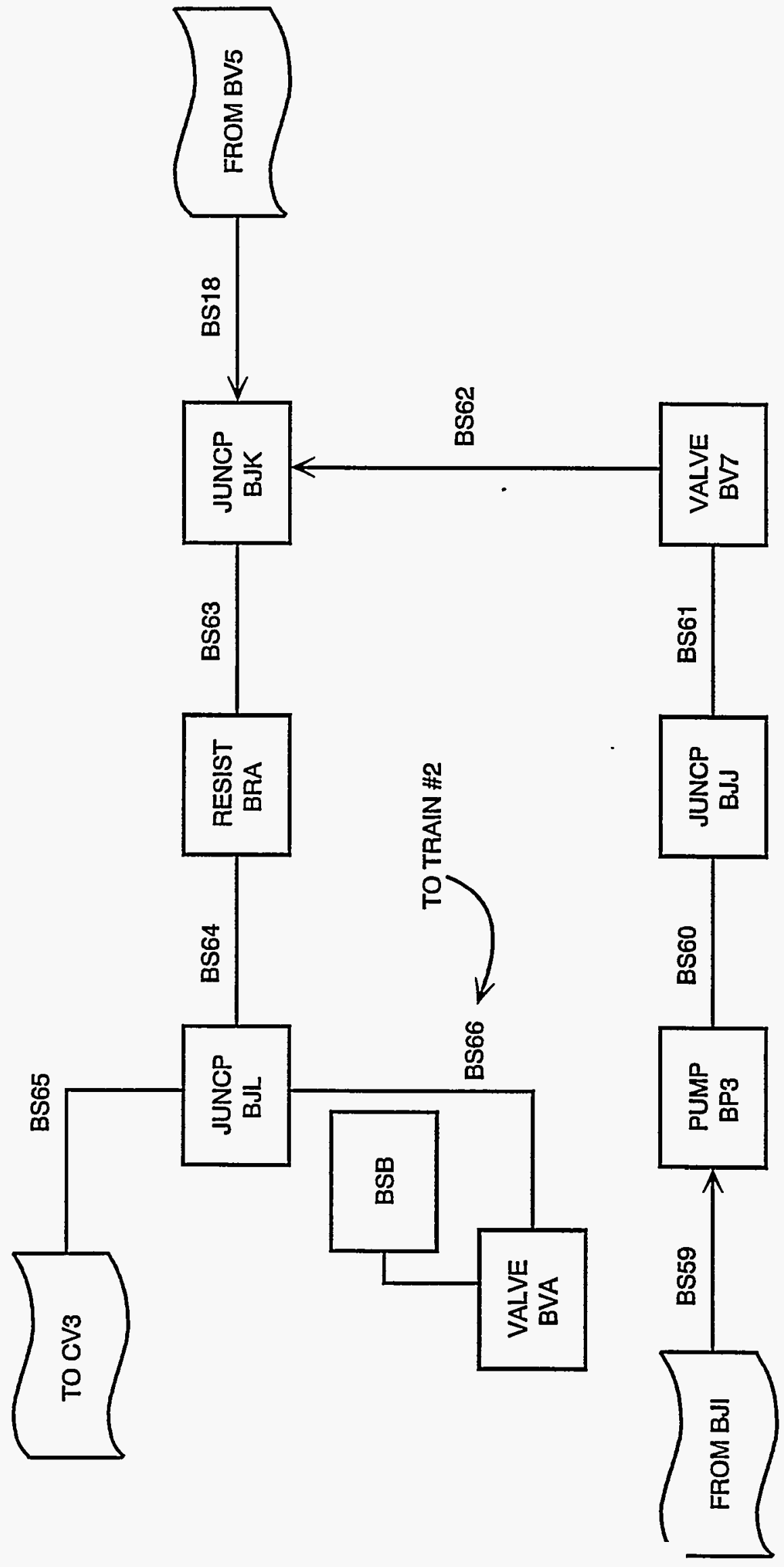

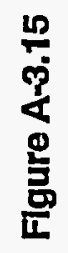

$$
\text { A-30 }
$$




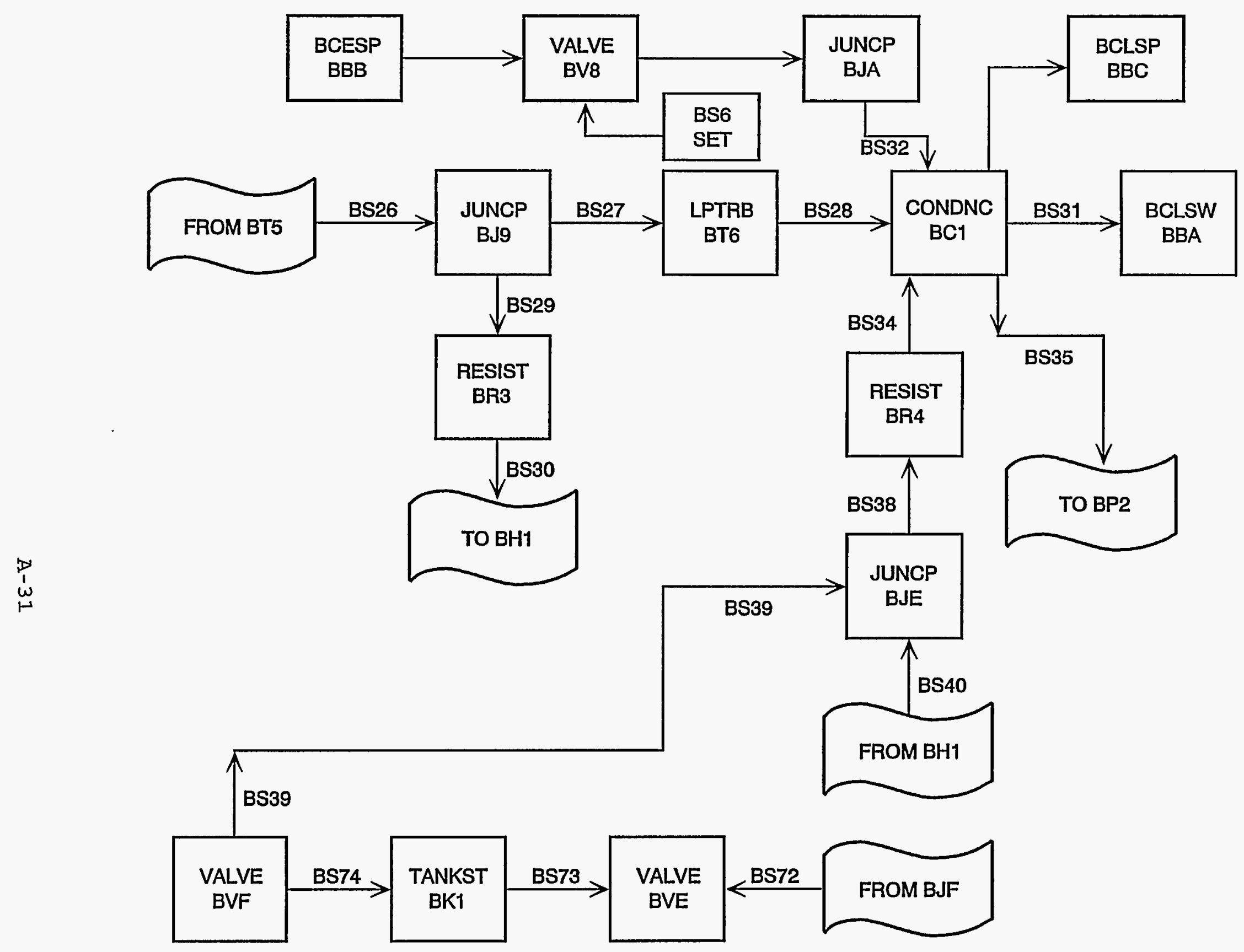

Figure A-3.16 
Figure A-3.17 shows the TRAX configuration for the condensate pump, ash cooler, and feed water heater. Condensate from the condenser in stream BS35 is pressurized in block BP2. The resulting flow is split amongst the train \# 2 ash cooler, stream BS41, train \# 1 ash cooler, stream SIK, and feed water heater inlet flow, stream BS43. Water from the ash cooler is returned to the TRAX model in stream SO6. Water from train \# 2 is mixed with stream SO6 in block BJG.

Figure A-3.18 shows the TRAX configuration for the steam cycle deaerator. The main feed water stream enters the deaerator as BS71. This flow is controlled by valve BVD. Flow from the ash coolers arrives in stream BS54. The deaerator is block BH2. Boiler feed water flows from the deaerator in stream BS51.

Table A-3.11 contains summary descriptions of the blocks shown in Figures A-3.16, A-3-17, and A-3.18. This summary will provide added insight during execution and analysis of the model.

\section{A.4 HOW TO USE MODEL}

The model provided with this report can be exercised to investigate various scenarios confined to the configuration as described in the appendix. Model variables such as volumes, controller tunings, set points, and time constants may be changed by the analyst. Also, controllers may be taken out of service and the gas turbine can be made to run on natural gas rather than carbonizer gas. To change the present plant design, the analyst must modify the model provided with the report. Changes to the present design include such things as removing or adding controllers, adding or deleting process equipment, or enhancing the customized or standard TRAX modules. This section will describe how the model can be exercised as provided, and how the model can be modified to reflect design changes. It is assumed that the reader has a rudimentary knowledge of the TRAX software and has some ACSL/FORTRAN coding skill.

\section{A.4.1 Exercising the Model}

PC-TRAX is run from the MODELS directory. Subdirectories of MODELS contain the executable code of the models. As discussed, there are two separate and distinct models which make up the commercial-sized APFBC power plant model. The model containing the standard TRAX modules, PFB2MDL1, must be stored in a different subdirectory than the model containing the custom ASCL code, PFB2MDL2.

As a demonstration, it is assumed that PC-TRAX is loaded on the F directory. In this scenario, PFB2MDL1 could be stored in subdirectory [F: $\backslash$ MODELS $\backslash C U S T O M]$ and PFB2MDL2 could be stored in subdirectory [F: \MODELS\CUSTOM-X]. In this case, PC-TRAX would be run in the [F: \MODELS] directory. 


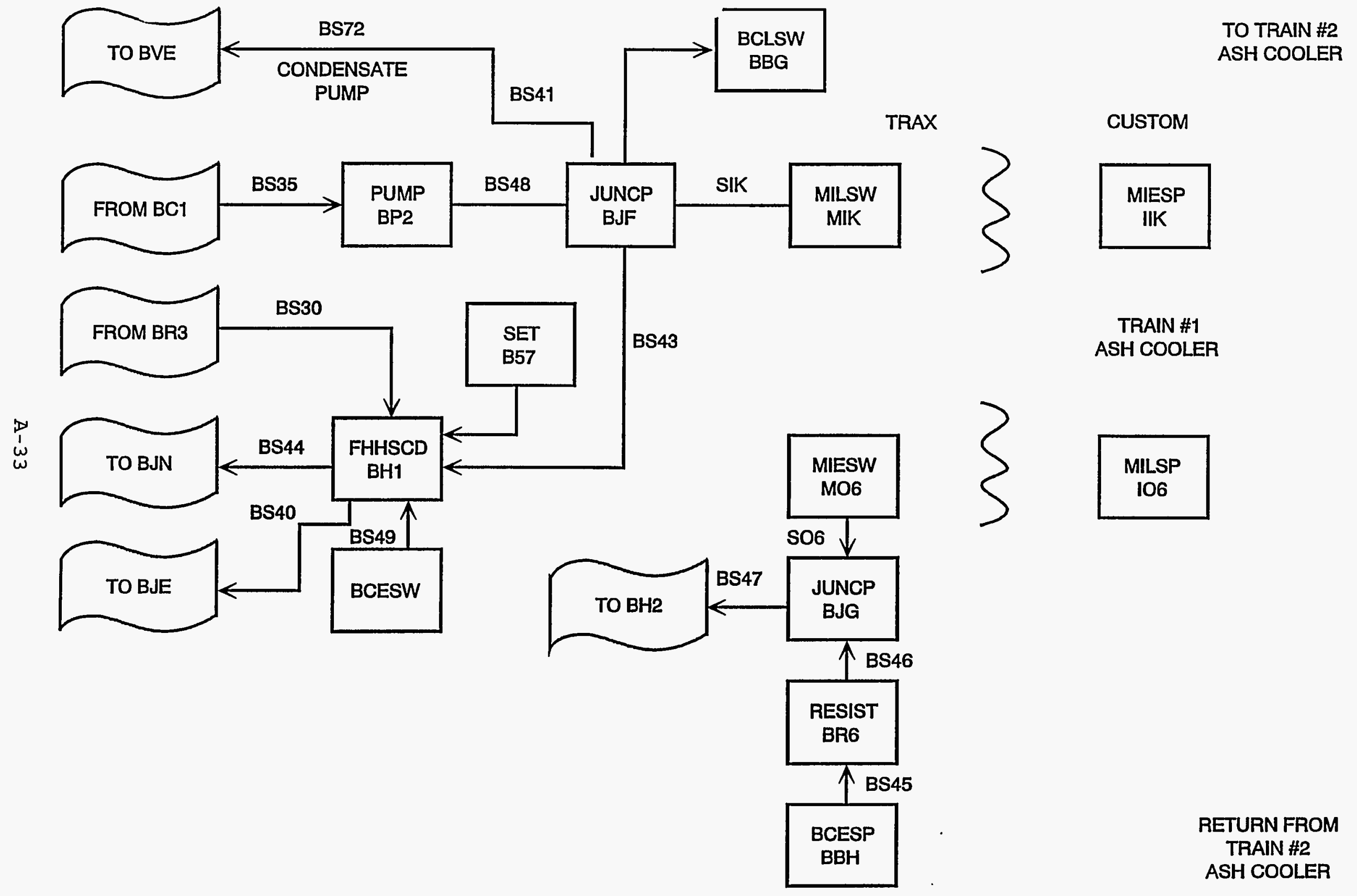

Figure A-3.17 


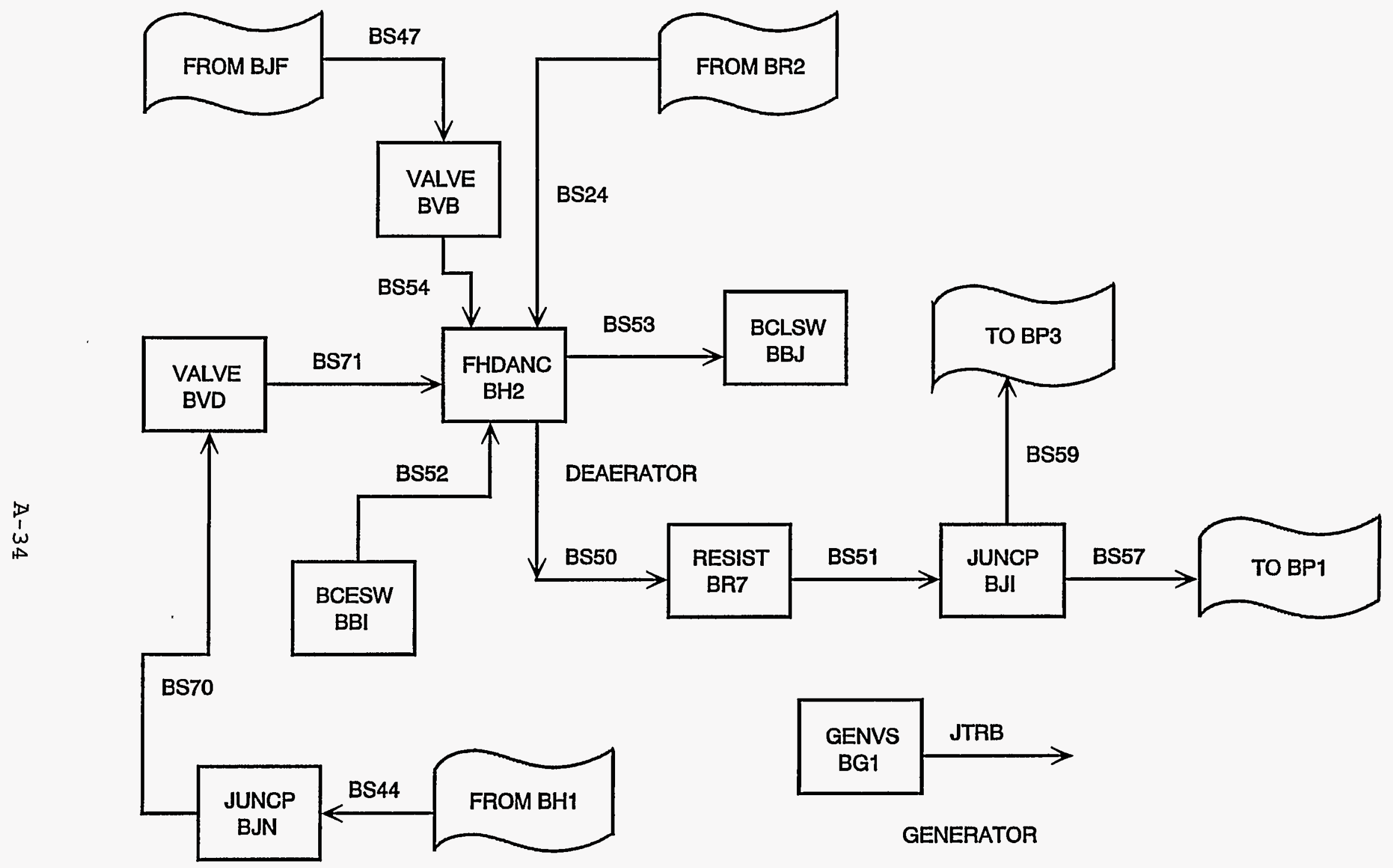

Figure A-3.18 
Table A-3.11 - L/P Turbine and Feed Water String Block Diagram Summary

\begin{tabular}{|l|l|l|}
\hline \multicolumn{1}{|c|}{ BLOCK } & TRAX NAME & \multicolumn{1}{c|}{ DESCRIPTION } \\
\hline BJ9 & JUNCP & Pressure node, steam splitter. \\
\hline BR3 & RESIST & Piping pressure loss. \\
\hline BT6 & LPTRB & L/P turbine with exhaust loss. \\
\hline BC1 & CONDNC & Condenser. \\
\hline BBC & BCLSP & Boundary condition, outlet cooling water flow. \\
\hline BBB & BCESP & Boundary condition, inlet cooling water flow. \\
\hline BV8 & VALVE & Control valve, cooling water flow. \\
\hline BS6 & SET & Set block, variable valve position. \\
\hline BJA & JUNCP & Pressure node. \\
\hline BBA & BCLSW & Boundary condition, condenser vent. \\
\hline BR4 & RESIST & Piping pressure loss. \\
\hline BJE & JUNCP & Pressure node, water mixer. \\
\hline BVE & VALVE & Control valve, storage tank inlet. \\
\hline BK1 & TANKST & Water storage tank. \\
\hline BVF & VALVE & Control valve, storage tank outlet. \\
\hline BP2 & PUMP & Condensate pump. \\
\hline BJF & JUNCP & Pressure node, water splitter. \\
\hline BBG & BCLSW & Boundary condition, train \#2 ash cooler flow. \\
\hline MIK & MILSW & TRAX model interface component. \\
\hline IIK & MIESP & Custom model interface component. \\
\hline IO6 & MILSP & Custom model interface component. \\
\hline MO6 & MIESW & TRAX model interface component. \\
\hline
\end{tabular}


Table A-3.11 - L/P Turbine and Feed Water String Block Diagram Summary (cont.)

\begin{tabular}{|l|l|l|}
\hline BLOCK NAME & \multicolumn{1}{|c|}{ TRAX } & \multicolumn{1}{c|}{ DESCRIPTION } \\
\hline BBH & BCESP & Boundary condition, train \#2 ash cooler return. \\
\hline BR6 & RESIST & Piping pressure loss. \\
\hline BJG & JUNCP & Pressure node, water mixer. \\
\hline BH1 & FHHSCD & Feed water heater. \\
\hline BJH & BCESW & Boundary condition, drain inlet. \\
\hline BS7 & SET & Set block, variable liquid height. \\
\hline BJN & JUNCP & Pressure node. \\
\hline BVD & VALVE & Control valve, BFW flow. \\
\hline BBI & BCESW & Boundary condition, recirculation flow. \\
\hline BH2 & FHDANC & Steam deaerator. \\
\hline BVB & VALVE & Control valve, ash cooler flow. \\
\hline BBJ & BCLSW & Boundary condition, deaerator vent. \\
\hline BR7 & RESIST & Piping pressure loss. \\
\hline BJI & JUNCP & Pressure node, water splitter. \\
\hline BG1 & GENVS & S/T generator. \\
\hline
\end{tabular}

To execute the models, enter <PCTRAX $>$ at the OS $/ 2$ command prompt of the [F:\MODELS] subdirectory. You will be asked to pick the model and time step. Both models are run simultaneously, therefore both PFB2MDL1 and PFB2MDL2 must be chosen. A time step of 0.1 seconds or less is suggested.

Following model selection, the program will build the appropriate model interfaces and load the program. Once the program is loaded, a window will appear with a menu bar across the top. Contained within the window are two subwindows, the first titled PC-TRAX Commands, the second titled PC-TRAX data log. It is desired to start the model from a stable, steady-state point. The recommended starting point corresponds to 100 percent of design load. To load this steady-state condition, open File from the menu, select Open IC from the submenu, open file IC000002.IC described as "time out 30000". The model was run for 30000 seconds and the variable values were saved in this file. Starting at this point provides for a more stable, steady-state condition than that at time zero.

It is recommended that the analyst remove the real-time constraint by entering <rt off $>$ at the PC-TRAX command box. This will save the analyst a considerable amount of time. 
Primary output is provided in the PC-TRAX data log window. A previously saved log

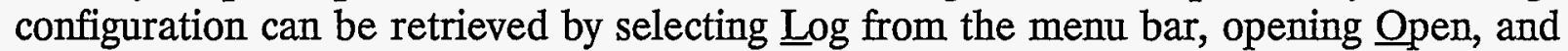
highlighting a *.LGS file. To create your own data log, select $\underline{L}$ og from the menu bar, open $\underline{L}$ og SetUp, and select which variables you would like to log. Variables can be logged into an electronic file or viewed in the data $\log$ window. It is up to the analyst to chose either one or the other. To log data to an electronic file which can be submitted to a printer type <mon on> at the PC-TRAX command prompt. The data will be stored in a PCTRAX.LOG file which can be printed after completion of the run.

Following completion of the log set-up, a log time interval should be chosen. This interval will set the time period between successive logged outputs. The default is one second. The time selected must be greater than the time step. To enter a log interval type $<$ logint $=$ _ $>$ at the PC-TRAX command window.

Before starting the model, a stop time must be entered into the program. This is accomplished by typing $<$ stoptime $=>$ at the TRAX command prompt. To start the model enter <run> at the PC-TRAX $\bar{X}$ command bar. The model will execute with the appropriate values logged into the data window. During execution, variable values may be plotted on the screen. To plot variables during model execution open Output from the menu bar and select Trend. A window will appear. An old trend configuration may be opened by selecting File, Open, and then highlighting a *.PLT file. A new trend

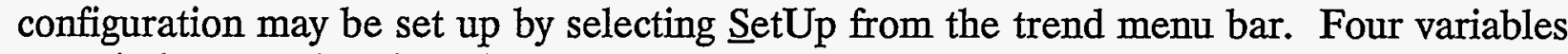
per window may be plotted.

Model execution can be terminated by freezing the program and typing < quit> at the PC-TRAX command. Program execution is halted by either typing <freeze $>$ at the PC-TRAX command box or hitting the F9 key. The freeze command can also allow the analyst to adjust certain model parameters and to view values not currently logged by typing < adjust> or < view> from the PC-TRAX command window.

The adjust command can also be executed while the model is running. The adjust command allows the analyst to do such things as initiate change in load, adjust controller tunings, take controllers out of automatic operation, close valves, bypass flows, and to modify component time constants. The block diagrams presented in Section A.3, the ACSL source code in Appendix L, and the instrumentation diagrams in Appendix I should be used when making adjustments to the model.

Following completion of the model execution, variable values may be plotted on the screen. To plot variables following model execution open Output from the menu bar and select Plot. A window will appear. An old plot configuration may be opened by selecting File, Open, and then highlighting a *.PLT file. A new plot configuration may be set up by selecting $\underline{S}$ etUp from the trend menu bar. Four variables per window may 
be plotted. Plots generated in this fashion may be submitted to a printer by selecting File and opening the Print box.

Additional run-time commands and instruction can be obtained by consulting the PC-TRAX Analyst Instruction Manual. The analyst should consult this document prior to using the software.

\section{A.4.2 Modifying the Model}

Modifying the process or control model requires that the analyst be well aware of the complete model configuration. The model configuration is presented in Section A.3. The analyst should also be comfortable with the customized ACSL code contained within the model and presented in Appendix L. The model should be backed-up and saved on disc prior to any modification. In this manner, the original model may be preserved should the modified version become corrupt.

To change the configuration, operating or physical parameters of the standard TRAX model, the analyst must go to directory [F: $\backslash$ MODELS $\backslash C U S T O M]$. At the OS $/ 2$ command prompt, enter <MCPARM PFB2MDL1>. The PC-TRAX manual outlines the necessary procedure for affecting model modifications. The menu bar at the bottom of the window serves as a good guide. Following modification, exit MCPARM. Enter $<$ TRAXGEN PFB2MDL1 $>$ to convert the new model to executable FORTRAN.

To change the configuration, operating or physical parameters of the TRAX components of the customized model, the analyst must go to directory [F:\MODELS $\backslash$ CUSTOM-X]. At the OS $/ 2$ command prompt, enter <MCPARM PFB2MDL2>. The PC-TRAX manual outlines the necessary procedure for affecting model modifications. The menu bar at the bottom of the window serves as a good guide. Following modification, exit MCPARM. Enter <TRAXGEN PFB2MDL2> to convert the new model to executable FORTRAN.

To modify the customized ACSL code, the analyst must go to directory [F: \MODELS \CUSTOM-X]. With a quality editor, edit PFB2MDL2.CUS to make the desired changes. The supporting FORTRAN in FORTRAN.CUS may be edited in the same manner. Following the editing changes, exit the editor and type <MCPARM PFB2MDL2 >. Generate the .CSL file by pressing the F4 and F5 keys. Exit MCPARM and enter <TRAXGEN PFB2MDL2> to convert the new model to executable FORTRAN.

Following model modifications, the model may be executed from the [F:|MODELS] directory. The same procedure as outlined in A.4.1 should be used to run the modified model. 


\section{B PC TRAX AND CUSTOMIZED INTERFACES}

Two models are used to simulate the PFBC-II combined cycle. The first, PFBZMDL1, contains standard TRAX modules. The second, PFB2MDL2, contains custom tailored ACSL code. This section describes the interface between the two models.

\section{B.1 INTRODUCTION}

The architecture of the PC-TRAX module interconnection scheme is that "Flow" nodes connect to "Pressure" nodes. Pressure nodes calculate pressure and pass the value to the upstream and downstream flow nodes. Likewise, Flow nodes calculate flow and pass the value to the upstream and downstream pressure nodes. Figure B-1.1 shows the flow of information between nodes.

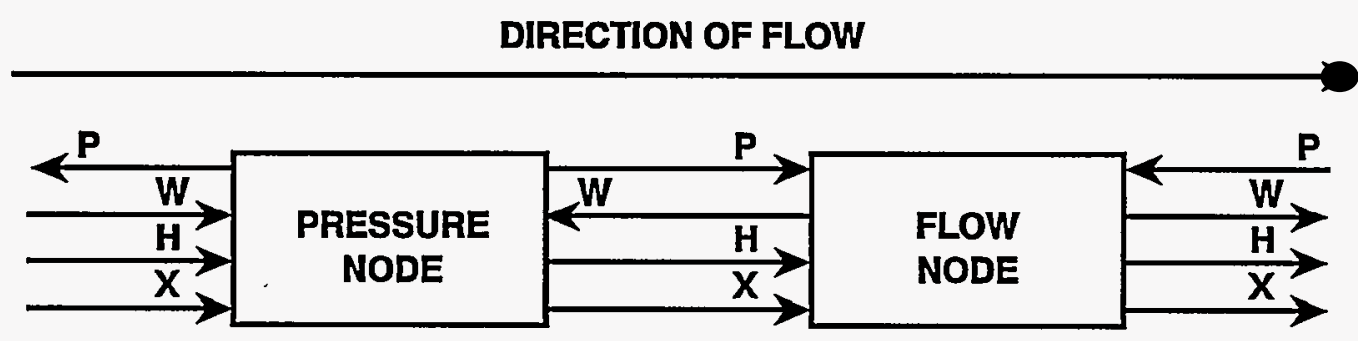

Figure B-1.1 - PC-TRAX Interconnection Scheme

As can be seen in Figure B-1.1, pressure is passed from pressure nodes, flow is passed from flow nodes, and enthalpy and composition flow downstream.

Modeling of the PFBC-II combined cycle power plant required custom tailored models for the carbonizer, CPFBC, FBHE, topping combustor, and ash cooler. Custom models were required because they do not exist amongst the PC-TRAX library of subroutines used to describe conventional power cycle equipment such as turbines and compressors. Also, the custom tailored models had to be interfaced with the standard PC-TRAX modules. Section B.2 describes the method used to interface the standard PC-TRAX modules and the custom tailored modules.

\section{B.2 MODEL INTERFACE}

Five custom tailored subsystem modules were coded in ACSL and interfaced with the standard PC-TRAX modules. The subsystems are listed in Table B-2.1 
Table B-2.1

Custom Tailored Modules

\begin{tabular}{|l|l|}
\hline SUBSYSTEM & NODE TYPE \\
\hline Carbonizer & Pressure \\
PFBC & Pressure \\
FBHE-Gas/Steam & Pressure/Flow \\
Ash Cooler & Flow \\
Topping Combustor & Pressure \\
\hline
\end{tabular}

There are four possible interface combinations. The four interface combinations are shown below. Steam is the assumed fluid, but air, gas, and oil are also possible.

For a component module that is a pressure node, such as the carbonizer, the following scheme would be used to pass information into and out of the module.
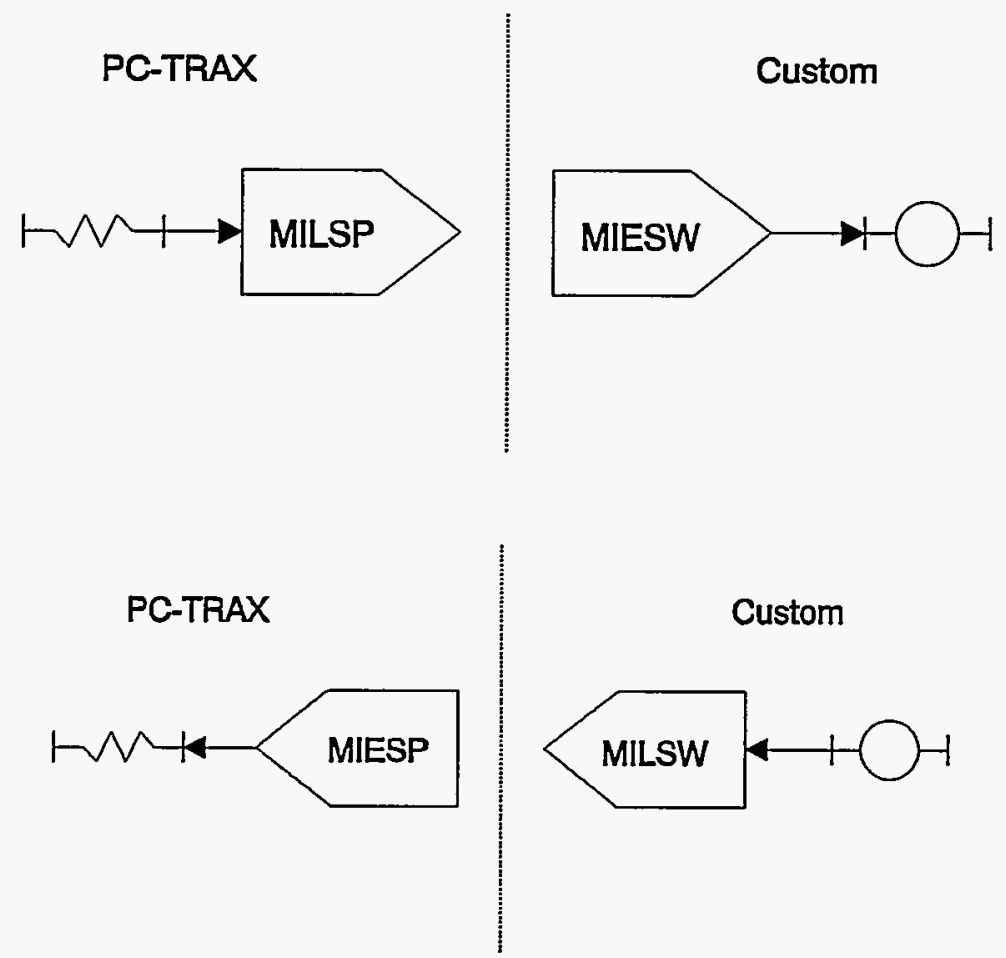

For a component module that is a flow node, such as the ash cooler, the following scheme would be used to pass information into and out of the module. 

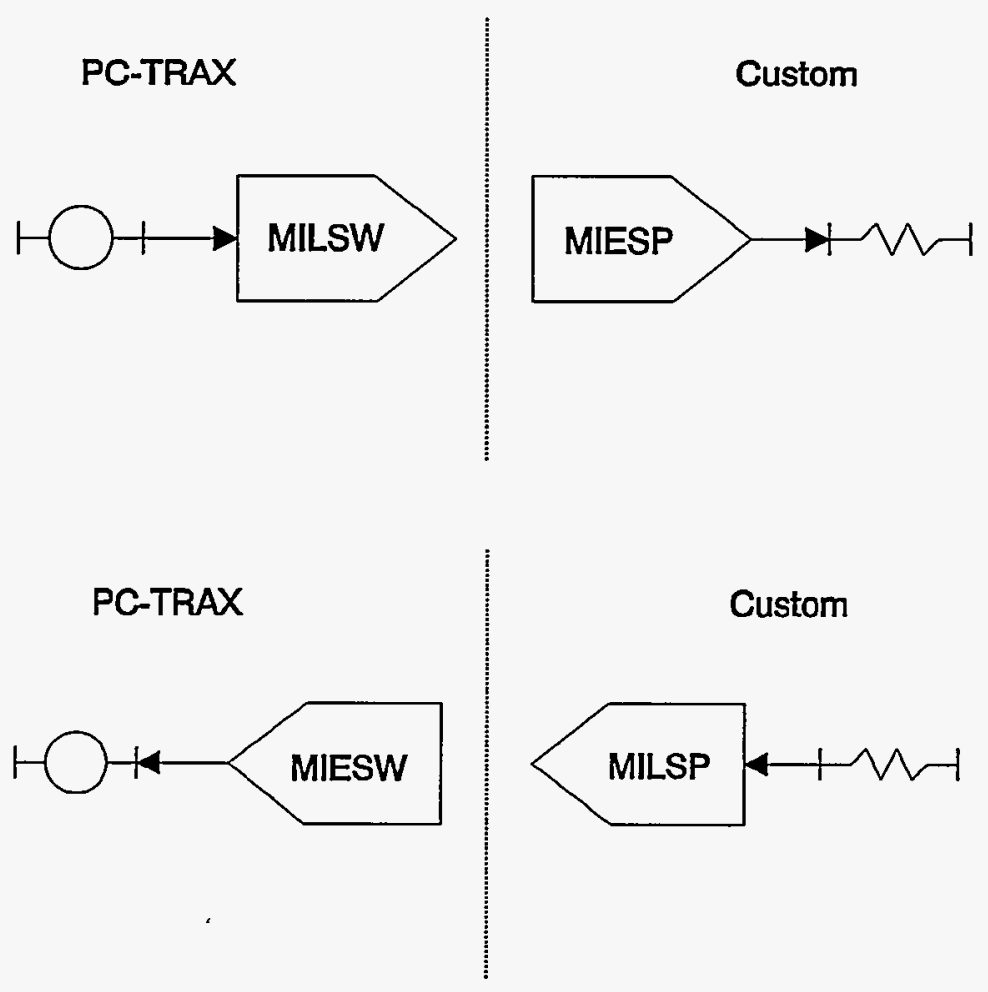

Custom

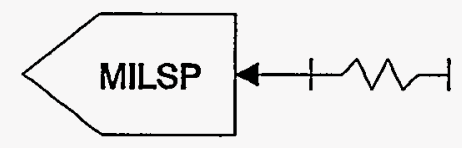

Further details can be found in the TRAX Analyst Instruction Manual.

\section{B.3 MODEL INTERFACE VARIABLES}

Streams which flow from the TRAX model to the custom model are identified in Table B-3.1. Those which flow from the custom side to the TRAX model are identified in Table B-3.2. Table B-3.3 contains a listing of all variables passed between modules using MIVAR.

Table B-3.1

TRAX/Custom Interface

\begin{tabular}{|l|l|l|}
\hline $\begin{array}{l}\text { STREAM } \\
\text { NAME }\end{array}$ & DESCRIPTION & $\begin{array}{l}\text { MI MODULE } \\
\text { TRAX / } \\
\text { CUSTOM }\end{array}$ \\
\hline SI1 & Carbonizer Primary Air & MILGP / \\
MIEGW \\
SI2 & Carbonizer Transport Air & $\begin{array}{l}\text { MILGP / } \\
\text { MIEGW } \\
\text { MUSP / MIESW }\end{array}$ \\
SI3 & Carbonizer Steam Flow &
\end{tabular}




\begin{tabular}{|c|c|c|}
\hline $\begin{array}{l}\text { STREAM } \\
\text { NAME }\end{array}$ & DESCRIPTION & $\begin{array}{l}\text { MI MODULE } \\
\text { TRAX / } \\
\text { CUSTOM }\end{array}$ \\
\hline SI4 & CPFBC Primary Air & $\begin{array}{l}\text { MULGP / } \\
\text { MIEGW }\end{array}$ \\
\hline SI5 & CPFBC Secondary Air & $\begin{array}{l}\text { MILGP / } \\
\text { MIEGW }\end{array}$ \\
\hline SI6 & Air Bypass To Topping Combustor & $\begin{array}{l}\text { MLGP / } \\
\text { MIEGW }\end{array}$ \\
\hline SI7 & Topping Combuster Fuel Inlet & $\begin{array}{l}\text { MILGP / } \\
\text { MIEGW }\end{array}$ \\
\hline SI8 & Topping Combuster Vitiated Air Inlet & $\begin{array}{l}\text { MILGP / } \\
\text { MIEGW }\end{array}$ \\
\hline SI9 & Water to FBHE Steam Drun & MILSP / MIESW \\
\hline SIA & FBHE Fluidizing Air Cell \#1 & $\begin{array}{l}\text { MILGP / } \\
\text { MIEGW }\end{array}$ \\
\hline SIB & FBHE Fluidizing Air Cell \#2 & $\begin{array}{l}\text { MILGP / } \\
\text { MIEGW }\end{array}$ \\
\hline SIC & FBHE Fluidizing Air Cell \#3 & $\begin{array}{l}\text { MULGP / } \\
\text { MIEGW }\end{array}$ \\
\hline SID & FBHE Fluidizing Air Cell \#4 & $\begin{array}{l}\text { MILGP / } \\
\text { MUEGW }\end{array}$ \\
\hline SIE & FBHE Fluidizing Air Cell \#5 & $\begin{array}{l}\text { MILGP / } \\
\text { MIEGW }\end{array}$ \\
\hline SIF & FBHE Fluidizing Air Cell \#6 & $\begin{array}{l}\text { MULGP / } \\
\text { MUEGW }\end{array}$ \\
\hline SIG & FBHE Fluidizing Air Cell \#7 & $\begin{array}{l}\text { MILGP / } \\
\text { MIEGW }\end{array}$ \\
\hline SIH & $\begin{array}{l}\text { Superheated Steam to FBHE Finishing } \\
\text { Superheater }\end{array}$ & MILSP / MIESW \\
\hline SII & Finishing Superheater Attempt Spray & MULSP / MIESW \\
\hline SIJ & Cold Reheat to FBHE & MILSW / MIESP \\
\hline SIK & BFW to Ash Cooler & MILSW / MIESP \\
\hline
\end{tabular}


Table B-3.2

Custom/TRAX Interface

\begin{tabular}{|c|c|c|}
\hline $\begin{array}{l}\text { STREAM } \\
\text { NAME }\end{array}$ & DESCRIPTION & $\begin{array}{l}\text { MI MODULE } \\
\text { TRAX / } \\
\text { CUSTOM }\end{array}$ \\
\hline SO1 & Carbonizer Fuel Gas & $\begin{array}{l}\text { MIEGP / } \\
\text { MILGW }\end{array}$ \\
\hline SO1 & CPFBC Vitiated Air & $\begin{array}{l}\text { MIEGP / } \\
\text { MULGW }\end{array}$ \\
\hline SO3 & Topping Combustor Exhaust & $\begin{array}{l}\text { MIEGP / } \\
\text { MILGW }\end{array}$ \\
\hline $\mathrm{SO} 4$ & Superheated Steam to $\mathrm{H} / \mathrm{P}$ Turbine & MIESP / MULSW \\
\hline SO5 & Hot Reheat to Turbine & MUESW / MUSP \\
\hline SO6 & BFW Out Ash Cooler & MIESW / MILSP \\
\hline
\end{tabular}


Table B-3.3

Model Interface Variables

\begin{tabular}{|l|l|l|}
\hline $\begin{array}{l}\text { VARIABLE } \\
\text { NAME }\end{array}$ & DESCRIPTION & $\begin{array}{l}\text { MODULE } \\
\text { FROM / TO }\end{array}$ \\
\hline WSORB & Carbonizer Sorbent Flow & Custom / TRAX \\
SZCOAL & Carbonizer Coal Flow & Custom / TRAX \\
VELTG & Carbonizer Transport Gas Velocity & Custom / TRAX \\
TCARB & Carbonizer Temperature & Custom / TRAX \\
VFBCN1 & FBHE Cell \#1 Gas Velocity & Custom / TRAX \\
VFBCN2 & FBHE Cell \#2 Gas Velocity & Custom / TRAX \\
VFBCN3 & FBHE Cell \#3 Gas Velocity & Custom / TRAX \\
VFBCN4 & FBHE Cell \#4 Gas Velocity & Custom / TRAX \\
VFBCN5 & FBHE Cell \#5 Gas Velocity & Custom / TRAX \\
VFBCN6 & FBHE Cell \#6 Gas Velocity & Custom / TRAX \\
VFBCN7 & FBHE Cell \#7 Gas Velocity & Custom / TRAX \\
LCHOPR & Char Hopper Solids Height & Custom / TRAX \\
TCOMB & CPFBC Temperature & Custom / TRAX \\
VELCPZ & CPFBC Primary Zone Velocity & Custom / TRAX \\
TSAO & Ash Cooler Solids Temp Out & Custom / TRAX \\
DRUMHT & FBHE Steam Drum Liquid Height & Custom / TRAX \\
WWPS & Primary Superheater Steam Flow & Custom / TRAX \\
TSFSO & Finishing superheater Steam & Custom / TRAX \\
TSFRO & Temperature & \\
& Finishing Reheater Steam & Custom / TRAX \\
C16OUT & Temperature & \\
C27OUT & Control Signal & TRAX / Custom \\
C18OUT & Control Signal Signal & TRAX / Custom \\
CVSSR & Conductance, FBHE Solids to & TRAX / Custom \\
CVSFS & Superheater & TRAX / Custom \\
& Renductance, FBHE Solids to & \\
\hline
\end{tabular}




\section{B.4 PRESSURE NODE INTERFACE INSTABILITIES}

Pressure instabilities have been experienced when using the flow node model interface. This would correspond to the second configuration discussed in Section B.2. This problem is most evident with the JUNCP blocks BJ3 and BJ4 found on the inlet and outlet of the customized reheater model interface. Due to time limitations, a short-cut "fix" has been used to overcome the instability. The "fix" involves increasing the $\mathrm{K}$ value of blocks BJ3 and BJ4 to 20,000. This must be done at run time with the adjust command.

The pressure instability problem at boundary interfaces is well known and understood by TRAX Corporation. They have suggested a more rigerous solution. Their solution is reproduced verbatim below.

We have seen a number of pressure instabilities with PC-TRAX pressure nodes at model boundaries. We avoid them wherever possible. Not that this is only a problem with PCTRAX pressure nodes and not with real pressure states found in large storage type modules like drums, tanks, the shell side of feedwater heaters, or the condenser. The technique I will describe below should alleviate any potential pressure instabilities. The only caveat is that it will work only when there is a single flow path leaving the PCTRAX "standard" model and returning to that same model. Consider the arrangement below:

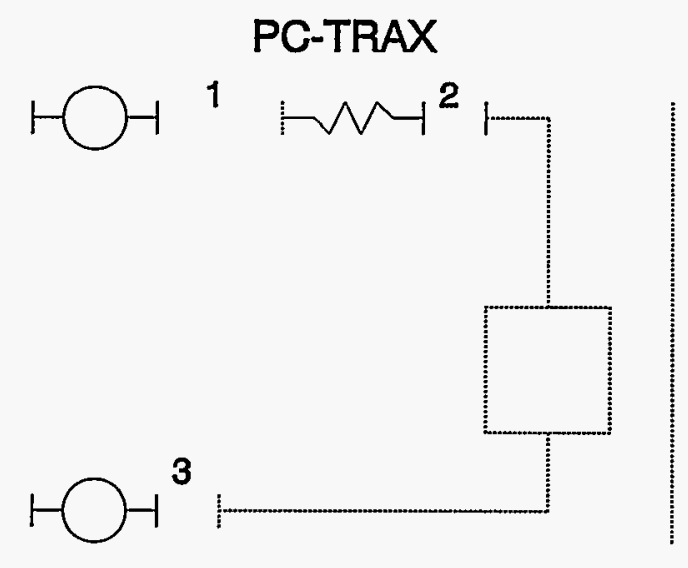

Custom

This technique will utilize only MIVAR modules and no other MI modules. You will need to perform two operations. First, you should create a block of code to connect the outlet of the RESIST module to the inlet of the lower JUNCP module. We need to use a block of code to make this connection rather than connecting hem directly so that we can path the enthalpy from your calculations in the Custom side of the model to the lower JUNCP module. This block of code should include the following statements: 


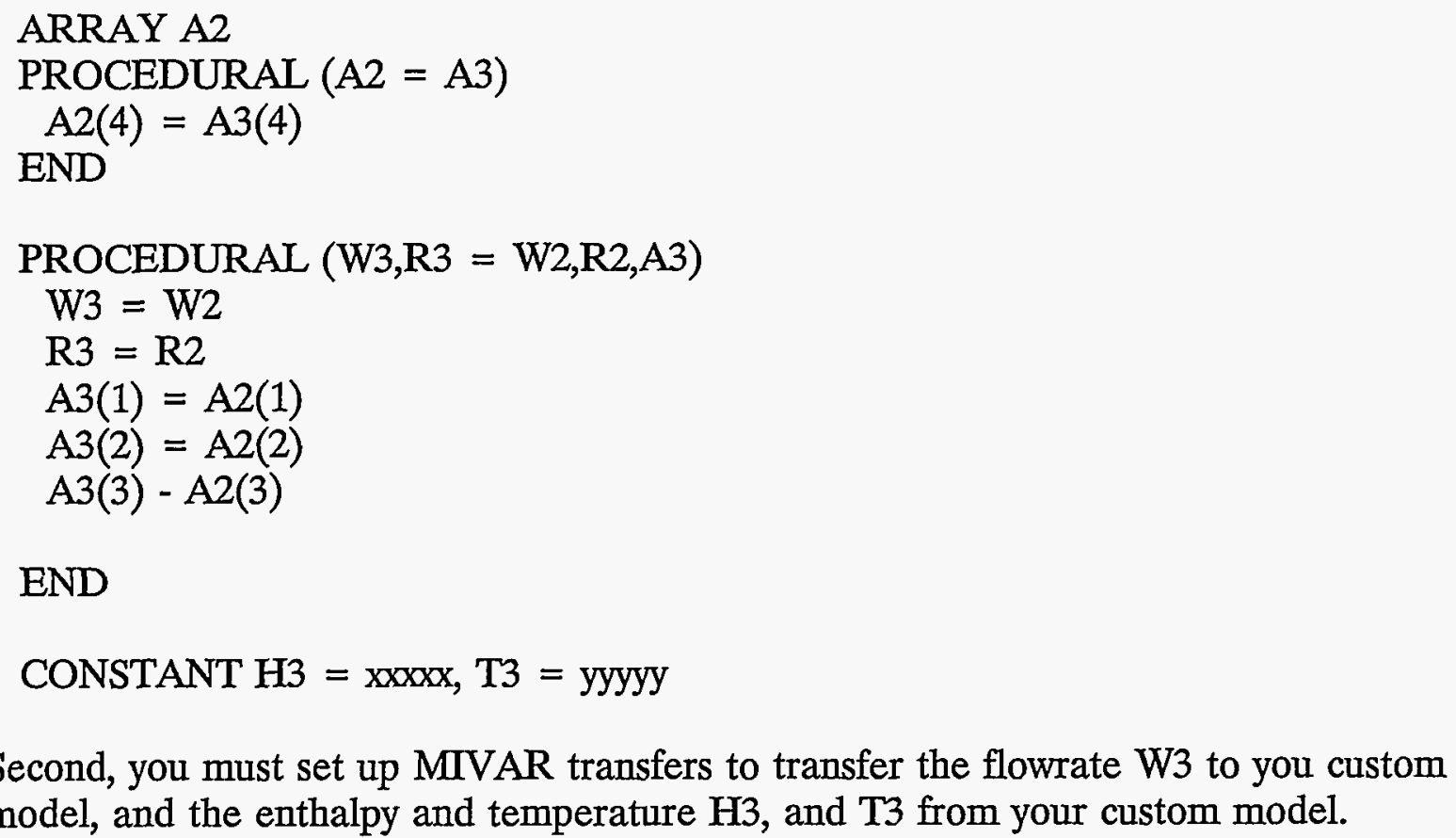
model, and the enthalpy and temperature $\mathrm{H} 3$, and T3 from your custom model. 


\section{CARBONIZER MODEL}

This section describes the rudiments of the customized carbonizer model which has been coded in ACSL. The reader is urged to refer to the ACSL code in Appendix L. The code is heavily documented and easily followed.

\section{C.1 CARBONIZER CHEMISTRY}

Certain chemical aspects of the carbonizer have minimal impacts on plant performance but would require significant amounts of computational time. Accordingly, the following simplifying assumptions were used in the carbonizer model. A brief listing of the assumptions used to generate the carbonizer thermochemistry is listed in Section C.1.1. The remainder of Section C.1 will address these assumptions in more detail.

\section{C.1.1 Carbonizer Chemistry Assumptions}

- Carbon Conversion is an Algebraic expression based on stoichiometry

- Gasification products $\mathrm{CO}$ and $\mathrm{H}_{2}$ (ideal gasifier)

- Methane yield is a function of temperature

- All fuel nitrogen released as $\mathrm{N}_{2}$

- All fuel hydrogen released as $\mathrm{H}_{2}$

- $100 \%$ sulfur capture if there is sufficient sorbent

- Water-gas shift equilibrium

- Calcination: Linear function between $1600^{\circ} \mathrm{F}$ and $1700^{\circ} \mathrm{F}$

- Instantaneous gas generation

- Carbonizer has both oxidizing and reducing modes

\section{Limitations: Emissions and chemical kinetics}

\section{C.1.2 Carbonizer Feed Composition}

The composition of the coal being fed to the carbonizer is shown in Table C-1.1.

The stoichiometric air for Pittsburgh No.8 Coal is:

$$
100 \% \text { Stoichiometry }=\frac{9.87 \mathrm{lb} \mathrm{Air}}{\mathrm{lb} \mathrm{Coal}}
$$

The composition of the sorbent being fed to the carbonizer is shown in Table C-1.2. 


\section{Table C-1.1}

Pittsburgh No. 8 Coal Composition

(Weight \%)

$\begin{aligned} 71.92 \% & \text { Carbon } \\ 4.69 \% & \text { Hydrogen } \\ 2.99 \% & \text { Sulfur } \\ 1.26 \% & \text { Nitrogen } \\ 6.33 \% & \text { Oxygen } \\ 2.50 \% & \text { Moisture (after drying) } \\ 10.31 \% & \text { Ash } \\ 51.23 \% & \text { Fixed Carbon } \\ 35.96 \% & \text { Volatile Matter } \\ 12,916 & \text { Btu/lb (HHV) } \\ 12,472 & \text { Btu/lb (LHV) }\end{aligned}$

Table C-1.2

Plum Run Dolomite Composition

(Weight \%)

$\begin{aligned} 54.5 \% & \text { Calcium Carbonate } \\ 43.3 \% & \text { Magnesium Carbonate } \\ 0.5 \% & \text { Moisture (after drying) } \\ 1.7 \% & \text { Inerts }\end{aligned}$

\section{C.1.3 Carbonizer Gas Generation}

The carbonizer can operate in either an oxidizing or reducing mode. Both modes of operation are described below.

\section{C.1.3.1 Reducing Zone}

Coal conversion and combustion are determined by the reaction stoichiometry, as shown in Figure C-1.1. For Pittsburgh No. 8 coal, the five reaction zones are tabulated in Table C-1.3. The minimum fuel gas heating value is equivalent to 6.6 percent carbon conversion at $0 \%$ stoichiometry. 


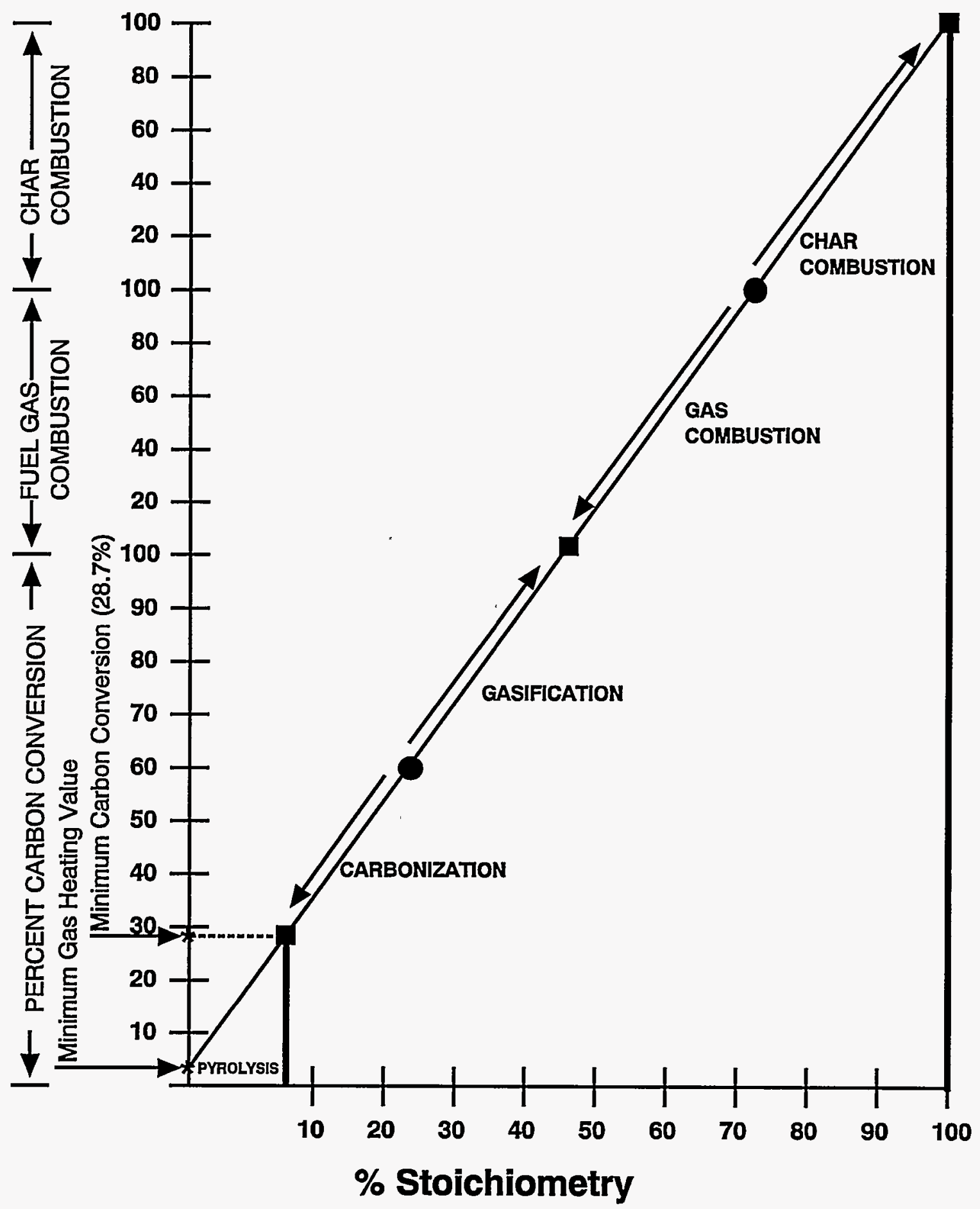

Figure C-1.1 - Reaction Zones 
Table C-1.3

Reaction Zones

\begin{tabular}{ll} 
Stoichiometry & Reaction \\
\hline $0 \%-10 \%$ & Pyrolysis \\
$10 \%-26 \%$ & Carbonization \\
$26 \%-43 \%$ & Gasification \\
$43 \%-72 \%$ & Gas Combustion \\
$72 \%-100 \%$ & Char Combustion
\end{tabular}

Pittsburgh No. 8 coal, dried to $2.5 \%$ moisture, has the mole ratios (referred to carbon) shown below.

$$
\mathrm{C} \mathrm{H}_{0.780} \mathrm{O}_{0.066} \mathrm{~N}_{0.015} \mathrm{~S}_{0.015}
$$

About 6.6 percent carbon is converted with inherent oxygen consumption. The oxygen requirement for total carbon conversion ( $42.15 \%$ stoichiometry) results in an air/fuel ratio of $4.16 \mathrm{lb}$ (air)/lb(coal). It is assumed that all fuel nitrogen and hydrogen are released as $\mathrm{H}_{2}$ and $\mathrm{N}_{2}$ into the gas phase.

Carbon conversion is represented by the equation:

$$
\mathrm{Fc}=0.022(\text { Stoich } \%)+0.066
$$

Minimum conversion is the conversion of non-fixed carbon:

$$
\mathrm{Fc}(\min )=1.00-(\text { Fixed Carbon/Total Carbon })
$$

For Pittsburgh No. 8 coal (51.23\% Fixed Carbon and 71.92\% Total Carbon), minimum carbon conversion is $28.76 \%$. The stoichiometry corresponding to minimum carbon conversion is $9.98 \%$. Below $9.98 \%$, char production is constant and the heating value of the gas is reduced.

Methane formation is modeled as a function of temperature and shown in the following equation:

$$
F_{\mathrm{CH} 4}=(-0.020133 * \mathrm{TEMP})+38.043
$$


The fuel gas composition is determined by the water gas shift. The reaction, shown below, can be evaluated at the actual process temperature or an alternative condition by using an approach temperature.

$\mathrm{CO}(\mathrm{g})+\mathrm{H}_{2} \mathrm{O}(\mathrm{g})$----- $\mathrm{H}_{2}(\mathrm{~g})+\mathrm{CO}_{2}(\mathrm{~g})$ (Exothermic)

$\mathrm{Kp}=\mathrm{P}\left(\mathrm{h}_{2}\right) * \mathrm{P}\left(\mathrm{co}_{2}\right) / \mathrm{P}(\mathrm{co}) * \mathrm{P}\left(\mathrm{h}_{2} \mathrm{O}\right)$ (Dimensionless)

HEAT OF REACTION (STP) $=-624 \mathrm{BTU} / \mathrm{lb} \mathrm{CO}$

The carbonizer chemistry model presented here is based on data collected by FWDC. Spider diagrams for $1600^{\circ} \mathrm{F}$ and $1700^{\circ} \mathrm{F}$ carbonizer operation are shown in Figures C-1.2 and C-1.3 respectively. A comparison to the model results is shown in Figure C-1.4.

\section{C.1.3.2 Oxidizing Zone}

In oxidized operation, it is assumed that $\mathrm{H}_{3} \mathrm{CO}$, and $\mathrm{CH}_{4}$ production are zero. The gas species exiting the vessel are $\mathrm{CO}_{2} \mathrm{H}_{2} \mathrm{O}$, and $\mathrm{O}_{2}$.

\section{C.1.4 Sulfur Capture and Solids Chemistry}

The dolomite calcination reactions are shown below:

$$
\begin{gathered}
\mathrm{CaCO}_{3}(\mathrm{~s}) \ldots \mathrm{CaO}(\mathrm{s})+\mathrm{CO}_{2}(\mathrm{~g}) \text { (endothermic) } \\
\text { Heat of reaction (STP) }=420 \mathrm{Btu} / \mathrm{lb} \text { (dolomite) } \\
\mathrm{MgCO}_{3}(\mathrm{~s})-\mathrm{MgO}(\mathrm{s})+\mathrm{CO}_{2}(\mathrm{~g}) \quad \text { (endothermic) } \\
\text { Heat of reaction (STP) }=225 \mathrm{Btu} / \mathrm{lb} \text { (dolomite) }
\end{gathered}
$$

It is assumed that all of the $\mathrm{MgCO}_{3}$ decomposes to $\mathrm{MgO}$ and $\mathrm{CO}_{2}$ Calcination of $\mathrm{CaCO}_{3}$ has been assumed to be a function of temperature. This function is shown below

$$
\begin{aligned}
& \text { Linear conversion } \mathrm{CaCO}_{3} \text { to } \mathrm{CaO} \\
& -\quad 0 \% @ \mathrm{~T}<1600^{\circ} \mathrm{F} \\
& -\quad 100 \% @ \mathrm{~T}>1700^{\circ} \mathrm{F}
\end{aligned}
$$

It is assumed that all of the fuel sulfur will be captured by $\mathrm{CaO}$ or $\mathrm{CaCO}_{3}$. Sulfur will exit the carbonizer as CaS. When the carbonizer operates in an oxidizing mode, sulfur will exit as $\mathrm{CaSO}_{4}$. Fuel sulfur reacts preferentially with the calcium species in the incoming sorbent. If the amount of calcium contained in the fresh sorbent flow is insufficient for 100 percent capture, then the fuel sulfur will react with any calcium contained within the solid bed or exit the vessel as elemental sulfur. 


$$
, 1 !
$$

$\therefore$.

Char-Sorbent Elowe (lb/h) $=75,315$

\begin{tabular}{lc}
\hline \multicolumn{2}{c}{ Char } \\
\hline$C$ & 41.102 \\
$H$ & 0.691 \\
$O$ & 0.565 \\
$N$ & 0.719 \\
S & 0.718 \\
Ash & 10.310 \\
Moisture & 0 \\
\cline { 2 - 2 } & 54.105
\end{tabular}

Spent Rolomite

\begin{tabular}{|c|c|}
\hline \multicolumn{2}{|c|}{ Spent Rolomit } \\
\hline $\begin{array}{l}\mathrm{CaCO}_{3} \\
\mathrm{CaO}\end{array}$ & 9.694 \\
\hline $\begin{array}{l}\mathrm{CaO} \\
\mathrm{MgO}\end{array}$ & $\begin{array}{l}0 \\
6.228\end{array}$ \\
\hline $\mathrm{CaS}^{\star}$ & 4.778 \\
\hline Inerts & 0.5103 \\
\hline Moisture & 0 \\
\hline & 21.210 \\
\hline
\end{tabular}

\begin{tabular}{|c|c|c|}
\hline $\mid \begin{array}{l}\operatorname{lllHV}(\mathrm{Blu} / \mathrm{lb}) \\
\text { LHV (Btu/lb) }\end{array}$ & $\begin{array}{l}11,815 \\
11,700\end{array}$ & $\begin{array}{l}\text { HHV (Btu/I } \\
\text { LHV (Btu/II }\end{array}$ \\
\hline & $\begin{array}{l}\text { HHV (Btu/lb) } \\
\text { LHV (Btu/lb) }\end{array}$ & $\begin{array}{l}8800 \\
8718\end{array}$ \\
\hline
\end{tabular}

á

Piltsburgh No. 8 Coal (Ultimate, wi\%) (Flew Rale $=100 / \mathrm{b} / \mathrm{h})$

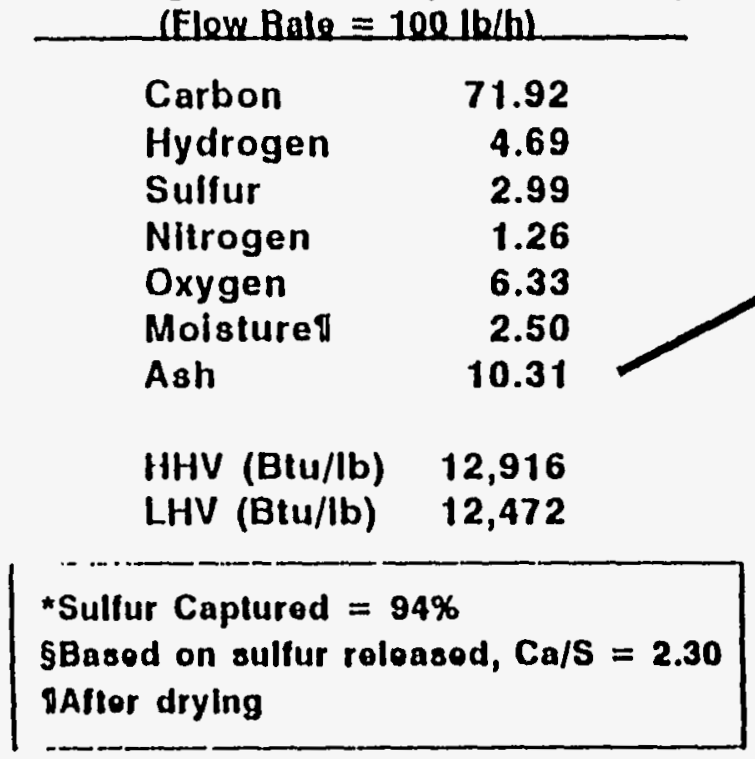

11/18/92, Rov. D

Euel Gas Flow $11 \mathrm{l} / \mathrm{h})=214.985$ HHV (Btu/Ib)

LHV (Btu/Ib) 2506

Molecular Weight

2247

LHV (Btu/sft $\left.{ }^{3}\right)$, wet

23.743

140

mol\% wl\%

CO $\quad 18.046 \quad 21.281$

$\begin{array}{lll}\mathrm{CO}_{2} & 8.791 & 16.291\end{array}$

$\begin{array}{lll}\mathrm{H}_{2} \mathrm{O} & 9.107 & 6.910\end{array}$

$\begin{array}{lll}\mathrm{H}_{2} & 16.566 & 1.407\end{array}$

$\mathrm{CH}_{4} \quad 3.968 \quad 2.679$

$\mathrm{C}_{2}$ 's 00

$\begin{array}{lll}\mathrm{NH}_{3} & 0.317 & 0.228\end{array}$

$\begin{array}{lll}\mathrm{H}_{2} \mathrm{~S} & 0.051 & 0.073\end{array}$

$\begin{array}{lll}\mathrm{N}_{2} & 42.679 & 50.332\end{array}$

$\begin{array}{lll}\text { Ar } & 0.475 & 0.799\end{array}$

Flum Run Dolomite (wt\%)

(Flow Rate $=30.02 \mathrm{lb} / \mathrm{h}$, $\mathrm{Cg} / \mathrm{S}=1.25) 5$

(Elow Bate $=144.284 \mathrm{~m} / \mathrm{h} / \mathrm{h})$

$\begin{array}{lr}\mathrm{N}_{2} & 108.069 \\ \mathrm{O}_{2} & 33.197 \\ \mathrm{H}_{2} \mathrm{O} & 1.101 \\ \mathrm{Ar} & 1.717\end{array}$

$\mathrm{CaCO}_{3}$

54.4

$\mathrm{MgCO}_{3}$

43.4

Moisture $\quad 0.5$

Inerts $\quad 1.7$

HHV

0
$H H V=1000 \mathrm{Btu} / \mathrm{lb}$

Relative Humidity $=50 \%$ at $70^{\circ} \mathrm{F}$

Skln Heat Los8es $=1292 \mathrm{Btu} / \mathrm{h}$ 
Char-Sorbent Flow $(\mathrm{lb} / \mathrm{h})=59.8203$

\begin{tabular}{|c|c|c|c|}
\hline \multicolumn{2}{|c|}{ Char } & & Spe \\
\hline C & 31.386 & & $\mathrm{CaCO}_{3}$ \\
\hline $\mathrm{H}$ & 0 & & $\mathrm{CaO}$ \\
\hline 0 & 0 & & $\mathrm{MgO}$ \\
\hline$N$ & 0.549 & & CaS* \\
\hline $\mathbf{S}$ & 0.548 & & Inerts \\
\hline Ash & 10.31 & & \\
\hline Moisture & 0 & & Molsture \\
\hline & 42.793 & & \\
\hline \multirow{2}{*}{$\begin{array}{l}\text { IHHV (Btu/lb) } \\
\text { LHV (Btu/lb) }\end{array}$} & 10,719 & & \multirow{2}{*}{$\begin{array}{l}\text { HHV (Btu/I } \\
\text { LHV (Btu/II }\end{array}$} \\
\hline & & & \\
\hline \multicolumn{3}{|c|}{$\begin{array}{l}\text { HHV (Btu/lb) } \\
\text { LHV (Btu/lb) }\end{array}$} & $\begin{array}{l}8196 \\
8196\end{array}$ \\
\hline \multicolumn{4}{|c|}{$\begin{array}{l}\text { Plitsburgh No. } 8 \text { Coal (Ullimale, wi\%) } \\
\text { (Elew Bate }=100 / \mathrm{b} / \mathrm{h}) \\
\end{array}$} \\
\hline & 71.92 & \\
\hline \multicolumn{2}{|c|}{ Hydrogen } & 4.69 & \\
\hline \multicolumn{2}{|c|}{ Sulfur } & 2.99 & \\
\hline \multicolumn{2}{|c|}{ Nitrogen } & 1.26 & \\
\hline \multirow{2}{*}{\multicolumn{2}{|c|}{$\begin{array}{l}\text { Oxygen } \\
\text { Molstureq }\end{array}$}} & 6.33 & \\
\hline & & 2.50 & \\
\hline \multicolumn{2}{|c|}{ Ash } & 10.31 & \\
\hline \multirow{2}{*}{\multicolumn{2}{|c|}{$\begin{array}{l}\text { HHV (Btu/lb) } \\
\text { LHV (Btu/lb) }\end{array}$}} & 12,916 & \\
\hline & & 12,472 & \\
\hline \multicolumn{4}{|c|}{$\begin{array}{l}\text { * Sulfur Caplured }=94 \% \\
\text { \$Based on sulfur roloasod, } \mathrm{Ca} / \mathrm{S}=2.14 \\
\text { IAfter drylng }\end{array}$} \\
\hline
\end{tabular}

11/18/92, Rov. B
Euel Gas Flow $(l \mathrm{~b} / \mathrm{h})=295.589$ HHV (Btu/lb)

LHV (Btu/lb)

2281

Molecular Weight 2070

LHV (Btu/sft ${ }^{3}$ ), wet

23.966

5.143

6.228

5.146

0.5103

mol\% wt\%

CO $20.991 \quad 24.525$

$\begin{array}{lll}\mathrm{CO}_{2} & 7.004 & 12.860\end{array}$

$\begin{array}{lll}\mathrm{H}_{2} \mathrm{O} & 7.378 & 5.546\end{array}$

$\begin{array}{lll}\mathrm{H}_{2} & 16.386 & 1.378\end{array}$

$\mathrm{CH}_{4} \quad 1.942 \quad 1.299$

$\mathrm{C}_{2}$ 's 0

$\begin{array}{lll}\mathrm{NH}_{3} & 0.2327 & 0.165\end{array}$

$\begin{array}{lll}\mathrm{H}_{2} \mathrm{~S} & 0.0392 & 0.0557\end{array}$

$\mathrm{N}_{2} \quad 45.521 \quad 53.328$

$\begin{array}{lll}\text { Ar } & 0.506 & 0.843\end{array}$

\section{PLANT}

CARBONIZER 14 atm-1700 $\mathrm{F}$

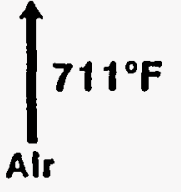

(Elow Bate $=209.1231 \mathrm{~b} / \mathrm{h}$ )

$\begin{array}{lr}\mathrm{N}_{2} & 156.895 \\ \mathrm{O}_{2} & 48.195 \\ \mathrm{H}_{2} \mathrm{O} & 1.610 \\ \mathrm{Ar} & 2.493\end{array}$

Relative Humidity $=50 \%$ at $70^{\circ} \mathrm{F}$ Skin Heat Losses $=1292 \mathrm{Btu} / \mathrm{h}$
Plum Run Dolomite (wt\%)

(Flow Rate $=30.02 \mathrm{lb} / \mathrm{h}$,
$415^{\circ} \mathrm{F}$
$\mathrm{Cg} / \mathrm{S}=1.7515$

$\begin{array}{lr}\mathrm{CaCO}_{3} & 54.4 \\ \mathrm{MgCO}_{3} & 43.4 \\ \text { Molsture } & 0.5 \\ \text { Inerts } & 1.7 \\ \text { HHV } & 0\end{array}$




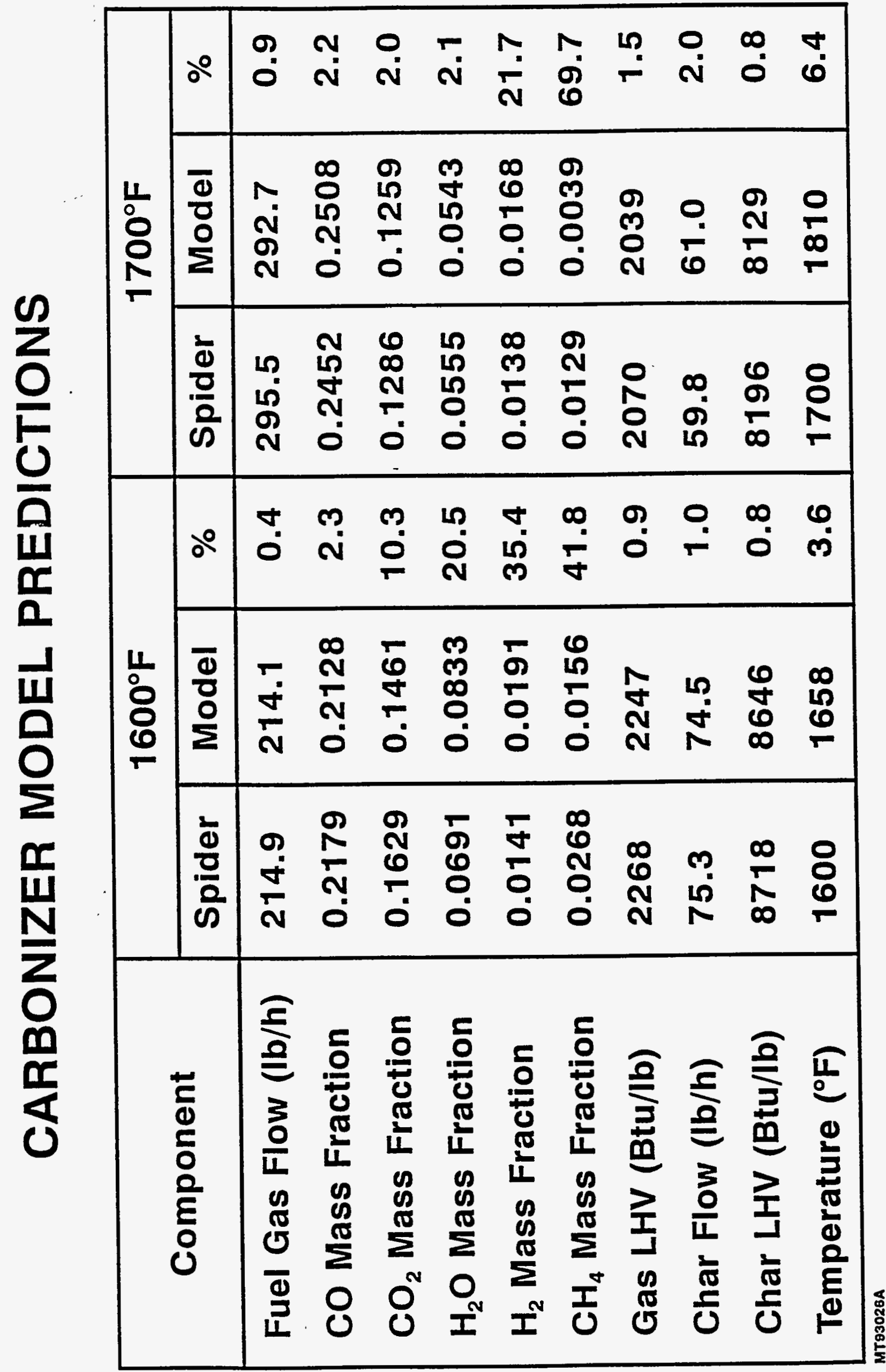




\section{C.2 HYDRODYNAMIC MODEL}

The primary assumptions used to generate the hydrodynamic model are listed in Section C.2.1. Details of the model are described in the remaining portion of this section.

\section{C.2.1 Carbonizer Hydrodynamic Model Assumptions}

Void Fraction:

Elutriation:

Carbon Density:

Ash Density:

Mean Particle Diameter:

Pressure Drop (Packed Bed):

Cyclone \& Cross-Flow Filter:

Sphericity
0.5

Terminal Velocity for Spherical Particles 77 wt\% Non-Converted Carbon $15 \mathrm{lb} / \mathrm{ft}^{3}$

$60 \mathrm{lb} / \mathrm{ft}^{3}$

595 microns

Ergun (595 micron)

$100 \%$ efficient

0.73

\section{C.2.2 Carbonizer Particle Elutriation}

An inventory of fifteen particle sizes is maintained in the carbonizer. The particle size distribution for the solid material (char and ash) instantaneously generated in the carbonizer is shown in Table C-2.1. The mean particle diameter, based on population, is 579.87 microns. The actual bed PSD is continually updated to account for changes in process conditions.

Superficial gas velocity is based on the carbonizer free-board diameter. The terminal velocity for each particle size is determined by iteratively solving the following three equations:

Reynolds Number:

Drag Coefficient:

$$
\mathrm{REY}=\frac{\rho \mathrm{g} \mathrm{V}_{\mathrm{t}} \mathrm{dp}}{\mu}
$$

Terminal Velocity:

$$
c_{d}=\frac{24}{\operatorname{REY}}+\frac{6}{1+\sqrt{\mathrm{R} \bar{E} \bar{Y}^{-}}}+0.4
$$

$$
V_{t}=\sqrt{\left[\frac{4 \operatorname{gd}_{p}\left(\rho_{s}-\rho_{g}\right)}{3 \rho_{g} C_{d}}\right]}
$$


Table C-2.1

Particle Size Distribution For Instantaneous Char Generated

$\begin{array}{rrr}\text { DIAMETER } & \text { \% ON } & \text { \% THRU } \\ 4760.00 & 0.20 & 99.80 \\ 3350.00 & 3.27 & 96.53 \\ 2380.00 & 11.67 & 84.86 \\ 1700.00 & 23.08 & 61.78 \\ 1400.00 & 6.33 & 55.45 \\ 1190.00 & 12.19 & 43.26 \\ 1000.00 & 6.01 & 37.25 \\ 850.00 & 10.20 & 27.05 \\ 710.00 & 5.50 & 21.55 \\ 595.00 & 4.70 & 16.85 \\ 297.00 & 10.44 & 6.41 \\ 149.00 & 3.62 & 2.79 \\ 105.00 & 0.53 & 2.26 \\ 74.00 & 0.51 & 1.75 \\ 44.00 & 0.60 & 1.15\end{array}$

Comparison of superficial and terminal velocities determine which size distributions are elutriated. The elutriated material is assumed to be 77 percent carbon. The remaining 23 percent is assumed ash and sorbent species present in amounts prorated form the bulk char generated. Any material not elutriated is added to the system solid inventory.

\section{C.2.3 Carbonizer Pressure Drop}

The minimum fluidization and superficial gas velocities are calculated for the bottom section of the carbonizer. The minimum fluidization velocity is calculated by:

$$
\frac{1.75}{\varnothing_{s} \xi_{m f}^{3}}\left[\frac{\mathrm{d}_{p} \mathrm{U}_{m} \rho_{g}}{\mu}\right]^{2}+\frac{150\left(1-\xi_{m f}\right)}{\varnothing_{s} \xi_{m f}^{3}}\left[\frac{\mathrm{d}_{p} \mathrm{U}_{m \rho g}}{\mu}\right]=\frac{\mathrm{d}_{p}^{3} \rho_{g}\left(\rho_{s}-\rho_{g}\right) \mathrm{g}}{\mu^{2}}
$$


Pressure drop for superficial gas velocities above the minimum fluidization velocity is calculated as:

$$
\frac{\Delta \mathbf{P}}{\mathrm{L}}=\left(\rho_{F}-\rho_{S}\right)(1-\xi) \frac{\mathrm{g}}{\mathrm{g}_{C}}
$$

Pressure drop for those below:

$$
\frac{\Delta \mathbf{P}}{\mathbf{L}}=\frac{150}{\mathbf{g}_{c}} \frac{\left(1-\xi_{m}\right)^{2}}{\xi_{m}^{3}} \frac{\mu \mathrm{V}}{\left(\varnothing_{s} \mathbf{D}_{p}\right)^{2}}+\frac{1.75}{\mathbf{G}_{c}} \frac{\left(1-\xi_{m}\right)}{\xi_{m}^{3}} \frac{\rho_{F} \mathrm{~V}^{2}}{\varnothing_{S} \mathbf{D}_{p}}
$$

\section{C.2.4 Carbonizer Pressure}

Carbonizer pressure is determined by the ideal gas law and gas material balance around the carbonizer. The gas balance is shown below in Figure C-2.1.

The pressure is then given by integrating:

$$
\left.\frac{\mathrm{dP}}{\mathrm{dt}}=\frac{\mathrm{mR}}{\mathrm{V}} \frac{\mathrm{dT}}{\mathrm{dt}}+\mathrm{mRT} \frac{\mathrm{d}(1 / \mathrm{V})}{\mathrm{dt}}+\dot{\mathrm{m}}_{\mathrm{STEAM}}+\dot{\mathrm{m}}_{\mathrm{AIR}}+\dot{\mathrm{m}}_{\mathrm{GEN}}-\dot{\mathrm{m}}_{\mathrm{FUEL} \mathrm{GAS}}\right]\left[\frac{\mathrm{RT}}{\mathrm{V}}\right)
$$

Pressure drops through the cyclone and barrier filter are assumed to be percentages of absolute pressure.

\section{C.3 CARBONIZER ENERGY BALANCE}

In determining the carbonizer heat balance, constant specific heats and an isothermal freeboard and bed are assumed. The carbonizer heat balance is shown schematically in Figure C-3.1. 


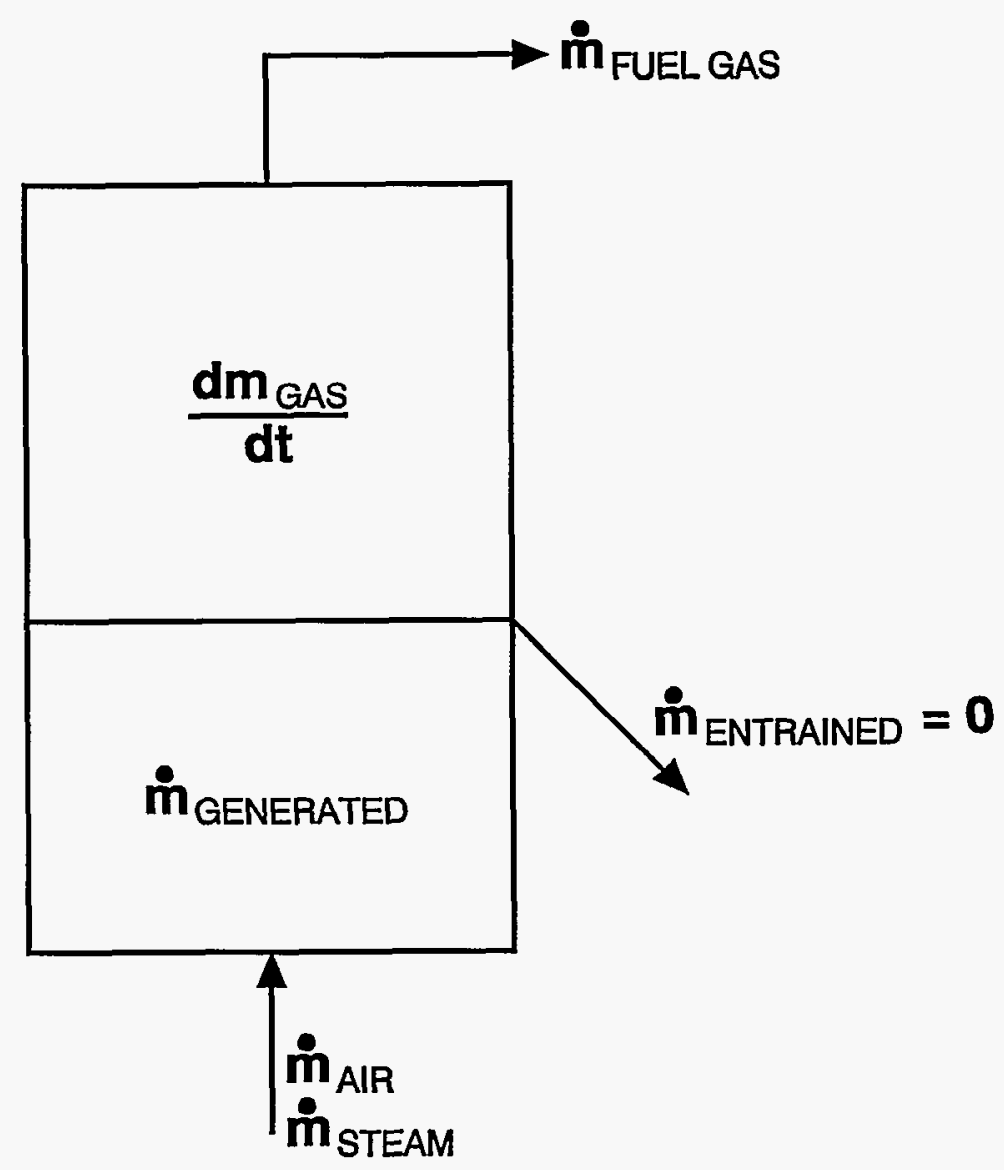

Figure C-2.1

Carbonizer Gas Balance 


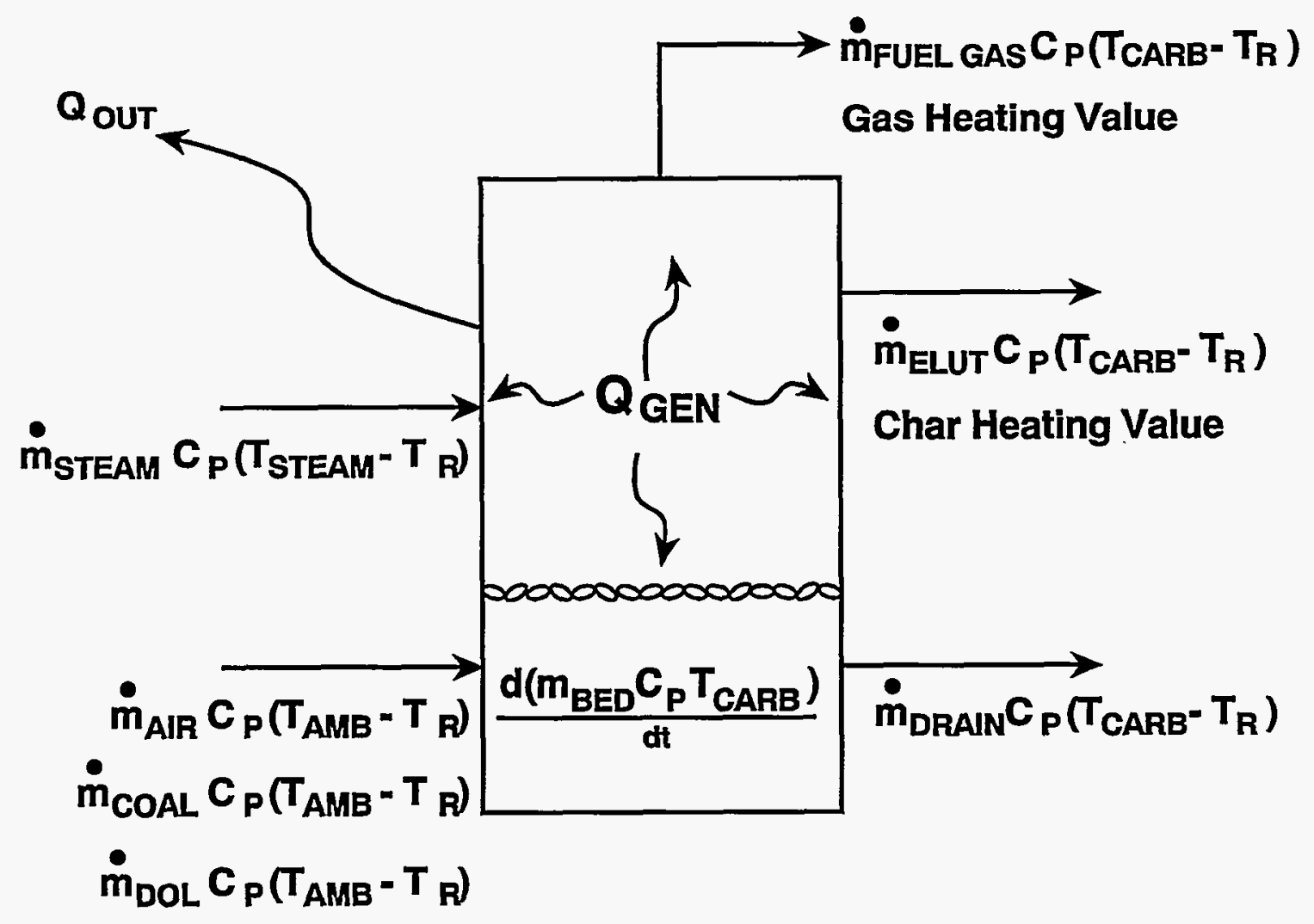

Coal Heating Value

Figure C-3.1 - CARBONIZER ENERGY BALANCE

The following differential is used to calculate the carbonizer temperature:

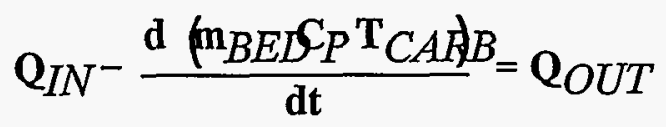

Energy input includes sensible and chemical energy of the incoming streams, as well as any exothermic reactions. Energy output includes the sensible and chemical energy of the exit streams as well as heat required for endothermic reactions and any energy lost. 
Heat lost from the carbonizer arises from losses to ambient as well as losses to the hard face refractory during temperature changes. Assuming that the hard face can be treated as a lumped system, the following differential is used to determine the hard face temperature.

$$
\frac{\mathbf{d T}_{H A R D}}{\mathbf{d t}}=\frac{\mathbf{h}_{B W \mathbf{A}_{B W}} \mathbf{T}_{C A R B} \mathbf{T}_{H A k D^{-}} \mathbf{Q}_{A M B}}{\mathbf{m}_{H A R \oint P_{\text {Iuse }}}}
$$

Changes in temperature will result in larger or smaller amounts of energy stored in the hard face.

Heat lost to ambient is determined from a refractory properties chart and is assumed to be constant. 


\section{PFBC MODEL}

This section describes the PFBC model which is part of the customized ACSL code. Appendix L should be referred to during the rending of this section.

\section{D.1 PFBC CHEMISTRY}

The assumptions in generating the chemistry portion of the PFBC model are presented in Section D.1.1. The solid-gas chemistry of the PFBC, for both oxidizing and reducing modes, will be discussed in the remainder of Section D.1.

\section{D.1.1 Combustor Assumptions}

- Instantaneous Gas Make

- $100 \%$ Combustion $\left(\mathrm{CO}_{2} \mathrm{CaSO}_{4}\right)$

- $\quad$ Constant Bed Level

- No Particle Attrition

- No Back Reaction: $\mathrm{CaO}+\mathrm{CO}_{2} \neq \mathrm{CaCO}_{3}$

- $\quad \mathrm{PFBC}$ has both oxidizing and reducing modes

\section{D.1.2 PFBC Gas Generation}

The PFBC uses air to combust char from the carbonizer. Usually, a large amount of excess air is used. Fresh coal and sorbent may be fed to the PFBC. Additionally, the PFBC may swing from oxidized to reduced modes of operation. In reduced mode, the gas generated in the PFBC is exactly as discussed in Section C-1. Therefore, only oxidized operation will be discussed in this section.

Under design conditions, char entering the PFBC has the composition shown in Table D-1.1.

The combustion process is assumed to be instantaneous. All carbon is converted to $\mathrm{CO}_{2}$. In cases where fresh coal is fired in the PFBC, all $\mathrm{H}_{2}$ is converted to $\mathrm{H}_{2} \mathrm{O}, \mathrm{N}_{2}$ and $\mathrm{O}_{2}$ enter into the gas phase. Any fuel bound sulfur will be captured by calcium species in the char/ash mixture. 
Table D-1.1

Design Char Composition

(Weight\%)

$\begin{array}{cl}13.81 & \text { Ash } \\ 9.41 & \mathrm{CaCO}_{3} \\ 0.0 & \mathrm{Ca0} \\ 58.77 & \mathrm{Carbon} \\ 9.01 & \mathrm{CaS} \\ 0.0 & \mathrm{CaSO}_{4} \\ 0.68 & \text { Inert } \\ 8.32 & \text { Mg0 } \\ 0.0 & \text { Sulfur }\end{array}$

\section{D.1.3 PFBC Solids Chemistry}

In the PFBC, calcination is a function of the partial pressure of $\mathrm{CO}_{2}$ and expressed in the following relationship:

For the following reaction,

$$
\mathrm{CaCO}_{3}(\mathrm{~s})-\mathrm{CaO}(\mathrm{s})+\mathrm{CO}_{2}(\mathrm{~g})
$$

the mass action expression,

$$
\mathrm{K}_{\mathrm{P}}=\mathrm{P}_{\mathrm{COMB}} \mathrm{Y}_{\mathrm{CO}_{2}}
$$

can be used to determine wheather $\mathrm{CaCO}_{3}$ will calcine. In the mass action $\mathrm{Kp}$ is smaller than that calculated by,

$K_{P}=e^{-\Delta G^{\circ} / R T}$

then, calcination will occur.

Any CaS generated in the PFBC, or entering with the char, is converted to $\mathrm{CaSO}_{4}$ Under design conditions, all sulfur is removed in the carbonizer. However, the PFBC model does have the capability of removing sulfur. These reactions are identical to those discussed in Section C.1. 


\section{D.2 HYDRODYNAMIC MODEL}

In generating the PFBC hydrodynamic model, it has been assumed that the solid circulation rate is a function of secondary zone superficial gas velocity. In this manner, solids circulation may approach a high value for large velocities and decrease to zero for low velocities. Other assumptions used in generating the PFBC hydrodynamics include: constant primary zone bed level, no solids particle attrition, and that the J-Valve is always sealed. The PFB hydrodynamics will be discussed in more detail below.

\section{D.2.1 Solids Charactization and Circulation}

The circulation of solids in the CPFBC subsystem is shown in Figure D-2.1. Solids exit the PFBC and enter the cyclone. The bulk of those solids fall into the FBHE, and are eventually returned to the PFBC.

Solid circulation rate is a function of the velocity in the secondary zone, as shown in Figure D-2.2.

For a given velocity, a percentage of a circulation rate can be determined. The assigned circulation rate will then vary with velocity. For instance, if a solids circulation of $7,000,000 \mathrm{lb} / \mathrm{hr}$ had been assigned as 95 percent at $10 \mathrm{ft} / \mathrm{sec}$, then, when the secondary zone superficial gas velocity drops to $5 \mathrm{ft} / \mathrm{sec}$, the corresponding solids circulation flow will drop to $5,968,421 \mathrm{lb} / \mathrm{hr}$.

Solids circulation is usually associated with the amount of flue gas produced by the PFB in the form of a ratio.

The solids/gas ratio in this study is assumed to be 2.5:1, which is typical of a pilot plant. Typical commercial solid/gas ratios are between 5:1 and 8:1, with the maximum solids/gas ratio at approximately 10:1.

An inventory of fifteen particle sizes is maintained in the PFBC circulation system. The PSD for the solids are listed in Table D-2.1.

This PSD is assumed to remain constant. The terminal velocity for each particle size is determined by an iterative procedure. Comparison of particle terminal velocities to superficial gas velocities in the secondary zone are then used to update the solid circulation rate. 


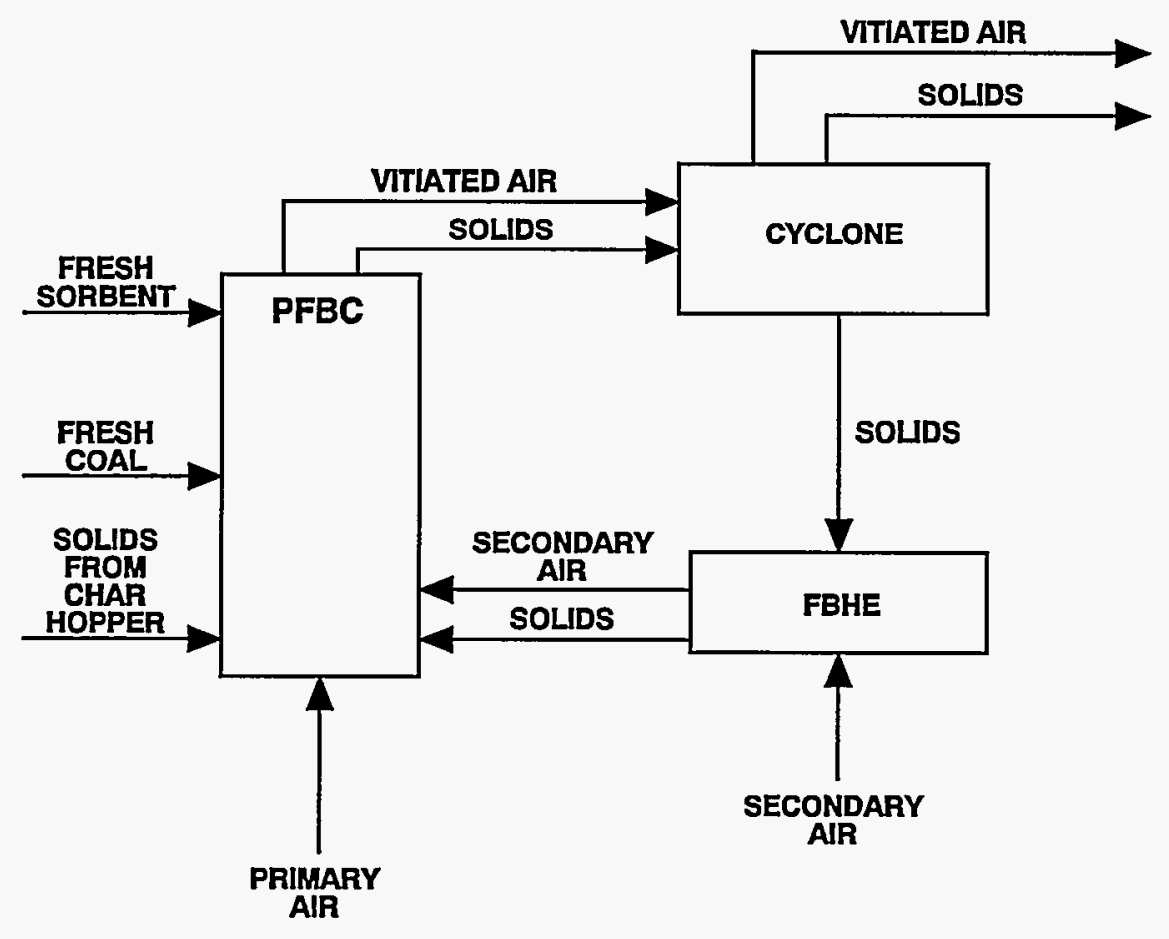

Figure D-2.1 - CPFBC Circulation Diagram

\section{D.2.2 PFBC Pressure}

The PFBC pressure drop is assumed to be the sum of the 10 foot fluidized bed in the primary combustion zone and a single phase flow pressure drop for the length of the secondary zone.

The PFBC pressure is determined by evaluating the following differential:

$\frac{\mathrm{dP}}{\mathrm{dt}}=\frac{\mathrm{mR}}{\mathrm{V}} \frac{\mathrm{dT}}{\mathrm{dt}}+\frac{\mathrm{RT}}{\mathrm{V}}\left(\dot{\mathrm{m}}_{\mathrm{NN}}-\dot{\mathrm{m}}_{\text {ou }}\right)$

Pressure drops through the cyclone and barrier filter are assumed to be percentages of absolute pressure. 


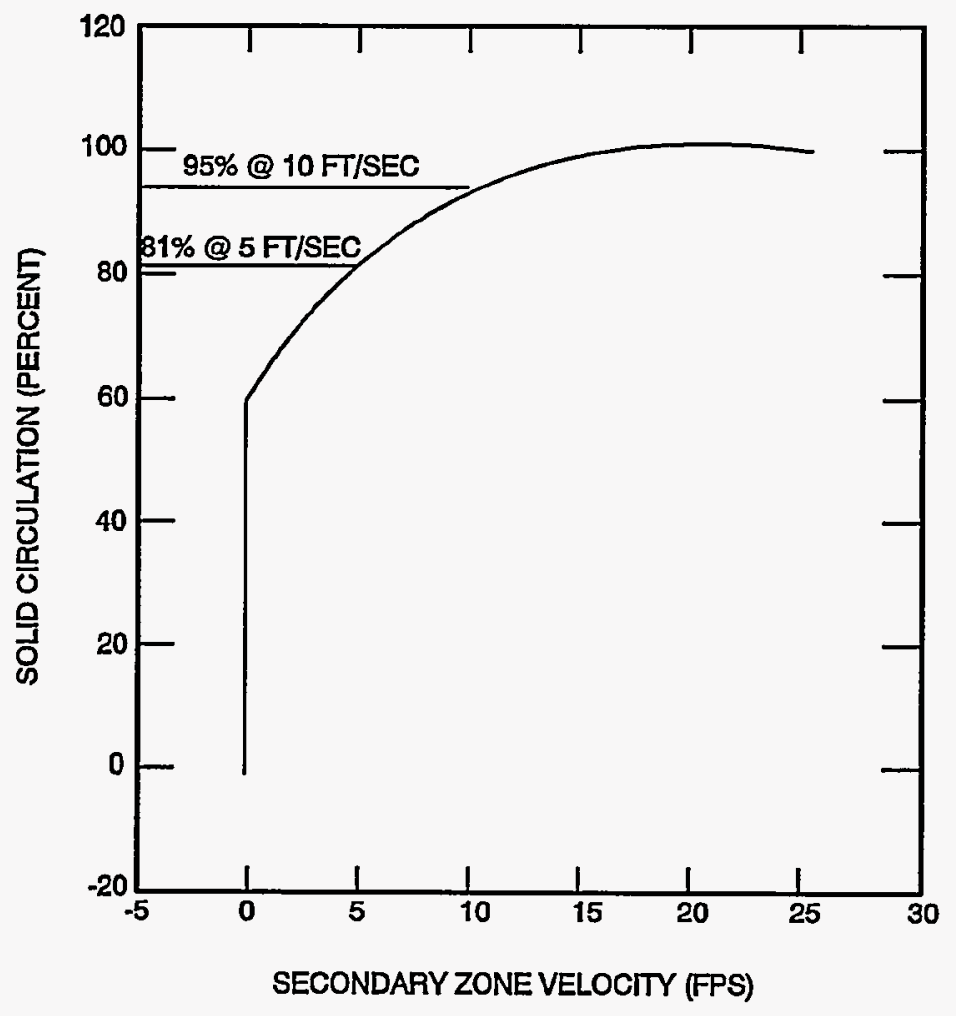

Figure D-2.2 - Solid Circulation and Secondary Zone Velocity

The solids mass balance for the PFBC is represented by the following equations, and shown schematically in Figure D-2.3:

$$
\begin{aligned}
& \dot{\mathrm{m}}_{\mathrm{CHAR}}+\dot{\mathrm{m}}_{\mathrm{CRC}}+\dot{\mathrm{m}}_{\mathrm{GEN}}=\dot{\mathrm{m}}_{\mathrm{OUT}} \\
& \dot{\mathrm{m}}_{\mathrm{CHAR}} \text { is Non-Carbon } \\
& \dot{\mathrm{m}}_{\mathrm{CRR}} \text { is Velocity Dependent } \\
& \dot{\mathrm{m}}_{\mathrm{GEN}} \text { is } \mathrm{CaS}-\mathrm{CaSO}_{4}
\end{aligned}
$$


Table D-2.1

PFBC Solids PSD Analysis

$\begin{array}{ccc}\text { Microns } & \text { \% On } & \text { \% Thru } \\ & & \\ 3350 & .03 & 99.97 \\ 2380 & .3 & 99.67 \\ 1700 & 2.37 & 97.3 \\ 1400 & 1.47 & 95.83 \\ 1190 & 2.09 & 93.74 \\ 1000 & 2.00 & 91.74 \\ 850 & 3.29 & 88.45 \\ 710 & 2.88 & 85.57 \\ 595 & 2.96 & 82.61 \\ 297 & 10.71 & 71.9 \\ 149 & 11.07 & 60.83 \\ 105 & 5.92 & 54.91 \\ 74 & 7.13 & 47.78 \\ 44 & 12.43 & 35.35 \\ 00 & 35.35 & 0\end{array}$

Figure D-2.3 - PFBC Solids Mass Balance

\section{D.3 ENERGY BALANCES}

The energy balance for the PFB combustor is presented in this section. Figure D-3.1 illustrates the energy components of the PFBC.

\section{D.3.1 PFB Combustor Energy Balance}

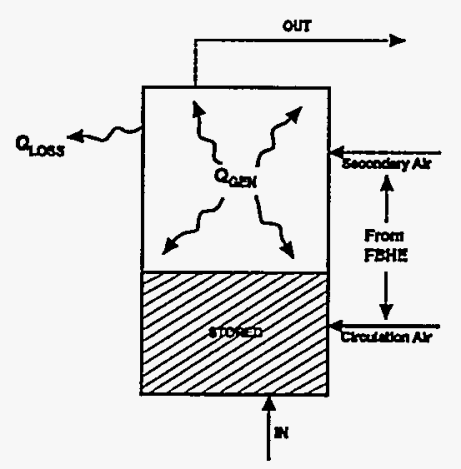


Figure D-3.1 - Combustor Energy Balance

The overall energy balance for the PFBC is represented by the following differential equation:

$$
\mathrm{Q}_{\mathbb{N}}-\frac{\mathrm{d}\left(\mathrm{m}_{\text {COMB }} \mathrm{C}_{\mathrm{P}} \mathrm{T}_{\text {COMB }}\right)}{\mathrm{dt}}=\mathrm{Q}_{\text {LOSS }}
$$

The inlet and outlet energy streams are listed below.

$$
\begin{aligned}
& \frac{\text { ENERGY IN: }}{\dot{\mathrm{m}}_{\text {PRIAR }} \mathrm{C}_{\mathrm{P}}\left(\mathrm{T}_{\text {COMP }}-\mathrm{T}_{\mathrm{R}}\right)} \\
& \begin{array}{|l|}
\dot{\mathrm{m}}_{\text {SECARR }} \mathrm{C}_{\mathrm{P}}\left(\mathrm{T}_{\text {SECAIR }}-\mathrm{T}_{\mathrm{R}}\right) \\
\dot{\mathrm{m}}_{\text {CHAR }} \mathrm{C}_{\mathrm{P}}\left(\mathrm{T}_{\text {CHAR }}-\mathrm{T}_{\mathrm{R}}\right) \\
\dot{\mathrm{m}}_{\text {CIRC }} \mathrm{C}_{\mathrm{P}}\left(\mathrm{T}_{\mathrm{CRC}}-\mathrm{T}_{\mathrm{R}}\right) \\
\text { Oxidation, Sulfation }
\end{array}
\end{aligned}
$$

ENERGY OUT:

$$
\begin{aligned}
& \mathrm{Q}_{\text {LOSS }} \\
& \dot{\mathrm{m}}_{\text {GASOUT }} \mathrm{C}_{\mathrm{P}}\left(\mathrm{T}_{\text {COMB }}-\mathrm{T}_{\mathrm{R}}\right) \\
& \dot{\mathrm{m}}_{\text {SOLOUT }} \mathrm{C}_{\mathrm{P}}\left(\mathrm{T}_{\text {COMB }}-\mathrm{T}_{\mathrm{R}}\right)
\end{aligned}
$$

\section{D.3.4 PFB Combustor Heat Loss}

The PFBC hard face refractory is treated as a lumped system with the dimensions shown in Figure D-3.2. A constant outside vessel temperature of $230^{\circ} \mathrm{F}$ is assumed. Therefore, heat loss to ambient is assumed constant. Heat stored in the hard face will vary with the PFBC temperature. 
Figure D-3.2 - Vessel Geometry

The temperature of the hard face refractory is determined by integrating:

$$
\frac{\mathbf{d T}_{R E F}}{\mathbf{d} \mathbf{T}}-\frac{\mathbf{h}_{i} \mathbf{A}_{i}}{\mathbf{m}_{R E F P}}\left(\mathbf{T}_{C O M B} \mathbf{T}_{R E F}=\boldsymbol{h}_{o} \mathbf{A}_{o}\left(\mathbf{T}_{S H E L L} \mathbf{T}_{\partial}\right.\right.
$$

Energy stored in the hard face is then calculated from $\mathrm{T}_{\mathrm{REF}}$

$$
D-8
$$




\section{E FLUID BED HEAT EXCHANGER MODEL}

This section describes the FBHE model which is part of the customized ACSL code. Additional description is provided by the documented code which can be found in Appendix L.

\section{E.1 INTRODUCTION}

The fluid bed heat exchanger is divided into an adiabatic (no heat transfer) section, a superheat section, and a reheat section, as shown in Figure E-1.1. The superheater section is further divided into three cells which contain bundle heat transfer surface for primary, secondary, and finishing superheat. Each of the three cells also have surface area for radiative and convection heat transfer to boiler tubes. The reheater pass is configured in a similar manner and provides tube bundles for steam generation, primary and secondary reheat.

The assumptions used to generate the FBHE model are:

- Constant Voidage

- Even Air Distribution/Bed Well Mixed

- Counter Flow Solids/Steam

- $\quad$ No Solid Elutriation

- No Entrained Gas From Cyclone Solids Flow

- $\quad$ Enclosed Wall Surface (Projected Area)

- No Combustion

- Minimum Fluidizing velocity for $\approx 50$ Micron

- Constant Exterior Heat Transfer Coefficients

- Isothermal (Bed/Freeboard)

- Constant Freeboard Emissivity $\approx 0.45$

- J-Valve Always Sealed

\section{E.2 HYDRODYNAMIC MODEL}

The FBHE hydrodynamic model will be discussed in two sections. Section E.2.1, will describe the hydrodynamics of the solid/air side. Section E.2.2 will describe the hydrodynamics of the water/steam side.

\section{E.2.1 Solids/Air Pass Hydrodynamic Model}

Air is used to fluidized each of the seven cells. Fluidizing air from the adiabatic section flows to the superheat and reheat sections in equal amounts. This would be cells 4 and 7 on Figure E-1.1. Air from the adiabatic section flowing to cell 4 would mix with the 


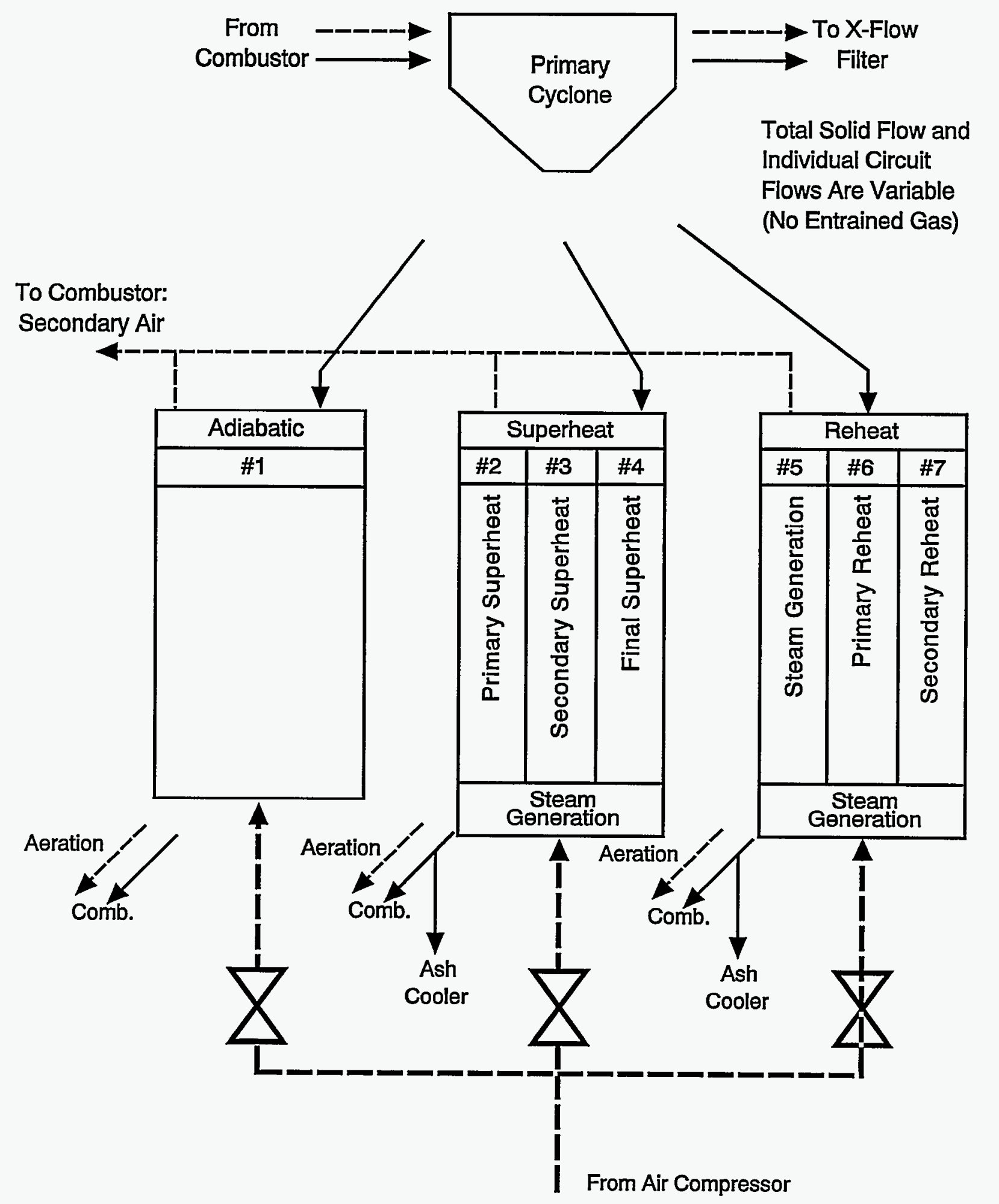

Figure E-1.1 - FBHE Configuration

$E-2$ 


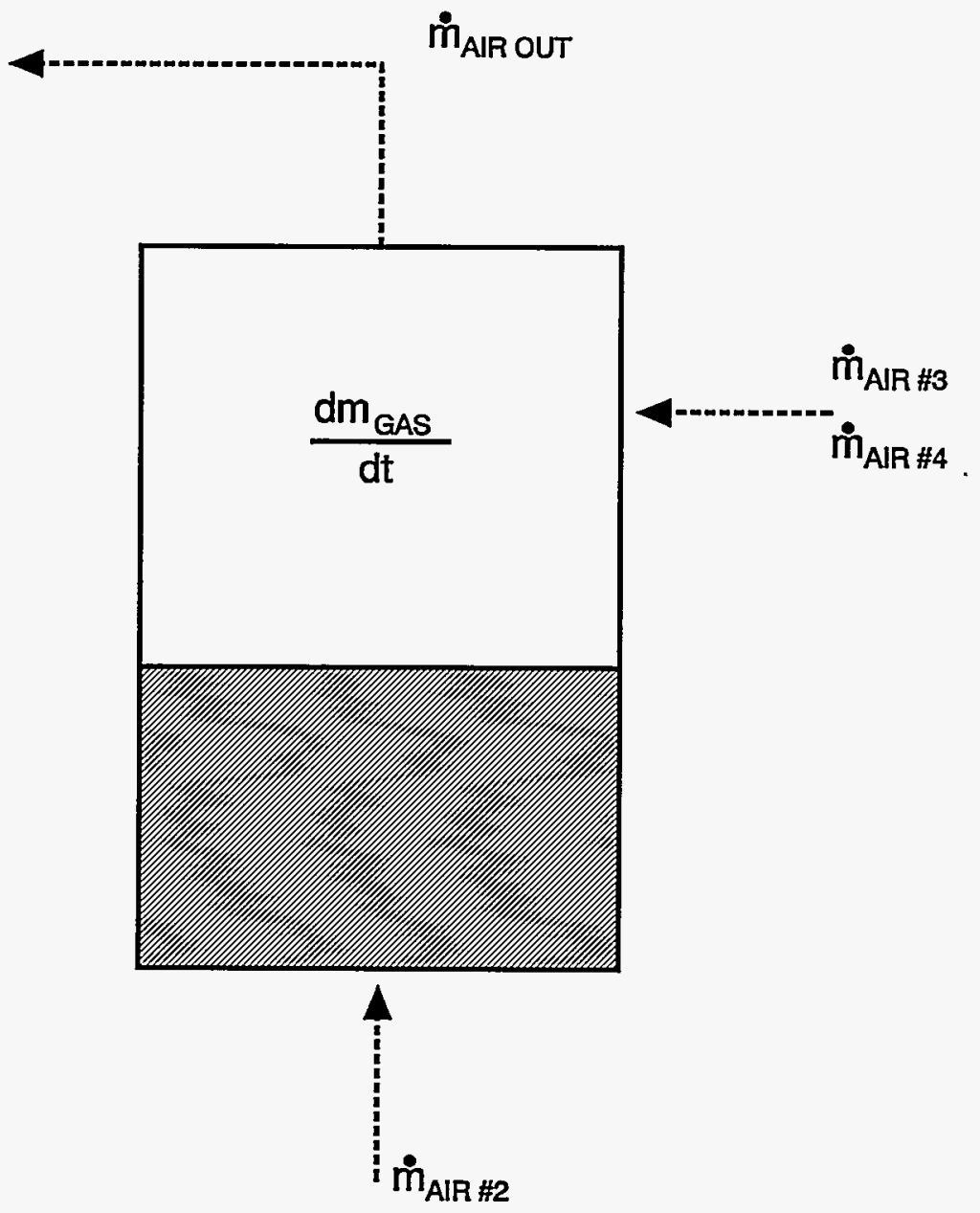

Figure E-2.1 - FBHE Cell \#2 Gas Schematic

air used to fluidize cell 4 and the combined mass would flow into cell 3 . In cell 3 , this air would mix with the air used to fluidize cell 3 . The combined mass would then flow to cell 2 where it would mix with air used to fluidize cell 2 . The combined air mass from cell 2 would then mix with air from cell 5 and exit the FBHE. Air from cell 5 is generated in the same manner described above but travels the path of cell 7 , to cell 6 , to cell 5. 
In each cell, both the minimum fluidization and superficial gas velocities are calculated. Minimum fluidization velocity is calculated via:

$$
\frac{1.75}{\varnothing_{\mathrm{s}} \xi_{\mathrm{mf}}{ }^{3}}\left[\frac{\mathrm{d}_{\mathrm{p}} \mathrm{U}_{\mathrm{m} f} \rho_{\mathrm{g}}}{\mu}\right]+\frac{150(1-\xi-\mathrm{mf})}{\varnothing_{\mathrm{s}}{ }^{2} \xi_{\mathrm{mf}}{ }^{3}}\left[\frac{\mathrm{d}_{\mathrm{p}} \mathrm{U}_{\mathrm{m}} \rho_{\mathrm{g}}}{\mu}\right]=\frac{\mathrm{d}_{\mathrm{p}}{ }^{3} \rho_{\mathrm{g}}\left(\rho_{\mathrm{s}}-\rho_{\mathrm{g}}\right) \mathrm{g}}{\mu^{2}}
$$

Pressure drop is calculated for each cell as either:

$$
\frac{\Delta \mathrm{P}}{\mathrm{L}}=\left(\rho_{\mathrm{F}}-\rho_{\mathrm{S}}\right)(1-\xi) \frac{\mathrm{g}}{\mathrm{g}_{\mathrm{c}}}
$$

for fluidized bed, or:

$$
\frac{\Delta \mathrm{P}}{\mathrm{L}}=\frac{150}{\mathrm{~g}_{\mathrm{c}}} \frac{\left(1-\xi_{\mathrm{m}}\right)^{2}}{\xi_{\mathrm{m}}{ }^{3}} \frac{\mu \mathrm{V}}{\left(\varnothing_{\mathrm{g}} \mathrm{D}^{2}\right)^{2}}+\frac{1.75}{\mathrm{~g}_{\mathrm{c}}} \frac{\left(1-\xi_{\mathrm{m}}\right)}{\xi_{\mathrm{m}}{ }^{3}} \frac{\rho_{\mathrm{F}} \mathrm{V}^{2}}{\varnothing_{\mathrm{s}} \mathrm{D}_{\mathrm{p}}}
$$

for nonfluidized conditions.

The FBHE gas side pressure is calculated by evaluating the following integral:

$$
\frac{\mathrm{dP}}{\mathrm{dt}}=\frac{\mathrm{mR}}{\mathrm{V}}\left(\frac{\mathrm{dT}}{\mathrm{dt}}\right)+\mathrm{mRT} \frac{\mathrm{d}\left(\frac{1}{\mathrm{v}}\right)}{\mathrm{dt}}+\left(\mathrm{\sum m}_{\mathrm{CELLS}}\right) \frac{\mathrm{RT}}{\mathrm{V}}
$$

The flow of air out the FBHE and into the CPFBC is calculated as:

$$
\mathrm{W}=\mathrm{C}_{\mathrm{FBHE}} \sqrt{\rho_{\mathrm{AVG}}\left(\mathrm{P}_{\mathrm{FBHE}}-\mathrm{P}_{\mathrm{COMB}}\right)}
$$

\section{E.2.2 Steam/Water Pass Hydrodynamic Model}

A schematic of the FBHE steam drum is shown in Figure E-2.2. Steam is generated on the tube side of the enclosure walls in FBHE cells 2 through 7. Each of these six cells contain convective and radiative heat transfer surface. Cell 5 contains a tube bundle which is also used to generate steam. 


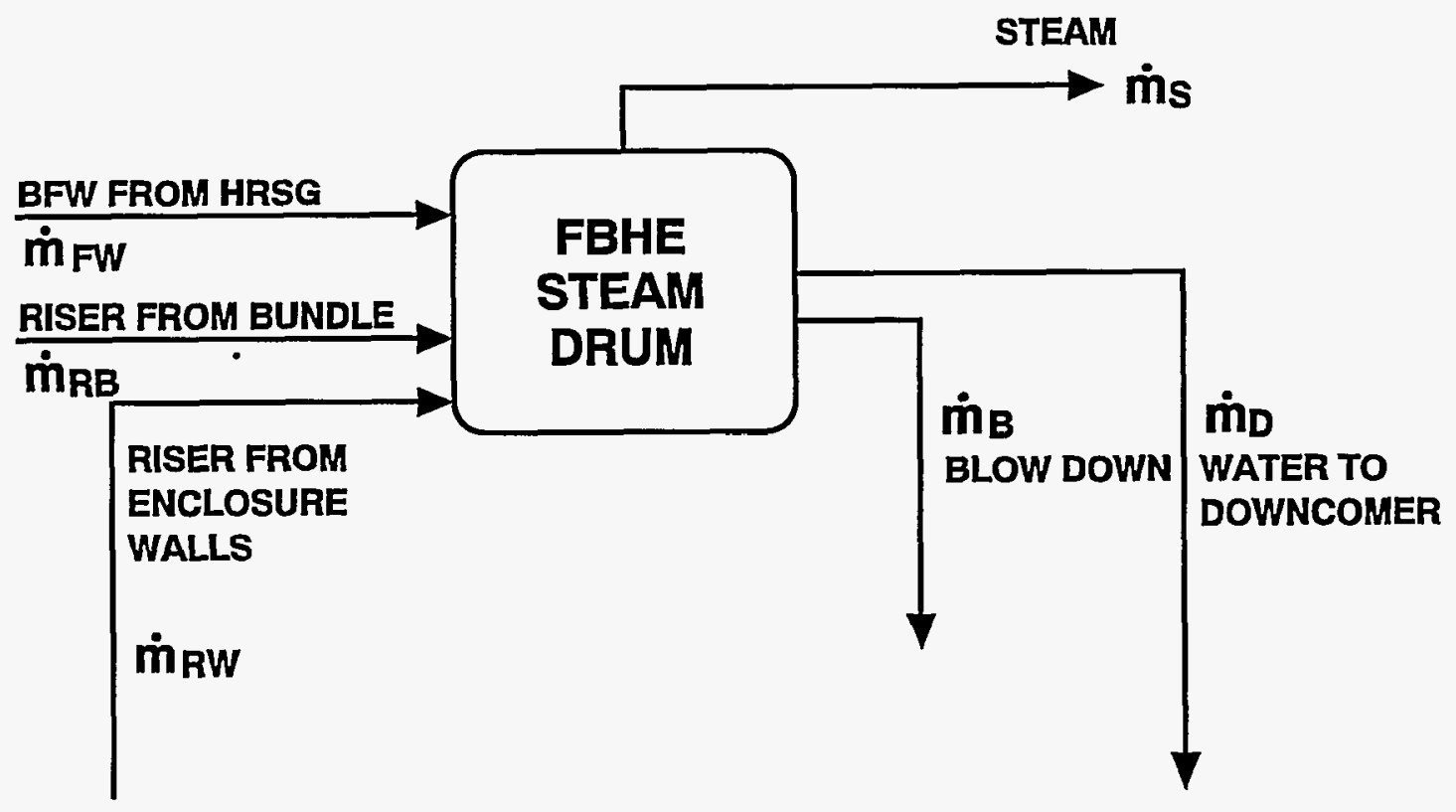

Figure E-2.2

FBHE Steam Drum Schematic

Bulk enthalpy and pressure in the drum are calculated by evaluating the respective integrals below.

$$
\begin{aligned}
& \frac{\mathrm{dP}}{\mathrm{dt}}=\frac{\left(\dot{\mathrm{m}}_{\mathrm{FW}}+\dot{\mathrm{m}}_{\mathrm{RB}}+\dot{\mathrm{m}}_{\mathrm{RW}}-\dot{\mathrm{m}}_{\mathrm{S}}-\dot{\mathrm{m}}_{\mathrm{D}}-\dot{\mathrm{m}}_{\mathrm{B}}\right)\left[\mathrm{h}+\frac{\rho}{(\partial / 2 \mathrm{~h})}\right]+\Sigma(\mathrm{mh})}{\mathrm{V}\left[1-\rho\left[\frac{(\partial \rho / \partial \mathrm{P})_{\mathrm{H}}}{(\partial \rho / \partial \mathrm{h})_{\mathrm{P}}}\right]\right]} \\
& \frac{\mathrm{dh}}{\mathrm{dt}}=\frac{(\Sigma \dot{\mathrm{m} h})}{\mathrm{V} \rho}
\end{aligned}
$$

Steam flow through the primary, secondary, and finishing superheater passes is calculated as:

$\mathrm{W}=\mathrm{C}_{\mathrm{FLOW}} \sqrt{\rho_{\mathrm{AVG}}\left(\mathrm{P}_{\mathrm{UP}}-\mathrm{P}_{\text {DOWN }}\right)}$ 
Flow in the primary and secondary reheater passes are calculated through use of the PC-TRAX subroutine FLOW. Subroutine FLOW is documented in the Programmers Manual.

Pressure and enthalpy of the superheater attemperator is calculated by integrating:

$$
\begin{aligned}
& \frac{\mathrm{dP}}{\mathrm{dt}}=\frac{\left(\mathrm{m}_{\mathrm{IN}}-\mathrm{m}_{\text {oUT }}\right)(\mathrm{h}+(\rho /(\partial \rho / \partial \mathrm{h})))+\Sigma(\dot{\mathrm{mh}})}{\mathrm{V}\left[1+\rho\left[\frac{(\partial \rho / \partial \mathrm{P})_{\mathrm{H}}}{(\partial \rho / \partial \mathrm{h})_{\mathrm{P}}}\right]\right]} \\
& \frac{\mathrm{dh}}{\mathrm{dt}}=\frac{(\Sigma \mathrm{mh})}{\mathrm{V} \rho}
\end{aligned}
$$

\section{E.3 FBHE ENERGY BALANCE}

For ease of description, the FBHE energy balance will be discussed in two parts. First, the solids/air side will be presented. Following, in Section E-3.2, the steam/water energy balance will be discussed.

\section{E.3.1 Solids/Air Energy Balance}

In each of the seven cells in the FBHE, the energy balance can be described as:

$$
\frac{\mathrm{dT}}{\mathrm{dt}}=\frac{\mathrm{Q}_{\mathrm{IN}}-\mathrm{Q}_{\mathrm{OUT}}}{\mathrm{m} \mathrm{C}_{\mathrm{P}}}
$$

In each of the seven cells, $Q_{\mathbb{N}}$ is the thermal energy contained in the entering air and solids, likewise, $Q_{\text {our }}$ Is the thermal energy in the exiting air and solids. In cells 2 through 7, $Q_{\text {out }}$ also contains the energy transferred to the steam/water system. Convective heat transfer takes place in the tube bundles and submerged wall sections. Radiative heat transfer takes place in the freeboard. This heat transfer is described below: 
Bundle Loss:

$\mathrm{Q}_{\text {BUNDLE }}=\frac{2 \pi \mathrm{L}\left(\mathrm{T}_{\mathrm{c}}-\mathrm{T}_{\text {STEAM }}\right)}{\left(1 / \mathrm{h}_{\mathrm{o}} \mathrm{r}\right)+\left(1 / \mathrm{h}_{\mathrm{i}} \mathrm{r}_{\mathrm{i}}\right)}$

$\mathrm{h}_{\mathrm{o}} \quad=$ constant

$\mathrm{h}_{\mathrm{i}}=$ calculated from steam conditions and geometry

Wall (Bed) Loss:

$\mathrm{Q}_{\mathrm{WALL}}=\frac{\operatorname{AREA}\left(\mathrm{T}-\mathrm{T}_{\text {STEAM }}\right)}{1 / \mathrm{h}_{\mathrm{o}}+1 / \mathrm{h}_{\mathrm{i}}}$

$\mathrm{h}_{\mathrm{o}}=$ Constant

$\mathrm{h}_{\mathrm{i}}=$ Calculated from steam conditions and geometry.

Wall (Freeboard) Loss:

$\mathrm{Q}_{\text {RADIATION }}=\epsilon \sigma \operatorname{AREA}\left[(\mathrm{T})^{4}-\left(\mathrm{T}_{\text {METAI }}\right)^{4}\right]$ $\epsilon=0.45$

$\mathrm{T}_{\text {METAL }}=$ Calculated from $\mathrm{Q}_{\mathrm{WALL}}(\mathrm{BED})$ equation

\section{E.3.2 Steam/Water Energy Balance}

In the FBHE, steam is generated in the enclosure wall as well as the tube bundle in cell 5. There are three superheat and two reheat tube bundles where convective heat transfer takes place.

Feedwater from the HRSG mixes with saturated water from the steam drum and enters the downcomer. The downcomer enthalpy is determined by integrating:

$$
\frac{d h_{d}}{d t}=\frac{\dot{\mathrm{m}}_{F W}}{\dot{\mathrm{m}}_{\mathrm{r}}}\left(\mathrm{h}_{\mathrm{FW}}-\mathrm{h}_{\mathrm{f}}\right)+\mathrm{h}_{\mathrm{f}}-\mathrm{h}_{\mathrm{d}}
$$


Enthalpy is the riser is calculated as:

$$
\frac{d h_{r}}{d t}=\frac{\dot{m}_{r}\left(h_{d}-h_{r}\right)+q_{\text {RISER }}}{V\left(\rho+h\left(\frac{\partial \rho}{\partial h}\right)\right]}
$$

Enthalpy changes in the six tube bundles is described by the following general expression:

$$
\frac{d h_{\text {oUT }}}{d t}=\frac{\dot{\mathrm{m}}\left(\mathrm{h}_{\mathrm{N}}-\mathrm{h}_{\text {oUT }}\right)+\mathrm{q}}{\rho \mathrm{V}}
$$




\section{F CHAR HOPPER MODEL}

This section presents the char hopper model which is part of the customized ACSL code. The char hopper model is very simple. The only affect is volume. Temperature and pressure affects are ignored, and there are no chemical reactions. See documented code for more details.

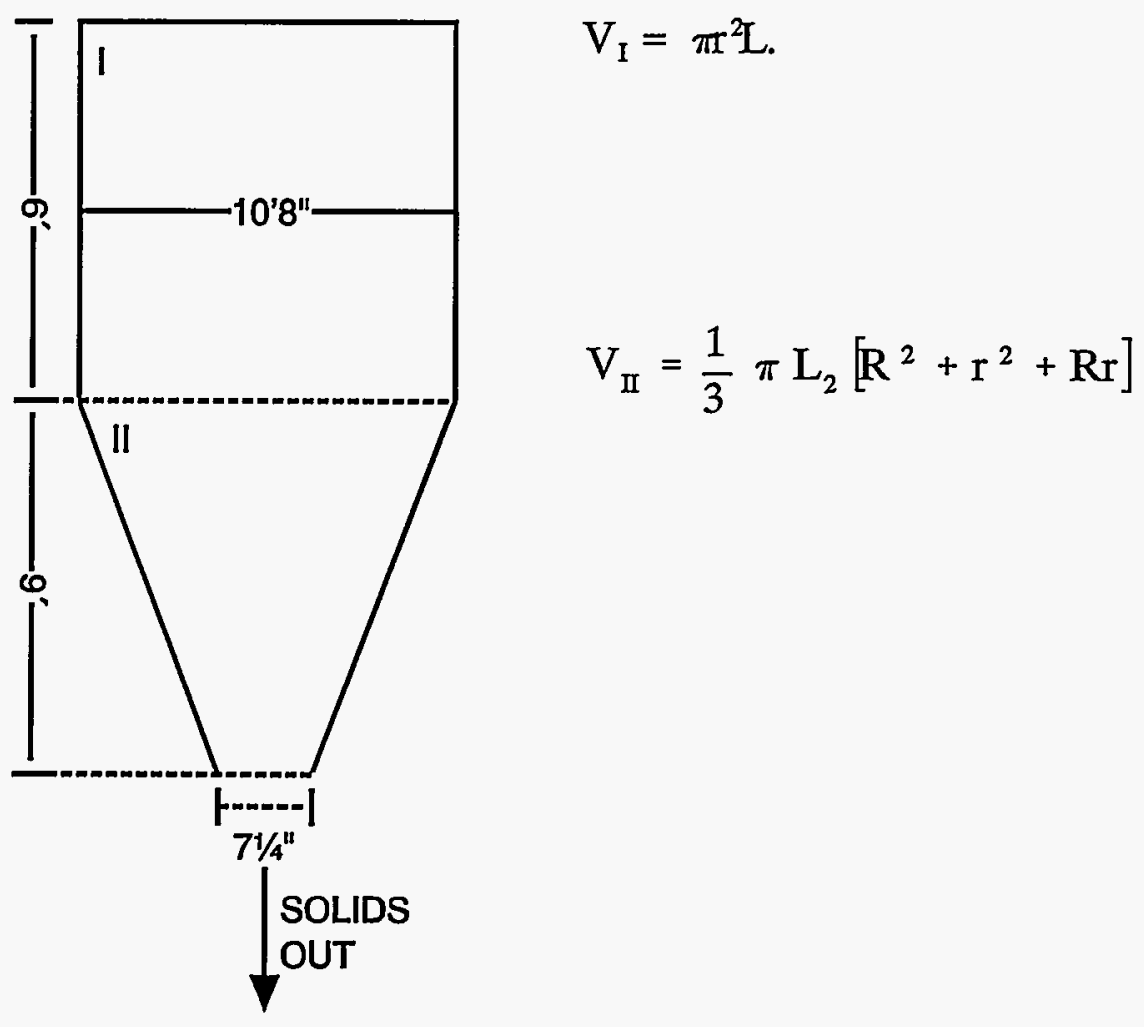

The mass of solids in tank is calculated as:

$\frac{\mathrm{dm}}{\mathrm{dt}}=\mathrm{m}_{\mathbb{N}}-\mathrm{m}_{\text {ouT }}$

Solids height then calculated form density and geometry. 


\section{G ASH COOLER MODEL}

This section describes the ash cooler model which is a part of the customized ACSL code. Figure G-1.1 shows a model schematic. The ACSL code is heavily documented and should be referred to during the reading of this seciton.

\section{G.1 THERMODYNAMIC MODEL}

The thermodynamic model of the ash cooler utilizes the NTU-effectiveness method. Use of this method involves the following three steps. It should be noted that there is no energy storage term.

1 Calculate the UA (thermal conductance) of the cooler at steady state conditions.

The thermal conductance calculated for this model is $20,249 \mathrm{Btu} / \mathrm{hr}{ }^{\circ} \mathrm{F}$

2 Calculate the number of heat transfer units (NTU) using the NTU-effectiveness method.

$$
\mathrm{N}_{\mathrm{TU}}=\frac{\mathrm{AU}}{\mathrm{C}_{\mathrm{MIN}}} \text {, where } \mathrm{C}_{\mathrm{MIN}}=\left(\mathrm{C}_{\rho} \dot{\mathrm{m}}\right)_{\mathrm{MIN}}
$$

3 Determine off-load performance using NTU-effectiveness parameters

The heat transfer effectiveness is calculated as:

$$
\epsilon=\frac{1-e^{-N_{T v}}\left(1-\left(C_{\min } / C_{\max }\right)\right)}{1-\left(C_{\min } / C_{\max }\right) e^{-N_{\pi v}}\left(1-\left(C_{\min } / C_{\max }\right)\right)}
$$

The rate of heat transfer is calculated as:

$\left.\mathrm{Q}=\mathrm{C}_{\mathrm{MNN}} \in \mathrm{T}_{\mathrm{HIN}}-\mathrm{T}_{\mathrm{CIN}}\right)$

This valve then determines the individual stream outlet temperatures.

\section{G.2 HYDRODYNAMIC MODEL}

The ash cooler model utilizes the PC-TRAX FLOW subroutine to calculate the appropriate hydrodynamic values for the water side. PC-TRAX subroutine FLOW is described in the TRAX Programmer Manual. There is no hydrodynamic description for the solids. 


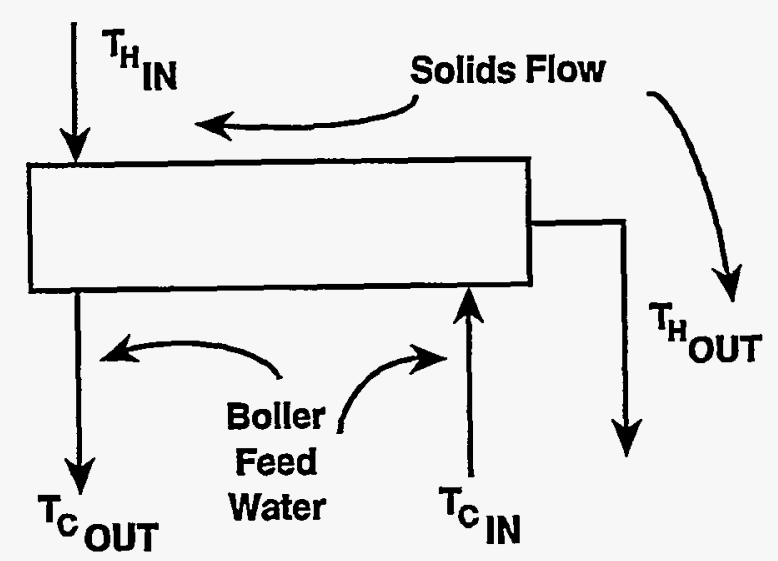

Figure G-1.1 - Ash Cooler Schematic 


\section{H TOPPING COMBUSTOR MODEL}

This section describes the topping combustor model contained in the customized ACSL code. A schematic of the topping combustor is shown in Figure H-1.1.

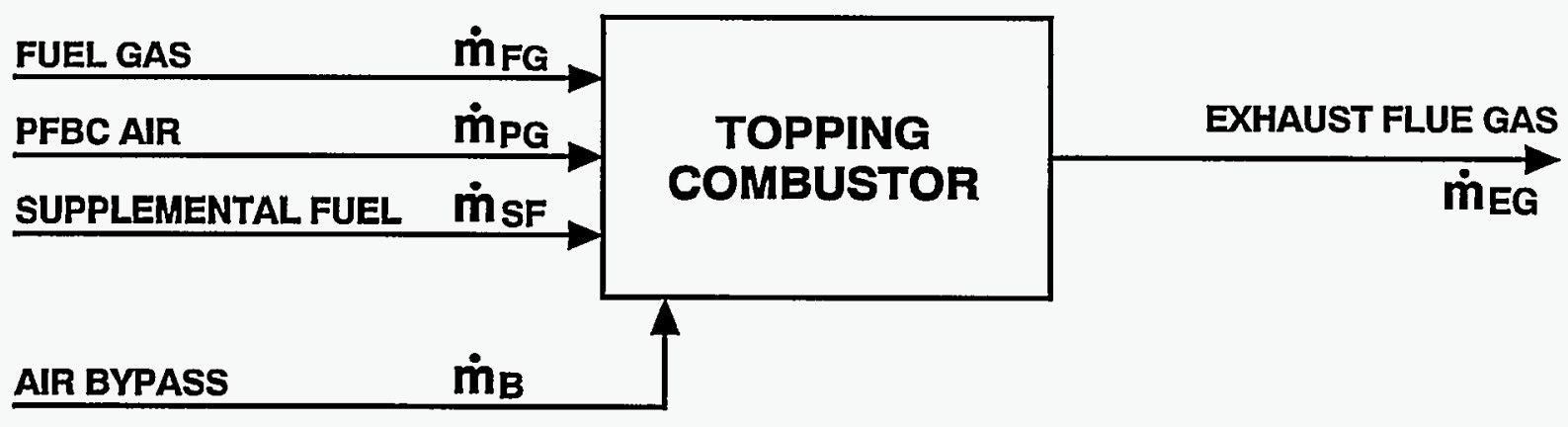

Figure H-1.1 Th

Topping Combustor Schematic e

tlet temperature is determined by:

$$
\frac{\mathrm{dT}}{\mathrm{dt}}=\frac{\Sigma\left(\mathrm{mC}_{\mathrm{P}} \Delta \mathrm{T}\right)_{\mathrm{IN}}+\mathrm{Q}_{\mathrm{COMB}}-\Sigma\left(\mathrm{mC}_{\mathrm{p}} \Delta \mathrm{T}\right)_{\mathrm{OUT}}-\mathrm{Q}_{\text {LOST }}}{\mathrm{mC}_{\mathrm{P}}}
$$

The heat loss accounts for losses to ambient as well as losses to the metal during transients.

The topping combustor outlet pressure calculated by evaluating the following differential:

$$
\frac{\mathrm{dP}}{\mathrm{dt}}=\frac{\mathrm{mR}}{\mathrm{V}}\left[\frac{\mathrm{dT}}{\mathrm{dt}}\right]+\left[\frac{\mathrm{RT}}{\mathrm{V}}\right]\left[\dot{\mathrm{m}}_{\mathrm{B}}+\dot{\mathrm{m}}_{\mathrm{SP}}+\dot{\mathrm{m}}_{\mathrm{PG}}+\dot{\mathrm{m}}_{\mathrm{FG}}-\dot{\mathrm{m}}_{\mathrm{EG}}\right]
$$

Pressure drop through the combustor is calculated as:

$$
\Delta \mathrm{p}=\left[\frac{\dot{\mathrm{m}}_{\mathrm{oUT}}}{\mathrm{C}_{\mathrm{FLOW}}}\right]\left(1 / \rho_{\mathrm{AVG}}\right)
$$




\section{INSTRUMENTATION DIAGRAMS}

The TRAX control modules used in this study represent typical hardware components found in power plant control schemes. This section contains simplified instrumentation diagrams, Scientific Apparatus Manufacturers Association (SAMA) diagrams, and block diagrams illustrating the control scheme as implemented in PC-TRAX for each control loop contained in the model. The block diagrams show the TRAX module name and component ID's for easy reference when using the model.

For this section, the intended audience is assumed to be familiar with the APFBC power plant concept as well as the TRAX-based dynamic model and accompanying software. The reader is also assumed to have some knowledge of process control and instrumentation. The PC-TRAX Analyst Instruction Manual should be consulted for individual TRAX control module calculation descriptions.

\section{CARBONIZER CONTROLS}

Figure I-1.1 contains a schematic showing the instrumentation and control modules associated with the carbonizer vessel. Six individual control loops are represented in the drawing and Figures I-1.2 and I-1.3 contain the SAMA diagrams for each loop. The individual control loops are described below.

As shown in Figure I-1.2, sorbent flow set point is established as a function of coal flow and maintained by a three mode (PID) controller. The PC-TRAX block diagram for sorbent flow control is shown in Figure I-1.4. Figure I-1.4 shows the set points, controller tunings, and transmitter ranges. Figure I-1.5 shows the function used to generate the sorbent flow set point as a function of dry coal fed to the carbonizer.

The block diagram in Figure I-1.6 shows the TRAX representation for carbonizer coal flow control. In this control scheme, coal flow is the leading variable. Coal flow and power output is varied by manually selecting the limit and rate of a ramp function. The ramp module establishes a coal flow set point. Flow is maintained by a PID controller. Figure I-1.6 contains the ramp limits, ramp rate, controller tuning, and transmitter range used in this control loop. Table I-1.1 contains a chart which shows percent of design coal flow as a function of transmitter signal range.

Figure I-1.7 shows the TRAX modules and configuration implemented for transport air flow control. Transport air flow is regulated by a PID controller to maintain a superficial gas velocity set point. As shown in Figure I-1.1, transport air flow is controlled by the inlet guide vanes (IGV's) of the transport air boost compressor. Controller trim with carbonizer coal flow is an optional parameter, but not investigated in the present study. Air flow set point, transmitter range, and controller tuning parameters can be found in Figure I-1.7. Controller demand signals created by the PID 
controller pass through auto-manual station C34 prior to being sent to compressor CC2 (compressor CC2 is shown in Figure A-3.5).

As illustrated in Figure I-1.2, carbonizer primary air flow is established as a function of coal flow and maintained by a PID controller. The set point signal is corrected by carbonizer bed temperature. The correction is generated by a PID controller that compares bed temperature to a set point of $1600^{\circ} \mathrm{F}$ and modifies the output of the primary air signal demand as required.

Figure I-1.8 illustrates the TRAX modules used in the primary air flow control scheme, as well as the controller set point, tuning constants, and transmitter ranges. Carbonizer primary air flow is controlled by the inlet guide vanes (IGV's) of the boost compressor. Figure I-1.9 shows the initial function used to generate the primary air flow based on dry coal feed to the carbonizer. Figure I-1.10 shows the function used to provide the plus or minus 25 percent correction for changes in the carbonizer bed temperature.

Auto-manual station C49, shown in Figure I-1.8, passes the PID created control demand signal to compressor CC1 (compressor CC1 is shown in Figure A-3.5).

As shown in Figure I-1.3, carbonizer steam flow set point is established as a function of coal flow and maintained by a PID controller. The PC-TRAX block diagram for carbonizer steam flow control is shown in Figure I-1.11. Figure I-1.11 shows the controller tunings and transmitter ranges associated with this control loop. Auto-manual station C54, shown in Figure I-1.11, passes the controller demand signal to valve CV3 (Valve CV3 can be found in Figure A-3.5). Figure I-1.12 contains the relationship used to generate the steam flow set point as a function of dry coal fed to the carbonizer.

Carbonizer steam flow is supplied by an extraction from the steam turbine. Steam temperature is maintained by desuperheating spray water regulated by a PID controller. Steam temperature is kept at $415^{\circ} \mathrm{F}$ or lower. Controller tuning parameters and transmitter ranges can be found in Figure I-1.13. Also shown is an optional control parameter utilizing total steam flow required. Auto-manual station C65, shown in Figure I-1.13, passes the control demand signal to valve BV7 (Valve BV7 can be seen in Figure A-3.15).

Carbonizer solids drain flow is established and maintained by the physical configuration of the carbonizer, i.e., the location of the overflow drain line that establishes the bed level in the carbonizer.

\section{I.2 PFB COMBUSTOR CONTROLS}

Figure I-2.1 contains a schematic showing the instrumentation and control elements associated with the char hopper, PFBC, and FBHE. Ten individual control loops are represented in the drawing and Figure I-2.2 contains the SAMA diagrams for each loop. 
The FBHE air flow control represents seven duplicate control loops, therefore, only one control loop is shown in Figure I-2.2. The individual control loops are described below.

Char inlet flow to the combustor indirectly follows coal flow. This is due to a PDD controller which maintains a set level in the char collection hopper. Figure I-2.3 is the block flow diagram illustrating the TRAX modules implemented in constructing the char hopper level control scheme. All set point, transmitter ranges, and tuning parameters are shown on the diagram.

Although not addressed in this report, it is possible that allowing the char hopper level to vary during load changes, which could increase the stability and response of the system. This concept will be explored in future studies.

As illustrated in Figure I-2.2, combustor secondary air flow is established as a function of coal flow and maintained by a PID controller. The set point signal is corrected by combustor bed temperature. The correction is generated by a PID controller that compares bed temperature to a set point of $1600^{\circ} \mathrm{F}$ and modifies the output of the PFBC secondary air signal demand as required.

Figure I-2.4 illustrates the TRAX modules used in the PFBC secondary air control scheme, as well as the controller set point, tuning constants, and transmitter ranges. Figure I-2.5 shows the initial function used to generate the PFBC secondary air flow based on dry coal feed to the carbonizer. Figure I-2.6 shows the function used to provide the plus or minus 25 percent correction for changes in the combustor bed temperature.

PFB Combustor secondary air flow is controlled by modulating valve PV2 and the gas turbine compressor IGV's. The GT compressor IGV's are utilized when the PFBC becomes air deficient at 100 percent of design load. This split ranging approach allows for greater control maneuverability at 100 percent of load. Valve PV2 is direct acting and responds over a controller demand signal range of 0 to 50 percent. The GT IGV's are also direct acting and respond over a controller demand signal range of 50 to 100 percent (Valve PV2 can be found in Figure A-3.4).

Figure I-2.7 shows the TRAX modules and configuration implemented for the PFBC primary air flow control. PFBC primary air flow is regulated by a PID controller to maintain a superficial gas velocity set point. Air flow is controlled by modulating the stem position on valve PV1 (Valve PV1 can be found in Figure A-3.4). Air flow set point, transmitter range, and controller tuning parameters can be found in Figure I-2.7. 


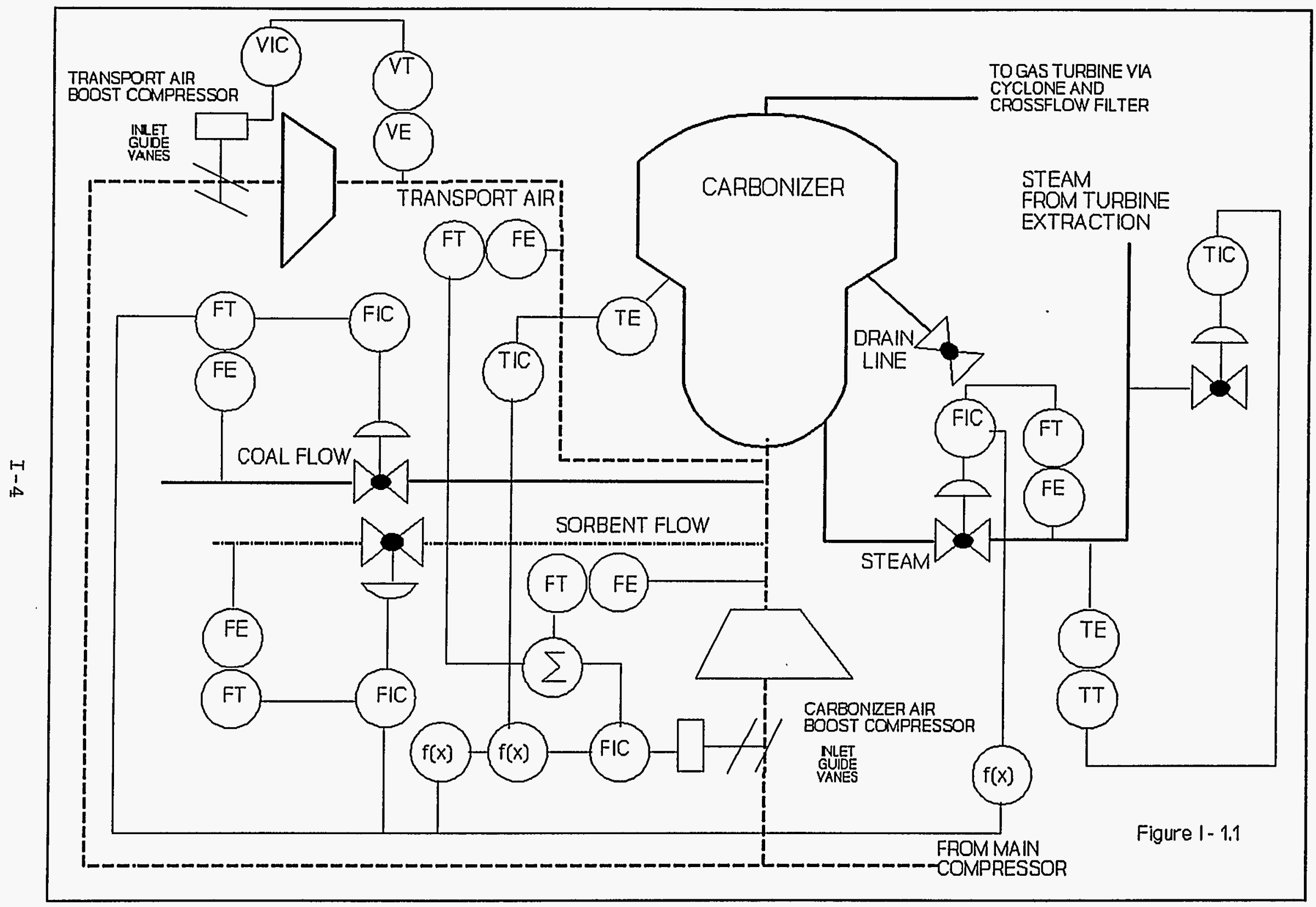




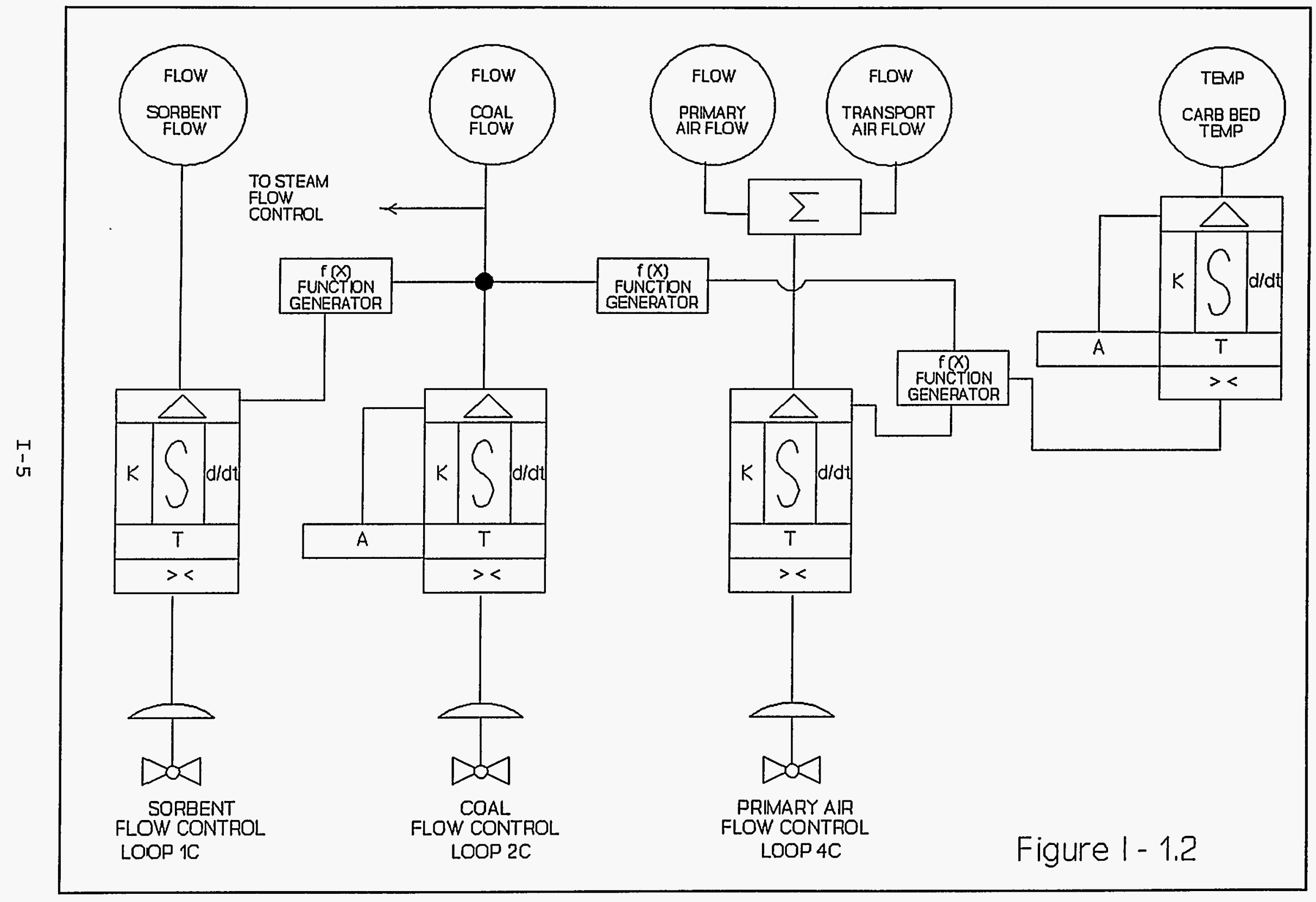




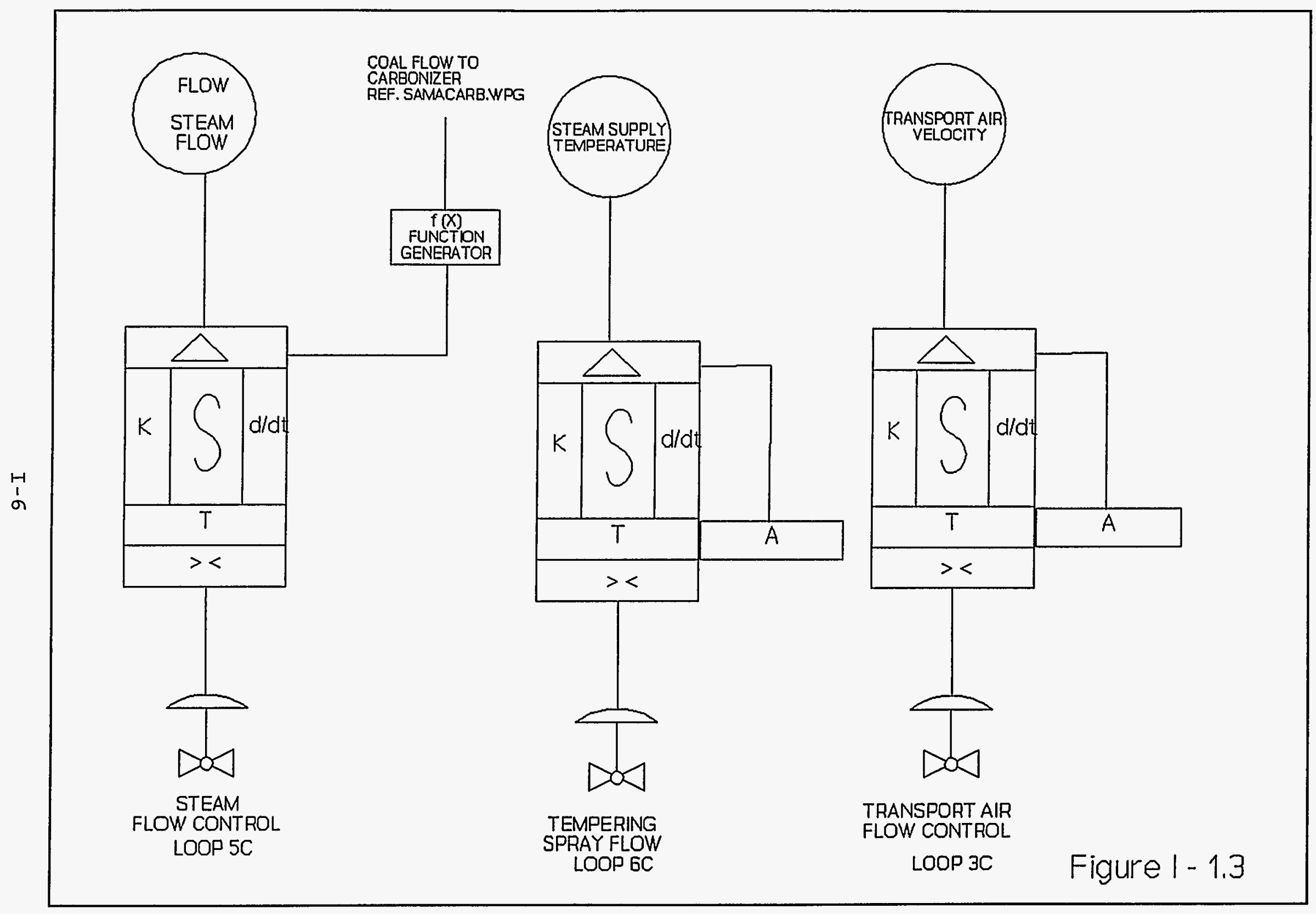




\section{CARBONIZER LOOP 1 SORBENT FLOW}

WSORB $=$ C16OUT

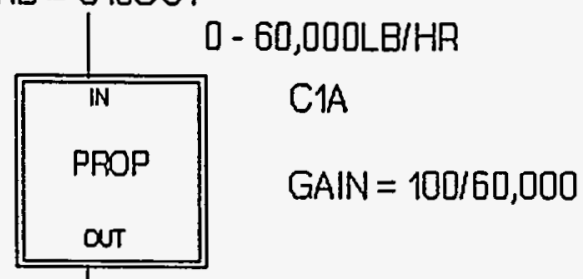

CIAOUT 0-100\%

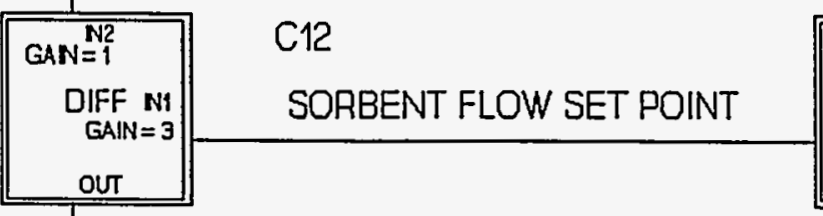

C12OUT SORBENT FLOW ERROR

$\mathrm{C} 13$

COAL FLOW WWZCOAL

0-180,000 LB/HR

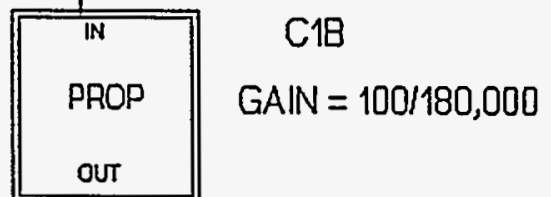

C18OUT 0-100\%

C11

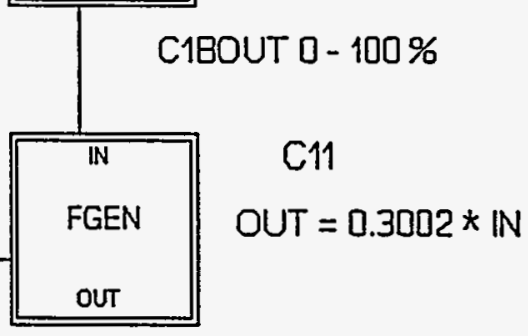

OUT

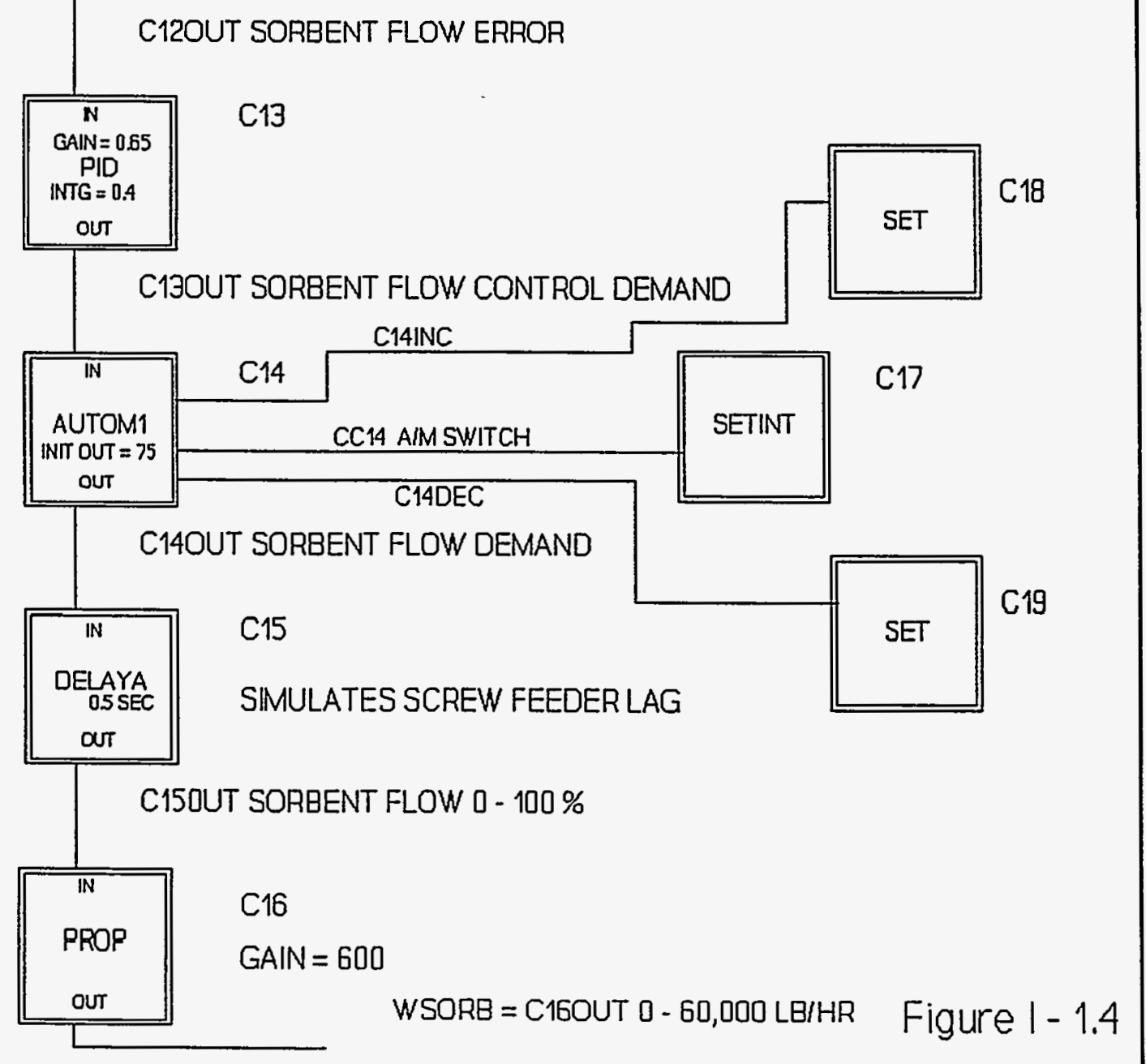




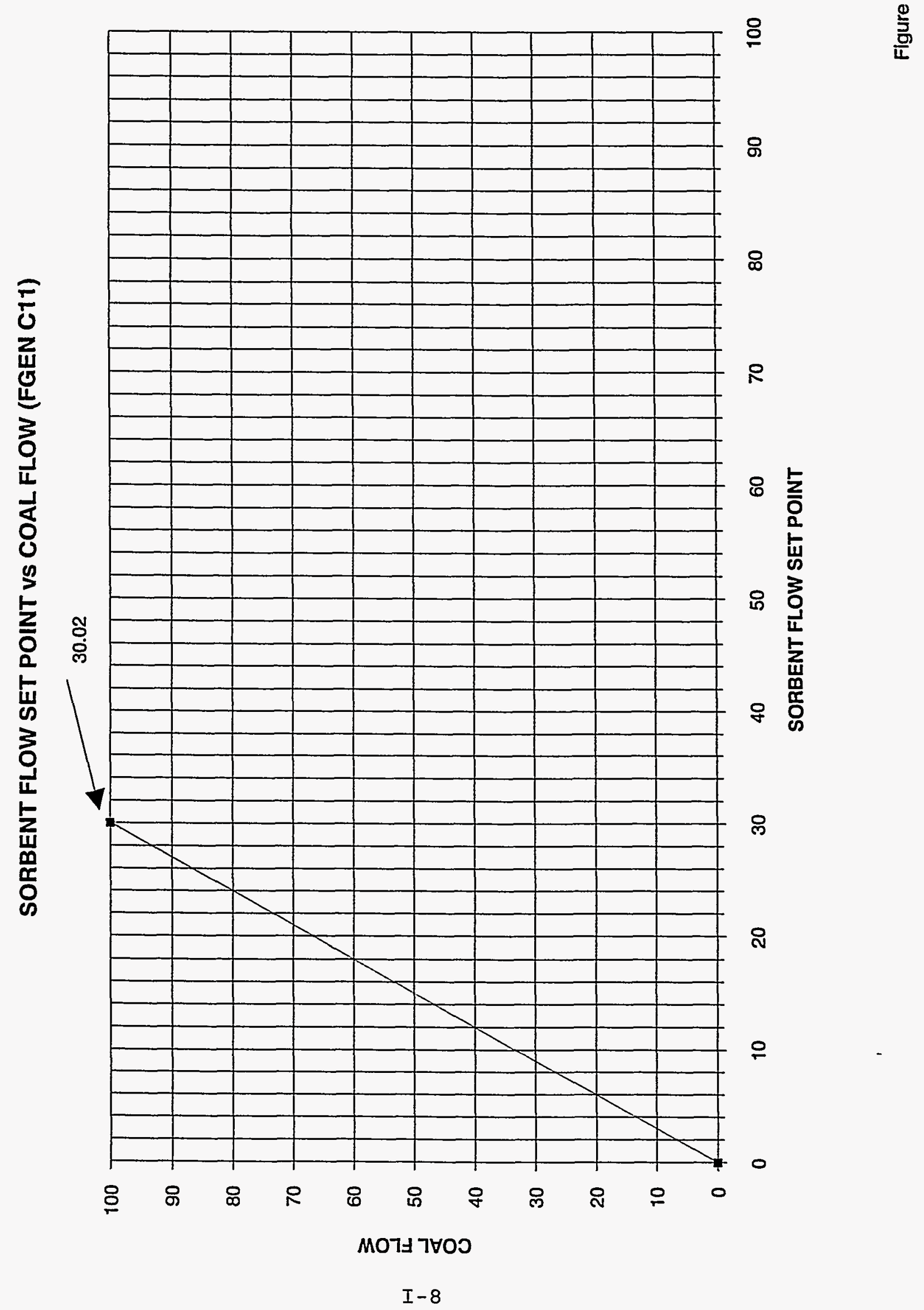




\begin{tabular}{|r|r|r|r|}
\hline COAL & \multicolumn{1}{|c|}{ COAL } & \multicolumn{1}{c|}{ COAL } & \\
\hline FLOW & FLOW & FLOW & $\%$ \\
\hline LB/HR & $\%$ OF DESIGN & \% OF SIGNAL & CHANGE \\
\hline 151,000 & 100 & $83.89 \%$ & \\
\hline 135,900 & 90 & $75.50 \%$ & $8 \%$ \\
\hline 120,800 & 80 & $67.11 \%$ & $8 \%$ \\
\hline 105,700 & 70 & $58.72 \%$ & $8 \%$ \\
\hline 90,600 & 60 & $50.33 \%$ & $8 \%$ \\
\hline 75,500 & 50 & $41.94 \%$ & $8 \%$ \\
\hline 60,400 & 40 & $33.56 \%$ & $8 \%$ \\
\hline 45,300 & 30 & $25.17 \%$ & $8 \%$ \\
\hline 30,200 & 20 & $16.78 \%$ & $8 \%$ \\
\hline 15,100 & 10 & $8.39 \%$ & $8 \%$ \\
\hline 0 & 0 & $0.00 \%$ & $8 \%$ \\
\hline
\end{tabular}




\section{CARBONIZER LOOP 2 COAL FLOW}

COAL FLOW $(W Z C O A L)=$ C1BOUT

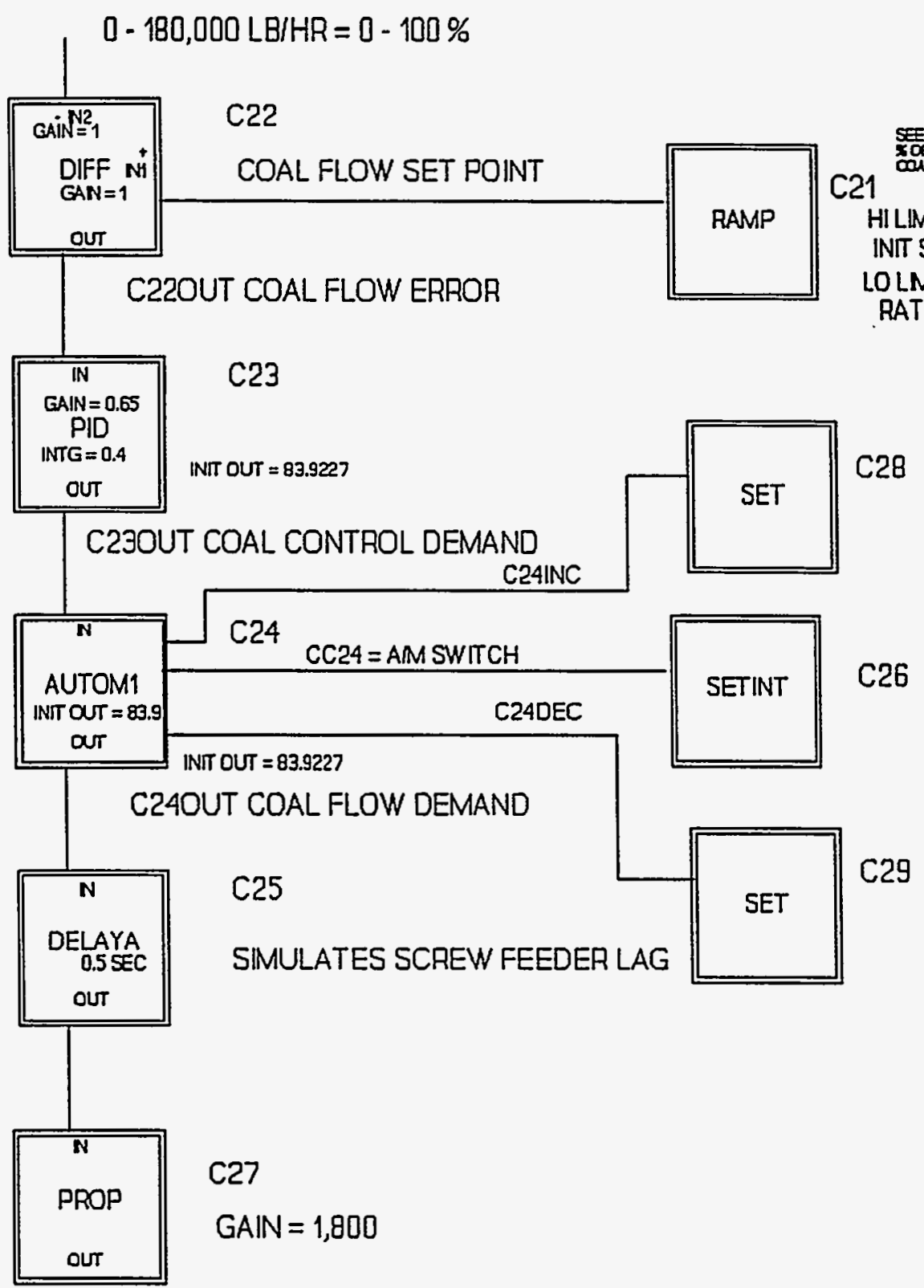

WZCOAL $=$ C27OUT $(0-180,000$ LB/HR $)$

Figure I- 1.6 


\section{CARBONIZER \\ LOOP 3 \\ TRANSPORT AIR FLOW}

TRANSPORT AIR FLOW VELOCITY (VELTG)

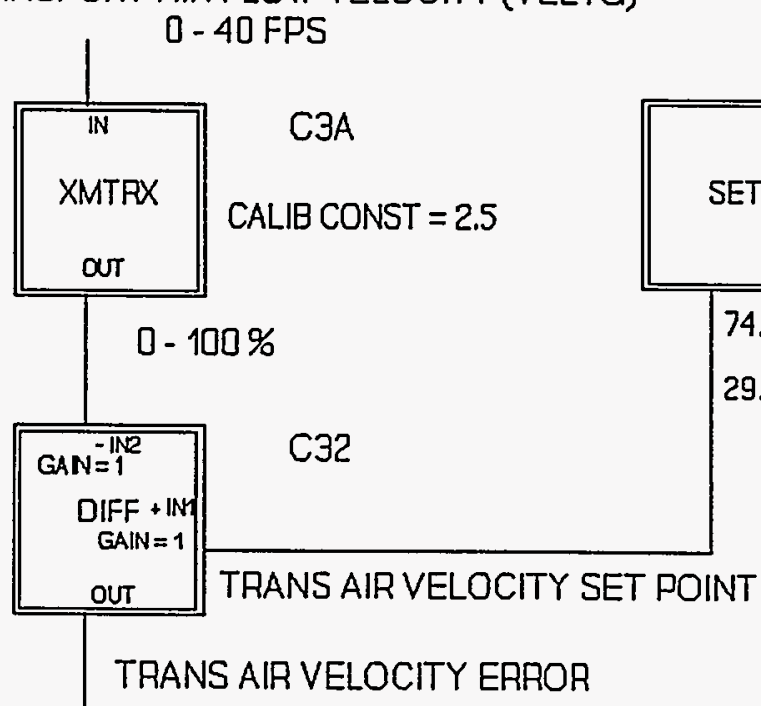

COAL FLOW (WZCOAL)
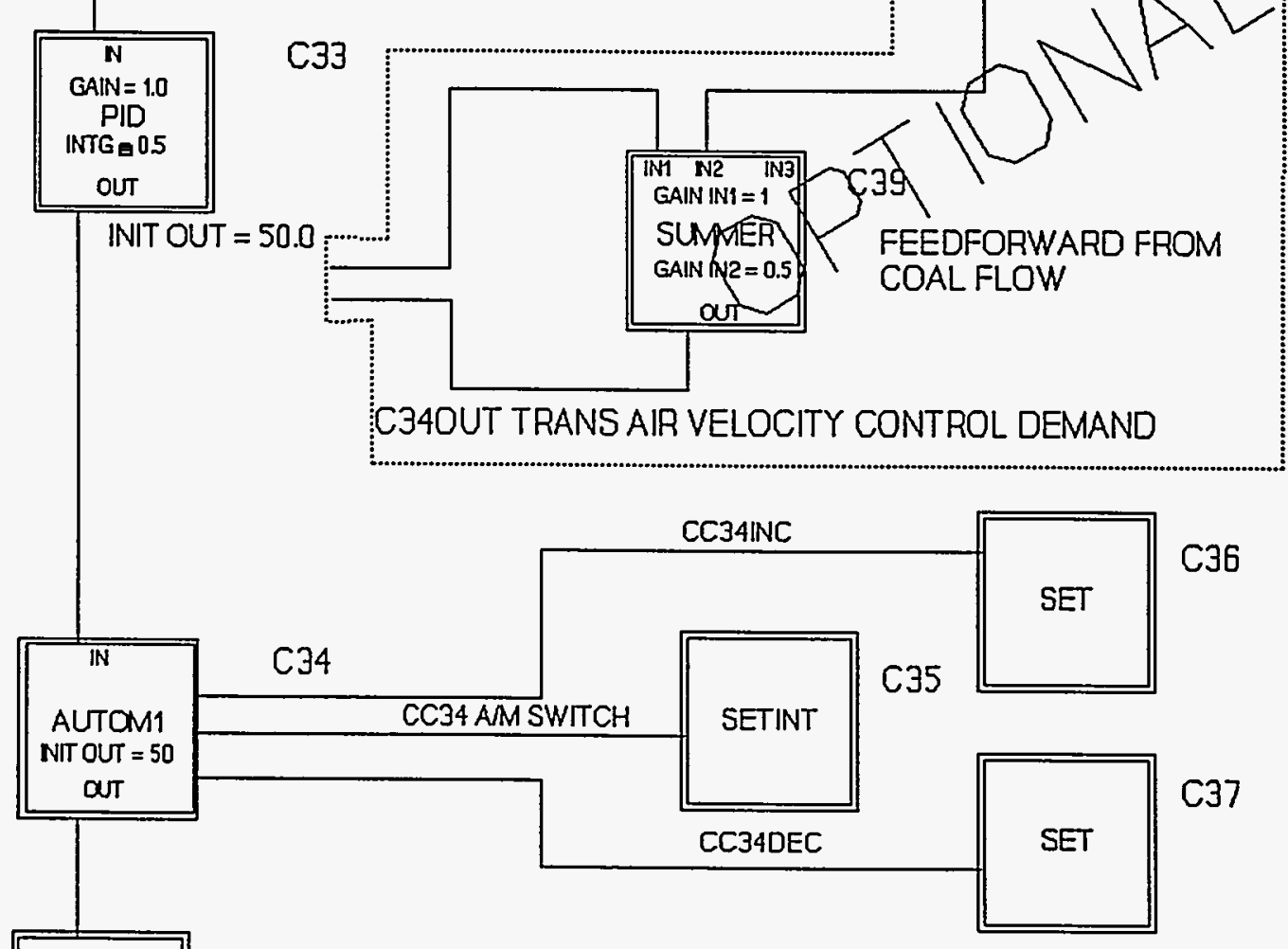

GV

CYCC2 TRANS AIR VELOCITY DEMAND

Figure 1-1.7 


\section{CARBONIZER \\ LOOP 4 \\ PRIMARY AIR FLOW}
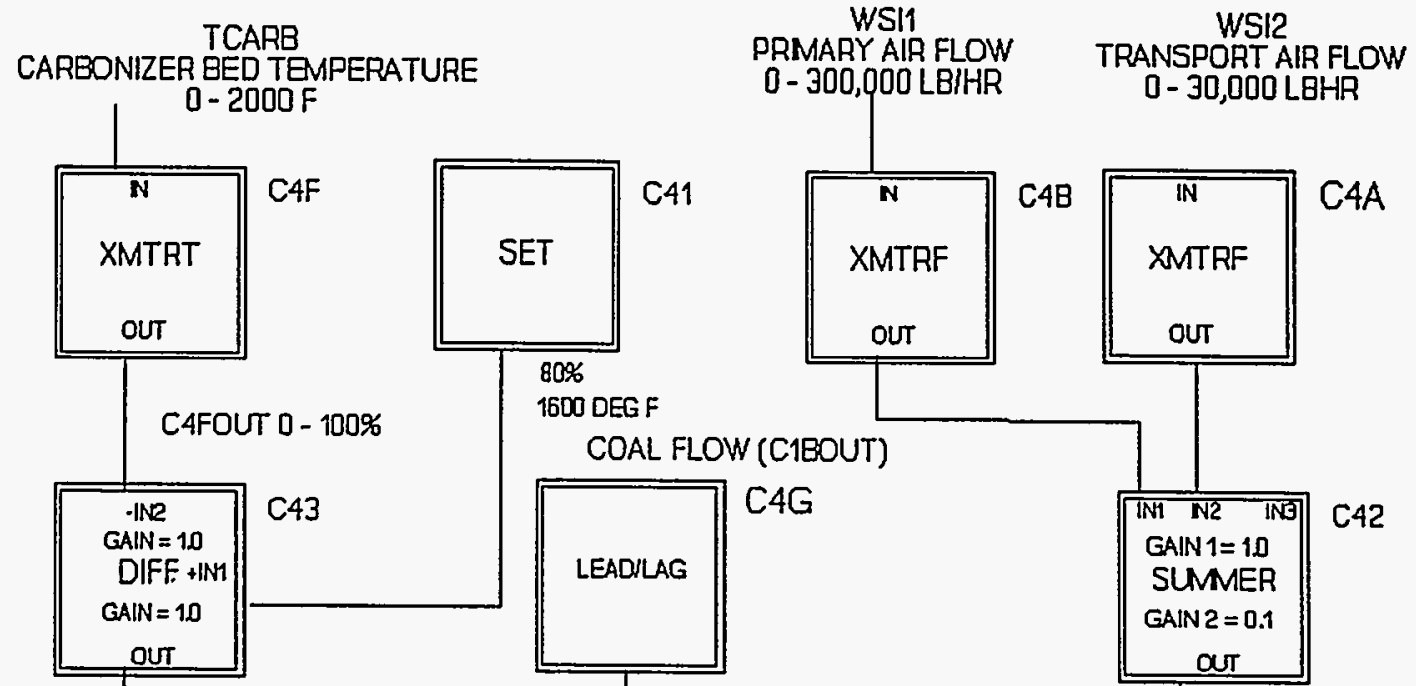

$0-300,000$ LBIHR

600 DEG $F$ COAL FLOW (C1BOUT)
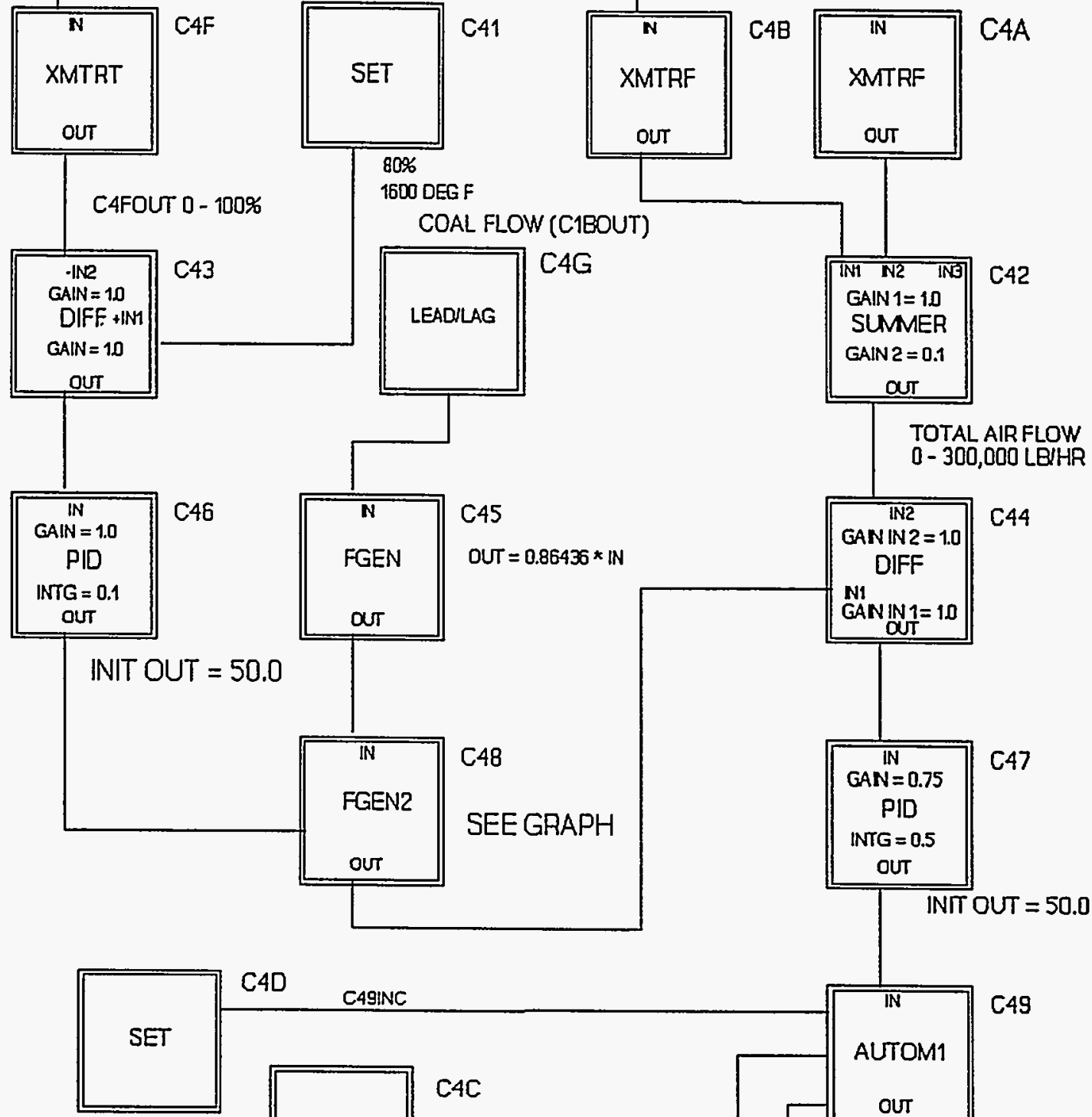

C4D
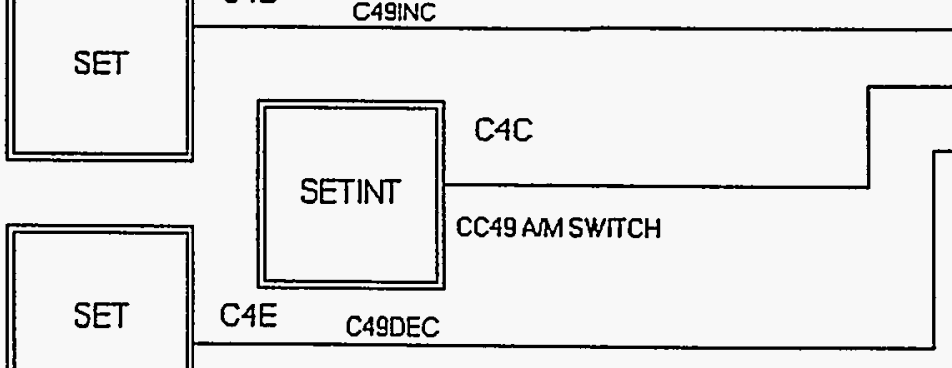

Figure | - 1.8 
COAL FLOW vs PRIMARY AIR FLOW SETPOINT (FGEN C45) LOOP 4C

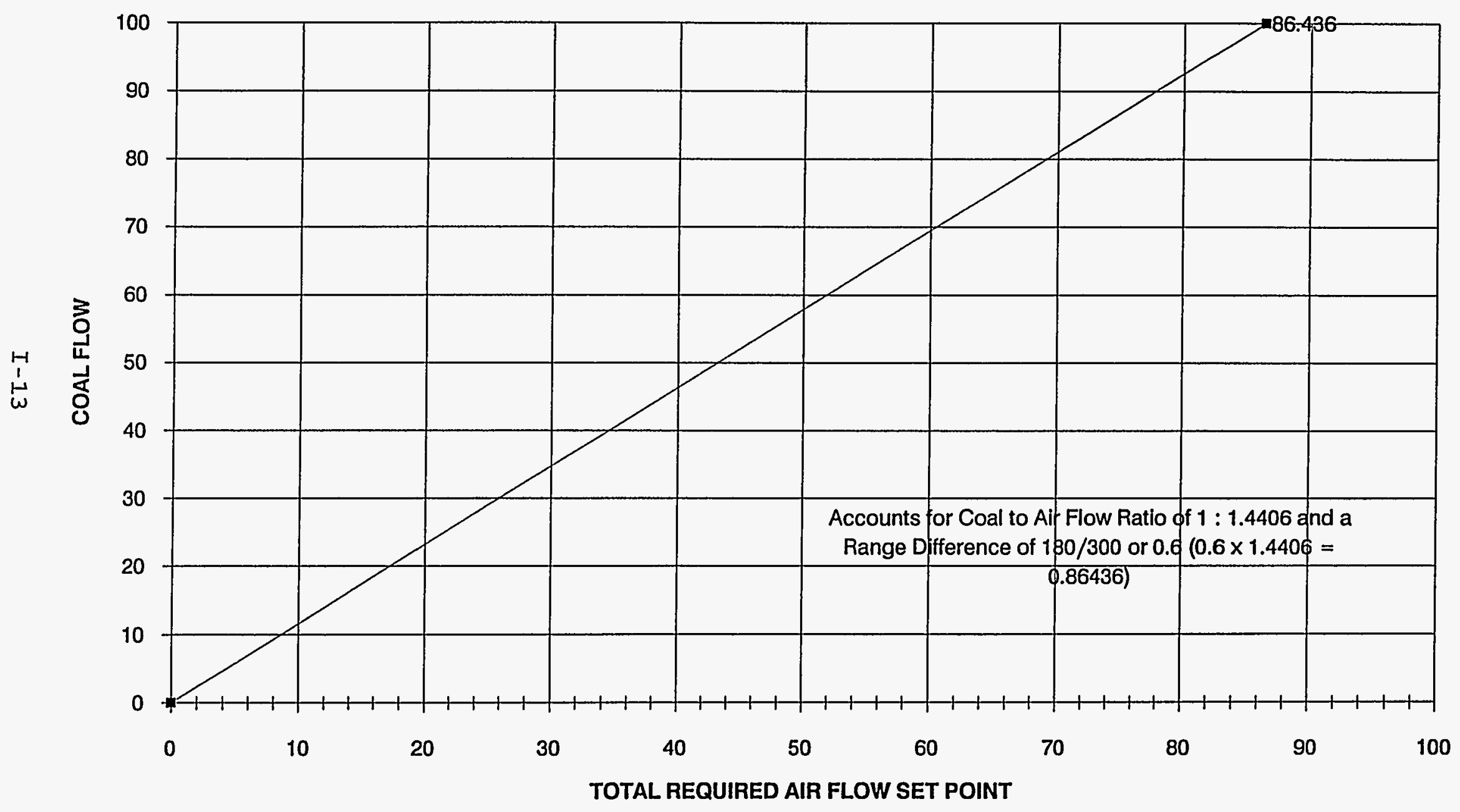


REQUIRED AIR FLOW C45OUT vs CORRECTED AIR FLOW (FGEN C48) LOOP 4C

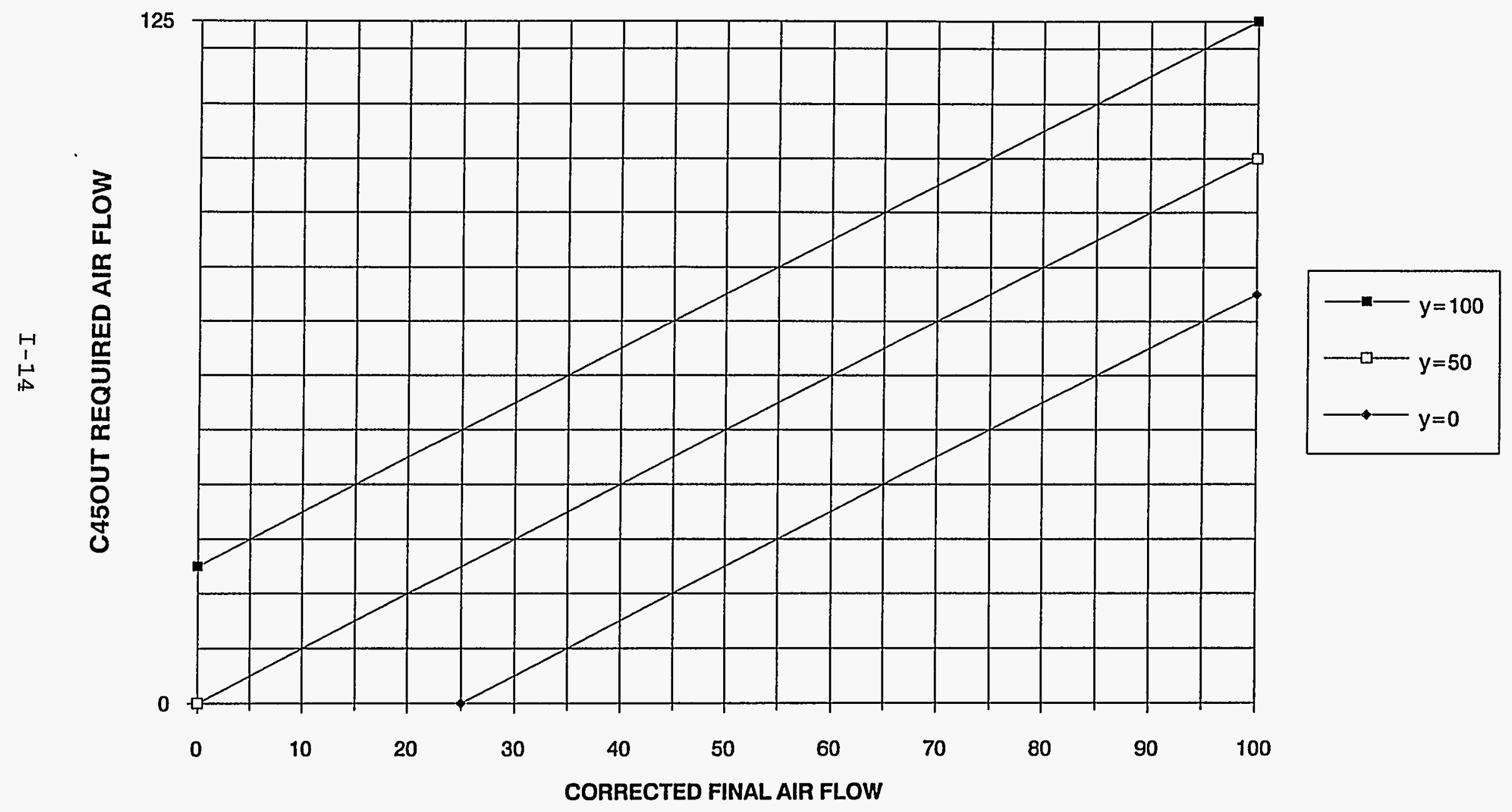




\section{CARBONIZER \\ LOOP 5 \\ STEAM FLOW}

\section{WSI3}

STEAM FLOW TO CARBONIZER

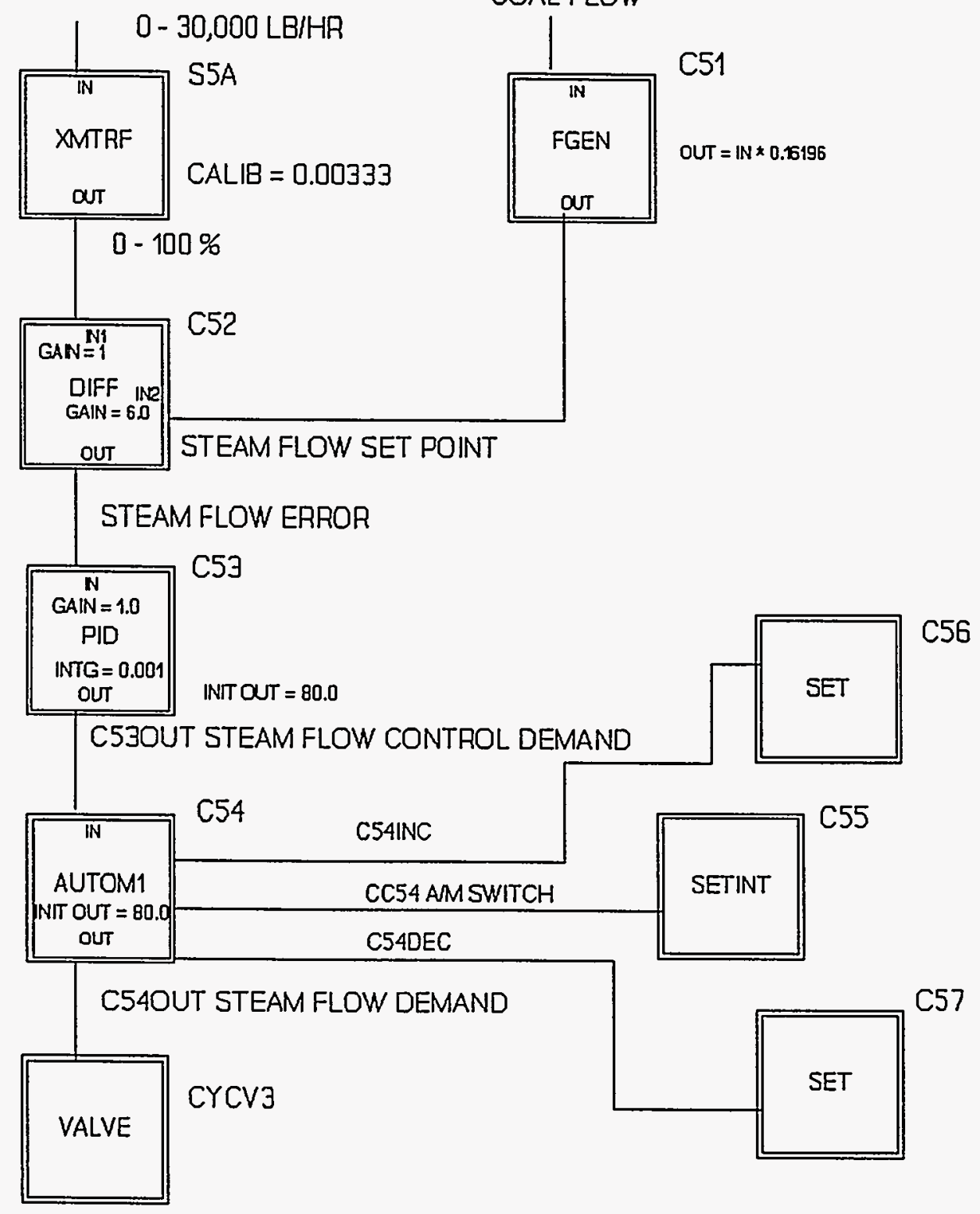

Figure | - 1.11 


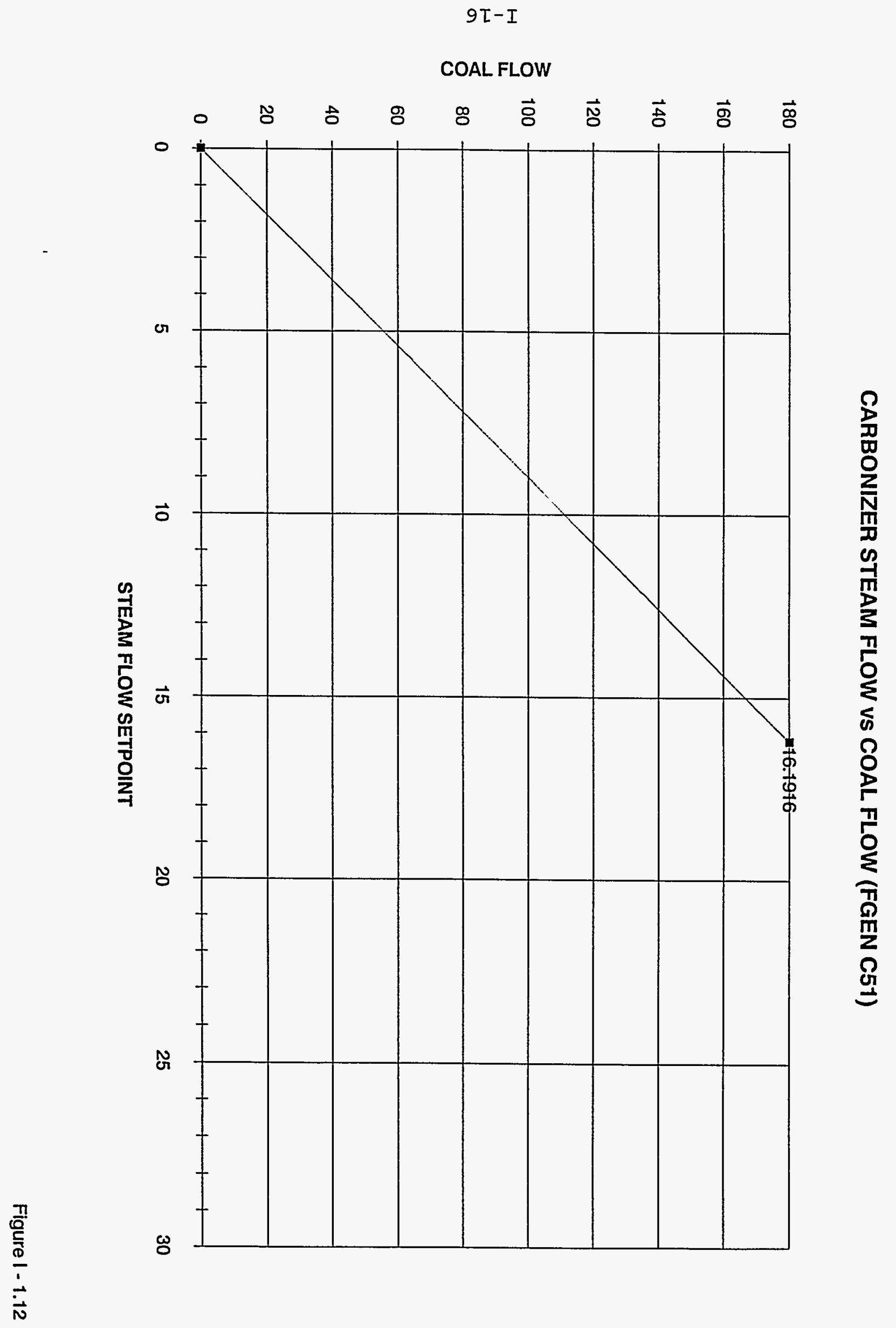




\section{CARBONIZER \\ LOOP 6 \\ CARBONIZER STEAM TEMPERATURE}

STEAM SUPPLY TEMPERATURE
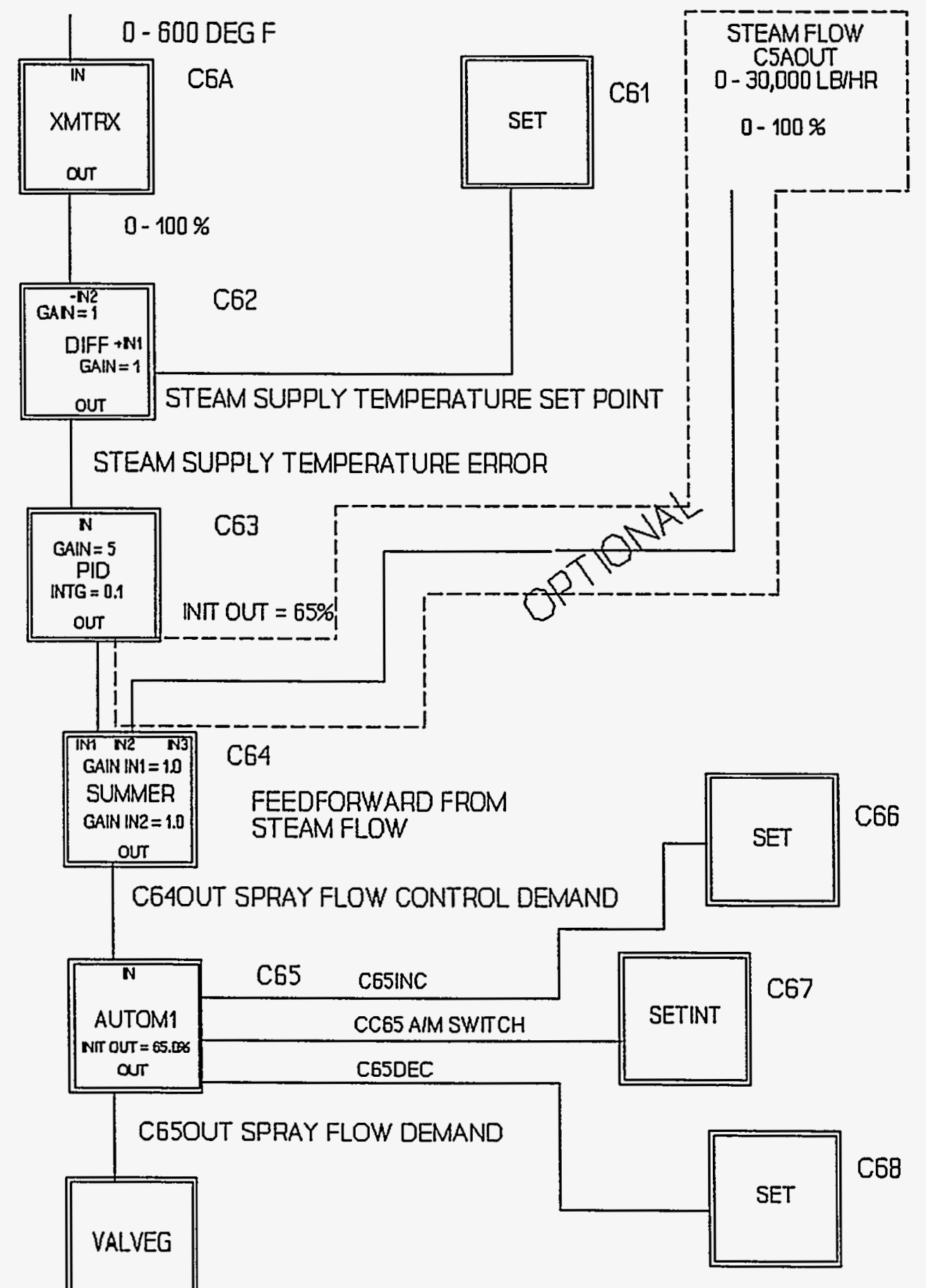

Figure 1-1.13 


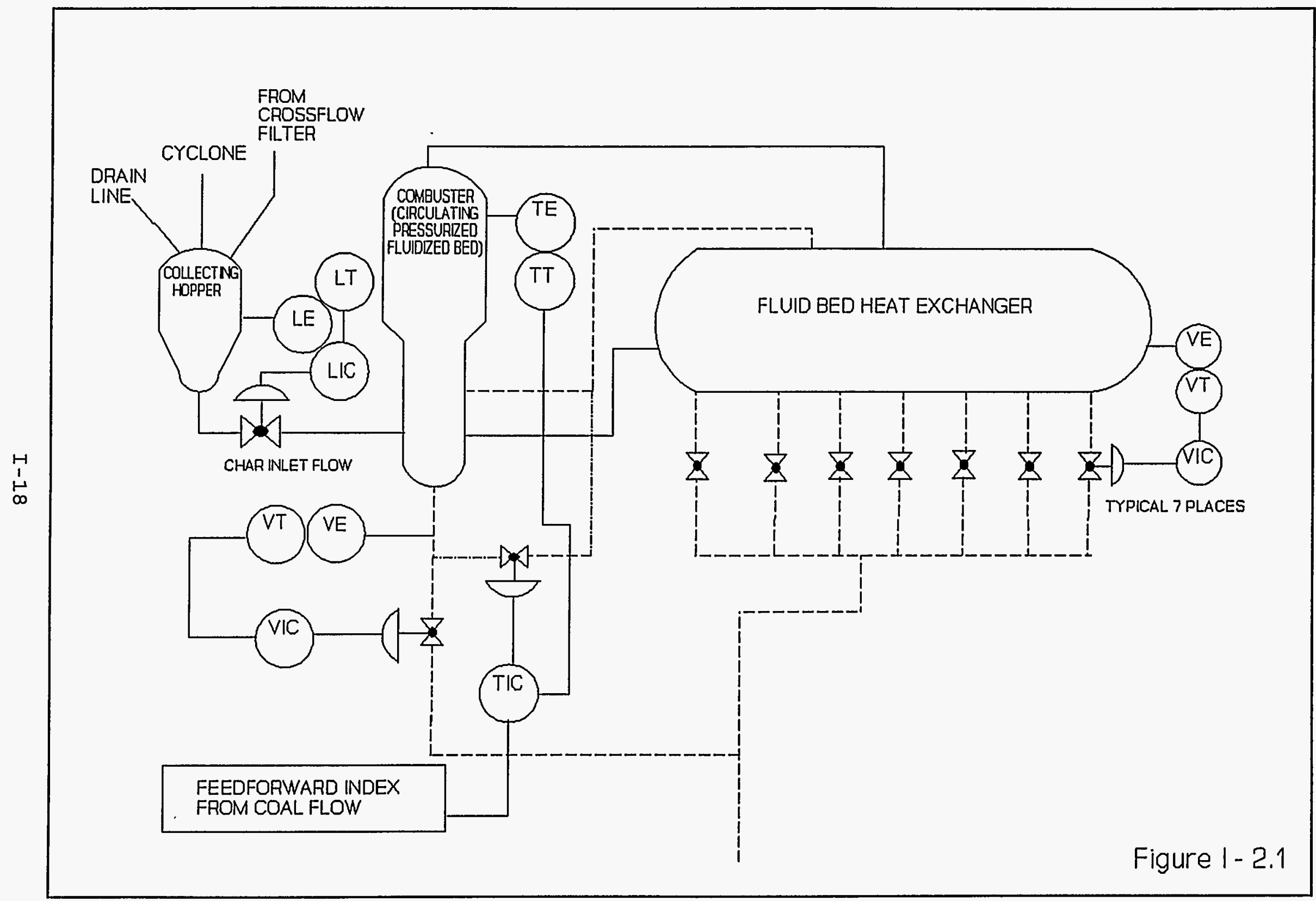




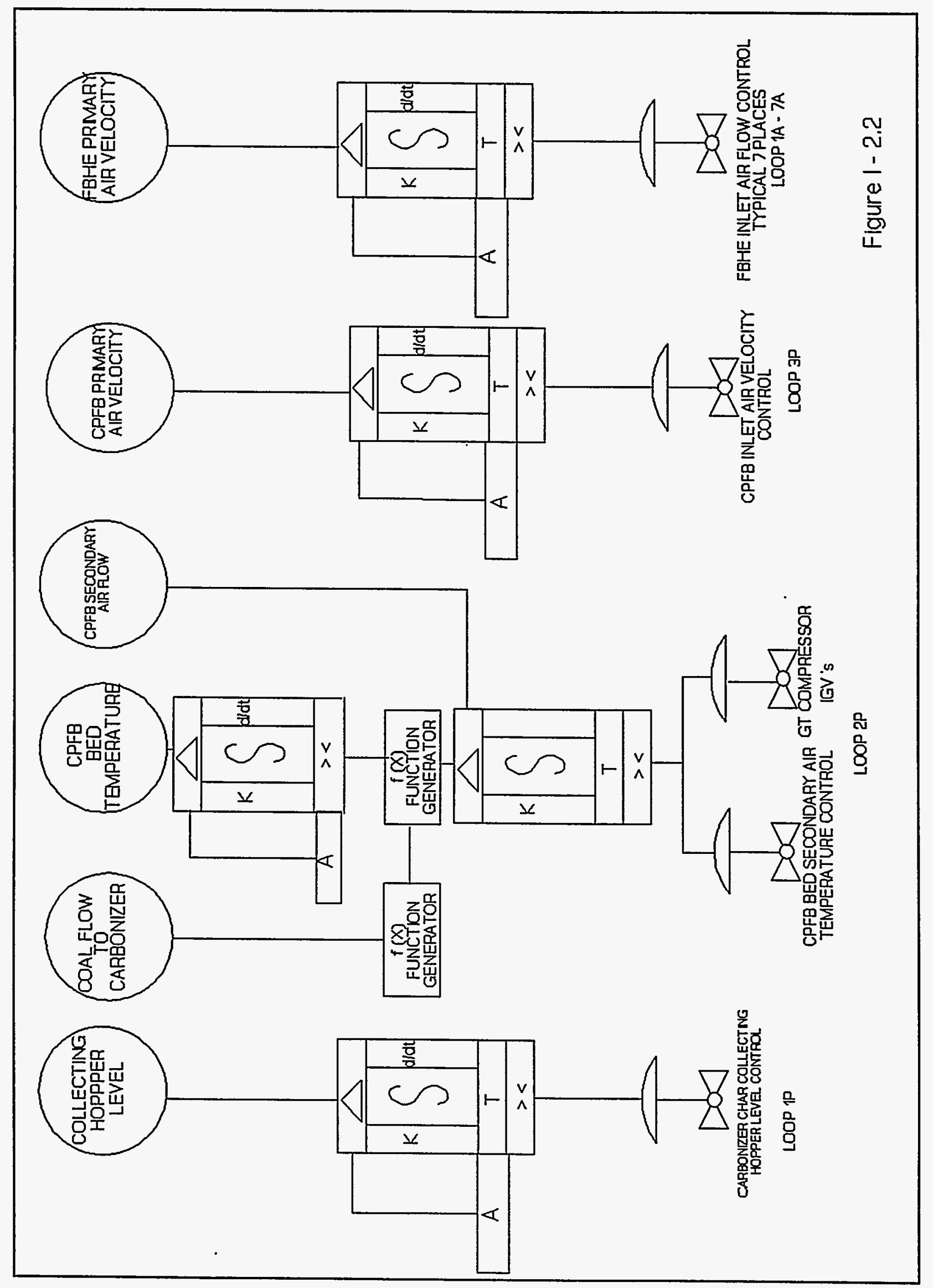




\section{PFB COMBUSTOR LOOP 1 \\ PFBC INLET FLOW \\ (COLLECTING HOPPER LEVEL)}

LCHOPR

CHAR COLLECTING HOPPER LEVEL

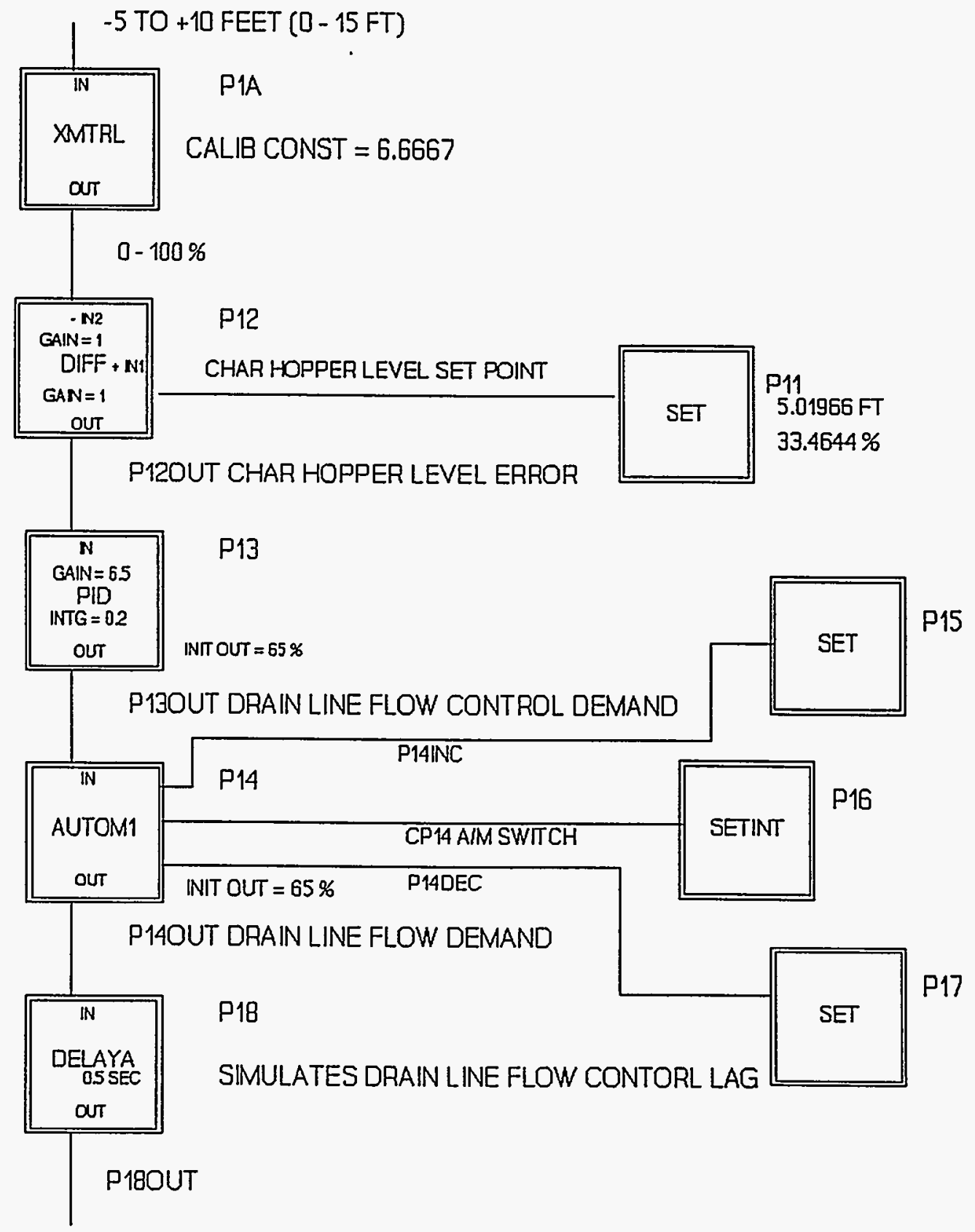

Figure I- 2.3 


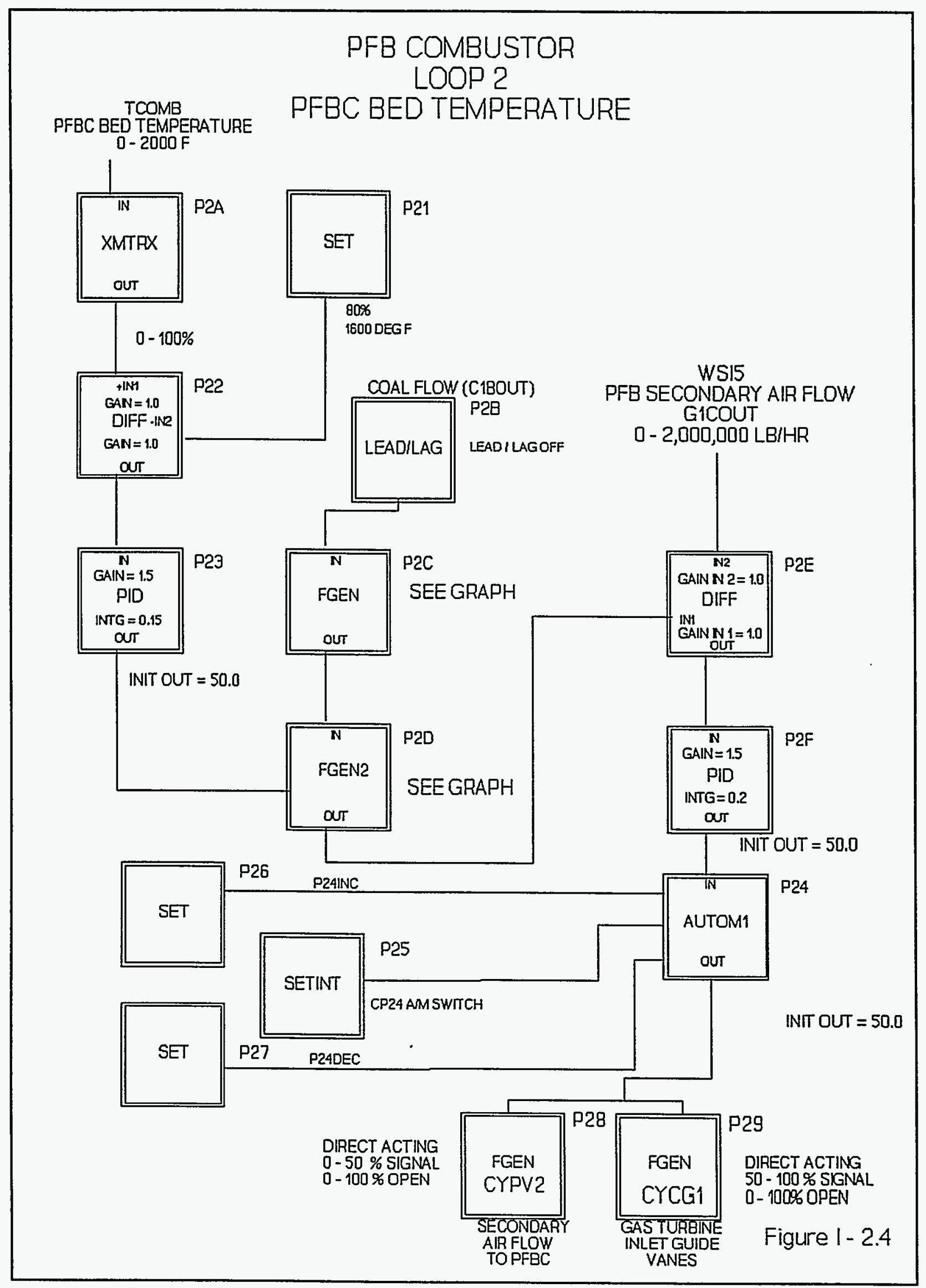


PFBC SECONDARY AIR FLOW vS COAL FLOW (FGEN P2C)

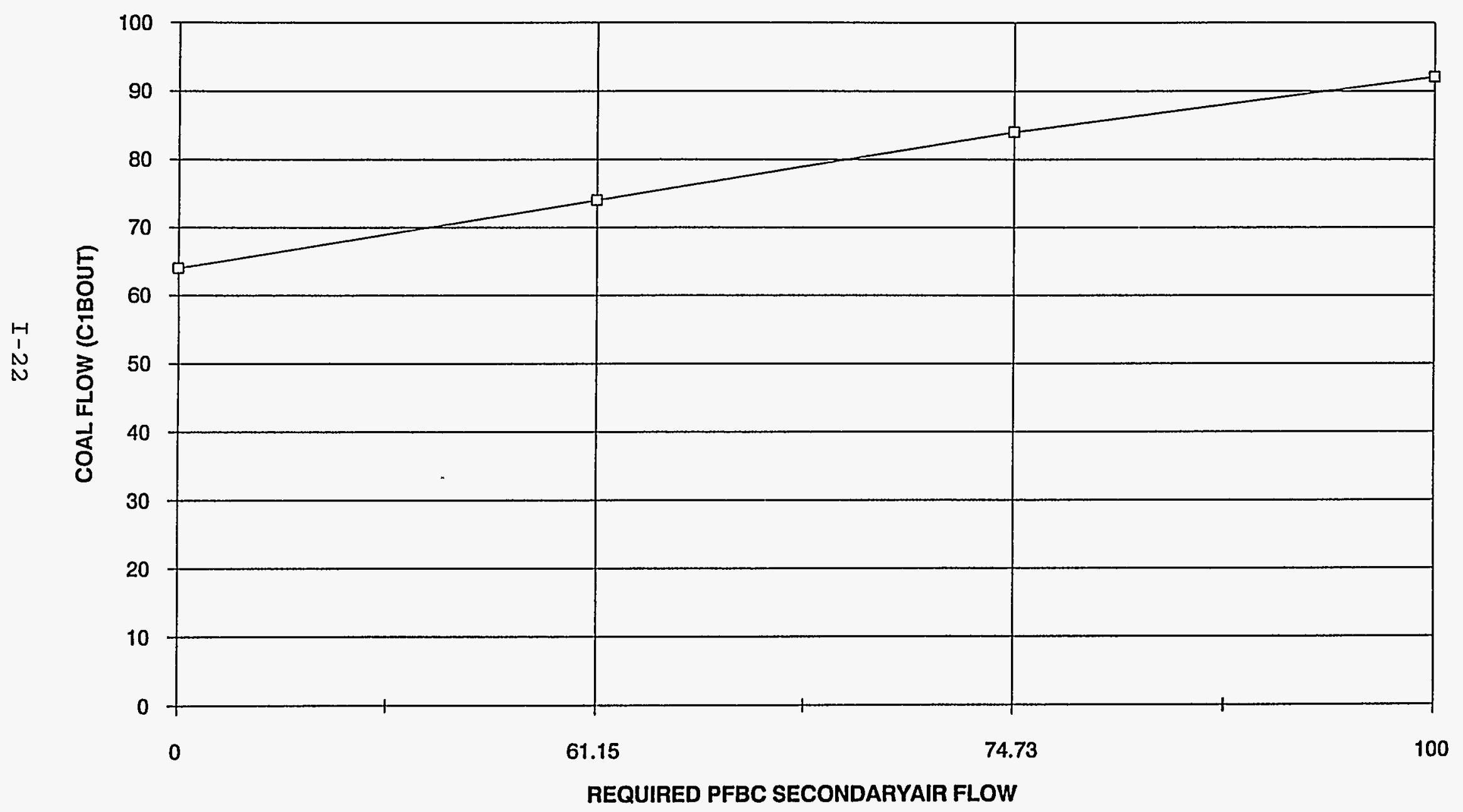

Figure I - 2.5 
REQUIRED AIR FLOW P2OUT vS CORRECTED AIR FLOW (FGEN P2D) LOOP 2P

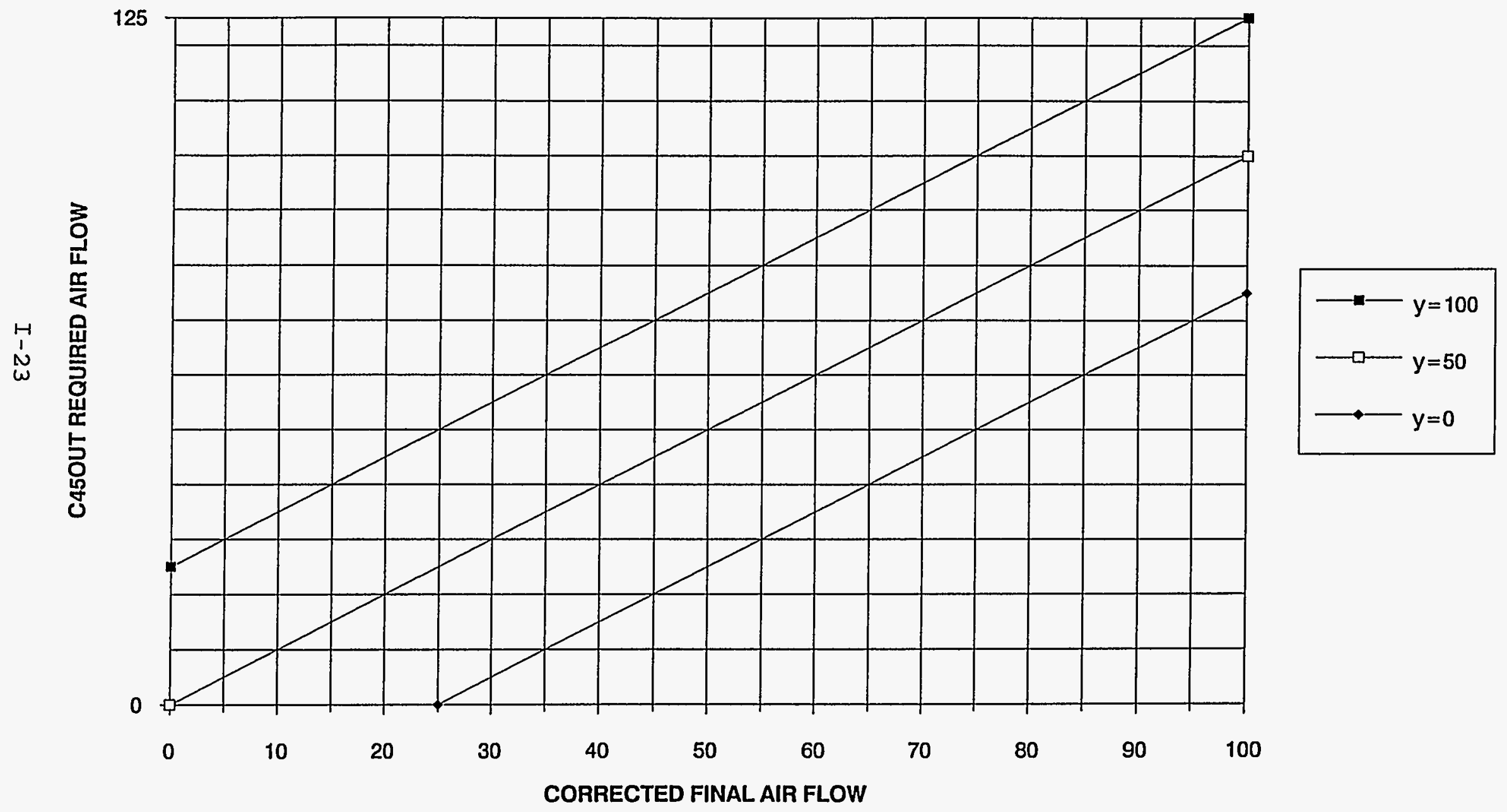




\section{PFB COMBUSTOR LOOP 3 \\ PFBC PRIMARY AIR FLOW}

VELCPZ

CPFBC PRIMAR AIR VELOCITY

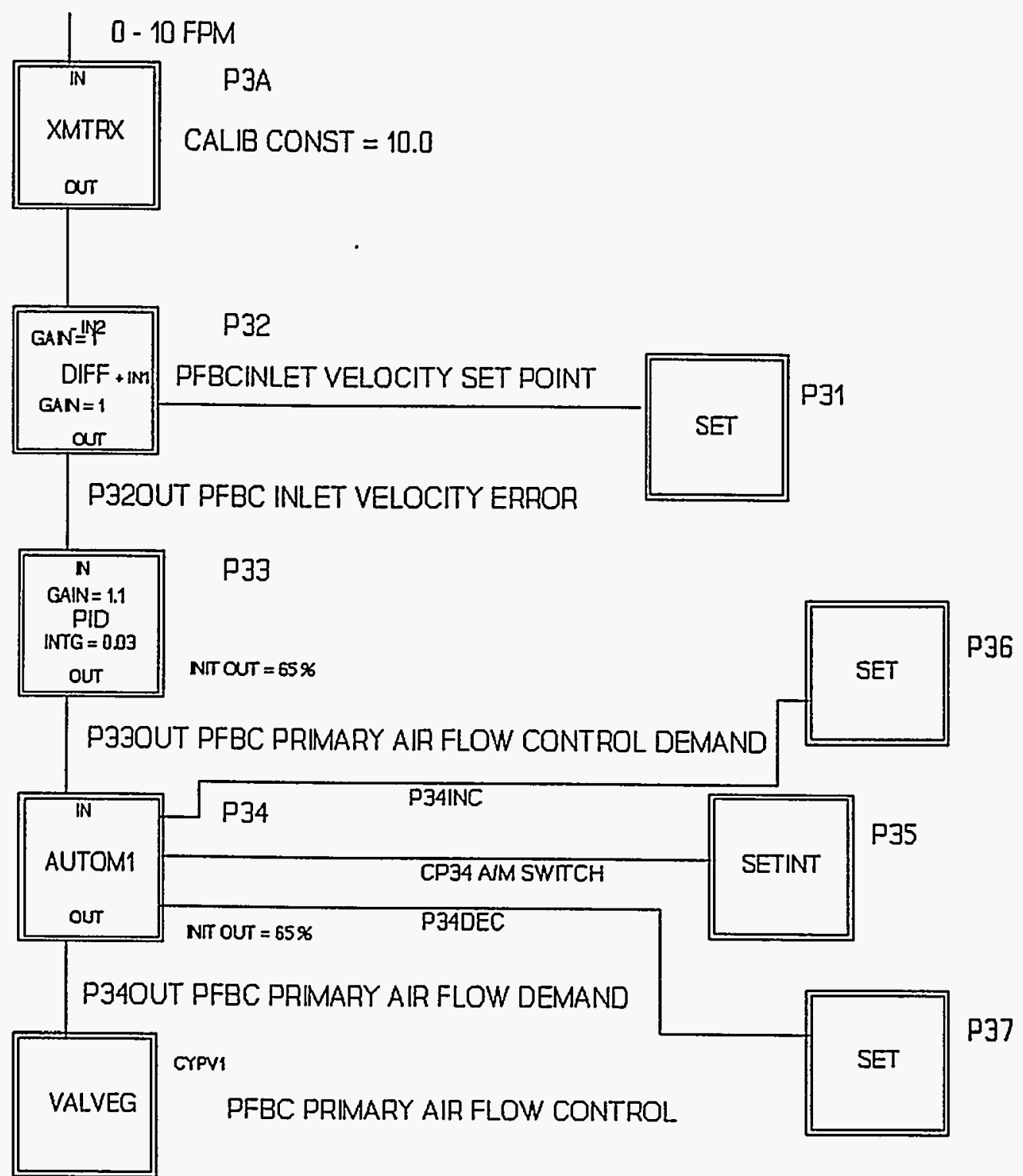

Figure 1- 2.7 
Air flow is controlled into each of the seven compartments of the FBHE by a PID controller to establish and maintain a superficial gas velocity regardless of load. Figure I-2.8 contains a block diagram showing the TRAX blocks used to generate the control loop, as well as turning parameters, set points, and transmitter ranges.

\section{I.3 PROCESS AIR HEADER PRESSURE CONTROL}

The GT compressor is a constant volume machine and therefore delivers a relatively constant mass flow of air. Power plant operation at less than 100 percent of design load requires less air than provided by the compressor. Air must be removed from the process air header to avoid developing a volume of high pressure at the compressor discharge. Air header pressure increases as the compressor continues to deliver the same air mass but less is removed due to decreased process requirements. The large pressure at the compressor discharge would decrease cycle efficiency because of increased compressor work.

Air mass, and indirectly pressure, in the air header is controlled to balance the available supply with the sum of the various demands. Total air flow to the carbonizer, which includes transport and primary air flow, along with the PFBC primary and secondary air flows and FBHE fluidizing air flows are summed to determine process air flow requirements. The summed value is then compared with a set point that represents total design air flow to develop a "surplus air flow" signal.

Figure I-3.1 contains a schematic showing the instrumentation and control elements associated with process air header pressure control. Figure I-3.2 contains the SAMA diagram for the control loop. As shown in Figure I-3.2, the "surplus air flow" signal controls the bypass valve to the topping combustor. If conditions warrant reductions in any process air requirements, a surplus air supply signal is reached and the bypass valve is opened.

Figures I-3.3 and I-3.4 contain block diagrams illustrating the TRAX modules implemented in constructing the control loop discussed in the previous paragraph. Figures I-3.3 and I-3.4 display the tuning parameters, set points, and transmitter ranges for each module. The PID controller, TRAX block G13, modulates valve GV1 after passing through auto-manual station G14 (Valve GV1 can be found in Figure A-3.1).

\section{I.4 STEAM GENERATOR DRUM LEVEL CONTROLS}

The high pressure steam drum levels on both the HRSG and FBHE are maintained by a three element, PID level controller. Steam flow out and feedwater flow in are maintained in balance with a trim to maintain water level at a fixed set point. The three element level controller is available as a package in the TRAX standard module library. Therefore, it does not have to be built by configuring individual TRAX blocks. 


\section{AIR GAS SYSTEM LOOP 1 THRU 7 \\ FBHE FLUIDIZING AIR FLOW}

VFBCNX

FBHE FLUIDIZING AIR VELOCITY
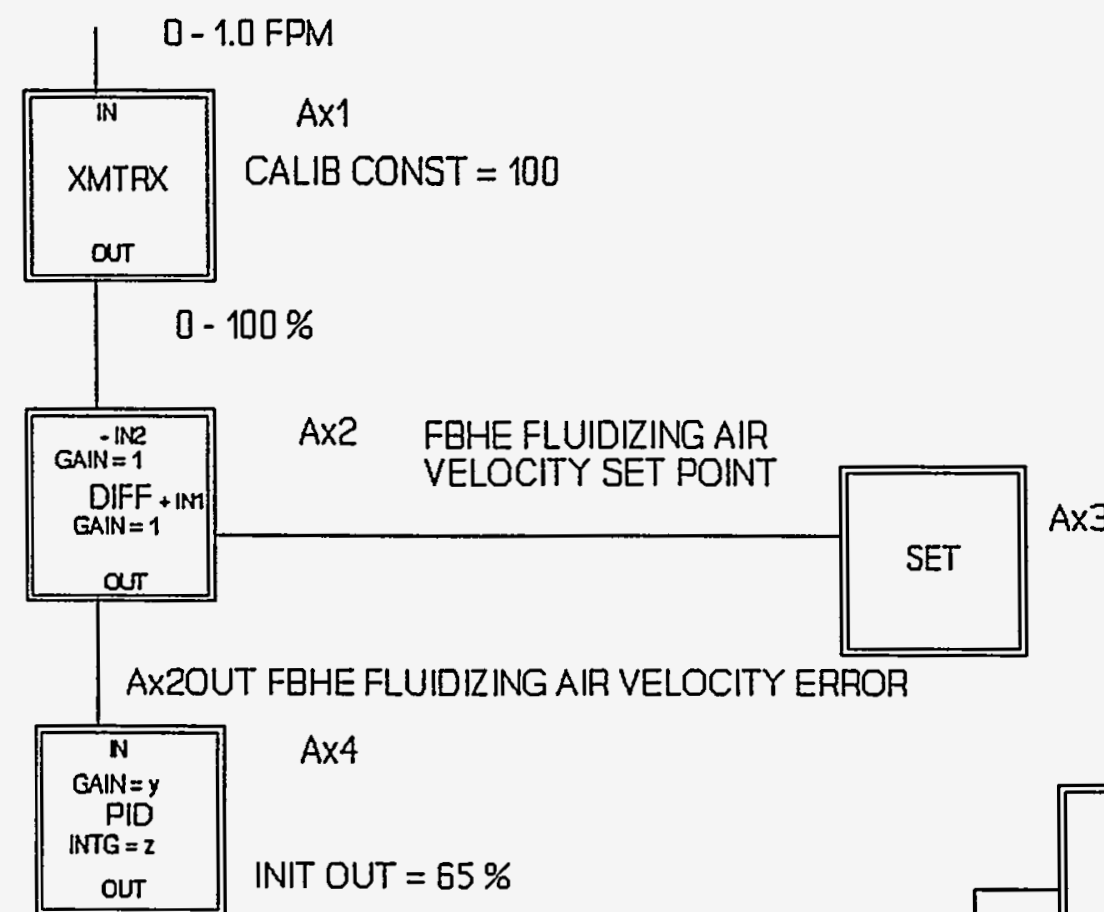

Ax4

AX4OUT FBBHE FLUIDIZING AIR CONTROL DEMAND INIT OUT $=65 \%$

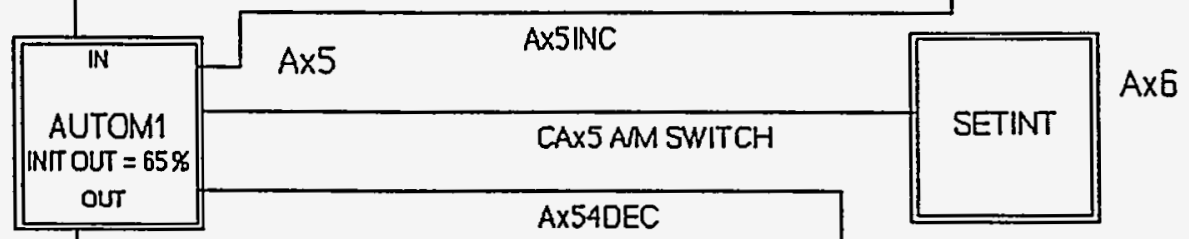

AX5OUT FBHE FLUIDIZING AIR DEMAND

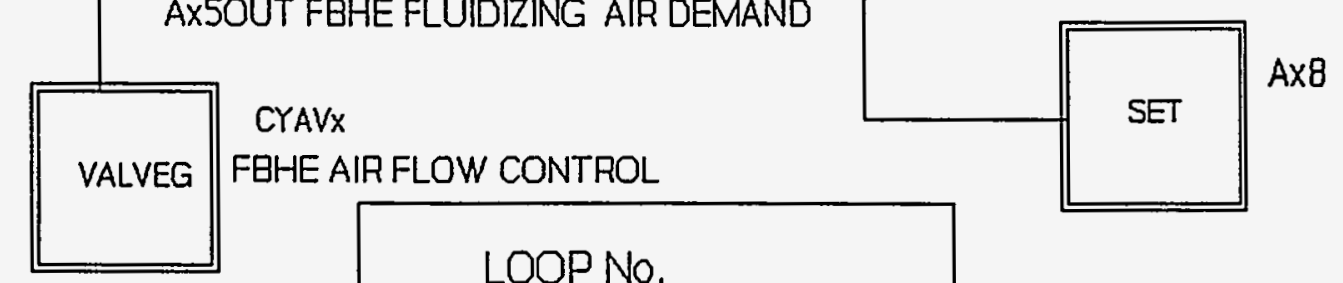

LOOP NO.

\begin{tabular}{|c|c|c|c|}
\hline$x$ & $y$ & $z$ & SET POINT \\
\hline 1 & 1.5 & 0.2 & 54.027 \\
\hline 2 & 3.0 & 0.3 & 54.119 \\
\hline 3 & 1.5 & 0.2 & 53.782 \\
\hline 4 & 3.0 & 0.3 & 53.773 \\
\hline 5 & 1.5 & 0.2 & 54.121 \\
\hline 6 & 1.5 & 0.2 & 53.876 \\
\hline 7 & 1.5 & 0.2 & 53.795 \\
\hline & & & \\
\hline
\end{tabular}

Figure I- 2.8 


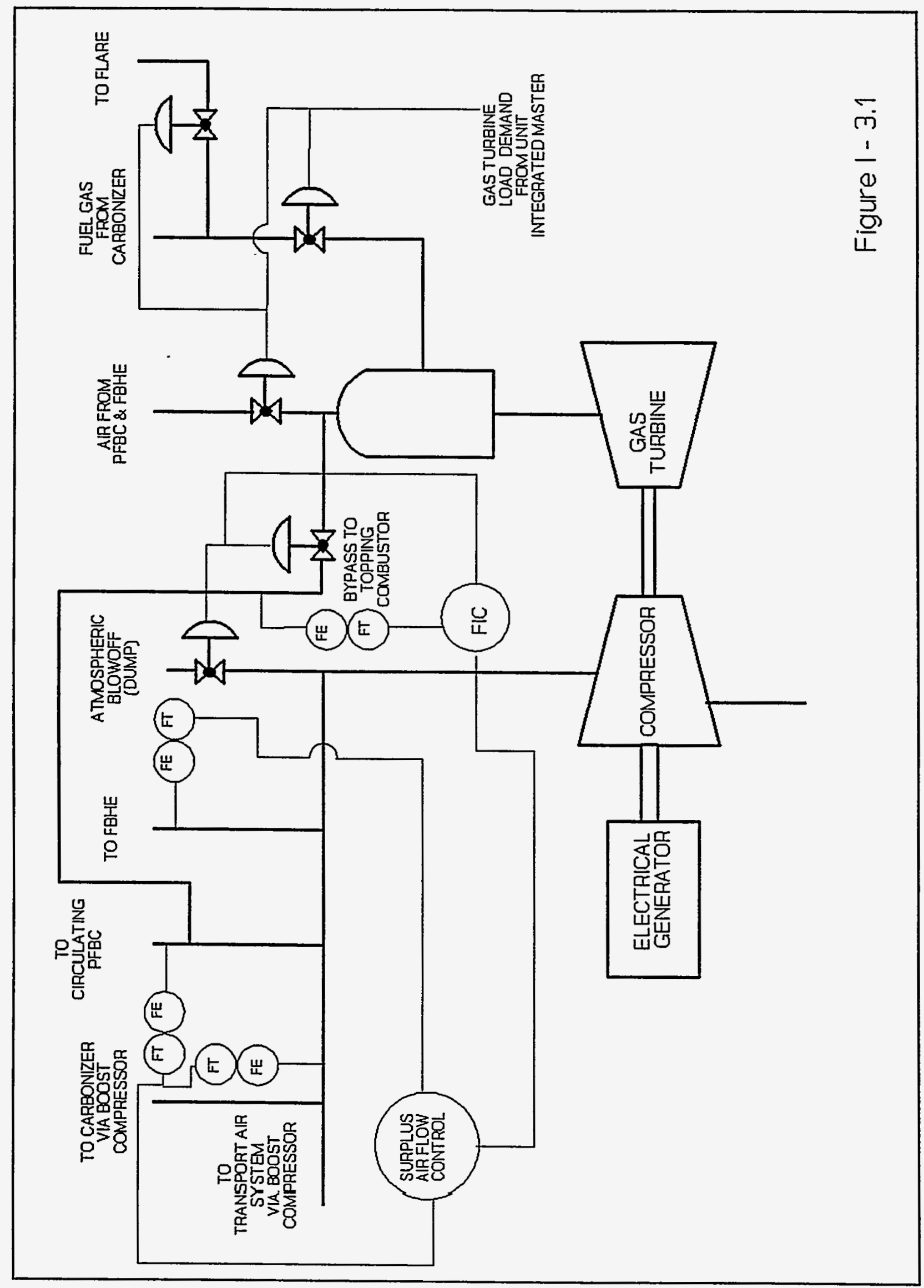

I-27 


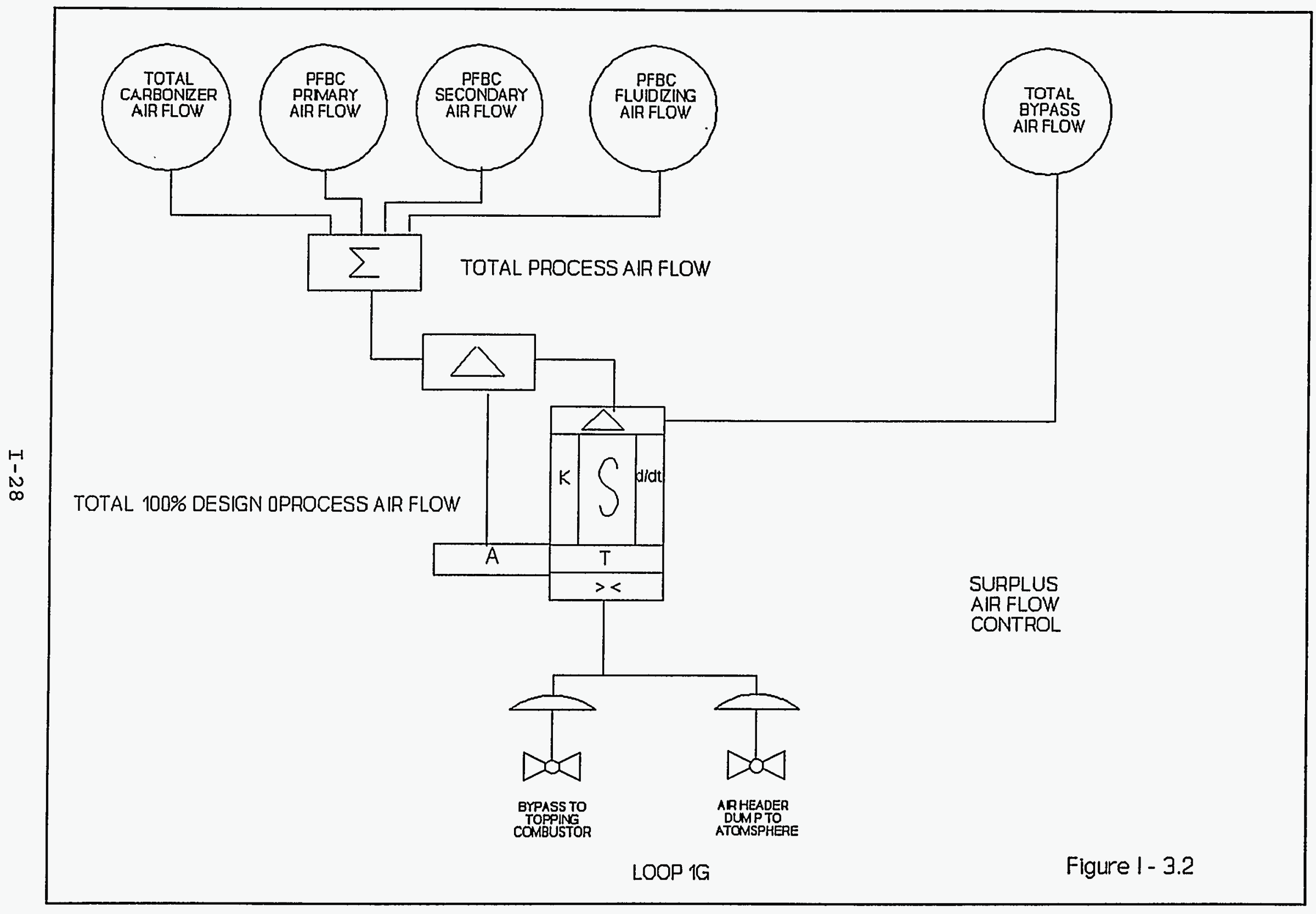




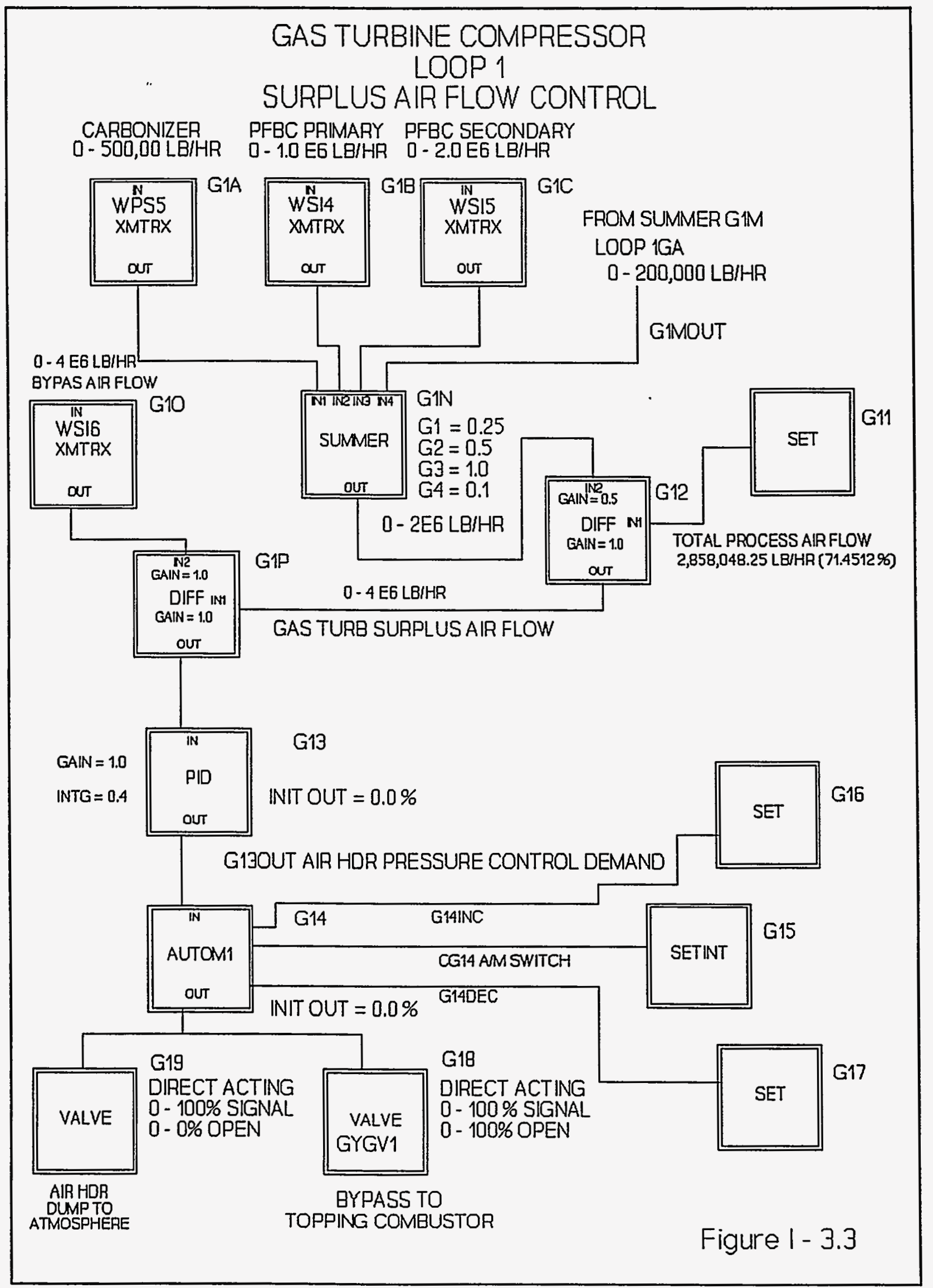




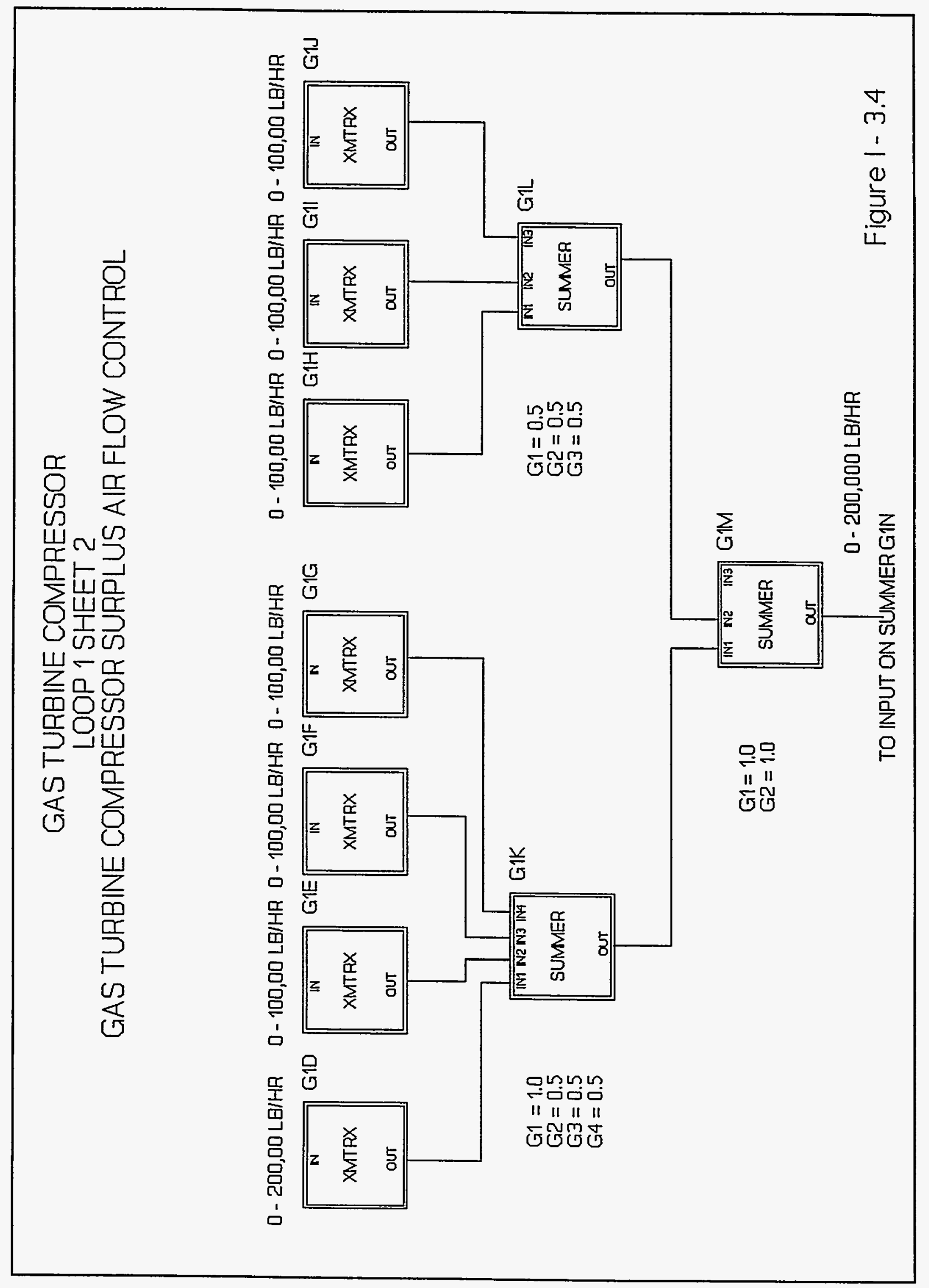


Figure I-4.1 contains a schematic showing the instrumentation and control modules associated with high pressure steam drum level control. Two duplicate control loops are represented in the drawing and Figure I-4.2 contains the SAMA diagram for the control loop. Figures I-4.3 and I-4.4 contain block diagrams illustrating the TRAX modules implemented in constructing the individual control loops for the HRSG and FBHE steam drums respectively.

Figures I-4.3 and I-4.4 contain the tuning parameters, set points, and transmitter ranges for each module. The three element level controller utilized for HRSG steam drum level control manipulates valve HV1. The controller for the FBHE steam drum manipulates valve PV3. These valves can be found in Figures A-3.10 and A-3.11 respectively.

\section{I.5 FBHE STEAM TEMPERATURE CONTROL}

In the present design, the FBHE superheater and reheater are sized such that design final steam temperature is attained at 100 percent of design load. This obviates the need for spray attemperation. For changes in plant load, final steam temperatures are maintained by manipulation of the solids flow in the FBHE by means of a solid diverter valve.

Figure I-5.1 contains a schematic showing the instrumentation and control modules associated with the FBHE steam temperature control. Figure I-5.2 contains the SAMA diagram for the control loop. The solids diverter for the superheat and reheat pass is regulated by a PID controller to maintain a desired final superheat and reheat steam temperature of $1000^{\circ} \mathrm{F}$. Figures I-5.3 and I-5.4 contain block diagrams illustrating the TRAX modules implemented in constructing the control loop. Also shown in Figures I-5.3 and I-5.4 are the tuning parameters, set points, and transmitter ranges for each module.

Steam temperature spray attemperation valves and the necessary control logic are provided in the model but the control demand signal is not connected to any hardware at this time. Figures I-5.5 and I-5.6 contain schematics of the instrumentation and controls associated with the superheat and reheat spray attemperators. Figures I-5.7 and I-5.8 contain the SAMA diagrams corresponding to the spray attemperators control loop. Figures I-5.9 and I-5.10 contain block diagrams illustrating the TRAX modules implemented in constructing the control loops. Figures I-5.9 and I-5.10 also contain the tuning parameters, set points, and transmitter ranges for each module. 


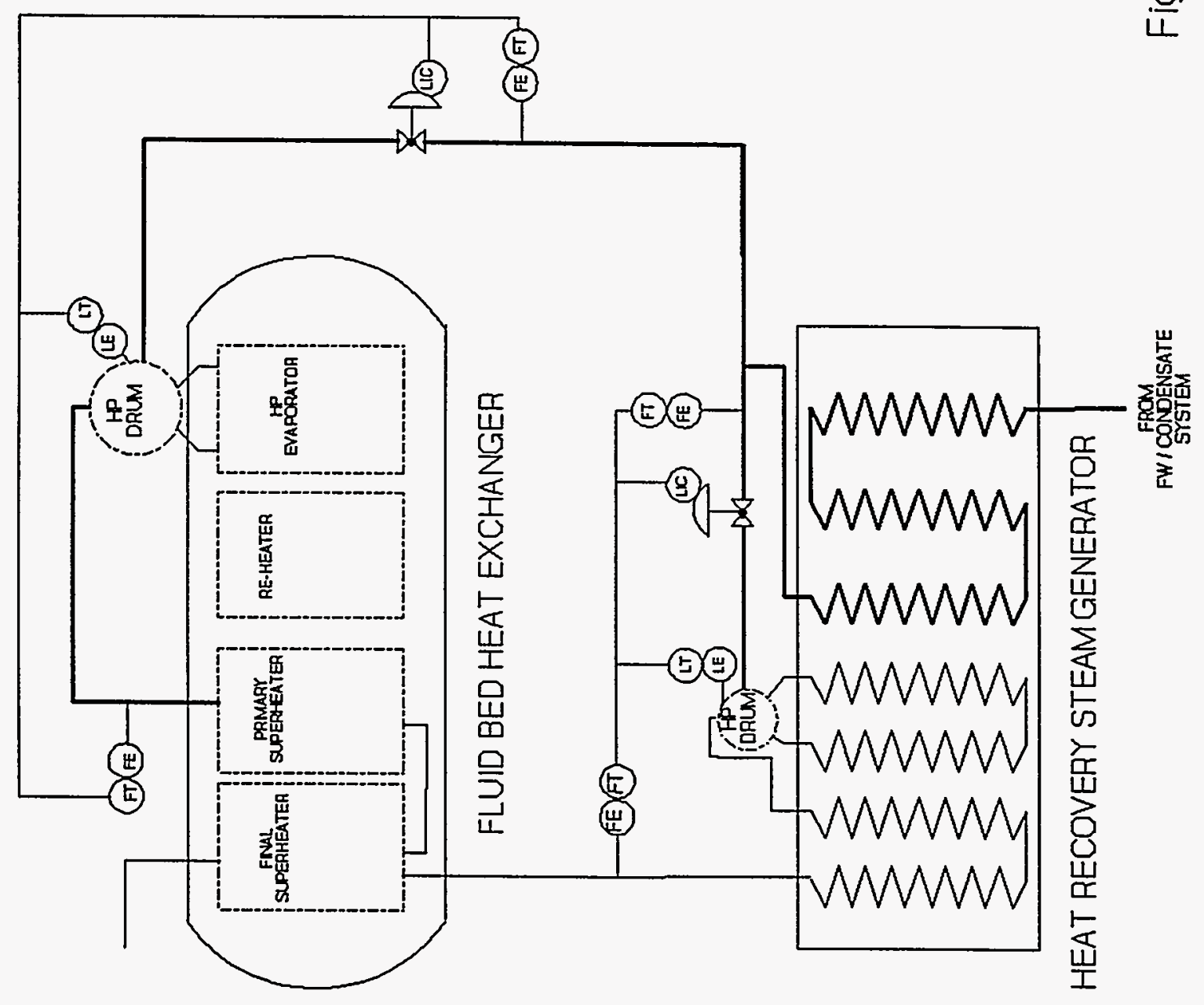




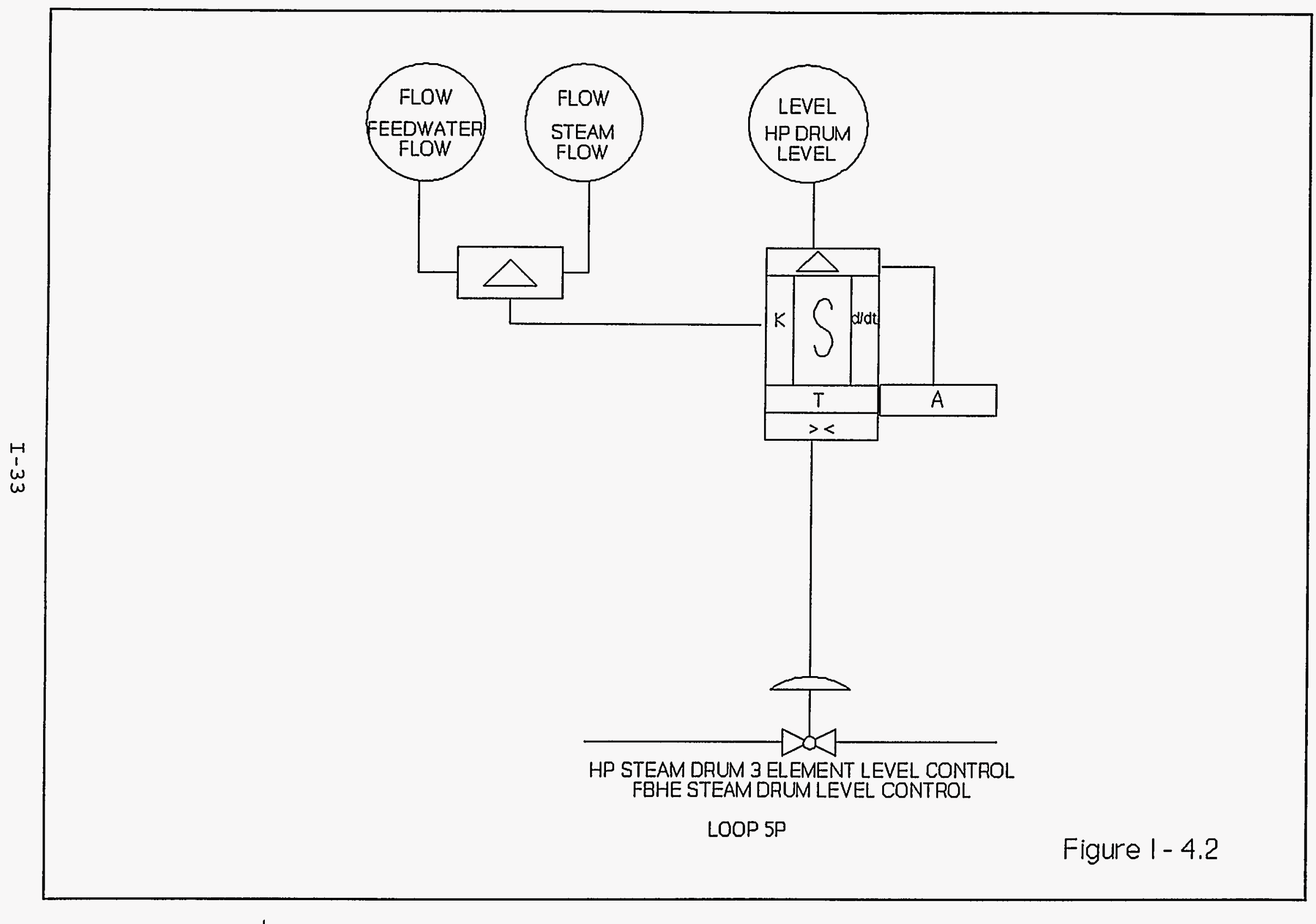




\section{HRSG \\ LOOP 1 \\ HRSG STEAM DRUM LEVEL}

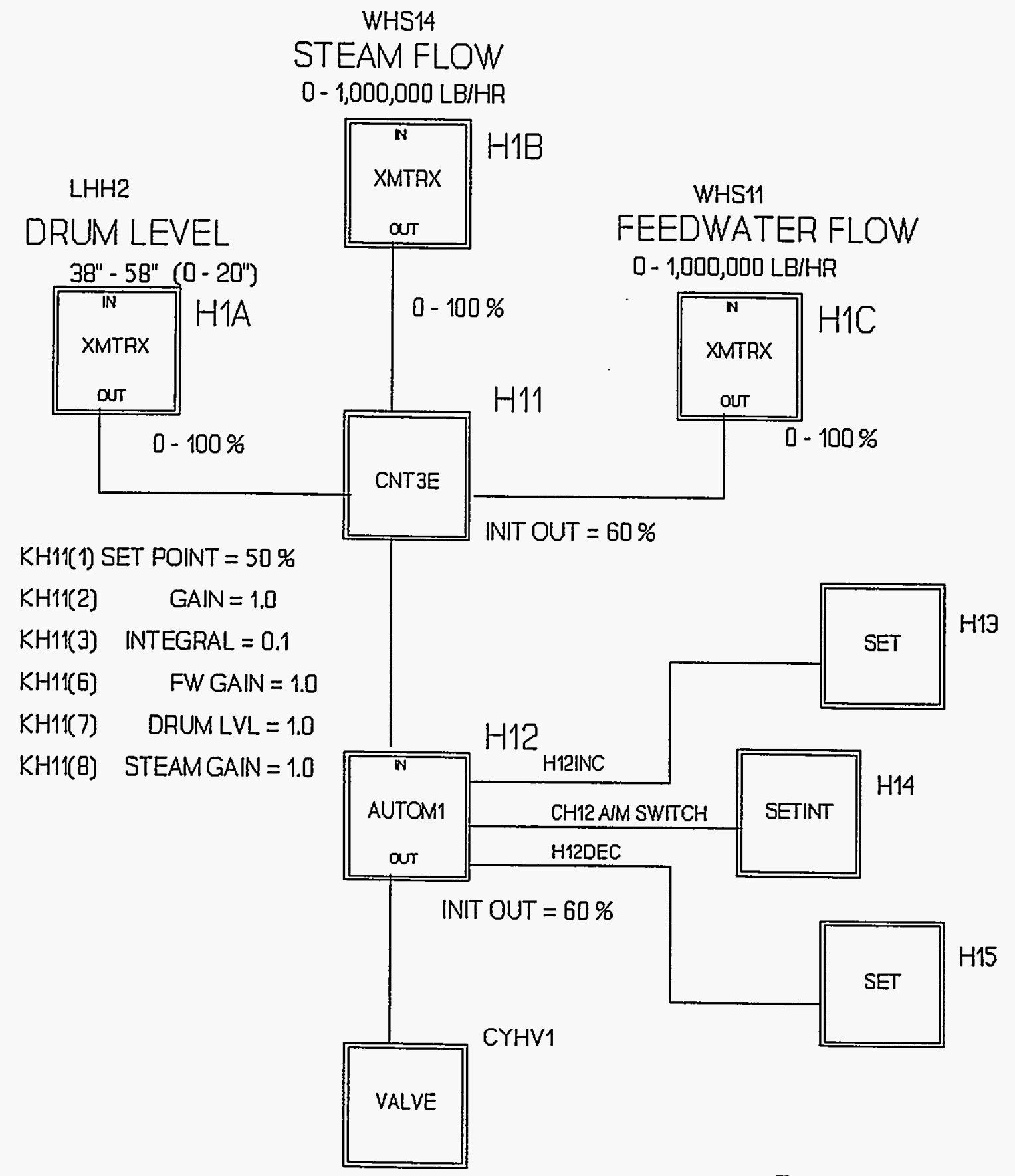

Figure I- 4.3 


\section{PFB COMBUSTOR \\ LOOP 5 \\ FBHE HP STEAM DRUM LEVEL}

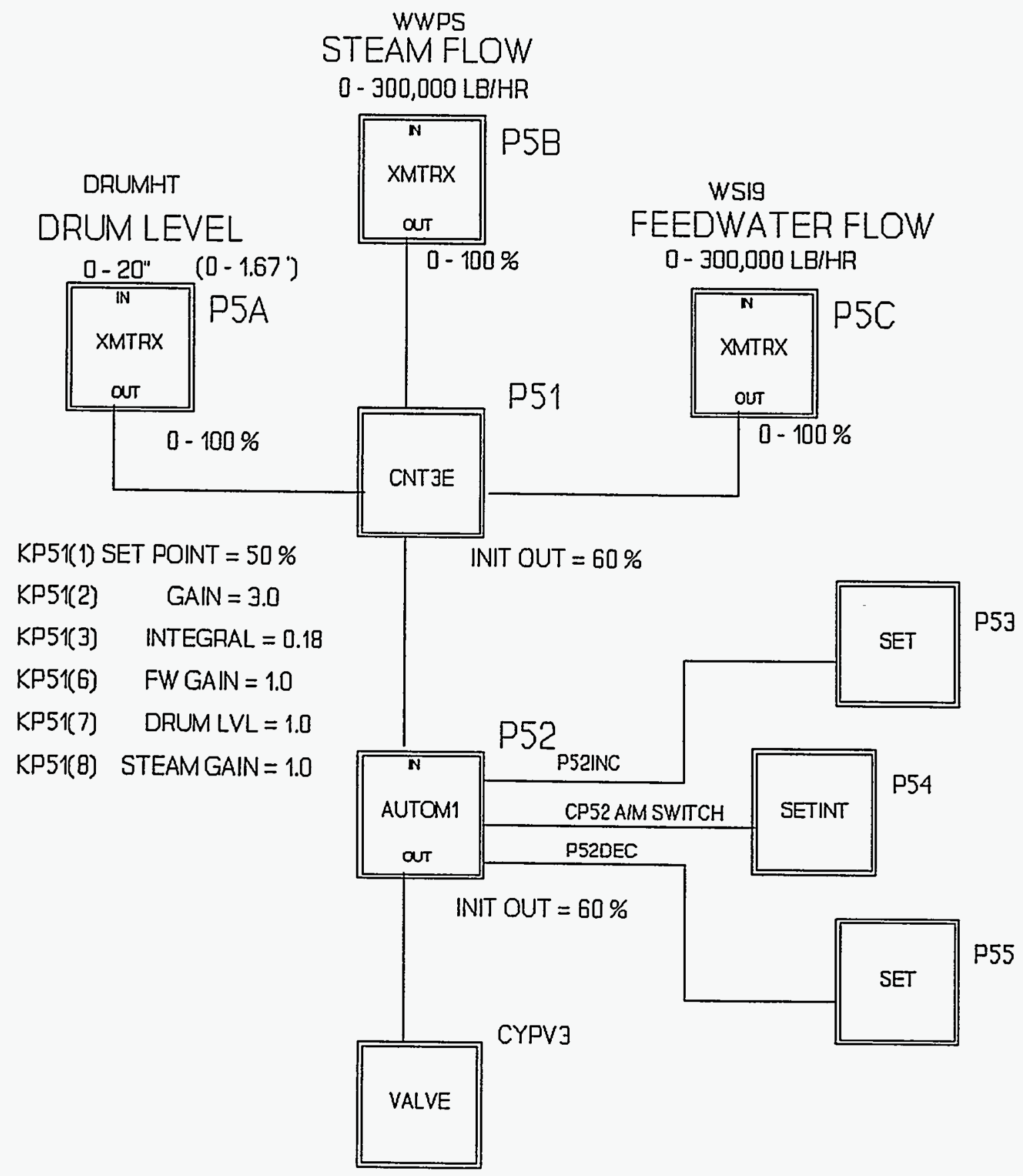

Figure I- 4.4 


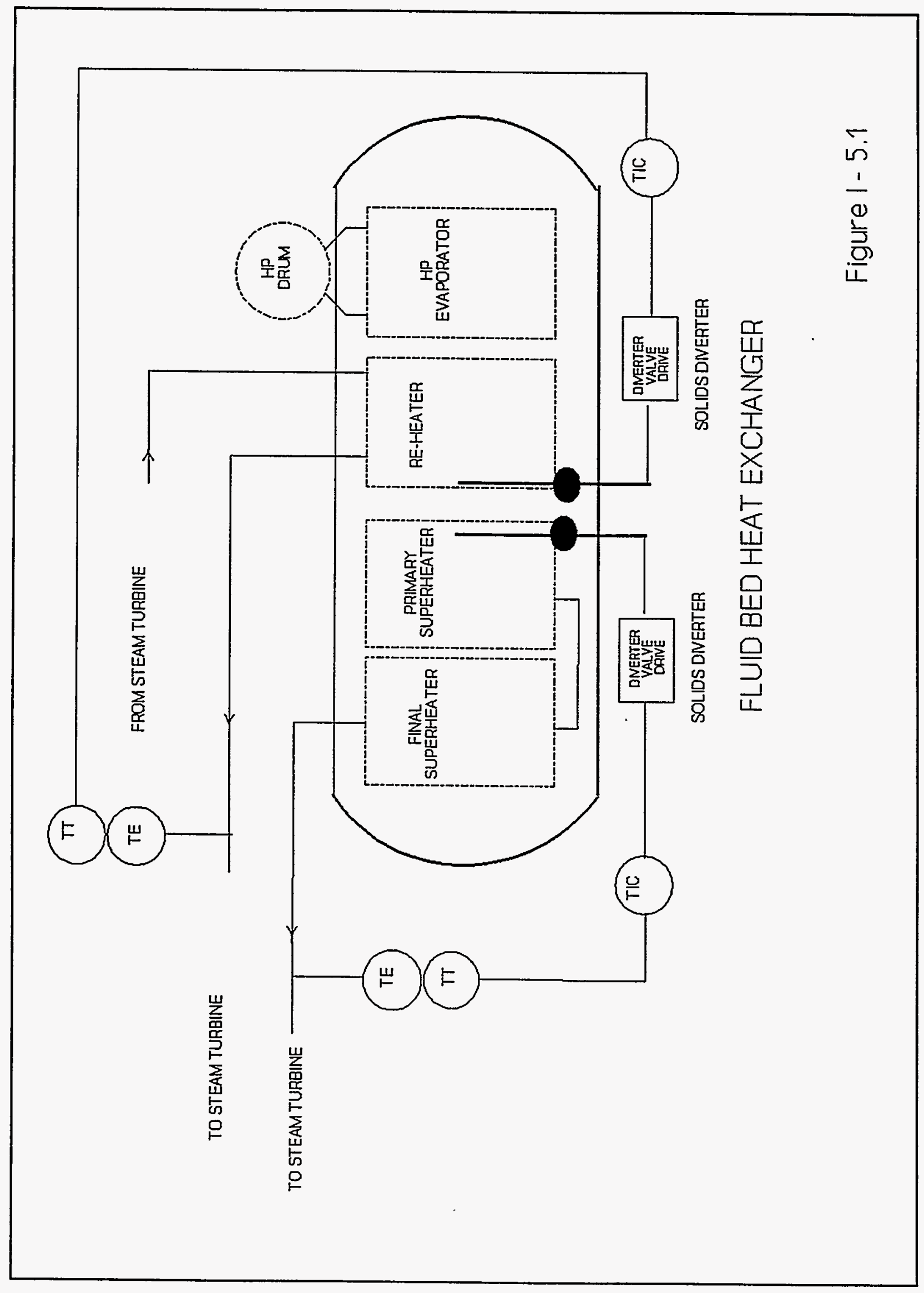




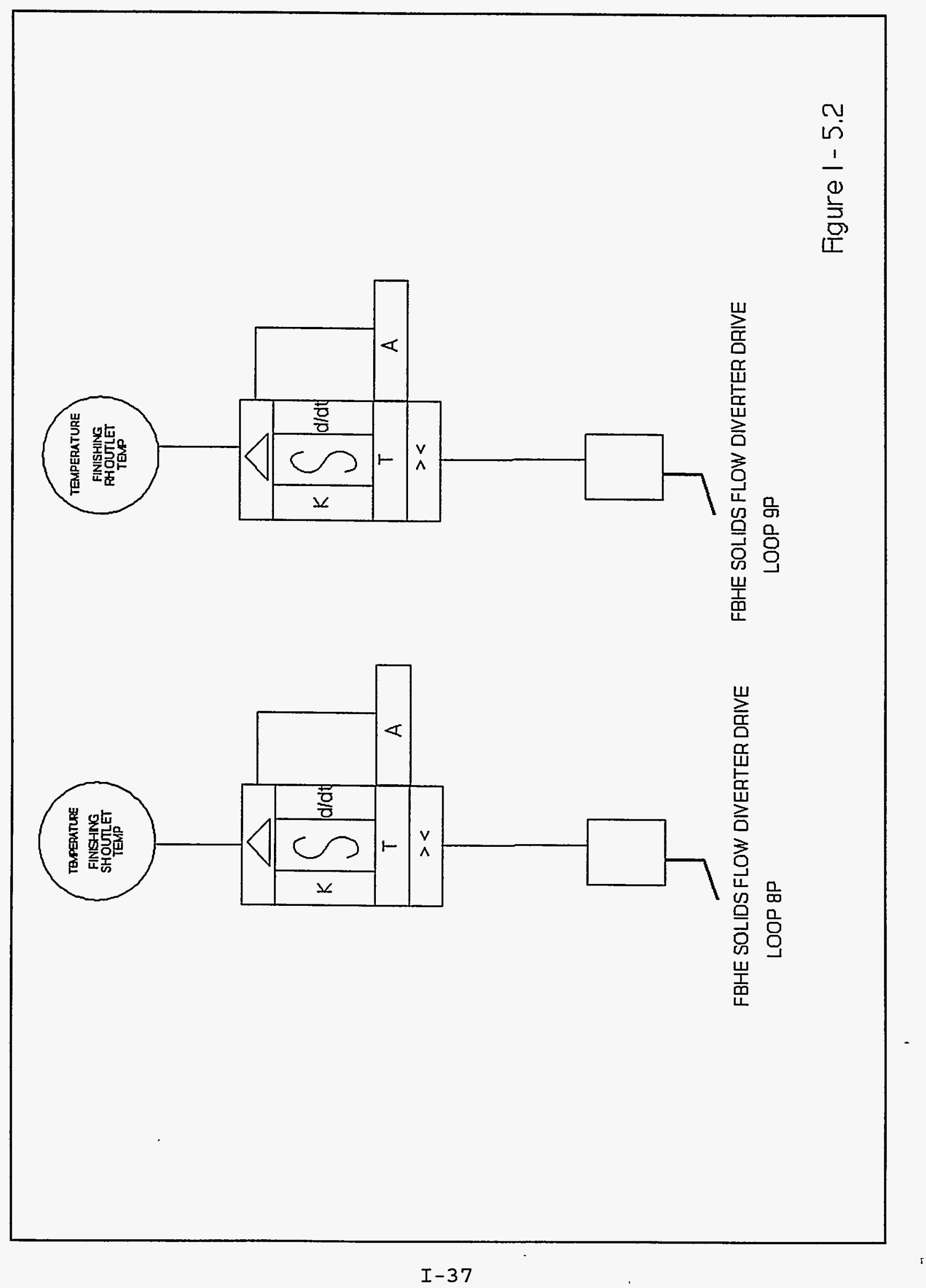




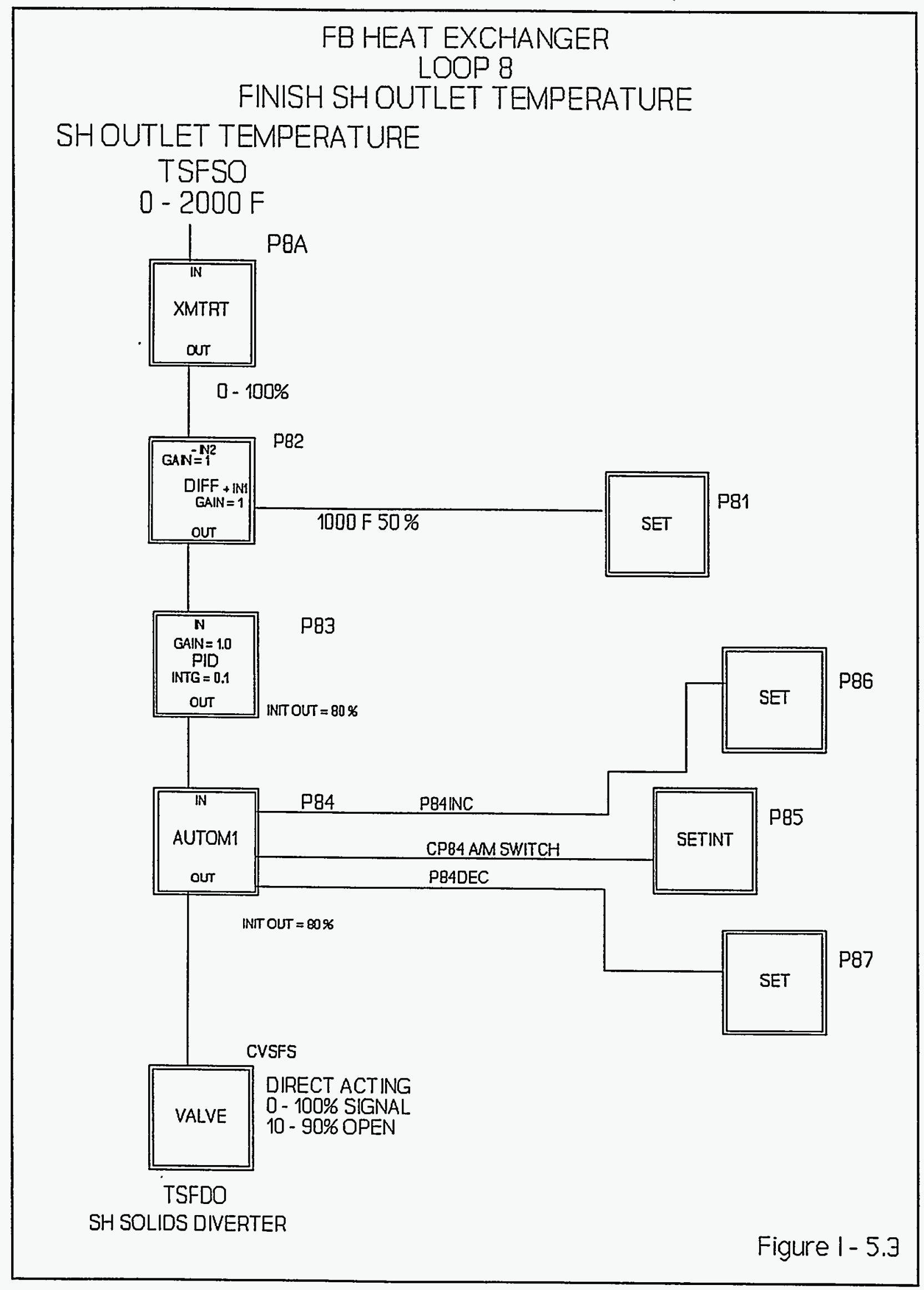




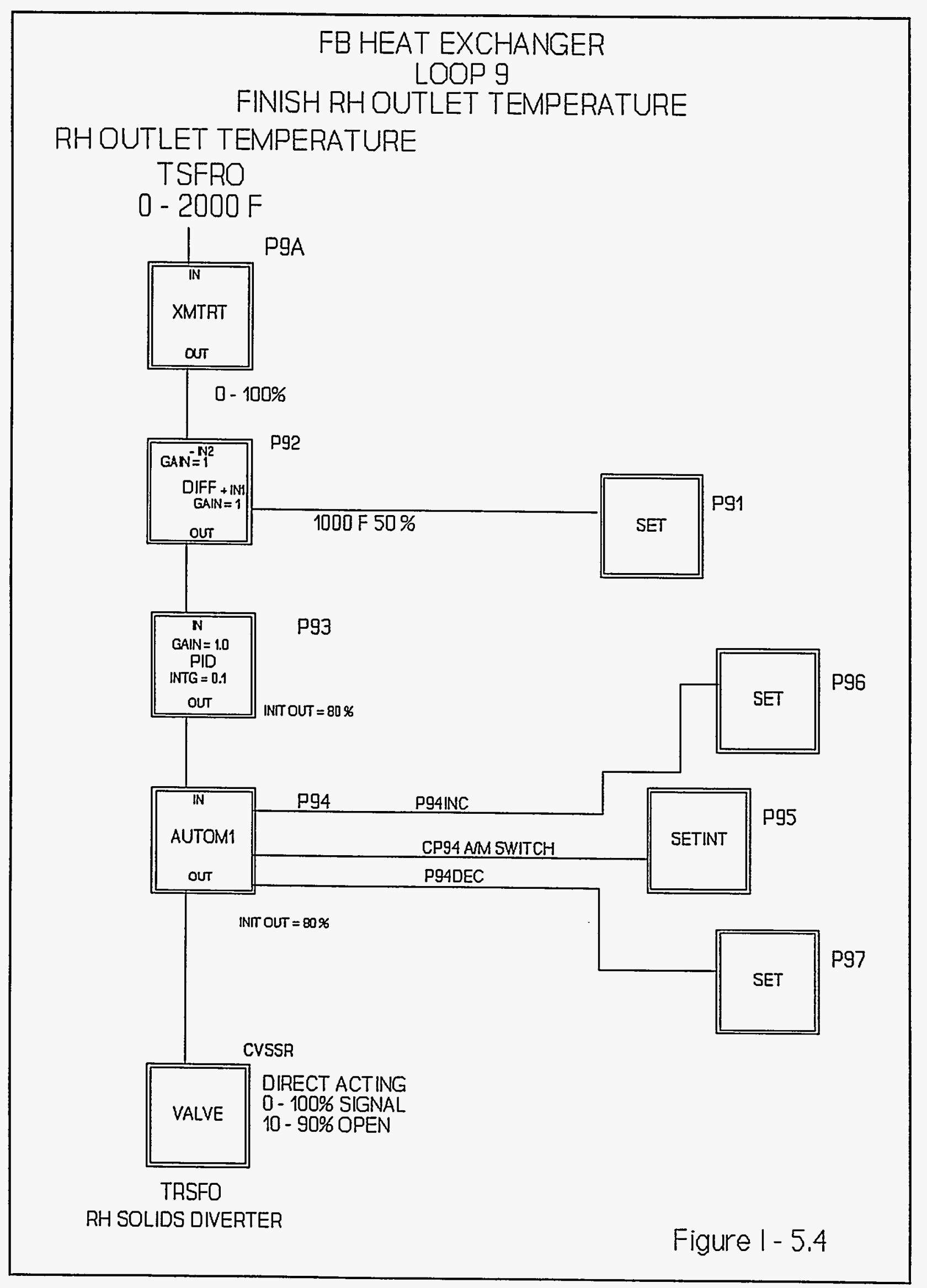




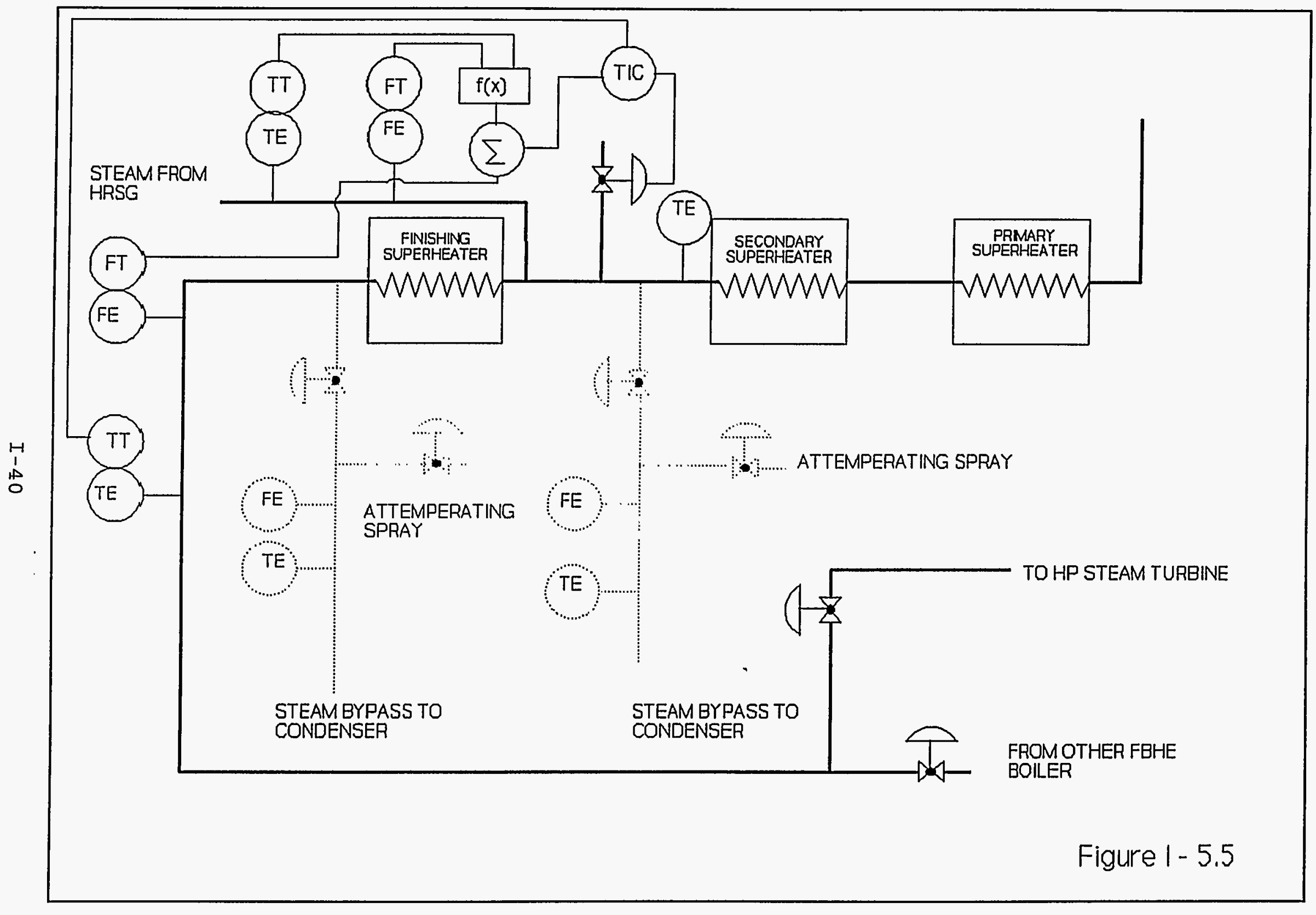




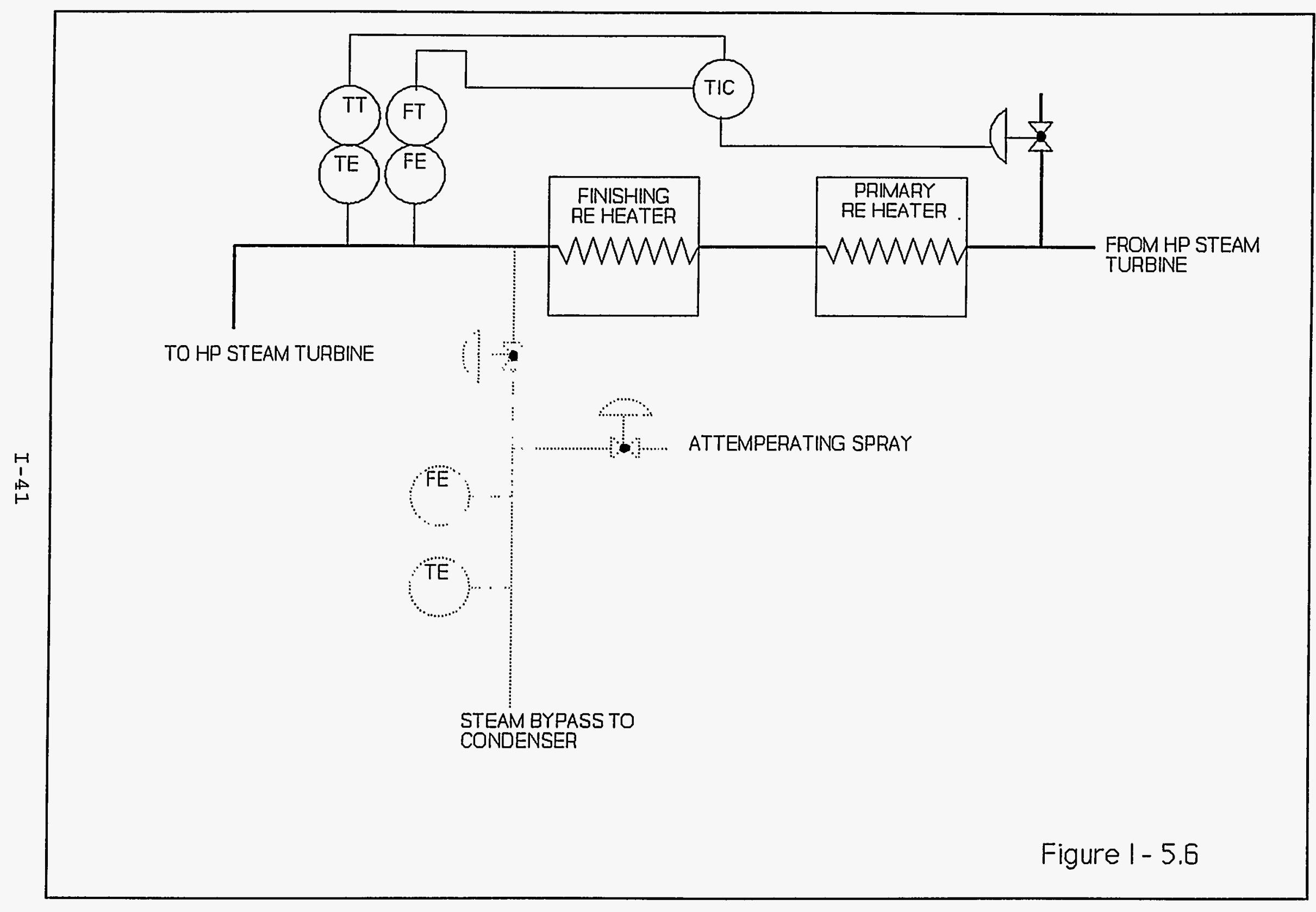




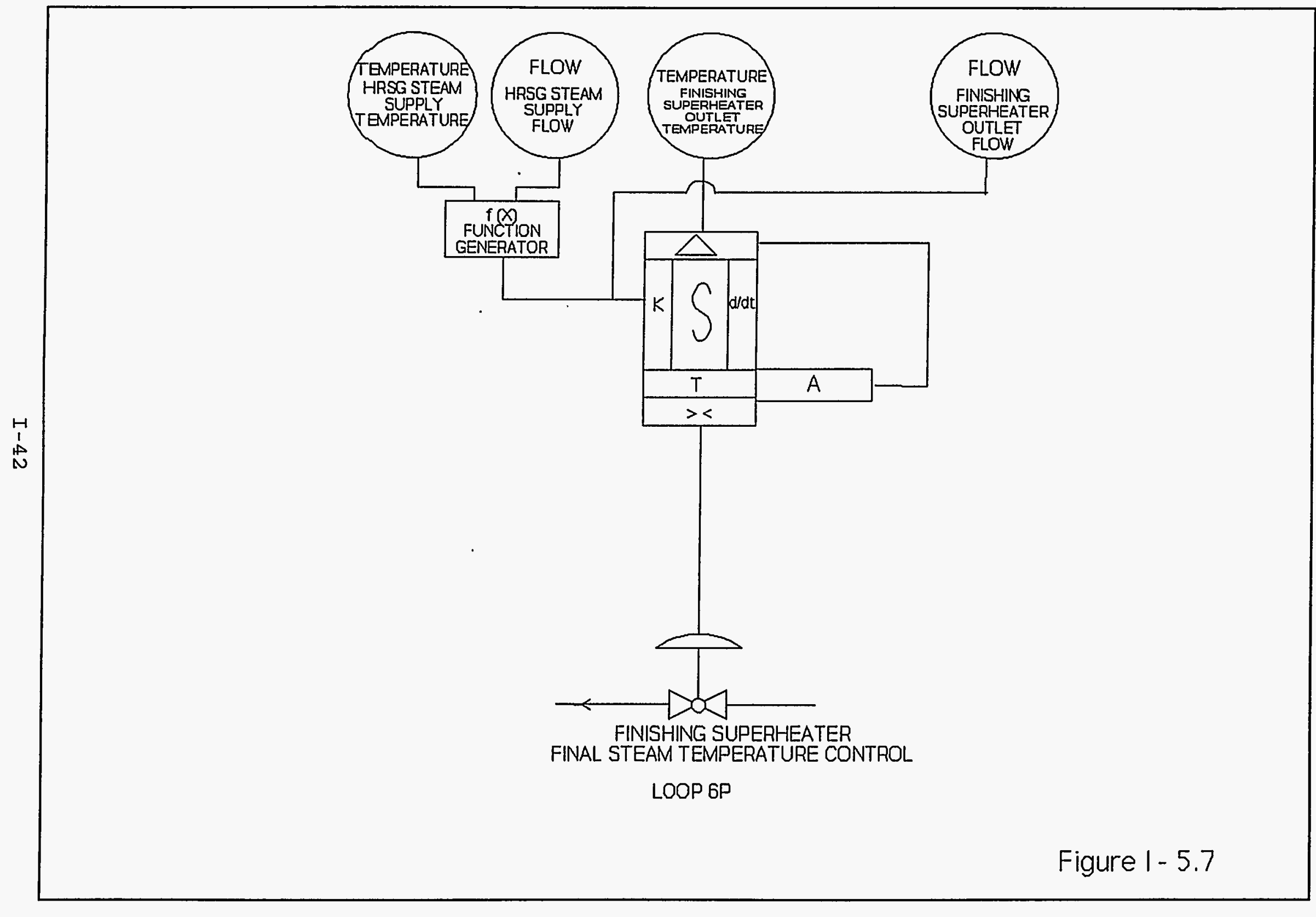




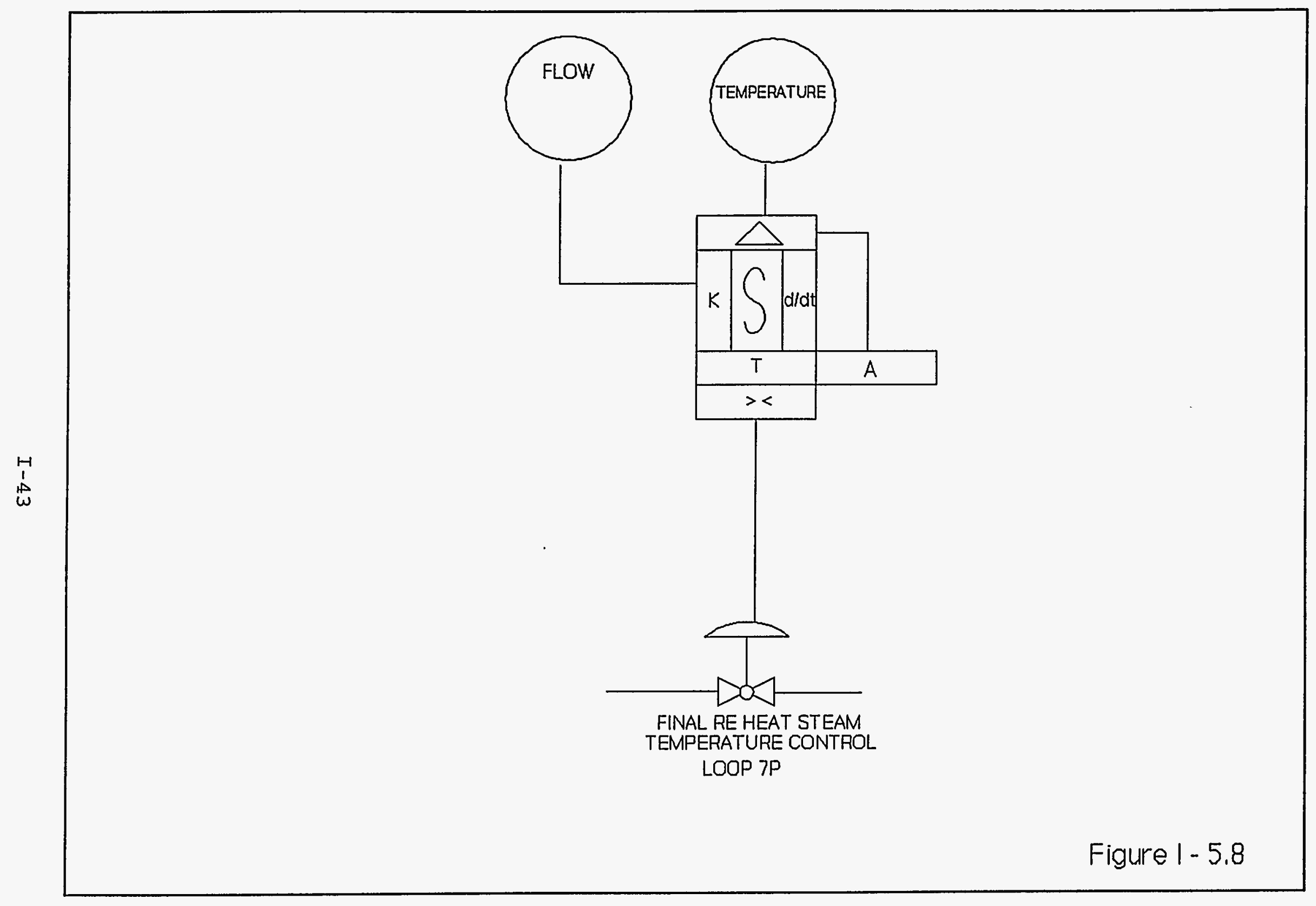


The control demand signal from the auto-manual stations P66 and P67, as shown in Figures I-5.9 and I-5.10, are presently not connected to a control valve. The controllers could be connected to valves and integrated into the control strategy very easily. The spray attemperator control loops were included so that they may be easily implemented in future work.

\section{I.6 STEAM TURBINE CONTROL}

High pressure steam generated in the HRSG and FBHE passes into the steam header prior to entering the steam turbine. Steam flow into the turbine is established and maintained by a PID controller such that a pre-set steam header pressure is achieved. This is commonly known as the "Steam Turbine Following Mode" of control. A single valve is used to simulate the high pressure steam turbine governor valve assembly.

Figure I-6.1 contains a schematic showing the instrumentation and control modules associated with maintaining the steam header pressure. Figure I- 6.2 contains the SAMA diagram for the control loop. Figure I-6.3 contains a block diagram illustrating the TRAX modules implemented in constructing the control loop. Also shown in Figure I-6.3 are the tuning parameters, set points, and transmitter ranges for each module. The PID controller, block S33, modulates valve BV1, which can be found in Figure A-3.13.

\section{I.7 STEAM AND CONDENSATE SYSTEM CONTROL}

Figure I-7.1 contains a schematic showing the instrumentation and control modules associated with the steam and condensate system control. Two primary control loops are represented in Figure I-7.1; deaerator storage tank level and condenser hotwell level.

Condenser hotwell level is maintained at a set level by a PID controller which regulates two valves. In Figure I-7.1, the two valves are indicated as Valve A, which is the spill over valve to the condensate storage tank, and Valve $B$, which is the makeup valve from the condensate storage tank. These valves are split ranged and opposite acting. The makeup valve, Valve B, is reverse acting and goes from open to close as the controller demand signal goes from 0 to 50 percent. The spill over valve, Valve A, is direct acting and opens as the controller demand signal goes from 50 to 100 percent. 


\section{FB HEAT EXCHANGER \\ LOOP 6 \\ FINAL SHOUTLET STEAM TEMPERATURE}

FINAL SHOUTLET TEMPERATURE SHOUTLET STEAM FLOW

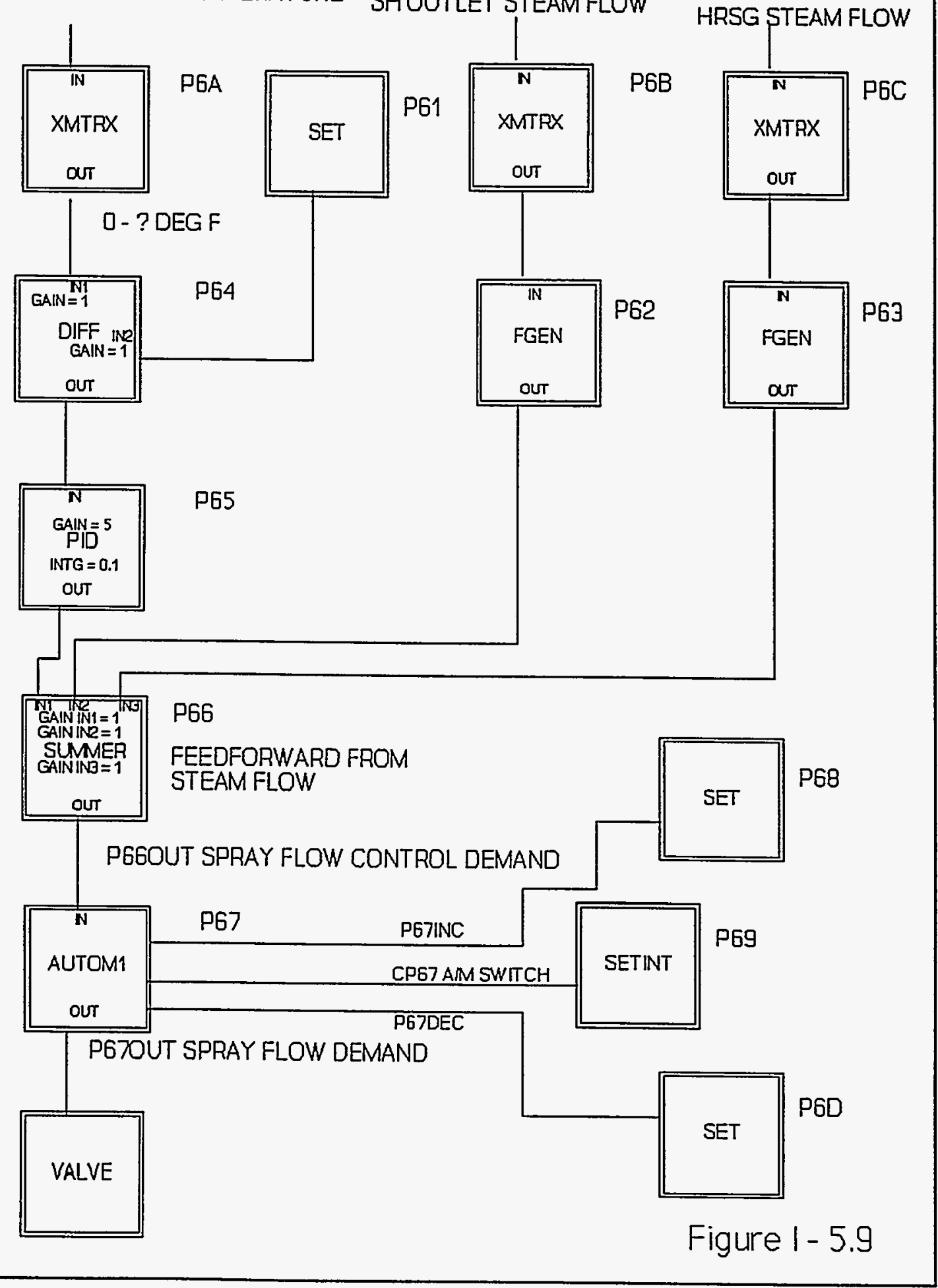




\section{FB HEAT EXCHANGER \\ LOOP 7 \\ FINAL RH OUTLET STEAM TEMPERATURE}

FINAL RHOUTLET TEMPERATURE RHOUTLET STEAM FLOW

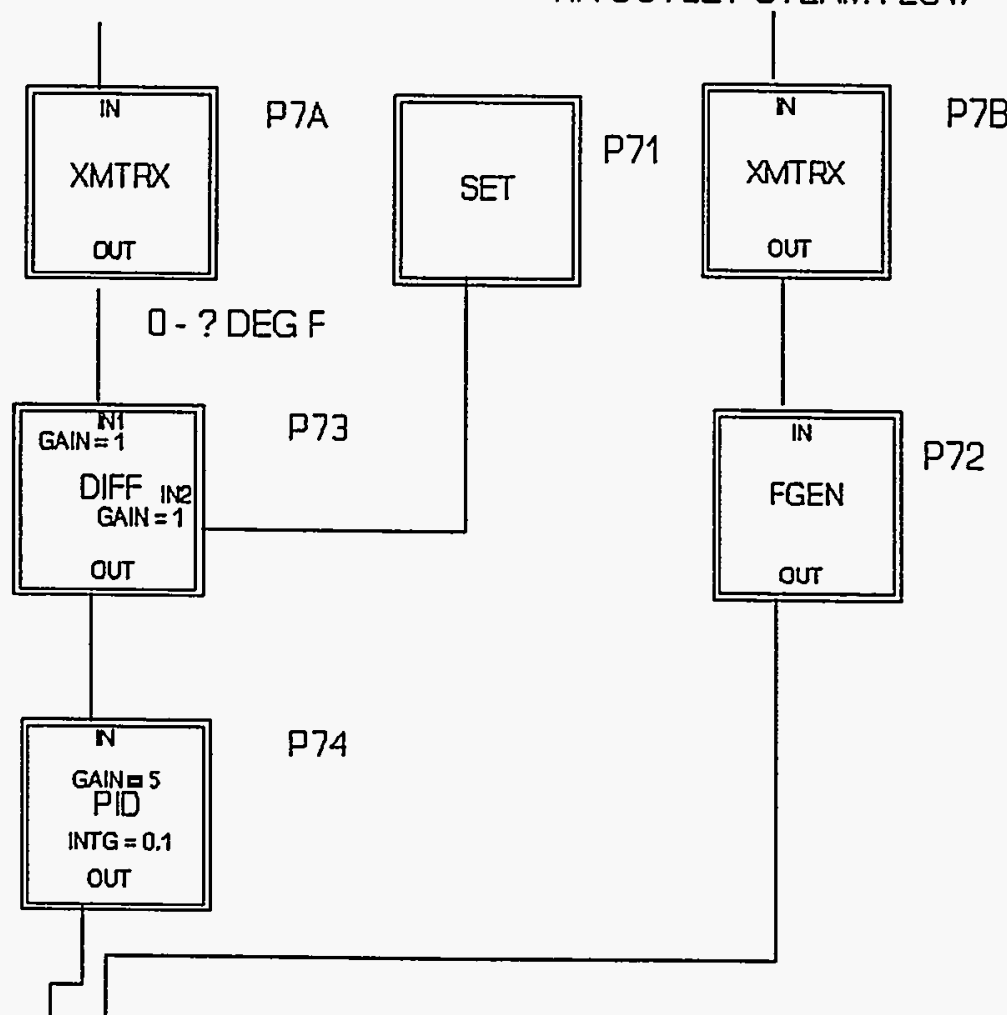

\begin{tabular}{||l|l}
\hline $\begin{array}{c}\text { II INE } \\
\text { GAN N1 }=1 \\
\text { SUMMER } \\
\text { GAN N2 }=1.0 \\
\text { OUT }\end{array}$ & F75 \\
\hline
\end{tabular}

PF50UT SPRAY FLOW CONTROL DEMAND

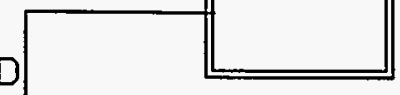

P77

PFOUT SPAYY FLOW CONTROL DEMAND
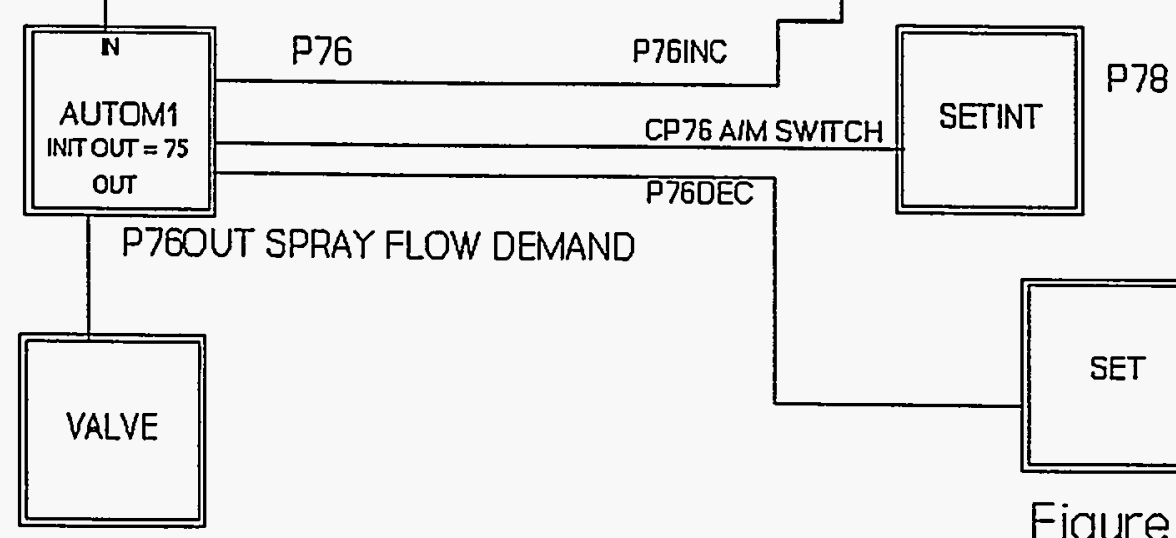

P760EC
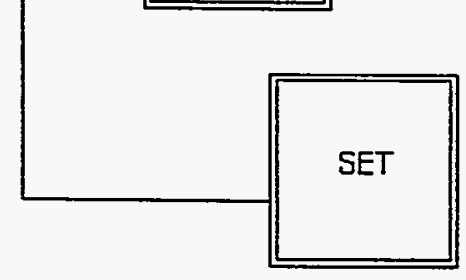

P79

Figure $1-5.10$ 


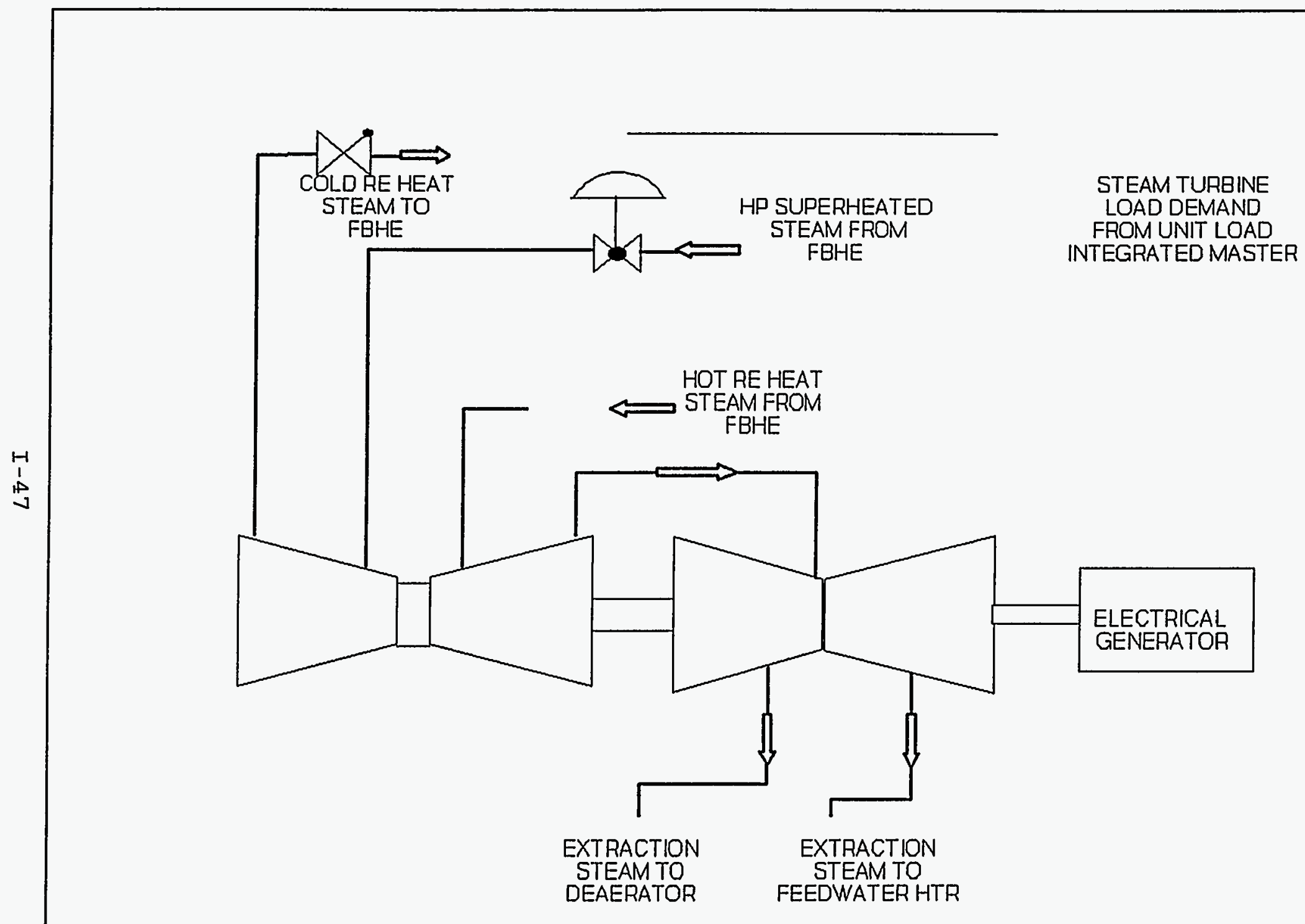

Figure I- 6.1 


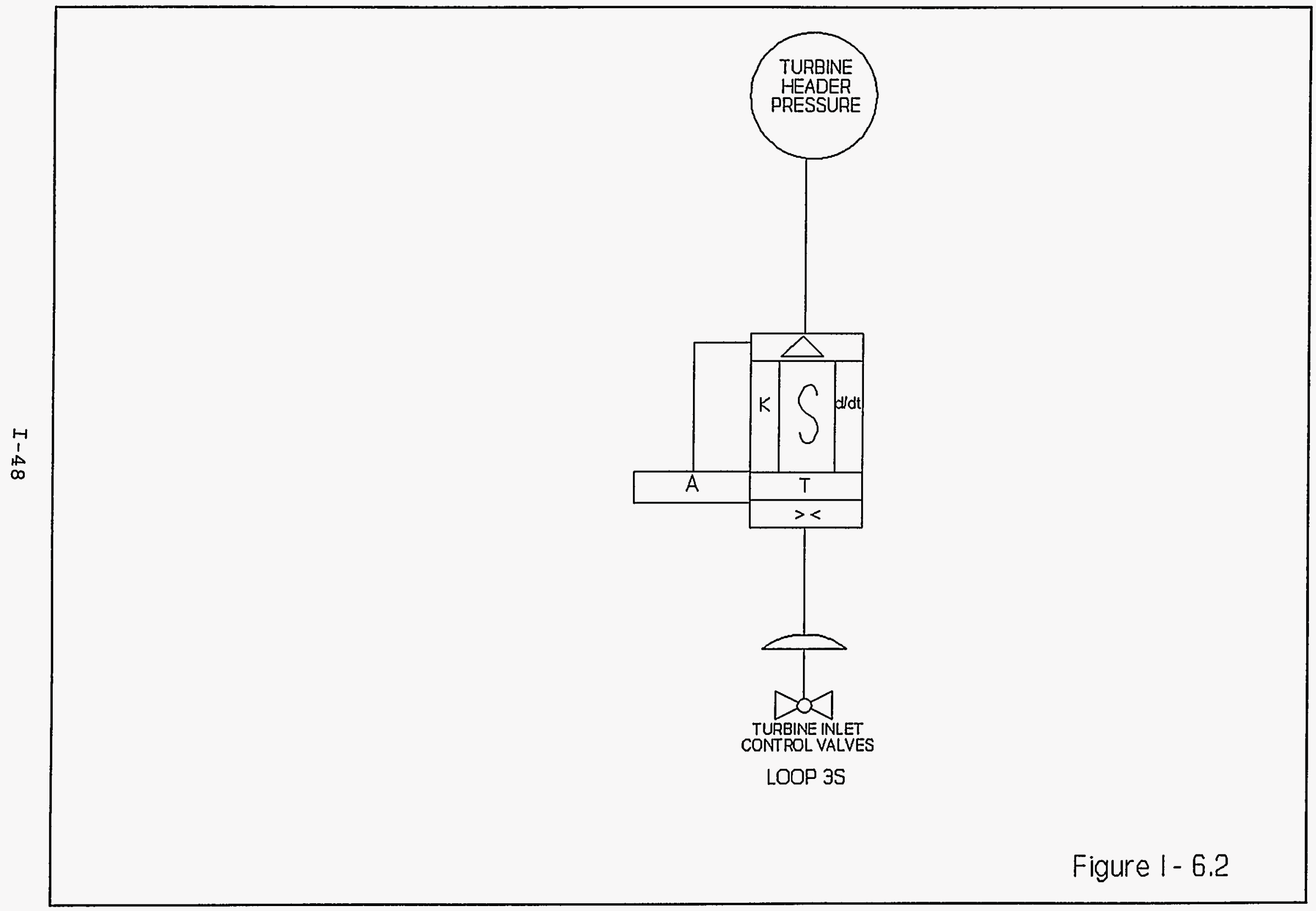




\section{STEAM CONDENSATE SYSTEM \\ LOOP 3 \\ TURBINE HEADER PRESSURE}

PBS4

TURBINE HEADER PRESSURE
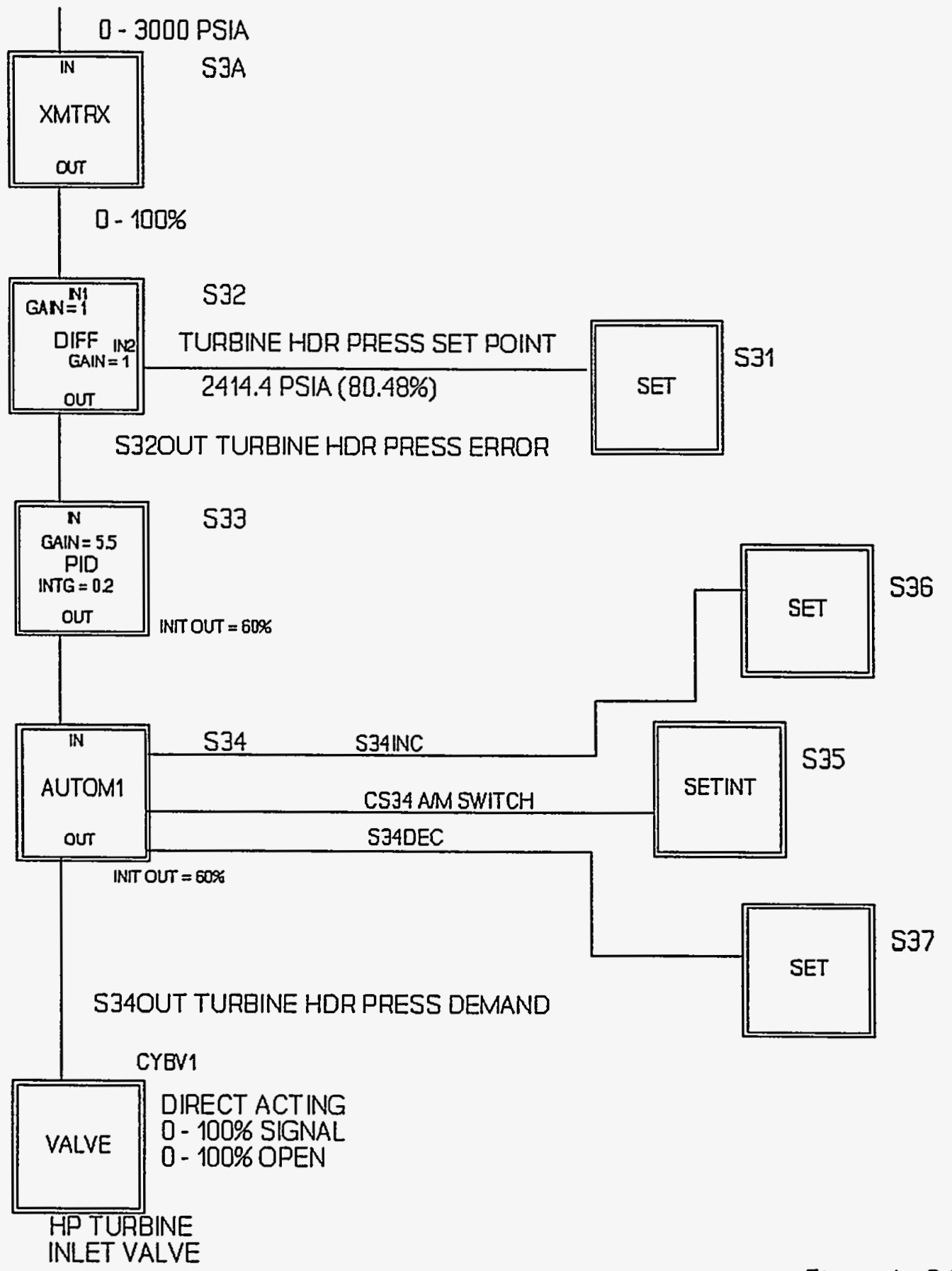

Figure 1- 6.3 


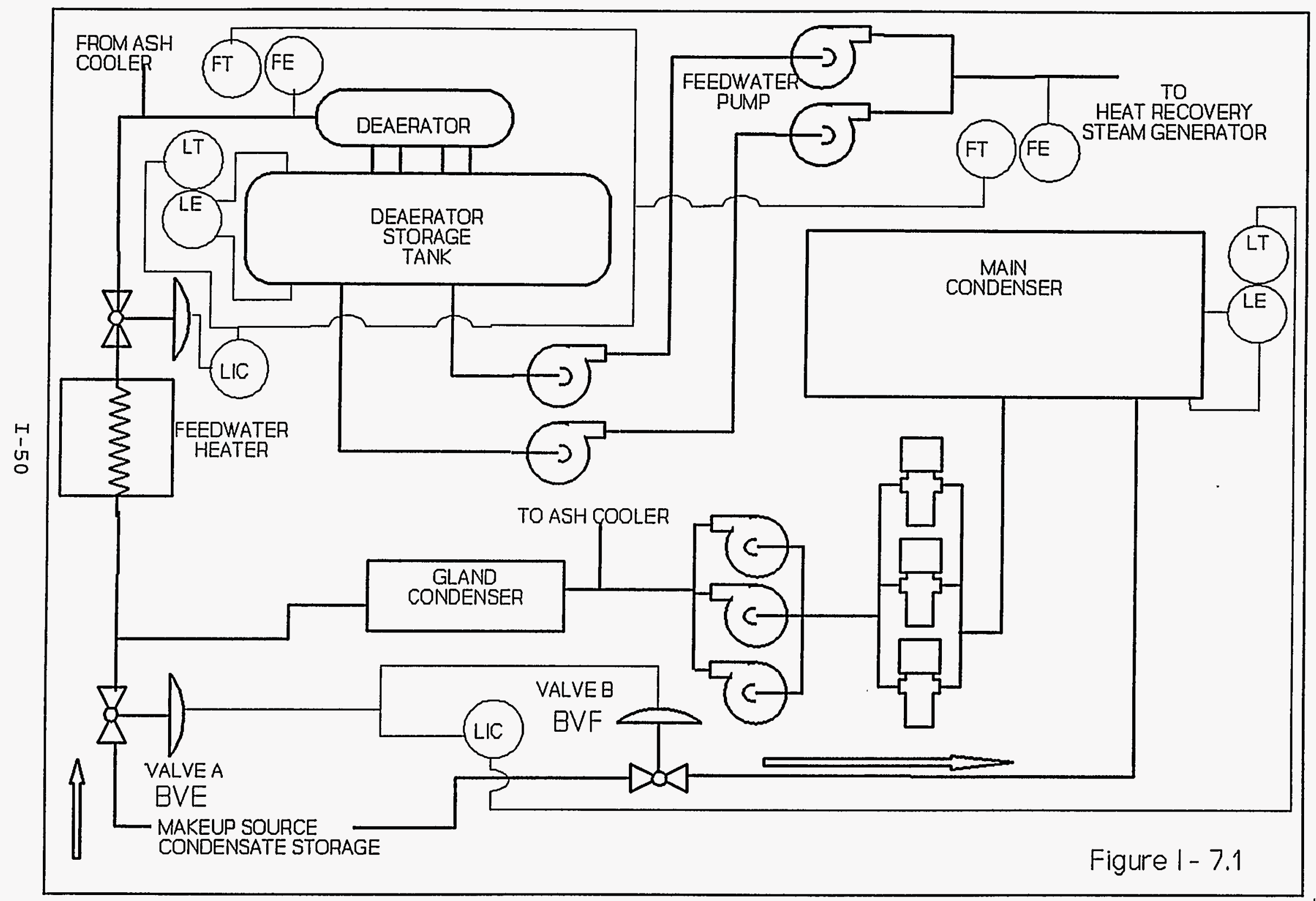




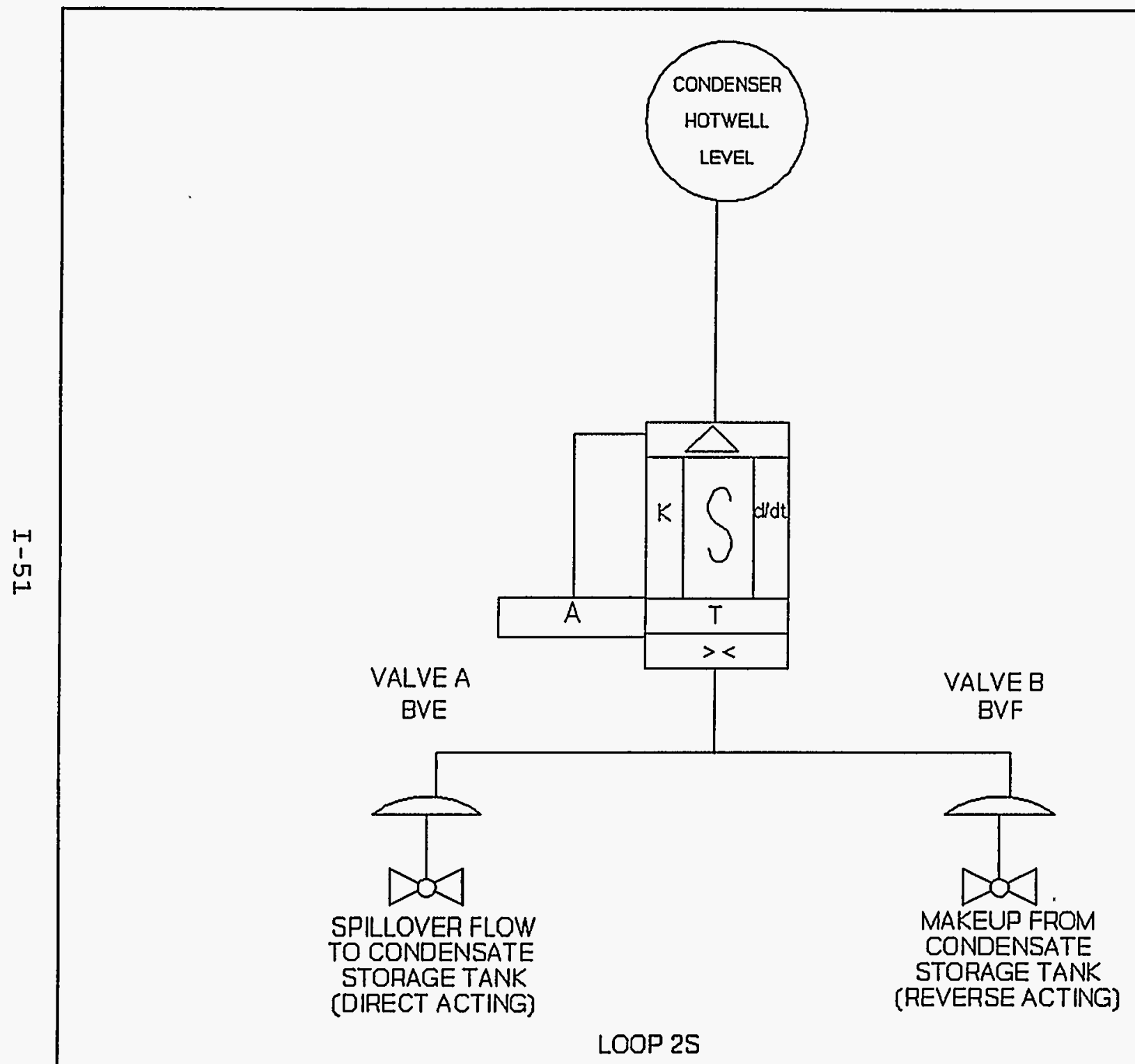

Figure I- 7.2 
Figure 1-7.2 contains the SAMA diagram for the condenser hotwell level control loop. Figure I-7.3 contains a block diagram illustrating the TRAX modules implemented in constructing the condensate hotwell level control loop. Also shown in Figure 1-7.3 are the tuning parameters, set points, and transmitter ranges for each module. The controller demand signal regulates valve BVE, which is valve A in Figure I-7.1, and valve BVF, which is valve B in Figure 1-7.1. These valves can be found in Figure A-3.16.

The deaerator storage tank level is maintained by a three element controller. Condensate flow into the deaerator is compared to feedwater flow out with a correction for level deviation. Level is controlled by regulating the condensate flow to the deaerator.

Figure I-7.4 contains the SAMA diagram for the deaerator storage tank level control loop. Figure I-7.5 contains a block diagram illustrating the TRAX modules implemented in constructing the control loop. Tabulated within the figure are the tuning parameters, set points, and transmitter ranges for each module. The control demand signal from the three element controller modulates valve BVD after passing through the auto-manual station. Valve BVD can be found in Figure A-3.18.

\section{I.8 ASH COOLER CONTROL}

Figure I-8.1 contains a schematic showing the instrumentation and control elements associated with the ash cooler. A portion of the condensate stream is diverted from the feed water piping system (gland condenser) through the ash cooler to remove sensible heat of the ash. The rate of flow is regulated by a PID controller which modulates a valve in the condensate return line to the deaerator. The controller attempts to establish and maintain a water discharge temperature at a set point of $206^{\circ} \mathrm{F}$.

The ash cooler control loop was initially utilized to prevent flashing in the ash cooler jacketed shell. Further analysis revealed that the control is unnecessary and becomes impossible to achieve at part load conditions. Therefore, the control loop has been placed in manual and the valve stem position remains fixed at 65 percent open. Flow though the ash cooler and the associated steam piping is due entirely to pressure differences.

Figure I-8.2 contains the SAMA diagram for the control loop illustrated in Figure I-8.1. Figure I-8.3 contains a block diagram illustrating the TRAX modules implemented in constructing the control loop. Also shown in Figure I-8.3 are the tuning parameters, set points, and transmitter ranges for each module. Demand from the auto-manual station modulates valve BVB. Automatic control can be regained by toggling the $\mathrm{A} / \mathrm{M}$ switch in block S45. Valve BVB can be found in Figure A-3.18. 


\section{STEAM CONDENSATE SYSTEM \\ LOOP 2 \\ CONDENSER HOTWELL LEVEL}

LBC1

CONDENSERHOTWELL LEVEL
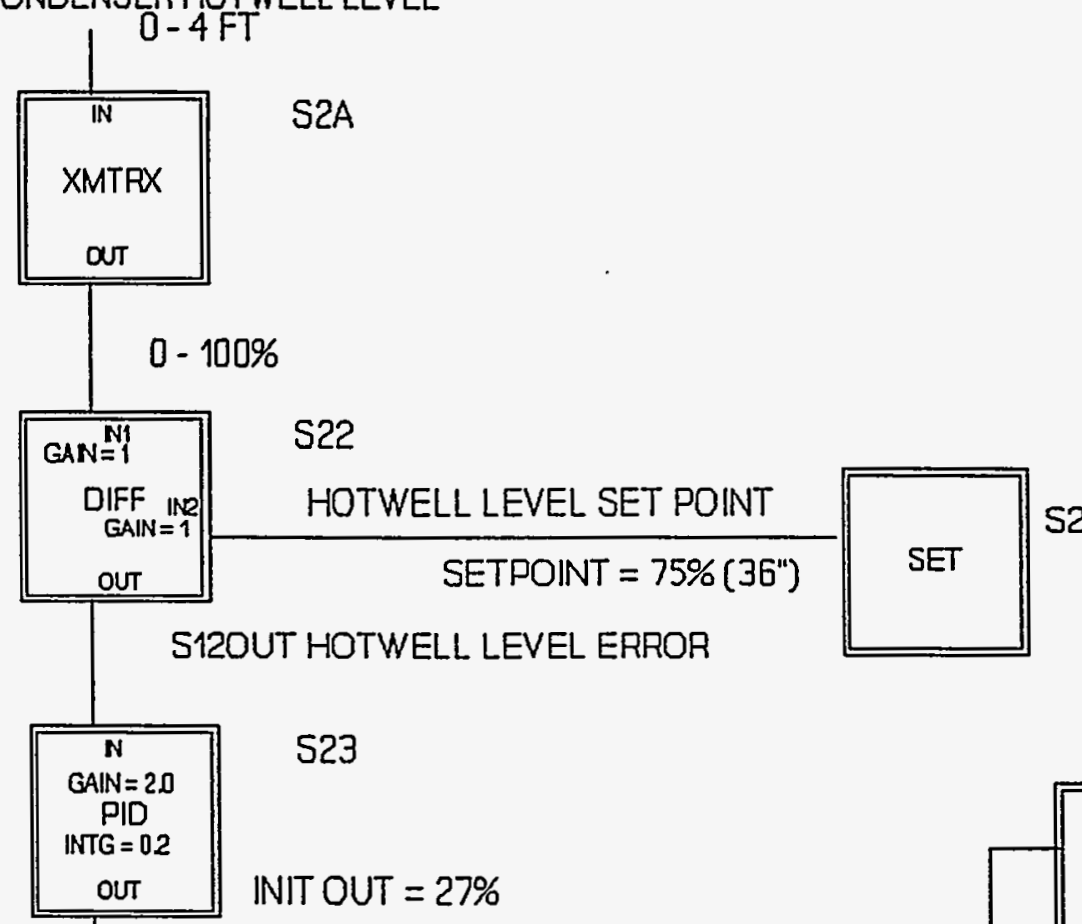

S13OUT HOTWELL LLEVEL CONTAOL DEMAND

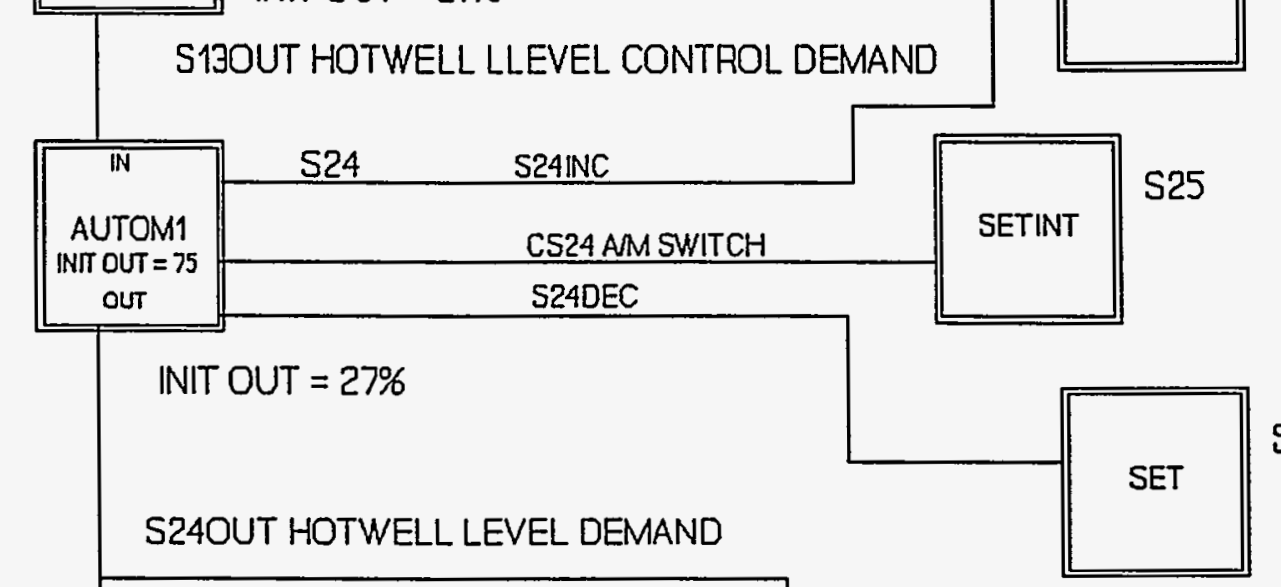

S24OUT HOTWELL LEVEL DEMAND

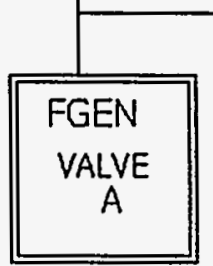

SPILLOVER FLOW TO

CONDENSATE STORAGE

CYBVE
528

DIRECT ACTING

55-100\% SIGNAL

0 - 100\% OPEN

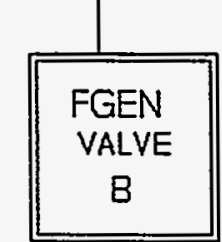

529

REVERSE ACTING

$0-45 \%$ SIGNAL 100 - 0\% DPEN
MAKEUP FROM

CONDENSATE STORAGE CYBVF

Figrue 1 - 7.3 


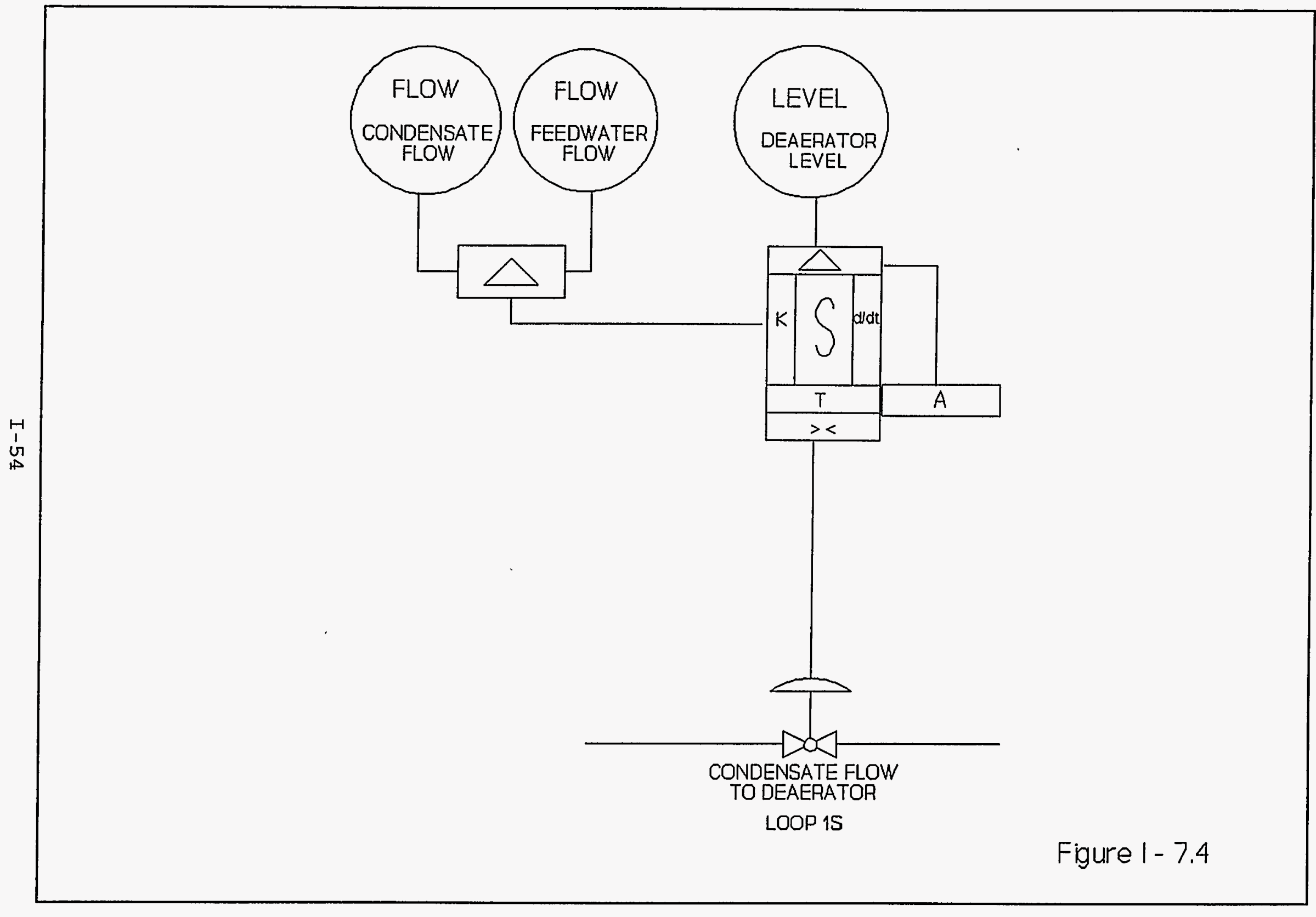




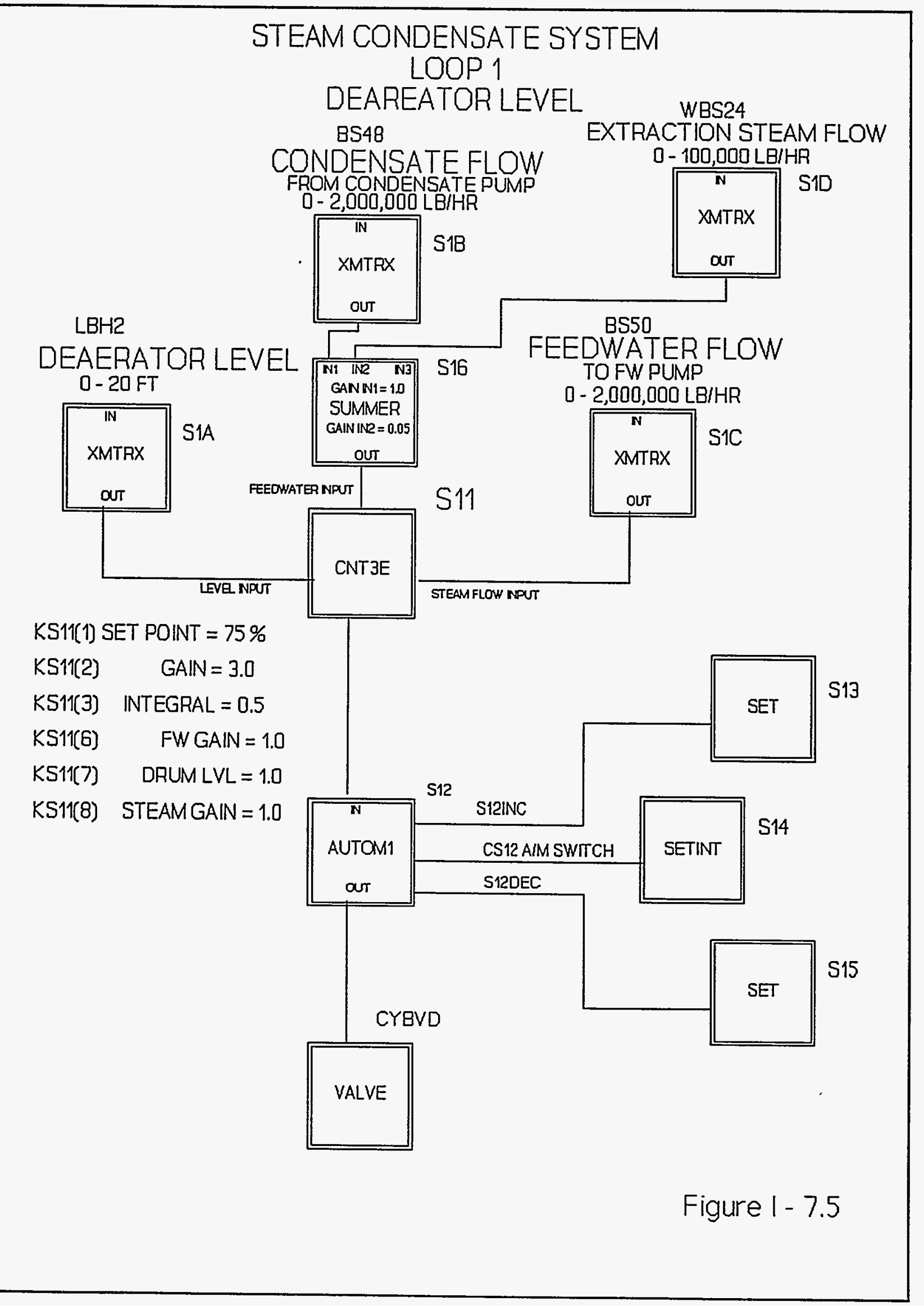




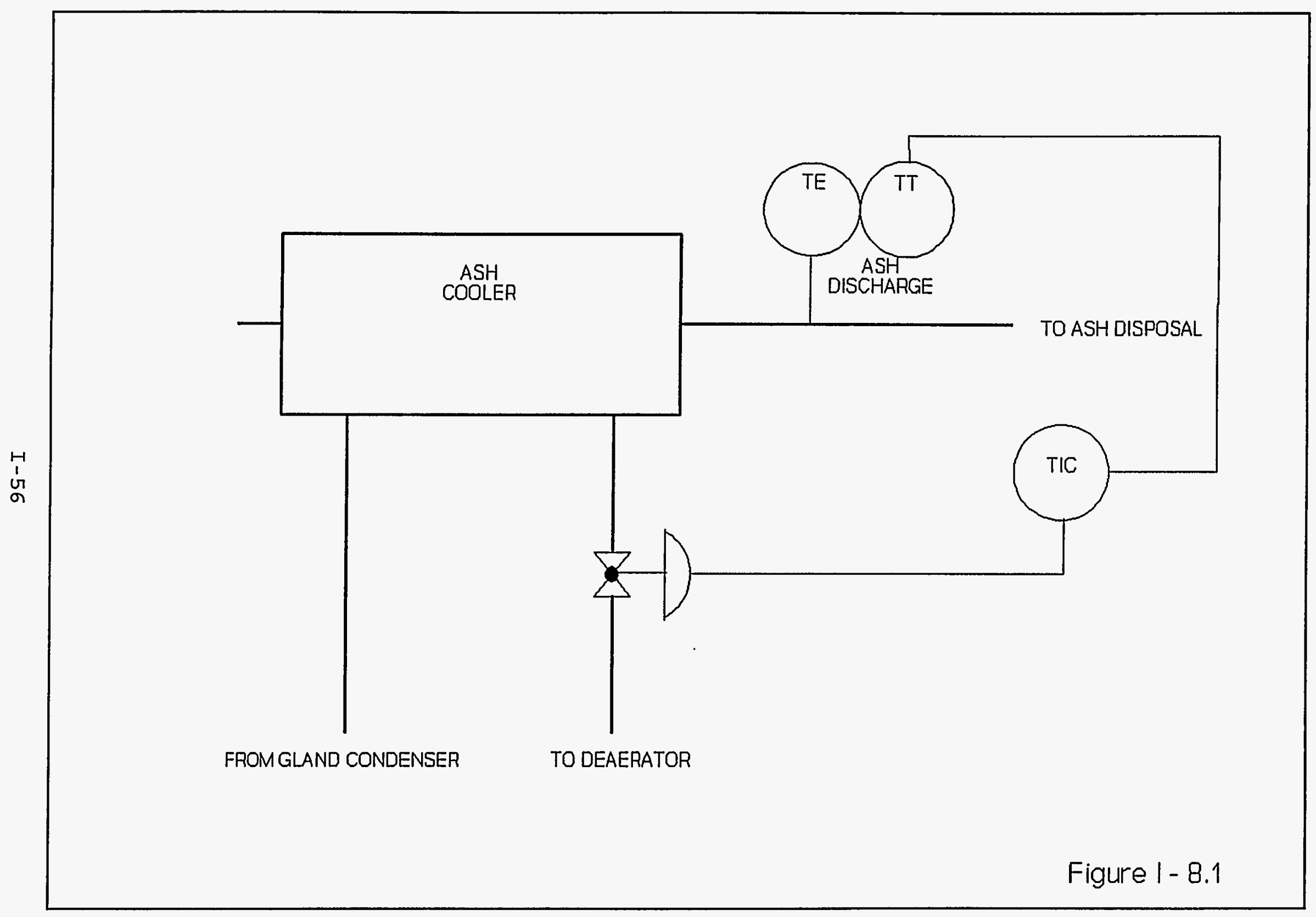




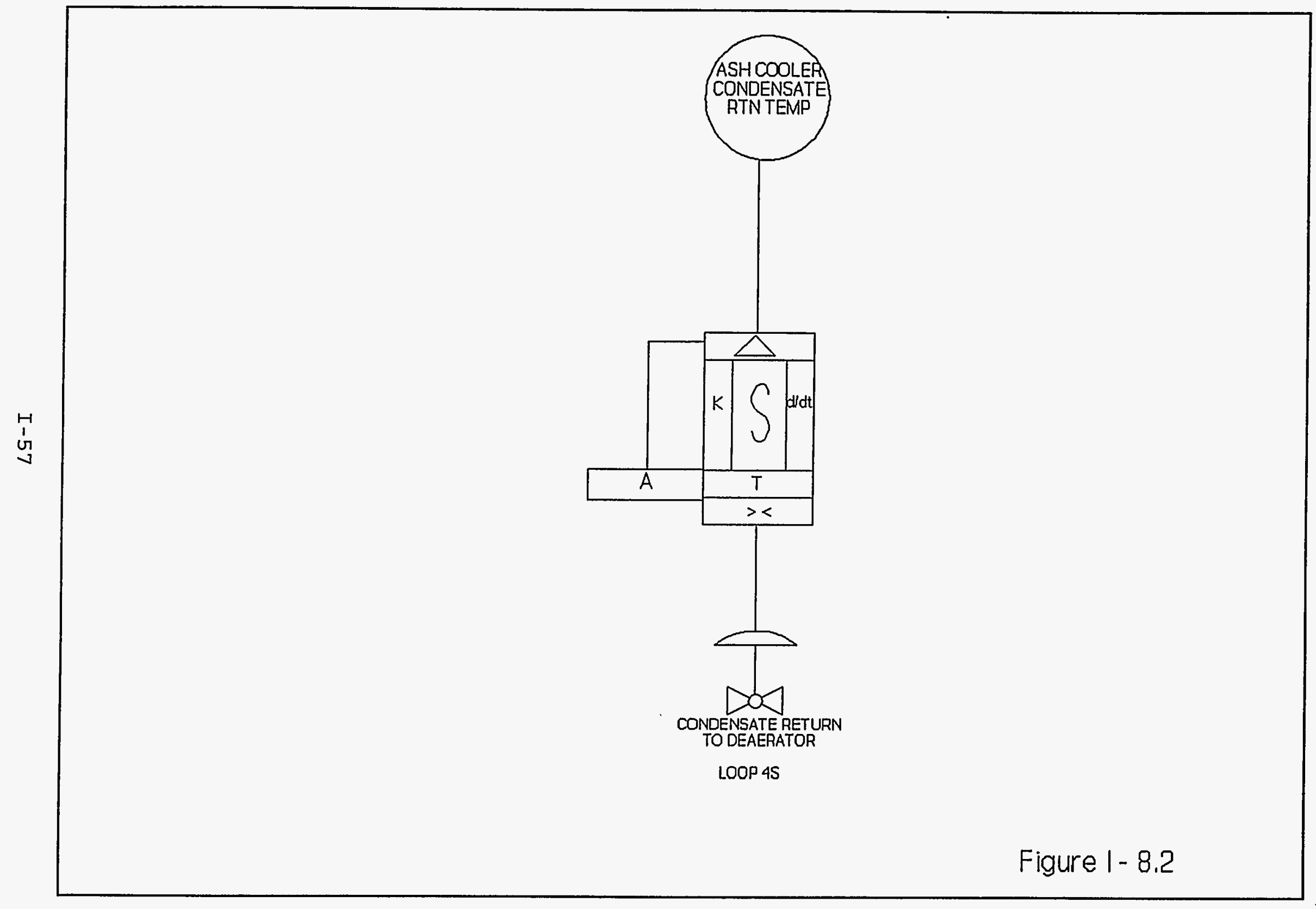




\section{STEAM CONDENSATE SYSTEM LOOP 4 ASH COOLER DISCHARGE TEMPERATURE}

TSO6

ASH COOLER WATER DISCHARGE TEMPERATURE

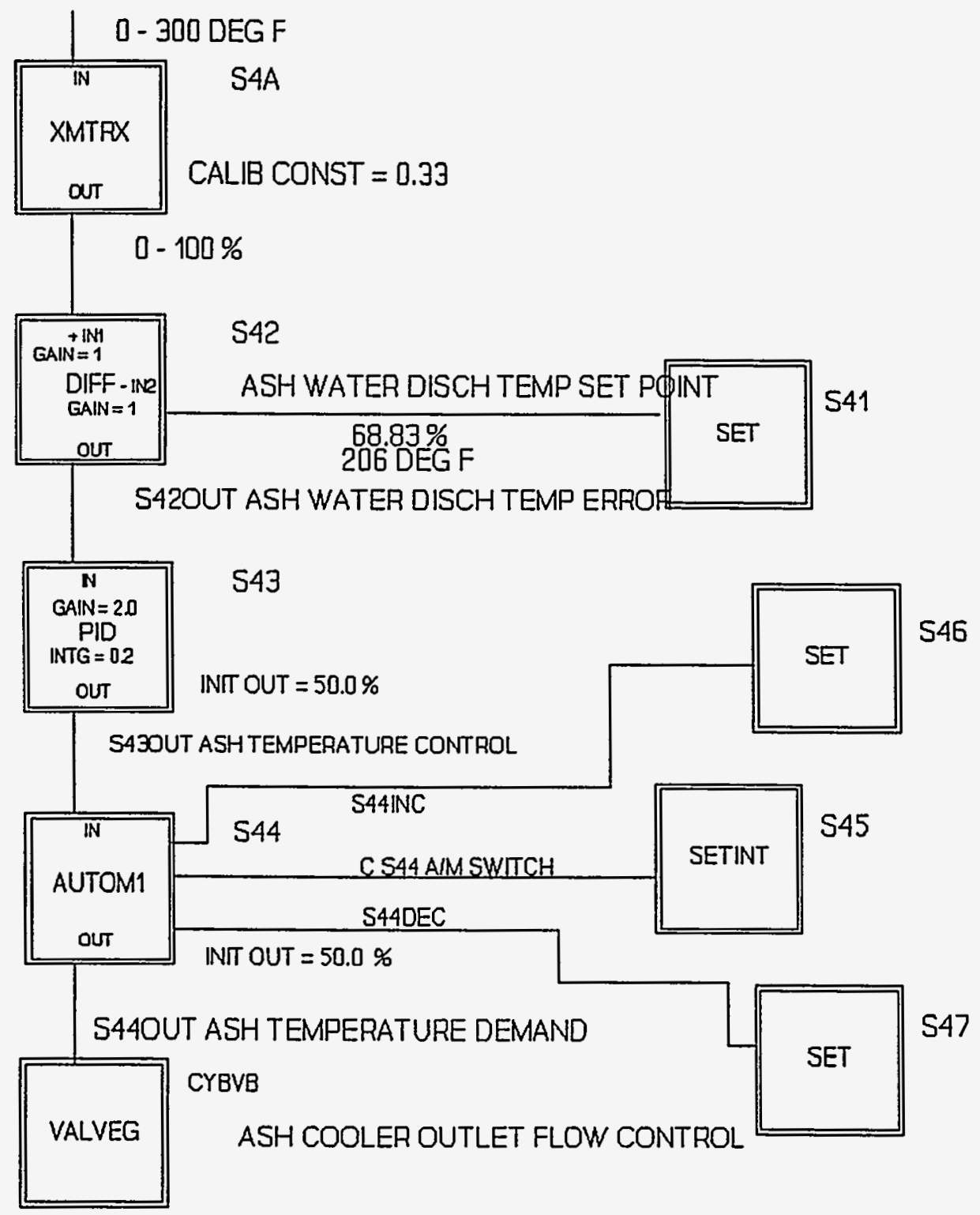

Figure I- 8.3 


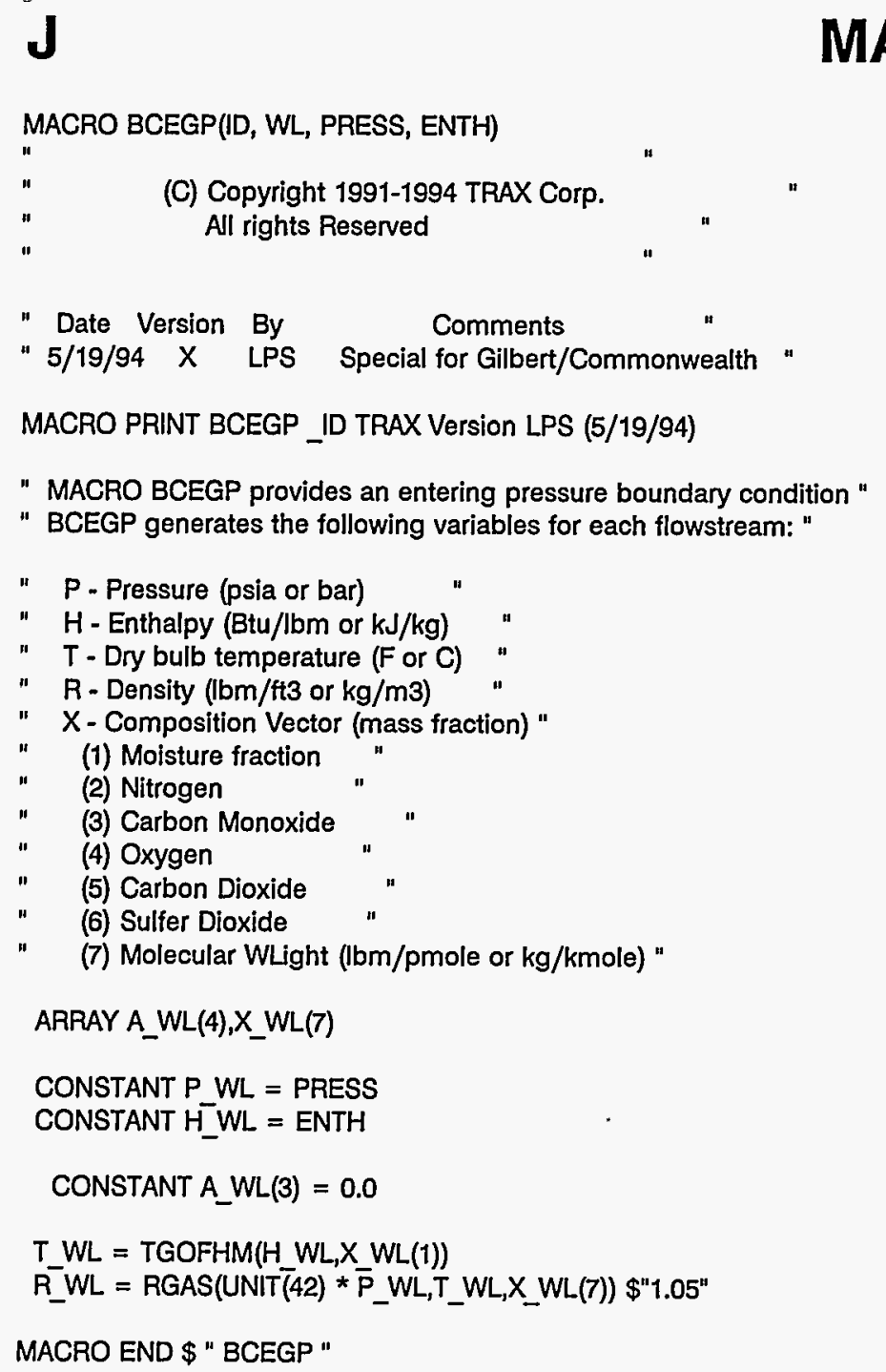


MACRO BCESP(ID,WL,PRESS,ENTH)

(C) Copyright 1991-1994 TRAX Corp. All rights Reserved

"This MACRO is an entering pressure boundary condition. It connects"

"to a downstream flow port."

" DATE Rev By

" 9-11-87 1.00 RDS

" 7-14-89 1.01 LPSmith

" 3-15-91 1.02 PJD

" 10-05-92 1.03 CGS

" $10-22-93 \quad 4$ LPS

" 03-04-94 5 MPM

" 5-19-94 6 LPS

Resets $P$ and $H$ to initial set

COMMENTS"

ORIGINAL RELEASE"

Renamed BCEP BCESP"

Converted to a(4)"

Implement SI Units"

Calc. Tout with part. press. "

points after reverse flow"

MACRO PRINT BCESP _ ID - TRAX Version 6 (5/19/94)

" INPUTS:"

" PRESS - Boundary condition pressure (psia or bar) "

" ENTH - Boundary condition enthalpy (Btu/lbm or $\mathrm{kJ} / \mathrm{kg}$ ) "

" OUTPUTS:"

" A WL(3)- NODE NUMBER OF UPSTREAM PRESSURE (NONE)"

" H_WL - ENTHALPY OF FLUID ENTERING MODEL (Btu/lbm or $\mathrm{kJ} / \mathrm{kg})$ "

" PWL - PRESSURE OF FLUID ENTERING MODEL (psia or bar)"

"TWL - TEMPERATURE OF FLUID ENTERING MODEL (F or $C$ ) "

ARRAY A_WL(4)

constant A_WL(3) $=0.0$

CONSTANT $P$ WL $=$ PRESS

Rev.6

CONSTANT H_WL $=$ ENTH

Rev.6

CONSTANT X_WL $=1$.

PROCEDURAL(T WL $=P$ WL,H WL,X WL,ZXMARK)

DUMMY $=1.608^{*} X W L^{{ }^{*} P} W L^{-} /\left(\left(1-X{ }^{-} W L\right)+1.608^{*} X[W L)\right.$ $T_{-} W L=T O F P H(D U M M Y, \bar{H}[W L)$ END

MACRO END \$ "BCESP"

Rev.4 


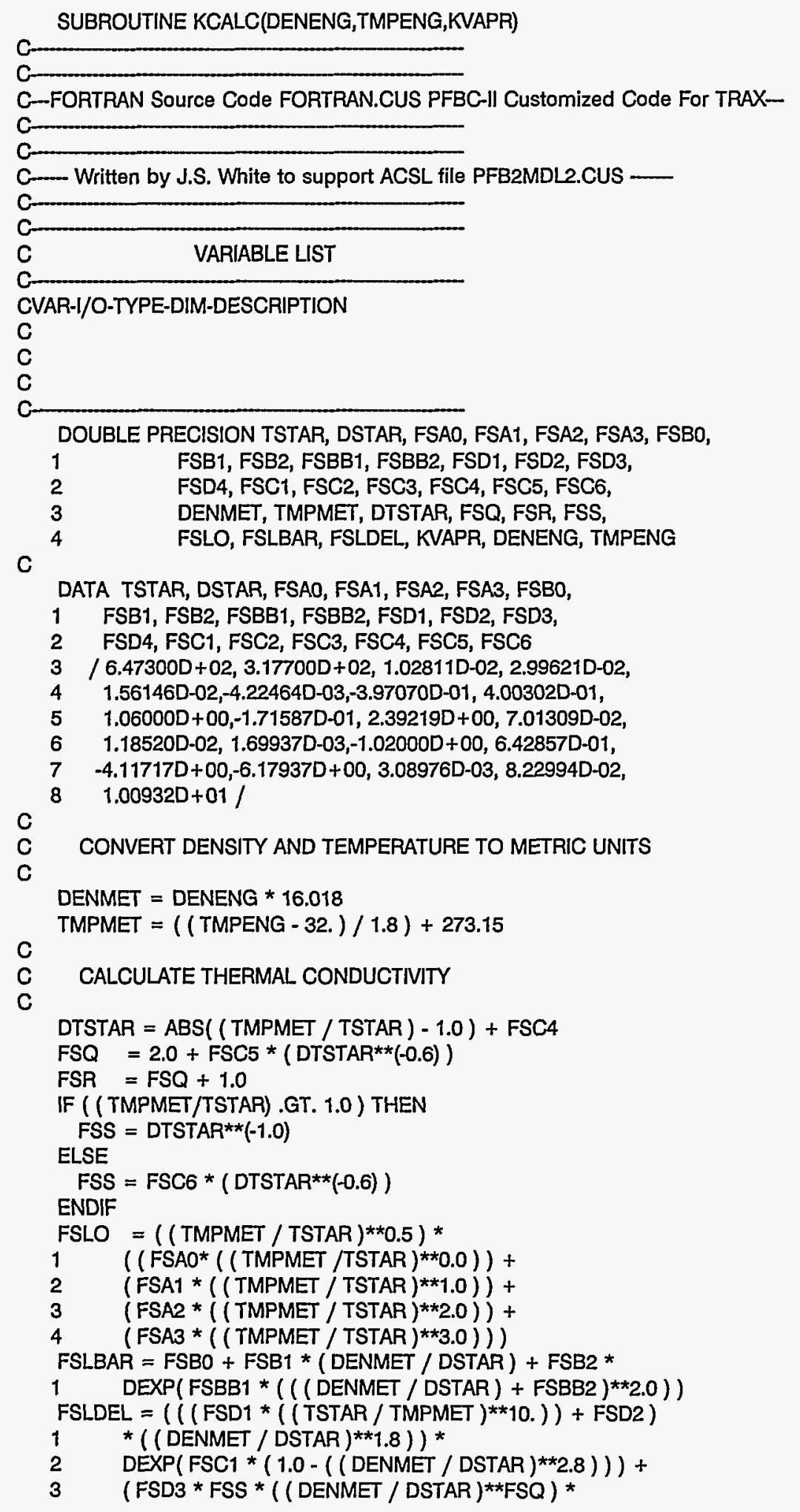

\section{K-1}




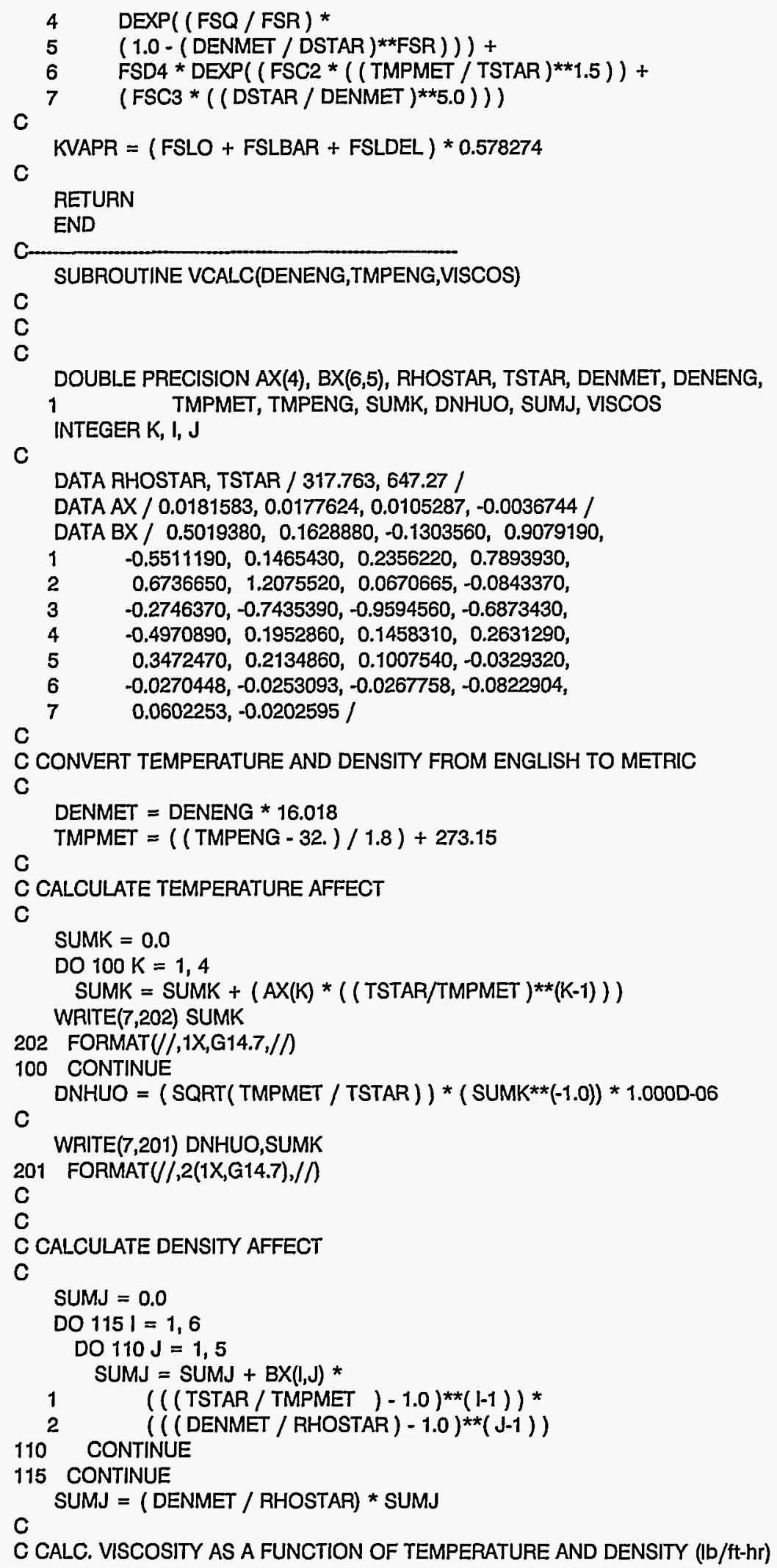

C CALC. VISCOSITY AS A FUNCTION OF TEMPERATURE AND DENSITY (Ib/ft-hr)

\section{$\boldsymbol{K}-2$}


C

C

VISCOS $=($ DNHUO * EXP(SUMJ $)) * 2419.11$

200 CONTINUE

RETURN

END

K-3 
ACSL Source Code PFB2MDL2.CUS PFBC-II Customized Code For TRAX

CODE DEVELOPED BY:

Jay $S$. White

Gilbert/Commonwealth, Inc. P.O. Box 1498

Reading, PA 19603
Mark R. Torpey

Foster Wheeler Dulp. Corp. 12 Peach Tree Hill Road Livingston, NJ 07039

VARIABLE LIST

\section{"VAR-I/O-TYPE-DIM-DESCRIPTION}

"ABW I R 1 CARBONIZER SOLID/WALL HEAT TRANFER AREA ( $\left(\mathrm{t}^{\wedge} 2\right.$ ) "ABWPZ I R 1 PRIMARY ZONE SOLID/WALL AREA FOR Q TRANSFER (ft^2) "ABWSZ I $R$ 1 SECONDARY ZONE SOLID/WALL AREA FOR $Q$ TRANSFER ( $\mathrm{ft}^{\wedge} 2$ "ACCNDT I R 1 ASH COOLER FLOW CONDUCTANCE

"ACDELZI R 1 ASH COOLER ELEVATION DIFFERENCE (ft)

"ACDUTY O R 1 ASH COOLER DUTY (Btu/hr)

"ACEFF O R 1 ASH COOLER, HEAT TRANSFER EFFECTIVENESS (dim) "ACNTU O R 1 ASH COOLER, NUMBER OF HEAT TRANSFER UNITS (dim) "AFX3 O R 4 INTERCONNECTION VARIABLE ARRAY FOR STREAM FX3 "AMWFX3 O R 1 AVERAGE MOLECULAR WEIGHT, MI VARIABLE FX3 "AMWSO1 O R 1 AVERAGE MOLECULAR WEIGHT, MI VARIABLE SO1 "AMWSO3 O R 1 AVERAGE MOLECULAR WEIGHT, MI VARIABLE SO3 "ASI1 I R 4 INTERCONNECTION VARIABLE ARRAY FOR STREAM SI1 "ASI2 I R 4 INTERCONNECTION VARIABLE ARRAY FOR STREAM SI2 "ASI3 I R 4 INTERCONNECTION VARIABLE ARRAY FOR STREAM SI3 "ASI4 I R 4 INTERCONNECTION VARIABLE ARRAY FOR STREAM SI4 "ASI5 I R 4 INTERCONNECTION VARIABLE ARRAY FOR STREAM SI5 "ASI6 I R 4 INTERCONNECTION VARIABLE ARRAY FOR STREAM SI6 "ASI7 I R 4 INTERCONNECTION VARIABLE ARRAY FOR STREAM SI7 "ASI8 I R 4 INTERCONNECTION VARIABLE ARRAY FOR STREAM SI8 "ASI9 I R 4 INTERCONNECTION VARIABLE ARRAY FOR STREAM SI9 "ASIA I R 4 INTERCONNECTION VARIABLE ARRAY FOR STREAM SIA "ASIB I R 4 INTERCONNECTION VARIABLE ARRAY FOR STREAM SIB "ASIC I R 4 INTERCONNECTION VARIABLE ARRAY FOR STREAM SIC "ASID I R 4 INTERCONNECTION VARIABLE ARRAY FOR STREAM SID "ASIE I R 4 INTERCONNECTION VARIABLE ARRAY FOR STREAM SIE "ASIF I R 4 INTERCONNECTION VARIABLE ARRAY FOR STREAM SIF "ASIG I R 4 INTERCONNECTION VARIABLE ARRAY FOR STREAM SIG "ASIH I R 4 INTERCONNECTION VARIABLE ARRAY FOR STREAM SIH "ASII I $R$ INTERCONNECTION VARIABLE ARRAY FOR STREAM SII "ASIJ I R 4 INTERCONNECTION VARIABLE ARRAY FOR STREAM SIJ "ASIK I R 4 INTERCONNECTION VARIABLE ARRAY FOR STREAM SIK "ASO1 O R 4 INTERCONNECTION VARIABLE ARRAY FOR STREAM SO1 "ASO3 O R 4 INTERCONNECTION VARIABLE ARRAY FOR STREAM SO3 "ASO4 O R 4 INTERCONNECTION VARIABLE ARRAY FOR STREAM SO4 "ASO5 O R 4 INTERCONNECTION VARIABLE ARRAY FOR STREAM SO5 "ASO6 O R 4 INTERCONNECTION VARIABLE ARRAY FOR STREAM SO6 "ATCOND I $R$ I SUPERHEATER ATTEMPERATOR FLOW CONDUCTANCE

"AVGMWZ O R 1 CARBONIZER FUEL GAS AVERAGE MOLECULAR WEIGHT(Ib/lbmole)" 
"AWETTD I R 1 GAS TURBINE WETTED AREA (ft^2)

"AXFBC1 I R 1 CROSS SECTIONAL AREA OF FBHE CELL \# $1\left(\mathrm{ft}^{\wedge} 2\right)$

"AXFBC2 I R 1 CROSS SECTIONAL AREA OF FBHE CELL \# $2\left(\mathrm{ft}^{\wedge} 2\right)$

"AXFBC3 I R 1 CROSS SECTIONAL AREA OF FBHE CELL \# $3\left(\mathrm{ft}^{\wedge} 2\right)$

"AXFBC4 I R 1 CROSS SECTIONAL AREA OF FBHE CELL \# 4 (f^^2)

"AXFBC5 I R 1 CROSS SECTIONAL AREA OF FBHE CELL \# $5\left(\mathrm{ft}^{\wedge} 2\right)$

"AXFBC6 I R 1 CROSS SECTIONAL AREA OF FBHE CELL \# 6 (ft^2)

"AXFBC7 I R 1 CROSS SECTIONAL AREA OF FBHE CELL \# $7\left(\mathrm{ft}^{\wedge} 2\right)$

"AXTAIR I $R$ 1 CROSS SECTIONAL AREA OF CARBONIZER TRANSPORT AIR (ft^2)"

"AXTFR I $R$ I INSIDE TUBE, CROSS SECT AREA, FBHE FINISHING R/H (ft^2)"

"AXTFS I R 1 INSIDE TUBE, CROSS SECT AREA, FBHE FINISHING S/H (ft^2)"

"AXTPR I R 1 INSIDE TUBE, CROSS SECT AREA, FBHE PRIMARY R/H (ft^2) "

"AXTPS I R 1 INSIDE TUBE, CROSS SECT AREA, FBHE PRIMARY S/H (ft^2) "

"AXTRSR I R 1 INSIDE TUBE, CROSS SECT AREA, FBHE DRUM RISER (ft²) "

"AXTSG I R 1 INSIDE TUBE, CROSS SECT AREA, FBHE STEAM GENRATN (ft^2)"

"AXTSS I $R$ I INSIDE TUBE, CROSS SECT AREA, FBHE SECONDARY S/H (ft^2)"

"BEDVLM O R 1 CARBONIZER SOLID BED VOLUME (ft^3)

"BHTCPZ O R 1 CPFBC PRIMARY ZONE BED HEIGHT (ft)

"C16OUT I R 1 CONTROL SIGNAL, CARBONIZER LOOP \# 1

"C27OUT I R 1 CONTROL SIGNAL, CARBONIZER LOOP \# 2

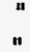

"CACC O R 1 ASH COOLER NTU-e, COLD FLUID CAPACITY RATE (Btu/hr-F) "

"CACH O R 1 ASH COOLER NTU-e, HOT FLUID CAPACITY RATE (Btu/hr-F) "

"CARBO2 O R 1 FLOW OF O2 TO CARBONIZER (lbmole/hr)

"CFSFS I R 1 FBHE SUPERHEATER CELLS SOLIDS FLOW CONDUCTANCE

"CFSSR I R 1 FBHE REHEATER CELLS SOLIDS FLOW CONDUCTANCE

"CGTCMB I R 1 TOPPING COMBUSTOR GAS FLOW CONDUCTANCE

"CHRASH O R 1 CARBONIZER SOLID CHAR GENERATION, ASH, (lb/hr)

"CHRCAC O R 1 CARBONIZER SOLID CHAR GENERATION, CaCO3, (lb/hr) "

"CHRCAO O R 1 CARBONIZER SOLID CHAR GENERATION, CaO, (lb/hr)

"CHRCAR O $R$ 1 CARBONIZER SOLID CHAR GENERATION, CARBON, (lb/hr) "

"CHRCAS O R 1 CARBONIZER SOLID CHAR GENERATION, CaS, (lb/hr)

"CHRCS4 O R 1 CARBONIZER SOLID CHAR GENERATION, CaSO4, (lb/hr)

"CHRGEN O $R$ 1 CARBONIZER TOTAL SOLID CHAR GENERATION (lb/hr)

"CHRINT O R 1 CARBONIZER SOLID CHAR GENERATION, INERTS, (lb/hr)

"CHRMGO O R 1 CARBONIZER SOLID CHAR GENERATION, MgO, (lb/hr)

"CHRSLF O R 1 CARBONIZER SOLID GHAR GENERATION, SULFUR, (lb/hr)

"CHSASH O R 1 CHAR COMPOSITION EXITING CHAR HOPPER, ASH (lb/hr) "

"CHSCAC O R 1 CHAR COMPOSITION EXITING CHAR HOPPER, CaCO3 (lb/hr) "

"CHSCAO O R 1 CHAR COMPOSITION EXITING CHAR HOPPER, CaO (lb/hr)

"CHSCAR O R 1 CHAR COMPOSITION EXITING CHAR HOPPER, CARBON (lb/hr) "

"CHSCAS O R 1 CHAR COMPOSITION EXITING CHAR HOPPER, CaS (ib/hr)

"CHSCS4 O R 1 CHAR COMPOSITION EXITING CHAR HOPPER, CaSO4 (lb/hr) "

"CHSINT O R 1 CHAR COMPOSITION EXITING CHAR HOPPER, INERTS (lb/hr) "

"CHSMGO O R 1 CHAR COMPOSITION EXITING CHAR HOPPER, MgO (lb/hr)

"CHSSLF O R 1 CHAR COMPOSITION EXITING CHAR HOPPER, SULFUR (lb/hr) "

"CIRCCD O R 1 FBHE STEAM DRUM RECIRCULATING FLOW CONDUCTANCE "CMAX O R 1 ASH COOLER MAXIMUM FLUID CAPACITY RATE (Btu/hr F)

"CMBASH O R 1 CPFBC CHAR GENERATION, ASH, (lb/hr)

"CMBCAC O R 1 CPFBC CHAR GENERATION, $\mathrm{CaCO3,}(\mathrm{lb} / \mathrm{hr})$

"CMBCAO O R 1 CPFBC CHAR GENERATION, $\mathrm{CaO}$, (b/hr)

"CMBCAR O R 1 CPFBC CHAR GENERATION, CARBON, (lb/hr)

"CMBCAS O R 1 CPFBC CHAR GENERATION, CaS, (lb/hr)

"CMBCH4 O R 1 CPFBC INSTANTANEOUS GAS MAKE, CH4, (lb/hr)

"CMBCO O R 1 CPFBC INSTANTANEOUS GAS MAKE, CO, (lb/hr)

"CMBCO2 $O R 1$ CPFBC INSTANTANEOUS GAS MAKE, CO2, (b/hr)

"CMBCS4 O R 1 CPFBC CHAR GENERATION, CaSO4, (lb/hr)

"CMBH2 O R 1 CPFBC INSTANTANEOUS GAS MAKE, H2, (lb/hr)

"CMBH2O O R 1 CPFBC INSTANTANEOUS GAS MAKE, H2O, (lb/hr)

"CMBINT O R 1 CPFBC CHAR GENERATION, INERT MATERIAL, (lb/hr)

"CMBMGO O $\mathrm{R} 1 \mathrm{CPFBC}$ CHAR GENERATION, MgO, (lb/hr)

"CMBN2 O R 1 CPFBC INSTANTANEOUS GAS MAKE, N2, (lb/hr)

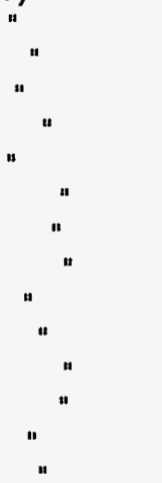


"CMBO2 O R 1 CPFBC INSTANTANEOUS GAS MAKE, O2, (lb/hr)

"CMBSLF O R 1 CPFBC CHAR GENERATION, SULFUR, (lb/hr)

"CMBSO2 O R 1 CPFBC INSTANTANEOUS GAS MAKE, SO2, (lb/hr)

"CMIN O R 1 ASH COOLER MINIMUM FLUID CAPACITY RATE (Btu/hr F)

"CNDFBH I R 1 FBHE FLUIDIZING AIR TO CPFBC FLOW CONDUCTANCE

"COMBST O R 1 CPFBC STOICHIOMETRY

"CONELZI R 1 CARBONIZER CONE HEIGHT (ft)

"CONEVZI R 1 CARBONIZER CONE VOLUME (ft^3)

"CPAIRT I R 1 HEAT CAPACITY, AIR (Btu/lb-F)

"CPCHAR I R 1 HEAT CAPACITY, CPFBC CHAR FEED (Btu/lb-F)

"CPCOL I R 1 HEAT CAPACITY, FRESH COAL PITT \# 8 (Btu/lb-F)

"CPDRN I R 1 HEAT CAPACITY, CARBONIZER DRAIN SOLIDS (Btu/lb-F)

"CPELU I R 1 HEAT CAPACITY, CARBONIZER ELUTRIATED SOLIDS (Btu/lb-F) "

"CPFGS I R 1 HEAT CAPACITY, CARBONIZER FUEL GAS (Btu/lb-F)

"CPFR I R 1 HEAT CAPACITY, STEAM IN FINISHING R/H (Btu/lb-F)

"CPFS I R 1 HEAT CAPACITY, STEAM IN FINISHING S/H (Btu/lb-F)

"CPGT I $R$ 1 HEAT CAPACITY, TOPPING COMBUSTOR EXHAUST GAS (Btu/lb-F)" "CPHARD I $R$ I HEAT CAPACITY, CARBONIZER HARD FACE REFRACT (Btu/lb-F) " "CPPR I R 1 HEAT CAPACITY, STEAM IN PRIMARY R/H (Btu/lb-F)

"CPPS I R 1 HEAT CAPACITY, STEAM IN PRIMARY S/H (Btu/lb-F)

"CPRFFB I R 1 HEAT CAPACITY, COMBUSTOR HARD FACE REFRACT (Btu/lb-F) "

"CPRSR I R 1 HEAT CAPACITY, TWO PHASE FLOW FBHE S/D RISER (Btu/lb-F)"

"CPSG I R 1 HEAT CAPACITY, STEAM GENERATION (Btu/lb-F)

"CPSLD I R 1 HEAT CAPACITY, SOLIDS IN PFBC/FBHE (Btu/lb-F)

"CPSLDS I R 1 HEAT CAPACITY, SOLIDS IN ASH COOLER (Btu/Ib-F)

"CPSRB I R 1 HEAT CAPACITY, DOLOMITE SORBENT (Btu/lb-F)

"CPSS I R 1 HEAT CAPACITY, STEAM IN SECONDARY S/H (Btu/lb-F)

"CPVA I R 1 HEAT CAPACITY, CPFBC VITIATED AIR (Btu/lb-F)

"CPWA I R 1 HEAT CAPACITY, WATER ENTERING ASH COOLER (Btu/lb-F) "

"CRATE O R 1 CPFBC/FBHE SOLIDS CIRCULATION RATE (lb/hr)

"CRBASH O R 1 CARBONIZER BED INVENTORY OF ASH (lb)

"CRBBED O R 1 TOTAL CARBONIZER BED INVENTORY (b)

"CRBCAC O R 1 CARBONIZER BED INVENTORY OF CaCO3 (lb)

"CRBCAO O R 1 CARBONIZER BED INVENTORY OF $\mathrm{CaO}$ (lb)

"CRBCAR O R 1 CARBONIZER BED INVENTORY OF CARBON (lb)

"CRBCAS O R 1 CARBONIZER BED INVENTORY OF CaS (lb)

"CRBCS4 O R 1 CARBONIZER BED INVENTORY OF CaSO4 (lb)

"CRBINT O R 1 CARBONIZER BED INVENTORY OF INERT MATERIAL (lb)

"CRBMGO O R 1 CARBONIZER BED INVENTORY OF MgO (lb)

"CRBSLF O R 1 CARBONIZER BED INVENTORY OF SULFUR (b)

"CVFBDN I R 1 CV ON FBHE DRAIN FLOW (dim)

"CVHOPR I R $1 \mathrm{CV}$ ON CHAR HOPPER SOLIDS OUTLET FLOW (dim)

"CVSFS I R $1 \mathrm{CV}$ ON FBHE SOLIDS FLOW TO SUPERHEATER PASS (dim)

"CVSSR I R $1 \mathrm{CV}$ ON FBHE SOLIDS FLOW TO REHEATER PASS (dim)

"DDDTGT O $R 1$ PRESSURE DROP INTEGRAL, TOPPING COMBUSTOR

"DDPDTA O R 1 PRESSURE DROP INTEGRAL, S/H ATTEMPERATOR

"DELHD I R 1 FBHE STEAM DRUM DOWNCOMER LENGTH ( $\mathrm{ft}$ )

"DHDTDC O R 1 CHANGE IN ENTHALPY WITH TIME, FBHE DOWNCOMER (dim) "

"DHDTDR O $R 1$ CHANGE IN ENTHALPY WITH TIME, FBHE STEAM DRUM (dim)

"DHDTFR O R 1 CHANGE IN ENTHALPY WITH TIME, FINISHING R/H (dim)

"DHDTFS O R 1 CHANGE IN ENTHALPY WITH TIME, FINISHING S/H (dim)

"DHDTPR O R 1 CHANGE IN ENTHALPY WITH TIME, PRIMARY R/H (dim)

"DHDTPS O R 1 CHANGE IN ENTHALPY WITH TIME, PRIMARY S/H (dim)

"DHDTRS O R 1 CHANGE IN ENTHALPY WITH TIME, FBHE STEAM RISER (dim) "

"DHDTSA O R 1 CHANGE IN ENTHALPY WITH TIME, S/H ATTEMPERATOR (dim) "

"DHDTSP O R 1 CHANGE IN ENTHALPY WITH TIME, S/H STEAM PIPING (dim) "

"DHDTSS O R 1 CHANGE IN ENTHALPY WITH TIME, SECONDARY S/H (dim)

"DIACFB I R 1 CPFBC SECONDARY ZONE DIAMETER (ft)

"DIACPZI R 1 CPFBC PRIMARY ZONE DIAMETER (ft)

"DIAELU I R 1 CARBONIZER FREEBOARD DIAMETER $(\mathrm{ft})$

"DIAHPR I R 1 CHAR HOPPER DIAMETER (ft) 
"DIAMFL I R 1 CARBONIZER FLUIDIZED ZONE SHELL DIAMETER (ft)
"DP1DP2 O R 1 RATIO 2 PHASE/ 1 PHASE STEAM PRESSURE DROP (dim) "DPATMP O R $1 \mathrm{~S} / \mathrm{H}$ ATTEMPERATOR PRESSURE DROP (psi)

"DPDTCZ O R 1 CHANGE IN PRESSURE WITH TIME, CARBONIZER (dim) "DPDTDR O R 1 CHANGE IN PRESSURE WITH TIME, FBHE STEAM DRUM (dim) "DPDTFB O $R 1$ CHANGE IN PRESSURE WITH TIME, FBHE (dim) "DPDTGT O R 1 CHANGE IN PRESSURE WITH TIME, TOPPING COMBUSTOR (dim) " "DPDTPC $O R 1$ CHANGE IN PRESSURE WITH TIME, CPFBC (dim) "DPDTSA O R 1 CHANGE IN PRESSURE WITH TIME, S/H STEAM ATTEMP (dim) " "DPDTSP O R 1 CHANGE IN PRESSURE WITH TIME, S/H STEAM MANIFOLD (dim) " "DPFB I R 15 CPFBC FREEBOARD SOLIDS PARTICLE DIAMETERS (ft) "DPFBCC I R 15 CPFBC FREEBOARD SOLIDS PARTICLE DIAMETERS (microns) " "DPFD I R 15 CARBONIZER SOLID FEED PARTICLE DIAMETERS (ft) "DPFEED I R 15 CARBONIZER SOLID FEED PARTICLE DIAMETERS (microns) " "DPSAIC I R 1 INITIAL CONDITION, S/H ATTEMP PRESSURE DROP (psi) "DPSPIC I R 1 INITIAL CONDITION, STM PIPING PRESSURE DROP (psi) "DPSTP I R 1 STEAM PIPING PRESSURE DROP (psi) "DPTERM O R 1 PRESSURE DROP INTEGRAL FOR S/H PIPING/GOVENOR "DRAINL I $R$ 1 CARBONIZER DRAIN HEIGHT (tt) "DRANCV I R 1 CARBONIZER DRAIN FLOW CV (dim) "DRDHDC O R 1 PARTIAL OF DENSITY W.R.T. ENTHALPY, FBHE DRUM DOWNCOMER" "DRDHDR O R 1 PARTIAL OF DENSITY W.R.T. ENTHALPY, FBHE STEAM DRUM " "DRDHPS O $R 1$ PARTIAL OF DENSITY W.R.T. ENTHALPY, S/H ATTEMPRTATOR " "DRDHRS O R 1 PARTIAL OF DENSITY W.R.T. ENTHALPY, FBHE DRUM RISER " "DRDHSP O R 1 PARTIAL OF DENSITY W.R.T. ENTHALPY, S/H STEAM PIPING " "DRDPDC O $R$ 1 PARTIAL OF DENSITY W.R.T. PRESSURE, FBHE DRUM DOWNCOMER" "DRDPDR O R 1 PARTIAL OF DENSITY W.R.T. PRESSURE, FBHE STEAM DRUM " "DRDPPS O $R$ I PARTIAL OF DENSITY W.R.T. PRESSURE, S/H ATTEMPRTATOR " "DRDPRS O R 1 PARTIAL OF DENSITY W.R.T. PRESSURE, FBHE DRUM RISER " "DRDPSP $O R 1$ PARTIAL OF DENSITY W.R.T. PRESSURE, S/H STEAM PIPING " "DRDTGT O $R$ I CHANGE IN DENSITY WITH TIME, TOPPING COMBUSTOR GAS " "DRDTGV O R 1 CHANGE IN DENSITY WITH TIME, S/H PIPING/GOVENOR "DRDTSA O R 1 CHANGE IN DENSITY WITH TIME, S/H ATTEMPERATOR "DRGCBD $O 115$ CARBONIZER SOLID BED PARTICAL DRAG COEFFICIENT "DRGPFB O 115 CPFBC SOLIDS DRAG COEFFICIENT "DRGPSF $O 115$ CARBONIZER INSTANTANEOUS CHAR DRAG COEFFICIENT "DRMDIA I 11 FBHE STEAM DRUM DIAMETER ( $\mathrm{ft}$ "DRNASH O R 1 FBHE DRAIN SOLIDS FLOW RATE, ASH (lb/hr) "DRNCAC O R 1 FBHE DRAIN SOLIDS FLOW RATE, CaCO3 (lb/hr) "DRNCAO O $R$ 1 FBHE DRAIN SOLIDS FLOW RATE, CaO $(\mathrm{lb} / \mathrm{hr})$ "DRNCAR O $R$ 1 FBHE DRAIN SOLIDS FLOW RATE, CARBON $(\mathrm{lb} / \mathrm{hr})$ "DRNCAS O $R 1$ FBHE DRAIN SOLIDS FLOW RATE, CaS (lb/hr) "DRNCS4 O R 1 FBHE DRAIN SOLIDS FLOW RATE, CaSO4 (lb/hr) "DRNINT O R 1 FBHE DRAIN SOLIDS FLOW RATE, INERT $(\mathrm{lb} / \mathrm{hr})$ "DRNMGO O $R$ 1 FBHE DRAIN SOLIDS FLOW RATE, MgO (lb/hr) "DRNSLF O R 1 FBHE DRAIN SOLIDS FLOW RATE, SULFUR (tb/hr) "DRNTLT O R 1 FBHE DRAIN TOTAL SOLIDS FLOW RATE (lb/hr) "DRNVLM I $R$ 1 CARBONIZER VOLUME AT DRAIN HEIGHT ( $\left.\mathrm{ft}{ }^{\wedge} 3\right)$ "DRUMHT O $R$ 1 FBHE STEAM DRUM LIQUID HEIGHT (ft)

"DSFR O R $1 \mathrm{~F} / \mathrm{R}$ STEAM DENSITY (Ib/ft^3)

"DSFS O R $1 \mathrm{~F} / \mathrm{S}$ STEAM DENSITY $\left(\mathrm{lb} / \mathrm{ft}^{\wedge} 3\right)$

"DSPR O R 1 P/R STEAM DENSITY (lb/ft^3)

"DSPS $O$ R $1 \mathrm{P} / \mathrm{S}$ STEAM DENSITY (ib/ft^ 3 )

"DSRSR O R 1 FBHE STEAM DRUM ENCLOSURE WALLS STEAM DENSITY (lb/f^3)" "DSSG O R 1 STEAM GENERATOR TUBE BUNDLE STEAM DENSITY (lb/ft^3) " "DSSS O R $1 \mathrm{~S} / \mathrm{S}$ STEAM DENSITY (Ib/ft^3) "DTDTBF O R 1 CHANGE IN TEMPERATURE W/ TIME CARBONIZER BARRIER FILTER" "DTDTC1 O R 1 CHANGE IN TEMPERATURE WITH TIME, FBHE CELL \# 1 (dim) " "DTDTC2 O R 1 CHANGE IN TEMPERATURE WITH TIME, FBHE CELL \# 2 (dim) " "DTDTC3 O R 1 CHANGE IN TEMPERATURE WITH TIME, FBHE CELL \# 3 (dim) " "DTDTC4 O R 1 CHANGE IN TEMPERATURE WITH TIME, FBHE CELL \# 4 (dim) " 
"DTDTC5 O R 1 CHANGE IN TEMPERATURE WITH TIME, FBHE CELL \# 5 (dim) " "DTDTC6 O R 1 CHANGE IN TEMPERATURE WITH TIME, FBHE CELL \# 6 (dim) " "DTDTC7 O R 1 CHANGE IN TEMPERATURE WITH TIME, FBHE CELL \# 7 (dim) " "DTDTCC $O R$ 1 CHANGE IN TEMPERATURE WITH TIME, CARBONIZER CYCLONE "DTDTCF $O$ R 1 CHANGE IN TEMPERATURE WITH TIME, CARBONIZER FILTER "DTDTCL O R 1 CHANGE IN TEMPERATURE WITH TIME, CPFBC FILTER "DTDTCZ O R 1 CHANGE IN TEMPERATURE WITH TIME, CARBONIZER (dim) "DTDTFB O R 1 CHANGE IN TEMPERATURE WITH TIME, FBHE FREEBOARD (dim) " "DTDTGP O R 1 CHANGE IN TEMPERATURE WITH TIME, VITIATED AIR PIPING " "DTDTGT O $R$ I CHANGE IN TEMPERATURE WITH TIME, TOPPING COMBUSTOR(dim)" "DTDTPC $O$ R 1 CHANGE IN TEMPERATURE WITH TIME, CPFBC (dim) "DTDTRF O R 1 CHANGE IN TEMPERATURE WITH TIME, CPFBC HARD FACE (dim) " "DTHARD O R 1 CHANGE IN TEMPERATURE WITH TIME, CARBONIZER HARD FACE " "DTMTGT O $R$ 1 CHANGE IN TEMPERATURE WITH TIME, TOP COMB METAL (dim) " "DVDTFB O R 1 CHANGE IN GAS VOLUME WITH TIME, FBHE FREEBOARD (dim) " "DWDTGV O R 1 CHANGE IN FLOWRATE, S/H PIPING "DWDTRS O R 1 CHANGE IN FLOWRATE, FBHE STEAM DRUM RISER "DWDTSA O R 1 CHANGE IN FLOWRATE, S/H ATTEMPERATOR "EFF I $R$ I CARBONIZER COMBUSTION EFFICIENCY (decimal) "EMISS I R 1 FBHE FREEBOARD EMISSITIVITY (decimal) "FBCIRC I R 1 CPFBC SOLIDS CIRCULATION RATE (lb/hr) "FBCYCN I R 1 CPFBC CYCLONE CAPTURE EFFICIENCY (decimal) "FBHASH O R 1 FBHE SOLIDS INVENTORY, ASH (Ib) "FBHCAC O R 1 FBHE SOLIDS INVENTORY, CaCO3 (lb) "FBHCAO O R 1 FBHE SOLIDS INVENTORY, CaO (lb) "FBHCAR O $R$ 1 FBHE SOLIDS INVENTORY, CARBON (lb) "FBHCAS O R 1 FBHE SOLIDS INVENTORY, CaS (lb) "FBHCS4 O R 1 FBHE SOLIDS INVENTORY, CaSO4 (lb) "FBHDRN O R 1 FBHE SOLIDS DRAIN FLOW RATE (lb/hr) "FBHEAXI R 1 FBHE CROSS SECTIONAL AREA (ft^2) "FBHEFB I $A$ I FBHE FREEBOARD HEIGHT (tt) "FBHEHT O R 1 FBHE SOLIDS HEIGHT (ft) "FBHINT O R 1 FBHE SOLIDS INVENTORY, INERT (lb) "FBHMGO O R 1 FBHE SOLIDS INVENTORY, MgO (lb) "FBHSLF O R 1 FBHE SOLIDS INVENTORY, SULFUR (lb) "FBHTLT O R 1 TOTAL FBHE SOLIDS INVENTORY (lb) "FBWEIR I $R$ 1 FBHE SOLIDS WEIR HEIGHT (ft) "FC O R 1 FRACTION CARBON CONVERTED IN CARBONIZER "FCCOMB O R 1 FRACTION CARBON CONVERTED IN COMBUSTOR "FCH4 O R 1 MOLE CH4 IN FUEL GAS PER MOLE CARBON IN COAL "FRACCC O $R 1$ EXTENT OF CALCINATION IN CPFBC (decimal) "FRBEDA I R 1 FBHE F/R IN-BED ENCLOSURE WALL AREA (ft^2) "FRCALC O R 1 PERCENT CALCINATION IN CARBONIZER (decimal) "FRCCH4 O R 1 MOLE CH4 IN FUEL GAS PER MOLE CARBON IN COAL "FRHI O R 1 FBHE F/R TUBE SIDE Q TRANFER COEFFICIENT (Btu/hr-ft²) " "FRPR O R 1 FBHE F/R TUBE SIDE PANDTL NUMBER (dim) "FRRE $O R \quad 1$ FBHE F/R TUBE SIDE REYNOLDS NUMBER (dim) "FRTD I R 1 FBHE F/R TUBE ID (ft) "FRTL I R 1 FBHE F/R TUBE LENGTH (ft) "FRWFBA I R 1 FBHE F/R ENCLOSURE WALL AREA ( $\left.\mathrm{ft}^{\wedge} 2\right)$ "FSBEDA I $R$ 1 FBHE F/S IN-BED ENCLOSURE WALL AREA (ft^2) "FSCOND I R 1 FBHE F/S FLOW CONDUCTANCE "FSHI O R 1 FBHE F/S TUBE SIDE Q TRANFER COEFFICIENT (Btu/hr-ft^2) " "FSPR O R 1 FBHE F/S TUBE SIDE PANDTL NUMBER (dim) "FSRE O R 1 FBHE F/S TUBE SIDE REYNOLDS NUMBER (dim) "FSSVEL O R 1 FBHE F/S TUBE SIDE STEAM VELOCITY (ft/sec) "FSTD I $R$ I FBHE F/S TUBE ID (ft) "FSTL I R 1 FBHE F/S TUBE LENGTH (ft) "FSWFBA I R 1 FBHE F/S ENCLOSURE WALL AREA (ft^2) "GASPRD O R 1 INSTANTANEOUS GAS MAKE FLOW RATE, CPFBC (lb/hr) "GTFILM I R 1 TOPPING COMBUSTOR METAL/GAS HEAT TRANSFER COEFFICIENT " 
"GTIC24 O R 1 TOPPING COMBUSTOR INLET FLOW,C2H4 (lb/hr)

"GTIC26 O R 1 TOPPING COMBUSTOR INLET FLOW,C2H6 (lb/hr)

"GTICAR O R 1 TOPPING COMBUSTOR INLET FLOW,CARBON (lb/hr)

"GTICH4 O R 1 TOPPING COMBUSTOR INLET FLOW,CH4 (lb/hr)

"GTICO O R 1 TOPPING COMBUSTOR INLET FLOW,CO (lb/hr)

"GTICO2 O R 1 TOPPING COMBUSTOR INLET FLOW,CO2 (lb/hr)

"GTIH2 O R 1 TOPPING COMBUSTOR INLET FLOW, H2 (lb/hr)

"GTIH2O O R 1 TOPPING COMBUSTOR INLET FLOW,H2O (lb/hr)

"GTIN2 O R 1 TOPPING COMBUSTOR INLET FLOW,N2 (lb/hr)

"GTIO2 O R 1 TOPPING COMBUSTOR INLET FLOW,O2 (lb/hr)

"GTISLF O R 1 TOPPING COMBUSTOR INLET FLOW,SULFUR (lb/hr)

"GTISO2 O R 1 TOPPING COMBUSTOR INLET FLOW,SO2 (lb/hr)

"GTMTCP I R 1 TOPPING COMBUSTOR METAL Cp (Btu/lb-F)

"GTMTLMI R 1 TOPPING COMBUSTOR METAL MASS (lb)

"GTOC24 O R 1 TOPPING COMBUSTOR OUTLET FLOW,C2H4 (lb/hr)

"GTOC26 O R 1 TOPPING COMBUSTOR OUTLET FLOW,C2H6 (lb/hr)

"GTOCAR O R 1 TOPPING COMBUSTOR OUTLET FLOW,CARBON (lb/hr)

"GTOCH4 O R 1 TOPPING COMBUSTOR OUTLET FLOW,CH4 (lb/hr)

"GTOCO O R 1 TOPPING COMBUSTOR OUTLET FLOW,CO (lb/hr)

"GTOCO2 O R 1 TOPPING COMBUSTOR OUTLET FLOW,CO2 (lb/hr)

"GTOH2 O R 1 TOPPING COMBUSTOR OUTLET FLOW,H2 (lb/hr)

"GTOH2O O R 1 TOPPING COMBUSTOR OUTLET FLOW,H2O (lb/hr)

"GTON2 O R 1 TOPPING COMBUSTOR OUTLET FLOW,N2 (lb/hr)

"GTOO2 O R 1 TOPPING COMBUSTOR OUTLET FLOW,O2 (lb/hr)

"GTOSLF O R 1 TOPPING COMBUSTOR OUTLET FLOW,SULFUR (lb/hr)

"GTOSO2 O R 1 TOPPING COMBUSTOR OUTLET FLOW,SO2 (lb/hr)

"GTQFRC I R 1 TOPPING COMBUSTOR FRACTIONAL HEAT LOSS (decimal)

"GTSFLW I A 1 TOPPING COMBUSTOR SUPPLEMENTAL FUEL FLOW (lb/hr)

"GTSTOI O R 1 TOPPING COMBUSTER STOICHIOMETRY

"HBW I R 1 CARBONIZER BED/WALL H.T.C. (Btu/hr-ft^2-F)

"HBWCPZI R 1 COMBUSTOR PRIMARY ZONE BED/WALL H.T.C. (Btu/hr-ft^2-F)"

"HBWCSZ I R 1 COMBUSTOR SECONDARY ZONE BED/WALL. H.T.C.(Btu/hr-ft^2-F)"

"HCRSTM I R 1 ENTHALPY OF CARBONIZER STEAM (Btu/lb)

"HDCIC O R 1 FBHE STEAM DRUM DOWNCOMER INLET ENTHALPY (Btu/lb)

"HDCIN O R 1 INITIAL COND, FBHE STEAM DRUM DOWNCOMR ENTHALPY(Btu/Ib)"

"HDOWNC O R 1 FBHE STEAM DRUM DOWNCOMER ENTHALPY (Btu/lb)

"HDOWNF O $R$ 1 FBHE STEAM DRUM DOWNCOMER Hf ENTHALPY (Btu/lb)

"HDOWNG O R 1 FBHE STEAM DRUM DOWNCOMER Hg ENTHALPY (Btu/lb)

"HDRMIC O R 1 INITIAL CONDITION FBHE STEAM DRUM BULK ENTHALPY(Btu/lb)"

"HDRMXF O R 1 FBHE STEAM DRUM DOWNCOMER Hf (Btu/lb)

"HDRUMF O $\mathrm{R} 1$ FBHE STEAM DRUM Hf ENTHALPY (Btu/lb)

"HDRUMG O R 1 FBHE STEAM DRUM Hg ENTHALPY (Btu/lb)

"HFBDRM O R 1 FBHE STEAM DRUM BULK ENTHALPY (Btu/lb)

"HFPSA O R $1 \mathrm{~S} / \mathrm{H}$ ATTEMPERATOR $\mathrm{Hf}(\mathrm{Biu} / \mathrm{lb})$

"HFSTP O R $1 \mathrm{~S} / \mathrm{H}$ PIPING Hf (Btu/lb)

"HFX3 O R 1 COMBUSTOR EXHUAST GAS ENTHALPY (Btu/lb)

"HGOVIC O R 1 INITIAL CONDITION, S/H PIPING ENTHALPY (Btu/lb)

"HGPSA O R $1 \mathrm{~S} / \mathrm{H}$ ATTEMPERATOR $\mathrm{Hg}(\mathrm{Btu} / \mathrm{lb})$

"HGSTP O R 1 S/H PIPING Hg (Btu/lb)

"HOPASH O R 1 CHAR HOPPER INVENTORY, ASH (lb)

"HOPCAC O R 1 CHAR HOPPER INVENTORY, CaCO3 (b)

"HOPCAO O R 1 CHAR HOPPER INVENTORY, CaO (lb)

"HOPCAR O R 1 CHAR HOPPER INVENTORY, CARBON (lb)

"HOPCAS O R 1 CHAR HOPPER INVENTORY, CaS (lb)

"HOPCS4 O R 1 CHAR HOPPER INVENTORY, CaSO4 (lb)

"HOPINT O R 1 CHAR HOPPER INVENTORY, INERT (Ib)

"HOPMGO O R 1 CHAR HOPPER INVENTORY, MgO (lb)

"HOPSLF O R 1 CHAR HOPPER INVENTORY, SULFUR (lb)

"HOPTLT O R 1 TOTAL CHAR HOPPER INVENTORY (lb)

"HPSAIC O R $1 \mathrm{lC}, \mathrm{S} / \mathrm{H}$ ATTEMPERATOR ENTHALPY (Btu/lb)

"HPSATT O R $1 \mathrm{~S} / \mathrm{H}$ ATTEMPERATOR ENTHALPY (Btu/lb)

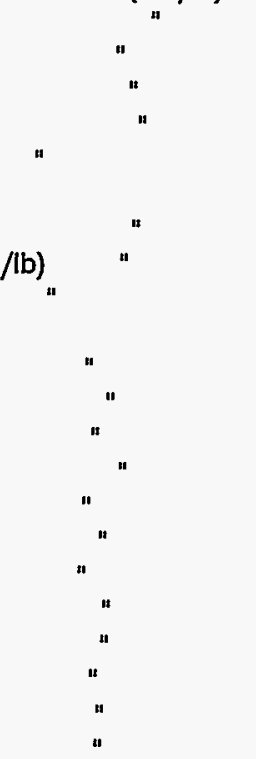


"HRISER O R 1 FBHE STEAM DRUM RISER ENTHALPY (Btu/lb)

"HRISRF O $R 1$ FBHE STEAM DRUM RISER ENTHALPY $\mathrm{f}(\mathrm{Btu} / \mathrm{lb})$

"HRISRG O R 1 FBHE STEAM DRUM RISER ENTHALPY $g(\mathrm{Btu} / \mathrm{lb})$

"HRSR O R 1 FBHE RISER AVERAGE STEAM ENTHALPY (Btu/lb)

"HRSAI O R 1 FBHE RISER INLET STEAM ENTHALPY (Btu/lb)

"HRSRIC I R 1 IC, FBHE RISER OUTLET STEAM ENTHALPY (Btu/lb)

"HRSRO O R 1 FBHE RISER OUTLET STEAM ENTHALPY (Btu/lb)

"HSFR O R $1 \mathrm{~F} / \mathrm{R}$ AVERAGE STEAM ENTHALPY (Btu/lb)

"HSFRI O R 1 F/R INLET STEAM ENTHALPY (Btu/lb)

"HSFRIC I R 1 IC, F/R OUTLET STEAM ENTHALPY (Btu/lb)

"HSFRO O R $1 \mathrm{~F} / \mathrm{R}$ OUTLET STEAM ENTHALPY (Btu/lb)

"HSFS O R $1 \mathrm{~F} / \mathrm{S}$ AVERAGE STEAM ENTHALPY (Btu/lb)

"HSFSI O R $1 \mathrm{~F} / \mathrm{S}$ INLET STEAM ENTHALPY (Btu/lb)

"HSFSIC I R 1 IC, F/S OUTLET STEAM ENTHALPY (Btu/lb)

"HSFSO O R $1 \mathrm{~F} / \mathrm{S}$ OUTLET STEAM ENTHALPY (Btu/lb)

"HSI1 O R $1 \mathrm{MI}$ ENTHALPY OF STREAM SI1 (Btu/lb)

"HSI2 O R 1 MI ENTHALPY OF STREAM SI2 (Btu/lb)

"HSI3 O $R 1$ MI ENTHALPY OF STREAM SI3 (Btu/lb)

"HSI4 O R $1 \mathrm{MI}$ ENTHALPY OF STREAM SI4 (Btu/lb)

"HSI5 O R 1 MI ENTHALPY OF STREAM SI5 (Btu/lb)

"HSI6 O R $1 \mathrm{MI}$ ENTHALPY OF STREAM SI6 (Btu/lb)

"HSI7 $O$ R 1 MI ENTHALPY OF STREAM SI7 (Btu/lb)

"HSI8 O $R$ I MI ENTHALPY OF STREAM SI8 (Btu/lb)

"HSI9 O R 1 MI ENTHALPY OF STREAM SI9 (Btu/lb)

"HSIA $O$ R 1 MI ENTHALPY OF STREAM SIA (Btu/lb)

"HSIB O R 1 MI ENTHALPY OF STREAM SIB (Btu/lb)

"HSIC O R 1 MI ENTHALPY OF STREAM SIC (Btu/lb)

"HSID O R 1 MI ENTHALPY OF STREAM SID (Btu/lb)

"HSIE O R 1 MI ENTHALPY OF STREAM SIE (Btu/lb)

"HSIF O R 1 MI ENTHALPY OF STREAM SIF (Btu/lb)

"HSIG O R 1 MI ENTHALPY OF STREAM SIG (Btu/lb)

"HSIH O R 1 MI ENTHALPY OF STREAM SIH (Btu/lb)

"HSII O R 1 MI ENTHALPY OF STREAM SII (Btu/lb)

"HSIJ O R 1 MI ENTHALPY OF STREAM SIJ (Btu/lb)

"HSIK O R 1 MI ENTHALPY OF STREAM SIK (Btu/lb)

"HSO1 O R 1 MI ENTHALPY OF STREAM SO1 (Btu/lb)

"HSO3 O R 1 MI ENTHALPY OF STREAM SO3 (Btu/lb)

"HSO4 O R $1 \mathrm{MI}$ ENTHALPY OF STREAM SO4 (Btu/lb)

"HSO5 O R 1 MI ENTHALPY OF STREAM SO5 (Btu/lb)

"HSO6 O R $1 \mathrm{Ml}$ ENTHALPY OF STREAM SO6 (Btu/lb)

"HSPRI O R 1 P/R INLET STEAM ENTHALPY (Btu/lb)

"HSPRIC I R 1 IC, P/R OUTLET STEAM ENTHALPY (Btu/lb)

"HSPRO O R 1 P/R OUTLET STEAM ENTHALPY (Btu/lb)

"HSPS O R $1 \mathrm{P} / \mathrm{S}$ AVERAGE STEAM ENTHALPY (Btu/lb)

"HSPSI O R $1 \mathrm{P} / \mathrm{S}$ INLET STEAM ENTHALPY (Btu/lb)

"HSPSIC I R 1 IC, P/S OUTLET STEAM ENTHALPY (Btu/lb)

"HSPSO O R 1 P/S OUTLET STEAM ENTHALPY (Btu/lb)

"HSPZ O R 1 P/R AVERAGE STEAM ENTHALPY (Btu/lb)

"HSSG O $R$ 1 STEAM GENERATION AVERAGE STEAM ENTHALPY (Btu/lb)

"HSSGI O $R$ 1 STEAM GENERATION INLET STEAM ENTHALPY (Btu/lb)

"HSSGO O R 1 STEAM GENERATION OUTLET STEAM ENTHALPY (Btu/lb)

"HSSS O $R 1 \mathrm{~S} / \mathrm{S}$ AVERAGE STEAM ENTHALPY (Btu/lb)

"HSSSI O R $1 \mathrm{~S} / \mathrm{S}$ INLET STEAM ENTHALPY (Btu/lb)

"HSSSIC I R 1 IC, S/S OUTLET STEAM ENTHALPY (Btu/lb)

"HSSSO O R $1 \mathrm{~S} / \mathrm{S}$ OUTLET STEAM ENTHALPY (Btu/lb)

"HSTMRF I R 1 CARBONIZER STEAM REFERENCE ENTHALPY (Btu/lb)

"HTAAC I R 1 ASH COOLER HEAT TRANSFER AREA (ft^2)

"HTCAC I R 1 ASH COOLER H.T.C. (Btu/hr-ft^2-F)

"HTHGOV O R $1 \mathrm{~S} / \mathrm{H}$ STEAM PIPING ENTHALPY (Btu/lb)

"HTMPIC I R 1 IC, S/H STEAM PIPING ENTHALPY (Btu/lb)

"I 011 INTEGER COUNTER 
"INRTNC I R 1 FBHE STEAM DRUM FLOW INERTENCE

"K1 O R 1 CARBONIZER CARBON MOLES

"K1COMB O R 1 COMBUSTOR CARBON MOLES

"K2 O R 1 CARBONIZER HYDROGEN MOLES

"K2COMB O R 1 COMBUSTOR HYDROGEN MOLES

"K3 O R 1 CARBONIZER OXYGEN MOLES

"KЗСОMB O R 1 COMBUSTOR OXYGEN MOLES

"KP O $R 1$ CARBONIZER WATER-GAS SHIFT EQUILIBRIUM CONSTANT "KPCALC O R 1 COMBUSTOR CALCINATION RXN EQUILIBRIUM CONSTANT "KPCOMB O R 1 COMBUSTOR WATER-GAS SHIFT EQUILIBRIUM CONSTANT "KSFR O R $1 \mathrm{~F} / \mathrm{R}$ STEAM THERMAL CONDUCTIVITY (Btu/hr-ft-F) "KSFS O R $1 \mathrm{~F} / \mathrm{S}$ STEAM THERMAL CONDUCTIVITY (Btu/hr-ft-F) "KSPR O R 1 P/R STEAM THERMAL CONDUCTIVITY (Btu/hr-ft-F) "KSPS O R 1 P/S STEAM THERMAL CONDUCTIVITY (Btu/hr-ft-F) "KSRSR O R 1 RSR STEAM THERMAL CONDUCTIVITY (Btu/hr-ft-F) "KSSG O R $1 \mathrm{~S} / \mathrm{G}$ STEAM THERMAL CONDUCTIVITY (Btu/hr-ft-F) "KSSS O R 1 S/S STEAM THERMAL CONDUCTIVITY (Btu/hr-ft-F) "LBED O R 1 CARBONIZER BED HEIGHT (ft)

"LBEDMXI R 1 MAXIMUM CARBONIZER BED HEIGHT (ft)

"LCHOPR O R 1 CHAR HOPPER HEIGHT (ft)

"LCMBPZI R 1 CPFBC PRIMARY ZONE HEIGHT (ft)

"LCMBSZ I R 1 CPFBC SECONDARY ZONE HEIGHT (ft)

"LHVC I $\mathrm{A}$ 1 LOWER HEATING VALUE, CARBON (Btu/lb)

"LHVC24 I R 1 LOWER HEATING VALUE, C2H4 (Btu/lb)

"LHVC26 I R 1 LOWER HEATING VALUE, C2H6 (Btu/lb)

"LHVCAS I R 1 LOWER HEATING VALUE, CaS (Btu/lb)

"LHVCBS O $R$ I LOWER HEATING VALUE, CPFBC SOLIDS (Btu/lb)

"LHVCH4 I R 1 LOWER HEATING VALUE, $\mathrm{CH} 4$ (Btu/lb)

"LHVCHR O $R$ 1 LOWER HEATING VALUE, CARBONIZER CHAR (Btu/lb)

"LHVCIR O R 1 LOWER HEATING VALUE, CPFBC/FBHE CIRCULATING (Btu/lb) "

"LHVCO I R 1 LOWER HEATING VALUE, CO (Btu/lb)

"LHVCOL I $R$ 1 LOWER HEATING VALUE, PITT \#8 (Btu/lb)

"LHVFGS O R 1 LOWER HEATING VALUE, CARBONIZER FUEL GAS (Btu/lb)

"LHVH2 I R 1 LOWER HEATING VALUE, H2 (Btu/lb)

"LHVS I R 1 LOWER HEATING VALUE, SULFUR (Btu/lb)

"LHWA O $R$ 1 LOWER HEATING VALUE, CPFBC VITIATED AIR (Btu/lb) "

"MASSGT O R 1 TOPPING COMBUSTOR GAS MASS (lb)

"MBED O R 15 CARBONIZER SOLID BED MASS ARRAGNED BY PSD (b)

"MEANDI I R 1 MEAN PARTICLE SIZE IN CARBONIZER SOLID BED (ft)

"MFFBHE O R 1 MINIMUM FLUIDIZATION VELOCITY IN FBHE (ft/sec)

"MGASC1 O R 1 GAS MASS AT EVALUATION TIME $t$, FBHE CELL \# 1 (b)

"MGASC2 O $R$ 1 GAS MASS AT EVALUATION TIME $t$, FBHE CELL \# 2 (ib)

"MGASC3 $O$ R 1 GAS MASS AT EVALUATION TIME $t$, FBHE CELL \# 3 (b)

"MGASC4 $O R 1$ GAS MASS AT EVALUATION TIME $t$, FBHE CELL \# 4 (ib)

"MGASC5 O R 1 GAS MASS AT EVALUATION TIME $t$, FBHE CELL \# 5 (lb)

"MGASC6 O R 1 GAS MASS AT EVALUATION TIME $t$, FBHE CELL \# 6 (lb)

"MGASC7 O R 1 GAS MASS AT EVALUATION TIME t, FBHE CELL \# 7 (lb)

"MHARD I $R 1$ CARBONIZER HARD FACE MASS (lb)

"MHRDFB I R 1 COMBUSTOR HARD FACE MASS (lb)

"MINFLU O R 1 CARBONIZER MINIMUM FLUIDIZATION VELOCITY ( $\mathrm{ft} / \mathrm{sec}$

"MSLDC1 O R 1 SOLID MASS AT EVALUATION TIME $t$, FBHE CELL \# 1 (ib)

"MSLDC2 $O R$ 1 SOLID MASS AT EVALUATION TIME t, FBHE CELL \# 2 (Ib)

"MSLDC3 O R 1 SOLID MASS AT EVALUATION TIME $t$, FBHE CELI \# 3 (lb)

"MSLDC4 O R 1 SOLID MASS AT EVALUATION TIME t, FBHE CELL \# 4 (lb)

"MSLDC5 O R 1 SOLID MASS AT EVALUATION TIME $t$, FBHE CELL \# 5 (lb)

"MSLDC6 $O R 1$ SOLID MASS AT EVALUATION TIME $t$, FBHE CELL \# 6 (lb)

"MSLDC7 O R 1 SOLID MASS AT EVALUATION TIME t, FBHE CELL \# 7 (b)

"MUCGAS O R 1 CARBONIZER GAS VISCOSITY (Ibf-sec/ft^2)

"MUFBHE O R 1 FBHE GAS VISCOSITY (ibf-sec/ft^2)

"MUFR O R 1 F/R STEAM VISCOSITY (lbf-sec/ft^2)

"MUFS O R 1 F/S STEAM VISCOSITY (Ibf-sec/tt^2)

$$
\text { " }
$$


"MUGASC O R 1 COMBUSTOR GAS VISCOSITY (Ibf-sec/ft"2)

"MUPR O R 1 P/R STEAM VISCOSITY (Ibf-sec/ft^2)

"MUPS O R 1 P/S STEAM VISCOSITY (lbf-sec/ft^2)

"MURSR O R 1 RSR STEAM VISCOSITY (lbf-sec/ft^2)

"MUSG O R 1 S/G STEAM VISCOSITY (Ibf-sec/ft^2)

"MUSS O R 1 S/S STEAM VISCOSITY (Ibf-Sec/tt^2)

"MWAVGT O R 1 TOPPING COMBUSTOR AVG. MOLECULAR WEIGHT OF GAS

"MWC I R 1 MOLECULAR WEIGHT, CARBON

"MWC2H4 I R 1 MOLECULAR WEIGHT, C2H4

"MWC2H6 I R 1 MOLECULAR WEIGHT, C2H6

"MWCAO I R 1 MOLECULAR WEIGHT, CaO

"MWCAS I R 1 MOLECULAR WEIGHT, CaS

"MWCC I R 1 MOLECULAR WEIGHT, CaCO3

"MWCH4 I R 1 MOLECULAR WEIGHT, $\mathrm{CH} 4$

"MWCO I R 1 MOLECULAR WEIGHT, CO

"MWCO2 I R 1 MOLECULAR WEIGHT, CO2

"MWCS4 I R 1 MOLECULAR WEIGHT, CaSO4

"MWH2 I R 1 MOLECULAR WEIGHT, H2

"MWH2O I R 1 MOLECULAR WEIGHT, H2O

"MWMGC I R 1 MOLECULAR WEIGHT, MgCO3

"MWMGO I R 1 MOLECULAR WEIGHT, MgO

"MWN2 I R 1 MOLECULAR WEIGHT, N2

"MWO I R 1 MOLECULAR WEIGHT, OXYGEN

"MWO2 I R 1 MOLECULAR WEIGHT, O2

"MWS I R 1 MOLECULAR WEIGHT, SULFUR

"MWSO2 I R 1 MOLECULAR WEIGHT, SO2

"O4CARB O R 1 O2 NECESSARY TO COMBUST CARBONIZER FUEL (lbmole)

"O4FUEL O R 1 O2 NECESSARY TO COMBUST COMBUSTOR FUEL (lbmole)

"P18OUT I R 1 CONTROL VARIABLE

"PCARB O R 1 CARBONIZER PRESSURE (psia)

"PCCYC O R 1 CPFBC CYCLONE PRESSURE (psia)

"PCFILT O R 1 CPFBC X-FILTER PRESSURE (psia)

"PCMBIC I R 1 IC, CPFBC PRESSURE (psia)

"PCOMB O R 1 CPFBC PRESSURE (psia)

"PCTCIR O R 1 PERCENT SOLIDS CIRCULATED IN CPFBC

"PCTOLD I R 1 PERCENT SOLIDS CIRCULATED IN CPFBC @ SOME GAS VEL

"PDFBHE I R 1 FBHE MEAN PARTICAL DIAMETER (ft)

"PDGTIC I R 1 IC, TOPPING COMBUST PRESSURE DROP (psia)

"PDRMIC I R 1 IC, FBHE STEAM DRUM PRESSURE DROP (psia)

"PDROPF O R 1 FBHE GAS SIDE PRESSURE DROP (psi)

"PDROPZ O R 1 CARBONIZER PRESSURE DROP (psi)

"PDRPFB O R 1 CPFBC PRESSURE DROP (pSi)

"PDRPGT O R 1 TOPPING COMBUSTOR PRESSURE DROP (psi)

"PFBDRM O R 1 FBHE STEAM DRUM PRESSURE (pSia)

"PFBHIC I R 1 IC, FBHE GAS SIDE PRESSURE DROP (psia)

"PFX3 O R 1 MI PRESSURE OF STREAM FX3 (psia)

"PGOVICI R 1 IC, S/H STEAM PIPING PRESSURE (psia)

"PGSO3B O R 1 MI VARIABLE SO3 - PRESSURE IN inH2O

"PGTCMB O R 1 TOPPING COMBUSTOR PRESSURE (psia)

"PGTIC I R 1 TOPPING COMBUSTOR PRESSURE (psia)

"PI I R 1 PI

"PPSAIC I R 1 IC, S/H ATTEMPERATOR PRESSURE (pSia)

"PPSATT O R 1 S/H ATTEMPERATOR PRESSURE (psia)

"PRBEDA I R 1 P/R ENCLOSURE WALL IN-BED H.T. AREA (ft^2)

"

"

"

"PRCC I R 1 CARBONIZER CYCLONE Q-CALC REFERENCE-PRESSURE (psia) "

"PRCF I R 1 CARBONIZER X FILTER Q-CALC REFERENCE-PRESSURE (psia) "

"PRCG I $R 1$ CARBONIZER PIPING Q-CALC REFERENCE-PRESSURE (psia)

"PRFF I R 1 COMBUSTER X FILTER Q-CALC REFERENCE-PRESSURE (psia) "

"PRFG I $R$ I COMBUSTER PIPING Q-CALC REFERENCE-PRESSURE (psia)

"PRHI O R 1 P/R TUBE SIDE H.T.C. (Btu/hr-ft^2-F)

"PRPR O $R$ 1 P/R TUBE SIDE PANNTL NUMBER (dim) 
"PRRE O R I P/R TUBE SIDE REYNOLDS NUMBER (dim) "PRSFBH O R 1 FBHE GAS-SIDE FREEBOARD PRESSURE (psia) "PRSGOV O R $1 \mathrm{~S} / \mathrm{H}$ STEAM PRESSURE (psia)

"PRSR O $R$ 1 FBHE RISER AVERAGE PRESSURE (psia)

"PRSRI O R 1 FBHE RISER INLET PRESSURE (psia)

"PRSRO O R 1 FBHE RISER OUTLET PRESSURE (psia)

"PRTD I R 1 P/R TUBE ID (ft)

"PRTL I R 1 P/R TUBE LENGTH (ft)

"PRWFBA I R 1 P/R ENCLOSURE WALL FREEBOARD AREA ( $\left(\mathbb{t}^{\wedge} 2\right)$ "PSBEDA I R 1 P/S ENCLOSURE WALL IN-BED H.T. AREA ( $\left.\mathrm{ft}^{\wedge} 2\right)$ "PSCOND I $R 1 \mathrm{P} / \mathrm{S}$ FLOW CONDUCTANCE

"PSDCFB O R 15 COMBUSTOR SOLID BED MASS BY PSD (lb) "PSDFED O R 15 CARBONIZER SOLID BED MASS BY PSD (ib) "PSFR O R 1 FBHE F/R AVERAGE PRESSURE (psia) "PSFRI O R 1 FBHE F/R INLET PRESSURE (psia) "PSFRO O $\mathrm{R} 1 \mathrm{FBHE}$ F/R OUTLET PRESSURE (psia) "PSFS O R $1 \mathrm{FBHE} F / S$ AVERAGE PRESSURE (psia) "PSFSI O R 1 FBHE F/S INLET PRESSURE (psia) "PSFSO O R 1 FBHE F/S OUTLET PRESSURE (psia) "PSHI O R 1 P/S TUBE SIDE H.T.C. (Btu/hr-ft^2-F) "PSI1 O R 1 MI PRESSURE OF STREAM SI1 (psia) "PSI2 O R 1 MI PRESSURE OF STREAM SI2 (psia) "PSI3 O R 1 MI PRESSURE OF STREAM SI3 (psia)

"PSI4 O R 1 MI PRESSURE OF STREAM SI4 (psia)

"PSI5 O R 1 MI PRESSURE OF STREAM SI5 (psia)

"PSI6 O R 1 MI PRESSURE OF STREAM SI6 (psia)

"PSI7 O R 1 MI PRESSURE OF STREAM SI7 (psia)

"PSI8 O R 1 MI PRESSURE OF STREAM SI8 (psia)

"PSI9 O R 1 MI PRESSURE OF STREAM SI9 (psia)

"PSIA O R 1 MI PRESSURE OF STREAM SIA (psia)

"PSIB O R 1 MI PRESSURE OF STREAM SIB (psia)

"PSIC O R 1 MI PRESSURE OF STREAM SIC (psia)

"PSID O R 1 MI PRESSURE OF STREAM SID (psia)

"PSIE O R $1 \mathrm{MI}$ PRESSURE OF STREAM SIE (psia)

"PSIF O R 1 MI PRESSURE OF STREAM SIF (psia)

"PSIG O $R \quad 1 \mathrm{MI}$ PRESSURE OF STREAM SIG (psia)

"PSIH O R 1 MI PRESSURE OF STREAM SIH (psia)

"PSII O R $1 \mathrm{MI}$ PRESSURE OF STREAM SII (psia)

"PSIJ O R 1 MI PRESSURE OF STREAM SIJ (psia)

"PSIK O R 1 MI PRESSURE OF STREAM SIK (psia)

"PSO1 O $R 1$ MI PRESSURE OF STREAM SO1 (psia)

"PSO3 O R 1 MI PRESSURE OF STREAM SO3 (psia)

"PSO4 O R 1 MI PRESSURE OF STREAM SO4 (psia)

"PSO5 O R 1 MI PRESSURE OF STREAM SO5 (psia)

"PSO6 $O \mathrm{R} 1 \mathrm{MI}$ PRESSURE OF STREAM SO6 (psia)

"PSPR O $R 1$ FBHE P/R AVERAGE PRESSURE (psia)

"PSPRI O R 1 FBHE P/R INLET PRESSURE (psia)

"PSPRO O $R$ 1 FBHE P/R OUTLET PRESSURE (psia)

"PSPRX O $R$ 1 FBHE P/S PRANTL NUMBER (dim)

"PSPS O R 1 FBHE P/S AVERAGE PRESSURE (psia)

"PSPSI O R 1 FBHE P/S INLET PRESSURE (psia)

"PSPSO O R 1 FBHE P/S OUTLET PRESSURE (psia)

"PSRE O R 1 FBHE P/S REYNOLDS NUMBER (dim)

"PSSG O R 1 FBHE S/G AVERAGE PRESSURE (psia)

"PSSG] O R 1 FBHE S/G INLET PRESSURE (psia)

"PSSGO O R 1 FBHE S/G OUTLET PRESSURE (psia)

"PSSS O R $1 \mathrm{FBHE} \mathrm{S/S} \mathrm{AVERAGE} \mathrm{PRESSURE} \mathrm{(psia)}$

"PSSSI O R 1 FBHE S/S INLET PRESSURE (psia)

"PSSSO O R 1 FBHE S/S OUTLET PRESSURE (psia)

"PSTD I R 1 FBHE P/S TUBE DIAMETER ( $f t)$

"PSTL I $R$ I FBHE P/S TUBE LENGTH (ft)

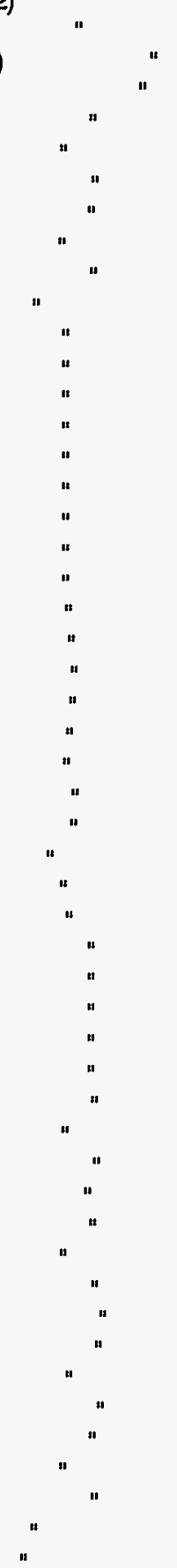


"PSWFBA I R 1 FBHE P/S ENCLOSURE WALL FREEBOARD AREA (ft^2) "PZCYC O R 1 CARBONIZER CYCLONE PRESSURE (psia) "PZFILT O R 1 CARBONIZER X FILTER PRESSURE (psia)

"QAC O R 1 ASH COOLER DUTY (Btu/hr)

"QBEDCB O R 1 CARBONIZER COMBUSTION RXNS DUTY (Btu/hr) "QBLOSS O R 1 CARBONIZER HEAT LOSS TO AMBIENT (Btu/hr) "QCALCN I R 1 HEAT LIBERATED, CaCO3 CALCINATION (Btu/lbmole) "QCAROX O R 1 CPFBC BED RXN-CARBON OXIDATION (Btu/hr) "QCASCB I R 1 HEAT LIBERATED, CaS OXIDATION (Btu/lbmole) "QCASOX O R 1 CPFBC CaS OXIDATION DUTY (Btu/hr) "QCCALC O R 1 CPFBC CALCINATION DUTY (Btu/hr) "QCCOMB I R 1 CARBON COMBUSTION (Btu/lb) "QCELL2 O R 1 FBHE CELL \#2, TOTAL HEAT TRANSFERRED (Btu/hr) "QCELL3 O R 1 FBHE CELL \#3, TOTAL HEAT TRANSFERRED (Btu/hr) "QCELL4 O R 1 FBHE CELL \#4, TOTAL HEAT TRANSFERRED (Btu/hr) "QCELLS O R 1 FBHE CELL \#5, TOTAL HEAT TRANSFERRED (Btu/hr) "QCELL6 O R 1 FBHE CELL \#6, TOTAL HEAT TRANSFERRED (Btu/hr) "QCELL7 O R 1 FBHE CELL \#7, TOTAL HEAT TRANSFERRED (Btu/hr) "QCFILT O R 1 HEAT LOSS IN CPFBC BARRIER FILTER (Btu/hr) "QCLINE O R 1 HEAT LOSS IN CPFBC GAS PIPING (Btu/hr) "QCSKIN O R 1 CPFBC SKIN HEAT LOSS (Btu/hr) "QFBLST O R 1 CPFBC AMBIENT HEAT LOSS (Btu/hr) "QFGCMB O R 1 CPFBC FUEL GAS OXIDATION (Btu/hr) "OFRBED O R 1 FBHE F/R IN-BED ENCLOSURE WALL DUTY (Biu/hr) "QFRBUN O R 1 FBHE F/R TUBE BUNDLE ENCLOSURE WALL DUTY (Btu/hr) "QFRWFB O R 1 FBHE F/R FREEBOARD ENCLOSURE WALL DUTY (Btu/hr) "QFSBED O R 1 FBHE F/S IN-BED ENCLOSURE WALL DUTY (Btu/hr) "QFSBUN O R 1 FBHE F/S TUBE BUNDLE ENCLOSURE WALL DUTY (Btu/hr) "QFSWFB O R 1 FBHE F/S FREEBOARD ENCLOSURE WALL DUTY (Btu/hr) "QGTCMB O R 1 TOPPING COMBUSTOR HEAT DUTY (Btu/hr) "QGTLST O R 1 TOPPING COMBUSTOR HEAT LOST TO AMBIENT (Btu/hr) "QGTMTL O R 1 TOPPING COMBUSTOR HEAT LOST TO METAL (Btu/hr) "QMGCO3 I R 1 HEAT LIBERATED, MgCO3 CALCINATION (Btu/lbmole) "QPOX I R 1 PARTIAL OXIDATION OF METHANE (Btu/lbmole) "QPRBED O R 1 FBHE P/R IN-BED ENCLOSURE WALL DUTY (Btu/hr) "QPRBUN O R 1 FBHE P/R TUBE BUNDLE ENCLOSURE WALL DUTY (Btu/hr) "QPRWFB O R 1 FBHE P/R FREEBOARD ENCLOSURE WALL DUTY (Btu/hr) "QPSBED O R 1 FBHE P/S IN-BED ENCLOSURE WALL DUTY (Btu/hr) "QPSBUN O R 1 FBHE P/S TUBE BUNDLE ENCLOSURE WALL DUTY (Btu/hr) "QPSWFB O R 1 FBHE P/S FREEBOARD ENCLOSURE WALL DUTY (Btu/hr) "QRCC I R 1 CARBONIZER CYCLONE Q-CALC REFERENCE-DUTY (Btu/hr) "QRCF I R 1 CARBONIZER X FILTER Q-CALC REFERENCE-DUTY (Btu/hr) "QRCG I R 1 CARBONIZER PIPING Q-CALC REFERENCE-DUTY (Btu/hr) "QRFF I R 1 COMBUSTER X FILTER Q-CALC REFERENCE-DUTY (Btu/hr) "QRFG I R 1 COMBUSTER PIPING Q-CALC REFERENCE-DUTY (Btu/hr) "QRISER O R 1 FBHE RISER DUTY (Btu/hr) "QRXSRB O R 1 CARBONIZER SORBENT RNX DUTY (Btu/hr) "QSCAC3 I R 1 DUTY FOR CaCO3 SULFUR CAPTURE (Btu/lbmole) " "QSCAO I R 1 DUTY FOR CaO SULFUR CAPTURE (Btu/lbmole) "QSCOMB I R 1 DUTY FOR CaCO3 SULFUR COMBUSTION (Btu/lbmole) "QSCPTR O R 1 CPFBC SULFUR CAPTURE DUTY (Btu/hr) "QSGBED O R 1 FBHE S/G IN-BED ENCLOSURE WALL DUTY (Btu/hr) "QSGBUN O R 1 FBHE S/G TUBE BUNDLE ENCLOSURE WALL DUTY (Btu/hr) " "QSGWFB O R 1 FBHE S/G FREEBOARD ENCLOSURE WALL DUTY (Btu/hr) "QSLFCP O R 1 DUTY REQUIRED FOR SULFUR CAPTURE IN CARBONIZER (Btu/hr)" "QSLFOXO R 1 CPFBC BED RXNS-SULFUR OXIDATION (Btu/hr) "QSSBED O R 1 FBHE S/S IN-BED ENCLOSURE WALL DUTY (Btu/hr) "QSSBUN O R $1 \mathrm{FBHE} \mathrm{S/S} \mathrm{TUBE} \mathrm{BUNDLE} \mathrm{ENCLOSURE} \mathrm{WALL} \mathrm{DUTY} \mathrm{(Btu/hr)}$ "QSSWFB O R 1 FBHE S/S FREEBOARD ENCLOSURE WALL DUTY (Btu/hr) "QZCYCL O R 1 CARBONIZER CYCLONE HEAT LOSS (Btu/hr)

"QZFILT O R 1 CARBONIZER BARRIER FILTER HEAT LOSS (Btu/hr) 
"QZLINE O R 1 CARBONIZER GAS PIPING HEAT LOSS (Btu/hr)

"RECBED O R 15 CARBONIZER SOLID BED PARTICLE REYNOLDS NUMBER

"REDPFB O R 15 CPFBC/FBHE SOLID PARTICLE REYNOLDS NUMBER

"REDPSF O R 15 CARBONIZER INSTANT CHAR PARTICLE REYNOLDS NUMBER

"RFRI I R 1 FBHE F/R INSIDE TUBE DIAMETER (ft)

"RFRO I R 1 FBHE F/R OUTSIDE TUBE DIAMETER (ft)

"RFSI I R 1 FBHE F/S INSIDE TUBE DIAMETER (ft)

"RFSO I R 1 FBHE F/S OUTSIDE TUBE DIAMETER (ft)

"RHCNDT I R $1 \mathrm{R} / \mathrm{H}$ FLOW CONDUCTANCE

"RHDEL Z I R 1 R/H HEIGHT (ft)

"RHOCBB O R 1 CARBONIZER INSTANT CHAR BULK DENSITY (Ib/ft^3)

"RHOCBP O $R$ 1 CARBONIZER SOLID BED BULK DENSITY (lb/ $/ \mathrm{t}^{\wedge} 3$ )

"RHOCFP O R 1 COMBUSTER INSTANT CHAR BULK DENSITY $\left(\mathrm{lb} / \mathrm{ft}^{\wedge} 3\right)$

"RHOCGS O R 1 CARBONIZER GAS MAKE DENSITY (lb/ft^3)

"RHOCN1 O R 1 FBHE CELL \#1 GAS DENSITY (lb/ft^3)

"RHOCN2 $O$ R 1 FBHE CELL \#2 GAS DENSITY (lb/ft³)

"RHOCN3 O R 1 FBHE CELL \#3 GAS DENSITY (lb/ft^3)

"RHOCN4 O R 1 FBHE CELL \#4 GAS DENSITY (lb/ft^3)

"RHOCN5 O R 1 FBHE CELL \#5 GAS DENSITY (lb/ft^3)

"RHOCN6 O R 1 FBHE CELL \#6 GAS DENSITY (lb/tt^3)

"RHOCN7 O R 1 FBHE CELL \#7 GAS DENSITY (lb/ft^3)

"RHOFBB O R 1 FBHE SOLID BULK DENSITY (Ib/tt^3)

"RHOFBH O R 1 FBHE FREEBOARD GAS DENSITY (lb/ft^3)

"RHOFBP O R 1 CPFBC FB SOLIDS BULK DENSITY (lb/ft^3)

"RHOFBV I R 1 FBHE FREEBOARD AVERAGE GAS DENSITY (lb/ft^3)

"RHOGSC O R 1 COMBUSTER FREEBOARD GAS DENSITY (lb/ft^3)

"RHOHPR O R 1 CHAR HOPPER SOLIDS DENSITY (lb/ft^3)

"RHORCP O $R$ 1 FBHE RECIRCULATED SOLIDS BULK DENSITY (lb/ft^3)

"ROWATM O R 1 S/H ATTEMPERATOR STEAM DENSITY (lb/ft^3)

"ROWDC O R 1 FBHE STEAM DRUM DOWNCOMER DENSITY (Ib/ft^3)

"ROWDDD O R 1 FBHE STEAM DRUM AVG. DENSITY (lb/ft^3)

"ROWDRF O R 1 FBHE STEAM DRUM $f$ DENSITY (lb/ft^3)

"ROWDRG O R 1 FBHE STEAM DRUM g DENSITY (lb/f^^3)

"ROWDRM O R 1 FBHE STEAM DRUM BULK DENSITY (lb/ft^3)

"ROWFS O R 1 FBHE F/S AVERAGE DENSITY (lb/ft^3)

"ROWFSI O R 1 FBHE F/S INLET DENSITY (lb/ft^3)

"ROWFSO O R 1 FBHE F/S OUTLET DENSITY (lb/ft^3)

"ROWGOV O R $1 \mathrm{~S} / \mathrm{H}$ STEAM PIPING AVG. DENSITY (lb/ft^3)

"ROWGVO O $\mathrm{R} 1 \mathrm{~S} / \mathrm{H}$ STEAM PIPING DENSITY $\left(\mathrm{lb} / \mathrm{ft}^{\wedge} ` 3\right)$

"ROWGVXO R 1 S/H STEAM PIPING DENSITY @ $\mathrm{t}(-)(\mathrm{lb} / \mathrm{ft} \wedge 3)$

"ROWPS O R 1 FBHE P/S AVERAGE DENSITY (lb/ft^3)

"ROWPSA O R 1 FBHE P/S INLET DENSITY $\left(\mathrm{lb} / \mathrm{ft}^{\wedge} 3\right)$

"ROWPSI O R 1 FBHE P/S OUTLET DENSITY $\left(\mathrm{lb} / \mathrm{ft}^{\wedge} 3\right)$

"ROWPSO O R 1 P/S STEAM AVG. DENSITY (ib/ft^3)

"ROWRSR O $R 1$ FBHE STEAM DRUM RISER DENSITY (lb/ft^3)

"ROWSAX O R 1 S/H ATTEMPERATOR DENSITY@ @ $\mathrm{t}(-)\left(\mathrm{lb} / \mathrm{ft}^{\wedge} 3\right)$

"ROWSS O R 1 FBHE S/S AVERAGE DENSITY (lb/f^^3)

"ROWSSI O R 1 FBHE S/S INLET DENSITY (Ib/ft^3)

"ROWSSO O R 1 FBHE S/S OUTLET DENSITY (Ib/ft^3)

"ROWSTP O R 1 S/H STEAM PIPING DENSITY (lb/ft^3)

"RPRI I $R$ 1 FBHE P/R INSIDE TUBE DIAMETER (ft)

"RPRO I R 1 FBHE P/R OUTSIDE TUBE DIAMETER (ft)

"RPSI I R 1 FBHE P/S INSIDE TUBE DIAMETER (ft)

"RPSO I R 1 FBHE P/S OUTSIDE TUBE DIAMETER (ft)

"RSGI I R 1 FBHE S/G INSIDE TUBE DIAMETER (ft)

"RSGO I R 1 FBHE S/G OUTSIDE TUBE DIAMETER (ft)

"RSI1 O R 1 MI DENSITY OF STREAM SI1 (lb/ft^3)

"RSI2 O $R$ 1 MI DENSITY OF STREAM SI2 (lb/ft^3)

"RSI3 O R 1 MI DENSITY OF STREAM SI3 (lb/ft^3)

"RSI4 O R 1 MI DENSITY OF STREAM SI4 $\left(\mathrm{lb} / \mathrm{ft}^{\wedge} 3\right)$

"RSI5 O R 1 MI DENSITY OF STREAM SI5 (lb/ft^3)

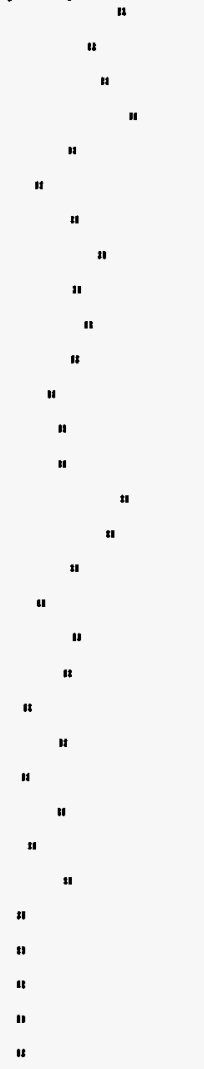


"RSI6 O R 1 MI DENSITY OF STREAM SI6 (lb/ $\left.\mathrm{ft}^{\wedge} 3\right)$

"RSI7 O R 1 MI DENSITY OF STREAM SI7 (lb/ft^3)

"RSI8 O R 1 MI DENSITY OF STREAM SI8 (lb/ft^3)

"RSI9 OO R 1 MI DENSITY OF STREAM SI9 $\left(\mathrm{lb} / \mathrm{ft}^{\wedge} 3\right)$

"RSIA O R 1 MI DENSITY OF STREAM SIA (lb/ $\left./ \mathrm{tt}^{\wedge} 3\right)$

"RSIB O R $1 \mathrm{MI}$ DENSITY OF STREAM SIB (lb/ft^3)

"RSIC O R 1 MI DENSITY OF STREAM SIC $\left(\mathrm{lb} / \mathrm{ft}^{\wedge} 3\right)$

"RSID O R 1 MI DENSITY OF STREAM SID (lb/ft^3)

"RSIE O R 1 MI DENSITY OF STREAM SIE (lb/ft^3)

"RSIF O R 1 MI DENSITY OF STREAM SIF (lb/ft^3)

"RSIG O R 1 MI DENSITY OF STREAM SIG (lb/ft^3)

"RSIH O R 1 MI DENSITY OF STREAM SIH (lb/ft^3)

"RSII O R $1 \mathrm{MI}$ DENSITY OF STREAM SII $\left(\mathrm{lb} / \mathrm{ft}^{\wedge} 3\right)$

"RSIJ O R 1 MI DENSITY OF STREAM SIJ (lb/t^ 3 )

"RSIK O R 1 MI DENSITY OF STREAM SIK $\left(\mathrm{lb} / \mathrm{ft}^{\wedge} 3\right)$

"RSO1 O R 1 MI DENSITY OF STREAM SO1 $\left(\mathrm{lb} / \mathrm{ft}^{\wedge} 3\right)$

"RSO3 O R 1 MI DENSITY OF STREAM SO3 (lb/ft^3)

"RSO4 O R 1 MI DENSITY OF STREAM SO4 (lb/ft^3)

"RSO5 O R 1 MI DENSITY OF STREAM SO5 (lb/ft^3)

"RSO6 O R 1 MI DENSITY OF STREAM SO6 (lb/ft^3)

"RSRHII O $R$ 1 RSR TUBE SIDE H.T.C. (Btu/hr-ft^2-F)

"RSRPR O $\mathrm{A} 1$ RSR TUBE SIDE PANNTL NUMBER (dim)

"RSRRE O R 1 RSR TUBE SIDE REYNOLDS NUMBER (dim)

"RSRTD O $R \quad 1$ RSR TUBE DIAMETER (tt)

"RSRVEL O R 1 RSR TUBE SIDE VELOCITY (ft/sec)

"RSSI I R 1 FBHE S/S INSIDE TUBE DIAMETER (ft)

"RSSO I R 1 FBHE S/S OUTSIDE TUBE DIAMETER ( $t$ )

"RTMPIC I $R 1$ IC, CARBONIZER BARRIER FILTER TEMPERATURE ( $F$

"SFRVEL O $R$ 1 F/R STEAM VELOCITY ( $\mathrm{ft} / \mathrm{sec})$

"SFXC24 I R 1 TOPPING COMB-SUPPLEMENTAL FUEL-MASS FRAC-C2H4

"SFXC26 I R 1 TOPPING COMB-SUPPLEMENTAL FUEL-MASS FRAC-C2H6

"SFXCAR I R 1 TOPPING COMB-SUPPLEMENTAL FUEL-MASS FRAC-CARBON

"SFXCH4 I R 1 TOPPING COMB-SUPPLEMENTAL FUEL-MASS FRAC-CH4

"SFXH2 I R 1 TOPPING COMB-SUPPLEMENTAL FUEL-MASS FRAC-H2

"SFXN2 I R 1 TOPPING COMB-SUPPLEMENTAL FUEL-MASS FRAC-N2

"SFXO2 I R 1 TOPPING COMB-SUPPLEMENTAL FUEL-MASS FRAC-O2

"SFXSLF I R 1 TOPPING COMB-SUPPLEMENTAL FUEL-MASS FRAC-SULFUR

"SGBEDA I R 1 S/G ENCLOSURE WALL IN-BED AREA (ft^2)

"SGHI O R 1 S/G TUBE SIDE H.T.C. (Btu/hr-ft"2-F)

"SGPR O R 1 S/G TUBE SIDE PANNTL NUMBER (dim)

"SGRE O R 1 S/G TUBE SIDE REYNOLDS NUMBER (dim)

"SGTD I R $1 \mathrm{~S} / \mathrm{G}$ TUBE ID (ft)

"SGTL I R 1 S/G TUBE LENGTH (ft)

"SGWFBA I $R$ 1 S/G ENCLOSURE WALL FREEBOARD AREA (ft^2)

"SPCOND I R $1 \mathrm{~S} / \mathrm{H}$ STEAM PIPING FLOW CONDUCTANCE

"SPDAMP I $R$ I S/H STEAM PIPING DAMPING FACTOR

"SPHCTY I R 1 SOLID PARTICAL SPHERICITY (dim)

"SPRVEL O R 1 P/R TUBE SIDE VELOCITY ( $\mathrm{ft} / \mathrm{sec})$

"SPSVEL O R $1 \mathrm{P} / \mathrm{S}$ TUBE SIDE VELOCITY $(\mathrm{ft} / \mathrm{sec})$

"SSBEDA I R $1 \mathrm{~S} / \mathrm{S}$ ENCLOSURE WALL FREEBOARD WALL SURFACE (f^^2)

"SSGVEL O R 1 S/G TUBE SIDE VELOCITY (ft/sec)

"SSHI O R $1 \mathrm{~S} / \mathrm{S}$ TUBE SIDE H.T.C. (Btu/hr-ft^2-F)

"SSPR $O R \quad 1 \mathrm{~S} / \mathrm{S}$ TUBE SIDE PANNTL NUMBER (dim)

"SSRE O R $1 \mathrm{~S} / \mathrm{S}$ TUBE SIDE REYNOLDS NUMBER (dim)

"SSSVEL O R 1 S/S TUBE SIDE VELOCITY (ft/sec)

"SSTD I R 1 S/S TUBE ID (ft)

"SSTL I R 1 S/S TUBE LENGTH (ft)

"SSWFBA I R 1 S/S ENCLOSURE WALL FREEBOARD AREA ( $\left.\mathrm{ft}^{\wedge} 2\right)$

"STEFAN I R 1 STEFAN BOLTZMAN CONSTANT (Btu/hr-ft^2-R^4)

"STOICH O R 1 CARBONIZER STOICHIOMETRY

"TACS I $R$ I ASH COOLER INLET STEAM TEMPERATURE (F)

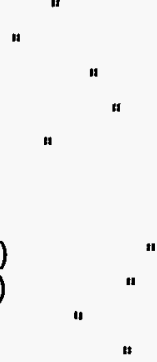

\section{$L-13$}


This Page Intentionally Left Blank

L-14 
"TRSRO O R 1 FBHE S/R OUTLET STEAM TEMPERATURE (F) "TSAI O R 1 ASH COOLER SOLIDS INLET TEMPERATURE ( $F$ "TSAO O R 1 ASH COOLER SOLIDS OUTLET TEMPERATURE (F) "TSFR O R 1 FBHE F/R AVERAGE STEAM TEMPERATURE (F) "TSFRI O R 1 FBHE F/R INLET STEAM TEMPERATURE (F) "TSFRO O R 1 FBHE F/R OUTLET STEAM TEMPERATURE (F) "TSFS O R 1 FBHE F/S AVERAGE STEAM TEMPERATURE ( $F$ "TSFSI O R 1 FBHE F/S INLET STEAM TEMPERATURE ( $F$ "TSFSO $O R \perp$ FBHE F/S OUTLET STEAM TEMPERATURE (F) "TSGSAT O $R 1 \mathrm{~S} / \mathrm{G}$ STEAM SATURATION TEMPERATURE (F) "TSI1 O R $1 \mathrm{MI}$ TEMP OF STREAM SI1 (lb/hr) "TSI2 O R 1 MI TEMP OF STREAM SI2 (lb/hr) "TSI3 O R 1 MI TEMP OF STREAM SI3 (lb/hr) "TSI4 O R 1 MI TEMP OF STREAM SI4 (lb/hr) "TSI5 O R 1 MI TEMP OF STREAM SI5 (lb/hr)

"TSI6 O R 1 MI TEMP OF STREAM SIG (lb/hr) "TSI7 O R 1 MI TEMP OF STREAM SI7 (lb/hr) "TSI8 O R 1 MI TEMP OF STREAM SI8 $(\mathrm{lb} / \mathrm{hr})$ "TSI9 0 R 1 MI TEMP OF STREAM SI9 (lb/hr) "TSIA O R 1 MI TEMP OF STREAM SIA ( $(\mathrm{b} / \mathrm{hr})$ "TSIB $O R \quad$ R MI TEMP OF STREAM SIB $(\mathrm{lb} / \mathrm{hr})$ "TSIC O R 1 MI TEMP OF STREAM SIC (lb/hr)

"TSID $O \mathrm{R} 1 \mathrm{MI}$ TEMP OF STREAM SID $(\mathrm{bb} / \mathrm{hr})$

"TSIE O R $1 \mathrm{MI}$ TEMP OF STREAM SIE $(\mathrm{lb} / \mathrm{hr})$

"TSIF $O R \quad R \quad \mathrm{MI}$ TEMP OF STREAM SIF $(\mathrm{lb} / \mathrm{hr})$

"TSIG O $R 1 \mathrm{MI}$ TEMP OF STREAM SIG (lb/hr)

"TSIH O R 1 MI TEMP OF STREAM SIH $(\mathrm{lb} / \mathrm{hr})$

"TSII O $R 1 \mathrm{MI}$ TEMP OF STREAM SII (lb/hr)

"TSIJ O R 1 MI TEMP OF STREAM SIJ (lb/hr)

"TSIK O R $1 \mathrm{MI}$ TEMP OF STREAM SIK $(\mathrm{lb} / \mathrm{hr})$

"TSO1 O R $1 \mathrm{MI}$ TEMP OF STREAM SO1 (lb/hr)

"TSO3 O R 1 MI TEMP OF STREAM SO3 (lb/hr)

"TSO4 O R 1 MI TEMP OF STREAM SO4 (lb/hr)

"TSO5 O R $1 \mathrm{MI}$ TEMP OF STREAM SO5 (lb/hr)

"TSOG O R $1 \mathrm{MI}$ TEMP OF STREAM SO6 (lb/hr)

"TSPR O R 1 FBHE P/R AVERAGE STEAM TEMPERATURE (F)

"TSPRI O R 1 FBHE P/R INLET STEAM TEMPERATURE (F)

"TSPRO O R 1 FBHE P/R OUTLET STEAM TEMPERATURE (F)

"TSPS O R $1 \mathrm{FBHE} \mathrm{P/S} \mathrm{AVERAGE} \mathrm{STEAM} \mathrm{TEMPERATURE} \mathrm{(F)}$

"TSPSI $O R 1$ FBHE P/S INLET STEAM TEMPERATURE (F) "TSPSO O $R 1$ FBHE P/S OUTLET STEAM TEMPERATURE ( $F$ "TSSG O R 1 FBHE S/G AVERAGE STEAM TEMPERATURE (F) "TSSGI O R 1 FBHE S/G INLET STEAM TEMPERATURE ( $F$ "TSSGO O R 1 FBHE S/G OUTLET STEAM TEMPERATURE ( $F$ "TSSS O R $1 \mathrm{FBHE} \mathrm{S/S} \mathrm{AVERAGE} \mathrm{STEAM} \mathrm{TEMPERATURE}(F)$ "TSSSAT O $R 1$ S/S STEAM SATURATION TEMPERATURE (F) "TSSSI O R 1 FBHE S/S INLET STEAM TEMPERATURE (F) "TSSSO O R 1 FBHE S/S OUTLET STEAM TEMPERATURE (F) "TWAI O $R$ I ASH COOLER INLET WATER TEMPERATURE (F) "TWAO O R 1 ASH COOLER OUTLET WATER TEMPERATURE (F) "TZCYC O R 1 CARBONIZER CYCLONE TEMPERATURE (F) "TZCYIC O R 1 INITIAL CONDITION, CARBONIZER CYCLONE TEMPERATURE (F) " "TZFILT $O R 1$ CARBONIZER BARRIER FILTER TEMPERATURE (F)

"TZFLIC O R 1 INITIAL CONDITION, CARBONIZER X FILTER TEMPERATURE (F) " "TZLINE $O R \quad 1$ CARBONIZER GAS PIPING TEMPERATURE (F) "TZLNIC O R 1 INITIAL CONDITION, CARBONIZER GAS PIPN TEMPERATURE (F) " "UNIT I R17O PC-TRAX UNIT VECTOR

"VDRMTT I R 1 FBHE STEAM DRUM SYSTEM VOLUME (ft^3)

"VELCFB O R 1 CPFBC SECONDARY ZONE VELOCITY (ft/sec)

"VELCPZO R 1 CPFBC PRIMARY ZONE VELOCITY (ft/sec)

"VELELU O R 1 CARBONIZER FREEBOARD VELOCITY (ft/sec) 
"VELFL O R 1 CARBONIZER TRANSITION GAS VELOCITY ( $\mathrm{tt} / \mathrm{sec}$ )

"VELTG O R 1 CARBONIZER TRANSPORT GAS VELOCITY (ft/sec)

"VFBCN1 O R 1 FBHE CELL \# 1 SUPERFICIAL GAS VELOCITY (ft/sec)

"VFBCN2 O R 1 FBHE CELL \# 2 SUPERFICIAL GAS VELOCITY (ft/sec)

"VFBCN3 O R 1 FBHE CELL \# 3 SUPERFICIAL GAS VELOCITY (ft/sec)

"VFBCN4 O R 1 FBHE CELL \# 4 SUPERFICIAL GAS VELOCITY (ft/sec)

"VFBCN5 O R 1 FBHE CELL \# 5 SUPERFICIAL GAS VELOCITY (ft/sec)

"VFBCN6 O R 1 FBHE CELL \# 6 SUPERFICIAL GAS VELOCITY (tt/sec)

"VFBCN7 O R 1 FBHE CELL \# 7 SUPERFICIAL GAS VELOCITY (ft/sec)

"VFBDRMI R 1 FBHE STEAM DRUM TANK VOLUME (ft`3)

"VFBGAS O R 1 CARBONIZER FREEBOARD GAS VOLUME (ft`3)

"VFBRSR I R 1 FBHE STEAM DRUM RISER VOLUME (ft^3)

"VGSFBH O R 1 FBHE GAS VOLUME (f^^3) @ t

"VGSFBL O R 1 FBHE GAS VOLUME (tt^3)@ $\mathrm{t}(-)$

"VGSPFB O R 1 CPFBC GAS VOLUME (tt`3)

"VOID O $R$ i SOLID VOIDAGE (decimal)

"VOLDC I R I FBHE STEAM DRUM DOWN COMER VOLUME (ft^3)

"VOLFBZI R 1 CARBONIZER FREEBOARD VESSEL VOLUME (ft`3)

"VOLMGT I R 1 TOPPING COMBUSTER VOLUME W/ DAMP FACTOR (ft^3)

"VOLPSA I R 1 S/H STEAM PIPING VOLUME (ft^3)

"VOLSTP I R $1 \mathrm{~S} / \mathrm{H}$ ATTEMPERATOR VOLUME (t^^3)

"VSUPR O R 1 FBHE AIR VELOCITY (ft/sec)

"WA2l O R 1 FLUIDIZING AIR FLOW TO FBHE CELL \# 2 (lb/hr)

"WA2O O R 1 TOTAL AIR FLOW LEAVING FBHE CELL \# $2(\mathrm{bb} / \mathrm{hr})$

"WA3I O R 1 FLUIDIZING AIR FLOW TO FBHE CELL \# 3 (lb/hr)

"WA3O O R 1 TOTAL AIR FLOW LEAVING FBHE CELL \# $3(\mathrm{lb} / \mathrm{hr})$

"WA4I O R 1 FLUIDIZING AIR FLOW TO FBHE CELL \# 4 (lb/hr)

"WA4O O R 1 TOTAL AIR FLOW LEAVING FBHE CELL \# 4 (b/h/hr)

"WA5I O R 1 FLUIDIZING AIR FLOW TO FBHE CELL \# 5 (lb/hr)

"WA5O O R 1 TOTAL AIR FLOW LEAVING FBHE CELL \# 5 (lb/hr)

"WA6I O R 1 FLUIDIZING AIR FLOW TO FBHE CELL \# 6 (lb/hr)

"WA6O O R 1 TOTAL AIR FLOW LEAVING FBHE CELL \# 6 (lb/hr)

"WA7I O R 1 FLUIDIZING AIR FLOW TO FBHE CELL \# 7 (lb/hr)

"WA7O O R 1 TOTAL AIR FLOW LEAVING FBHE CELL \# 7 (b/ $/ \mathrm{hr})$

"WAAD O R 1 AIR FLOW TO FBHE ADIBATIC SECTION (lb/hr)

"WADRTN O R 1 SOLIDS FROM FBHE ADIABATIC SECTION TO CPFBC (bb/hr) "

"WCBAIR O R 1 TOTAL CPFBC AIR FLOW (lb/hr)

"WCBASH O R 1 TOTAL ASH FLOW FROM CARBONIZER TO CHAR HOPPER (Ib/hr) "

"WCBCAC O R 1 TOTAL CaCO3 FLOW FROM CARBONIZER TO CHAR HOPPER (lb/hr)"

"WCBCAO O R 1 TOTAL CaO FLOW FROM CARBONIZER TO CHAR HOPPER (lb/hr) "

"WCBCAR O R 1 TOTAL CARBON FLOW FROM CARBONIZER TO CHAR HOPPER(b/hr)"

"WCBCAS O R 1 TOTAL CaS FLOW FROM CARBONIZER TO CHAR HOPPER (lb/hr) "

"WCBCS4 O R 1 TOTAL CaSO4 FLOW FROM CARBONIZER TO CHAR HOPPER (b/ $/ \mathrm{hr})$ "

"WCBINT O R 1 TOTAL INERT FLOW FROM CARBONIZER TO CHAR HOPPER (b/hr)"

"WCBMGO O R 1 TOTAL MgO FLOW FROM CARBONIZER TO CHAR HOPPER (lb/hr) "

"WCBSLF O R 1 TOTAL SULFUR FLOW FROM CARBONIZER TO CHAR HOPPER(lb/hr)"

"WCCOALI R 1 CPFBC COAL FLOW (lb/hr)

"WCHRGN O $R$ 1 CARBONIZER INSTANTANEOUS CHAR $(\mathrm{lb} / \mathrm{hr})$

"WCMBF O R 1 TOTAL SOLIDS FLOW FROM CARBONIZER TO CHAR HOPPER(lb/hr)"

"WCPRIM O R 1 CPFBC PRIMARY AIR FLOW (lb/hr)

"WCRAIR O R 1 TOTAL CARBONIZER AIR (b/hr)

"WCRAR1 O R 1 CARBONIZER PRIMARY AIR (lb/hr)

"WCRAR2 O R 1 CARBONIZER TRANSPORT AIR (b/hr)

"WCRCIC I R 1 INITIAL CONDITION, FBHE STEAM DRUM CIRC RATE, (lb/hr) "

"WCRSTM O R 1 CARBONIZER STEAM FLOW (lb/hr)

"WCSECD O R 1 CPFBC SECONDARY AIR FLOW (b/hr)

"WCSHOT O R 1 CPFBC SECONDARY AIR FBHE- CCPFBC (lb/hr)

"WCSORB O R 1 CPFBC SORBENT FLOW (lb/hr)

"WDCIRC O R 1 FBHE STEAM DRUM RECIRULATION RATE (lb/hr)

"WDRMB O R 1 FBHE STEAM DRUM BLOW DOWN (lb/hr)

"WDRN O R 1 CARBONIZER DRAIN FLOW (b/hr) 
"WEBASH O R 1 CARBONIZER BED MATERIAL ELUTRIATED, ASH (lb/hr) " "WEBCAC O $\mathrm{R} 1$ CARBONIZER BED MATERIAL ELUTRIATED, $\mathrm{CaCO} 3(\mathrm{lb} / \mathrm{hr})$ " "WEBCAO O R 1 CARBONIZER BED MATERIAL ELUTRIATED, CaO (lb/hr) " "WEBCAR O R 1 CARBONIZER BED MATERIAL ELUTRIATED, CARBON (lb/hr) " "WEBCAS O $R$ 1 CARBONIZER BED MATERIAL ELUTRIATED, CaS (lb/hr) " "WEBCS4 O R 1 CARBONIZER BED MATERIAL ELUTRIATED, CaSO4 (lb/hr) " "WEBINT O R 1 CARBONIZER BED MATERIAL ELUTRIATED, INERT (lb/hr) "WEBMGO O R 1 CARBONIZER BED MATERIAL ELUTRIATED, $\mathrm{MgO}(\mathrm{lb} / \mathrm{hr})$ " "WEBSLF O R 1 CARBONIZER BED MATERIAL ELUTRIATED, SULFUR (lb/hr) " "WELASH O R 1 CARBONIZER INSTANTANEOUS CHAR ELUTRIATED, ASH $(\mathrm{lb} / \mathrm{hr})$ " "WELCAC O R 1 CARBONIZER INSTANTANEOUS CHAR ELUTRIATED, CaCO3 (lb/hr)" "WELCAO O R 1 CARBONIZER INSTANTANEOUS CHAR ELUTRIATED, CaO (lb/hr)" "WELCAR O R 1 CARBONIZER INSTANTANEOUS CHAR ELUTRIATED, CARBON(lb/hr)" "WELCAS O R 1 CARBONIZER INSTANTANEOUS CHAR ELUTRIATED, CaS $(\mathrm{lb} / \mathrm{hr})$ " "WELCS4 O R 1 CARBONIZER INSTANTANEOUS CHAR ELUTRIATED, CaSO4 (lb/hr)" "WELINT O R 1 CARBONIZER INSTANTANEOUS CHAR ELUTRIATED, INERT (lb/hr)" "WELMGO O R 1 CARBONIZER INSTANTANEOUS CHAR ELUTRIATED, $\mathrm{MgO}$ (lb/hr) " "WELSLF O R 1 CARBONIZER INSTANTANEOUS CHAR ELUTRIATED, SULFUR(lb/hr)" "WELUB O R 15 CARBONIZER BED MATERIAL PSD ELUTRIATED (lb/hr) "WELUBT O R 1 CARBONIZER BED MATERIAL ELUTRIATED (lb/hr) "WELUF O R 15 CARBONIZER INSTANTANEOUS CHAR PSD ELUTRIATED (lb/hr) " "WELUFT O R 1 CARBONIZER INSTANTANEOUS CHAR ELUTRIATED (lb/hr) "WFBASH O R 1 FBHE SOLIDS INVENTORY, ASH (Ib) "WFBCAC O R 1 FBHE SOLIDS INVENTORY, CaCO3 (lb) "WFBCAO O R 1 FBHE SOLIDS INVENTORY, CaO (lb) "WFBCAR O R 1 FBHE SOLIDS INVENTORY, CARBON (lb) "WFBCAS O R 1 FBHE SOLIDS INVENTORY, CaS (lb) "WFBCS4 O R 1 FBHE SOLIDS INVENTORY, CaSO4 (lb) "WFBINT O R 1 FBHE SOLIDS INVENTORY, INERT (lb) "WFBMGO O R 1 FBHE SOLIDS INVENTORY, MgO (lb) "WFBSLF O R 1 FBHE SOLIDS INVENTORY, SULFUR (lb) "WFBTLT O R 1 TOTAL FBHE SOLIDS INVENTORY (lb) "WFGCH4 O R 1 CARBONIZER FUEL GAS FLOW, CH4 (lb/hr) "WFGCO O R 1 CARBONIZER FUEL GAS FLOW, CO (lb/hr) "WFGCO2 O R 1 CARBONIZER FUEL GAS FLOW, CO2 (lb/hr) "WFGH2 O R 1 CARBONIZER FUEL GAS FLOW, H2 (lb/hr) "WFGH2O O R 1 CARBONIZER FUEL GAS FLOW, H2O (lb/hr) "WFGN2 O R 1 CARBONIZER FUEL GAS FLOW, N2 (ib/hr) "WFGO2 O R 1 CARBONIZER FUEL GAS FLOW, O2 (lb/hr) "WFGSO2 O R 1 CARBONIZER FUEL GAS FLOW, SO2 (lb/hr) "WFLWPF O R 1 CHAR HOPPER SOLIDS DISCHARGE FLOW (lb/hr) "WFSLDS O R 1 ASH COOLER SOLIDS FLOW, (lb/hr) "WFSRTN O R 1 SOLIDS FLOW FROM FBHE S/H PASS TÓ CPFBC, (lb/hr) " "WFX3 O R 1 MI FLOW OF STREAM FX3 (lb/hr) "WGASPD O $\mathrm{R} 1$ CARBONIZER INSTANTANEOUS GAS MAKE, (lb/hr) "WGTBRN O R 1 TOPPING COMBUSTOR EXHAUST, (lb/hr) "WJVEL O R 1 FLOW CARBONIZER PRIMARY AIR (lb/hr)

"WMCBO2 O R 1 O2 TO COMBUSTOR (lbmole/hr)

"WMCH4 O R 1 CARBONIZER FUEL GAS FLOW, CH4 (lbmole/hr) "WMCO O R 1 CARBONIZER FUEL GAS FLOW, CO (lbmole/hr) "WMCO2 O R 1 CARBONIZER FUEL GAS FLOW, CO2 (lbmole/hr) "WMEXO2 O R 1 CARBONIZER FUEL GAS FLOW, O2 (lbmole/hr) "WMH2 O R 1 CARBONIZER FUEL GAS FLOW, H2 (lbmole/hr) "WMH2O O R 1 CARBONIZER FUEL GAS FLOW, H2O (lbmole/hr) "WMN2 O R 1 CARBONIZER FUEL GAS FLOW, N2 (lbmole/hr) "WMSO2 O R 1 CARBONIZER FUEL GAS FLOW, SO2 (lbmole/hr) "WRCASH O R 1 FBHE SOLIDS RECIRCULATION TO CPFBC, ASH (lb/hr) "WRCC I R 1 CARBONIZER CYCLONE Q-CALC REFERENCE-FLOW $/ \mathrm{lb} / \mathrm{h}$ "WRCCAC O R 1 FBHE SOLIDS RECIRCULATION TO CPFBC, $\mathrm{CaCO} 3(\mathrm{lb} / \mathrm{hr})$ " "WRCCAO O R 1 FBHE SOLIDS RECIRCULATION TO CPFBC, CaO (lb/hr) "WRCCAR O R 1 FBHE SOLIDS RECIRCULATION TO CPFBC, CARBON (lb/hr) " 
"WRCCAS O R 1 FBHE SOLIDS RECIRCULATION TO CPFBC, CaS (lb/hr) "WRCCS4 O R 1 FBHE SOLIDS RECIRCULATION TO CPFBC, CaSO4 (b/hr) " "WRCF I R 1 CARBONIZER X FILTER Q-CALC REFERENCE-FLOW (lb/hr) " "WRCG I R 1 CARBONIZER PIPING Q-CALC REFERENCE-FLOW (b/hr) " "WRCMGO O R 1 FBHE SOLIDS RECIRCULATION TO CPFBC, MgO (lb/hr) "WRCNRT O R 1 FBHE SOLIDS RECIRCULATION TO CPFBC, INERTS (lb/hr) "WRCSLF O R 1 FBHE SOLIDS RECIRCULATION TO CPFBC, SULFUR (lb/hr) "WRCTLT O R 1 TOTAL FBHE SOLIDS RECIRCULATION TO CPFBC (lb/hr) "WRFF I R 1 COMBUSTER X FILTER Q-CALC REFERENCE-FLOW $(\mathrm{lb} / \mathrm{hr})$ "WRFG I R 1 COMBUSTER PIPING Q-CALC REFERENCE-FLOW (lb/hr) "WRSR O R 1 FBHE STEAM RISER FLOW (lb/hr)

"WSAD O R 1 SOLIDS TO FBHE ADIABATIC SECTION $(\mathrm{lb} / \mathrm{hr})$ "WSFS O R 1 FBHE F/S STEAM FLOW (lb/hr)

"WSI1 O R 1 MI FLOW OF STREAM SI1 (b/hr)

"WSI2 O R 1 MI FLOW OF STREAM SI2 (lb/hr)

"WSI3 O R 1 MI FLOW OF STREAM SI3 (lb/hr)

"WSI4 O R 1 MI FLOW OF STREAM SI4 (lb/hr)

"WSI5 O R 1 MI FLOW OF STREAM SI5 (lb/hr)

"WSI6 O R 1 MI FLOW OF STREAM SI6 (b/hr)

"WSI7 O R 1 MI FLOW OF STREAM SI7 (lb/hr)

"WSI8 O R 1 MI FLOW OF STREAM SI8 (lb/hr)

"WSI9 O R 1 MI FLOW OF STREAM SI9 (lb/hr)

"WSIA O R 1 MI FLOW OF STREAM SIA (lb/hr)

"WSIB O R 1 MI FLOW OF STREAM SIB (b/hr)

"WSIC O R 1 MI FLOW OF STREAM SIC (ib/hr)

"WSID O R $1 \mathrm{MI}$ FLOW OF STREAM SID (lb/hr)

"WSIE O R $1 \mathrm{MI}$ FLOW OF STREAM SIE (ib/hr)

"WSIF O R 1 MI FLOW OF STREAM SIF (lb/hr)

"WSIG O R $1 \mathrm{MI}$ FLOW OF STREAM SIG (lb/hr)

"WSIH O R 1 MI FLOW OF STREAM SIH (lb/hr)

"WSII O R 1 MI FLOW OF STREAM SII (Ib/hr)

"WSIJ O R $1 \mathrm{MI} \mathrm{FLOW} \mathrm{OF} \mathrm{STREAM} \mathrm{SIJ}(\mathrm{lb} / \mathrm{hr})$

"WSIK O R 1 MI FLOW OF STREAM SIK (lb/hr)

"WSO1 O R $1 \mathrm{MI}$ FLOW OF STREAM SO1 $(\mathrm{lb} / \mathrm{hr})$

"WSO3 O R $1 \mathrm{MI}$ FLOW OF STREAM SO3 $(\mathrm{lb} / \mathrm{hr})$

"WSO4 O R $1 \mathrm{MI}$ FLOW OF STREAM SO4 $(\mathrm{b} / \mathrm{hr})$

"WSO5 O R $1 \mathrm{MI} \mathrm{FLOW} \mathrm{OF} \mathrm{STREAM} \mathrm{SO5} \mathrm{(lb/hr)}$

"WSO6 O R $1 \mathrm{MI}$ FLOW OF STREAM SO6 (b/hr)

"WSORB I R 1 SORBENT FLOW TO CARBONIZER (lb/hr)

"WSPILL O R 1 SOLIDS SPILLAGE FROM CARBONIZER (lb/hr)

"WSRRTN O R 1 FBHE SOLIDS FROM R/H RETURNED TO CPFBC (lb/hr)

"WSSR O R 1 FBHE SOLIDS TO R/H PASSAGE (lb/hr)

"WWACH4 O R 1 CPFBC VITIATED AIR CH4 FLOW (lb/hr)

"WVACO O R 1 CPFBC VITIATED AIR CO FLOW $(\mathrm{lb} / \mathrm{hr})$

"WWACO2 O R 1 CPFBC VITIATED AIR CO2 FLOW (ib/hr)

"WVAH2 O R 1 CPFBC VITIATED AIR H2 FLOW (lb/hr)

"WWAH2O O R 1 CPFBC VITIATED AIR H2O FLOW (lb/hr)

"WVAN2 O R 1 CPFBC VITIATED AIR N2 FLOW $(\mathrm{lb} / \mathrm{hr})$

"WVAO2 O R 1 CPFBC VITIATED AIR O2 FLOW (lb/hr)

"WWASO2 O R 1 CPFBC VITIATED AIR SO2 FLOW (lb/hr)

"WWFR O R 1 STEAM FLOW THROUGH F/R (lb/hr)

"WWFS O R 1 STEAM FLOW THROUGH F/S (lb/hr)

"WWFSX O R 1 F/S STEAM FLOW @ t(-) (b/hr)

"WWPR O R 1 STEAM FLOW THROUGH P/R (ib/hr)

"WWPS O R 1 STEAM FLOW THROUGH P/S (lb/hr)

"WWSG O R 1 STEAM FLOW THROUGH S/G $(\mathrm{lb} / \mathrm{hr})$

"WWSS O R 1 STEAM FLOW THROUGH S/S (lb/hr)

"WWSSX O $R$ R 1 S/S STEAM FLOW @ t(-) (lb/hr)

"WXFASH O R 1 SOLIDS TO BARRIER FILTER, ASH (lb/hr)

"WXFCAC O R 1 SOLIDS TO BARRIER FILTER, СaCO3 (lb/hr)

"WXFCAO O R 1 SOLIDS TO BARRIER FILTER, $\mathrm{CaO}(\mathrm{lb} / \mathrm{hr})$

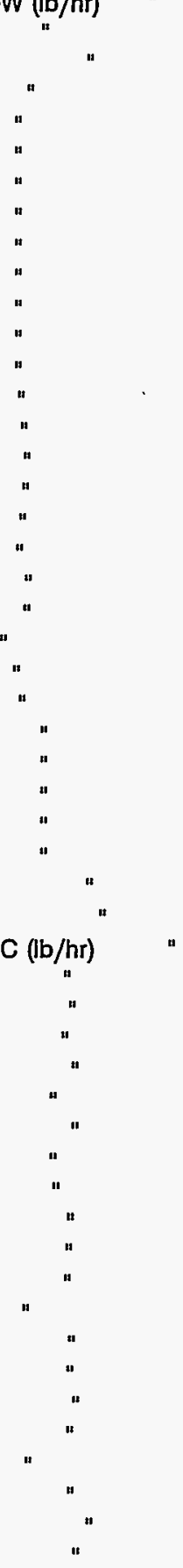


"WXFCAR O $R 1$ SOLIDS TO BARRIER FILTER, CARBON (lb/hr) "WXFCAS O R 1 SOLIDS TO BARRIER FILTER, CaS (lb/hr) "WXFCS4 O R 1 SOLIDS TO BARRIER FILTER, CaSO4 (lb/hr) "WXFINT O R 1 SOLIDS TO BARRIER FILTER, INERTS (lb/hr) "WXFMGO O $\mathrm{R} 1$ SOLIDS TO BARRIER FILTER, MgO (lb/hr) "WXFSLF O R 1 SOLIDS TO BARRIER FILTER, SULFUR (lb/hr) "WXFTLT O R 1 TOTAL SOLIDS TO BARRIER FILTER (lb/hr) "WZCOAL I R 1 CARBONIZER COAL FLOW (lb/hr)

"XASHCLI R 1 COAL MASS FRACTION, ASH

"XCCHAR O R 1 MASS FRACTION CARBON IN CARBONIZER INSTANTANEOUS CHAR" "XCCOAL I R 1 COAL MASS FRACTION, CARBON "XCCSRB I R 1 MASS FRACTION CaCO3 IN SORBENT "XCELUB O $R \quad 1$ CARBON MASS FRACTION-CARBONIZER ELUTRIATED BED MATL " "XCELUF O R 1 CARBON MASS FRACTION-CARBONIZER ELUTRIATED CHAR MATL " "XDRMBK O R 1 FBHE STEAM DRUM BULK MOISTURE FRACTION "XFGCH4 O R 1 CARBONIZER FUEL GAS MASS FRACTION, $\mathrm{CH} 4$ "XFGCO O R 1 CARBONIZER FUEL GAS MASS FRACTION, CO "XFGCO2 O $R$ 1 CARBONIZER FUEL GAS MASS FRACTION, CO2 "XFGH2 O R 1 CARBONIZER FUEL GAS MASS FRACTION, H2 "XFGH2O O R 1 CARBONIZER FUEL GAS MASS FRACTION, H2O "XFGN2 O R 1 CARBONIZER FUEL GAS MASS FRACTION, N2 "XFGO2 O R 1 CARBONIZER FUEL GAS MASS FRACTION, O2 "XFGSO2 O R 1 CARBONIZER FUEL GAS MASS FRACTION, SO2 "XFX3 O R 7 CPFBC VITIATED AIR MASS FRACTION VECTOR "XGTC24 O R 1 TOPPING COMBUSTOR EXHUAST MASS FRACTION, C2H4 "XGTC26 O R 1 TOPPING COMBUSTOR EXHUAST MASS FRACTION, C2H6 "XGTCAR O R 1 TOPPING COMBUSTOR EXHUAST MASS FRACTION, CARBON "XGTCH4 O R 1 TOPPING COMBUSTOR EXHUAST MASS FRACTION, CH4 "XGTCO O R 1 TOPPING COMBUSTOR EXHUAST MASS FRACTION, CO "XGTCO2 O R 1 TOPPING COMBUSTOR EXHUAST MASS FRACTION, CO2 "XGTH2 O R 1 TOPPING COMBUSTOR EXHUAST MASS FRACTION, H2 "XGTH2O O R 1 TOPPING COMBUSTOR EXHUAST MASS FRACTION, H2O "XGTN2 O $R 1$ TOPPING COMBUSTOR EXHUAST MASS FRACTION, N2 "XGTO2 O R 1 TOPPING COMBUSTOR EXHUAST MASS FRACTION, O2 "XGTSLF O R 1 TOPPING COMBUSTOR EXHUAST MASS FRACTION, SULFUR "XGTSO2 O R 1 TOPPING COMBUSTOR EXHUAST MASS FRACTION, SO2 "XH2OAR I $R$ 1 MASS FRACTION OF H2O IN CARBONIZER AIR FEED "XH2OCB I R 1 MASS FRACTION OF H2O IN COMBUSTER AIR FEED "XH2OCLI I $\mathrm{R}$ I COAL MASS FRACTION, H2O "XH2OSB I R 1 MASS FRACTION H2O IN SORBENT "XHCOALI R 1 COAL MASS FRACTION, H2 "XINSRB I R 1 MASS FRACTION INERT IN SORBENT "XMGSRB I R 1 MASS FRACTION MgCO3 IN SORBENT "XNCOAL I R 1 COAL MASS FRACTION, N2 "XOAIR I $R$ I MASS FRACTION OF O2 IN CARBONIZER AIR "XOCOALI $R$ I COAL MASS FRACTION, O2 "XRCASH O R 1 CPFBC/FBHE SOLIDS CIRCULATION MASS FRACTION, ASH "XRCCAC O R 1 CPFBC/FBHE SOLIDS CIRCULATION MASS FRACTION, $\mathrm{CaCO} 3$ " "XRCCAO O R 1 CPFBC/FBHE SOLIDS CIRCULATION MASS FRACTION, CaO "XRCCAR O R 1 CPFBC/FBHE SOLIDS CIRCULATION MASS FRACTION, CARBON " "XRCCAS O R 1 CPFBC/FBHE SOLIDS CIRCULATION MASS FRACTION, CaS "XRCCS4 O R 1 CPFBC/FBHE SOLIDS CIRCULATION MASS FRACTION, CaSO4 " "XRCINT O R 1 CPFBC/FBHE SOLIDS CIRCULATION MASS FRACTION, INERT " "XRCMGO O R 1 CPFBC/FBHE SOLIDS CIRCULATION MASS FRACTION, MgO " "XRCSLF O R 1 CPFBC/FBHE SOLIDS CIRCULATION MASS FRACTION, SULFUR " "XRISER O R 1 FBHE STEAM DRUM RISER QUALITY "XRVCAO O R 1 MASS FRACTION CaO IN CPFBC/FBHE RECIRCULATED SOLIDS " "XSCOAL I R 1 COAL MASS FRACTION, SULFUR "XSI1 O R 7 MASS FRACTION VECTOR, STREAM SI1 "XSI2 O $R$ T MASS FRACTION VECTOR, STREAM SI2 "XSI3 O R 1 MASS FRACTION VECTOR, STREAM SI3

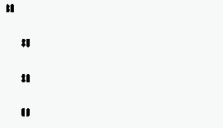


"XSI4 O R 7 MASS FRACTION VECTOR, STREAM SI4

"XSI5 O R 7 MASS FRACTION VECTOR, STREAM SI5

"XSI6 O R 7 MASS FRACTION VECTOR, STREAM SI6

"XSI7 O R 7 MASS FRACTION VECTOR, STREAM SI7

"XSI8 O R 7 MASS FRACTION VECTOR, STREAM SI8

"XSI9 O R 1 MASS FRACTION VECTOR, STREAM SI9

"XSIA O R 7 MASS FRACTION VECTOR, STREAM SIA

"XSIB O R 7 MASS FRACTION VECTOR, STREAM SIB

"XSIC O R 7 MASS FRACTION VECTOR, STREAM SIC

"XSID O R 7 MASS FRACTION VECTOR, STREAM SID

"XSIE O R 7 MASS FRACTION VECTOR, STREAM SIE

"XSIF O R 7 MASS FRACTION VECTOR, STREAM SIF

"XSIG O R 7 MASS FRACTION VECTOR, STREAM SIG

"XSIH O $R$ 1 MASS FRACTION VECTOR, STREAM SIH

"XSII O R 1 MASS FRACTION VECTOR, STREAM SII

"XSIJ O R 1 MASS FRACTION VECTOR, STREAM SIJ

"XSIK O R 1 MASS FRACTION VECTOR, STREAM SIK

"XSO1 O R 7 MASS FRACTION VECTOR, STREAM SO1

"XSO3 O R 7 MASS FRACTION VECTOR, STREAM SO3

"XSO4 O R 1 MASS FRACTION VECTOR, STREAM SO4

"XSO5 O R 1 MASS FRACTION VECTOR, STREAM SO5

"XSO6 O R 1 MASS FRACTION VECTOR, STREAM SO6

"XVACH4 O R 1 CPFBC VITIATED AIR MASS FRACTION, CH4 (decimal)

"XVACO O R 1 CPFBC VITIATED AIR MASS FRACTION, CO (decimal) "XVACO2 O R 1 CPFBC VITIATED AIR MASS FRACTION, CO2 (decimal) "XVAH2 O R 1 CPFBC VITIATED AIR MASS FRACTION, H2 (decimal) "XVAH2O O R 1 CPFBC VITIATED AIR MASS FRACTION, H2O (decimal) "XVAN2 O $R$ 1 CPFBC VITIATED AIR MASS FRACTION, N2 (decimal) "XVAO2 O R 1 CPFBC VITIATED AIR MASS FRACTION, O2 (decimal) "XVASO2 O R 1 CPFBC VITIATED AIR MASS FRACTION, SO2 (decimal) "YCO2FB O R 1 CPFBC VOLUME FRACTION CO2 (decimal) "ZXDELT I R 1 EVALUATION INTERVAL "ZXWRTF WRITE FLAG

H

"

"

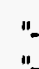

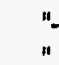

$$
\text { : }
$$

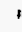$$
\text { " }
$$

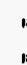

"

$$
\text { " }
$$

$$
\text { " }
$$

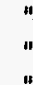

"

$"$

"

"

" DIMENSIONALIZATION AND INITIAL CONDITIONS

DESCRIPTION: CALCULATES FLOWRATES AND FLOW PARTIALS ENTERING" AND LEAVING A STEAM/WATER FLOW-FLOW TYPE MODULE" (SEE PC/TRAX PROGRAMMER MANUAL)

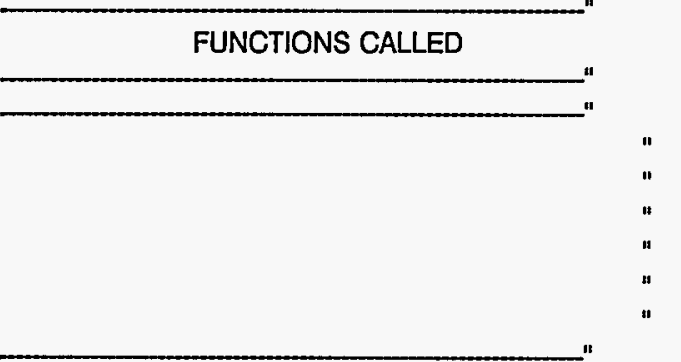




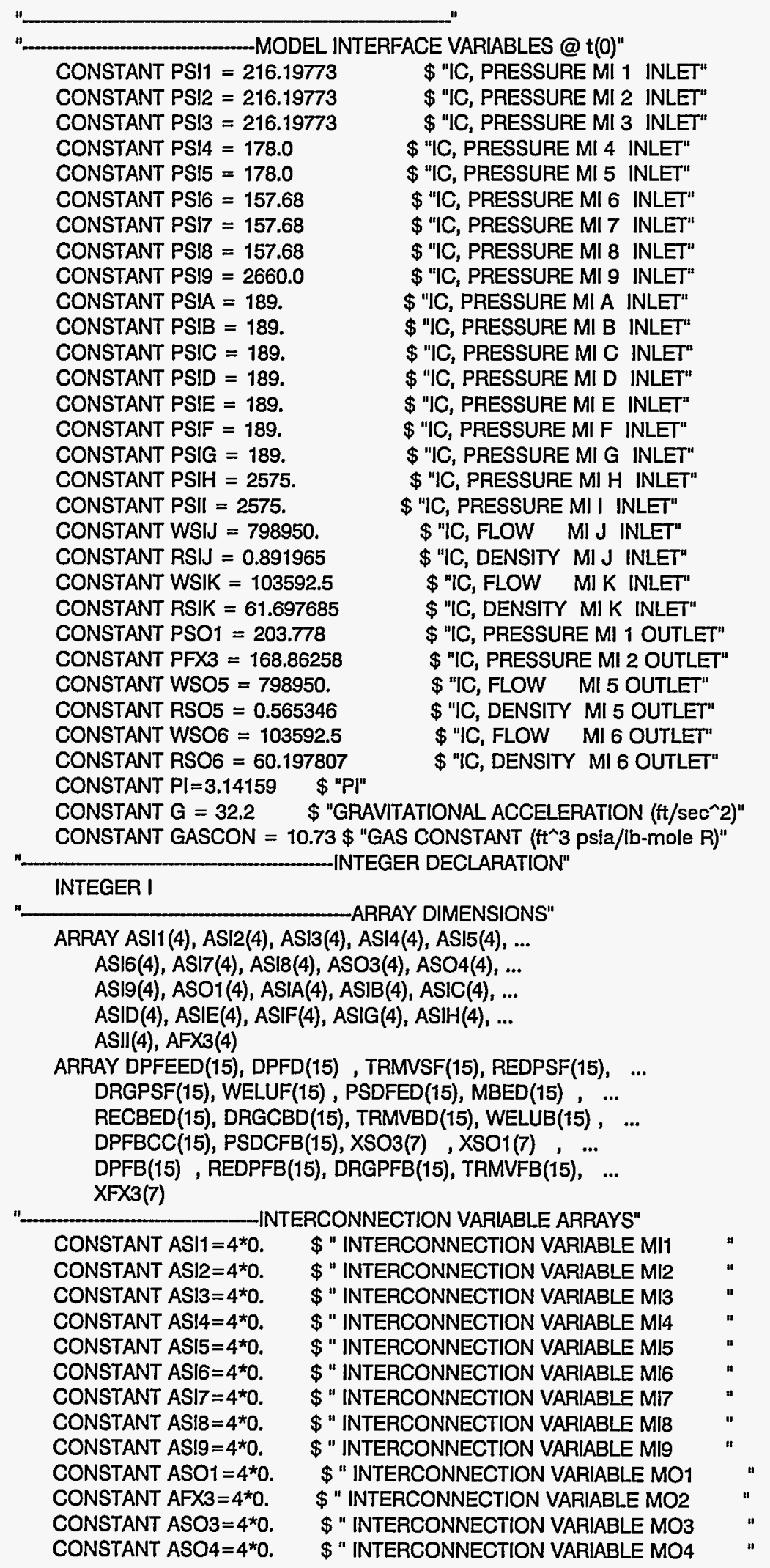


CONSTANT ASIA $=4^{\star} 0$. CONSTANT ASIB $=4^{\star} 0$. CONSTANT ASIC $=4 * 0$. CONSTANT ASID $=4 \star 0$. CONSTANT ASIE $=4^{\star} 0$. CONSTANT ASIF $=4^{\star} 0$. CONSTANT ASIG $=4^{\star}$. CONSTANT ASIH $=4 * 0$. CONSTANT AS\| $=4{ }^{\star} 0$.
$\$$ " INTERCONNECTION VARIABLE MIA

$\$$ " INTERCONNECTION VARIABLE MIB

$\$$ " INTERCONNECTION VARIABLE MIC

$\$$ " INTERCONNECTION VARIABLE MID

$\$$ "INTERCONNECTION VARIABLE MIE

$\$$ " INTERCONNECTION VARIABLE MIF

$\$ "$ INTERCONNECTION VARIABLE MIG

$\$$ " INTERCONNECTION VARIABLE MIH $\$$ "INTERCONNECTION VARIABLE MII CONSTANT MWC $=12.01115 \$$ "MOLECULAR WEIGHT OF M-CARBON " CONSTANT MWCAO $=56.0794 \$$ "MOLECULAR WEIGHT OF CaO CONSTANT MWCAS $=72.144 \$$ "MOLECULAR WEIGHT OF CaS CONSTANT MWCC $=100.08935 \$$ "MOLECULAR WEIGHT OF CaCO3 CONSTANT MWCH4 $=16.04303 \$$ "MOLECULAR WEIGHT OF CH4 CONSTANT MWC2H4 $=28.05418 \$$ "MOLECULAR WEIGHT OF C2H4 CONSTANT MWC2H6 $=30.07012 \$$ "MOLECULAR WEIGHT OF C2H6 CONSTANT MWCO $=28.01055 \$$ "MOLECULAR WEIGHT OF CO CONSTANT MWCO2 $=44.00995 \$$ MOLECULAR WEIGHT OF CO2 CONSTANT MWCS4 $=136.1416 \$$ "MOLECULAR WEIGHT OF CaSO 4 CONSTANT MWH2 $=2.01594 \$$ "MOLECULAR WEIGHT OF H2 CONSTANT MWH2O $=18.0153 \$$ "MOLECULAR WEIGHT OF H2O CONSTANT MWMGC $=84.32135 \$$ "MOLECULAR WEIGHT OF MgCO3 CONSTANT MWMGO $=40.3114 \$$ "MOLECULAR WEIGHT OF MgO CONSTANT MWN2 $=28.0134 \$$ "MOLECULAR WEIGHT OF N2 CONSTANT MWO $=15.9994 \$$ "MOLECULAR WEIGHT OF M-OXYGEN " CONSTANT MWO2 $=31.9988 \$$ "MOLECULAR WEIGHT OF O2 CONSTANT MWS $=32.064$ \$ "MOLECULAR WEIGHT OF M-SULFUR " CONSTANT MWSO2 $=64.0628 \$$ "MOLECULAR WEIGHT OF SO2

"—_Ltu/lbmole)___HEAT OF REACTION VALUES" CONSTANT QCALCN $=76719.8 \$$ "HEAT REQUIRED BY CaCO3 CALCINATION" CONSTANT QCASCB $=412853.0 \$$ "HEAT LIBERATED BY CaS COMBUSTION " CONSTANT QCCOMB $=169325.7 \$$ "HEAT LIBERATED DURING C COMBUSTION" CONSTANT QSCOMB $=127615.0 \$$ "HEAT LIBERATED DURING S COMBUSTION" CONSTANT QMGCO3 = 50326.1 \$ "HEAT REQUIRED BY MgCO3 CALCINATION" CONSTANT QSCAC3 = $146378.6 \$$ "HEAT REQUIRED CaCO3 SULFUR CAPTURE" CONSTANT QSCAO $=69654.5 \$$ "HEAT REQUIRED CaS SULFUR CAPTURE " CONSTANT QPOX $=140896.8 \$$ "HEAT LIBERATED BY PARTIAL X OF CH4"

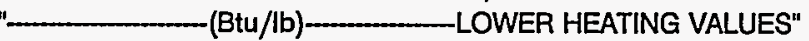

CONSTANT LHVCOL $=12472.0$ CONSTANT LHVCO $=4347.0$ CONSTANT LHVH2 $=51623.0$ CONSTANT LHVCH $4=21495.0$ CONSTANT LHVC24 $=20275.0$ CONSTANT LHIVC26 $=20418.0$ CONSTANT LHVC $=14093.0$ CONSTANT LHVS $=3980.0$ CONSTANT LHVCAS $=5734.0$ \$ "LHV OF PITT \#8 COAL "
\$"LHV OF CO
\$"LHV OF H2 " "LHV OF CH4
\$"LHV OF C2H4 "
\$ "LHV OF C2H6
\$ "LHV OF C2H
"LHV OF CARBON "
\$"LHV OF SULFUR " "
\$ "LHV OF CAS (Btu/lb-F)—COMPONENT SPECFIC HEAT VALUES"

CONSTANT CPELU $=0.30 \quad \$$ "Cp OF ELUTRIATED CARB. MATERIAL " CONSTANT CPDRN $=0.13025 \$$ "Cp OF CARBONIZER DRAIN MATERIAL " CONSTANT CPFGS $=0.323$ CONSTANT CPAIRT $=0.26$ CONSTANT CPCOL $=0.30$ CONSTANT CPSRB $=0.22$ CONSTANT CPVA $=0.26646$ CONSTANT CPSLD $=0.268$ CONSTANT CPSLDS $=0.22445$ CONSTANT CPGT $=0.282885$ CONSTANT CPCHAR $=0.25$ CONSTANT CRBCOR $=7372$. $\$$ "Cp OF CARBONIZER FUEL GAS $\$$ "Cp OF AIR $\$$ "Cp OF FRESH COAL $\$$ "Cp OF FRESH SORBENT $\$ " C p$ OF CPFBC VITIATED AIR $\$$ "Cp OF FBHE/CPFBC SOLIDS $\$ " \mathrm{Cp}$ OF SOLIDS IN ASH COOLER $\$$ "Cp OF G/T EXHAUST GAS $\$$ "Cp OF CPFBC CHAR FEED $\$$ "CARB CORRECTION (Btu/hr) 


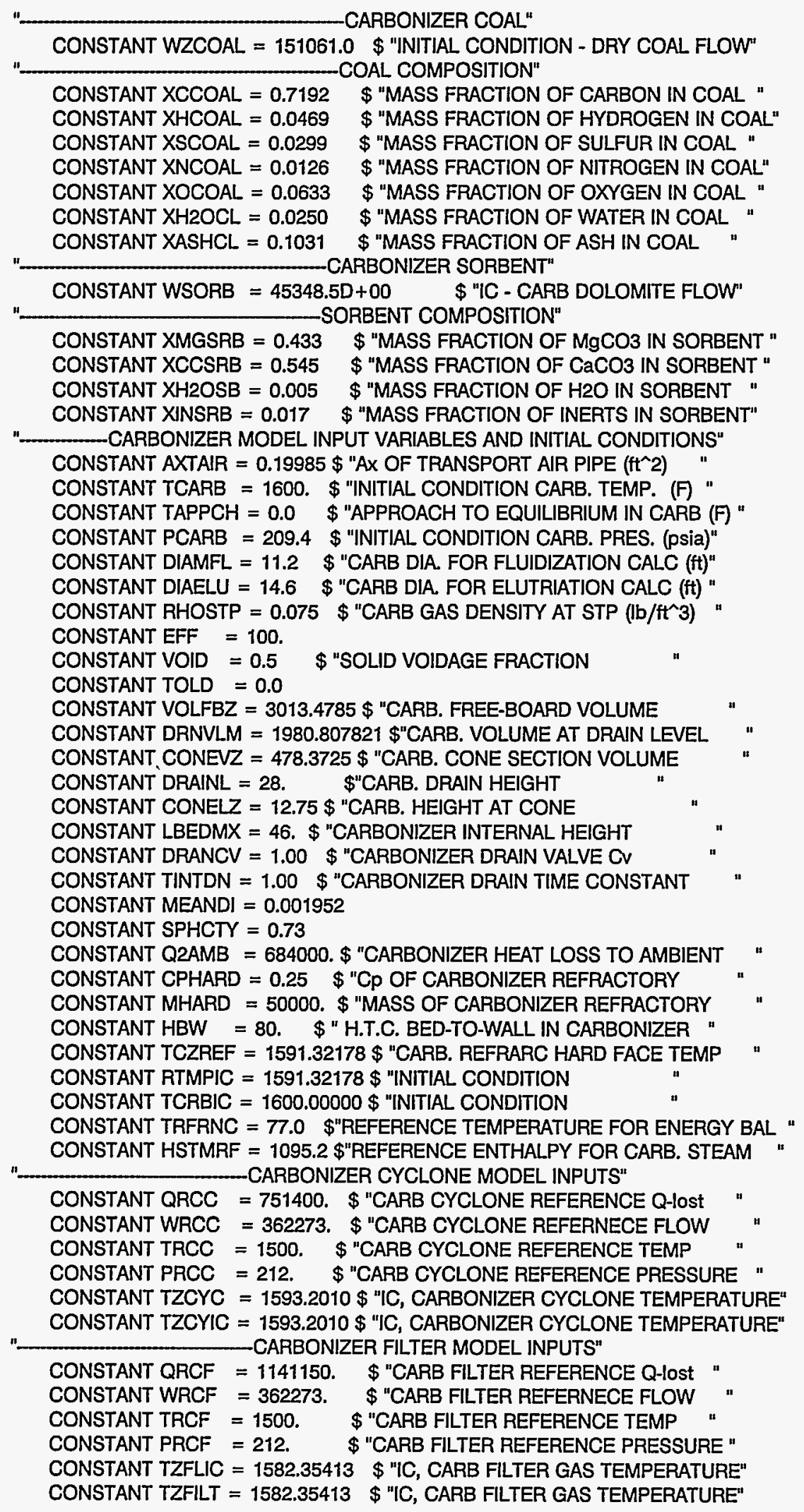




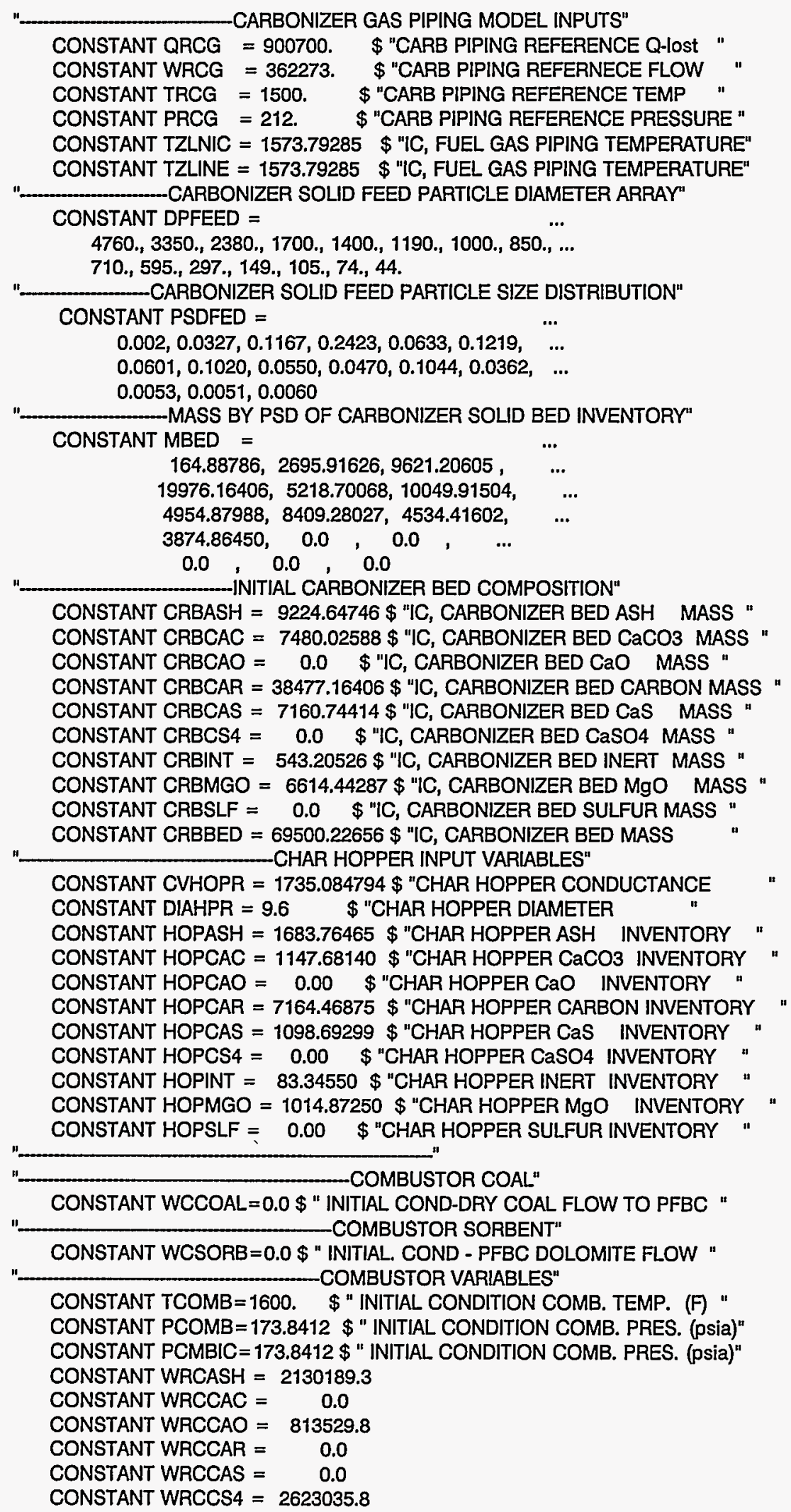


CONSTANT WRCNRT $=105442.7$

CONSTANT WRCMGO $=1283950.4$

CONSTANT WRCSLF $=0.0$

CONSTANT WRCTLT $=6956148.0$

CONSTANT YCO2FB $=0.0612$

CONSTANT TFBHE $=1250$.

CONSTANT WCSHOT $=378237$.

"-

CONSTANT DPFBCC $=$ 3350., 2380., 1700., 1400., 1190., 1000., 850., $\quad \ldots$

710., 595., 297., 149., 105., 74., 44., 0.00001

"___ CPFBC FREEBOARD SOLIDS PARTICLE SIZE DISTRIBUTION"

CONSTANT PSDCFB =

$0.0003,0.0030,0.0237,0.0147,0.0209,0.0200, \cdots$

$0.0329,0.0288,0.0296,0.1071,0.1107,0.0592, \ldots$

$0.0713,0.1243,0.3535$

"___ COMBUSTOR FILTER MODEL INPUTS"

CONSTANT QRFF $=3139350$. \$ "COMB FILTER REFERENCE Q-lost "

CONSTANT WRFF $=2529673$. "COMB FILTER REFERNECE FLOW "

CONSTANT TRFF $=1600 . \$$ "COMB FILTER REFERENCE TEMP

CONSTANT PRFF $=203$. \$ "COMB FILTER REFERENCE PRESSURE "

CONSTANT TCFLIC $=1595.67993 \$$ "IC, CPFBC X-FLOW FILTER TEMP "

CONSTANT TCFILT $=1595.67993 \$ " I C$, CPFBC X-FLOW FILTER TEMP

"COMBUSTOR GAS PIPING MODEL INPUTS"

CONSTANT QRFG $=3490800$. \$ "COMB PIPING REFERENCE Q-lost "

CONSTANT WRFG $=$ 2529673. "COMB PIPING REFERNECE FLOW "

CONSTANT TRFG $=1600$. \$ "COMB PIPING REFERENCE TEMP "

CONSTANT PRFG $=203$. \$ "COMB PIPING REFERENCE PRESSURE "

CONSTANT TCLNIC $=1590.83215 \$$ "IC, CPFBC GAS PIPING TEMP

CONSTANT TCLINE $=1590.83215 \$ " I C$, CPFBC GAS PIPING TEMP

CONSTANT QCORPC $=58000 . \$$ "PFBC CORRECTION $(\mathrm{Btu} / \mathrm{hr})$

CONSTANT DIACFB $=18.0 \$$ "CPFBC SECONDARY ZONE DIAMETER

CONSTANT DIACPZ $=12.0 \$$ "CPFBC PRIMARY ZONE DIAMETER

CONSTANT LCMBSZ $=70.5 \$$ "CPFBC SECONDARY ZONE HEIGHT

CONSTANT LCMBPZ $=15.0 \$$ "CPFBC PRIMARY ZONE HEIGHT

CONSTANT BHTCPZ $=10.0 \$$ "CPFBC BED HEIGHT FOR DEL-P CALC

CONSTANT HBWCPZ $=40.0 \$$ "CPFBC PRIM. ZONE BED-WALL H.T.C.

CONSTANT HBWCSZ $=80.0 \$$ "CPFBC SECD. ZONE BED-WALL H.T.C.

CONSTANT QFBLST $=2275400 . \$$ "CPFBC AMBIENT Q LOST

CONSTANT MHRDFB $=123311 . \$$ "CPFBC HARD FACE MASS

CONSTANT TCMBIC $=1600 . \$ " I C$, CPFBC TEMPERATURE

CONSTANT CPRFFB $=0.25 \$$ "CPFBC HARD FACE $\mathrm{Cp}$

CONSTANT TFBREF $=1593.33813 \$$ "CPFBC HARD FACE TEMPERATURE "

CONSTANT HTMPIC $=1593.33813 \$$ "CPFBC HARD FACE TEMP., I.C.

CONSTANT TAOFBH =

CONSTANT TAOFBH $=1050 . \$$ "IC, FBHE FREEBOARD AIR TEMP "

CONSTANT AXFBC1 $=288.2 \$$ "FBHE CELL \# 1 CROSS SECTIONAL AREA "

CONSTANT AXFBC2 $=52.7 \$$ "FBHE CELL \# 2 CROSS SECTIONAL AREA

CONSTANT AXFBC3 $=83.9 \$$ "FBHE CELL \# 3 CROSS SECTIONAL AREA

CONSTANT AXFBC4 $=52.7 \$$ "FBHE CELL \# 4 CROSS SECTIONAL AREA

CONSTANT AXFBC5 $=82.3 \$$ "FBHE CELL \# 5 CROSS SECTIONAL AREA

CONSTANT AXFBC6 $=100.1 \$$ "FBHE CELL \# 6 CROSS SECTIONAL AREA

CONSTANT AXFBC7 $=82.3 \$$ "FBHE CELL \# 7 CROSS SECTIONAL AREA

CONSTANT TADIC $=1584.45276 \$ " I C, F B H E$ ADIABATIC TEMPERATURE

CONSTANT TC7IC $=1332.36707 \$$ "IC,FBHE CELL \# 7 TEMPERATURE

CONSTANT TC6IC $=1117.62939 \$ " \mathrm{IC}, F B H E$ CELL \# 6 TEMPERATURE

CONSTANT TC5IC $=1050.00256 \$$ "IC,FBHE CELL \# 5 TEMPERATURE

CONSTANT TC4IC $=1379.86829 \$$ "IC,FBHE CELL \# 4 TEMPERATURE

CONSTANT TC3IC $=1178.41797 \$ " I C, F B H E$ CELL \# 3 TEMPERATURE CONSTANT TC2IC $=1050.00256 \$ " I C, F B H E$ CELL \# 2 TEMPERATURE CONSTANT PDFBHE $=0.00016403 \$$ "FBHE MEAN PARTICAL DIAMETER 
CONSTANT FBCIRC $=7000000 . \$$ "CPFBC SOLID CIRCULATION RATE CONSTANT FBCYCN $=0.999 \$$ "CPFBC CYCLONE EFFICIENCY CONSTANT PCTOLD $=0.973 \$$ "CPFBC PERCENT RECIRC VALUE CONSTANT FBHEAX $=593.92 \$$ "FBHE CROSS SECTIONAL AREA CONSTANT RHOFBV $=0.301 \$$ "AVERAGE AIR DENSITY IN FBHE CONSTANT QFBSI9 $=10754704$.

CONSTANT CVFBDN $=1.0$

CONSTANT FBWEIR $=10 . \$$ "FBHE DRAIN WEIR HEIGHT

CONSTANT FBHEFB $=15 . \$$ "FBHE FREEBOARD HEIGHT

CONSTANT CFSFS $=10968.74988 \$$ "CONDUCTANCE, FBHE SUPERHEATER "

CONSTANT CFSSR $=19445.772 \$$ "CONDUCTANCE, FBHE REHEATER

CONSTANT PRSFBH $=184.84487 \$$ "IC,FBHE FREEBOARD PRESSURE

CONSTANT PFBHIC $=184.84487 \$ " I C$,FBHE FREEBOARD PRESSURE

CONSTANT TFBHLT $=1050.00256 \$ " I C, \mathrm{t}(-)$ FBHE AIR OUTLET T

CONSTANT VGSFBL $=11878.399 \$ " I C, t(-)$ FBHE AIR VOLUME

CONSTANT CNDFBH $=223778.2096 \$$ "FBHE DUCT AIR CONDUCTANCE FBHE INITIAL SOLIDS INVENTORY"

CONSTANT FBHASH $=109126.1$ \$F.B.H.E. ASH IC INVENTORY "

CONSTANT FBHCAC $=0.0$ \$ "F.B.H.E. CaCO3 IC INVENTORY "

CONSTANT FBHCAO $=41675.8$ \$F.B.H.E. CaO IC INVENTORY "

CONSTANT FBHCAR $=0.0 \$$ "F.B.H.E. CARBON IC INVENTORY "

CONSTANT FBHCAS $=\quad 0.0 \quad \$$ "F.B.H.E. CaS IC INVENTORY "

CONSTANT FBHCS4 $=134373.7 \$$ "F.B.H.E. CaSO4 IC INVENTORY "

CONSTANT FBHINT $=5401.7 \$$ "F.B.H.E. INERT IC INVENTORY "

CONSTANT FBHMGO $=65774.7 \$$ "F.B.H.E. MgO IC INVENTORY " CONSTANT FBHSLF $=0.0 \$ " F . B . H . E$. SULFUR IC INVENTORY

"--INITAL CONDITIONS AND GEOMETRY OF FBHE ENCLOSURE WALLS STEAM SIDE" CONSTANT WRSR $=1099229.76 \$ " I C$, FLOW IN FBHE ENCLOSURE CONSTANT TRSRI $=677.5018 \$ " I C$, FBHE ENCLOSURE RISER TEMP " CONSTANT TRSRO $=677.5018 \$ " I C$, FBHE ENCLOSURE RISER TEMP " CONSTANT PRSRI $=2660$. \$ "IC, FBHE ENCLOSURE RISER PRES CONSTANT PRSRO $=2660 . \quad \$ " I C$, FBHE ENCLOSURE RISER PRES " CONSTANT HRSRI $=751.82$ \$ "IC, FBHE ENCLOSURE RISER H IN " CONSTANT HRSRO $=804.75 \$ " I C$, FBHE ENCLOSURE RISER H OUT " CONSTANT AXTRSR $=0.031416 \$$ "FBHE ENCLOSURE WALLS AX CONSTANT RSRTD $=0.200000 \$$ "FBHE ENCLOSURE WALLS TUBE ID

"_-INITAL CONDITIONS AND GEOMETRY OF FBHE FINISH SUPER STEAM SIDE" CONSTANT WWFS $=798950$. \$ "IC, FLOW THROUGH FINISHING SUPER " CONSTANT TSFSI $=930 . \quad \$ " I C$, FINISHING SUPER INLET TEMP " CONSTANT TSFSO $=1000 . \$ " I C$, FINISHING SUPER OUTLET TEMP " CONSTANT PSFSI $=2573.0 \$$ "IC, FINISHING SUPER INLET PRES " CONSTANT PSFSO $=2537.4 \$ " I C$, FINISHING SUPER OUTLET PRES " CONSTANT HSFSI $=1401.48 \$ " I C$, FINISHING SUPER INLET ENTH " CONSTANT HSFSIC $=1456.78 \$ " I C$, FINISHING SUPER OUTLET ENTH " CONSTANT HSFSO $=1456.78 \$$ "IC, FINISHING SUPER OUTLET ENTH " CONSTANT AXTFS $=0.008797$ \$ "FINISHING SUPER INSIDE AX CONSTANT FSTD $=0.105833 \$$ "FINISHING SUPER TUBE ID CONSTANT FSTL $=2664.57$ "FINISHING SUPERS TUBE LENGTH " CONSTANT RFSO $=0.083333$ \$ "FINISHING SUPER TUBE OUTSIDE RADI" CONSTANT RFSI $=0.052917$ "FINISHING SUPER TUBE INSIDE RADI " CONSTANT FSBEDA $=85.7$ "FBHE FINISHING SUPER WALL AREA " CONSTANT FSWFBA $=85.7$ \$ "FBHE FINISHING SUPER FREEBRD AREA" CONSTANT QFSX $=2675667.571$

"_-INITAL CONDITIONS AND GEOMETRY OF FBHE SCNDRY SUPER STEAM SIDE" CONSTANT WWSS $=190838.5 \$ " I C$, FLOW IN SECONDARY SUPER " CONSTANT TSSSI $=734$. \$ "IC, FBHE SECD SUPER INLET TEMP " CONSTANT TSSSO $=930 . \quad \$ " I C$, FBHE SECD SUPER OUTLET TEMP " CONSTANT PSSSI $=2617.8$ \$"IC, FBHE SECD SUPER INLET PRES " CONSTANT PSSSO $=2575.0$ \$"IC, FBHE SECD SUPER OUTLET PRES " CONSTANT HSSSI $=1211.21$ \$ "IC, FBHE SECD SUPER INLET ENTH " CONSTANT HSSSO $=1404.83 \$ " I C$, FBHE SECD SUPER OUTLET ENTH " 
CONSTANT HSSSIC $=1404.83$ CONSTANT AXTSS $=0.01327$ CONSTANT SSTD $=0.13000$ CONSTANT SSTL $=3173.1$ CONSTANT RSSO $=0.083333$ CONSTANT RSSI $=0.065$ CONSTANT SSBEDA $=212.39$ CONSTANT SSWFBA $=212.39$

"I__INITAL CONDITIONS AND GEO CONSTANT WWPS $=190838$ CONSTANT TSPSI $=677.5$ CONSTANT TSPSO $=734$. CONSTANT PSPSI $=2660$. CONSTANT PSPSO $=2617.8$ CONSTANT HSPSI $=1072.82$ CONSTANT HSPSO $=1211.21$ CONSTANT HSPSIC $=1211.21$ CONSTANT AXTPS $=0.013616$ CONSTANT PSTD $=0.13167$ CONSTANT PSTL $=2029.59$ CONSTANT RPSO $=0.083333 \$$ "FBHE PRIM SUPER TUBE RADIUS IN" CONSTANT RPSI $=0.06583$ "FBHE PRIM SUPER TUBE RADIUS OUT " CONSTANT PSBEDA $=167.9651$ \$ "FBHE PRIM SUPER BED WALL AREA " CONSTANT PSWFBA $=167.9651$ \$ "FBHE PRIM SUPER FREEBOEARD AREA "

"-INITAL CONDITIONS AND GEOMETRY OF FBHE FINISH REHEAT STEAM SIDE" CONSTANT WWFR $=798950$. \$ "FBHE FINISHING REHEAT FLOW CONSTANT TSFRI $=785$. CONSTANT TSFRO $=1000$. CONSTANT PSFRI $=520$. CONSTANT PSFRO $=480$. CONSTANT HSFRI $=1402.98$ CONSTANT HSFRO $=1520.92$ CONSTANT AXTFR $=0.018265$ CONSTANT FRTD $=0.15250$ CONSTANT FRTL $=\mathbf{5 7 1 5 . 2 8}$ CONSTANT RFRO $=0.09375$ CONSTANT RFFI $=0.07625$ CONSTANT FRBEDA $=140.33$ CONSTANT FRWFBA $=140.33$

"INITAL CONDITIONS AND GEOME CONSTANT WWPR $=798950$. CONSTANT TSPRI $=612$. CONSTANT TSPRO $=785$. CONSTANT PSPRI $=\mathbf{5 2 0}$. CONSTANT PSPRO $=520$. CONSTANT HSPRI $=1304.03$ CONSTANT HSPRO $=1402.98$ CONSTANT AXTPR $=0.019483$ CONSTANT PRTD $=0.15750$ CONSTANT PRTL $=5130.47$ CONSTANT RPRO $=0.09375$ CONSTANT RPRI $=0.07875$ CONSTANT PRBEDA $=262.835$ CONSTANT PRWFBA $=262.835$ $\$ " I C, F B H E$ FINISH REHEAT INLET TEMP" $\$$ "IC,FBHE FINISH REHEAT OUTLET TEMP" $\$$ "IC,FBHE FINISH REHEAT INLET PRES" $\$$ "IC,FBHE FINISH REHEAT OUTLET PRES" $\$$ "IC,FBHE FINISH REHEAT INLET ENTH" $\$$ "IC,FBHE FINISH REHEAT OUTLET ENTH" $\$$ "FBHE FINISHING REHEAT AX $\$$ "FBHE FINISHING REHEAT TUBE ID " $\$$ "FBHE, FINISH REHEAT TUBE LENGTH " $\$$ "FBHE, FINISH REHEAT TUBE RADIS IN" $\$$ "FBHE, FINISH REHEAT TUBE RADI OUT" $\$$ "FBHE F. REHEAT IN-BED WALL AREA " $\$$ "FBHE F. REHEAT WALL AREA

METRY OF FBHE PRIMARY REHEAT STEAM SIDE" $\$$ "IC, FBHE PRIM REHEAT FLOW $\$$ "IC, FBHE PRIM REHEAT INLET TEMP " $\$$ "IC, FBHE PRIM REHEAT OUTLET TEMP" $\$$ "IC, FBHE PRIM REHEAT INLET PRES " $\$$ "IC, FBHE PRIM REHEAT OUTLET PRES " $\$$ "IC, FBHE PRIM REHEAT INLET ENTH " $\$$ "IC, FBHE PRIM REHEAT OUTLET ENTH " $\$$ "FBHE PRIM REHEAT AX $\$$ "FBHE PRIM REHEAT TUBE ID $\$$ "FBHE PRIM REHEAT TUBE LENGTH $\$$ "FBHE PRIM REHEAT TUBE RADIUS OUT " \$ "FBHE PRIM REHEAT TUBE RADIUS IN " $\$$ "FBHE PRIM REHEAT IN-BED AREA $\$$ "FBHE PRIM REHEAT WALL AREA "INITAL CONDITIONS AND GEOMETRY OF FBHE STM GENERATION STEAM SIDE" CONSTANT WWSG $=427478.24 \$$ "IC, FBHE STEAM GEN FLOW CONSTANT TSSGI $=677.5018 \$$ "IC, FBHE STM GEN INLET TEMP CONSTANT TSSGO $=677.5018 \$$ "IC, FBHE STM GEN OUTLET TEMP " CONSTANT PSSGI $=2660$. CONSTANT PSSGO $=2660$. CONSTANT HSSGI $=752.82$
$\$ " I C$, FBHE STM GEN INLET PRES

$\$$ "IC, FBHE STM GEN OUTLET PRES " $\$$ "IC, FBHE STM GEN INLET ENTH 
CONSTANT HSSGO $=804.75 \$$ "IC, FBHE STM GEN OUTLET ENTH "

CONSTANT AXTSG $=0.0143139 \$$ "FBHE STEAM GEN AX

CONSTANT SGTD $=0.13500 \$$ "FBHE STEAM GEN TUBE ID

CONSTANT SGTL $=1173.62037 \$$ "FBHE STM. GEN. TUBE LENGTH

CONSTANT RSGO $=0.08333$ \$ "FBHE STM GEN TUBE RADIUS OUTSIDE "

CONSTANT RSGI $=0.0675$ "FBHE STM GEN TUBE RADIUS INSIDE "

CONSTANT SGBEDA $=254.84225 \$$ "FBHE STM. GEN. IN-BED AREA "

CONSTANT SGWFBA $=254.84225 \$$ "FBHE STM. GEN. WALL AREA

CONSTANT STEFAN $=0.1714 \mathrm{D}-08 \$$ "STEFAN BOLTZMAN CONSTANT CONSTANT EMISS $=0.45 \quad \$$ "FBHE FREEBOARD EMISSIVITY

CONSTANT QCELL7 $=102514442.4 \$$ "IC, Q TRANSFERED IN FBHE CELL \#7" CONSTANT QCELL6 $=89225627.1 \$$ "IC, Q TRANSFERED IN FBHE CELL \#6" CONSTANT QCELL5 $=26595608.8 \$$ "IC, Q TRANSFERED IN FBHE CELL \#5" CONSTANT QCELL4 $=46966863.9 \$$ "IC, $Q$ TRANSFERED IN FBHE CELL \#4" CONSTANT QCELL3 = 46366376.9 \$ "IC, Q TRANSFERED IN FBHE CELL \#3" CONSTANT QCELL2 = 31871328.7 \$ "IC, Q TRANSFERED IN FBHE CELL \#2" -INPUT VARIABLES FOR FBHE STEAM DRUM CALCULATIONS"

CONSTANT PFBDRM $=2660 . \$$ "IC, FBHE STEAM DRUM PRESSURE

CONSTANT HFBDRM $=816.632625 \$ " I C$, FBHE STEAM DRUM ENTHALPY "

CONSTANT WDCIRC $=1526708$. \$ "IC, FBHE STEAM DRUM CIRC RATE "

CONSTANT HDOWNC $=741.2005 \$ " I C$, FBHE DRUM DOWNCOMER ENTH "

CONSTANT HDCIC $=741.2005 \$ * I C$, FBHE DRUM DOWNCOMER ENTH

CONSTANT VOLDC $=60.0$ \$ "FBHE STEAM DRUM DOWNCOMER VOLUME "

CONSTANT HRISER $=791.075$ \$IC, FBHE DRUM RISER ENTHALPY "

CONSTANT HRSRIC $=791.075 \$ " I C$, FBHE DRUM RISER ENTHALPY "

CONSTANT DELHD $=28$. \$ "FBHE STEAM DRUM DOWNCOMER HEIGHT "

CONSTANT VFBRSR $=60.0$ \$ "FBHE STEAM DRUM RISER VOLUME

CONSTANT CIRCCD $=13835.9762 \$$ "FBHE CIRCULATION CONDUCTANCE "

CONSTANT INRTNC $=7.0848819 \$$ "FBHE CIRC FLOW INERTANCE

CONSTANT WCRCIC $=1526708$. $\$$ "IC,FBHE CIRCULATION RATE "

CONSTANT VDRMTT $=320.00$ \$ "FBHE STEAM DRUM SYSTEM VOLUME "

CONSTANT VFBDRM $=200.00$ \$ "FBHE STEAM DRUM VOLUME

CONSTANT WDRMB $=0.0$ \$ FBHE STEAM DRUM BLOW DOWN

CONSTANT DRMDIA $=8 . \quad \$$ "FBHE STEAM DRUM DIAMETER

CONSTANT WDRMS $=190838.5$

CONSTANT PDRMIC $=2660$. \$ "IC, FBHE STEAM DRUM PRESSURE "

CONSTANT HDRMIC $=816.632625 \$ " I C$, FBHE STEAM DRUM ENTHALPY

"INPUT VARIABLES FOR STEAM S/H, R/H AND ASSOCIATED PIPING"

CONSTANT HTHGOV $=1456.78$

CONSTANT PRSGOV $=2440$.

CONSTANT HGOVIC $=1456.78$

CONSTANT PGOVIC $=2440$.

CONSTANT VOLSTP $=10$.

CONSTANT ROWGVX $=3.27581$

CONSTANT WWFSX $=798950$.

CONSTANT DPSPIC $=97.41$

CONSTANT ROWSAX $=3.71868$

CONSTANT WWSSX $=190838.5$

CONSTANT DPSAIC $=2.00000$

CONSTANT HSFRIC $=1520.92$

CONSTANT HSPRIC $=1402.98$

CONSTANT RHCNDT $=139525.0608$

CONSTANT RHDELZ $=0.0$

CONSTANT PSCOND $=10983.73409 \$$ "PRIM SUPER FLOW CONDUCTANCE "

CONSTANT FSCOND $=71273.91691 \$$ "FINISH SUPER FLOW CONDUCTANCE "

CONSTANT ATCOND $=69977.20507 \$$ "ATTEMPERATOR FLOW CONDUCTANCE "

CONSTANT SPCOND $=44725.83706 \$$ "FBHE STEAM PIPING CONDUCTANCE "

CONSTANT PPSATT $=2573.0 \quad \$ " I C$, FBHESTEAM DRUM PS OUTLET PRES"

CONSTANT HPSATT $=1401.48 \$$ "IC, FBHESTEAM DRUM PS OUTLET ENTH"

CONSTANT PPSAIC $=2573.0 \$$ "IC, FBHESTEAM DRUM PS OUTLET PRES" 
CONSTANT HPSAIC $=1401.48 \$$ "IC, FBHESTEAM DRUM PS OUTLET ENTH" CONSTANT WPSATM $=0.0$

CONSTANT VOLPSA $=10.0 \$$ "VOLUME OF PRIM SUPR PIPING

CONSTANT SADAMP $=1000$.

CONSTANT SPDAMP $=1000$.

GAS TURBINE COMBUSTOR MODEL INPUT VARIABLES"

CONSTANT SFXCAR $=0.0 \$ " G / T$ SUPPLEMENTAL FUEL WT. $\%$ CARBON " CONSTANT SFXCH4 $=0.0 \$ " \mathrm{G} / \mathrm{T}$ SUPPLEMENTAL FUEL WT. \% METHANE " CONSTANT SFXC24 $=0.0 \$ " G / T$ SUPPLEMENTAL FUEL WT. $\%$ ETHENE CONSTANT SFXC26 $=0.0 \$ " G / T$ SUPPLEMENTAL FUEL $W T$. $\%$ ETHANE CONSTANT SFXH2 $=0.0 \$ " G / T$ SUPPLEMENTAL FUEL WT. $\%$ HYDROGEN " CONSTANT SFXN2 $=0.0 \$ " G / T$ SUPPLEMENTAL FUEL WT. \% NITROGEN" CONSTANT SFXO2 $=0.0 \$$ "G/T SUPPLEMENTAL FUEL WT. \% OXYGEN" CONSTANT SFXSLF $=0.0 \$ " G / T$ SUPPLEMENTAL FUEL WT. \% SULFUR " CONSTANT GTSFLW $=0.0 \$ " G / T$ SUPPLEMENTAL FUEL MASS FLOW " CONSTANT TGTCMB $=2350$.

CONSTANT TGTIC $=2350$.

CONSTANT RS3OLD $=0.15699$

CONSTANT PDGTIC $=\mathbf{5 . 8 6 8 8}$

CONSTANT PGTCMB $=151.811$

CONSTANT PGTIC $=151.811$

CONSTANT VOLMGT $=42000 . \$$ "G/T\&PIPING VOLUME W/ DAMPING FACTOR " CONSTANT QGTCOR $=0.0$

CONSTANT GTQFRC $=0.015719$

CONSTANT CGTCMB $=3154680.668 \$ " \mathrm{G} / \mathrm{T}$ COMB CONDUCTANCE CONSTANT TGTMTL $=1500 . \$ " I C, G / T$ COMBUSTOR LINER TEMP CONSTANT TGTMIC $=1500 . \$ " I C, G / T$ COMBUSTOR LINER TEMP CONSTANT GTFILM $=134 . \$$ "FILM COEFFICIENT CONSTANT AWETTD $=98.09 \$$ "WETTED AREA CONSTANT GTMTLM $=1500$. CONSTANT GTMTCP $=0.25$ ASH COOLER MODEL VARIABLES"

CONSTANT HTCAC $=12.5$ \$ "OVERALL HTC IN ASH COOLER " CONSTANT HTAAC $=1619.921$ \$ "HEAT TRANSFER AREA IN ASH COOLER" CONSTANT ACCNDT $=3426.1302 \$$ "ASH COOLER WATER CONDUCTANCE CONSTANT ACDELZ $=0.0$ \$ "ASH COOLER ELEVATION DIFFERENCE "

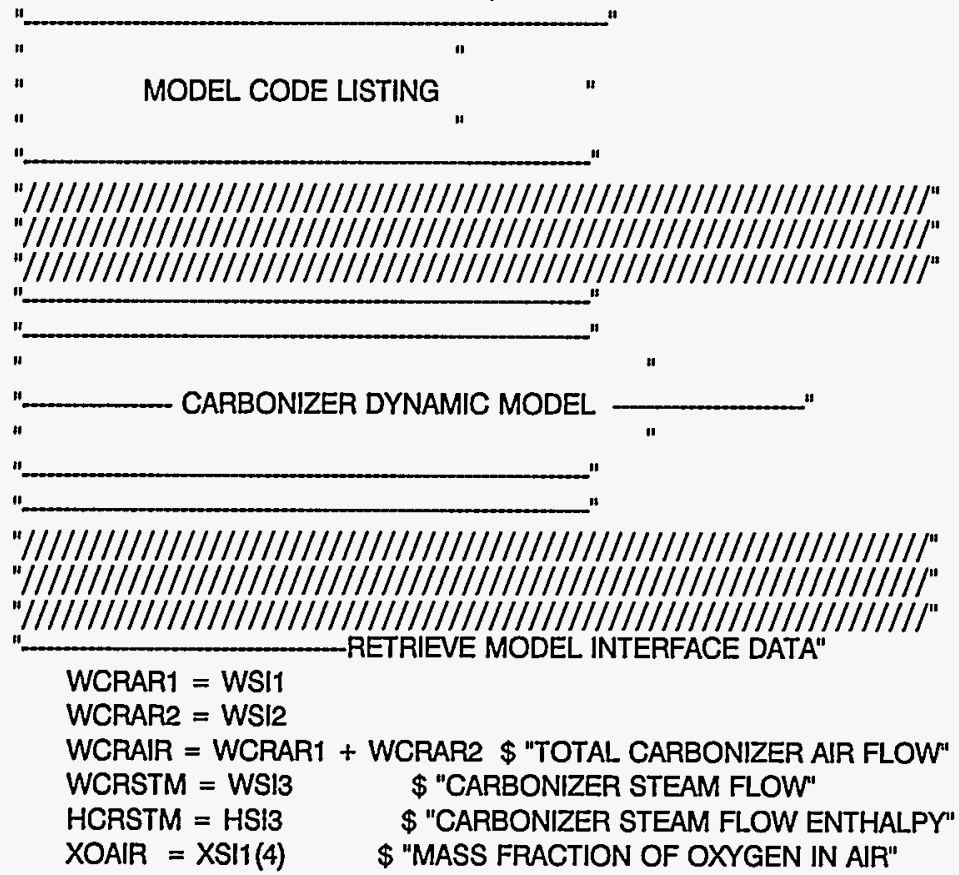




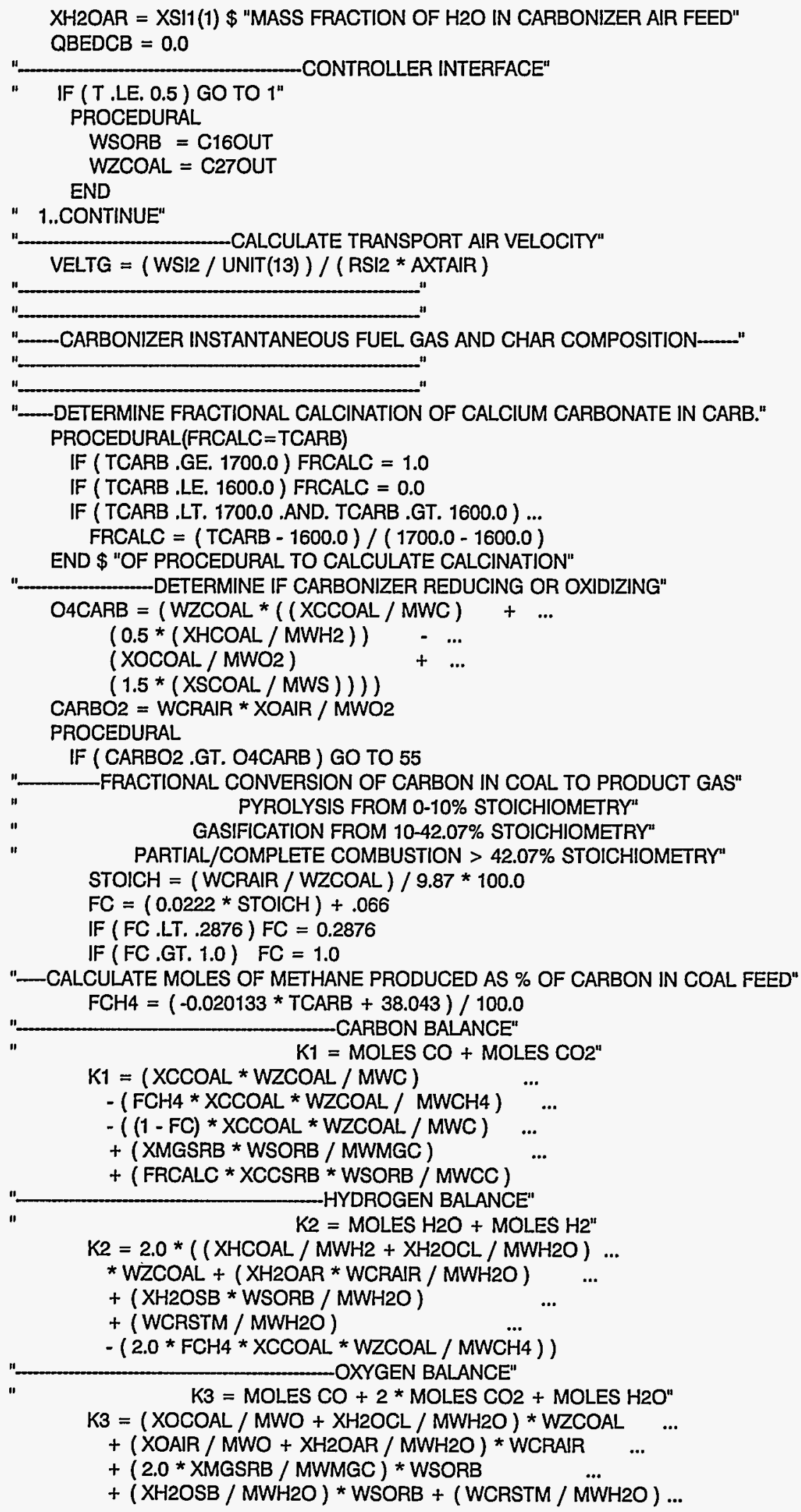


$+(2.0$ * FRCALC * XCCSRB * WSORB / 100.0)

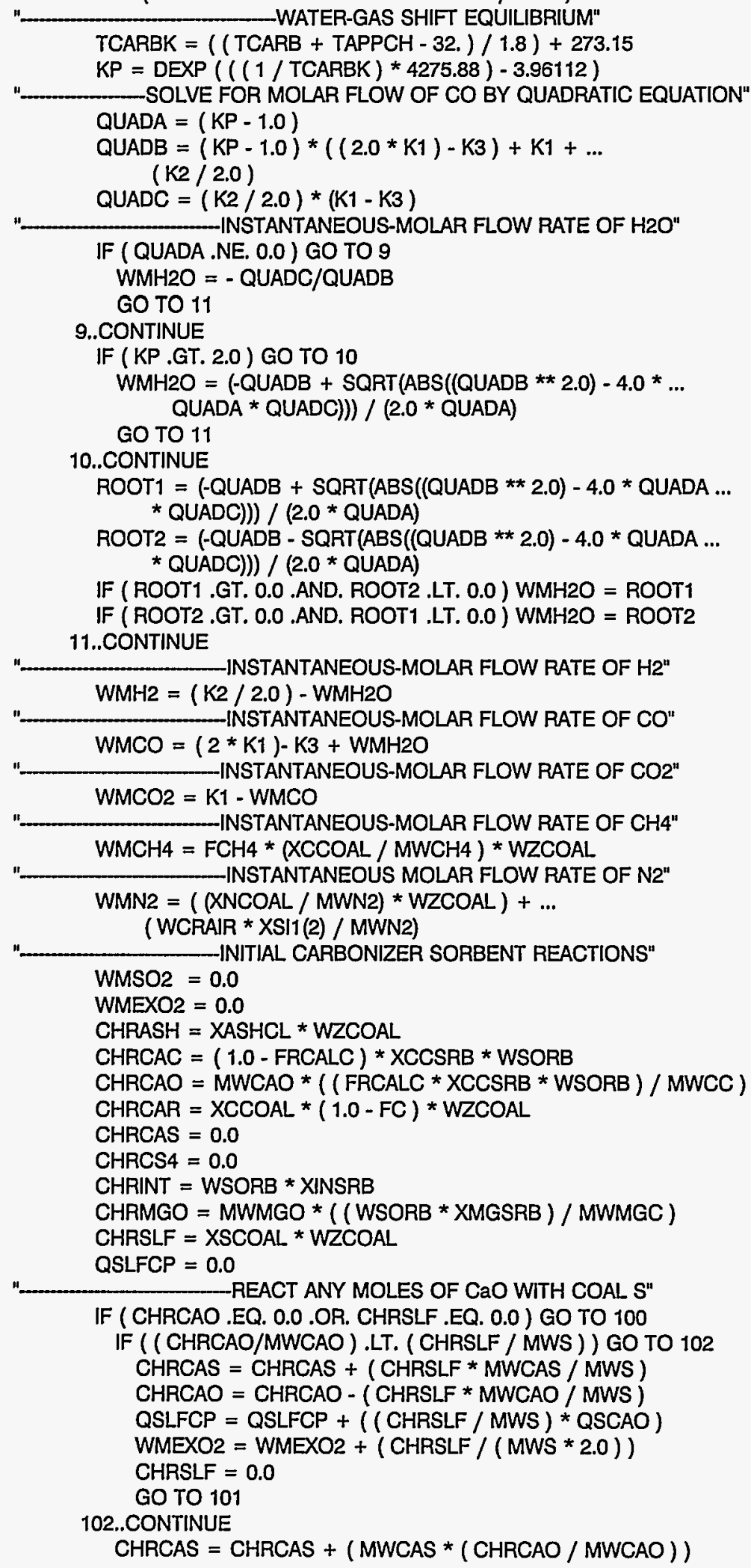
WATER-GAS SHIFT EQUILIBRIUM" 


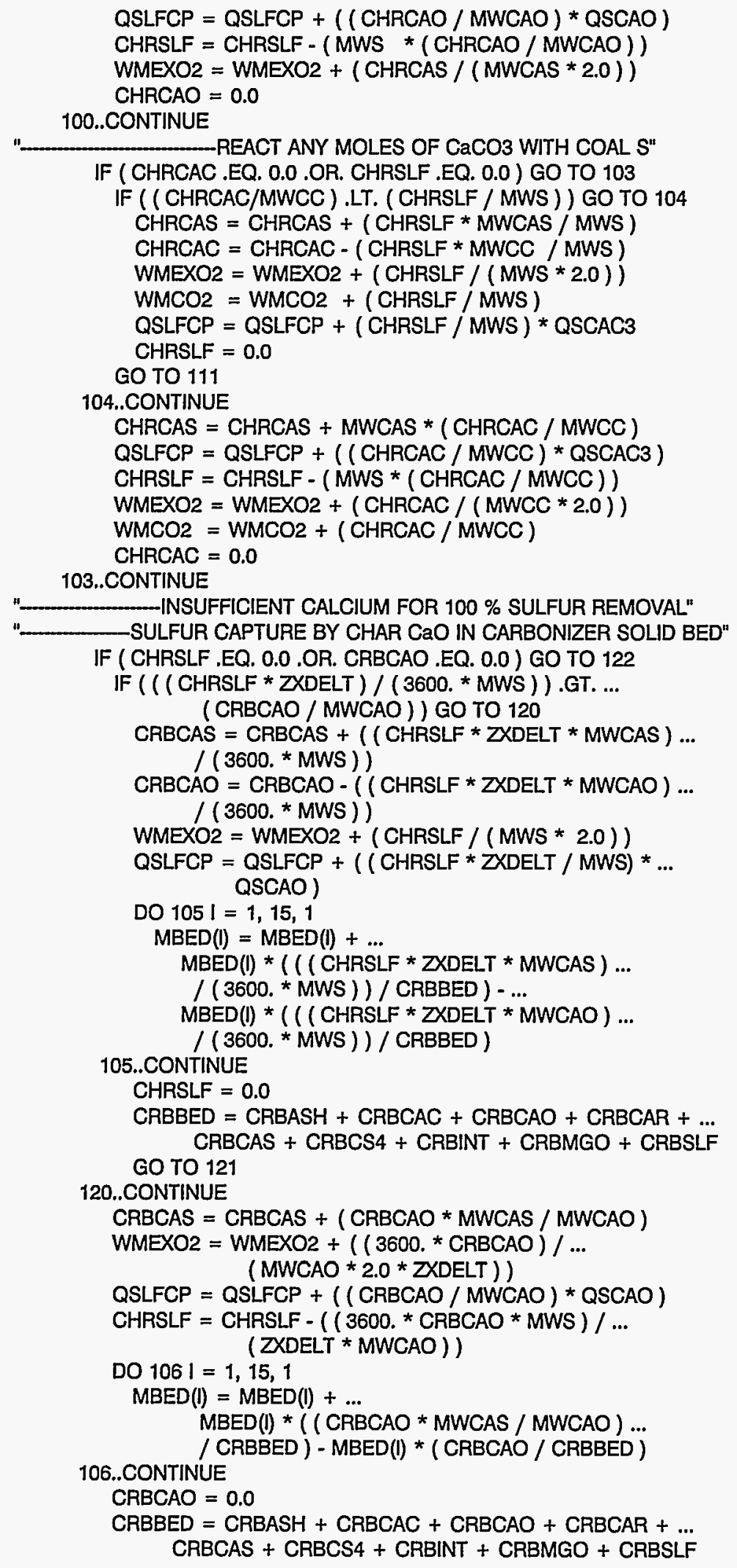


122..CONTINUE

SULFUR CAPTURE BY CHAR CaCO3 IN CARBONIZER SOLID BED"

IF ( CHRSLF .EQ. 0.0 .OR. CRBCAC .EQ. 0.0) GO TO 131

IF $\left(\left((\right.\right.$ CHRSLF * ZXDELT $) /\left(3600 .{ }^{*}\right.$ MWS $\left.)\right) . G T . .$. (CRBCAC / MWCC ) ) GO TO 130

CRBCAS $=$ CRBCAS $+(($ CHRSLF * ZXDELT *.. MWCAS $) /(3600$. * MWS $))$

CRBCAC $=$ CRBCAC $-(($ CHRSLF $*$ ZXDELT * ... MWCC ) / (3600. * MWS ))

WMEXO2 $=$ WMEXO2 $+($ CHRSLF $/($ MWS * 2.0 $))$

WMCO2 $=$ WMCO2 $+($ CHRSLF $/$ MWS $)$

QSLFCP $=$ QSLFCP + ( ( CHRSLF / MWS $)$ * QSCAC3 $)$

DO $107 \mid=1,15,1$

$\operatorname{MBED}(I)=\operatorname{MBED}()+\ldots$

MBED $(l)$ * ( ( ( CHRSLF * ZXDELT * MWCAS ) ...

/ (3600. * MWS $)) /$ CRBBED $)-\ldots$

MBED $(l)$ * ( ( ( CHRSLF * ZXDELT * MWCC $) \ldots$

107..CONTINUE /( $3600 . *$ MWS ) ) / CRBBED)

CHRSLF $=0.0$

CRBBED $=$ CRBASH + CRBCAC + CRBCAO + CRBCAR + ... GO TO 131 CRBCAS + CRBCS4 + CRBINT + CRBMGO + CRBSLF

130..CONTINUE

CRBCAS $=$ CRBCAS $+($ CRBCAC $*$ MWCAS $/$ MWCC $)$

WMEXO2 $=$ WMEXO2 $+((3600 . *$ CRBCAC $) / \ldots$

$(Z X D E L T * M W C C * 2.0))$

WMCO2 $=$ WMCO2 $+((3600 . *$ CRBCAC $) / \ldots$

(ZXDELT * MWCC))

CHRSLF $=$ CHRSLF $-\left(\left(3600 .{ }^{*}\right.\right.$ CRBCAC * MWS $) / \ldots$ ( ZXDELT * MWCC))

QSLFCP $=$ QSLFCP + ( ( CRBCAC $/$ MWCC $) *$ QSCAC3 $)$

DO $108 \mathrm{I}=1,15,1$

$\operatorname{MBED}(l)=\operatorname{MBED}(I)+\ldots$

MBED $(l)$ * ( ( CRBCAC * MWCAS / MWCC ) ...

108..CONTINUE / CRBBED ) - MBED $(l) *($ CRBCAC / CRBBED )

CRBCAC $=0.0$

CRBBED $=$ CRBASH + CRBCAC + CRBCAO + CRBCAR $+\ldots$ CRBCAS + CRBCS4 + CRBINT + CRBMGO + CRBSLF

101..CONTINUE

111..CONTINUE

121..CONTINUE

131..CONTINUE

"-MASS FLOW OF INSTANTANEOUS CHAR GENERATED"

WCHRGN $=$ CHRASH + CHRCAR + CHRCAS + CHRCAO + CHRCAC + ..

CHRMGO + CHRSLF + CHRINT + CHRCS4

-LIMIT WMEXO2 TO POSTIVE NUMBER"

IF (WMEXO2 .LT. 0.0) WMEXO2 $=0.0$

"COMBUST O2 IN FUEL GAS LIBERATED DURING CONCEPTUAL SORBENT REACTIONS"

-H2 COMBUSTION TO H2O"

IF (WMH2 .GT. (WMEXO2 * 2.0) ) GO TO 140

$W M H 2 O=W M H 2 O+W M H 2$

WMEXO2 $=$ WMEXO2 - WMH2 $/ 2.0$

" $\quad$ QBEDCB $=$ QBEDCB + ( LHVH2 *WMH2 * MWH2 $) "$

$W M H 2=0.0$

GO TO 141

140..CONTINUE

WMH2O $=$ WMH2O + WMEXO2 $* 2.0$

WMH2 $=W M H 2-W M E X O 2 * 2.0$

QBEDCB $=$ QBEDCB + ( LHVH2 * MWH2 * 2.0 * WMEXO2 $) "$ 
WMEXO2 $=0.0$

141..CONTINUE

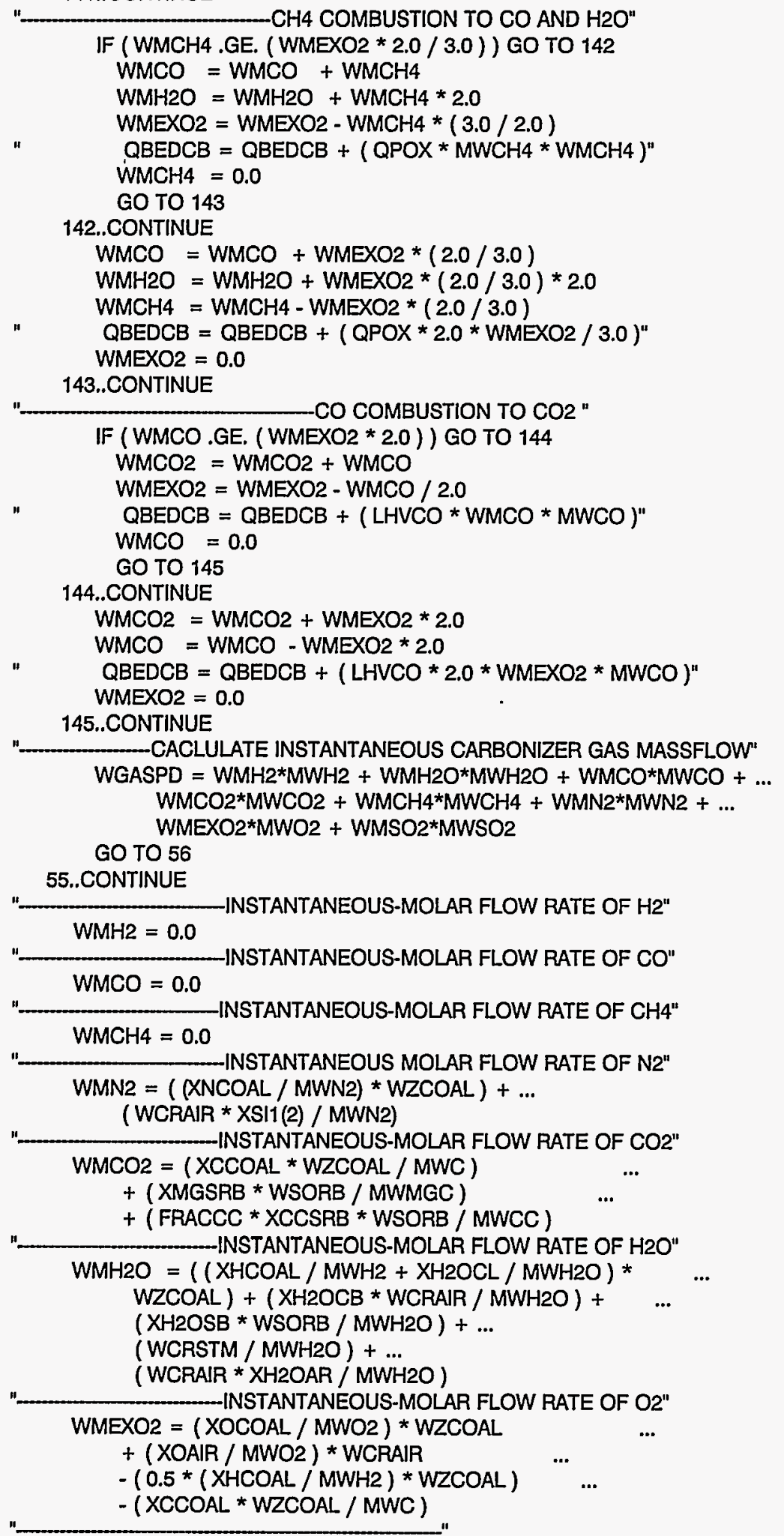




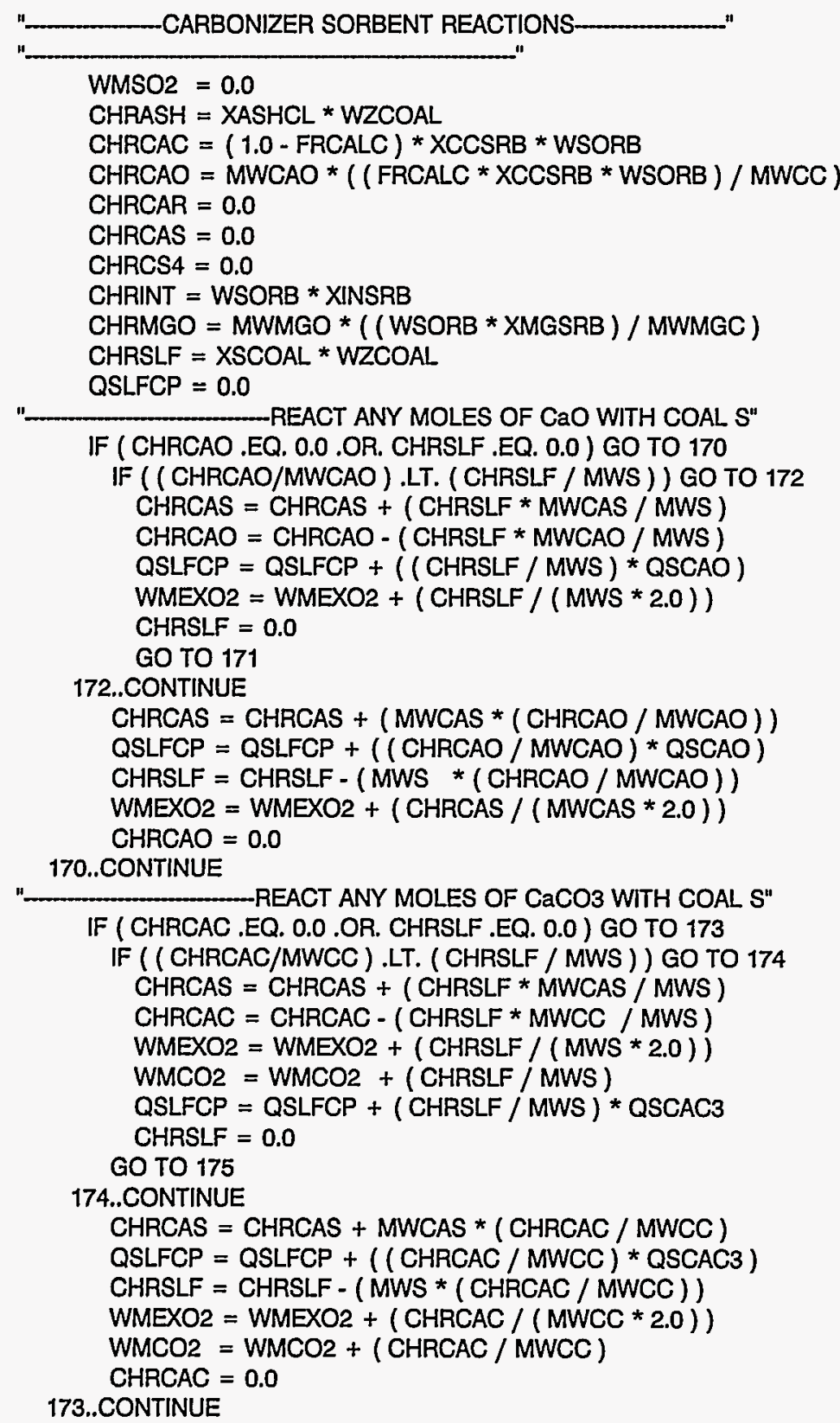

"LINSUFFICIENT CALCIUM FOR $100 \%$ SULFUR REMOVAL"

"_..._..... SULFUR CAPTURE BY CHAR CAO SULFUR IN CARBONIZER BED"

IF (CHRSLF .EQ. 0.0 .OR. CRBCAO .EQ. 0.0) GO TO 180

IF $((($ CHRSLF * ZXDELT $) /(3600$ * MWS $)) . G T . .$. ( CRBCAO / MWCAO ) ) GO TO 176

CRBCAS $=$ CRBCAS $+(($ CHRSLF * ZXDELT * MWCAS $) / \ldots$ (3600. * MWS ))

CRBCAO $=$ CRBCAO $-(($ CHRSLF * ZXDELT * MWCAO $) / \ldots$ (3600. * MWS ))

WMEXO2 $=$ WMEXO2 $+($ CHRSLF $/($ MWS * 2.0 $))$

QSLFCP $=$ QSLFCP + ( (CHRSLF * ZXDELT / MWS $)$ * QSCAO $)$

DO $181 \mathrm{I}=1,15,1$

$\operatorname{MBED}(l)=\operatorname{MBED}(l)+\ldots$

MBED $(l) *((($ CHRSLF * ZXDELT * MWCAS $) ..$. 


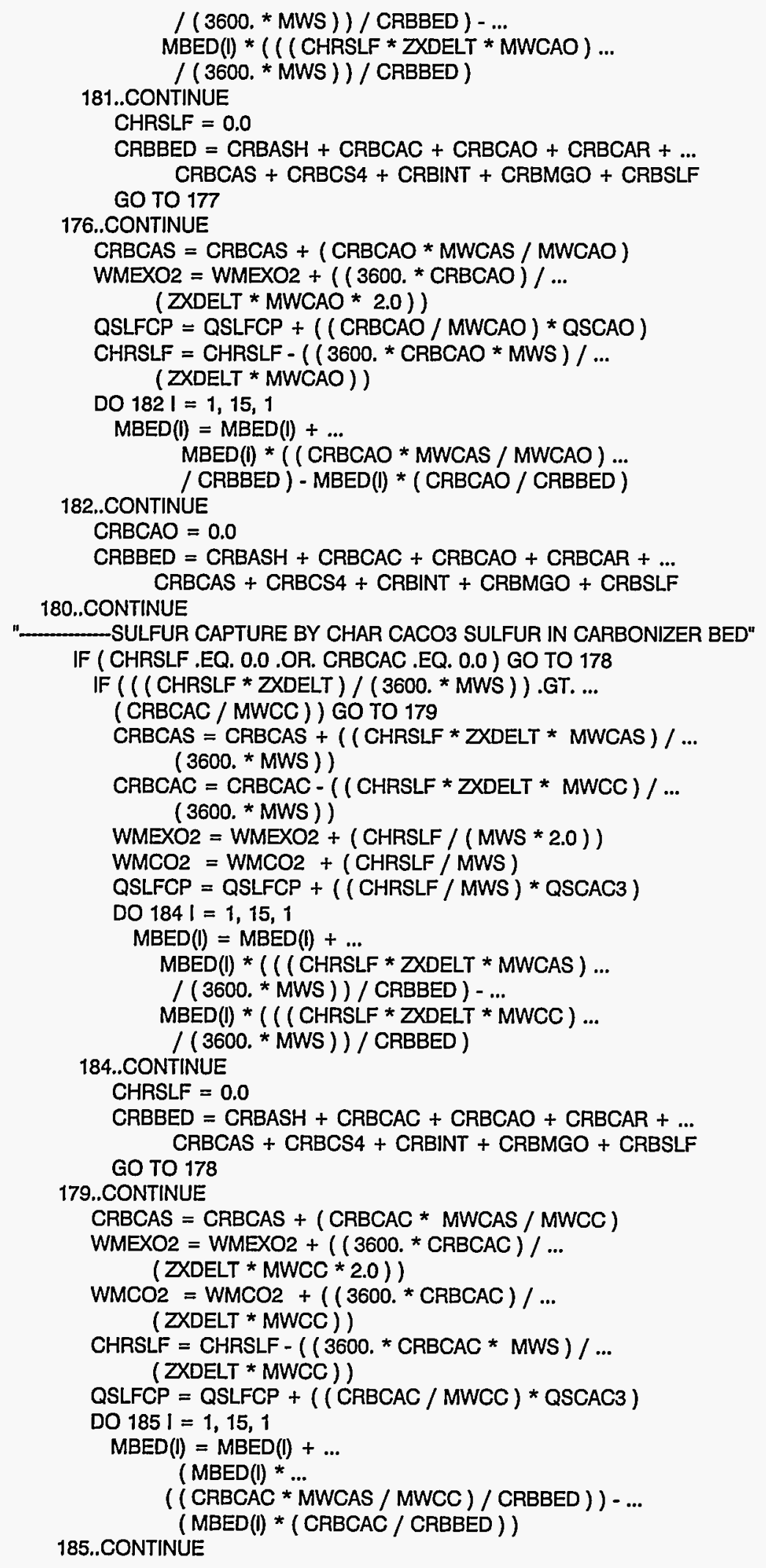




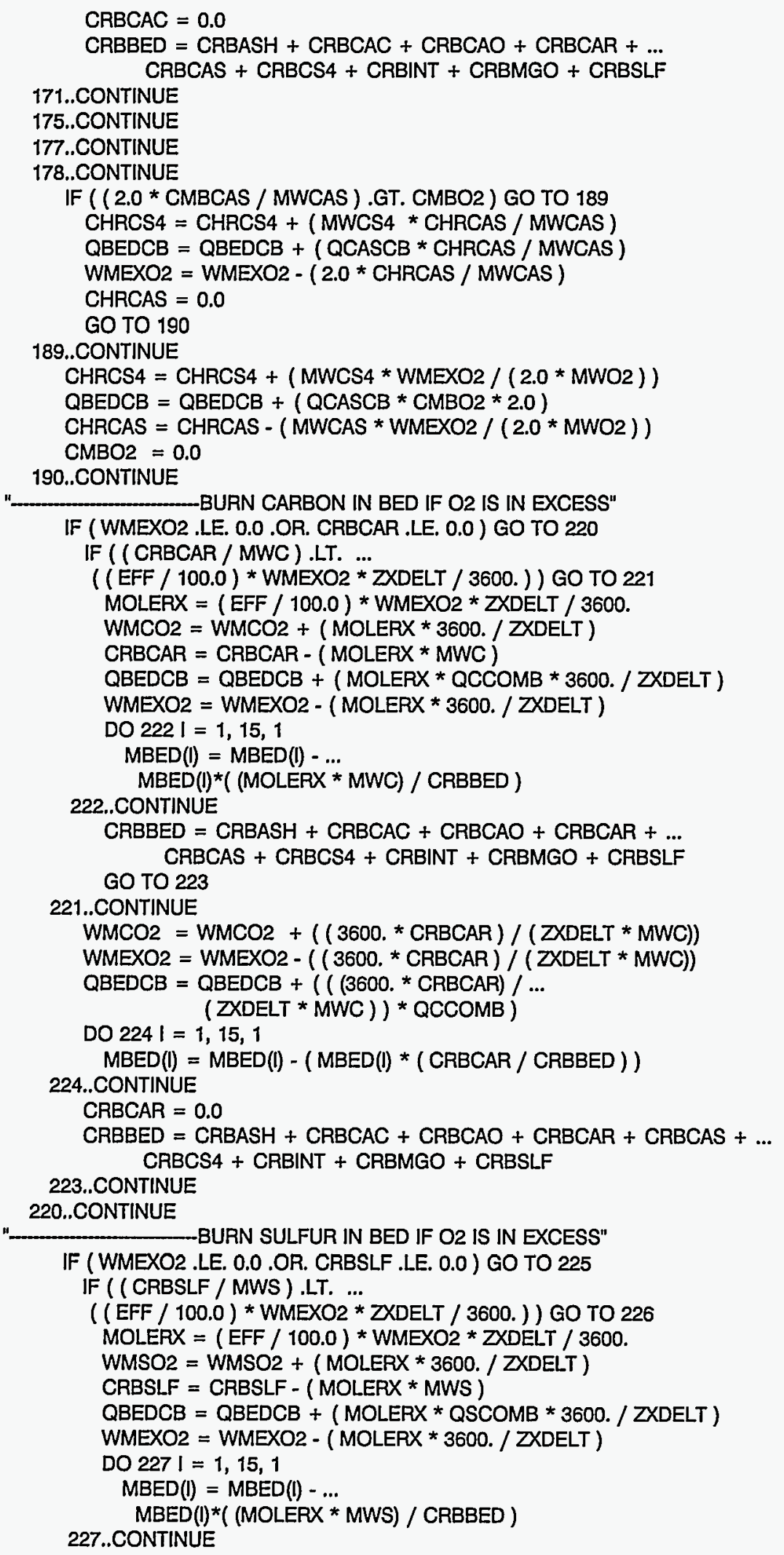




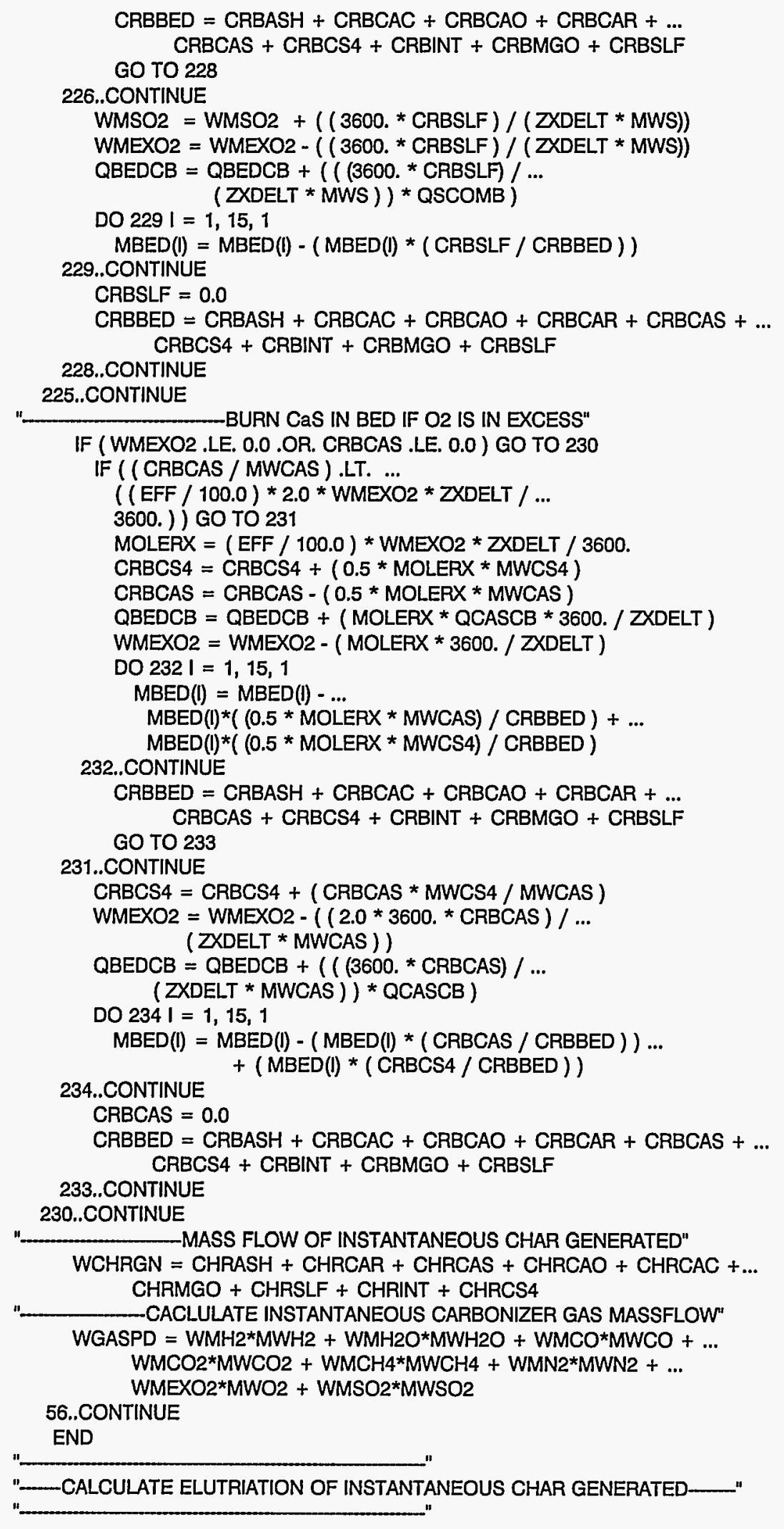




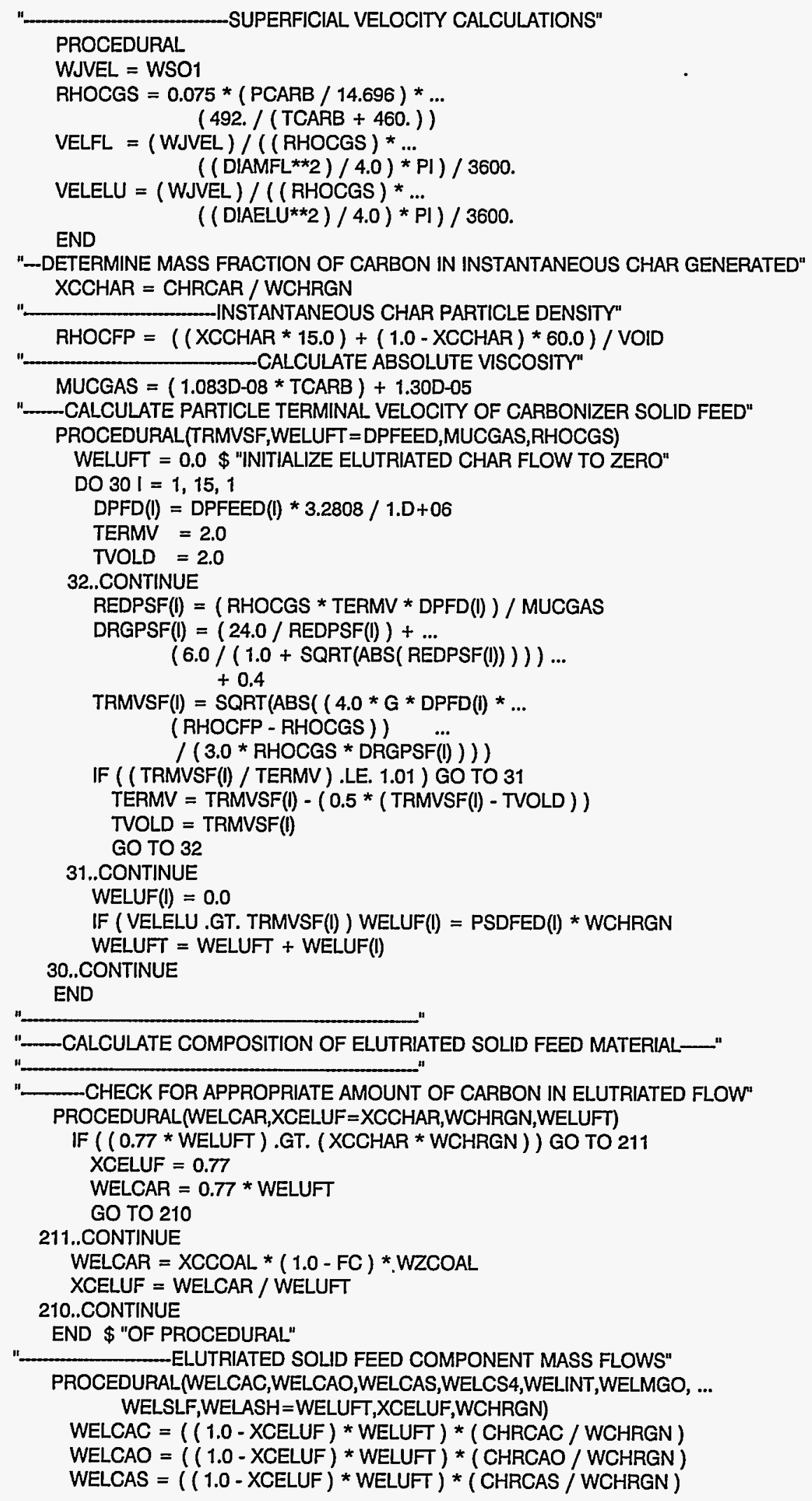


WELCS $4=((1.0-$ XCELUF $) *$ WELUFT $) *($ CHRCS $4 /$ WCHRGN $)$

WELINT $=((1.0-$ XCELUF $) *$ WELUFT $) *($ CHRINT $/$ WCHRGN $)$

WELMGO $=((1.0-$ XCELUF $) *$ WELUFT $) *($ CHRMGO $/$ WCHRGN $)$

WELSLF $=((1.0-$ XCELUF $) *$ WELUFT $) *($ CHRSLF $/$ WCHRGN $)$

WELASH $=$ WELUFT - WELINT - WELSLF - WELMGO - WELCAS - ... WELCAO - WELCAC - WELCAR - WELCS4

END

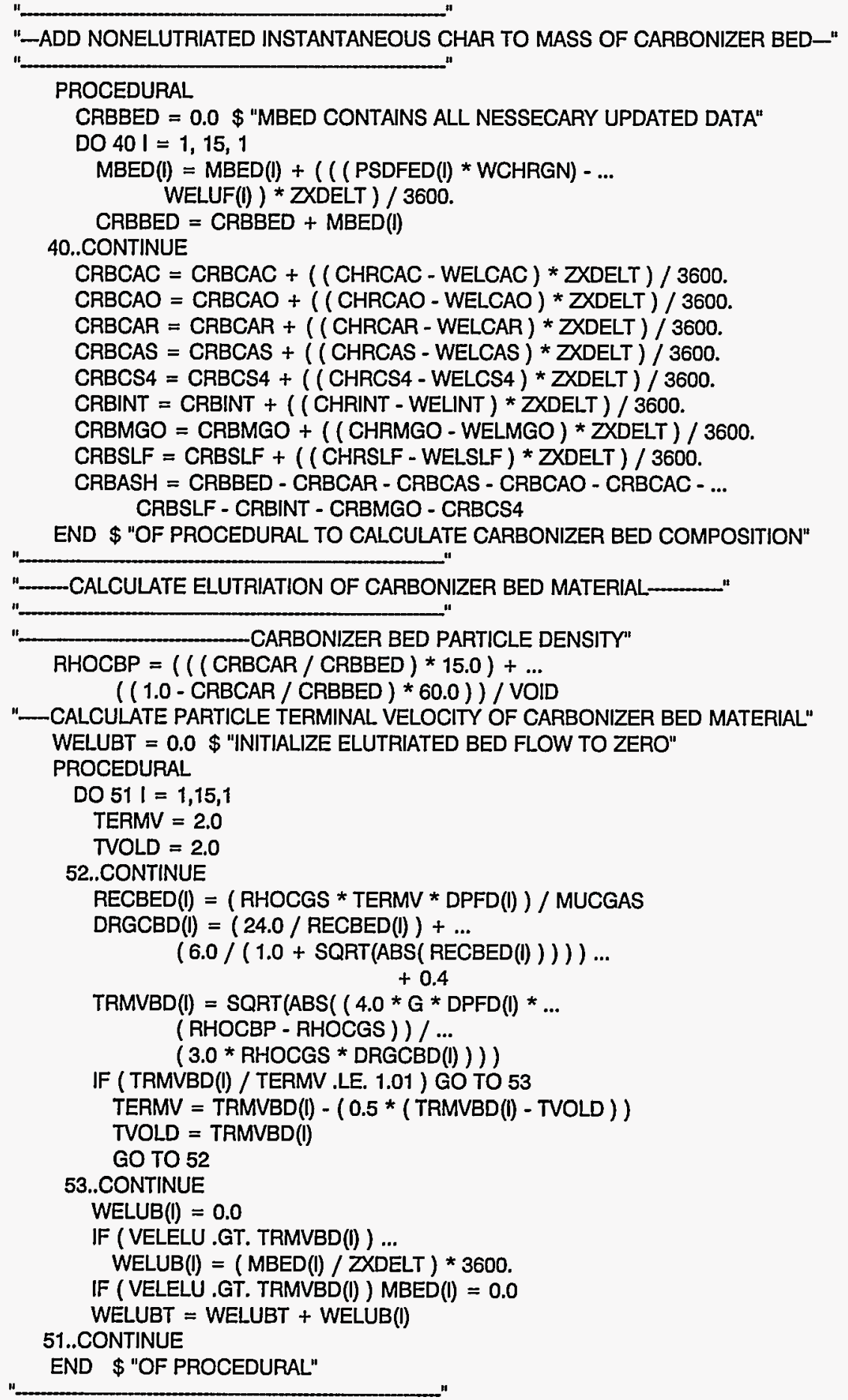




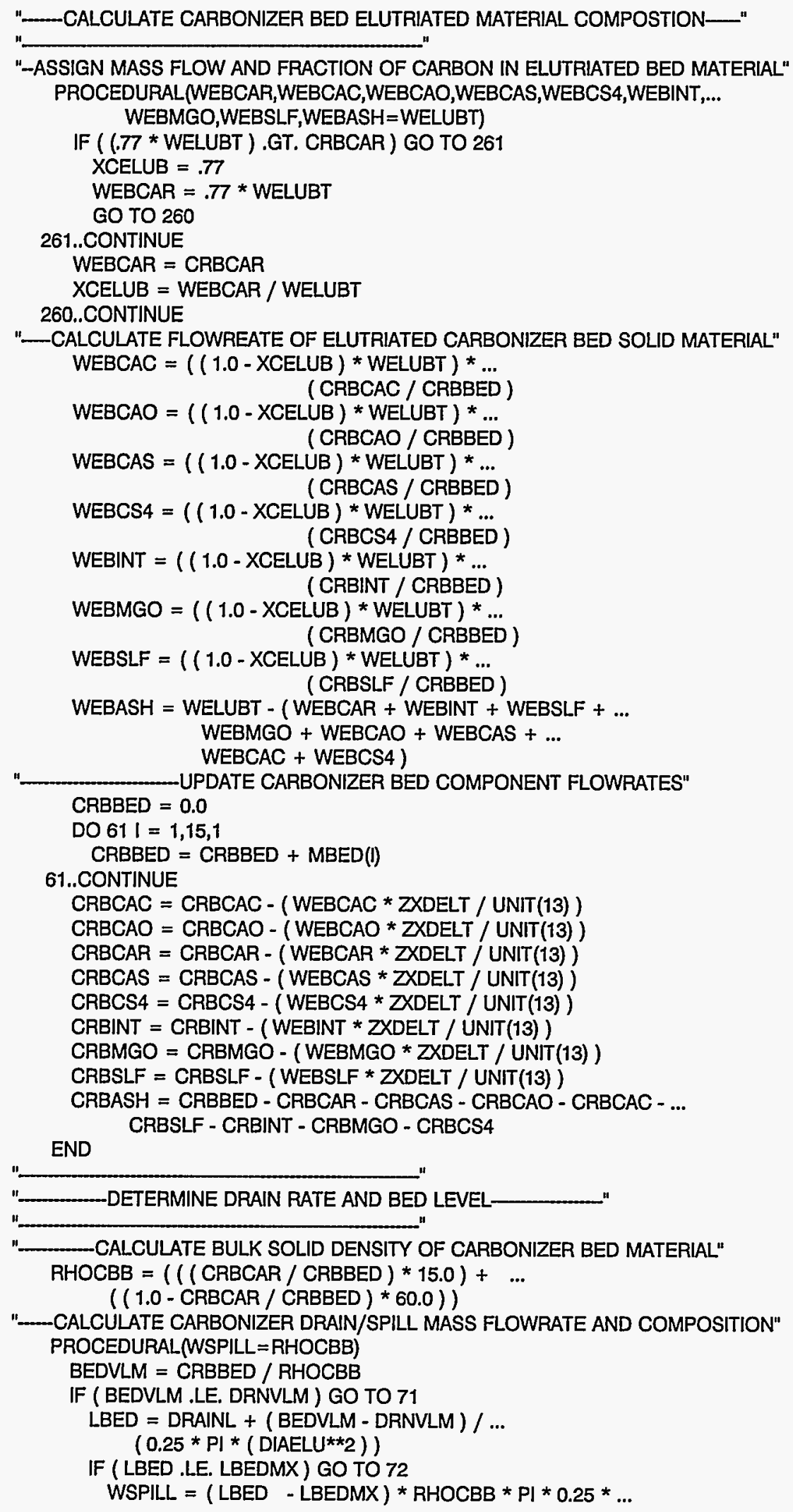




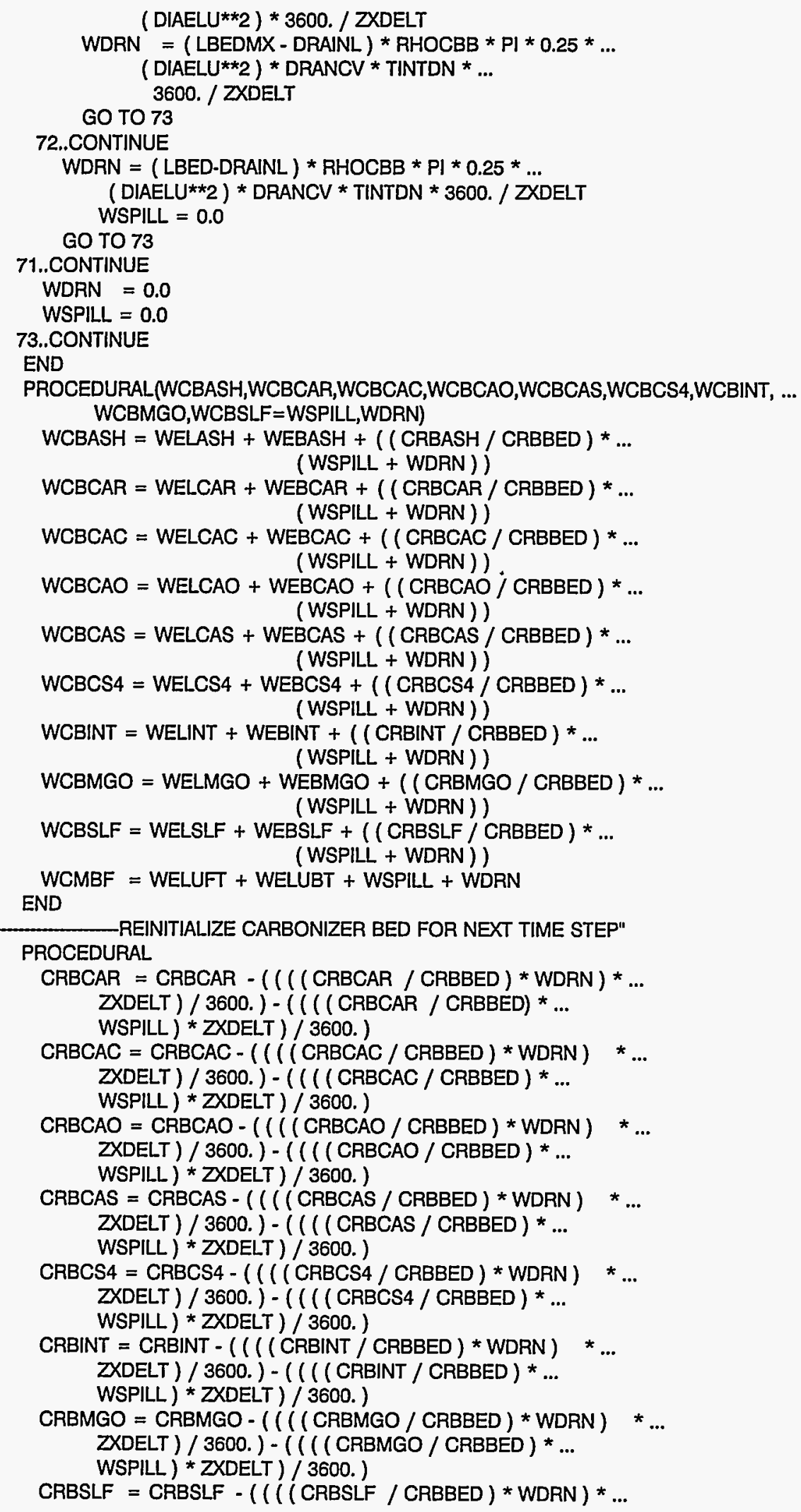




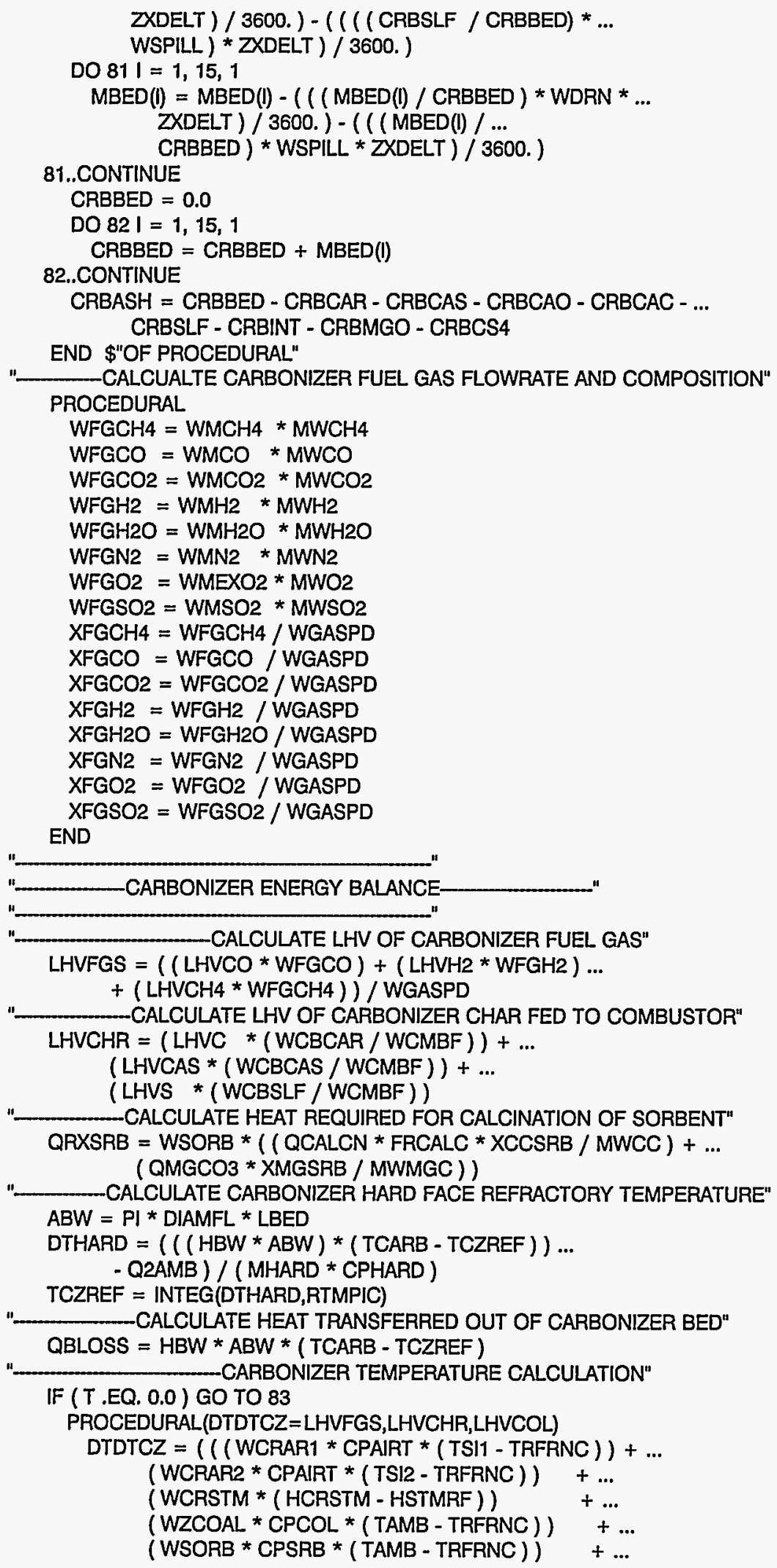



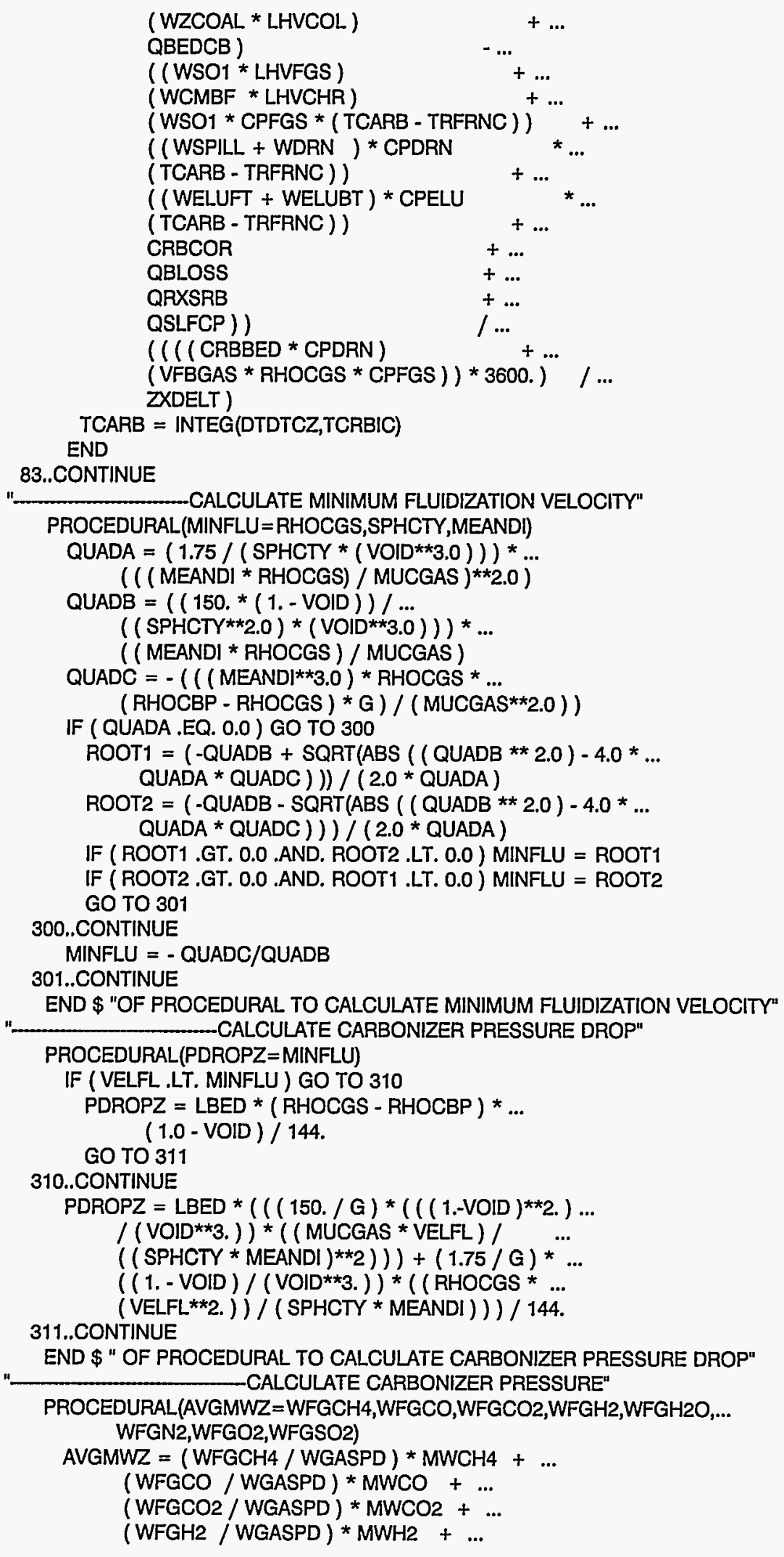


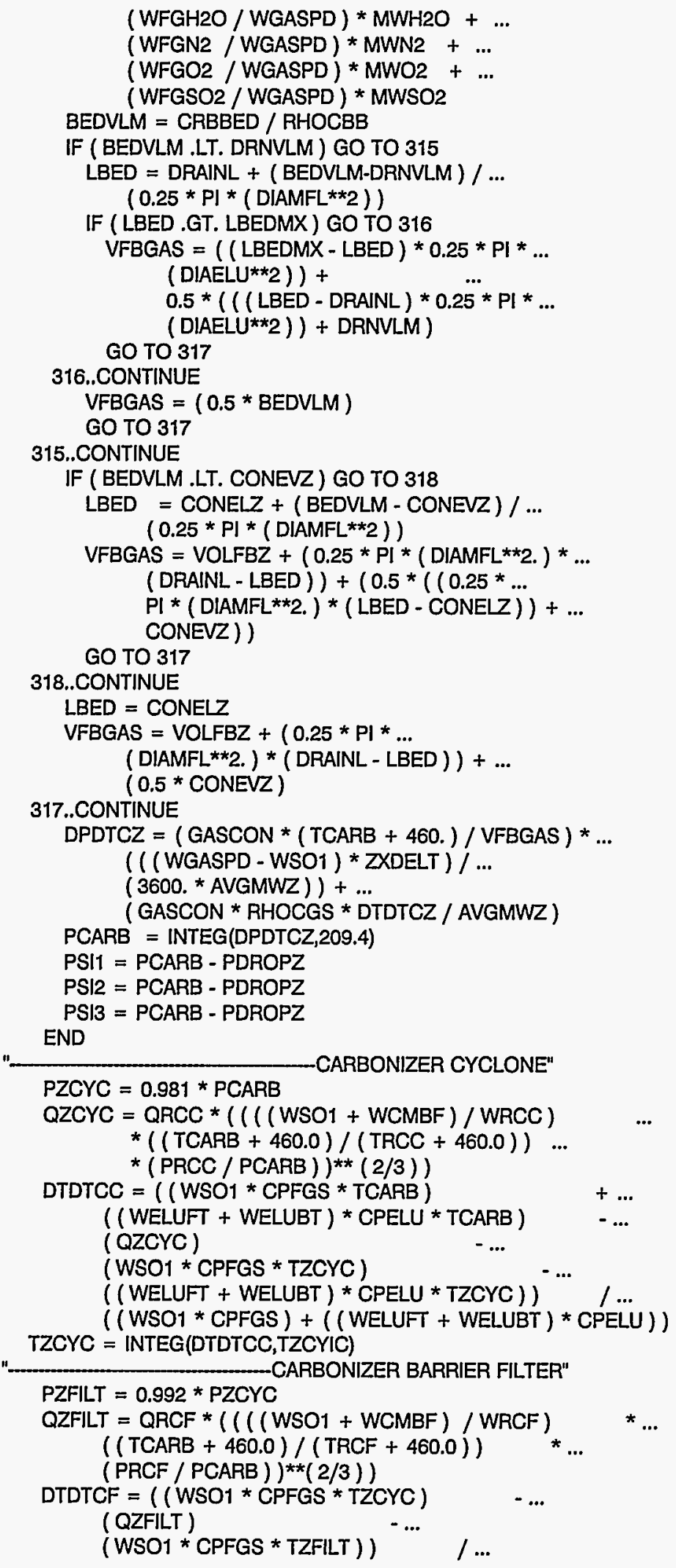


(WSO1 * CPFGS)

TZFILT $=$ INTEG(DTDTCF,TZFLIC)

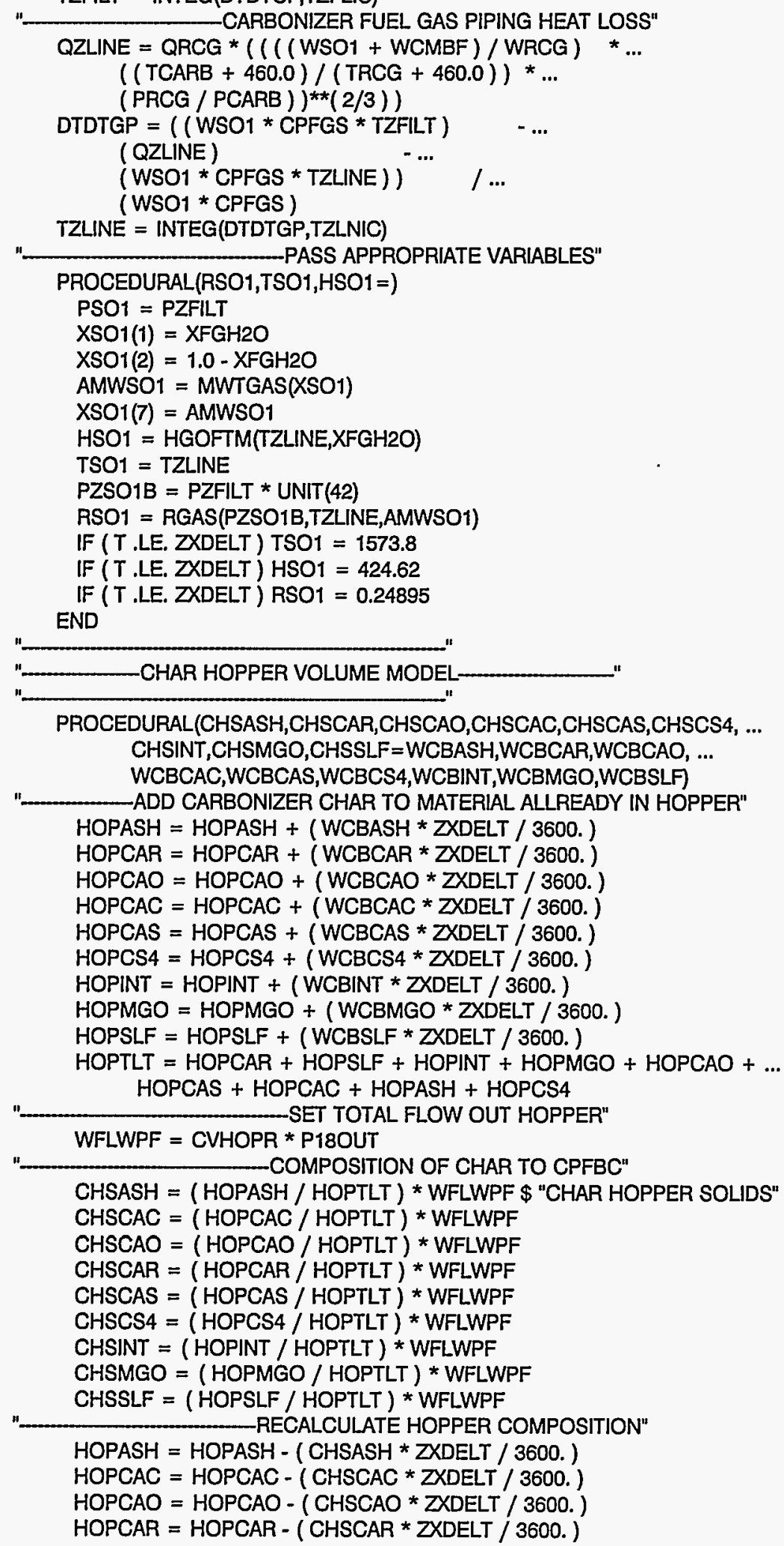




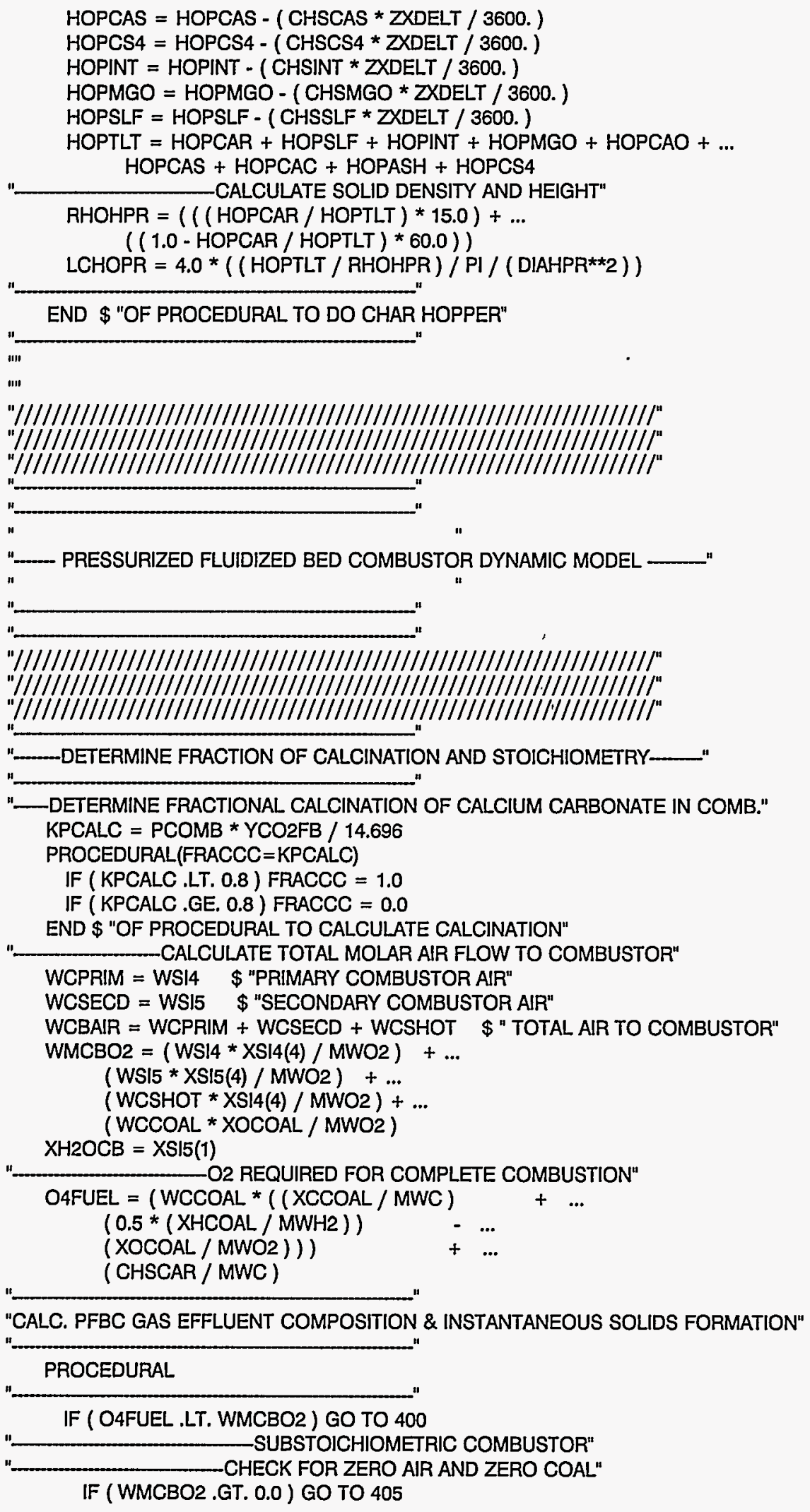




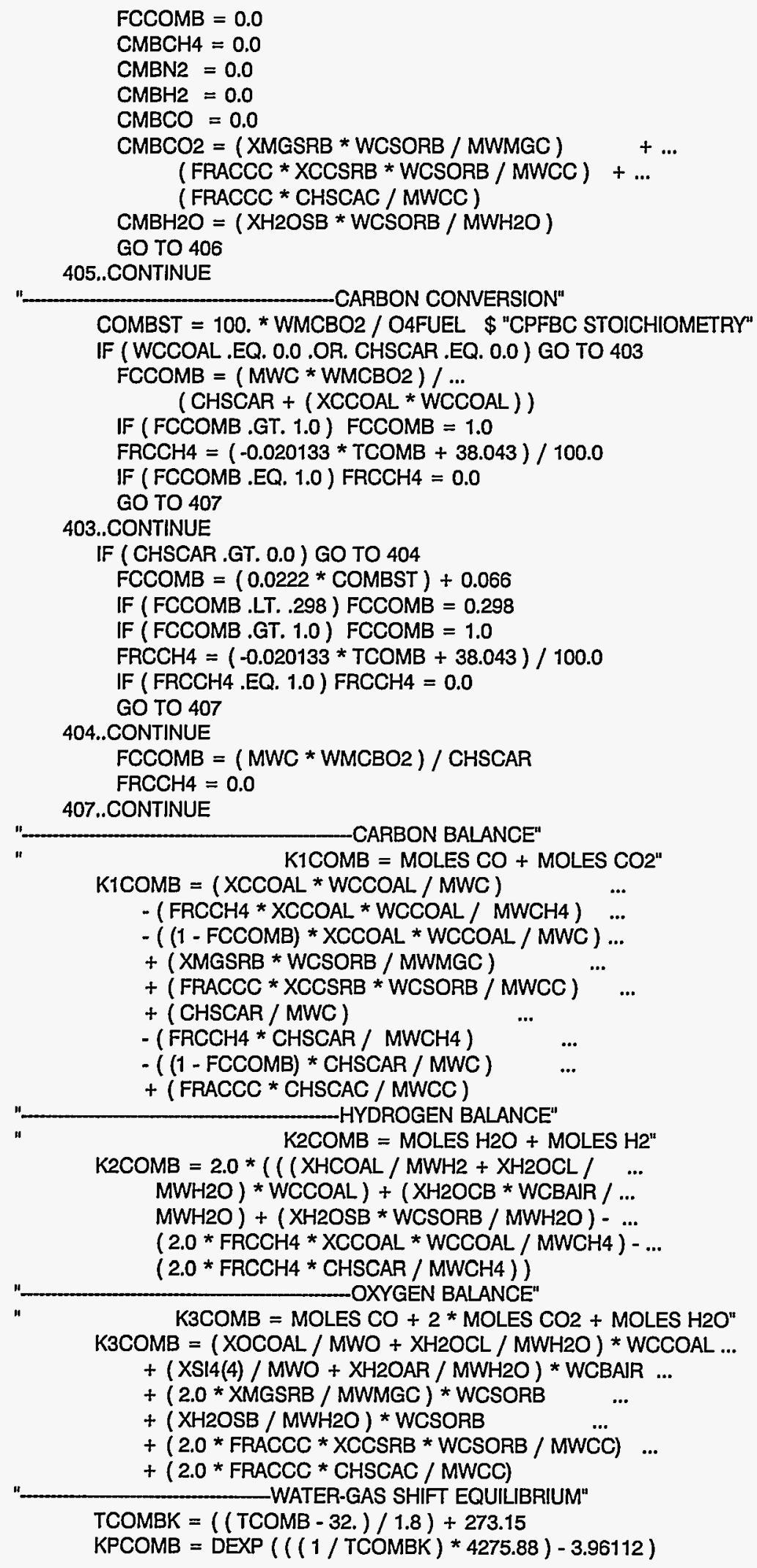




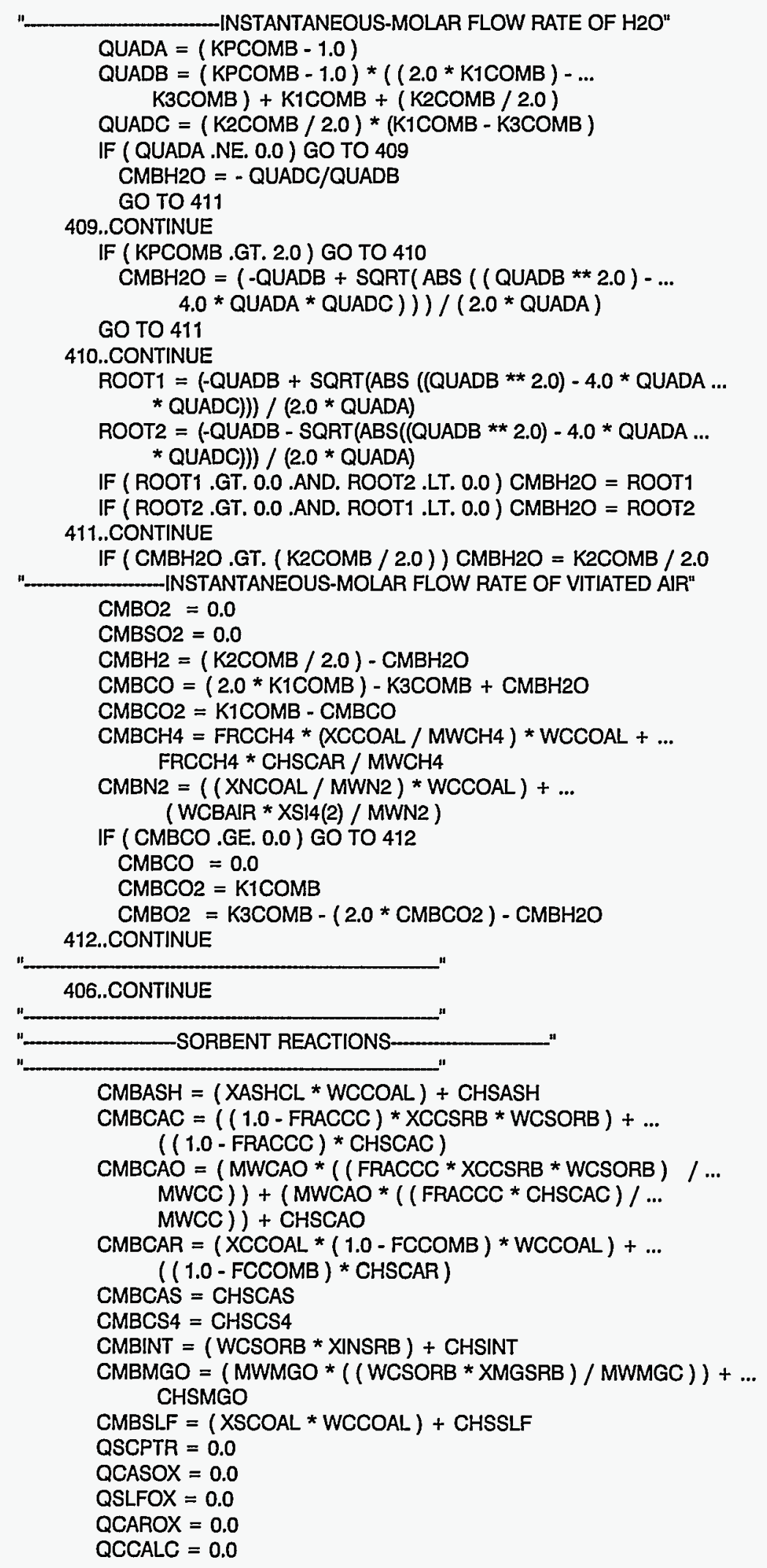




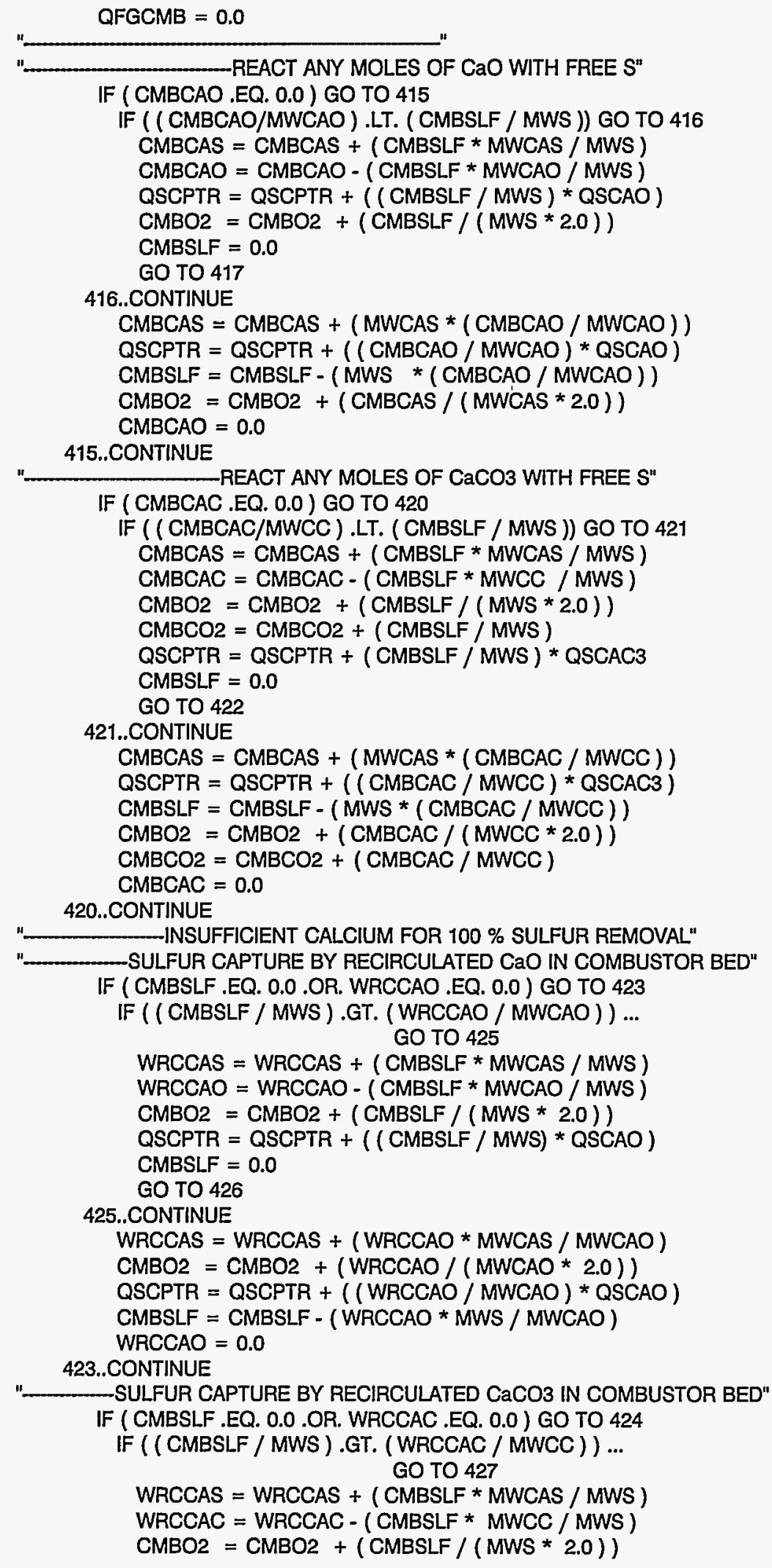




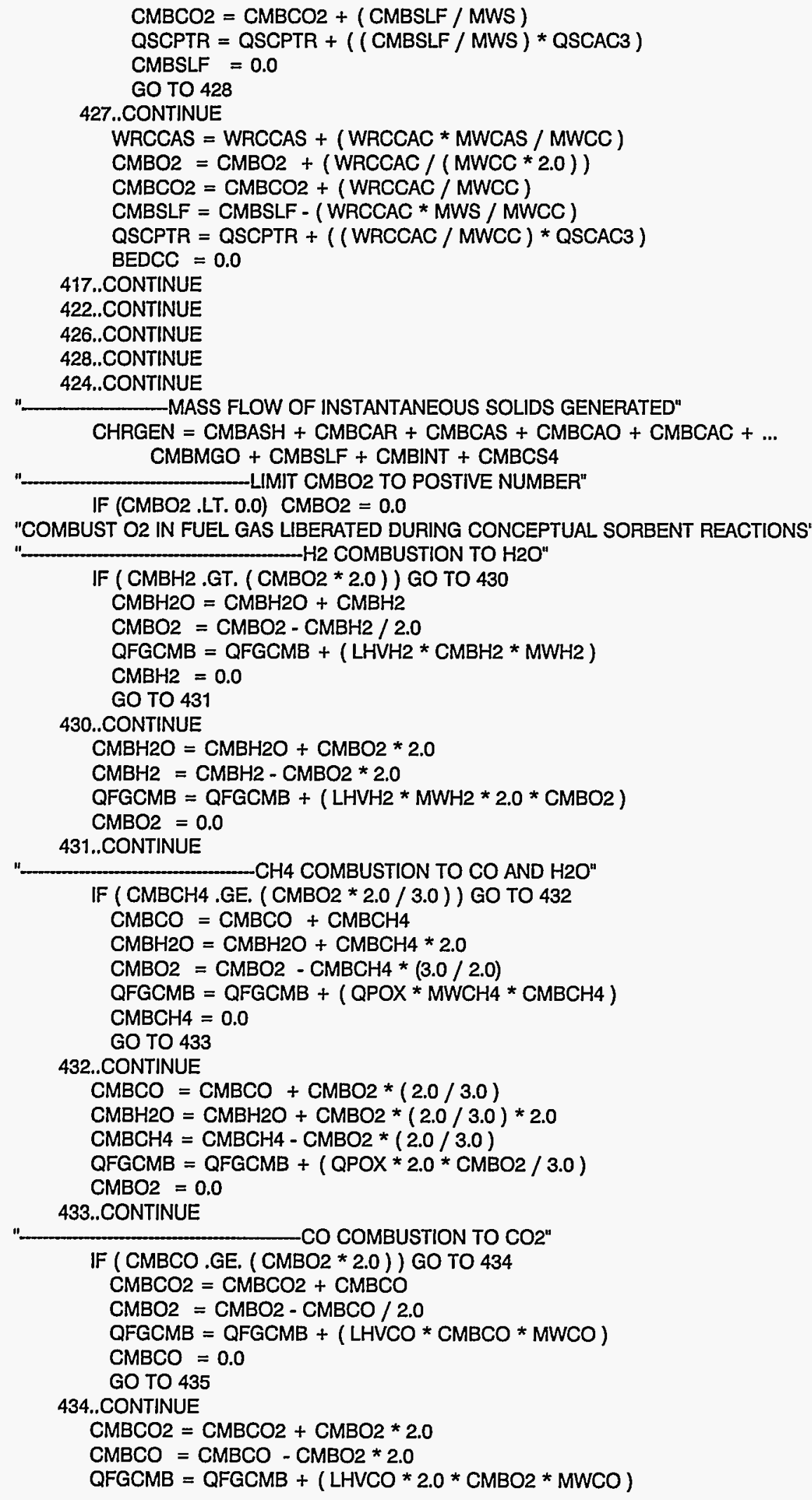


$\mathrm{CMBO} 2=0.0$

435..CONTINUE

IF (KPCALC .GE. 0.8) GO TO 436

CMBCO2 $=$ CMBCO2 $+($ WRCCAC $/$ MWCC $)$

WRCCAO $=$ WRCCAO $+($ WRCCAC * MWCAO $/$ MWCC $)$

QCCALC $=$ QCCALC + $($ QCALCN * WRCCAC $/$ MWCC $)$

WRCCAC $=0.0$

GO TO 437

436..CONTINUE

IF ( (WRCCAO / MWCAO) .GT. CMBCO2) GO TO 438

WRCCAC $=$ WRCCAC $+($ WRCCAO $*$ MWCC $/$ MWCAO $)$

$\mathrm{CMBCO} 2=\mathrm{CMBCO} 2-($ WRCCAO $/$ MWCAO $)$

QCCALC $=$ QCCALC $-($ QCALCN * WRCCAO $/$ MWCAO $)$

WRCCAO $=0.0$

GO TO 437

438..CONTINUE

WRCCAC $=$ WRCCAC $+($ CMBCO2 $*$ MWCC $)$

WRCCAO $=$ WRCCAO $-($ CMBCO2 * MWCAO $)$

QCCALC $=$ QCCALC $-($ QCALCN * CMBCO2 $)$

$\mathrm{CMBCO} 2=0.0$

437..CONTINUE

CACLULATE INSTANTANEOUS COMBUSTOR GAS MASSFLOW"

GASPRD $=$ CMBH2*MWH2 $+\mathrm{CMBH}_{2}{ }^{*} \mathrm{MWH} 2 \mathrm{O}+\mathrm{CMBCO}^{*} \mathrm{MWCO}+\ldots$

GO TO 401

CMBCO2*MWCO2 + ${ }^{\star} M B C H 4^{\star} M W C H 4+C M B N 2{ }^{*} M W N 2+\ldots$

$\mathrm{CMBO}^{\star}{ }^{\mathrm{MWO}} 2+\mathrm{CMBSO}^{\star} \mathrm{MWSO} 2$

400..CONTINUE

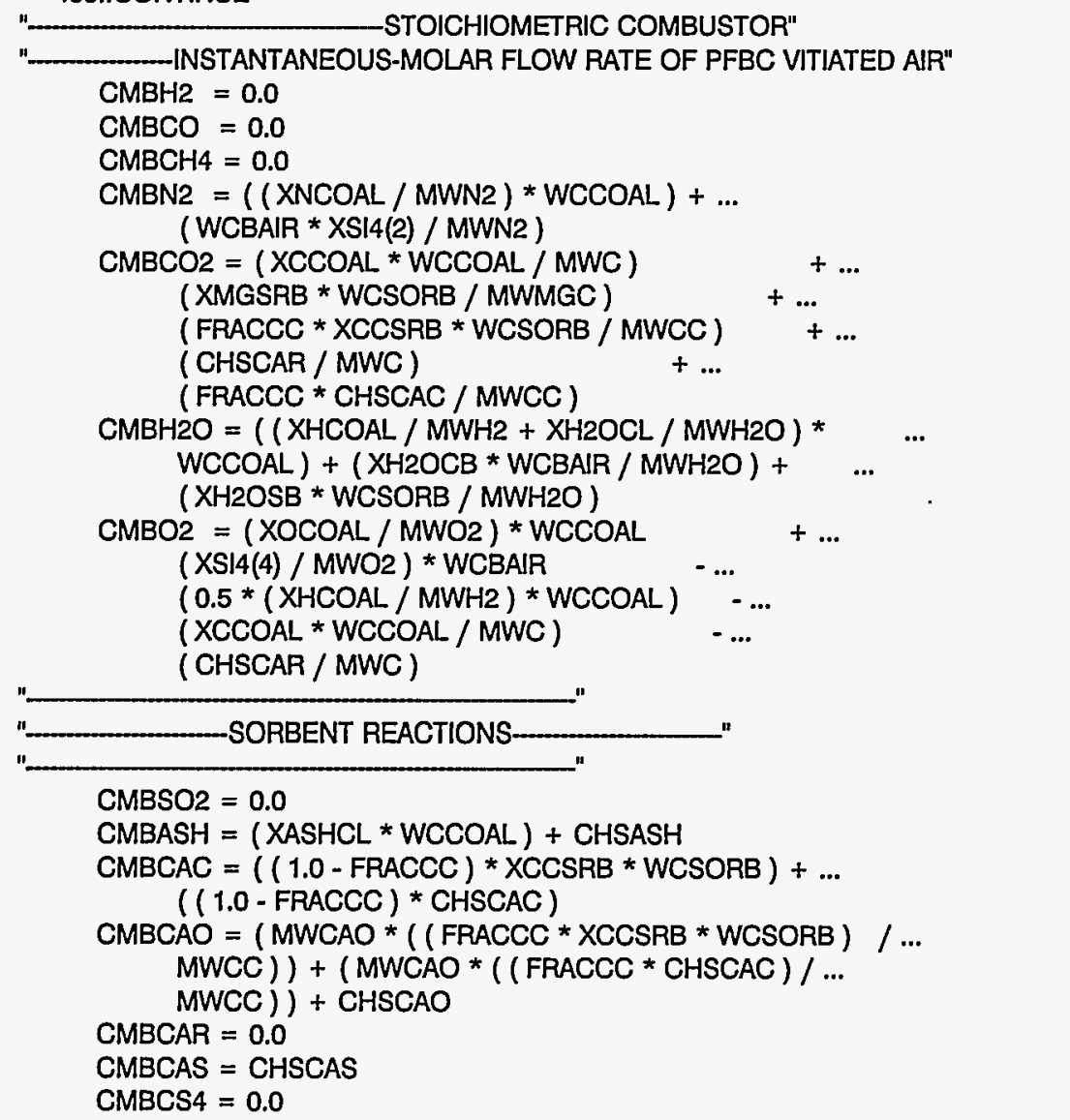




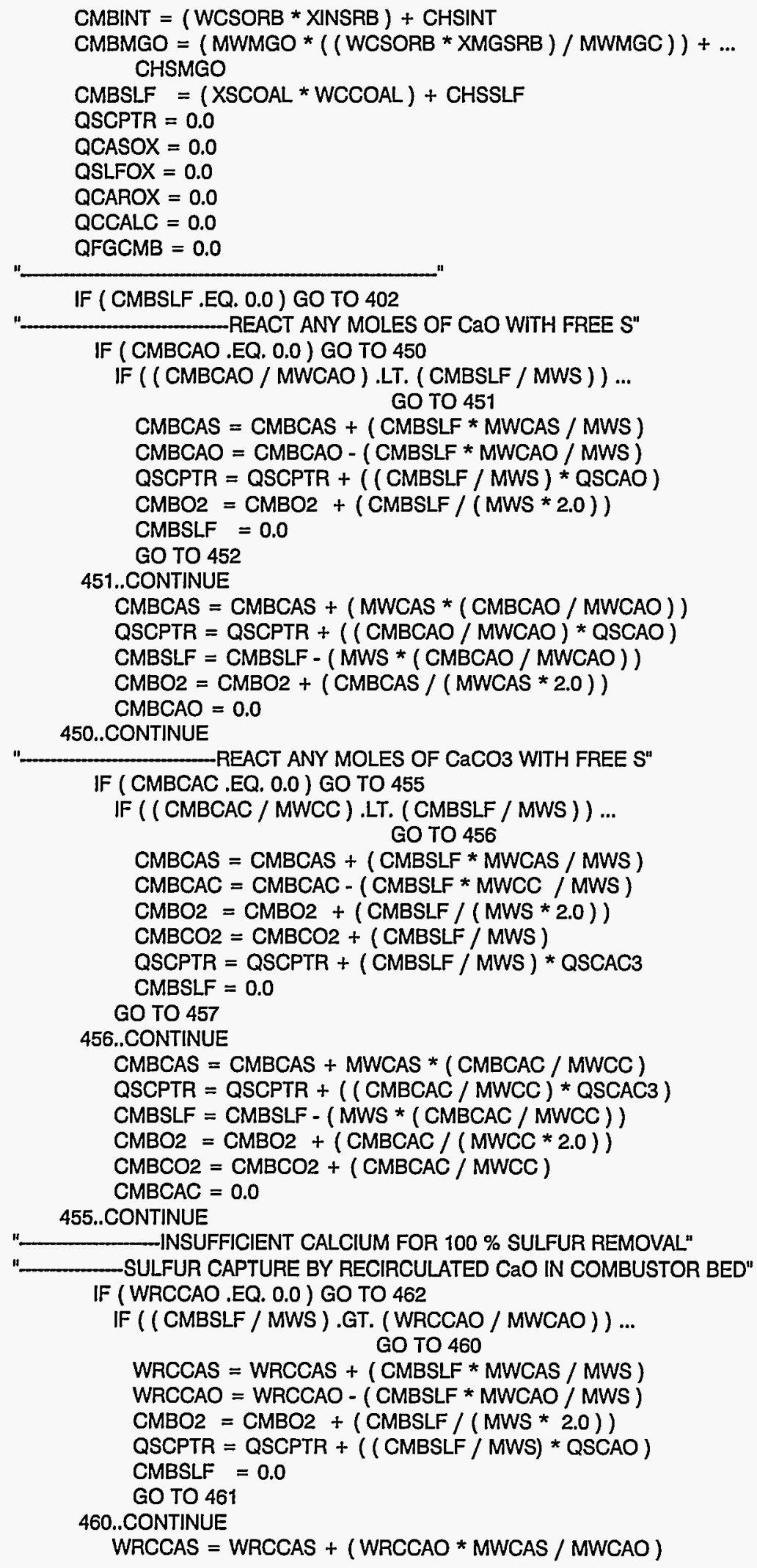




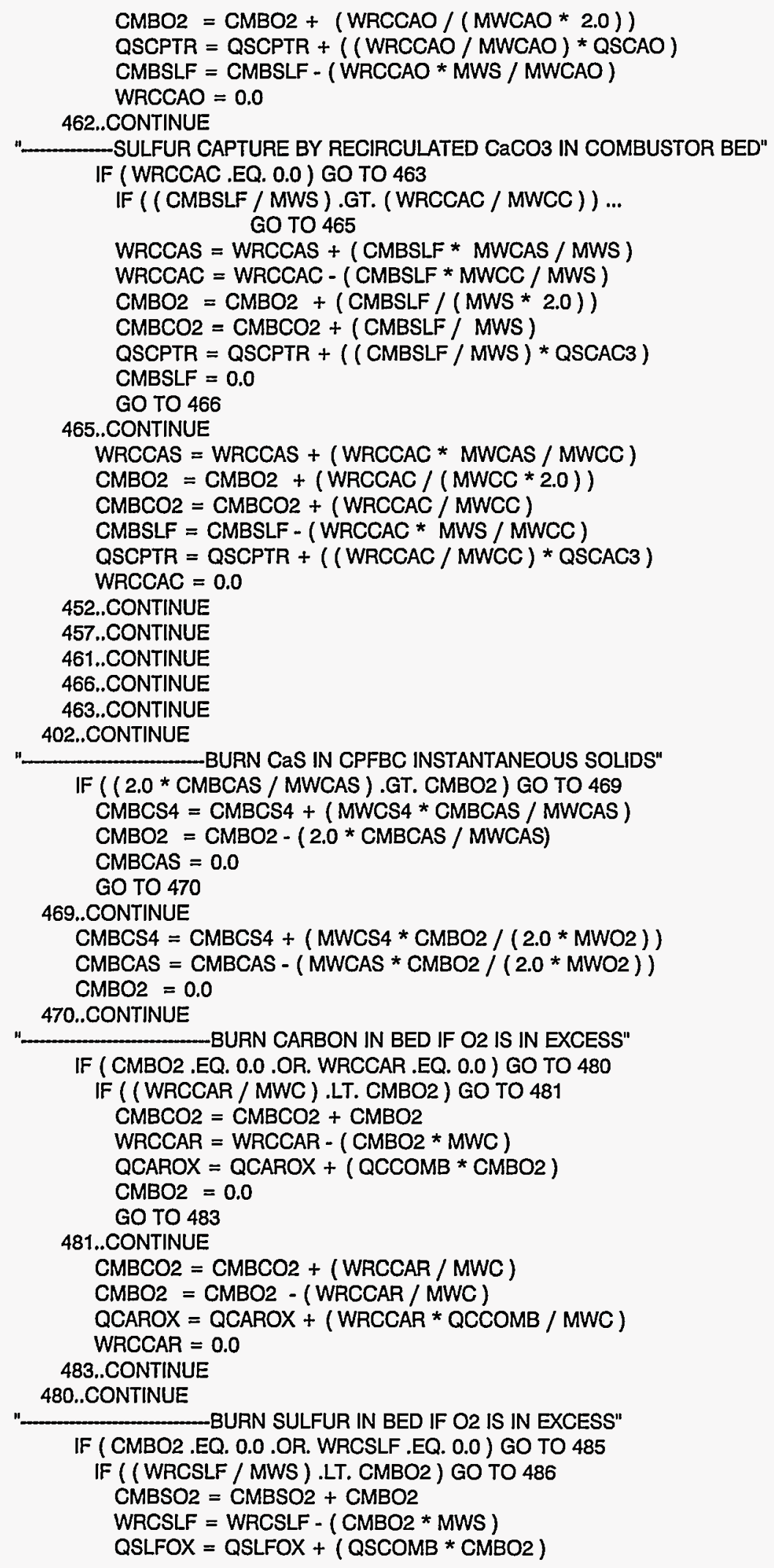




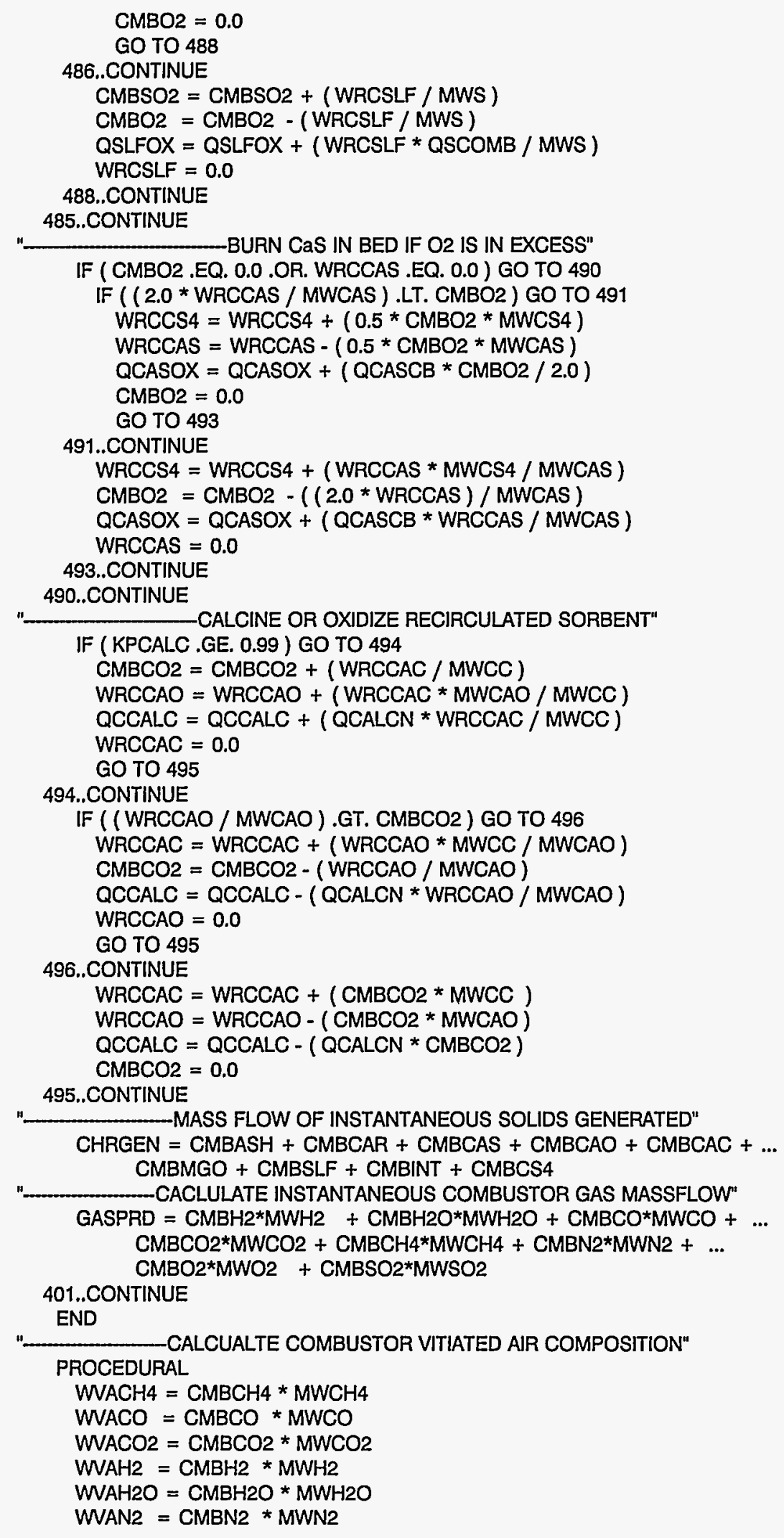




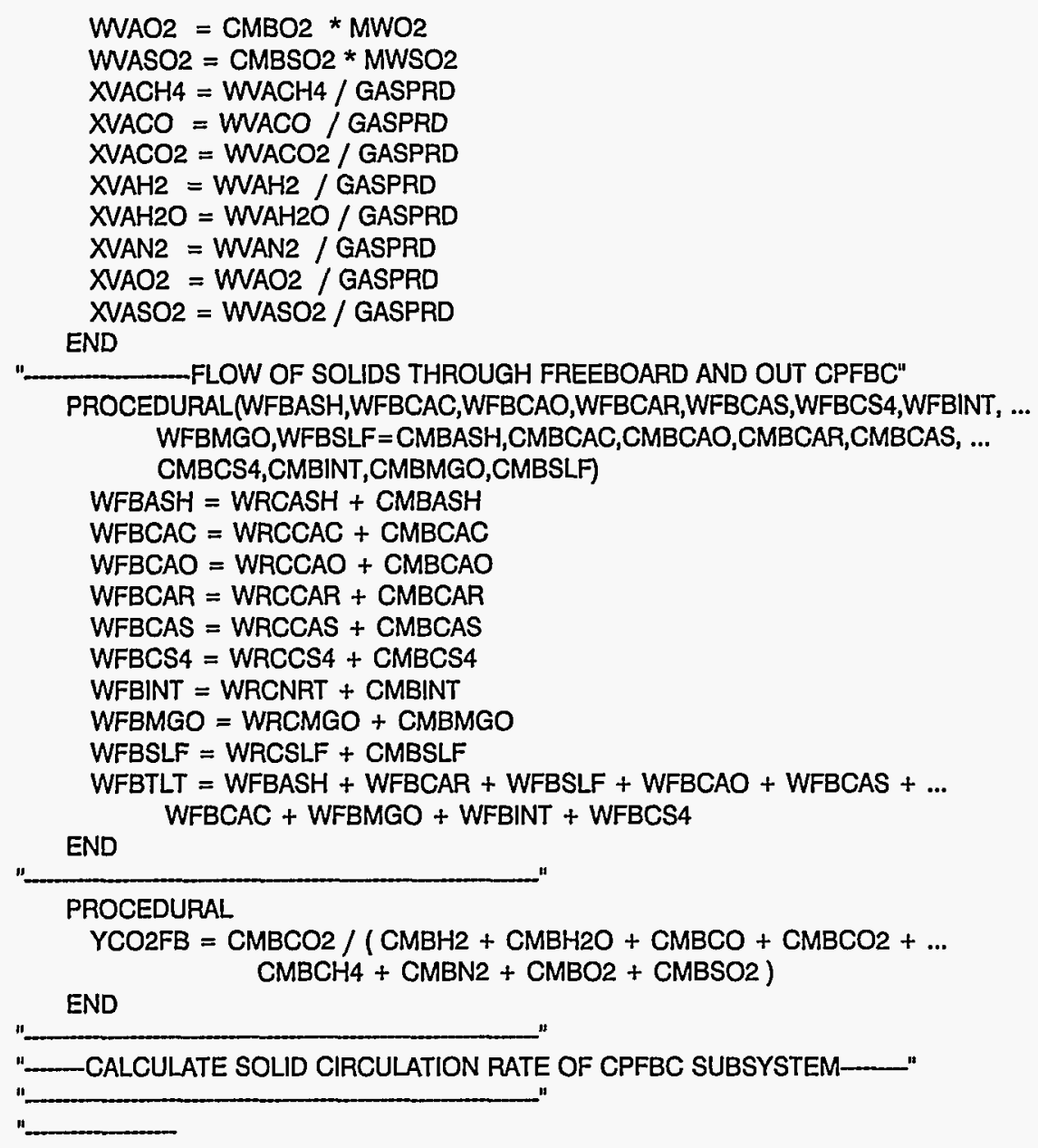

